Ergänzungshefte

zu den Jahresheften des

Österreichischen Archäologischen Institutes

Heft 16

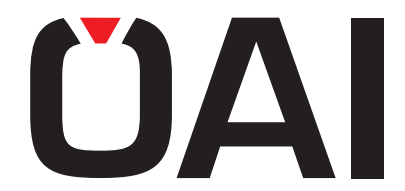

ÖSTERREICHISCHES ARCHÄOLOGISCHES

I NST I TUT
Carola Kintrup

Attische Sarkophage aus Ephesos

Mit einem Beitrag von Walter Prochaska 


\section{Carola Kintrup}

\section{ATTISCHE SARKOPHAGE AUS EPHESOS}

Mit einem Beitrag von

Walter Prochaska 
ERGÄNZUNGSHEFTE ZU DEN JAHRESHEFTEN DES

ÖSTERREICHISCHEN ARCHÄOLOGISCHEN INSTITUTES

HEFT 16

WIEN 2017 
Carola Kintrup

\title{
ATTISCHE SARKOPHAGE AUS EPHESOS
}

\author{
Mit einem Beitrag \\ von \\ Walter Prochaska
}

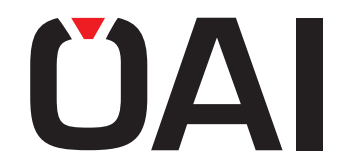


Herausgeber

Österreichisches Archäologisches Institut

Franz Klein-Gasse 1

A-1190 Wien

«www.oeaw.ac.at/oeai〉

Das Österreichische Archäologische Institut ist eine Forschungseinrichtung der

Österreichischen Akademie der Wissenschaften

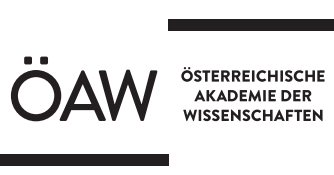

Scientific Board

Sabine Deschler-Erb, Universität Basel

Musa Kadioğlu, Universität Ankara

Gabriela Krist, Universität für angewandte Kunst Wien

Karl Reber, Universität Lausanne

Salvatore Ortisi, LMU München

Frank Vermeulen, Universität Gent

Veröffentlicht mit Unterstützung des Austrian Science Fund (FWF): PUB 447

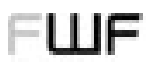

Eigentümer \& Verleger

Verlag Holzhausen GmbH

Leberstraße 122

A-1110 Wien

Verlagsleitung: Robert Lichtner

〈www.verlagholzhausen.at〉

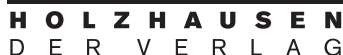

Redaktion und Lektorat: Barbara Beck-Brandt, Judith Kreuzer

Satz und Layout: Andrea Sulzgruber

Umschlaggestaltung: Büro Pani; Andrea Sulzgruber

Alle Rechte vorbehalten

1. Auflage 2017

Verlagsort: Wien - Herstellungsort: Wien - Printed in the EU

ISSN 1727-2505

ISBN 978-3-902976-82-6

Copyright (C) 2017 Verlag Holzhausen GmbH

Die verwendete Papiersorte ist aus chlorfrei gebleichtem Zellstoff hergestellt, frei von säurebildenden Bestandteilen und alterungsbeständig.

Bibliografische Information der Österreichischen Nationalbibliothek und der Deutschen Nationalbibliothek: Die ÖNB und die DNB verzeichnen diese Publikation in den Nationalbibliografien; detaillierte bibliografische Daten sind im Internet abrufbar. Für die Österreichische Bibliothek: «http://onb.ac.at〉, für die Deutsche Bibliothek: 〈http://dnb.ddb.de〉.

Sofern vom Verlag nicht anders verlautbart, wird der Text dieser Werkfassung bis auf Weiteres unter der Lizenz »Creative Commons (CC) BY 4.0« zur Verfügung gestellt. Nähere Informationen zu dem Umfang dieser Lizenz sind unter «http://creativecommons.org/licenses/by/4.0/> abrufbar. Für alle weiteren Inhalte, die im Text dieser Werkfassung enthalten sind, hat die Nutzerin/der Nutzer selbst auf eigene Kosten die von ihr/ihm benötigten Bewilligungen, insbesondere zur Bearbeitung, Vervielfältigung, Verbreitung und Zurverfügungstellung, beizuschaffen. 


\section{Inhalt}

Vorwort der Grabungsleiterin ........................................................... 9

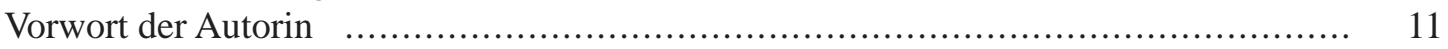

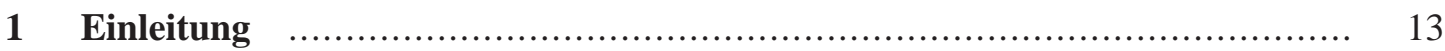

2 Sarkophage aus dem Grabhaus der Claudia Antonia Tatiane $\quad$.................... 21

2.1 Kastenfragmente mit Klinendeckel des Schlachtsarkophags des

[Quintus] Aemilius Aristides (Kat. 1)

2.2 Kastenfragmente mit Klinendeckel eines Amazonomachie-Sarkophags

(Kat. 2)

3 Attische Sarkophage und Kastenfragmente nach Themen geordnet

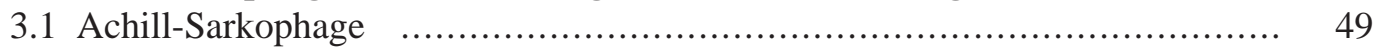

3.1.1 Beschädigter Kasten eines Achill-Sarkophags (Kat. 3) ................... 49

3.1.2 Fragment eines Achill-Sarkophags (Kat. 4) $\quad$............................... 60

3.1.3 Eckfragment eines Achill-Sarkophags (Kat. 5) ........................... 62

3.2 Sarkophage mit Amazonomachie ............................................. 65

3.2.1 Fragmentierter Kasten mit Amazonomachie (Kat. 6) ..................... 65

3.2.2 Fragment mit Amazonomachie (Kat. 7) ................................ 72

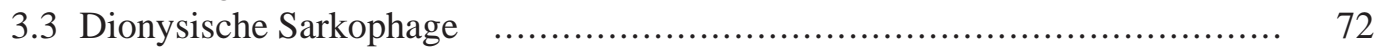

3.3.1 Fragment eines dionysischen Sarkophags (Kat. 8) ........................ 72

3.3.2 Fragment eines dionysischen Sarkophags (Kat. 9) ....................... 74

3.4 Eroten-Weinlese-Sarkophage und/oder dionysische Sarkophage;

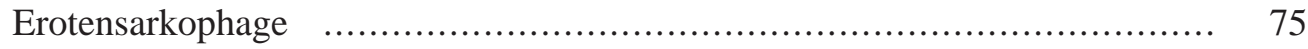

3.4.1 Fragmentierter Kasten eines Eroten-Weinlese-Sarkophags (Kat. 10) .... 75

3.4.2 Fragment eines dionysischen oder eines Eroten-Weinlese-Sarkophags

(Kat. 11) ......................................................................... 79

3.4.3 Fragment eines dionysischen oder eines Eroten-Weinlese-Sarkophags

(Kat. 12) ........................................................................ 80

3.4.4 Fragment eines dionysischen oder eines Eroten-Weinlese-Sarkophags (Kat. 13) .......................................................................... 81

3.4.5 Fragment mit jugendlichem Kopf (Eros [?]) (Kat. 14) ................... 82

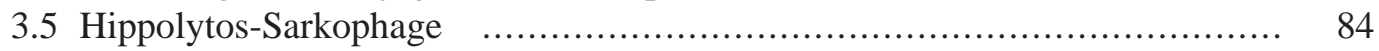

3.5.1 Kastenfragmente eines Hippolytos-Sarkophags (Kat. 15) ............... 84

3.5.2 Eckfragment eines Hippolytos-Sarkophags (Kat. 16) $\quad$...................... 98

3.5.3 Fragment eines Hippolytos-Sarkophags (?) (Kat. 17) .................... 100

3.6 Sarkophage mit Schlachtszenen ................................................ 101

3.6.1 Fragment mit einer Schlachtszene (Kat. 18) ............................ 101

3.6.2 Fragment mit einer Schlacht bei Schiffen (Kat. 19) ....................... 102

3.6.3 Fragment mit einer Schlacht bei Schiffen (Kat. 20) ....................... 104 
4 Attische Kastenfragmente ohne genaue thematische Zuordnung

4.1 Eckfragment mit Trompeter (Kat. 21) …..................................... 107

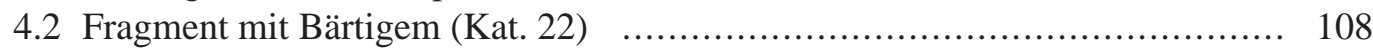

4.3 Eckfragment eines oberen Kastenabschlusses mit Kriegerkopf (Kat. 23) ..... 109

4.4 Fragment mit oberem Kastenabschluss und Kopf eines Jünglings (Kat. 24) .. 110

4.5 Kopf eines Kriegers (Kat. 25) ................................................... 111

4.6 Fragment eines oberen Kastenbereichs mit Ornament und Kopf (Kat. 26) .... 112

4.7 Fragment des oberen Kastenbereichs mit einem Trompeter (Kat. 27) ......... 114

4.8 Fragment eines Kastens mit Sockelzone (Kat. 28) .............................. 115

4.9 Fragment eines Kastenreliefs (Kat. 29) ..................................... 116

4.10 Kastenfragment mit Kriegerbein (Kat. 30) .................................. 117

4.11 Fragment mit oberem Kastenabschluss und Pferdekopf (Kat. 31) ............ 118

4.12 Kastenfragment mit Pferdehinterteil (Kat. 32) ................................. 119

4.13 Unteres Eckfragment eines Kastenreliefs mit Pferdehinterteil (Kat. 33) ..... 120

4.14 Rückseitenfragment mit Löwen (Kat. 34) ..................................... 121

4.15 Fragment eines oberen Kastenabschlusses mit Mäander (Kat. 35) ............. 122

4.16 Fragment eines Kastenbodens mit Sockel (Kat. 36) ............................. 123

4.17 Fragment einer Sockelecke (Kat. 37) ..................................... 124

4.18 Fragment der Oberseite eines Sarkophags mit Falz (Kat. 38) ................. 125

5 Klinen-Riefel-, Girlanden- und Säulensarkophage

5.1 Fragment eines Klinen-Riefel-Sarkophags (Kat. 39) …...................... 127

5.2 Fragment eines Klinen-Riefel-Sarkophags (Kat. 40) $\quad$............................ 128

5.3 Fragment eines Girlandensarkophags (Kat. 41) ............................... 129

5.4 Zwei Fragmente eines attischen Säulensarkophags (?) (Kat. 42) …............ 130

6 Attische Sarkophagdeckelfragmente

6.1 Großes Fragment eines Klinendeckels (Kat. 43) .............................. 133

6.2 Eckfragment eines Klinendeckels (Kat. 44) ................................... 134

6.3 Fragment der Vorderseite eines Klinendeckels (Kat. 45) ........................ 135

6.4 Fragment der Vorderseite eines Klinendeckels (Kat. 46) ....................... 136

6.5 Linke Ecke eines Klinendeckels (Kat. 47) .................................... 138

6.6 Fragment der Schmalseite eines Klinendeckels (Kat. 48) …................... 138

\section{Lokale Sarkophagfragmente}

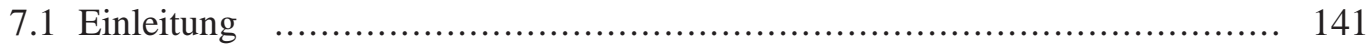

7.2 Kastenfragment mit fallender Amazone (Kat. L1) ............................ 141

7.3 Kastenfragment mit Leda und dem Schwan (Kat. L2) ........................... 143

7.4 Kastenfragment mit Leda (?) (Kat. L3) ..................................... 145

7.5 Kastenfragment eines Eroten-Weinlese-Sarkophags (?) (Kat. L4) ............. 146

7.6 Fragment eines Kastens: Fliehende (?) und Kniender mit Kind (Kat. L5) ..... 148

7.7 Fragment mit Löwenprotom (Kat. L6) ….................................. 149

7.8 Fragment eines Dachdeckels (Kat. L7) ...................................... 150

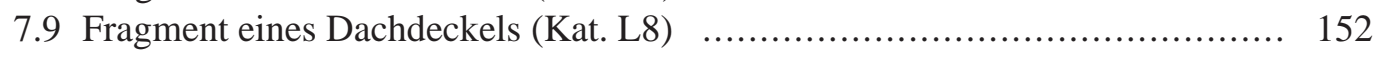

7.10 Fragment eines Dachdeckels (Kat. L9) ....................................... 153

8 Die Marmore der Sarkophagfragmente L1-L8 (Walter Prochaska)

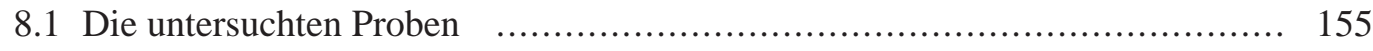

8.2 Die Untersuchungsmethoden ................................................... 155

8.2.1 Petrografische Beschreibung .......................................... 156 
8.3 Die analytischen Ergebnisse ...................................................... 158

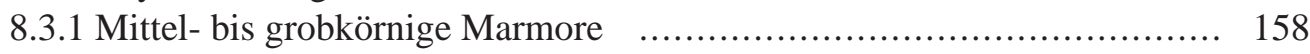

8.3.2 Feinkörnige Marmore .................................................... 161

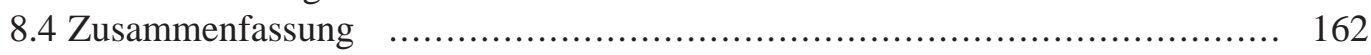

9 Ergebnisse zu den attischen Sarkophagen und den lokalen Fragmenten aus Ephesos

9.1 Attische Sarkophage ............................................................... 163

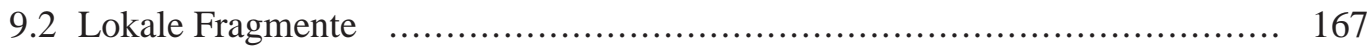

9.3 Die Fundorte der attischen Sarkophage und lokalen Fragmente (Carola Kintrup - Maria Aurenhammer)

10 Zusammenfassung - Summary - Özet

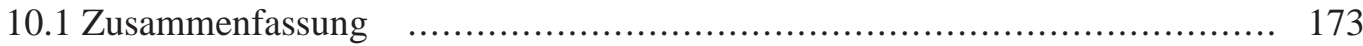

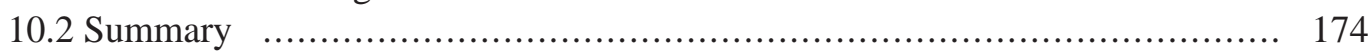

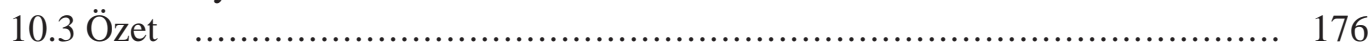

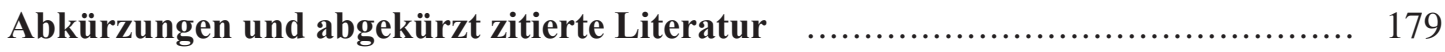

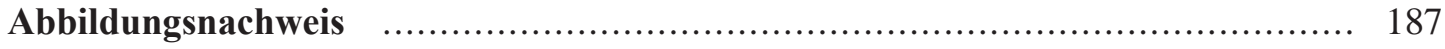

Tafeln 



\section{Vorwort der Grabungsleiterin}

Fünfzehn Jahre nach dem Erscheinen der Monografie von Ernst Rudolf zu den attischen Sarkophagen aus Ephesos liegt nun eine weitere Studie zu dieser Objektgruppe vor. Notwendig geworden war diese neuerliche Bearbeitung einerseits aufgrund von Neufunden, andererseits wegen eines Perspektivenwandels attischer sowie attisch beeinflusster Handwerkskunst in Kleinasien.

Die Basis der Untersuchung bildet die gründliche Dokumentation aller eindeutig klassifizierbaren Fragmente sowohl in Ephesos als auch in den dazugehörigen Depots. Die Niki Gail zu verdankende professionelle fotografische Aufnahme der Stücke trug maßgeblich zu der Qualität der vorliegenden Arbeit bei und bietet damit die Grundlage für weitere vergleichende Studien.

Bald zeigte sich, dass sich unter den sog. attischen Sarkophagen auch welche befanden, die zwar stilistisch eindeutig dieser Gruppe zuzuordnen waren, deren Material allerdings auf eine lokale Herkunft schließen ließ. Archäometrische Untersuchungen und ein Vergleich mit den ephesischen Marmorsteinbrüchen durch Walter Prochaska brachten schließlich den Nachweis einer lokalen Produktion von Sarkophagen attischen Typs in Ephesos.

Die genaue Autopsie der Stücke führte allerdings auch dazu, die im Freien aufgestellten Exemplare konservatorisch zu analysieren und einer Schadbildkartierung zu unterziehen. Eine im Rahmen einer Diplomarbeit von Barbara Rankl erfolgte eingehende Untersuchung des Amazonensarkophags hatte zur Folge, dass dieser nun nicht mehr im Freien Wind und Wetter ausgesetzt ist, sondern im Efes Müzesi einen geschützten Platz gefunden hat.

Maria Aurenhammer ist es zu verdanken, die wissenschaftliche Beschäftigung mit den ephesischen Sarkophagen in Angriff genommen und Carola Kintrup mit der Bearbeitung der attischen Gruppe betraut zu haben. Friedrich Krinzinger nahm das Projekt in das Forschungsprogramm der Ephesos-Grabung auf. Wenn die Studie nun gedruckt vorliegt, so ist dies vielen Personen zu verdanken, die aufgrund der beruflichen Neuorientierung der Autorin helfend eingegriffen und das Manuskript vollendet haben. In erster Linie ist es wiederum Maria Aurenhammer, deren Engagement weit über eine Projektleitung hinausging. Martin Steskal übernahm die Koordination der Sarkophag-Forschung und integrierte diese sinnvollerweise in seine übergreifende Studie zu den ephesischen Nekropolen. Barbara Beck-Brandt und Judith Kreuzer übernahmen Lektorat und Redaktion, Andrea Sulzgruber Satz und Layout. Dem Verlag Holzhausen sei für die autorenfreundliche Begleitung während des Entstehungsprozesses des Buches großer Dank ausgesprochen.

Wie bei allen Feldprojekten sind es die türkischen Behörden und Kooperationspartner, die durch den gewährten Zugang zu dem Material und unterstützende Hilfe letztendlich erst eine Bearbeitung ermöglicht haben. Sie wurden nicht müde, die Depots immer wieder auf- und zuzusperren, damit wir jeder noch so kleinen Frage nachgehen konnten. Daher gilt auch ihnen ein herzliches Dankeschön! 



\section{Vorwort der Autorin}

Der vorliegende Band beinhaltet die attischen Sarkophage und deren Nachahmungen aus Ephesos, und zwar vor allem die Funde aus Grabungen des Österreichischen Archäologischen Instituts, aber auch jene aus Grabungen des Efes Müzesi in Selçuk und die Ankäufe dieses Museums sowie ephesische Sarkophage, die in englische Sammlungen gelangten. Die Studie erwuchs aus dem von 2000 bis 2006 vom Fonds zur Förderung der wissenschaftlichen Forschung unterstützten Projekt zu den Sarkophagen aus Ephesos, im Rahmen dessen Margarete Heinz zunächst alle Sarkophage und Sarkophagfragmente sichtete und dokumentierte. Aufgrund der großen Materialfülle wurde der Verfasserin in einem fortgeschrittenen Stadium des Projekts die Publikation der attischen Sarkophage übertragen. Das Manuskript wurde 2011 abgeschlossen, spätere Literatur konnte nur in Einzelfällen eingearbeitet werden.

Finanziert wurden die Aufnahme und Bearbeitung der attischen Sarkophage durch das ÖAI unter Friedrich Krinzinger und Sabine Ladstätter in den Jahren 2005 und 2011.

Für eine wunderbar intensive, produktive und freundschaftliche Zusammenarbeit möchte ich mich in erster Linie bei Margarete Heinz und der Projektleiterin Maria Aurenhammer bedanken, auf deren Initiative ich zu der Mitarbeit an dem Sarkophag-Projekt eingeladen wurde.

Mein Dank ergeht an die Direktoren und die Kolleginnen und Kollegen des Efes Müzesi in Selçuk, insbesondere an Mustafa Büyükkolanc1, die Museumsfunde zugänglich machten und in großzügiger Weise für die Bearbeitung zur Verfügung stellten.

Ebenso großzügig und hilfreich waren Rita Amedick, Johanna Auinger, Niki Gail, Guntram Koch, Georg Plattner, Martin Steskal und Hans Taeuber mit Hinweisen und Informationen zu verschiedenen Stücken, Publikationsgenehmigungen und Fotos. Ernst Rudolf stellte dankenswerterweise seine Unterlagen zu den Sarkophagen aus Ephesos dem Archiv des Österreichischen Archäologischen Instituts zur Verfügung. 



\section{Einleitung}

Die attischen Sarkophage ${ }^{1}$ bilden mit den stadtrömischen und den kleinasiatischen Sarkophagen die drei großen Gruppen der kaiserzeitlichen Sarkophagplastik². Die Produktion attischer Sarkophage mit figürlichen Friesen setzt um 140 n. Chr. ein ${ }^{3}$, das Ende wird nach der Mitte des 3. Jahrhunderts veranschlagt. In der älteren Literatur wurde der sog. Herulereinfall im Jahre 267 n. Chr. dafür verantwortlich gemacht ${ }^{4}$, in der jüngeren werden vornehmlich allgemeine wirtschaftliche Gründe dafür angegeben 5 .

In der Forschung stellte F. Matz d. Ä. bereits 1873 die attischen Sarkophage als eine autonome Gattung vor ${ }^{6}$. Im Rahmen des Corpus der Antiken Sarkophagreliefs (ASR) übernahm C. Robert in Band III 2 von 19047 bereits die Ergebnisse W. Altmanns ${ }^{8}$, der die attische Herkunft der "griechischen« und "griechisch-römischen« Gruppe bei Roberts vorangegangenen CorpusBänden ermittelt hatte ${ }^{9} .1930$ zeigte G. Rodenwaldt in seinem Artikel zu dem Klinensarkophag von S. Lorenzo ${ }^{10}$, dass für die attischen Sarkophage »kunstgeschichtliche Maßstäbe« gelten und infolge dessen eine relativ-chronologische Ordnung aufgestellt werden kann. Die Publikationen von B. G. Kallipolitis ${ }^{11}$ im Jahre 1958 und insbesondere jene von F. Matz ${ }^{12}$ und N. Himmelmann ${ }^{13}$ im darauffolgenden Jahr lieferten wertvolle Hinweise für die Erarbeitung einer relativen Chronologie attischer Sarkophage, welche auf die gesamte Gattung anwendbar sind. In der Rezension von A. Giulianos Listenwerk von $1962^{14}$ konnte H. Wiegartz weitere Grundlagen für die Erstellung relativchronologischer Reihen geltend machen ${ }^{15}$, welche in ein Gerüst aus absolut zu datierenden Sarkophagen eingebettet werden können ${ }^{16}$. In Anwendung und Erweiterung dessen erarbeitete er anhand der attischen Sarkophagfragmente aus Myra ${ }^{17}$ weitere Kriterien bezüglich der tektonischen, stilistischen und bildtypologischen Entwicklung attischer Sarkophage ${ }^{18}$.

1 Zu dem Ursprung des Begriffs »Sarkophag«: Koch - Sichtermann 1982, 23-25. Zu dem Begriff »attisch« s. zusammenfassend Rodenwaldt 1930, 124, und s. u. mit Anm. 6-8.

2 Nach Rogge 1995, 15, wurde die Zahl der erhaltenen attischen Sarkophage und Sarkophagfragmente auf mindestens 1500 Stücke geschätzt, die Zahl der stadtrömischen Stücke auf etwa 6 000, während von der Hauptgruppe der kleinasiatischen Sarkophage nur ca. 400 Stück nachweisbar sind. Einen Überblick jüngeren Datums über die attischen Sarkophage bietet Koch 2012, 35-56.

3 s. Wiegartz 1974, 361; Wiegartz 1977, 385; Koch - Sichtermann 1982, 369. 456; Koch 1993, 97. 108. Zu dem Beginn der Produktion attischer Sarkophage in spättrajanisch-frühhadrianischer Zeit: Himmelmann-Wildschütz, 1959, 25; F. Matz, Gnomon 31, 1959, 697 (Rez. zu Kallipolitis 1958); Wiegartz 1965b, 614.

4 So Giuliano 1962, 15; K. Schauenburg, Gymnasium 70, 1963, 284 (Rez. zu Giuliano 1962); G. M. A. Hanfmann, Gnomon 49, 1977, 825; Saverkina 1979, 13. Zu dieser Invasion von germanischen Stämmen in Griechenland (sog. Herulereinfall) vgl. in jüngerer Zeit Goltz - Hartmann 2008, 285 f.; Martin - Grusková 2014, 102.110.

5 s. Rodenwaldt 1930, 186-189; Wiegartz 1965b, 614 f.; Wiegartz 1975, 251; Koch - Sichtermann 1982, 457-460; Linant de Bellefonds 1985, 12; Koch 1993, 108-110; Stefanidou-Tiveriou 1993, 133-139; Kintrup 2016a, Kap. 8; S. 208 mit Anm. 1155; S. 215.

6 Matz 1873, 11-18. Zu dem Begriff »Sarkophag« s. o. Anm. 1.

7 Robert 1904, $170 \mathrm{f}$.

8 Altmann 1902, 86-94.

9 Zu der frühen Konzeption der ASR-Bände und zu deren weiteren Planung: Wiegartz 1971, 86-92. Zur Forschungsgeschichte: Wiegartz 1978, 667-676.

10 Rodenwaldt 1930, 116-189.

11 Kallipolitis 1958, passim.

12 F. Matz, Gnomon 31, 1959, 693-698 (Rez. zu Kallipolitis 1958).

13 Himmelmann-Wildschütz 1959, 25-31 (zu attischen Erotensarkophagen).

14 Giuliano 1962, passim.

15 Wiegartz 1965b, 612-617.

16 Zu Eckdaten einer Chronologie, s. u. mit Anm. 58-74.

17 Wiegartz 1975, 161-251.

18 Zu dem Begriff der »Tektonik«: Gabelmann 1977, 199 f. 
Nach den Publikationen des Sarkophag-Corpus zu den dionysischen Sarkophagen ${ }^{19}$ und den Meleager-Sarkophagen ${ }^{20}$, die auch die attischen Exemplare berücksichtigten, erschien 1995 erstmals ein Corpus-Band, der ausschließlich attische Sarkophage, nämlich die attischen Achill- und Hippolytos-Sarkophage ${ }^{21}$, untersuchte. Die ausführliche und detaillierte Bearbeitung trägt der Bedeutung der attischen Sarkophage, die als Leitgattung der kaiserzeitlich attischen Plastik gelten können ${ }^{22}$, Rechnung.

Eine wertvolle Sammlung attischer Sarkophage beinhaltet auch das »Handbuch der Archäologie, Römische Sarkophage« von $1982^{23}$, obschon eine eingehende Untersuchung der einzelnen Exemplare an der Stelle selbstverständlich nicht möglich war ${ }^{24}$. Einen aktuelleren Überblick zur Situation in der Türkei bietet G. Koch ${ }^{25}$. Für die attischen Importe in Ephesos sind die beiden Monografien von E. Rudolf ${ }^{26}$ als grundlegende Arbeiten neueren Datums zu nennen ${ }^{27}$.

Die Besonderheiten der attischen Sarkophage und ihre Abgrenzung gegenüber den zwei anderen großen Gruppen der kaiserzeitlichen Sarkophagplastik lassen sich wie folgt darstellen ${ }^{28}$ : Attische Sarkophage wurden in Athen aus pentelischem Marmor gefertigt ${ }^{29}$. Alle vier Seiten eines attischen Sarkophags sind reliefiert. In aller Regel bieten die Sarkophage mit Figurenfriesen zwei Hauptansichtsseiten - die Vorderseite und eine Schmalseite. Die zweite Schmalseite und noch deutlicher die Rückseite wurden in der Ausführung hingegen vernachlässigt ${ }^{30}$. Das bei stadtrömischen Sarkophagen so beliebte Einfügen von Porträtköpfen in einen mythologischen Zusammenhang kommt auf attischen Sarkophagen nicht vor. Es ist ein charakteristisches Merkmal der attischen Sarkophage, dass sich Begebenheiten aus einem menschlichen und solche aus einem mythischen Kontext nicht kombiniert auf einer Sarkophagseite finden ${ }^{31}$. Ein seltenes Beispiel, bei dem die verschiedenen Seiten eines Sarkophags mythische und menschliche Kontexte zeigen, findet sich auf einem Sarkophag in Athen, Magazin bei der Akademie Platons ${ }^{32}$. Auch das zweioder mehrmalige Auftreten einer Figur auf einer Sarkophagseite ist bei attischen Sarkophagen

19 Matz 1968. »Korrekturen und Erweiterungen« zu den dionysischen Sarkophagen: Wiegartz 1977, 386-388. Allgemein zu der Vorgehensweise bei einer »chronologischen Ordnung der attischen Sarkophage«: Wiegartz 1977, $384 \mathrm{f}$.

20 Koch 1975, passim.

21 Rogge 1995, passim.

22 Wiegartz 1977, 383; Rogge 1995, 18.

23 Vgl. Koch - Sichtermann 1982, 366-475; 390-392 zu »Amazonen«. Den Kapiteln »Schlacht vor Troja«, Koch Sichtermann 1982, 405-410, und »Schlacht bei den Schiffen vor Troja und bei Marathon«, Koch - Sichtermann 1982, 410-414, sind Listen angefügt. Die Liste der Schlachtsarkophage beinhaltet 70 Stück, Koch - Sichtermann 1982, 408-410, die der Sarkophage mit der Schlacht bei den Schiffen vor Troja 21 Stück, Koch - Sichtermann 1982, 413 f.; die Anzahl der Amazonomachie-Sarkophage wird mit ca. 85 Exemplaren veranschlagt: Koch - Sichtermann 1982, 391 Anm. 2. Zu zwei Fragmenten mit der Schlacht bei Marathon: Koch - Sichtermann 1982, 414; Kintrup 2016a, Kap. 5.2.9. Die attischen Importe in Ephesos finden auf S. 520 Erwähnung. s. dazu auch in einem zusammenfassenden Aufsatz mit dem Titel »Kaiserzeitliche Sarkophage in Ephesos« von G. Koch (Koch 1999, 555-563).

24 »Da die attischen Sarkophage zum überwiegenden Teil nur unzureichend publiziert sind, lässt sich diese bedeutende Gattung kaiserzeitlicher Plastik nur in vorläufiger Weise beurteilen.«, so Koch - Sichtermann 1982, 368.

25 Koch 2010, 111-182.

26 Rudolf 1989, passim; Rudolf 1992, passim.

27 Allgemein zur Forschungsgeschichte von Ephesos s. z. B. Wohlers-Scharf 1995, 42-44; Wiplinger - Wlach 1995; Friesinger - Krinzinger 1999. Zu den Forschungen der letzten Jahrzehnte vgl. die wissenschaftlichen Jahresberichte des ÖAI bis 2009 in den ÖJh, ab dem Bericht 2008 auch online abrufbar: <https://www.oeaw.ac.at/oeai/ kommunikation/jahresberichte/> (24. 7. 2017).

${ }^{28}$ Vgl. die Einleitung des Corpus-Bandes zu den attischen Achill- und Hippolytos-Sarkophagen bei Rogge 1995, 15-18, sodass hier Entsprechendes in Kürze und mit Verweisen dargestellt werden kann.

29 s. Wiegartz 1974, 347; Koch - Sichtermann 1982, 374.

30 Koch - Sichtermann 1982, 369; Koch 1993, 20. Vgl. dazu stadtrömische Sarkophage: Koch - Sichtermann 1982, 63-65; Koch 1993, 17. 43. Zu kleinasiatischen Sarkophagen: Koch - Sichtermann 1982, 498 f.; Koch 1993, 21 f.

31 Vgl. Koch - Sichtermann 1982, 378; Koch 1993, 98.

32 Koch - Sichtermann 1982, 379 f. 432 Nr. 56 Abb. 408. 460. 469; Vanderpool 1964, 293 Taf. 91, 1; Wiegartz 1975, 197 mit Anm. 208; 216 mit Anm. 306; Oakley 2011, 13 f. 70 f. Nr. 4 Taf. 4-6. 
die Ausnahme, während bei den stadtrömischen die kontinuierende Darstellungsweise üblich, ja sogar typisch ist ${ }^{33}$.

Die Darstellungen attischer Sarkophage sind vornehmlich der griechischen Mythologie entlehnt. Neben den Amazonomachie-Sarkophagen als größter Gruppe, gefolgt von Schlachtszenen $^{34}$, finden sich häufig Achill-, Hippolytos- und Meleager-Szenen ${ }^{35}$. Eroten, dionysische Sarkophage und auch solche mit dekorativem Schmuck sind recht zahlreich vertreten, Musen, Meerwesen und Darstellungen aus dem Menschenleben bleiben die Ausnahme ${ }^{36}$. Das Themenspektrum unterscheidet sich damit deutlich von den stadtrömischen Sarkophagen, auf denen sich eine größere Zahl an Mythen findet ${ }^{37}$. Auf stadtrömischen Exemplaren sind im Gegensatz zu den attischen Sarkophagen Jahreszeitendarstellungen und Szenen aus dem Themenkreis Menschenleben ${ }^{38}$ sehr beliebt. Hierher gehören auch die stadtrömischen Schlachtsarkophage, welche Schlachten gegen Gallier oder allgemein gegen Barbaren darstellen ${ }^{39}$. Die attischen Schlachtsarkophage zeigen dagegen keine Figuren, die ikonografisch als Barbaren gekennzeichnet sind. Bei den Sarkophagen mit Kämpfen bei Schiffen, einer Thematik, die für stadtrömische Sarkophage nicht belegt ist, sind zwei Fragmente in Brescia ${ }^{40}$ und Pola ${ }^{41}$ erhalten, die orientalisch charakterisierte Barbaren zeigen ${ }^{42}$.

Die Datierung attischer Sarkophage anhand von Porträts, wie es bei stadtrömischen Sarkophagen üblich ist, kann aufgrund der wenigen erhaltenen Stücke nur selten erfolgen. Einige frühe Beispiele zeigen singuläre Darstellungen, bei denen Köpfe von Relieffiguren am Sarkophagkasten Porträtzüge tragen. In zwei Fällen - ein Löwenjäger zu Pferd auf der Vorderseite eines Sarkophags in Patras ${ }^{43}$ und ein reitender Eberjäger auf der linken Schmalseite des bereits genannten Sarkophags in Athen ${ }^{44}$ - wird trotz der wenig prägnanten, sondern eher summarisch gearbeiteten Gesichtszüge eine Datierung um 150/160 angesetz ${ }^{45}$. Bei der ebenfalls einzigartigen Darstellung von Faustkämpfern im Vatikan scheinen die Köpfe im Nachhinein überarbeitet worden zu sein ${ }^{46}$. Eine Datierung über die Porträts der Klinenfiguren ist erst ab 160/170 n. Chr. möglich: In dieser Zeit vollzog sich der Wechsel von Dach- zu Klinendeckeln ${ }^{47}$, welche durch die gelagerten Figuren

33 So Koch - Sichtermann 1982, 377 f. mit den wenigen attischen Beispielen. Dort ist auch der Achill-Sarkophag in Woburn Abbey genannt, aber s. dazu hier unter Kat. 3.

34 Zu der Deutung der Schlacht- und Epinausimachie-Sarkophage als mythologische Darstellungen s. Kintrup 2016a, 205.

35 Zu einer Vielzahl anderer Mythen, die in geringer Zahl belegt sind, s. Oakley 2011.

36 Koch 1993, 97 f.; Beispiele zu dem Bereich Menschenleben: Wiegartz 1975, 196 f.

37 Dazu Koch - Sichtermann 1982, 89 f.; 376; Koch 1993, 97.

38 Koch - Sichtermann 1982, 90-126; Amedick 1991.

39 Koch - Sichtermann 1982, 90-92; Koch 1993, 66 f.

40 Zingerle 1907, 157 Abb. 50; Koch - Sichtermann 1982, 412. 413. 414 Nr. 22; 459 Abb. 446; Stella 2003, 94 (Abb.) 101 (Abb.); Kintrup 2016a, Kap. 5.2.9 Nr. 77.

41 Zingerle 1907, 157-162 Taf. 5; Ciliberto 1996, 62 f. 105 f. Nr. 84 Taf. 11 d-f.; Cambi 2002, 162 f. Abb. 249; Kintrup 2016a, Kap. 5.2.9 Nr. 162.

42 Da sich beide Stücke auch durch andere Kriterien von den übrigen Exemplaren absetzen, werden sie im CorpusBand der attischen Sarkophage mit Schlachtszenen in einem Exkurs behandelt, s. Kintrup 2016a, Kap. 5.2.9. Zur ausführlichen Deutung der zwei Fragmente auf die Schlacht bei Marathon im Vergleich: Zingerle 1907, 159-162. Lit. zu den früheren Deutungen des Brescianer Reliefs auf die Marathonschlacht bei Zingerle 1907, 162 Anm. 11; s. auch Wiegartz 1975, 197 Anm. 209.

43 Wiegartz 1975, 177 Anm. 99; 182; Koch - Sichtermann 1982, 379 f. Abb. 406.

44 s. o. Anm. 32; Wiegartz 1975, 177 Anm. 99; 182; Orlandos 1963, 14-16 Abb. 15-18; Daux 1964, 690-692 Abb. 15-18; Oakley 2011, 13 f. 70 f. Nr. 4 Taf. 4-6.

45 Koch - Sichtermann 1982, 380. Vgl. auch Rogge 1993, 111 mit Anm. 7: »Als wirkliche Porträts mag man die Köpfe der Jäger aber nicht bezeichnen ...«.

46 Inv. 9482: Wiegartz 1975, 196 f.; Himmelmann 1970a, H. 9, 14 Anm. 1; Koch - Sichtermann 1982, 381 Abb. 407; Koch 1993, 52. Zwei weitere Sarkophage, in Kephisia und Myra, seien hier erwähnt. Sie haben je auf einer Schmalseite einen Tondo mit einer Bildnisbüste, die aber nicht ausgeführt wurde, s. dazu ausführlich Wiegartz 1975, 177 Taf. 88, C.

47 Etwas später veranschlagt wird der Wechsel zu Klinendeckeln bei Wiegartz 1975, 188 f.; Wiegartz 1977, 386; Koch - Sichtermann 1982, 371 f.; Rogge 1993, 112 f. 116 f. s. auch hier unter Kat. 1 mit Anm. 127. 
und die Porträtköpfe dem Bedürfnis der Inhaber nach individueller Repräsentation entgegenkamen $^{48}$. Es wurden aber bei Weitem nicht alle Porträts ausgeführt, sondern die Köpfe oftmals in Bosse belassen ${ }^{49}$.

Die Bedeutung von Sarkophagen im Kontext eines Grabbaus ist im Hinblick auf eine Chronologie der Sarkophage zweitrangig. Aus der Aufstellung mehrerer Sarkophage in einem Grabbau lassen sich zwar Schlüsse auf die Belegungsabfolge ziehen, jedoch handelt es sich dabei lediglich um eine relative Chronologie ${ }^{50}$.

Neben Porträts von Klinenfiguren können Inschriften einen chronologischen Aussagewert haben, sind aber auf attischen Sarkophagen leider sehr selten ${ }^{51}$. Auftraggeber ließen Inschriften für die es keinen kanonischen Platz gab - nachträglich anbringen, wodurch sich die unterschiedlichen Positionen der Anbringung ergaben. Inschriften finden sich am oberen Kastenabschluss und an der Sockelzone ${ }^{52}$, sie konnten an Dach- und Klinendeckeln ${ }^{53}$ oder bei frühen Stücken sogar am Kasten in den Relieffries - auf den frei bleibenden Reliefgrund zwischen den Figuren - eingearbeitet $\operatorname{sein}^{54}$.

Der Aussagewert von Inschriften für eine absolute Chronologie ist bei attischen Sarkophagen eingeschränkt. Beispielsweise gilt für zwei Sarkophage in Tyros ${ }^{55}$, dass die Inschriften wohl nicht bei der Erstbestattung, sondern erst bei einer später erfolgten Wiederverwendung angebracht

48 Vgl. Wiegartz 1975, 177.

49 s. z. B. den Amazonomachie-Sarkophag in Thessaloniki Inv. 1245: Koch - Sichtermann 1982, 391 mit Anm. 11; 458 Abb. 421; Kintrup 1998, 212 f. Taf. 94, 3; Kintrup 2016a, Kap. 3.2.13 Nr. 247; den Schlachtsarkophag in Tyros Inv. 4048/4049: Koch - Sichtermann 1982, 407. 410 Nr. 67; 459. 467; Chéhab 1985, 600 f. Taf. 122-125; Kintrup 2016a, Kap. 4.2.13 Nr. 262; oder den Achill-Sarkophag in Tyros Inv. 328: Chéhab 1968, 28-34; 75 f. 82 f. Taf. 13-16; Koch - Sichtermann 1982, 385 f. 458; Rogge 1995, 143 f. Nr. 42 Taf. 52, 1. Zu weiteren Beispielen s. die Auflistung bei Rogge 1993, 111 mit Anm. 9-11. Für eine Zusammenstellung und Erörterung der Begründungen, warum die Porträtköpfe nicht ausgeführt wurden, s. Koch - Sichtermann 1982, 611-614. Die in Bosse belassenen Köpfe können ein Indiz für eine Vorratswirtschaft der attischen Werkstätten sein, s. dazu Kintrup 2016a, Kap. 8 S. 215.

50 Zu Grabbauten mit attischen Sarkophagen und z. T. mit lokalen Stücken: Koch - Sichtermann 1982, 368 mit Anm. 33; Koch 1993, 44 mit Anm. 195; Rogge 1993, 111; Rogge 1995, 16 mit Anm. 7-10. Wiegartz 1975, 177 f.

51 Von den bei stadtrömischen Sarkophagen so beliebten Inschriften-Tabulae wurde bei attischen Stücken nur in Ausnahmefällen Gebrauch gemacht: Rogge 1995, 17 mit Anm. 17. Allgemein zu Sarkophagen mit Inschriften: Koch - Sichtermann 1982, 25-27, z. B. Abb. 109. 114. 119. 248. 282. 285; Koch 1993, 47-49 Abb. 29 f.

52 s. z. B. den Schlachtsarkophag des Aemilius Aristides, Kat. 1 (Taf. 5 Abb. 9): Eine Inschrift ist auf der oberen Leiste und eine unter den Sockelornamenten der Vorderseite eingemeißelt. Bei dem dionysischen Sarkophag in Thessaloniki Inv. 1247, ist eine Inschrift auf der Sockelzone angebracht: Matz 1968, 112-116 Nr. 11 Taf. 18 Beil. 7; Castritius 1970, 93-110; Koch - Sichtermann 1982, 420-422 Abb. 450.

53 Bei einem Amazonomachie-Sarkophag in Tyros Inv. 2772/2773, s. Chéhab 1968, 36-40; 81 f. Taf. 17-21; Chéhab 1984, 451-453 Taf. 77-79; Kintrup 2016a, Kap. 3.2.1 Nr. 259, findet sich eine Inschrift auf der Vorderseite und eine auf der rechten Schmalseite des Dachdeckels im Giebelfeld. Ein Epinausimachie-Sarkophag in Tyros Inv. 4038/4039, s. Koch - Sichtermann 1982, 373 Anm. 64; 411 f.; 413 Nr. 10; 445; 459; 467 Abb. 444; Linant de Bellefonds 1985, 28-30. 99-101. 106-108. 119 f. 179 Taf. 35 f. 37, 1; Kintrup 2016a, Kap. 5.2.8 Nr. 261 bietet eine Inschrift auf der rechten Schmalseite des Klinendeckels. - Ein Klinendeckel in Ioannina, s. I. Vokotopoulou, ADelt 30, 1975 (1983) Chron 213, Taf. 121, 3, und der Meleager-Sarkophag Split 1076A, s. Koch 1975, 145 f. Nr. 178 Taf. 139 a, zeigen die Inschrift auf der Vorderseite der Matratze. Auf der Oberseite des Klinenauflagers findet sich die Inschrift des Erotensarkophags Ostia 34/34A: Calza 1940, 211-213 mit Abb. 112-114; Koch Sichtermann 1982, 430 Nr. 22; Koch 1993, 105 Abb. 61.

54 So bei zwei dionysischen Sarkophagen in Athen und Istanbul. Sarkophag des Magnos Eryades, Athen Inv. 1185: Matz 1968, 103 f. Nr. 7 Taf. 7, 2; 8; Wiegartz 1977, 388 Anm. 90; Koch - Sichtermann 1982, 456. Istanbul Inv. 1417, s. Matz 1968, 98 f. Nr. 1, Taf. 1, 1; Koch - Sichtermann 1982, Abb. 447. Die Inschrift befindet sich jeweils zwischen zwei Figuren in der Mitte der Vorderseite. - Der Achill-Sarkophag Neapel Inv. 124325: Koch Sichtermann 1982, Abb. 411; Rogge 1995, 133 Nr. 19 Taf. 26, 2; 30, 2; 31, zeigt eine Inschrift zwischen und über den Köpfen der Frontseitenfiguren; zwei Buchstaben wurden auf die Innenansicht des Schilds Achills graviert. Das Fragment eines Meleager-Sarkophags, Brüssel Inv. A 1546: Koch 1975, 139 f. Nr. 162 Taf. 129 c, bietet eine Inschrift, die zwischen den Figuren auf dem Reliefgrund eingemeißelt ist, und eine weitere Inschrift darüber auf dem gewölbten Profil über einem Rundstab.

55 s. o. Anm. 53. 
wurden und somit als Anhaltspunkte für die Datierung des Sarkophags wertlos sind ${ }^{56}$. Zudem geben Inschriften durch ihre Schrifttypen oder Schlussfolgerungen auf den Inhalt der Texte oft nur indirekte Hinweise auf die Datierung, weswegen nur eine grobe chronologische Einordnung zu gewinnen ist ${ }^{57}$.

Von den folgenden Exemplaren lassen sich dennoch chronologische Eckdaten für die attischen Sarkophage ableiten:

Einen besonderen Stellenwert hat der Sarkophag des Prokurators Aemilius Aristides in Ephesos, hier Kat. 1 (Taf. 1-25), der Inschriften und ein Deckelporträt aufweist. An einem Postament unter dem Sarkophag ist eine Abtretungsurkunde angebracht ${ }^{58}$, die durch die Nennung der Konsuln um 204 n. Chr. zu datieren ist ${ }^{59}$ und somit einen wichtigen Fixpunkt in der Chronologie darstellt. Das Deckelporträt des Aemilius Aristides ist nun aber stilistisch in die Jahre um 220 einzuordnen und damit deutlich später als der Sarkophag anzusetzen. Dies führt zu der Schlussfolgerung, dass das Porträt erst nach dem Tod des Aristides selbst ausgeführt wurde und nicht schon bei Aufstellung des Sarkophags anlässlich des Todes seiner Frau ${ }^{60}$.

Der Schlachtsarkophag des Aemilius Aristides mag eine Ausnahmeerscheinung sein, aber ein zeitlicher Abstand zwischen der Fertigung eines Sarkophags und der Ausarbeitung der Klinenporträts sollte zumindest als Möglichkeit in Betracht gezogen werden ${ }^{61}$. Demzufolge können die folgenden chronologisch geordneten Datierungen von Sarkophagen besonders anhand von Klinenporträts als nützliche Anhaltspunkte für die zeitliche Einordnung angesehen werden, die aber in Übereinstimmung mit tektonischen und ikonografischen Kriterien des Sarkophagkastens gebracht werden sollten ${ }^{62}$.

- Amazonomachie-Sarkophag in Paris: um 160-170 n. Chr. ${ }^{63}$

- Schlachtsarkophag des Aemilius Aristides in Ephesos: Kasten um 204 n. Chr., Deckelporträt um 220 n. Chr. ${ }^{64}$

56 Zu weiteren Beispielen mehrfacher Belegung s. Rogge 1993, 122 mit Anm. 153; Rey-Coquais 1979, 286-288.

57 s. z. B. den Sarkophag des Magnos Eryades in Athen, s. o. Anm. 54, der anhand der Inschrift um 160 n. Chr. angesetzt wird, s. F. Matz, Gnomon 31, 1959, 697 (Rez. zu Kallipolitis 1958); Wiegartz 1965b, 614. - Die Sockelinschrift des dionysischen Sarkophags der Poplia Antia Damokratia in Thessaloniki Inv. 1247, s. o. Anm. 52, bietet Anhaltspunkte für eine Datierung aufgrund prosopografischer Hinweise: Castritius 1970, 97. Des Weiteren wird in der Inschrift eine so hohe Geldstrafe für die unautorisierte Benutzung der Grablege genannt, dass anzunehmen ist, die Inschrift stammte aus einer Zeit der fortgeschrittenen Geldentwertung im 3. Jh. n. Chr. In Kombination mit stilistischen Kriterien wurde der Sarkophag an das Ende der attischen Sarkophage, »mindestens in die sechziger Jahre des 3. Jh.s« gesetzt, Wiegartz 1965b, 614. Zu einer Datierung des Sarkophags anhand tektonischer Kriterien s. Wiegartz 1977, 386 f., bes. 388 mit Anm. 90. s. Wiegartz 1977, 383-388 zu übergeordneten Kriterien für eine Chronologie attischer Sarkophage, die an den dionysischen Sarkophagen beschrieben und überprüft werden, aber durchaus auch auf andere Gruppen anwendbar sind.

58 Inschrift und Sekundärliteratur s. hier Kat. 1.

59 Zu den Konsuln s. Degrassi 1952, 57. 178.

${ }^{60}$ s. ausführlicher zu den Datierungen von Sarkophag und Porträt unter Kat. 1.

61 Stilistisch greifbare Differenzen werden vielleicht dadurch verursacht, dass Exemplare längere Zeit in der Werkstatt unverkauft verblieben, der Transportweg weit und zeitaufwendig war, oder eine Ausführung der Porträts mit Verzögerung in Auftrag gegeben wurde oder zur Ausführung gelangte. Man stelle sich nur vor, dass ein Sarkophagbesitzer zwar den Sarkophag aufstellen ließ, aber sein Porträt noch nicht zu seinen Lebzeiten darauf ausgeführt sehen wollte. s. auch u. mit Anm. 97.

62 s. dazu z. B. einen Amazonomachie-Sarkophag in London, British Museum Inv. GR 1846.8-31.1, GR 1846.831.2, GR 1846.8-31.3: Robert 1890, 129-132 Nr. 110 Taf. 45 Abb. 110-110 c.; Koch - Sichtermann 1982, 391 mit Anm. 13; 398 mit Anm. 9; 458; Walker 1990, 40 f. Nr. 45 Taf. 18; Kintrup 2016a, Kap. 3.2.9 Nr. 130. Zwei Klinenporträts gelten als zugehörig, da sie zusammen mit dem Sarkophagkasten gefunden wurden. Die Porträts werden um 240-250 n. Chr. eingeordnet, aber eine Datierung des Kastens ist aufgrund tektonischer, ornamentaler, ikonografischer und stilistischer Kriterien eher ein wenig früher, nämlich um 240 n. Chr., zu veranschlagen.

${ }^{63}$ Louvre Inv. Ma 2119: Zu Beschreibung und Datierung der beiden Porträts s. Rüsch 1969, 81 f. 115 Nr. P12; Bergmann 1977, 82 Anm. 322; Koch - Sichtermann 1982, 389 f. 391 f. 440 Nr. 36; 456. 458 Abb. 420; Baratte 1985, 256-261 Nr. 166 mit Abb.; Kintrup 2016a, Kap. 3.1.1.1.1 Nr. 152.

64 Ausführlich s. hier Kat. 1. 
- Klinen-Riefel-Sarkophag in Athen: um 230/240 n. Chr. ${ }^{65}$

- Sarkophag mit dem Kampf bei den Schiffen vor Troja in Damaskus: um 230/240 n. Chr. ${ }^{66}$

- Amazonomachie-Sarkophag in London: Kasten um 240 n. Chr., wohl zugehörige Deckelporträts um 240-250 n. Chr. ${ }^{67}$

- Achill-Sarkophag in Rom: um die Mitte des 3. Jahrhunderts n. Chr. ${ }^{68}$

- Schlachtsarkophag in Tyros: um die Mitte des 3. Jahrhunderts n. Chr. ${ }^{69}$ (Es handelt sich um eine grobe Einordnung anhand einer unvollendet gebliebenen Scheitelzopffrisur des erhaltenen weiblichen Porträtkopfes.)

- Achill-Sarkophag in Beirut: um die Mitte des 3. Jahrhunderts oder kurz danach ${ }^{70}$

Datierungen, die über die sechziger Jahre des 3. Jahrhunderts n. Chr. hinausgehen, basieren auf dem Stil der Sarkophagreliefs: der dionysische Sarkophag in Thessaloniki Inv. 124771 , ein Fragment mit Eroten, ebenfalls in Thessaloniki ${ }^{72}$, und der Pelops-Sarkophag in Athen ${ }^{73}$ gehören an das Ende der Reihe der attischen Sarkophage und damit an das Ende ihrer Produktion um 260/270 n. Chr. ${ }^{74}$.

Das Desiderat einer neuen Vorlage der attischen Sarkophage aus Ephesos wurde von der Scientific Community immer wieder angesprochen. Die vorliegende Arbeit versteht sich als Materialvorlage: Es werden die attischen Sarkophage und Fragmente aus Ephesos unter 48 Katalognummern neu besprochen - ein Zuwachs von 16 Stück gegenüber früheren Studien ${ }^{75}$. Zudem werden sie zu einem großen Anteil mit neuen Aufnahmen vorgelegt ${ }^{76}$. Eine zusammenfassende Schau aller Sarkophage aus Ephesos und die Behandlung übergreifender Fragestellungen bleibt der aktuell in Bearbeitung befindlichen Gesamtpublikation aller Sarkophaggattungen aus Ephesos vorbehalten, zumal die attischen Sarkophage nur einen kleinen Teil ausmachen.

Neben den in den diversen Depots des Ephesos Museums in Selçuk aufbewahrten Objekten befinden sich heute einige attische Exemplare aus Ephesos in den Museen von Izmir, Oxford und

65 Nationalmuseum Inv. 1497: Koch - Sichtermann 1982, 457; Goette 1991, 323-325 Taf. 98 f.; Bielefeld 1993, 93 f. Taf. 41. Früher, nämlich spätseverisch, datiert L’Orange 1933, 12 Nr. 9. Deutlich später, um 250 n. Chr., angesetzt von Rodenwaldt 1930, 134, und Wiegartz 1965b, 614.

66 Nationalmuseum Inv. 25662: Zur Beschreibung und Datierung des Porträts s. Kintrup 2000, 125-137; Kintrup 2016a, Kap. 5.2.4.1 Nr. 84; Koch 1989a, 188, datiert das Porträt um 240/250 n. Chr., so auch Koch 1989b, 177, und Koch 1996, 203 f., mit der Vermutung, dass das Porträt in Syrien ausgeführt wurde.

67 s. o. Anm. 62.

68 Museo Capitolino Inv. 218: L’Orange 1933, 9-11 Nr. 2; Wiegartz 1965b, 614; Koch - Sichtermann 1982, 7 f. 366 Anm. 1; 373 Anm. 68; 383-385; 457 f. Abb. 413; Rogge 1995, 45. 136-138 Nr. 24 Taf. 44-47; 49 f. 68.

69 Inv. 3951/3952: Koch - Sichtermann 1982, 405 f. 410 Nr. 66. 459. Abb. 443; Koch 1989a, 197-199 mit Abb. 47-50; Chéhab 1985, 501 f. Taf. 89-92; Rogge 1995, 65 f. 144 f. Nr. 43 Taf. 9; Kintrup 2016a, Kap. 4.2.17 Nr. 260.

70 Nationalmuseum Inv. 607: Koch - Sichtermann 1982, 373 Anm. 68; 377 Anm. 5; 385. 457 f. Abb. 414; Rogge 1995, 48 f. 126 f. Nr. 6 Taf. 52, 2; 53 f. 59, 2; 65, 1.

71 Diese Datierung wird durch die Sockelinschrift, s. o. Anm. 52. 57, unterstützt.

72 Wiegartz 1965b, 614; Stefanidou-Tiveriou 1997, 176-178 Nr. 137 (mit weiterer Lit.); 390 f. Abb. 350 f.

73 Koch - Sichtermann 1982, 404 f. Abb. 438; Stefanidou-Tiveriou 1993, 133 Taf. 58, 3; Oakley 2011, 46-49. $93-95$ Nr. 61; Taf. 54 f. 56, 1.

74 Koch - Sichtermann 1982, 457. s. o. mit Anm. 4 f.

75 Vgl. dazu: 20 Exemplare, die von Rudolf 1989 und 1992 bearbeitet worden waren, plus 10 Nachträge bei Koch 1991, 819 (Rez. zu Rudolf 1989), bzw. 32 Exemplare, die zuletzt von Koch 1999, 557, genannt wurden. In den Katalog hier wurden zwei weitere Exemplare nicht aufgenommen: 1. Auf einem alten Negativ (ÖAI Neg. I 265) ist ein männlicher, kurzgelockter Kopf abgebildet, da aber weder Fundort, Aufbewahrungsort noch eine Inventarnummer dazu gefunden wurden, ist es nicht einmal möglich, eine Zugehörigkeit zu einem Sarkophag abzusichern, sodass der Kopf nicht in den Katalog aufgenommen wurde. 2. Der bei Koch 1991, 819 Nachträge Nr. 5, erwähnte Kopf: »o. Nr. (?), im Museum (im 1. Raum, 4. Vitrine an rechter Seite, oben rechts): stark nach links gewandter, fragmentierter, bärtiger Kopf; scheint nach der Wiedergabe der Brauen, Augen und des Mundes zu einem attischen Sarkophag zu gehören.« Der Kopf ist an der genannten Stelle nicht mehr zu finden und ohne eine Abbildung, ohne Aufbewahrungsort oder Inventarnummer auch nicht auffindbar.

76 So bereits angemahnt: Koch 1991, 819. 
Woburn Abbey, einige sind verschollen. Im Rahmen der neuen Bearbeitung der attischen Sarkophage wurden schwerpunktmäßig Kriterien der Tektonik, Ornamentik, Ikonografie und des Stils untersucht. Diese Kriterien bilden die Grundlage für die Datierung der einzelnen Objekte und die Erstellung einer Chronologie der Gattung vor Ort.

Bei der Materialaufnahme in Ephesos ließ bei einigen Fragmenten allein die Makroskopie der Marmorsorte Zweifel an der attischen Provenienz aufkommen. Dieser Verdacht wurde durch die Analyse der Marmorproben bestätigt (s. hier Kap. 8). Technische, stilistische und typologische Kriterien verstärkten die Zweifel. Da aufgrund der genannten Kriterien eine Zugehörigkeit zu den stadtrömischen oder kleinasiatischen Sarkophagen ebenfalls auszuschließen war, wurde eine Fertigung in einer lokalen Werkstatt angenommen. Diese Fragmente finden sich hier unter den Katalognummern L1-L9.

Der Bedeutung für die attischen Sarkophage - nicht nur jener aus Ephesos - Rechnung tragend, wird mit dem Sarkophag des Aemilius Aristides aus dem Grabbau der Antonia Tatiane begonnen. Es folgen der Amazonomachie-Sarkophag aus demselben Grabbau und dann die anderen Sarkophage und Fragmente, nach Möglichkeit thematisch geordnet. 



\section{Sarkophage aus dem Grabhaus der Claudia Antonia Tatiane}

Im April 2005 wurden die Sarkophage des Grabhauses der Claudia Antonia Tatiane (Taf. 1) und die Kastenfragmente des attischen Hippolytos-Sarkophags aus einem Grabhaus der Nekropole nördlich des ephesischen Hafenkanals (Kat. 15) neu aufgenommen.

Die in 32 Kisten - vermischt mit anderen Skulpturenfragmenten (!) - gelagerten Fragmente der Sarkophage wurden aus dem im Grabungsgelände befindlichen Depot (Efes Kapalı Deposu) in das Efes Müzesi in Selçuk transportiert, dort systematisch sortiert, aufgenommen und fotografiert. So konnten 8 Stücke mit bearbeiteter Reliefoberfläche als »sicher nicht zum Tatiane-Grab oder zum Hippolytos-Sarkophag zugehörig « aussortiert werden, weitere 22 Stücke ohne bearbeitete Reliefoberfläche folgten, da sie weder aufgrund des Materials noch durch Bearbeitungsspuren einem bestimmten Sarkophag hätten zugeordnet werden können. Weitere 3 Fragmente wurden aufgrund ihrer Größe oder Kleinheit ${ }^{77}$ als nicht zu den Sarkophagen des Tatiane-Grabes oder dem Hippolytos-Sarkophag passend ausgeschieden ${ }^{78}$.

Des Weiteren konnten die früheren Zuweisungen F. Eichlers, die z. T. durch Buchstaben ${ }^{79}$ auf den Fragmenten angegeben sind, überprüft und neben wenigen Anpassungen etliche Zuordnungen aufgrund der Maße, des Marmors, des Stils oder der Oberflächenbehandlung vorgenommen werden.

Aus dem Grabhaus der Tatiane hat der Schlachtsarkophag des Prokurators [Quintus] Aemilius Aristides eine besondere Bedeutung für die Gattung der attischen Sarkophage, da Name und Rang des Sarkophaginhabers inschriftlich am Sarkophag überliefert sind und der Porträtkopf des Aemilius Aristides auf dem Klinendeckel erhalten ist. Zudem findet sich auf dem Postament des Sarkophags eine zugehörige, datierbare Inschrift ${ }^{80}$.

\subsection{Kastenfragmente mit Klinendeckel des Schlachtsarkophags des [Quintus] Aemilius Aristides (Kat. 1 Taf. 1-25)}

Gefunden in Ephesos, Grabhaus der Claudia Antonia Tatiane ${ }^{81}$ (1928-1929) (Taf. 1 Abb. 1). Feinkörniger, weißer Marmor.

Kasten: VS rekonstruiert ca. H 120; L 270; D 22. - Rechte Ss: H 120,5; H Bildfeld 63; L 119. Deckel: H 126; L 264; T 118.

Zu Einzelmaßen von Fragmenten s. u. bei deren Beschreibung.

77 Alle Maßangaben in dem Manuskript meinen cm.

78 Dies sind: Der rechte rundplastische Vorderlauf eines Pferdes, der deutlich zu groß (L 35) für die Zugehörigkeit zu den Sarkophagen ist. - Zu klein (H 13; L 8) für eine Zuordnung zu den Sarkophagen ist ein Fragment einer rechten Körperseite mit Ansatz des Beins aus hellem Marmor. Auf dem Fragment ist »r. Hüfte« und ein Pfeil » « vermerkt. - Nach dem Marmor - mit stärkeren Glimmereinschlüssen - und der Größe passt zu dem vorgenannten ein Pferdebein mit Huf (L 10,5).

79 Kleinasiatischer Säulensarkophag = A (neue Bearbeitung M. Heinz); attischer Schlachtsarkophag des Aemilius Aristides = B (hier Kat. 1); attischer Amazonomachie-Sarkophag = C (hier Kat. 2); attischer Hippolytos-Sarkophag = E (hier Kat. 15) - gehörte nicht zum Grabhaus der Tatiane. Für den von Eichler angenommenen »Sarkophag D = Erotensarkophag konnten keine eindeutigen Belege gefunden werden.

80 s. auch die Einleitung zu den attischen Sarkophagen.

81 Das Grabhaus befindet sich südöstlich des Magnesischen Tors vor der Stadtmauer, es wurde nach der Ausgrabung zugeschüttet. Zur Lage: Groh 2006, 111 f. und hier im Fundortplan Taf. 81 Abb. 330. 
Die Teile des Sarkophags sind mittlerweile auf verschiedene Aufbewahrungsorte verteilt:

- Depots des Efes Müzesi: Rechte Schmalseite, Inv. 12 (alte Inv. 1589), und zahlreiche Kastenfragmente im Efes Müzesi, Efes Kapalı Deposu.

- Die aus mehreren Fragmenten zusammengefügte rechte Ecke der Vorderseite sowie ein anpassendes Fragment der rechten Schmalseite, die aus der rekonstruierten Schmalseite herausgebrochen sind, befinden sich im Efes Müzesi Selçuk.

- Inschriftendepot, Regal 1470-1488, Inv. 2451a: wiederentdecktes Inschriftenfragment.

- Izmir, Archäologisches Museum Inv. 34: Klinendeckel mit Porträtkopf des Aristides.

- Izmir, Historisches und Kunsthistorisches Museum (İzmir Tarih ve Sanat Müzesi) Inv. 1555. 1556. 1013: drei Kriegerköpfe.

Lit.: Skizzenbuch 1928/29, Inv. 2370. 2371. 2451 (Keil); Keil 1929, 46-51 Abb. 26; Keil 1930, 7-12; Rodenwaldt 1930, 135 f.; Rodenwaldt 1933, 182 Anm. 8; Eichler 1944/45, 128 f. Nr. 1; Eichler 1946, 88 Anm. 10; 89 Anm. 16; 89 f. Anm. 24; 94 Anm. 42; 96 mit Anm. 45; Andreae 1956a, 87 f. mit Anm. 6; Kallipolitis 1958, 23 Nr. 107; Himmelmann-Wildschütz 1959, 26 Anm. 9; Giuliano 1962, 47 Nr. 249; Wiegartz 1965b, 614; RE Suppl. XII (1970) 1677 s. v. Ephesos (W. Alzinger); Bammer u. a.1974, 90 f.; Wiegartz 1974, 368 mit Anm. 55; Hanfmann 1975, 68 Abb. 144; Wiegartz 1975, 214 Anm. 292; Giuliano - Palma 1978, 36 Nr. 3 Taf. 36, 89; Koch - Sichtermann 1982, 373 Anm. 68; 407; 409 Nr. 28; 457; 459; 466 Abb. 441; Koch 1982, 180. 693 Nr. 5; Rudolf 1989, 40 f. 44. »Ephesos B« Taf. 20 f. Abb. 28-30; Wrede 1990, 35 Abb. 36. 37. 43; Rudolf 1992, passim; Rogge 1993, 111 mit Anm. 12; 118 Anm. 105; 119 Anm. 116; Rogge 1995, 17 f.; Rogge 1998, 208 Taf. 93, 1; Pietsch 1999, 456 f. 460 Taf. 93 f. (zum Grabhaus); Kintrup 2000, 127 f. mit Anm. 11 und 13; Russenberger 2015, 178 f. Abb. 89; 320. 612 f. Anm. 65; Kintrup 2016a, Kap. 4.2.1; 4.3 S. 143. 147 Nr. 87.

Zu den Inschriften: Keil 1929, 47-51 Abb. 27; Wenger 1929, 328-344; Degrassi 1952, 57. 178; Reynolds - WardPerkins 1952, 30 Nr. 10; Pflaum 1960, 677 f. Nr. 250; Ferrari 1966, 33; IvE 2051. 2121. 2204A; Rudolf 1992, 18-21; 28-32; 32-34 Taf. 1 Abb. 2; Taf. 10-12; Taf. 29; İplikçioğlu 1993, 28-30; Reynolds 1999, 134; HarterUibopuu 2014, 159-161.

Der Klinendeckel (Taf. 4 Abb. 8) wurde bereits 1911 entdeckt, weil er aber zu dem Zeitpunkt nicht gehoben werden konnte, geriet er in Vergessenheit und wurde erst 1928 wiederentdeckt. Nach ihrer Freilegung wurden die Klinendeckel des Grabhauses der Claudia Antonia Tatiane in das Archäologische Museum nach Izmir gebracht.

Trotz des fragmentarischen Zustands des Kastens gelang F. Eichler bereits 1930 eine erste zeichnerische Rekonstruktion der rechten Schmalseite (Taf. 1 Abb. 2). Eine Anpassung der Fragmente der rechten Schmalseite wurde in etwas abgeänderter Form erst 1962 vorgenommen. Die so restaurierte Sarkophagseite war im Ephesos Museum Selçuk bis 1983/1984 ausgestellt (Taf. 2 Abb. 3) und kam anschließend in das Depot. Die aus mehreren Fragmenten zusammengefügte Ecke mit dem Torso der weiblichen Eckfigur ${ }^{82}$ (VS: H 55; L 16) (Taf. 3 Abb. 4-6) sowie das anpassende Fragment mit deren linkem Bein und dem rechten Arm des Verwundeten, der die rechte Hand des Helfers auf der Schulter hat (Taf. 3 Abb. 7) ${ }^{83}$, sind aus der rechten Schmalseite erneut herausgebrochen und werden heute im Depot des Museums aufbewahrt. Das Fragment der rechten Schmalseite mit dem linken Bein der weiblichen Eckfigur erhielt eine eigene Inventarnummer (Inv. 8/4/77), wodurch sich erklärt, dass das Fragment von G. Koch ${ }^{84}$ als Einzelfragment separat beschrieben wurde. Das Fragment Inv. 8/4/77 wurde von M. Heinz `wiederentdeckt « und die Zugehörigkeit zur rechten Schmalseite des Aristides-Sarkophags erkannt.

Die rechte Schmalseite (Inv. 12; alte Inv. 1589) im Efes Kapalı Deposu, der Klinendeckel (Inv. 34) mit dem Porträtkopf des Aristides im Archäologischen Museum in Izmir (Taf. 4 Abb. 8) und drei zugehörige Kriegerköpfe (Inv. 1555. 1556. 1013) im Historischen und Kunsthistorischen Museum in Izmir konnten in Augenschein genommen werden. Ein Fragment mit einem Teil der

\footnotetext{
82 Zur Benennung s. u.

83 Die Unterseite des Fragments ist glatt abgesägt.

84 Koch 1991, 819 Nr. 9.
} 
griechischen Inschrift (Inv. 2451a) konnte im Inschriftendepot in Ephesos (Regal 1470-1488) erneut aufgefunden werden.

Von der Vorderseite, der linken Schmalseite und der Rückseite des Kastens sind nur Fragmente erhalten. Die linke Schmal- und die Rückseite wurden im Vergleich zur Vorderseite und rechten Schmalseite weniger aufwendig gearbeitet. Auf den Fragmenten der Vorder- und rechten Schmalseite sind die Augenbrauen eingetieft, auch Augen- und Mundwinkel, Ohren- und Nasenlöcher sowie die Haare der Krieger sind mit Bohrungen versehen.

\section{Inschriften $^{85}$}

Auf der Vorderseite des Kastens waren oben und unten je einzeilige Inschriften angebracht ${ }^{86}$. Für die lateinische Inschrift auf der oberen Leiste wurde ein Mäanderdekor zwischen zwei Eckfeldern abgearbeitet. Die Buchstabenhöhe der lateinischen Inschrift beträgt maximal 4,7 cm; die Buchstabenhöhe der griechischen Inschrift liegt bei 3-3,5 cm. Die griechische Inschrift wurde an der Sockelzone unter den Sockelornamenten angebracht (Taf. 5 Abb. 9).

Lateinische Inschrift

- - - Aristi]DES P[ro(curator)] AVGG ${ }^{87}$

Griechische Inschrift

[KYINTOYAIMI $\Lambda$ I]OY KYINTOYY[IOYAPI $\Sigma T] E I \Delta O Y$ EПI[TPO]ПOY $[T \Omega N \Sigma E B A \Sigma T \Omega N]]^{88}$

Die Inschriftenreste in Latein und Griechisch identifizieren den Verstorbenen als Aemilius Aristides ${ }^{89}$ und nennen seinen Titel, Prokurator.

Von den Fragmenten mit Stücken der Inschriften wurden wieder aufgefunden:

- Fragment 1 (Taf. 7 Abb. 14)

Skizzenbuch 1928/29, Inv. 2370 (IvE 2204A): Fragment Inv. 2370a (im Skizzenbuch ist unter der Inv. 2370a nur das linke Stück mit Inschrift der anpassenden Fragmente abgebildet)

L 38,7; H 15,5. Zwei anpassende Fragmente mit dem rechten Ende der lateinischen Inschrift und dem folgenden rechten oberen Eckfeld sowie darunter ein lesbisches Kyma. Auf dem Stein steht »B 21 I + B 21 II .

- Fragment 2 (Taf. 7 Abb. 15)

Fragment Inv. 2370b

L 13,2; H 9,8. Fragment der lateinischen Inschrift mit geringen Resten des lesbischen Kymas darunter. Auf dem Fragment ist »B 23« vermerkt.

85 Wichtige Hinweise zu den Inschriften werden Hans Taeuber verdankt.

36 s. die Rekonstruktion Rudolf 1992, Taf. 29, hier Taf. 5 Abb. 9.

87 »Aristides, Prokurator der Augusti«: Lesung nach Rudolf 1992, 19. 32-34 Taf. 12. 29. Eine andere Lesung bieten IvE 2204A, und İplikçioğlu 1993, 29 f.

- - - (?) proc.] AVGG.[

- - - e]QES R[omanus - - - (= eq(u)es)

Römischer Ritter und Beamter, wohl Prokurator, unter zwei gemeinsam regierenden Augusti. Diese Lesung nach Rudolf erscheint wahrscheinlicher, da der Titel Procurator Augustorum auch in der griechischen Inschrift,

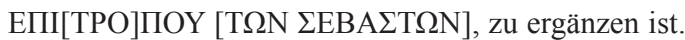

88 s. IvE 2204A; İplikçioğlu 1993, 29; Rudolf 1992, 18 f. 32-34 Taf. 10 f. 29.

89 Der Name Quintus ist an dem Sarkophag nur für den Vater belegt und für den Sohn dann in einer weiteren Inschrift aus Sabratha, die mit dem Sarkophaginhaber in Verbindung gebracht wird: Reynolds - Ward-Perkins 1952, 30 Nr. 10; Pflaum 1960, 677 f. Nr. 250. 
- Fragment 3 (Taf. 7 Abb. 16)

Skizzenbuch 1928/29 Inv. 2451 (IvE 2204A): Fragment Inv. 2451c

L 5,3; H 11. Fragment mit dem Beginn der griechischen Inschrift (s. u.). Auf dem Stein steht »B Fußleiste $\lll$.

- Fragment 4 (Taf. 7 Abb. 17)

Fragment Inv. 2451a

H 25; L 23. Das Fragment galt als verschollen, zumal es von F. Eichler bereits 1962 nicht mehr aufgefunden worden war. Nun konnte es im Inschriftendepot wieder entdeckt werden ${ }^{90}$.

Das Sockelfragment hatte wohl ursprünglich noch Teile von Flechtband und lesbischem Kyma über der griechischen Inschrift erhalten, darauf lässt zumindest eine Skizze aus dem Nachlass Eichlers schließen ${ }^{91}$. Eventuell könnte der untere Teil des zusammengesetzten Fragments Nr. 26 (Taf. 13 Abb. 41) angepasst haben.

- Fragment 5 (Taf. 7 Abb. 18)

Fragment Inv. 2451b

L 23,3; H 6. Zwei anpassende Fragmente mit Teilen der griechischen Inschrift.

- Fragment 6 (Taf. 7 Abb. 19)

Fragment, Inv. nicht gefunden

Ein weiteres Fragment ist im Skizzenbuch abgebildet: L 27,5; H 22,5. Anpassende Fragmente der Sockelzone mit Flechtband, lesbischem Kyma und Resten der griechischen Inschrift.

- Fragment 7 (Taf. 8 Abb. 20)

Skizzenbuch 1928/29 Inv. 2371 (IvE 2121)

Eine weitere griechische Inschrift, die auf dem Postament unter dem Schlachtsarkophag angebracht war (Taf. 8 Abb. 20) ${ }^{92}$. Es handelt sich dabei um eine Urkunde, die sich durch die Nennung zweier Konsuln in das Jahr $204 \mathrm{n}$. Chr. datieren lässt ${ }^{93}$. Die beiden Augusti in den oben genannten Inschriften am Sarkophagkasten können somit nur Septimius Severus und Caracalla gewesen sein.

Die Urkunde besagt, dass Claudia Antonia Tatiane ihrem Bruder Aemilius Aristides in ihrem Grab Raum für einen Sarkophag abtritt. Der Text stellt eindeutig den Bezug zu dem Tod der Ehefrau des Aemilius Aristides her: Sarkophag und Raum im Grabhaus der Antonia Tatiane wurden für die Bestattung der Frau des Aemilius Aristides in Anspruch genommen ${ }^{94}$. Im Jahre $204 \mathrm{n}$. Chr. konnte der Sarkophag auch nicht für Aemilius Aristides bestimmt gewesen sein, denn die Inschrift einer Basis im Theater von Ephesos, die den Prokurator in jenen Jahren als Stifter von Statuen der kaiserlichen Familie nennt ${ }^{95}$, belegt, dass er 208/209 n. Chr. noch lebte.

\footnotetext{
90 Hinweis Johanna Auinger.

91 s. Rudolf 1992, Abb. 17.

92 s. Keil 1929, 48-50 Abb. 27; IvE 2121; Rudolf 1992, 28-32 Taf. 1 Abb. 2; İplikçioğlu 1993, 28 f.; Harter-Uibopuu 2014, 159-161.

93 Degrassi 1952, 57. 178; Wenger 1929, 329.

94 Rudolf 1992, 29; Harter-Uibopuu 2014, $160 \mathrm{f}$.

95 IvE 2051. Zu dieser und der griechischen Inschrift im Grabbau auch İplikçioğlu 1993, 28-30. Zu der in der Literatur zu dieser Inschrift oft genannten Datierung 208/211: Rudolf 1992, 29 Anm. 111.
} 
Porträt (Taf. 6)

Dass Raum und Sarkophag nicht für Aemilius Aristides selbst gedacht waren, wird auch durch sein auf dem Klinendeckel erhaltenes Porträt ${ }^{96}$ unterstützt. Das Porträt ist nach den im Folgenden untersuchten Vergleichsstücken nämlich erst kurz vor bis um 220 n. Chr. anzusetzen ${ }^{97}$.

Dem Porträtkopf des Aemilius Aristides (Taf. 6 Abb. 10-13) fehlt die Nase; weitere Beschädigungen betreffen die Augenbrauen, die Oberlippe und das Kinn. Seiten- und Rückansicht des Porträts sind vernachlässigt ausgeführt. Grobe Meißelspuren setzen im Haar hinter den Ohren an. Auf der Halsrückseite belegen Bearbeitungsspuren, dass die >Nackenstütze` abgearbeitet wurde ${ }^{98}$. Dadurch sowie durch die Ausarbeitung des Porträts ist anzunehmen, dass es in einer lokalen Bildhauerwerkstatt hergestellt wurde.

Der Porträtkopf zeigt eine leicht kantige Kopfform. Aemilius Aristides trägt kurzes, plastisch ausgeführtes Haupt- und Barthaar, wobei das Haupthaar aus einer etwas erhöhten Kalotte gearbeitet ist. Zwei Stirnfalten sind eingetieft, und über den Oberlidern ist je eine gebohrte Linie eingearbeitet. Die Augen sind mit einem geritzten Irisumriss und einer herzförmig gebohrten Pupille gestaltet ${ }^{99}$.

Im Rahmen der Kaiserporträts bieten zwei Porträts des Macrinus (217-218 n. Chr.), die im Kapitolinischen Museum mit Inv. $1757^{100}$ und Inv. 460 ${ }^{101}$ aufbewahrt werden, Parallelen zu dem Klinenbildnis des Aemilius Aristides. Beide Porträts haben eine länglichere Kopfform sowie einen längeren Bart als das Klinenbildnis. Das Porträt Inv. 460 zeigt Kaiser Macrinus im Vergleich zu Inv. 1757 mit einem längeren Bart; Bart- und Haartracht sind plastischer und aufwendiger gearbeitet, selbst die Rückseite ist nicht auffallend vernachlässigt. Das schlichter gearbeitete Porträt Inv. 1757 mit deutlich vernachlässigter Rückseite weist zu dem Bildnis des Aemilius Aristides mit seiner für Klinenporträts üblichen Vereinfachung der Ausführung engere Parallelen auf. Bei dem Aristides- und dem Macrinus-Porträt finden sich Ähnlichkeiten in Bezug auf die Haargestaltung, die strähnig bis teilweise flockig gearbeitet ist. Kontur und Höhe der Haarkalotte sind vergleich-

96 Die häufiger in der Porträtforschung diskutierte Problematik einer Unterscheidung von >Modegesicht $<$ und Individualgesicht ist hier von geringer Bedeutung, da die Benennung geklärt ist und es im Rahmen dieser Untersuchung nicht um die individuellen Züge des Porträts geht, sondern vor allem darum, chronologische Anhaltspunkte für eine Datierung zu erhalten - nach Möglichkeit anhand von Vergleichen mit Kaiserporträts, da diese datiert sind. Es geht also um den Nachweis der Übertragung der Charakteristika eines (Kaiser-)Porträts, des >Zeitgesichts und der >Modefrisur`, auf ein Privatporträt zum Zwecke der Datierung. Dass vorhandene Merkmale, wie etwa Stirnfalten, auch individuell zutreffend dargestellt wurden, ist damit nicht ausgeschlossen. Um die Problematik eines Stilvergleichs von Klinenporträts und ihrer Parallelen unterschiedlicher Provenienz und unterschiedlicher Qualität zu minimieren, konzentrieren sich die Untersuchungen auf Charakteristika von Gesicht und Frisur des Porträts und der Vergleiche.

97 Allgemein sollte die Möglichkeit eines zeitlichen Abstands von der Fertigung eines Sarkophags bis zu der Ausführung der Deckelporträts in Betracht gezogen werden. So mögen Sarkophaginhaber ihre Grablege durchaus schon zu Lebzeiten gekauft haben und vielleicht auch schon aufgestellt haben lassen, doch mag es ihnen widerstrebt sein, ihr Porträt bereits auf der Grablege ausgeführt zu sehen. Weitere Möglichkeiten für einen zeitlichen Abstand sind vorstellbar: Einige Sarkophage blieben lange beim Hersteller, da sich kein Käufer fand. Der Transport in die Provinzen des Römischen Reiches konnte sicher einige Zeit dauern. Oder aber die Fertigung der Porträts durch lokale Bildhauer vor Ort nahm einige Zeit in Anspruch, bzw. wurde erst beim Tode des Inhabers in Auftrag gegeben. Durch die Kombination einiger der genannten Faktoren kann so eine zeitliche Differenz entstehen, die stilistisch zu fassen ist.

98 Nackenstützen verstärkten die in Bosse gefertigten Köpfe des Deckels für den Transport. Für in Bosse belassene Köpfe s. als Beispiele den Amazonomachie-Sarkophag in Thessaloniki Inv. 1245: Kintrup 2016a, Kap. 3.2.13 Nr. 247, den Schlachtsarkophag in Tyros Inv. 4048/4049: Kintrup 2016a, Kap. 4.2.13 Nr. 262, oder den AchillSarkophag in Tyros Inv. 328: Rogge 1995, 143 f. Nr. 42 Taf. 52, 1. Zu weiteren Beispielen s. die Auflistung bei Rogge 1993, 111 mit Anm. 9-11. Eine Zusammenstellung und Erörterung der Begründungen, warum die Porträtköpfe nicht ausgeführt wurden, s. Koch - Sichtermann 1982, 611-614; Zanker - Ewald 2004, 49 mit Anm. 76 (zu stadtrömischen Sarkophagen). Die in Bosse belassenen Köpfe können ein Indiz für eine Vorratswirtschaft der attischen Werkstätten sein, s. auch Kintrup 2016a, Kap. 8 S. 215.

99 Dazu und zu dem Folgenden s. ebenso Kintrup 2016a, Kap. 4.2.1.1.

100 Fittschen - Zanker 1994, 112 f. Nr. 95 Taf. 116 f.

101 Fittschen - Zanker 1994, 113 f. Nr. 96 Taf. 118 f. 
bar, die Stirnhaare sind leicht aufgeworfen, die kurzen Strähnen an den Schläfen nach hinten gekämmt und ein auffallender Abstand von den Ohren zum Wangenbart ist bei beiden zu erkennen. Beide haben tief liegende Augen; Blick und Kopf sind bei Aemilius Aristides deutlicher nach links gewendet. Die Mundpartie scheint verwandt, ist aber bei dem Klinenporträt beschädigt.

Auch zwei ephesische Privatporträts im Museum Selçuk (Inv. 84 und Inv. 2/32/83) zeigen Übereinstimmungen mit dem Klinenporträt des Aemilius Aristides. Der Kopf mit der Inv. 2/32/83 aus dem Hanghaus $2^{102}$ bietet durch seine Form, die Augenbildung sowie die kurze Bart- und Haartracht Parallelen zu dem Aemilius-Aristides-Kopf. Das Porträt im Museum Selçuk steht im Vergleich zu dem des Aristides auf einer weiterentwickelten Stilstufe; es präsentiert eine a-pennaGliederung des Haares, die in spätseverische Zeit weist ${ }^{103}$. Auch das Porträt Inv. 84 wird in die Regierungszeit des Alexander Severus (222-235 n. Chr.) datiert ${ }^{104}$. Der fragmentierte Kopf erlaubt keine Vergleiche der Haarbildung, ist aber durch seine geritzte und gebohrte Augenbildung mit dem Aristides-Porträt vergleichbar. Die Gestaltung des Barts ist weniger plastisch und zeigt Auflösungstendenzen, die im Vergleich zu dem Sarkophagporträt fortgeschritten sind, sodass Letzteres etwas eher anzusetzen ist ${ }^{105}$.

\section{Datierung}

Auf den genannten Vergleichen basierend, wird für das Sarkophagporträt des Aemilius Aristides eine Datierung kurz vor bis um $220 \mathrm{n}$. Chr. angenommen.

Die in der früheren Forschung auftretenden Probleme, die Datierung des Deckelporträts, das um bis zu $230 \mathrm{n}$. Chr. angesetzt wurde, mit der datierenden Zessionsurkunde und den tektonischen Anhaltspunkten des Sarkophagkastens, die in die Jahre um 200 n. Chr. weisen ${ }^{106}$, in Einklang zu bringen, werden durch die Differenzierung zwischen einer Datierung für den Sarkophag und einer für das Klinenporträt gelöst. Die Inschrift im Theater von Ephesos aus den Jahren 208/209 n. Chr. stellt den terminus post quem für den Tod des Aemilius Aristides dar. Dies wird durch den Porträtkopf unterstützt, der um $220 \mathrm{n}$. Chr. angesetzt werden konnte und somit höchstwahrscheinlich erst nach dem Tod des Aristides ausgeführt worden war. Die Abtretungsurkunde des Jahres 204 n. Chr. hingegen bietet den terminus ante quem für den Bau des Grabhauses und für die Fertigung des Schlachtsarkophags ${ }^{107}$. Dies stimmt auch mit den Befunden zu Tektonik, Ornamentik, Ikonografie und Stil am Sarkophagkasten überein, wie im Folgenden gezeigt wird.

102 Aurenhammer 1983, 133-140 Abb. 12 f.; zuletzt E. Rathmayr in: H. Thür - E. Rathmayer (Hrsg.), Hanghaus 2 in Ephesos. Die Wohneinheit 6. Baubefund, Ausstattung, Funde, FiE 8, 9 (Wien 2014) 368 f. 372. 392. 395.403 Kat. S 37 Taf. 154.

103 s. M. Aurenhammer in: Rudolf 1992, 34 f. Diesem Kopf an die Seite zu stellen ist ein Porträt mit fraglicher Identifizierung als Gordian I. Die Benennung des Kopfes gilt nur unter der Prämisse, dass sein Bildnis wohl vor seiner Regierungszeit, 220-230 n. Chr., entstanden ist, s. Fittschen - Zanker 1994, 123 f. Taf. 127 f. Als Privatporträt behandelt bei Meischner 1982, 421 Nr. 39; 423. 427 f. 430 Abb. 32, mit einer Datierung 205-215 n. Chr. Zu dem Sarkophagporträt bietet es einen eher allgemeinen Vergleich durch die Kopfform und die kurze Bart- und Haartracht. Die Bart- und Haargliederung zeigt eine frühe Stufe der a-penna-Technik, »wie sie sich ... zwischen 220 und 230 n. Chr. nachweisen lässt«. Fittschen - Zanker 1994, 124. In Bezug darauf ist das Bildnis weiterentwickelt als das des Aemilius Aristides. - Ein im Gesichtstypus vergleichbares Köpfchen aus der Wohneinheit 2 des Hanghauses 2 nennt M. Aurenhammer in: Rudolf 1992, 35 mit Anm. 148: İnan - Alföldi-Rosenbaum 1979, 181 f. Nr. 143 Taf. 116; zuletzt Christof 2010, 665 B-S9 Taf. 284.

104 Zum Vergleich s. Wiegartz 1974, 368 Anm. 55. Zur Datierung s. İnan - Rosenbaum 1966, 130 Nr. 157 Taf. $93,1$. 2, in Übereinstimmung mit Alzinger 1955, 27-29 Abb. 15 f. Dem Vergleich und der Datierung stimmt M. Aurenhammer zu in: Rudolf 1992, 34 f. Eine Datierung des Aristides-Porträts in die Jahre 220/230 schlug bereits Wiegartz 1965b, 614 aus stilistischen Gründen vor; dem folgend Koch - Sichtermann 1982, 407. 457.

105 So M. Aurenhammer in: Rudolf 1992, 35.

106 Lit. zur früheren Forschung s. Rudolf 1992, 28-32.

107 So auch Rudolf 1992, 29. Einzuwenden wäre lediglich, dass der Sarkophag möglicherweise erst beim Tode der Frau des Aemilius Aristides geordert wurde, damit wäre seine Fertigung in den Jahren 204/205 anzunehmen. 


\section{Sarkophagkasten: oberer Kastenabschluss und Sockelzone}

Auf den bevorzugt gearbeiteten Sarkophagseiten, nämlich der Vorder- und der rechten Schmalseite, wird der obere Kastenabschluss von Perlstab, Eierstab, lesbischem Kyma und einer breiten oberen Leiste gebildet. Die obere Leiste ist auf der rechten Schmalseite durch einen Metopenmäander ${ }^{108}$ mit Blütenfüllung dekoriert, während auf der Vorderseite das Mäanderdekor zugunsten der lateinischen Inschrift entfernt wurde. Auf der Vorderseite rahmen Eckfelder mit Meerwesen die obere Leiste.

Vergleiche für den Metopenmäander mit Rosetten als Dekor der oberen Leiste sind bei einigen Sarkophagen und Fragmenten mit unterschiedlichen Themen zu finden, so etwa bei dem Fragment eines Amazonomachie-Sarkophags in Athen ${ }^{109}$, den Fragmenten der Epinausimachie-Sarkophage in Tarent ${ }^{110}$, Plovdiv ${ }^{111}$ und Messene ${ }^{112}$, der Achill-Sarkophage in Adana ${ }^{113}$ und Neapel ${ }^{114}$, bei dem Freiermord des Odysseus in Athen ${ }^{115}$ und dem Fragment eines dionysischen Sarkophags in Theben $^{116}$. Die genannten Vergleiche können alle an das Ende des 2. und den Beginn des 3. Jahrhunderts n. Chr. datiert werden. Im Verlauf der folgenden Entwicklung verschwindet dieses Dekor von den oberen Leisten und es werden zunehmend vegetabile Schmuckformen verwendet, wobei die oberen Leisten zugleich niedriger werden.

Zwei sicher zu positionierende Fragmente belegen, dass die linke Schmalseite und die Rückseite vernachlässigt ausgeführt waren: Das Eckpostament Fragment 21 (Taf. 8 Abb. 21. 22) zeigt, dass die linke Schmalseite weniger sorgfältig gearbeitet war, und die Abbildungen des verschollenen Fragments der rechten oberen Ecke der rechten Schmalseite (Taf. 8 Abb. 23. 24) belegen, dass die obere Leiste auf der Rückseite ohne Dekor blieb, aber lesbisches Kyma und Eierstab - nur im Ansatz erhalten - auch auf der Rückseite vorhanden waren. Das lesbische Kyma ist dabei für eine Rückseite außergewöhnlich gut gearbeitet. In der Regel werden auf Rückseiten der attischen Sarkophage um die Jahrhundertwende lediglich nichtornamentierte Profile ${ }^{117}$ angegeben, während gut ausgeführte Rückseiten selten sind ${ }^{118}$.

Der Sockel des Sarkophags wird auf allen Seiten von Eckpostamenten begrenzt. Für die Sockelzone gilt, wie für den oberen Kastenabschluss, dass auf der Vorder- und der rechten Schmalseite die Profile und Ornamente bevorzugt ausgeführt waren. Auf der Vorder- (Taf. 5 Abb. 9) und der rechten Schmalseite (Taf. 2 Abb. 3) wird die Sockelzone zwischen den Eckpostamenten von einem seltenen dreireihigen Flechtband ${ }^{119}$, darüber einem lesbischen Kyma und der Standleiste

108 Die prägnante kurze Bezeichnung »Metopenmäander« wird von Rudolf 1992, 16. 19 übernommen, da beide Bestandteile des Dekors treffend in einem Begriff vereinigt sind; s. alternative längere Beschreibungen, z. B. als »Hakenkreuzmäander mit eingestreuten Rosetten auf quadratischen Platten« bei Rogge 1995, 125, oder »Kreuzmäander mit zwischengefügten Quadraten« bei Leon 1971, 279 f. Taf. 77, 4; 139, 3.

109 Depot der 3. Ephorie: Orlandos 1962, 11-14 Abb. 14; Daux 1963, 694-697 Abb. 13; Kintrup 2016a, Kap. 3.1.3.3 Nr. 46.

110 R. Belli Pasqua in: Andreassi 1995, 186 f. 201-205 Nr. VI.11; Kintrup 2016a, Kap. 5.1.1.1 Nr. 241.

111 Mateev 1982, 258-260 Abb. 1; Kintrup 2016a, Kap. 5.2.2 Nr. 161.

112 Themelis 1998, 8 f. Plan 5 Abb. 4 (Grabbau); Kintrup 2016a, Kap. 5.2.2 Nr. 139.

113 Budde 1964, 9-15 Taf. 1; Rogge 1995, 125 Nr. 1 Taf. 2, 1.

114 Koch - Sichtermann 1982, 383 Anm. 10 Abb. 411; Rogge 1995, 133 Nr. 19 Taf. 26, 2. 31.

115 Koch - Sichtermann 1982, 415 f. Anm. 17; Oakley 2011, 37. 86 Nr. 46 Taf. 35, 1.

116 Matz 1968, 120 Nr. 21 Taf. 26, 6.

117 s. z. B. Achill-Sarkophage in Adana und Beirut: Rogge 1995, 125 Nr. 1 Taf. 23, 4; 127 f. Nr. 7 Taf. 23, 1, einen Hippolytos-Sarkophag in Beirut: Rogge 1995, 151 Nr. 56 Taf. 83, 1, oder einen Amazonomachie-Sarkophag in Tyros: Chéhab 1984, 451-453 Taf. 77-79; Kintrup 2016a, Kap. 3.2.1 Nr. 259.

118 So z. B. Achill-Sarkophag in Neapel: Rogge 1995, 133 Nr. 19 Taf. 42, 2.

119 Der Begriff »dreireihig« bezeichnet die drei Reihen der Augen, welche die Kreuzungspunkte der geflochtenen Bänder ausfüllen. Zur Definition sowie zu einer Diskussion alternativer Bezeichnungen, s. Ganzert 1984, 155-160 Taf. 28. Innerhalb der attischen Sarkophage ist ein dreireihiges Flechtband als Sockelornament die Ausnahme, während in der Regel ein zweireihiges Flechtband erscheint, s. z. B. den Amazonomachie-Sarkophag hier in Ephesos (Kat. 6 Taf. 41 Abb. 169), ein Amazonomachie-Fragment in Istanbul, Archäologisches Museum Inv. 63: Koch - Sichtermann 1982, 391 mit Anm. 6; 458; Kintrup 2016a, Kap. 3.1.1.3 Nr. 101, Epinausimachie-Fragmente in Antalya, Archäologisches Museum Inv. A. 275: Koch 1975, 143 f. Nr. 172 Taf. 137 c-d; Kintrup 2016a, Kap. 
für die Figuren gebildet. Auf dieser Seite befand sich auch unter dem dreireihigen Flechtband die griechische Inschrift (Taf. 5 Abb. 9). Ein Flechtband und ein über ihm angeordnetes lesbisches Kyma sind typische Elemente im gut gegliederten Aufbau von Sockelzonen des letzten Viertels des 2. Jahrhunderts und des Beginns des 3. Jahrhunderts n. Chr. ${ }^{120}$, bei einem Schlachtsarkophag sind sie aber nur hier gesichert belegt.

Hier werden zuerst die Fragmente des oberen Kastenabschlusses und daran anschließend die Fragmente der Sockelzone im Einzelnen genannt. Alle Fragmente sind mit der Aufschrift »B« gekennzeichnet, sodass im Folgenden nur noch eventuelle zusätzliche Aufschriften angeführt werden.

Als Fragmente des oberen Kastenabschlusses sind erhalten:

Mit dem bereits oben genannten Fragment 1 (Taf. 7 Abb. 14) hat sich neben dem rechten Ende der lateinischen Inschrift das rechte obere Eckfeld mit einem von ursprünglich wohl zwei antithetisch gestellten Meereswesen erhalten.

- Fragment 8 (Taf. 9 Abb. 25)

Mit Fragment 8 (L 8; H 15,5; D 15,3) sind ebenfalls zwei anpassende Fragmente des oberen linken Eckfelds der Vorderseite sowie Reste eines unterhalb befindlichen lesbischen Kymas vorhanden. In der profilierten Rahmung ist der gewundene Schwanz mit einer gezackten Flosse am Ende zu erkennen. Der Stein ist mit »B Ecke« beschriftet.

Auf der rechten Schmalseite wurde der Metopenmäander seitlich von Eckfeldern eingefasst, wobei das linke wohl einen Oktopus zeigte und das rechte ein Rankendekor. Belege liefern die folgenden Fragmente:

- Fragment 9 (Taf. 9 Abb. 26)

Das Fragment 9 eines Eckfeldes (L 12,5; H 5,3; D 15) ist wegen seiner sorgfältigen Ausführung an einer bevorzugt gearbeiteten Seite zu rekonstruieren. Da die oberen Ecken der Vorderseite und die rechte obere Ecke der rechten Schmalseite (verschollener Kopf mit Eckfeld) belegt sind, kann das Fragment nur an die linke obere Ecke der rechten Schmalseite gehört haben. Die vielarmige Darstellung lässt einen Oktopus vermuten. In den Ritzen der Rahmung scheinen sich gelblich orange Farbreste erhalten zu haben.

- Fragment 10 (Taf. 9 Abb. 27)

Das ebenfalls gut gearbeitete Fragment 10 eines oberen Eckfeldes (L 5,5; H 7,8) zeigt ein Rankenmotiv. Der Stein ist mit »B 22 « beschriftet. Das Eckfeld weist eine einfachere Rahmung auf als die Eckfelder der Vorderseite und als Fragment 9. Die verschollene rechte obere Ecke der rechten Schmalseite ist in Form einer Skizze und einer Aufnahme im Archiv des ÖAI überliefert (Taf. 8 Abb. 23 f.). Das Eckfeld über dem Kriegerkopf war nach Ausweis der Abbildungen mit einem Rankenmotiv ohne gesonderte Rahmung geschmückt. Demnach gehörte Fragment 10 zu diesem Eckfeld.

Alternativ wäre noch eine Zuordnung zu der linken Schmalseite möglich; diese Zuweisung ist aber weniger wahrscheinlich, da das Eckpostament Fragment 21 (Taf. 9 Abb. 21) dokumentiert, dass die linke Schmalseite deutlich summarischer ausgeführt wurde: die Oberfläche ist nicht einmal geglättet, Bearbeitungsspuren blieben sichtbar.

- Fragment 11 (Taf. 9 Abb. 28)

Bei Fragment 11 handelt es sich um ein keilförmiges mit Falz von der Oberseite des Kastens (L 9,5; H 5,5). Bei einem Bruchstück der Innenseite des Sarkophags sind, soweit erhalten, die

5.2.1 Nr. 5 sowie Achill-Sarkophage in Adana: Budde 1964, $9-15$ Taf. 1; Rogge 1995, Taf. 2, 1, in Beirut: Rogge 1995, Taf. 1, 1; 7, 2, in London: Rogge 1995, Taf. 32, 1, den Hippolytos-Sarkophage in Istanbul: Rogge 1995, Taf. 76, 2, oder den Meleager-Sarkophag in Athen: Koch 1975, Taf. 128, 1.

120 s. die Beispiele o. Anm. 119. 
oberen $4 \mathrm{~cm}$ grob geglättet, darunter beginnt die mittlere Spitzmeißelarbeit, die typisch ist für Innenseiten attischer Sarkophage.

- Fragment 12 (Taf. 9 Abb. 29)

Das Fragment trägt die Aufschriften »B oben« und »Dübel « auf der Seite mit mittlerer Zahneisenbearbeitung (L 17; H 6). »Dübel« meint wahrscheinlich das Klammerloch; Klammerlöcher sind zumeist auf den Schmalseiten zu finden.

- Fragment 13 (Taf. 9 Abb. 30)

Das Fragment 13 (L 13,5; H 8) zeigt eine geglättete, rechtwinklige Eintiefung. Die Vermutung, dass es sich um ein Eckfeld handelt, liegt nahe. Weil keine Reliefreste vorhanden sind, wird es sich um ein Eckfeld einer vernachlässigt bearbeiteten Sarkophagseite handeln. Da zudem das verschollene Fragment der rechten oberen Ecke der rechten Schmalseite belegt, dass auf der Rückseite wohl keine Eckfelder vorhanden waren, darf angenommen werden, dass sich hier eines der linken Schmalseite erhalten hat.

Die folgenden Fragmente des oberen Kastenabschlusses lassen sich am Sarkophagkasten nicht genau positionieren, aber anhand ihrer Ausführung den bevorzugten oder nachlässig ausgeführten Seiten zuordnen. Einige Fragmente haben Reste des oberen Kastenabschlusses erhalten sowie darunter befindliche Teile des Relieffrieses und werden daher unten angeführt (Nr. 48-50).

- Fragment 14 (Taf. 9 Abb. 31)

Fragment 14, ein einzelnes Ei (L 5; H 9,5), gehört nach seiner hohen und geglätteten Ausarbeitung zu einer bevorzugten Sarkophagseite. Da auf der rechten Schmalseite nur wenige Elemente des Eierstabs fehlen, gehört das Fragment wahrscheinlich zu der Vorderseite.

Den weniger sorgfältig gearbeiteten Sarkophagseiten werden die folgenden Fragmente des oberen Kastenabschlusses zugeordnet. Sie verfügen weder über die Höhe des Reliefs, die Tiefe der Bohrungen noch den Grad an Glättung wie jene der Ansichtsseiten. Die Fragmente Nr. 15-19 zeigen alle eine nichtdekorierte obere Leiste sowie Teile des lesbischen Kymas und des Eierstabs.

- Fragment 15 (Taf. 10 Abb. 32)

Das Fragment (L 12,5; H 17) trägt die Aufschrift »B 29« in roter Farbe.

- Fragment 16 (Taf. 10 Abb. 33)

Fragment 16 besteht aus zwei Teilen (L 19; H 15,5). Die Aufschrift »B 28« mit Bleistift ist auf der Abbildung auf dem helleren linken Stück zu erkennen, »B 30« ist auf dem dunkleren rechten Stück verzeichnet.

- Fragment 17 (Taf. 10 Abb. 34)

Bei Fragment 17 handelt es sich um zwei anpassende Fragmente (L 33; H 19) des oberen Kastenabschlusses sowie ein einzelnes Ei (das 3. von links) - dieses passt unter der Bruchlinie an. Hier ist die Aufschrift »B 27 « mit Bleistift auf dem linken Teilstück zu erkennen, während »B 26« auf dem rechten Stück nur noch zu erahnen ist.

- Fragment 18 (Taf. 10 Abb. 35)

Das Fragment (L 16; H 13,5) zeigt - mit Bleistift geschrieben - »B 32«.

- Fragment 19 (Taf. 10 Abb. 36)

Drei anpassende Fragmente (L 39; H 18,5) des oberen Kastenabschlusses. Auf dem Stein ist »B 31 I + B 31 II + B 31 III« verzeichnet.

- Fragment 20 (Taf. 10 Abb. 37)

Bei dem Fragment (L 13; H 13,5) hat sich nur ein sehr kleiner Ansatz des Eierstabs unter dem lesbischen Kyma erhalten.

Die den nachlässiger bearbeiteten Sarkophagseiten zugeordneten Fragmente des oberen Kastenabschlusses ergeben gemeinsam bereits eine Länge von 132,5 cm, obwohl keine anpassenden 
Teile vorhanden sind. Somit wird deutlich die Länge von $119 \mathrm{~cm}$ überschritten, die die rechte Schmalseite aufzuweisen hat. Theoretisch wäre möglich, dass nur Fragmente der Rückseite erhalten sind, was jedoch einen kaum anzunehmenden Zufall darstellen würde. Zu vermuten ist daher, dass der obere Kastenabschluss der linken Schmalseite und der Rückseite gleich gut ausgeführt waren; in diesem Sinn sind auch auf den Abbildungen des verschollenen Fragments (Taf. 9 Abb. 23. 24) die Reste neben dem Kopf der Eckfigur zu vergleichen.

Von der Sockelzone sind erhalten:

Unter dem Flechtband befand sich auf der Vorderseite die griechische Inschrift. So finden die Fragmente mit Inschriftenresten, Fragment Nr. 3-6, durch die Ergänzung der Inschrift ihren Platz am Kasten (Taf. 5 Abb. 9). Zudem ist das rechte Eckpostament der rechten Schmalseite, Inv. 12 (Taf. 2 Abb. 3), mit dem anschließenden linken Eckpostament der Rückseite (Taf. 19 Abb. 91) größtenteils erhalten; beide zeigen ein Tierdekor.

Am Kasten sicher zu positionieren sind weiterhin die folgenden Fragmente:

- Fragmente 21 und 22 (Taf. 8 Abb. 21. 22)

Mit Fragment 21 (L 12,5; H 19,5; T 8,5) und Fragment 22 (L 11; H 10,5) sind zwei wahrscheinlich anpassende Fragmente (L Fragment 21 und 22: 16,5) des linken Eckpostaments der Vorderseite erhalten. Das teilweise zu erkennende Dekor der Vorderseite zeigt einen Baum und das Hinterteil eines liegenden Tiers, vielleicht eines Löwen; über der Standleiste sind Gewandfalten vorhanden. Das Dekor der linken Schmalseite ist nicht sicher zu identifizieren; es handelt sich wohl ebenfalls um das Hinterteil eines Tiers. Auf Fragment 22 steht »B Sockelecke«.

Fragment 22, 23 und auch Fragment 24 sind nicht in den abgebildeten Rekonstruktionszeichnungen von F. Eichler (Taf. 1 Abb. 2) und C. Rudolf (Taf. 5 Abb. 9) berücksichtigt.

- Fragment 23 (Taf. 11 Abb. 38)

Auch ein Fragment des rechten Eckpostaments der Vorderseite (L 10,5; H 7) ist erhalten. Es ist der Teil erhalten, der direkt unter dem mit Dekor geschmückten Feld - in Analogie zu der linken Ecke ist auch eine Tierdarstellung anzunehmen - ansetzte sowie das links davon beginnende Flechtband. Die Aufschriften lauten: »Ecksockel Rechts B unten«.

- Fragment 24 (Taf. 11 Abb. 39)

Auf der linken Bruchfläche des Fragments 24 sind ein Pfeil nach oben sowie - auf dem Kopf stehend - die Aufschriften »Flechtband«, »links« und »B« verzeichnet. Es handelt sich um das linke Ende des Flechtbands mit einem kleinen Ansatz des lesbischen Kymas darüber und Resten des Eckpostaments links (L 5; H 15). Nach der Ausführung des Flechtbands gehörte das Fragment zu einer bevorzugten Sarkophagseite, also an die linke Ecke der Vorderseite oder der rechten Schmalseite.

- Fragment 25 (Taf. 11 Abb. 40)

Nach den groben Bearbeitungsspuren an der Unterseite zu urteilen, gehört das Fragment 25 dem Sarkophagboden an. Da die zwei geglätteten Flächen im rechten und linken Winkel angebracht sind, muss es sich um ein Eckstück handeln.

Die folgenden Fragmente der Sockelzone ohne Anpassung lassen sich anhand ihrer Ausführung zumeist den sorgfältig oder vernachlässigt gearbeiteten Sarkophagseiten zuordnen. Den Sockeln der detailliert gearbeiteten Sarkophagseiten gehören die Fragmente Nr. 26-32 an:

- Fragment 26 (Taf. 11 Abb. 42)

Aus sechs anpassenden Stücken bestehendes Fragment (L 42; H 17,5) mit lesbischem Kyma und Flechtband. Aufschriften: »Zu B 11«.

- Fragment 27 (Taf. 11 Abb. 43)

Zwei anpassende Stücke (L 23; H 14) von lesbischem Kyma und Flechtband. Auf dem Stein steht »B $3 \ll$. 
- Fragment 28 (Taf. 11 Abb. 44)

Das aus vier Teilen bestehende Fragment 28 (L 33; H 13) hat unter dem lesbischen Kyma die Ansätze des Flechtbands erhalten. Auf dem Stein ist »B 18« vermerkt.

- Fragment 29 (Taf. 12 Abb. 45)

Auch das aus zwei Stücken bestehende Fragment 29 (L 18,5; H 8) bietet einen Ausschnitt des lesbischen Kymas. Auf dem Stein steht »B 7«.

- Fragment 30 (Taf. 12 Abb. 46)

Fragment 30 besteht aus zwei anpassenden Stücken (L 13; H 11,5) mit den erkennbaren Aufschriften »Flechtband « auf dem linken Teilstück sowie »Kyma« und »B« auf dem rechten. Auf dem rechten Bruchteil sind keine Reliefreste vorhanden, auf dem linken sind von dem Flechtband nur die rahmenden Rücksprünge erhalten; das Flechtband selbst ist komplett abgeschlagen. Darüber ist ein kleiner Ansatz des lesbischen Kymas zu erkennen.

- Fragment 31 (Taf. 12 Abb. 47)

Fragment 31 ist ein Flechtband (L 10,5; H 7) mit der Aufschrift »B 8«.

- Fragment 32 (Taf. 12 Abb. 48)

Fragment 32 (L 9; H 12) ist das Stück eines Flechtbands.

- Nicht näher einer Seite zugeordnet ist Fragment 33 (Taf. 12 Abb. 49):

Das Fragment (L 12,5; H 5) zeigt außer Bruchflächen nur ein Stück der Standleiste. Auf dem Fragment steht »B Fußleiste«. Es kann lediglich aufgrund der anscheinend gut geglätteten Standleiste einer bevorzugten Sarkophagseite zugeordnet werden.

- Ein weiteres Fragment sei hier erwähnt, da es möglicherweise auch zu dem Aristides-Sarkophag gehört, aber besonders aufgrund der größer erscheinenden Proportionen vorerst dem Hippolytos-Sarkophag (Kat. 15) zugeordnet wurde (s. u. Fragment 49) (Taf. 60 Abb. 242).

- Fragmente 34 und 35 (Taf. 12 Abb. 50. 51)

Die Fragmente 34 (L 13; H 5,5) und 35 (L 17; H 6) sind zu klein für eine sichere Zuordnung an eine betonte oder vernachlässigte Sarkophagseite. Bei beiden Fragmenten ist jeweils nur der obere Teil des lesbischen Kymas erhalten.

Auf den bevorzugt gearbeiteten Sarkophagseiten ist das lesbische Kyma dadurch gekennzeichnet, dass der obere Teil des Spornblatts und der Zwischenblüte gebohrte Konturen zeigt, während diese Konturen auf den vernachlässigten Seiten nicht aufgebohrt sind.

Den vernachlässigt gearbeiteten Sarkophagseiten gehören somit die Sockelfragmente Nr. 36-44 an:

- Fragment 36 (Taf. 12 Abb. 52)

Der erhaltene Teil des lesbischen Kymas (L 13,5; H 6) lässt im Ansatz erkennen, dass die Konturen des Spornblatts nicht gebohrt sind.

- Fragmente 37-40 (Taf. 13 Abb. 53-56)

Bei allen vier Fragmenten ist ein Stück des lesbischen Kymas erhalten, das darunter befindliche Flechtband ist abgeschlagen. Auf Fragment 37 (L 18; H 13) ist »B Rückseite unten « direkt unter dem lesbischen Kyma noch zu erkennen sowie »Eck L« auf der rechten Bruchfläche. Weiterhin steht auf dem Stein »B Rs«, auf Fragment 38 (L 17,5; H 12,5) »B Rs«. Auf Fragment 39 (L 15; H 13) ist »B 15 Rs« vermerkt, auf Fragment 40 (L 9,5; H 8) »B 14 Rs«.

- Fragment 41 (Taf. 13 Abb. 57)

Fragment 41 ist der mittlere Teil eines lesbischen Kymas (L 9; H 8) mit dem Vermerk »B As od Rs«.

- Fragment 42 (Taf. 13 Abb. 58)

Fragment 42 besteht aus dem unteren Teil eines lesbischen Kymas (L 11; H 6). Auf dem Stein steht »B Rs«. 
- Fragmente 43 und 44 (Taf. 13 Abb. 59. 60).

Bei den Fragmenten 43 (L 10; H 6) und 44 (L 6,5; H 6) handelt es sich um Teile eines Flechtbands, aber im Unterschied zu den Fragmenten der bevorzugten Seiten mit dem außergewöhnlichen dreireihigen Flechtband ${ }^{121}$ ist ein zweireihiges mit weniger Wölbung erhalten, wodurch sich eine Zuordnung zu einer vernachlässigten Seite des Sarkophags ergibt. Auf Fragment 43 ist »B 6« und auf Fragment 44 »B 5« vermerkt.

- Fragment 45 (Taf. 11 Abb. 41)

Das Fragment (L 13,5; H 4) trägt die Aufschrift »Fußleiste« in dem konkav gerundeten Abschnitt, bei dem es sich wohl um die Innenseite des Sarkophags (?) handelt. Die Orientierung ist unsicher.

\section{Sarkophagkasten: Relieffriese}

\section{Rechte Schmalseite}

$\mathrm{Zu}$ einem größeren Teil rekonstruiert ist die bevorzugt ausgeführte rechte Schmalseite mit der Inv. 12 (alte Inv. 1589) im Efes Kapalı Deposu des Efes Müzesi erhalten (Taf. 1 Abb. 2; Taf. 2 Abb. 3) $)^{122}$.

Die Schlachtszene der rechten Schmalseite wird von zwei über Eck gestellten Figuren gerahmt, nämlich links von einer weiblichen Figur und rechts von einem behelmten Krieger ${ }^{123}$. Die weibliche Figur ${ }^{124}$ kann in Analogie etlicher Vergleiche, etwa einem Amazonomachie- und einen Epinausimachie-Sarkophag in Thessaloniki ${ }^{125}$, zu einer Nike/Amazone ergänzt werden ${ }^{126}$. Nach den Abbildungen (Taf. 8 Abb. 23. 24) ragte der Kriegerkopf in das lesbische Kyma, reichte aber nicht bis zu der oberen Leiste. Der Kopf der Nike/Amazone darf in Bezug auf die Höhe sehr ähnlich rekonstruiert werden, denn rahmende Figuren ersetzten in der Entwicklung der attischen Sarkophagplastik stützende Eckfiguren, die bis direkt an die obere Leiste reichten. Mit dem Wechsel

121 s. o. mit Anm. 119.

122 s. zur Forschungsgeschichte auch die Einleitung und o. mit Anm. 83 f.

$123 \mathrm{Zu}$ dem verschollenen Kriegerkopf, s. o. unter Fragment 10.

124 Rudolf 1992, 16 Anm. 31 vermutet, dass der dort Abb. 21 gezeigte Kopf zu einer Nike/Amazone der Sarkophagvorderseite gehörte. Dies ist abzulehnen, denn zu dem Frisurtypus finden sich keine Vergleiche auf attischen Sarkophagen. Des Weiteren wurde der Kopf »im Hanghaus 1, Raum B, gefunden, Fundnr. H 62/2, Museum Selçuk Inv. 2455. Die Zugehörigkeit ist also sehr fraglich.« So Nachricht M. Aurenhammer, Brief 9. 6. 2000. s. dazu auch M. Aurenhammer in: C. Lang-Auinger (Hrsg.), Hanghaus 1 in Ephesos. Funde und Ausstattung, FiE 8, 4 (Wien 2003) 172 f. und bes. 174 mit Anm. 250; 202 Nr. S 69 Taf. 102 f. Das Köpfchen wird dort in das 4. Jh. n. Chr. datiert.

125 Amazonomachie: Archäologisches Museum Inv. 283, s. Koch - Sichtermann 1982, 391 mit Anm. 10; 458; Stefanidou-Tiveriou 1997, 166-169 Nr. 134; 380-383 Abb. 336-340; Kintrup 1998, 209 f. 214 f. Taf. 93, 4; Kintrup 2016a, Kap. 3.2.3 Nr. 245. Epinausimachie: Archäologisches Museum Inv. 1246, s. Koch - Sichtermann 1982, 411. 412. 414 Nr. 18; 416. 459 Abb. 445; Stefanidou-Tiveriou 1997, 169-174 Nr. 135; 384-387 Abb. 341-346; Kintrup 2016a, Kap. 5.2.6 Nr. 248.

126 Stefanidou-Tiveriou 1997, 166 f. 170 f. beschreibt die Eckfiguren der beiden Sarkophage in Thessaloniki jeweils als »Amazonen-Niken«. Zu der Benennung hier: Waffen als Attribute, Kleidung, Frisur und Stellung haben ihre besten Parallelen unter Niken und Viktorien, s. dazu einige ausgewählte Vergleichsbeispiele aus klassischer und hellenistischer Zeit: Goulaki-Voutira - Grote 1992, 862 f. Nr. 137 Taf. 572; 866 Nr. 165 Taf. 576; 882 Nr. 383 Taf. 589; 884 Nr. 419 Taf. 591; 886 Nr. 482 Taf. 594. Zur Problematik der Nike Apteros s. Goulaki-Voutira - Grote 1992, 902. Weiterhin zu Beispielen römischer Zeit: Vollkommer 1997, 244 Nr. 42 Taf. 170; 245 Nr. 69 Taf. 172; 246 Nr. 78 Taf. 172; 246 Nr. 80 Taf. 172. Zu der häufigen Verwendung in der Sepulkralkunst: Vollkommer 1997, 269. Vgl. auch die stadtrömischen Amazonomachie-Sarkophage in Rom, Museo Capitolino Inv. 726, Grassinger 1999, 237 Nr. 94 Taf. 91, 1; 92, 1, und San Simeon, Grassinger 1999, 242 f. Nr. 104 Taf. 104. 105, 2, die als Vorbilder oder Mittler in der ikonografischen Tradition für die zwei frühen attischen Amazonomachie-Gruppen gelten können, s. Kintrup 2016a, Kap. 6.1.1. Ohne Flügel und mit einer Pelta auf der Schulter bieten die Eckfiguren nun aber auch Anlehnungen an die Ikonografie von Amazonen. In Abänderung von Stefanidou-Tiveriou 1997, s. o., ist die Bezeichnung als »Nike/Amazone« gewählt, da die ikonografischen Anlehnungen an Niken stärker hervortreten. 
von Dach- zu Klinendeckeln in der Zeit um 160/170 n. Chr. ${ }^{127}$ übernimmt bei den attischen Sarkophagen der Kasten formal eine Funktion als Klinenuntergestell, die obere Leiste eine als Auflager für die Klinenmatratze und stützende Eckfiguren können die Funktion als Klinenbeine übernehmen. Die stützenden Eckfiguren werden dann durch rahmende Figuren wie diese hier ersetzt ${ }^{128}$, wobei in aller Regel männliche Eckfiguren verwendet werden; eine Nike/Amazone bleibt bei den Schlachtsarkophagen die Ausnahme.

Neben der Nike/Amazone ist rechts im Vordergrund eine Helfergruppe ${ }^{129}$ dargestellt $^{130}$. Ein stehender Krieger hat einem verwundeten Kämpfer am Boden seine rechte Hand über dessen rechte Schulter an den Armansatz gelegt, um ihn zu halten. Mit dem Schild in der Linken verteidigt er sich und seinen Kameraden gegen den Angriff eines mit einer Chlamys bekleideten Reiters von rechts. Reste des Pferdekopfes (über der linken Schulter des Reiters) und des Pferdeschweifs (eingraviert links hinter dem Torso des Knienden) sind erhalten. Auch die Haltung des schräg positionierten Torsos unterstützt eine Rekonstruktion als Reiter. Dem stehenden Krieger fehlen der Kopf, der rechte Arm sowie der linke ab dem Oberarm. Dem Verwundeten fehlen die rechte Hand, der Unterkörper und Teile der Beine. Zu der Helfergruppe präsentiert ein Amazonomachie-Sarkophag in Tyros, der ebenfalls um 200 n. Chr. entstanden ist, die beste Parallele ${ }^{131}$. Eine variierte Fassung der Helfergruppe kommt auch auf den Schiffskampfsarkophagen vor ${ }^{132}$. Somit ist für das 3. Jahrhundert $n$. Chr. belegt, dass für diesen Typus der Helfergruppen die Möglichkeit eines Austauschs innerhalb der verwandten Themen der attischen Sarkophage mit Schlachtszenen bestand ${ }^{133}$.

Dem Reiter fehlen im Wesentlichen der Kopf und Teile der Schultern. Auf der zeichnerischen Rekonstruktion der rechten Schmalseite von F. Eichler (Taf. 1 Abb. 2) sind der linke Ellenbogen des Helfenden, die rechte Hand des Verwundeten und der Kopf des Reiters noch abgebildet. Ellenbogen- und Handfragment scheinen verschollen, aber der Reiterkopf ist erhalten und befindet sich im Historischen und Kunsthistorischen Museum in Izmir Inv. 1555 (Taf. 14 Abb. 61). Der auf Seitenansicht gearbeitete, behelmte Kriegerkopf mit polierter Oberfläche ist nach links gewendet (H 11; L 9,5; T 7). Seine rechte Gesichtsseite ist versintert. Bestoßen sind der linke Ohrrand, Kinn, Mund und Nase, Helmkamm und Haare. Punktbohrungen finden sich in den Haaren und Nasenlöchern, in dem Augenwinkel links innen und in den Mundwinkeln; die Ohröffnung

127 Für diese Datierung liefert der früheste vollständige Amazonomachie-Sarkophag in Paris, Musée du Louvre Inv. Ma 2119, s. Koch - Sichtermann 1982, 389 f. 391 f. 440 Nr. 36; 456. 458 Abb. 420; Baratte 1985, 256-261 Nr. 166; Kintrup 2016a, Kap. 3.1.1.1 und 3.3 S. 97 Nr. 156 wichtige Anhaltspunkte, denn die Klinenporträts sind erhalten. Zu einem Wechsel von Dach- zu Klinendeckeln ab 170/180 n. Chr.: Wiegartz 1975, 188 f.; Wiegartz 1977, 386; Koch - Sichtermann 1982, 371 f.; Rogge 1993, 112 f. 116 f. 120-122. Früher, kurz vor der Mitte des 2. Jhs. n. Chr., wird der Wechsel angesetzt von Wrede 1977, 395-431, bes. 427-431; Wrede 1990, 43-46. Dazu s. auch Stefanidou-Tiveriou 2007, 263-270.

128 Zu Entwicklung und Bedeutungswechsel der Eckfiguren, s. z. B. Rogge 1993, 117 mit Anm. 92-96; Rogge 1995, 38 mit Anm. 147; Kintrup 2016a, Kap. 3.3 S. 97-100; Kap. 8 S. 208. Vgl. auch hier unter Kat. 3 (Achill-Sarkophag in Woburn Abbey) oder Kat. 6 (Amazonen-Sarkophag Inv. 260).

129 Kintrup 2016a, 36. 39. 45 Typus H II.

130 Die aus mehreren Teilstücken zusammengesetzte rechte Ecke der Vorderseite mit der Nike/Amazone und dem anpassenden Stück der rechten Schmalseite (rechte Hand des Helfers auf der rechten Schulter des Verwundeten) sind aus der rekonstruierten Schmalseite herausgebrochen und befinden sich im Depot des Efes Müzesi, ausführlicher dazu s. o. mit Anm. 83 f.

131 Chéhab 1984, 451-453 Taf. 77-79; Kintrup 2016a, Kap. 3.2.1 Nr. 259 Helfer und Verwundeter sind mit einer Chlamys bekleidet.

132 s. ein Vorderseitenfragment in Brescia, Koch - Sichtermann 1982, 412. 413. 414 Nr. 22; 459 Abb. 446; Linant de Bellefonds 1985, 121 Taf. 37, 2; Stella 1998, 63 mit Abb.; Kintrup 2016a, Kap. 5.2.9 Nr. 77 und ein Fragment ebenfalls in Ephesos (hier Kat. 20 Taf. 66 Abb. 278), das in Analogie dazu zu rekonstruieren ist.

133 Dieser Typus der Helfergruppen ist zudem interessant, da er sich auf späten Schlachtsarkophagen in einer weiterentwickelten Form nachweisen lässt, s. die Exemplare in St. Petersburg: Saverkina 1979, 24 f. Nr. 5 Taf. 11-13; Koch - Sichtermann 1982, 407. 409 Nr. 45: 459; Kintrup 2016a, Kap. 4.2.19 Nr. 237 und in Xanthos: Demargne 1966, 451-461 Abb. 4; Giuliano - Palma 1978, 39 Nr. 7 Taf. 46, 111; Koch - Sichtermann 1982, 390 Anm. 1. 410 Nr. 68; Kintrup 2016a, Kap. 4.2.16 Nr. 269. Der Verwundete ist dort frontal abgebildet und die zunehmende Darstellung frontaler Ansichten ist als datierendes Merkmal zu verwerten. 
ist tiefer gebohrt. Der Halsansatz ist erhalten, eine Falte am Hals ist eingetieft, ebenso sind es die Augenbrauen.

Im Hintergrund neben der Nike/Amazone erscheint ein behelmter Kopf nach rechts, dessen Gesicht durch eine Bruchlinie stark beschädigt ist. Der Krieger hält in der Linken einen Schild und hat seine Rechte mit einem Schwert erhoben; die Hand samt Schwertknauf ist über der linken Schulter der Nike/Amazone auszumachen.

In der Mitte der Schmalseite, unter dem Reiter, kniet ein Grieche. Erhalten sind der Oberkörper mit seinem nach oben ausgestreckten linken Arm sowie sein aufgestelltes rechtes Bein. Auf der Zeichnung Eichlers ist ein weiteres Fragment seiner linken Brustseite mit Chlamys und dem erhobenen linken Armansatz vorhanden.

Es folgt eine Kampfgruppe, bestehend aus einem behelmten Angreifer und einem am Boden sitzenden Krieger. Bei dem in einer Dreiviertelansicht Stehenden sind das Gesicht, der linke Arm, der rechte Unterarm, der rechte Fuß sowie die linke Leiste mit dem Oberschenkelansatz verloren. Dem Krieger am Boden fehlen der Kopf samt eines Teils der Brust sowie Teile der Beine und seines rechten Arms. Der Angreifer hat sein Schwert mit der Rechten gefasst und versucht von oben zuzustoßen, während der Sitzende mit seiner Linken von unten an Hand und Schwert des Angreifers fasst, um so den Stoß abzuwehren.

Die Figuren zeigen sich muskulös und gut proportioniert. Die erhaltenen Gewandfalten weisen zwar einige Bohrlinien auf, sind aber dennoch plastisch gestaltet.

\section{Vorderseite und linke Schmalseite}

Da die Fragmente der bevorzugt ausgeführten rechten Schmalseite zu einem erheblichen Teil eingepasst werden konnten, sind die restlichen gut ausgearbeiteten Fragmente mit großer Wahrscheinlichkeit der Vorderseite zuzuordnen - oder z. T. vielleicht auch der linken Schmalseite. Von den Fragmenten der Relieffriese, die den vernachlässigt gearbeiteten Sarkophagseiten zuzuweisen sind, konnten keine Stücke eindeutig der linken Schmalseite zugeordnet werden. Die flache Ausführung und die sichtbaren Bearbeitungsspuren sind typisch für Rückseiten. Die vernachlässigten Schmalseiten sind zwar in der Regel weniger aufwendig als die bevorzugten Seiten ausgeführt, aber zumeist erkennbar sorgfältiger als die Rückseiten. Daher ist es wahrscheinlich, dass - sofern erhalten - Fragmente der linken Schmalseite unter denen zu suchen sind, die hier als »gut ausgearbeitet « klassifiziert wurden.

Die folgenden Fragmente lassen sich aufgrund ihrer Ausführung der Vorderseite zuteilen. Anpassend an die Nike/Amazone ist auf der Vorderseite der rechte Teil der Rückenansicht eines nackten Kämpfers von der Schulter bis zum Knie erhalten sowie die linke Körperseite mit einem Teil des linken Oberschenkels eines ebenfalls nackten Knienden, der seinen linken Arm erhoben hatte (Taf. 3 Abb. 4. 6). Bei dem Stehenden in Rückenansicht zeigen die Reste seines rechten Arms, dass dieser nach unten angewinkelt war. Vergleiche bieten Angreifer einer Haarreißergruppe ${ }^{134}$, die auf einer der frühen Gruppen der Amazonomachie-Sarkophage - nur auf Vorderseiten und bevorzugt ausgeführten Schmalseiten - häufiger belegt sind ${ }^{135}$. Allerdings ist die Figur hier im Hintergrund des folgenden Knienden dargestellt, sodass die Rekonstruktion zu einer Haarreißergruppe unwahrscheinlich ist. Sehr wahrscheinlich ist dies jedoch bei dem Knienden: seine Haltung lässt sich sehr gut zu dem Knienden einer Haarreißergruppe mit frontalem Angreifer links ergänzen ${ }^{136}$. Glücklicherweise ist tatsächlich ein Fragment erhalten, das zu dieser Rekonstruktion passt (s. das folgende Fragment 46). Die Reste vor der Pubis des Knienden erklären sich dann als Zehen des Angreifers, der ihm in die Leiste tritt ${ }^{137}$.

\footnotetext{
134 Kintrup 2016a, 35. 37. 41 Typus K I.

135 s. z. B. die Vorderseite des Amazonomachie-Sarkophags in Paris, s. o. Anm. 127.

136 Kintrup 2016a, 35. 37. 41 Typus K II.

137 s. z. B. die Vorderseite und die rechte Schmalseite des Schlachtsarkophags in Tyros: Grabungen, Inv. 3951/3952: Koch - Sichtermann 1982, 405 f. 410 Nr. 66; 459 Abb. 443; Chéhab 1985, 501 f. Taf. 89-92; Rogge 1995, 65 f. 144 f. Nr. 43 Taf. 9; Kintrup 2016a, Kap. 4.2.17 Nr. 260.
} 
- Fragment 46 (Taf. 14 Abb. 62)

Das Fragment (L 20; H 23) ist durch seine Ausführung eindeutig der Vorderseite zuzuordnen. Es zeigt den nackten Oberkörper eines Kriegers mit Schwertgurt quer über der Brust. Der vordere Teil seiner Schwertklinge ist vorhanden und auch die rechte Hand, die sich gegen seine linke Körperseite drückt und belegt, dass die Figur zu dem Angreifer einer Haarreißergruppe zu ergänzen ist.

Nach F. Eichler ${ }^{138}$ dürften sich Reste der linken Eckfigur erhalten haben:

- Fragment 47 (Taf. 14 Abb. 63)

F. Eichler deutet das der Vorderseite zugeordnete Fragment (L 10; H 24,5) als »Rest des Bauches und des rechten Oberschenkels eines Nackten « und vermutet, dass die Falten zur linken Eckfigur der Hauptseite gehört haben dürften. Um $180^{\circ}$ gedreht, könnte es sich bei dem Fragment jedoch um eine linke Schulter und einen Armansatz vor Gewandfalten handeln.

Die folgenden Fragmente Nr. 48-50 enthalten Reste des oberen Kastenabschlusses, gehören daher an den oberen Rand des Relieffrieses:

- Fragment 48 (Taf. 14 Abb. 64)

Aus zwei größeren Teilen und dem Teil eines Eis des Eierstabs zusammengesetzt (L 30; H 39) ist Fragment 48. Die Oberseite ist erhalten, der Falz fehlt. Auf dem Stein ist »B 33« vermerkt; auf dem Ei »zu B 33«. Auf einem alten Foto im Archiv des ÖAI (Neg. II 408) ist notiert: »Sark B Hptseite B $34+33 \ll$. Zu erkennen sind Reste des Perl- und Eierstabs sowie unterhalb ein Teil eines Schilds ${ }^{139}$.

- Fragment 49 (Taf. 15 Abb. 65)

Das Fragment (L 8,5; H 22,5) mit der Aufschrift »B 39« zeigt den unteren Teil eines Schilds mit dem linken Unterarm eines Kriegers im Schildband; unter dem Schild erscheinen Gewandfalten über einem abgewinkelten Knie. Dieser Abschnitt wird in den Notizen F. Eichlers als Kniender mit Schild am linken Unterarm gedeutet, aber das Knie ist in deutlich flacherem Relief gearbeitet und gehört zweifellos einer Hintergrundfigur an. Vermutlich trägt ein stehender Krieger den Schild am Arm, während das rechten Knie wohl eines Reiters im Hintergrund sichtbar wird, wie dies z. B. bei einem Amazonomachie-Sarkophag in Tyros ${ }^{140}$ der Fall ist; die Figuren vor der rechten Ecke der Front sind etwas weiter voneinander entfernt gezeigt. Zu dem Schild könnten - so auch Eichler - die folgenden zwei Fragmente gehören:

- Fragment 50 (Taf. 15 Abb. 66)

Fragment 50 (L 5; H 11) zeigt einen Schildrand mit der linken Hand am Schildgriff.

- Fragment 51 (Taf. 15 Abb. 67)

Fragment 51 (L 3,5; H 6,5) besteht aus zwei kleinen, anpassenden Teilen eines rundplastisch gearbeiteten Schildrandes.

- Fragment 52 (Taf. 15 Abb. 68)

Auf dem Fragment (L 31; H 26) steht »B 36«. Unter dem bestoßenen Perlstab erscheint eine Trompete nach rechts; das Kopfprofil des Tubicen ist im Ansatz vorhanden. Die Tuba wird überschnitten von einem länglichen, gerundeten Gegenstand; vielleicht handelt es sich um eine Hand an einem Speer.

138 Wiedergegeben bei Rudolf 1992, 23 mit Anm. 71.

139 Im Nachlass F. Eichlers im Archiv des ÖAI (Karton »N L Eichler 24«) findet sich eine Zeichnung mit dem Versuch der Kombination dieses Fragments, B 34 + 33, mit dem folgenden Fragment eines Schilds, B 39. Eine Anpassung muss noch vorgenommen werden.

140 Grabungen, Inv. 2772/2773: Chéhab 1968, 36-40; 81 f. Taf. 17-21; Chéhab 1984, 451-453 Taf. 77-79; Koch 1989a, 194. 195 mit Abb. 43; 208; Kintrup 1998, 207-210 Taf. 92, 2; Kintrup 2016a, Kap. 3.2.1 Nr. 259. 
- Fragment 53 (Taf. 15 Abb. 69)

Das stärker versinterte Fragment (L 15; H 21) mit dem Vermerk »B 35« zeigt Reste des Perlstabs und darunter einen erhobenen rechten Unterarm mit der Hand um eine Waffe sowie bewegte Gewandfalten.

- Fragment 54 (Taf. 15 Abb. 70)

Fragment 54 (L 6,5; H 14,5) beinhaltet die rechte Seite des Oberkörpers eines Griechen, der eine Chlamys mit Scheibenfibel trägt. Der Ansatz vermittelt, dass der rechte Arm erhoben war; die Brustwarze ist leicht erhaben angegeben. In seinem Rücken sind weitere Reliefreste - vielleicht Falten - vorhanden, die zeigen, dass die Figur auf seitliche Ansicht ausgerichtet war.

- Fragment 55 (Taf. 16 Abb. 71)

Bei diesem Fragment (L 20; H 10,5; D 13) ist die Orientierung unsicher. Zu erkennen ist ein etwa dreieckiges Stück des Reliefgrundes, im Vordergrund verläuft der Unterschenkel einer Figur, eines Pferdes oder der Unterarm einer Figur schräg über einen gerundeten Abschnitt mit zwei parallel eingetieften Linien, vielleicht Hautfalten. Dahinter erscheint eventuell eine weitere Körperpartie.

- Fragment 56 (Taf. 16 Abb. 72)

Fragment (L 9,5; H 8,5) eines Pferdekopfes mit Mähne nach rechts; rechtes Ohr oben weggebrochen.

- Fragment 57 (Taf. 16 Abb. 73)

Fragment (L 10; H 5,5) mit Segment eines Schilds (?) und dahinter Gewandfalten.

- Fragment 58 (Taf. 16 Abb. 74)

Fragment (L 20; H 6,5) mit der Aufschrift »B 9« zeigt die Standleiste und Zehen eines linken Fußes.

- Fragment 59 (Taf. 16 Abb. 75)

Fragment 59 (L 22,5; H 11,5; DW 6,5) mit der Aufschrift »B Hauptseite«, zwei Unterschenkel, die einander überdecken. Handelte es sich um eine liegende Figur, dann wäre der untere, weggebrochene Absatz als Stück der Standleiste zu erklären. Es bleibt Reliefgrund frei, der sorgfältig geglättet ist.

Weiterhin der Vorderseite zuzuordnen ist ein Kriegerkopf, der sich im Historischen und Kunsthistorischen Museum in Izmir befindet:

- Fragment Inv. 1556 (Taf. 17 Abb. 76. 77) ist ein fast rundplastischer, behelmter Kriegerkopf mit polierter Oberfläche, der in Dreiviertelansicht nach rechts gedreht ist (H 14; L max. 12; L Ansichtsseite 10; $\mathrm{T}$ 10). Bestoßungen an der Nasenspitze, an der Unterlippe an seinem rechten Ohr, am Helmrand, Helmkamm und an den Haaren. Punktbohrungen in den Haaren, Nasenlöchern, Augenwinkeln innen und Mundwinkeln, Mundlinie und Ohröffnung sind tief gebohrt. Der Halsansatz ist erhalten, eine Falte am Hals eingetieft.

Ebenfalls im Historischen und Kunsthistorischen Museum in Izmir wird ein weiterer Kriegerkopf aufbewahrt:

- Fragment Inv. 1013 (Taf. 17 Abb. 78. 79), bei dem es sich um einen behelmten Kriegerkopf handelt, unterhalb der Nase weggebrochen (H 9; L 11; T 7,5). Ein kleiner Ansatz des Reliefgrunds ist erhalten. Das rechte Ohr und der obere Teil des Helmkamms fehlen; die Oberfläche ist leicht verrieben und mit rezenten Kratzern versehen. Dieser Kopf hat im Unterschied zu den Köpfen des Reiters der rechten Schmalseite (Inv. 1555) und des Kopfes Inv. 1556 keine polierte Oberfläche. Demnach gehörte er der linken Schmalseite an. Punktbohrungen finden sich in den Haaren, Nasenlöchern, Augenwinkeln innen und Mundwinkeln, Mundlinie und Ohröffnung sind tief gebohrt. Die Augenbrauen sind zart eingetieft.

Die folgenden, allseits gebrochenen Fragmente tragen nicht Eichlers Aufschrift »B«, sie wurden aufgrund der Maße, des Marmors und des Stils dem Aristides-Sarkophag zugeordnet. Bei 
Fragmenten 60 und 61 ergab der Vergleich mit dem Nachlass Eichlers, dass auch er für diese eine Zugehörigkeit zum Aristides-Sarkophag B angenommen hatte ${ }^{141}$.

- Fragment 60 (Taf. 18 Abb. 80)

Das Fragment 60 (L 20; H 10) zeigt in seiner abgebildeten Orientierung, die nicht gesichert ist, links Gewandfalten und davor eine Fläche, die links einen Rand aufweist. Ein Stück der erhaltenen Rückseite weist Spitzmeißelarbeit auf, die etwas tiefer, >buckliger erscheint als die sonst bei B erhaltenen Innenseiten des Sarkophags. Im Nachlass Eichlers findet sich eine Zeichnung des Fragments. Die Reliefreste sind ebenfalls als Falten und Schildrest gedeutet, aber die Orientierung ist im Unterschied zur hier gewählten um $90^{\circ}$ nach rechts gedreht. Die Zeichnung trägt den Vermerk »wahrscheinlich aus Sarkophag B«.

- Fragment 61 (Taf. 18 Abb. 81)

Das Fragment 61 (L 5; H 23) trägt die Aufschriften »Kopf « und »L. Arm«. Nach Notizen Eichlers - mit Zeichnung - handelt es sich um »Reste von 2 Figuren aus Sarkophag B«.

- Fragment 62 (Taf. 18 Abb. 82. 83)

Das Fragment 62 (L 15; H 8) des nackten Oberkörpers eines Kämpfers wirkt fast rundplastisch, auf der linken Seite des Fragments sind Reste des Reliefgrundes vorhanden. Der Bauchnabel des Kriegers ist erhalten, darüber eine Falte. Entlang seiner linken Körperseite verläuft ein Gewandrand; ein Schwertgurt liegt quer über der Brustpartie. In den Ritzen des Schwertgurts waren rötliche Farbreste zu erkennen, bei denen es sich wohl nicht um Versinterungen handelt. Die angespannte Muskulatur lässt auf eine Torsion nach rechts schließen, die Hüfte wirkt vorgeschoben. Demnach könnte es sich um einen Reiter handeln, der seine Rechte zum Schlag erhoben hat, wie beispielsweise der Reiter im Zentrum der Vorderseite eines Schlachtsarkophags in Tyros ${ }^{142}$.

- Fragment 63 (Taf. 18 Abb. 84)

Fragment 63 (L 9,5; H 9,5) ist Teil eines Pferdemauls nach rechts.

Ein weiteres Fragment wurde in einer der Kisten in einem Depot des Efes Müzesi Selçuk gefunden, in denen die Fragmente der Sarkophage des Tatiane-Grabhauses vermischt mit den Fragmenten des Hippolytos-Sarkophags aus der Nähe des Hafenkanals gelagert waren. Insofern ist auch hier die Frage nach der Zugehörigkeit zu einem der Sarkophage zu stellen.

- Fragment 64 (Taf. 18 Abb. 85)

Unter einer fein geglätteten oder polierten Fläche erscheinen kleine Löckchen mit Resten von Punktbohrungen. Hier ist sehr wahrscheinlich ein Stück des Unterkörpers eines Mannes mit Pubis erhalten. Die Größe, der Absatz zur Pubis und die Bildung der Schamhaare entspricht - soweit zu erkennen - nicht derjenigen der Körper, die »E« zugeordnet wurden (vgl. dort die Fragmente 6 [Taf. 52 Abb. 201] und 35-37 [Taf. 57 Abb. 228-230]). Das Fragment könnte demnach eher den Sarkophagen »B« oder »C« zuzuschreiben sein, aber diese bieten keine konkreten Vergleiche. Irritierend ist zudem die Oberseite des Fragments, zumal sie sehr gerade abgetrennt erscheint, was allerdings bei dem Aristides-Sarkophag durchaus belegt ist (s. die Bruchlinien der rechten Schmalseite [Taf. 2] und Anm. 83).

\section{Rückseite}

Von der nachlässig gearbeiteten Rückseite sind allseitig gebrochene Fragmente erhalten. Zweifelsfrei der Rückseite zugehörig ist - anpassend an den `Eckkrieger der rechten Schmalseite und daher in Inv. 12 (alte Inv. 1589) inbegriffen - ein rechter Fuß über der Standleiste (Taf. 19 Abb. 91).

141 Zur Benennung der Sarkophage s. o. Anm. 79.

142 Nekropole Inv. 4048/4049: Koch - Sichtermann 1982, 407. 410 Nr. 67; 459. 467; Chéhab 1985, 600 f. Taf. 122-125; Kintrup 2016a, Kap. 4.2.13 Nr. 262. 
Aufgrund der flachen Ausführung und der vernachlässigten Ausarbeitung mit z. T. deutlich sichtbaren Bearbeitungsspuren ebenfalls der Rückseite zuzuordnen sind:

- Fragment 65 (Taf. 19 Abb. 86. 87)

Ein aus zwei Fragmenten zusammengesetzter behelmter Kopf (L 10,5; H 10,5) nach rechts. Nach Eichler hatte das Teilstück mit dem Helm die »Mus. Inv. 137«143.

- Fragment 66 (Taf. 19 Abb. 88)

Über der Standleiste sind Zehen eines linken Fußes und ein Huf zu erkennen (L 15; H 10). Das Fragment trägt den Vermerk »B Rs« ${ }^{144}$.

- Fragment 67 (Taf. 19 Abb. 89)

Das Fragment (L 10; H 11) zeigt ein Stück der Standleiste mit Huf nach rechts; links überschnitten von einem undeutlichen Reliefrest ${ }^{145}$.

- Fragment 68 (Taf. 19 Abb. 90)

Bei Fragment 68 handelt es sich um eine Extremität oder einen Pferdehuf über einer Standleiste (L 12; H 13).

- Fragment 69 (Taf. 20 Abb. 92)

Es handelt sich um einen angewinkelten rechten Arm mit - übertrieben dargestellt - angespanntem Bizeps (L 10; H 10,5). Das Fragment ist nicht mit der Aufschrift »B« gekennzeichnet, aber im Nachlass Eichlers als zugehörig beschrieben, nach Eichler: »li. eingewinkelter Arm mit stark gewölbtem Biceps«.

- Fragment 70 (Taf. 20 Abb. 93)

Fragment 70 ist eine Extremität (L 12,5; H 6). Auf dem Fragment ist »zu B 1 Rs.« notiert.

- Fragment 71 (Taf. 20 Abb. 94)

Ebenfalls eine Extremität zeigt Fragment 71 (L 14,5; H 7).

- Fragment 72 (Taf. 20 Abb. 95)

Die Orientierung des Fragments ist unsicher, da die Darstellung nicht gedeutet werden kann. Auf dem Fragment (L 12,5; H 5) steht »B Rückseite«.

- Fragment 73 (Taf. 20 Abb. 96)

Auch bei Fragment 73 ist die Orientierung unsicher. Vielleicht handelt es sich um ein Stück der Standleiste mit einem gerundeten Reliefrest (L 6; H 18).

Die Fragmente der Rückseite wie behelmter Kopf, Füße, vermutlich im Ausfallschritt, Hufe und angewinkelter Arm lassen am ehesten an eine Schlachtszene denken ${ }^{146}$, wobei das folgende Fragment möglicherweise einen genaueren Hinweis geben kann:

- Fragment 74 (Taf. 20 Abb. 97)

Zu erkennen sind vier Finger einer rechten Hand, die etwas greift (L 5,5; H 7,5) ${ }^{147}$. Die Orientierung ist nicht gesichert. Es ist unwahrscheinlich, dass es sich um eine Haarreißergruppe handelt, denn zumeist fasst dort die Linke den Gegner und in den wenigen Fällen, bei denen ein rechts stehender Angreifer in Frontalansicht eine reitende Figur mit der Rechten gefasst hat, handelt es sich um frühe Amazonomachie-Sarkophage ${ }^{148}$. Zudem scheint es sich hier nicht um den Kopf oder Haarschopf eines Gegners zu handeln, sondern um einen kleineren, rundlichen Gegenstand.

143 Vgl. Rudolf 1992, 24 Nr. 1.

144 Vgl. Rudolf 1992, 24 Nr. 5.

145 Vgl. Rudolf 1992, 24 Nr. 6.

146 Rudolf 1992, 24 vermutete eine Darstellung der Lösung Hektors in einem Schema der 2. Hälfte des 2. Jhs. n. Chr., aber genauere Hinweise darauf sind nicht aufgeführt.

147 Vgl. Rudolf 1992, 24 Nr. 9.

148 Kintrup 2016a, 35. 37. 42 Typus K III. 
Es könnte ein Stein gemeint sein - dann wäre es wahrscheinlich die Hand eines Kentauren, der einen solchen gegriffen hat; auf der Rückseite wäre somit eine Kentauromachie dargestellt gewesen. Kentauren erscheinen einige Male auf Rückseiten attischer Sarkophage ${ }^{149}$ und sind dort mit Steinen und Keulen bewaffnet, so auf der Rückseite eines Schlachtsarkophags in Athen ${ }^{150}$, eines Amazonomachie-Sarkophags in London ${ }^{151}$, eines dionysischen Sarkophags in Kyrene ${ }^{152}$ und auf einem Rückseitenfragment in Split ${ }^{153}$. Diese Rekonstruktion anhand eines nur kleinen Fragments bleibt hypothetisch, auch wenn die übrigen Fragmente der Rückseite ihr nicht widersprechen ${ }^{154}$.

\section{Deckel}

Der Klinendeckel (H 126; L 264; T 118; Taf. 4 Abb. 8) im Archäologischen Museum von Izmir (Inv. 34) ist bis auf einige Bruchflächen im Bereich der linken Schmalseite (Taf. 21 Abb. 98) und entlang der Unterkante der Rückseite (Taf. 21 Abb. 99) gut erhalten. Die Unterseite des Deckels weist grobe Spitzmeißelarbeit auf, der Falz ist etwas feiner gearbeitet (Taf. 22 Abb. 100). Gurte und geglätteter Reliefgrund laufen von der Matratzenfront auf der Oberseite der Matratze bis zu dem Gewand der Gelagerten weiter, nach hinten ist dann die Oberseite regelmäßig und fein gepickt, eingerahmt von einem eingetieften Rand vor den Klinenlehnen (Taf. 22 Abb. 101). Die Ausarbeitung der Rückseite der Klinenfiguren ist ebenfalls vernachlässigt.

Der Porträtkopf des Aemilius Aristides wurde bereits besprochen (Taf. 6 Abb. 10-13); der Porträtkopf der Frau fehlt ${ }^{155}$. Die Frau liegt links vor dem Mann. Beide stützen sich mit ihrem linken Arm auf ein Kissen, dessen Ecken mit kleinen Quasten verziert sind (Taf. 23 Abb. 102). Beide sind mit einen Ärmelchiton und einem Mantel darüber bekleidet. Dessen sorgsam ausgeführte Falten breiten sich über die Kissen nach vorn zur Klinenfront aus. Die Frau hält in ihrer rechten Hand eine kleine Blütenkette (Taf. 22 Abb. 101), Aemilius Aristides hat eine teilweise geöffnete Schriftrolle in der linken (Taf. 23 Abb. 102).

Die Klinenmatratze ist auf der Front durch gestreifte Gurte in vier rechteckige Bildfelder untergliedert, die mit Meerwesen und Eroten in flachem Relief dekoriert sind (Taf. 24 Abb. 104. 105). Von links nach rechts trägt auf den ersten drei Bildfeldern je ein Triton ${ }^{156}$ eine Nereide ${ }^{157}$ auf dem Rücken, nur bei dem vierten rechten Feld sitzt eine Nereide auf einem Meereskentaur. Auf den beiden linken Feldern sind die Tritone nach rechts dargestellt, während auf den beiden rechten Feldern Triton und Meereskentaur nach links gewendet sind. Delfine und Eroten bereichern

149 Zu Kentauromachien s. Koch - Sichtermann 1982, 398 f.; Leventopoulou - Sengelin 1997, 671-721; 720 (zu möglichen Deutungen).

150 Robert 1890, 131 f.; Koch - Sichtermann 1982, 407. 408 Nr. 14; 458; Kintrup 2016a, Kap. 4.2.5 Nr. 55.

151 Koch - Sichtermann 1982, 391 mit Anm. 13; 398 mit Anm. 9; 458; Walker 1990, 40 f. Nr. 45 Taf. 18; Kintrup 2016a, Kap. 3.2.9 Nr. 130.

152 Matz 1968, 83 f. 116-118 Nr. 11A Taf. 21, 2.

153 Koch - Sichtermann 1982, 398 f. Abb. 424; Cambi 1988, 124-127 Nr. 30 Taf. 17.

154 Einen Vergleich für eine Schlachtszene bietet z. B. die Rückseite eines Amazonomachie-Sarkophags in Thessaloniki, Archäologisches Museum Inv. 276: Koch - Sichtermann 1982, 391 mit Anm. 14; 458. Kintrup 2016a, Kap. 3.2.5 Nr. 244; dort sind Krieger im Ausfallschritt an die Ecken der Rückseite gestellt.

155 Auch wenn die Köpfe erhalten sind, sind die Porträts oft nicht ausgeführt, sondern die Köpfe in Bosse belassen. s. z. B. einen Schlachtsarkophag in Tyros, Nekropole Inv. 4048/4049: Koch - Sichtermann 1982, 407. 410 Nr. 67; 459. 467; Chéhab 1985, 600 f. Taf. 122-125; Kintrup 2016a, Kap. 4.2.13 Nr. 262, oder einen Achill-Sarkophag ebenfalls in Tyros, Nekropole Inv. 328/329: Chéhab 1968, 28-34; 75 f. 82 f. Taf. 13-16; Koch - Sichtermann 1982, 385. 458; Rogge 1995, 45 f. 143 f. Nr. 42 Taf. 52, 1. Weitere Beispiele s. Rogge 1993, 111 mit Anm. 9. Einen Überblick zu den Begründungen, warum Porträtköpfe nicht ausgeführt wurden, samt Erörterungen bieten Koch - Sichtermann 1982, 611-614.

156 Vgl. LIMC VIII (1997) 68-73 s. v. Triton; 73-85 s. v. Tritones (N. Icard-Gianolio).

157 Zu zahlreichen Belegen, s. Icard-Gianolio - Szabados 1992, 785-824; s. dort z. B. Taf. 458.470 f. 515 und die stadtrömischen Sarkophage auf Taf. 473. 478. 482. 487. Icard-Gianolio - Szabados 1992, 798 Nr. 178 Taf. 477 Nr. 178 führen die Bildfelder des Klinendeckels des Aristides-Sarkophags auf und nennt als Vergleich auch das Deckelfragment in Wien, hier Kat. 46 Taf. 77 Abb. 314. 
die Szenen ${ }^{158}$. Das erhaltene rechte Fulcrum (Taf. 23 Abb. 103) zeigt im vertikalen Teil einen abwärts gerichteten Delfin, der einen Oktopus geschnappt hat, während der horizontale Teil als Entenkopf gestaltet ist. Die Reste des linken Fulcrums lassen auf eine symmetrische Ergänzung schließen. Die linke Schmalseite des Deckels ist zwar zu einem Großteil weggebrochen, aber ein Stück des Dekors der Außenseite ist noch vorhanden (Taf. 21 Abb. 98). Wie auf den Außenseiten der rechten Schmal- und der Rückseite (Taf. 21 Abb. 99) vollständiger erhalten, waren auch hier rechteckige Felder - je drei auf den Schmalseiten und sechs auf der Rückseite - mit Rhomben und Rosetten als Verzierung angebracht.

Es handelt sich um einen als typisch zu bezeichnenden Klinendeckel attischer Werkstätten. Dabei können die Dekorationen der Klinenmatratze, der Außenseiten der Kline und der Fulcra Variationen aufweisen, wie der Vergleich mit dem Amazonomachie-Sarkophag ebenfalls aus dem Grabhaus der Tatiane (Kat. 2 Taf. 30-32) lehrt ${ }^{159}$. Das flache Relief und die Motive der Klinenmatratzen können als Nachahmungen der kostbaren dekorativen Bezugsstoffe realer Klinenpolster verstanden werden ${ }^{160}$.

In den Fundkisten des Komplexes ${ }^{161}$ in einem Depot des Efes Müzesi wurden fünf Fragmente von Klinendeckeln entdeckt, die alle auf der Rückseite mit der Aufschrift »TG« (Tatiane-Grab) versehen sind.

- Fragment 75 (Taf. 25 Abb. 106)

Das Fragment (L 6,5; H 14) stammt aus dem unteren Bereich einer Klinenaußenseite, denn ein auf die Unterseite umbiegendes Stück unter dem Kassettendekor ist erhalten. Vom Dekor ist die untere linke Ecke eines Rechtecks mit der linken Seite einer Rosette vorhanden. Die Kassettenrahmung besteht aus einer profilierten und darin einer flachen Leiste. Die Oberfläche des Fragments ist gut geglättet.

- Fragment 76 (Taf. 25 Abb. 107. 108)

Eckstück (rechte Seite L 5; linke Seite L 7; H 8) einer Klinenaußenseite mit Ablauf zur Unterseite. Die rechte Seite des Fragments scheint etwas besser geglättet zu sein. Bei dem Aristides-Sarkophag wäre dieses Fragment nur an der Ecke der linken Schmalseite zur Rückseite passend; das Fragment an die Ecken der Vorderseite gehörig zu rekonstruieren, ist nicht möglich, da sich dann Reste der Fulcra erhalten haben müssten. Die Ecke zeigt auf jeder Seite den Ansatz klammerförmiger Linien, wie sie auch zwischen den Kassetten üblich sind.

- Fragment 77 (Taf. 25 Abb. 109)

Eckfragment (rechte Seite L 10,5; linke Seite L 5; H 14) einer Klinenaußenseite mit Ablauf zur Unterseite. Die rechte Seite des Fragments zeigt die untere linke Ecke eines Rechtecks. Die Rahmung besteht aus einer profilierten und darin einer flachen Leiste. Die innere Leiste ist im Vergleich zu Fragment 75 im unteren Abschnitt etwas niedriger gebildet, was aber vielleicht im Rahmen der handwerklich bedingten Abweichungen liegen mag. Es ist nicht zu entscheiden, ob die linke Seite des Fragments besser geglättet ist. An dem Aristides-Sarkophag wäre dieses Fragment nach seiner Form an den Ecken zur Rückseite möglich; die entsprechenden erhaltenen Stücke am Deckel sind ebenfalls nicht fein geglättet. Die untere profilierte Leiste wird wie bei Fragment 76 auch auf der besser erhaltenen linken Schmalseite von den Ansätzen der klammerartigen Linien überschnitten.

\footnotetext{
158 Im Einzelnen s. Rudolf 1992, $26 \mathrm{f}$.

159 s. dort auch etliche Beispiele in Anm. 174.

160 So bereits Keil 1929, 48. s. in der Folge z. B. Rodenwaldt 1930, 135. 167. 178-180. 184; Linant de Bellefonds 1985, 29 Anm. 2; Rogge 1993, 118 f.; Ciliberto 1998, 245-247. Zu den rechteckigen Feldern mit Rhomben und Rosetten auf den Außenseiten der Klinen s. Weber 2002, 499, der vermutet, dass vielleicht »das Gestänge des Klinenrahmens durch vier senkrechte Stege angedeutet« ist, welche »durch flache, rautenförmig gesetzte Streben stabilisiert sind «. Zu Vorbildern der Fulcra s. z. B. Faust 1989, 63 f.

161 s. o. Einleitung und Forschungsgeschichte.
} 
- Fragment 78 (Taf. 25 Abb. 110)

Das Fragment (L 10; H 6) hat ein umbiegendes Stück zur Unterseite unter einer profilierten Rahmung des Kassettendekors erhalten. Das Fragment ist weniger gut geglättet als Nr. 75.

- Fragment 79 (Taf. 25 Abb. 111)

Das Fragment (L 5; H 9) bietet die Ecke eines Rechtecks mit einer Seite einer Füllblüte. Die Orientierung ist nicht gesichert. Die Kassettenrahmung besteht aus einer flachen Leiste; wahrscheinlich handelt es sich bei dem Rest darunter um eine weitere Rahmung, wie dies z. B. bei dem Fragment, welches in der Stützmauer des Atriums der Johannesbasilika verbaut ist, zu beobachten ist (Kat. 48 Taf. 77 Abb. 317 f.). Die Oberfläche des Fragments ist nicht so gut geglättet wie bei Fragment 75 und gehört damit wohl auf eine nachgeordnete Schmal- oder Rückseite. Aufgrund der erhaltenen Profilierung ist eine Zugehörigkeit zum Aristides-Sarkophag jedenfalls auszuschließen.

Fragment 79 sowie die anderen vier Fragmente können auch nicht zum Amazonomachie-Sarkophag »C« gehört haben, denn dessen Deckel trägt ein vegetabiles Dekor, aber kein Dekor auf den Außenseiten der Kline (s. Kat. 2 Taf. 31 f.). Es bleibt somit eine rein hypothetische Möglichkeit der Zuordnung zum Hippolytos-Sarkophag »E«, für den ein Klinendeckel zu fordern ist; dann wäre die Aufschrift »TG « nicht korrekt.

Für die Entscheidung, ob die vier Fragmente Nr. 75-78 zum Aristides-Sarkophag gehören, sind das Dekor und die Oberflächenglättung als Kriterien heranzuziehen. Fragment 75 ist deutlich besser geglättet als die Fragmente Nr. 76-78. Bei den Eckfragmenten Nr. 76 und 77 ist nicht sicher zu entscheiden, ob die rechte Seite des Fragments Nr. 76 und die linke Seite von Fragment 77 besser geglättet sind. Leider können die Fotos des Klinendeckels des Aristides-Sarkophags keinen Aufschluss geben, ob und wie sich der Grad der Glättung an den Schmalseiten und der Rückseite unterscheidet. Der Klinendeckel stand bei der Untersuchung vor Ort in einer Nische an der Wand, sodass dazu keine Ergebnisse gewonnen werden konnten. Das Kassettendekor, dessen rahmende Leisten und das Blütendekor von Nr. 75 passen zu dem Aristides-Sarkophag. Mögliche handwerklich bedingte Abweichungen berücksichtigend, könnten diesbezüglich auch die Fragmente Nr. 76-78 passen. Allerdings zeigen die Eckfragmente Nr. 76 und 77 klammerförmige Linien, die nach Ausweis der Fotos an dem Aristides-Sarkophag nicht an den Ecken vorhanden sind, sondern nur zwischen den Kassetten. Ist dem so, gehören die Eckfragmente Nr. 76 und 77 nicht zu dem Deckel des Sarkophags des Aristides.

\section{Datierung}

Der Sarkophag datiert um 200 n. Chr., der Porträtkopf um 220 n. Chr. ${ }^{162}$.

\subsection{Kastenfragmente mit Klinendeckel eines Amazonomachie-Sarkophags \\ (Kat. 2 Taf. 26-32)}

Gefunden in Ephesos, Grabhaus der Claudia Antonia Tatiane (1928-1929) (Taf. 1 Abb. 1). In den Aufzeichnungen F. Eichlers sind die Fragmente des Amazonomachie-Sarkophags unter der Bezeichnung »Sarkophag $\mathrm{C}^{163}$ aufgeführt.

Die Kastenfragmente ohne Inv. sind im Efes Kapalı Depot Inv. 352 ist im Efes Müzesi Selçuk gelagert. Deckel: Izmir, Archäologisches Museum Inv. 2.

162 Zu dem zeitlichen Abstand s. o. Anm. 97.

163 s. o. Anm. 79. 
Deckel: L 226,5; H (max.) 80; T 109. Durch die Maße des Deckels können für den Kasten ähnliche Ausmaße in Länge und Tiefe angenommen werden.

Lit.: Keil 1929, 47 f. Abb. 28; Keil 1930, 11; Rodenwaldt 1930, 135 f. 139 Anm. 3; 186; Eichler 1944/45, 129 Nr. 2; Eichler 1946, 89 Anm. 16; Kallipolitis 1958, Nr. 124; Haas 1959, 119; Giuliano 1962, Nr. 252; Koch - Sichtermann 1982, 372 Anm. 48; 466; Rudolf 1989, 44-46 »Ephesos C« Taf. 22 f. Abb. 31-35; Koch 1991, 816-819; Rudolf 1992, 25 f. Abb. 41; Rogge 1993, 119 Anm. 118 und 126; 120 Anm. 129; Kintrup 1998, 212 Anm. 26; Kintrup 2016a, Kap. 3.2.8 Nr. 90.

Feinkörniger, weißer Marmor mit starken Glimmerschiefereinschlüssen. Anhand der Ausführung lassen sich keine Fragmente eindeutig den nachlässiger gearbeiteten Sarkophagseiten zuordnen. Die Innenseite des Kastens zeigt eine mittlere bis grobe Spitzmeißelarbeit.

Drei Fragmente (eines aus zwei anpassenden Stücken), bei denen auf der geglätteten Seite »C« vermerkt ist, sind nicht abgebildet, da eine nähere Zuordnung zu dem Sarkophag nicht möglich ist. Die Fragmente zeigen keine Reliefreste; bei dem kleinsten ist fraglich, ob es sich um eine geglättete Fläche oder nur um einen glatten Bruch handelt.

\section{Kastenfragmente}

Neben Fragmenten des Relieffrieses sind Bruchteile des oberen Kastenabschlusses und der Sockelzone vorhanden.

- Fragment 1 (Taf. 26 Abb. 112-114)

Inv. 352: Das größte, allseitig gebrochene Fragment (L 69; H 27; DW 12; Rh 9-10; T 46) ist aus anpassenden Stücken zusammengesetzt. Ein kleines Fragment ist noch an der linken Figur angeklebt, während ein weiteres Fragment, das auf einer alten Aufnahme im Archiv des ÖAI über diesem angepasst ist (Abb. 113), 2002 bereits fehlte. Eine weitere alte Aufnahme ist ebenfalls von Interesse: Dort fehlen zwar die angeklebten Teile der linken Figur, aber das Stück ist noch nicht in der Mitte gebrochen. Neben dem linken Reliefrand ist deutlich mehr Bruchfläche erhalten, und wie es scheint - war der Boden des Sarkophags in voller Breite vorhanden (Abb. 114).

Unter der Standleiste zurückgesetzt, erscheint als Ornamentband des Sockels ein Blattfries mit Tieren; der Kopf eines Panthers nach rechts ist erhalten. Über der Standleiste sind einige Figurenreste zu erkennen. Links kniet eine Amazone. Sie hat ihr rechtes Bein untergeschlagen, neben ihrem Knie mit Gewandresten auf dem Oberschenkel erscheint ihr aufgestellter linker Fuß in einem Stiefel mit dem für Amazonen typischen Überschlag. Rechts hockt oder sitzt mit angezogenen Beinen eine zweite Figur. Da sie ein knielanges Gewand trägt, wird es sich ebenfalls um eine Amazone handeln. Zwischen den beiden liegt eine sphrygische Mütze dem aufgestellten linken Bein der linken Amazone erscheinen Stücke der Brust und der Beine eines Pferdes, das in die Knie gebrochen ist. Die Brust und das linke Bein des Pferdes sind durch Bohrkonturen umrissen. Hinter dem rechten Bein der hockenden Figur sind Reste ihres linken Beins mit einem Ansatz des Stiefelrandes vorhanden. Eine erst 1998 in Brescia entdeckte Vorderseite mit Amazonomachie ${ }^{164}$ bietet sich als motivischer Vergleich für die ephesischen Amazonomachie-Fragmente durch die Figuren einer sitzenden und einer knienden Amazone an. Die Vorderseite in Brescia mit einer Datierung um 230 n. Chr. offeriert zudem durch eine Standleiste mit einem unter dieser zurückspringenden vegetabilen Sockeldekor (Akanthusblattfries) weitere Vergleichsmöglichkeiten zu diesem Fragment.

164 G. Quattrocchi, Un museo tutto case e chiese, Archeo XV, Nr. 6 (172), Juni 1999, 93 mit Abb. (seitenverkehrt); F. Morandini in: C. Bertelli - G. P. Brogiolo (Hrsg.), Il futuro dei Longobardi (Ausstellungskatalog Brescia) (Mailand 2000) 525 f. Nr. 499 Abb. 373; Morandini 2000, 184-190, Abb. 4; Kintrup 2016a, Kap. 3.2.7.1 und 3.2.7.2 Nr. 78. 
- Fragment 2 (Taf. 27 Abb. 115)

Ein weiteres Fragment des Sockels mit Blattranken (L 10; H 7) zeigt unterhalb der Ranken Raspelspuren, während auf den Blättern keine Bearbeitungsspuren zu sehen sind. Die Ausführung der Blätter scheint derjenigen der zuvor genannten Stücke vergleichbar; aufgrund der Bearbeitungsspuren ist keine eindeutige Zuordnung des Fragments zu einer sorgfältig oder vernachlässigt gearbeiteten Sarkophagseite möglich.

- Fragment 3 (Taf. 27 Abb. 116)

Das Fragment, welches bereits von F. Eichler dem Amazonomachie-Sarkophag zugeordnet wurde, ist allseitig gebrochen (L 9; H 12; D 13). Über einer Leiste, die mit einem vegetabilen Ornament geschmückt ist, liegt der Kopf einer toten Amazone. Bohrungen finden sich in den Nasenlöchern und im Philtrum, als Eckpunkte und in der Mitte des Mundes; die Linien der geschlossenen Augen und der Augenbrauen sind fein eingetieft. Bei dem Ornament handelt es sich wohl um zwei Rosetten, die von Ranken umschlossen werden. Diese schmücken als Dekor die Standleiste oder die obere Leiste eines Eckpostaments. Da die Standleiste von Fragment 1 (Inv. 352: Taf. 26 Abb. 112) ohne Verzierung blieb, gibt es mehrere Möglichkeiten der Zuordnung dieses Fragments: Das Rosettendekor erscheint nur über einem Eckpostament, das Fragment gehört somit an eine Ecke des Sockels; das Dekor erscheint auf der Standleiste, aber nicht auf derselben Sarkophagseite, oder aber das Fragment gehörte doch nicht zu demselben Sarkophag. Für Rosetten als Dekor auf der Standleiste oder als Dekor der Eckpostamente lassen sich der Achill-Sarkophag in Paris ${ }^{165}$ und die Hippolytos-Sarkophage in St. Petersburg ${ }^{166}$ und Tyros ${ }^{167}$, die alle in das zweite Viertel des 3. Jahrhunderts n. Chr. gehören, vergleichen.

Der obere Kastenabschluss des Amazonomachie-Sarkophags »C « bietet eine obere Leiste mit Tieren, die zwischen Blattwerk eingestreut sind, und ein ungewöhnliches Kyma, bestehend aus Gorgonenhäuptern, die durch vertikale, konsolenartige Gliederungselemente getrennt sind.

Bei den Fragmenten Nr. 4-6, die dies dokumentieren, ist die Oberseite samt Falz intakt. Die Wanddicke beträgt dort $15 \mathrm{~cm}$, davon $4 \mathrm{~cm}$ für den Falz. Auf der Rückseite der Fragmente der Innenseite des Sarkophags - sind, soweit erhalten, die oberen $4 \mathrm{~cm}$ grob geglättet, darunter beginnt die mittlere bis grobe Spitzmeißelarbeit.

Für das Gorgonenkyma der Fragmente Nr. 4-6 und den Blattfries des Sockels auf Fragment 1 bietet der Achill-Sarkophag in Rom, Museo Capitolino ${ }^{168}$ eine enge Parallele. Der Achill-Sarkophag wird über die Porträtköpfe um 250 n. Chr. datiert.

- Fragment 4 (Taf. 27 Abb. 117)

Bei Fragment 4 (L 16,5; H 10) ist ein Tier nach links - vielleicht ein Löwe - auf der oberen Leiste erhalten. Auf dem senkrechten Gliederungselement zwischen den z. T. erhaltenen Gorgonenhäuptern ist oben ein Akanthusblatt zu erkennen, das mit vier Punktbohrungen versehen ist. Weitere Bohrungen finden sich in den Haaren, am Mund und in den Nasenlöchern. Die erhaltene Augenbraue ist als feine Linie eingetieft.

- Fragment 5 (Taf. 27 Abb. 118)

Das aus drei Stücken zusammengesetzte Fragment 5 (L 25; H 10; D 15,5) zeigt auf der oberen Leiste ein Akanthusbüschel, Akanthusranken und darunter wieder Reste zweier Gorgonenhäupter sowie der trennenden Glieder dazwischen. Dieses Fragment wurde von E. Rudolf ${ }^{169}$ und S. Rogge ${ }^{170}$ als zu dem Hippolytos-Sarkophag »E « (Kat. 15 Taf. 51 Abb. 198) gehörig beschrieben und abgebildet, gehört aber nach Stil und Ausführung zu den Fragmenten 4 und 6 und somit zu dem Amazonomachie-Sarkophag.

165 s. Rogge 1995, 134 Nr. 21 Taf. 48. 67, 1.

166 Ermitage A.432: Rogge 1995, 154 f. Nr. 64 Taf. 90. 94, 2; 95, 2; 110, 4.

167 s. Rogge 1995, Nr. 70 Taf. 91. 93, 3.

168 Rogge 1995, 136 f. Nr. 24 Taf. 44. 49. Weitere Vergleiche zum Gorgonenkyma s. Rogge 1993, 120 Anm. 129.

169 Rudolf 1989, 47 f. Abb. 38.

170 Rogge 1995, 152 Nr. 58 Taf. 112, 7. 
- Fragment 6 (Taf. 27 Abb. 119)

Die obere Leiste des kleinsten Fragments ist in einer Länge von $5 \mathrm{~cm}$ erhalten ( $\mathrm{L}$ an der Innenseite des Sarkophags 11; H 12,5). Das Gorgonenhaupt wird bis an die Haare von einem nicht weiter identifizierbaren Reliefrest überschnitten.

- Fragment 7 (Taf. 27 Abb. 120)

Des Weiteren ist dem oberen Kastenabschluss ein Fragment (L 11; H 10) mit Falz und Klammerloch zuzuordnen.

Neben den oben beschriebenen Figuren des Fragments 1 (Inv. 352: Taf. 26) zeigen die folgenden allseitig gebrochenen Fragmente Reste von Figuren:

- Fragment 8 (Taf. 28 Abb. 121)

Das aus vier Stücken zusammengesetzte Fragment 8 (L 38; H 13,5; Rh 8) lässt links den bekleideten Körper wahrscheinlich einer Amazone erkennen und rechts das Bein einer Amazone mit Stiefelüberschlag. Bei dem Reliefrest im Hintergrund könnte es sich um ein eingewinkeltes Pferdebein handeln - für die Ferse eines Fußes scheinen die Proportionen zu groß zu sein. Falls das Bein mit Stiefelüberschlag zu einer Reiterin oder stehenden Amazone gehörte, wird die Amazone links wohl kniend dargestellt gewesen sein.

- Fragment 9 (Taf. 28 Abb. 122)

Das Fragment (L 18; H 12) zeigt vermutlich eine Löwenfellsatteldecke auf einem Pferd, wobei der Löwenkopf wohl von einem Zügel überschnitten wird. Für die Schabracke ist beispielsweise der späte Amazonomachie-Sarkophag in Thessaloniki ${ }^{171}$ oder der späte Schlachtsarkophag in Tyros $^{172}$, wo ein Pantherfell als Satteldecke dient, zu vergleichen.

- Fragment 10 (Taf. 28 Abb. 123)

Auf den ersten Blick überdeckt bei Fragment 10 (L 25; H 20; D 16) das stark angewinkelte rechte Bein einer Figur mit einem erkennbaren Stiefelrand wohl einen Pferdehals sowie einen Schild mit Gorgoneion als Schildzeichen. Vor dem Stiefel erscheint ein länglicher Reliefrest (Zügel oder eher Speer [?]).

Die Orientierung des Fragments bereitet Schwierigkeiten. Bei der hier abgebildeten Ausrichtung erscheinen die Reste der Pferdemähne unten. Bei Drehung des Fragments um $90^{\circ}$ nach rechts wirkt der Pferdehals richtig, aber für ein derart nach oben abgewinkeltes Bein fehlt eine Parallele. Auch bei Deutung des sgedrehten Stiefelrandes a als Gewandsaum einer reitenden Figur fehlt eine Parallele; es könnte sich vielleicht um eine Amazone handeln, die von ihrem stürzenden oder gestürzten Pferd absteigt.

Weitere Fragmente (Nr. 11-14) zeigen Reste von Unterschenkeln mit Stiefeln:

- Fragment 11 (Taf. 28 Abb. 124)

Beinfragment (L 7; H 10; D 6). Stück des Unterschenkels mit dem Überschlag eines Stiefels.

- Fragment 12 (Taf. 28 Abb. 125)

Beinfragment (H 10). Gezackter Überschlag eines Stiefels; links oben ist der Ansatz des Reliefgrundes erkennbar.

171 Koch - Sichtermann 1982, 391 mit Anm. 11; 458 Abb. 421; Kintrup 1998, 212 f. Taf. 94, 3; Kintrup 2016a, Kap. 3.2.13 Nr. 247.

172 Grabungen, Inv. 3951/3952: Koch - Sichtermann 1982, 378 mit Anm. 2; 388 f. 405. 407. 410 Nr. 66; 459. 467 Abb. 443; Chéhab 1985, 501 f. Taf. 89-92; Rogge 1995, 144 f. Nr. 43 Taf. 9, 2; Kintrup 2016a, Kap. 4.2.17 Nr. 260. 
- Fragment 13 (Taf. 28 Abb. 126)

Fragment mit Stiefelrand (L 8; H 9). Hier erscheint nicht der typische gezackte Überschlag der Amazonen, sondern ein wulstiger Rand. Demnach wird es sich eher um einen Griechen handeln, wobei aber auch diese Form für Amazonen belegt ist ${ }^{173}$.

- Fragment 14 (Taf. 28 Abb. 127)

Reste des Stiefels und Stiefelüberschlags mit einer fein eingetieften Linie (L 6; H 9,5).

Bei den zwei folgenden Fragmenten ist die Orientierung nicht gesichert:

- Fragment 15 (Taf. 29 Abb. 128)

Fragment mit Gewandfalten (wie abgebildet: L 7,5; H 8,5). Hier kann es sich - unter dem erhaltenen Gewandende hervorkommend - um ein angewinkeltes Knie oder um einen Ellenbogen handeln.

- Fragment 16 (Taf. 29 Abb. 129)

Aus vier anpassenden Stücken bestehendes Fragment. Die gezeigte Orientierung erscheint wegen der >am Boden liegenden` Gewandfalten am wahrscheinlichsten (L 34; H 15; DW 7; Rh 5). Rechts in den Reliefgrund eingetieft verlaufen zwei Linien parallel, die als nur flach angegebenes Bein oder auch als Schildrand gedeutet werden können.

- Fragment 17 (Taf. 29 Abb. 130)

Bei dem in einer Scheibenform erhaltenen Fragment sind Raspelspuren zu erkennen. Es kann sich um die >Scheiber eines Pferdekopfes mit den Ansätzen für beide Ohren handeln.

- Fragment 18 (Taf. 29 Abb. 131)

Bei dem aus drei anpassenden Stücken bestehenden Fragment (L 22,5; H 16) handelt es sich, dem Verlauf der Falten und den unten erhaltenen Resten einer waagerechten Fläche nach zu urteilen, um ein Gewand, das auf dem Boden aufliegt. Das Motiv passt zu einer Amazone, vielleicht einer Haarreißergruppe, wie auf dem Amazonomachie-Sarkophag aus der Nekropole nördlich des Hafenkanals (Kat. 6 Taf. 40-44, und dort die Gruppen an der rechten Ecke der Vorderseite und auf der rechten Schmalseite).

- Fragment 19 (Taf. 29 Abb. 132)

Das kleine Fragment (L 15,5; H 4,5; D 10,5) zeigt mittig zwischen Bruchflächen Teile von Gewandfalten, die nicht näher zu bestimmen sind. In den Faltentälern sind sehr deutliche Bohrspuren zu erkennen.

Die folgenden allseits gebrochenen Fragmente tragen nicht F. Eichlers Aufschrift »C«. Sie wurden nach Maßen, Marmor und Stil dem Amazonomachie-Sarkophag zugeordnet:

- Fragment 20 (Taf. 29 Abb. 133)

Das aus zwei anpassenden Stücken bestehende Fragment (L 10,5; H 9,5; D 6,5) zeigt links vor der Bruchkante ähnliche Bohrspuren wie Fragment 19 und etwas nach links versetzt unter dem rechten Faltental eine Punktbohrung. Zu erkennen sind große Falten und ein schräg nach rechts oben verlaufendes Gewandende.

- Fragment 21 (Taf. 29 Abb. 134)

Eingetiefte Bohrlinien in Verbindung mit Falten finden sich auch auf diesem Fragment (L 16; H 10; D 9), dessen Orientierung nicht sicher ist. Rechts vor der Bruchfläche dürfte es sich um die Konturlinie einer Figur handeln.

173 s. z. B. auf dem Amazonomachie-Sarkophag in Thessaloniki, s. Koch - Sichtermann 1982, 391 mit Anm. 11; 458 Abb. 421; Stefanidou-Tiveriou 1993, 133 Taf. 58, 2; Kintrup 1998, 212 f. Taf. 94, 3; Kintrup 2016a, Kap. 3.2.13.2 Nr. 247. 
- Fragment 22 (Taf. 29 Abb. 135)

Das Fragment (L 8; H 8) trägt die Aufschrift »Knie links«, doch augenscheinlich handelt es sich hier um das Fragment eines rechten Knies mit den Resten eines Gewandsaums.

- Fragment 23 (Taf. 30 Abb. 136)

Das mit einigen Versinterungen behaftete Fragment zeigt einen Pferdekopf nach rechts (L 11; H 11,5) mit detailliert angegebenen Adern und einer auf der Mitte des Kopfes eingetieften Linie.

- Fragment 24 (Taf. 30 Abb. 137)

Das Fragment (L 5,5; H 6,5) enthält ein Pferdemaul nach rechts mit gebohrten Nüstern und mit einer eingetieften Linie auf der Mitte des Kopfes, wie das auch auf Fragment 23 der Fall ist.

Deckel (Taf. 30 Abb. 138-141; Taf. 31. 32)

Bei dem Deckel (L 226,5; H [max.] 80; T 109), der sich im Garten des Archäologischen Museums in Izmir Inv. 2 befindet, handelt es sich um einen Klinendeckel. Der Deckel ist mit Ausnahme der Köpfe des Ehepaars, des größeren Teils des männlichen Oberkörpers und der vorderen rechten Ecke erhalten. Die Matratze der Kline ist auf der Front mit Akanthusranken in flachem Relief und eingestreuten Tieren versehen. Von links nach rechts (Taf. 30 Abb. 138-141) handelt es sich um einen Hasen nach links, einen Hund nach rechts, einen Eber nach links, einen springenden Ziegenbock nach rechts, einen Hund nach links; das folgende nach rechts springende Tier ist nicht mehr zu identifizieren. Die Ranken entspringen einem Akanthusbüschel in der Mitte der Vorderseite. Das vorhandene linke Fulcrum der Kline endet in einem Vogelkopf, während der vertikale Teil mit Ranken verziert ist. Die Schmalseiten (Taf. 32) zeigen an der Außenseite jeweils ein Kyma aus stehenden Akanthusblättern. Überraschenderweise erscheint darunter je eine als Klinenauflager zu verstehende Leiste, die nur auf der linken Schmalseite ein Dekor aus Blättern und Ranken trägt (Taf. 32 Abb. 145). Die Leiste der Rückseite (Taf. 31 Abb. 143) ist wie die der rechten Schmalseite (Taf. 32 Abb. 144) nicht dekoriert. Die Außenseite der Kline wurde auf der Rückseite ohne Dekor gepickt belassen (Taf. 31 Abb. 143).

Vergleiche für das Dekor der Kline und der Matratze lassen sich auf etlichen Sarkophagen unterschiedlicher Thematik finden. S. Rogge hat in ihrem Beitrag zu Tektonik und Ornamentik attischer Sarkophage bereits entsprechende Vergleichsstücke zusammengestellt ${ }^{174}$. Alle Exemplare gehören in das zweite Drittel des 3. Jahrhunderts und grenzen so auch die Datierung der Sarkophagfragmente in Ephesos und des Deckels in Izmir auf diese Zeitspanne ein.

174 Rogge 1993, 119 Anm. 118; 119 Anm. 126. Die dort genannten Vergleichsstücke, unter denen sich auch der hier bearbeitete Deckel und ein weiteres Fragment in Ephesos befinden, sind im Folgenden mit leicht erweiterter Lit. aufgeführt. - Vergleiche für die Vorderseite der Matratze: Achill-Sarkophag in Beirut, Nationalmuseum Inv. 607/8: Koch - Sichtermann 1982, 373 Anm. 68; 377 Anm. 5; 385. 457 f. Abb. 414; Rogge 1995, 48 f. 126 f. Nr. 6 Taf. 52, 2; 59, 2. - Hippolytos-Sarkophag in Tyros, Nekropole Inv. 330: Rogge 1995, 157 f. Nr. 70 Taf. 88, 4; Linant de Bellefonds 1985, 22-24. 33. 135-138 Taf. 1, 4; 48. - Hippolytos-Sarkophag in Beirut Inv. 4229/30: Linant de Bellefonds 1985, 25 f. 33. 151 f. Taf. 2, 2; 59, 1; Rogge 1995, 152 Nr. 57 Taf. 84, 1; 102. 106, 1. - Klinendeckel in Kyrene, Depot (vormals Sculpture Museum): Pietrogrande 1930, 117 f. Nr. 10 Abb. 15. - Fragment einer Ecke eines Klinendeckels in Ephesos, hier Kat. 47 Taf. 77 Abb. 315 f. - Fragmentierter Klinendeckel in Xanthos: Coupel - Demargne 1976, 114 Abb. 22. - Klinen-Riefel-Sarkophag in Athen, beim Hephaisteion: Gasparri 1974/75, 382 Abb. 88; Goette 1991, Taf. 96, 1; 97, 1; Goette 1993, Taf. 45, 1. - Klinen-Riefel-Sarkophag in Salerno, Kathedrale: Rodenwaldt 1930, 134-138 Abb. 15 f.; Koch 1980, 56-64 Abb. 5-7. 9; Goette 1991, Taf. 109. - Vergleiche zum Akanthuskyma der Schmalseiten: Amazonomachie-Sarkophag in Jerusalem, Rockefeller Archaeological Museum Inv. S 995 (Inv. des Kastens: S 887): Fischer 1998, 208 Nr. 213; 225 f. Abb. 213 c-d; Kintrup 2016a, Kap. 3.2.11 Nr. 112. - Achill-Sarkophag in Beirut Inv. 607/8, s. o. - Hippolytos-Sarkophag in Arles, Musée Lapidaire d’Art Païen Inv. P 541: Rogge 1995, 150 Nr. 50 Taf. 103, 2. - Hippolytos-Sarkophag in Beirut Inv. 4229/30, s. o. - Fragment einer Ecke eines Klinendeckels in Ephesos, hier Kat. 47 Taf. 77 Abb. 315 f. - Klinen-Riefel-Sarkophag in Salerno, Kathedrale, s. o. 


\section{Datierung}

Zusammenfassend können folgende Anhaltspunkte für eine Datierung herangezogen werden: Alle Vergleichsstücke für den Deckel gehören in das zweite Drittel des 3. Jahrhunderts n. Chr. Dies wird durch die Vergleichsstücke für das Rosettendekor der Standleiste auf Fragment 3 bestätigt, die alle auf das zweite Viertel des 3. Jahrhunderts n. Chr. verweisen. Die AmazonomachieVorderseite in Brescia mit einer Datierung um 230 n. Chr. ${ }^{175}$ zeigt in Bezug auf Ikonografie und Ornamentik Parallelen mit den ephesischen Fragmenten. Für das Gorgonenkyma und auch den Blattfries des Sockels bietet zudem der Achill-Sarkophag in Rom, Museo Capitolino ${ }^{176}$, der aufgrund der Porträtköpfe um 250 n. Chr. angesetzt werden kann, eine gute Parallele. Die ephesischen Fragmente dürften dazwischen einzuordnen sein: es wird eine Datierung um 240 n. Chr. vorgeschlagen. In die späte Zeit gehört dann auch der Hippolytos-Sarkophag »E« (Kat. 15 Taf. 51 Abb. 198-200), dessen Fragmente ein Sockeldekor mit Akanthusblättern und einen oberen Kastenabschluss ebenfalls mit Gorgoneion überliefern. Das Gorgonenkyma gehört zu den experimentellen Schmuckformen, die selten verwendet wurden und nur im zweiten Drittel des 3. Jahrhunderts $n$. Chr. belegt sind.

Um 240 n. Chr.

176 Rogge 1995, 68 Anm. 344; 92. 136 f. Nr. 24 Taf. 44. 49. Weitere Vergleiche zum Gorgonenkyma s. Rogge 1993, 120 Anm. 129. 



\title{
3 Attische Sarkophage und Kastenfragmente nach Themen geordnet
}

\author{
3.1 Achill-Sarkophage
}

3.1.1 Beschädigter Kasten eines Achill-Sarkophags (Kat. 3 Taf. 33-38)

Woburn Abbey. Vor 1828 in den Besitz des Duke of Bedford gelangt.

Gefunden in Selçuk, verbaut im >Tor der Verfolgung`.

VS: H 96; L 258; D 21. - RS: H 105; L 189; D 13.

Linke Ss: H 113; L 126; D 26. - Rechte Ss: H 109; L 58; D 15.

Lit.: Robert 1890, 57-61 Nr. 47 (mit älterer Lit.); 221 (Nachträge) Taf. 22 Abb. 47-47 c; Taf. 23 Abb. 47’. 47’. 47’ a. 47’ c; Benndorf 1906, 108 f.; Reinach 1912, 537; Robert 1919, 549 f. Abb. 47 d. 47’”; Eichler 1944/45, 129 Nr. 6; Kallipolitis 1958, 28 Nr. 160; Alzinger 1962, 187; Giuliano 1962, 47 Nr. 250; Keil 1964, 32 f.; Brommer 1974, 71 Nr. 11; 91 Nr. 6; 97 Nr. 6; 99 Nr. 1; Wiegartz 1975, 198-204; Giuliano - Palma 1978, $49-51$ Nr 4 Taf. 57; 140-141; Kossatz-Deissmann 1981, 117 Nr. 477; 142. 144 Nr. 630 Taf. 120; 147. 156 Nr. 706 Taf. 129; 161; LIMC I (1981) 833 Nr. 2 Taf. 664 s. v. Antilochos (O. Touchefeu-Meynier); Koch - Sichtermann 1982, 377. 385-387. 389. 400 Anm. 7; 403 Anm. 12; 458 Abb. 418; Linant de Bellefonds 1985, 49. 57-59. 68-70. 90 f. 169-171. 176 f. 179 Taf. 9, 1-2; 10; 14, 1-2; 18; Rudolf 1989, 11-19. 43 »Ephesos A« (mit ausführlicher Lit.) Abb. 2. 4-14 sowie Frontispiz; Angelicoussis 1992, 78-83 Nr. 63 Abb. 27-33; 273 f. 299-311; Rogge 1993, 116 Anm. 77; Rogge 1995, 49-51. 59-61. 64 f. 67 f. 145 f. Nr. 45 (mit weiterer Lit.) Taf. 59, 1; 60 f. 71, 1; 73, 1; Wohlers-Scharf 1995, 42-44 Abb. 20 f.; Koch 1999, 555 Anm. 7; 557; Scherrer 2000, 190 f. Abb. 1; Rogge 2008, 586 Anm. 25; 589 Anm. 38; 590 Anm. 43; 591 Abb. 5; Schwarz 2008, 737-747; Stefanidou-Tiveriou 2014, 516 f. Abb. 5; 521 f.; Bevilacqua 2015, 334-338.

Durch die genannten Bearbeitungen, besonders von Rudolf 1989, Angelicoussis 1992 sowie Rogge 1995 im Rahmen des Sarkophag-Corpus, kann auf umfangreiche Bibliografien, ausführliche Angaben zur Fund- und Forschungsgeschichte des Exemplars - hier in Kürze wiedergegeben - , detaillierte Beschreibungen und Untersuchungen zurückgegriffen werden.

Die einzelnen Platten des zerstückelten Sarkophags wurden nebeneinander als Fries im >Tor der Verfolgung s verbaut (Taf. 33). Erste Kunde darüber geben bereits J. Spon und G. Wheler im Jahre $1678^{177}$. Zu Beginn des 19. Jahrhunderts wurden die Platten aus dem Mauerverband entfernt und gelangten vor 1828 nach Woburn Abbey in den Besitz des Duke of Bedford. Als die Platten aus dem Tor gelöst wurden, brachen u. a. ein großes Stück der Sockelzone und kleine Teile des Figurenfrieses der Vorderseite ab. In einem weniger beschädigten Zustand sind die Platten auf Zeichnungen (hier Taf. 34) überliefert, die jedoch im Hinblick auf die Wiedergabe von Details einige zeichnerische Missverständnisse bergen ${ }^{178}$. Das große Sockelfragment wurde vor Ort belassen und bei österreichischen Ausgrabungen am >Tor der Verfolgung wieder aufgefunden: O. Benndorf fotografierte das Fragment 1895 für das Sarkophag-Corpus ${ }^{179}$. Im Corpus-Band

177 Spon - Wheler 1678, 325.

178 s. z. B. Pitton de Tournefort 1717, 391. Abgebildet bei Robert 1890, 58 mit Abb.; Taf. 23 Abb. 47'. 47'c, und s. bei Angelicoussis 1992, 80 Abb. 31; 81 Abb. 33. Des Weiteren s. Choiseul-Gouffier 1782, 1 (als Vignette); Taf. 121 (>Tor der Verfolgung`). Ebenfalls abgebildet bei Robert 1890, 58 mit Abb.; Taf. 23 Abb. 47'” und bei Angelicoussis 1992, 81 Abb. 32. Weiterhin s. Views in the Ottoman Dominion in Europe in Asia and some of the Mediterranean Islands from the Original Drawings taken for Sir Robert Ainslie by Luigi Mayer (London 1810) Taf. 37: <https:// digitalcollections.nypl.org/items/510d47d9-6103-a3d9-e040-e00a18064a99> (1. 8. 2017). s. die Abbildung auch bei Rudolf 1989, Frontispiz; 13 Anm. 15 zu den Fehlern der Zeichnung. Vgl. zuletzt Bevilacqua 2015, 334-337, zur Verbauung der Platten im >Tor der Verfolgung « weiter unten Kap. 9.3.

179 Das Originalfoto Benndorfs und das zugehörige Negativ gelten als verschollen. 
Roberts von $1919^{180}$ ist das Fragment abgebildet (hier Taf. 35 Abb. 151) und zeichnerisch an die Vorderseite angepasst ${ }^{181}$ (hier Taf. 35 Abb. 152). Leider ist das Fragment heute verschollen. Ein bei Michaelis 1882 noch beschriebenes und abgebildetes Fragment eines Fußes am Boden ${ }^{182}$ ist bei Robert nicht mehr erwähnt und somit wohl auch verschollen.

Alle vier Seiten sind weitgehend und nach oben in voller Höhe erhalten, aber sie weisen neben Verwitterungsspuren Beschädigungen auf: Auf der Vorderseite (Taf. 35 Abb. 150) fehlen die Sockelzone und der untere Bereich des Figurenfrieses. Zwei kleinere Fragmente konnten hier wieder eingepasst werden: erstens Teile des Wagenrades und der rechte Unterschenkel des sog. Achill überdeckt vom linken Unterschenkel Hektors und zweitens ein Brustpanzer, der zwischen der dritten und zweiten Figur vor der rechten Ecke am Boden liegt. Zwischen diesen Figuren fehlt ein Stück des oberen Kastenabschlusses. Neben der Figur an der linken Ecke verläuft der Bruch, der die linke Schmalseite abtrennte und Beschädigungen der Eckfigur und der rechts folgenden Figuren hervorrief. Es fehlen insbesondere rundplastisch gearbeitete Partien der Figuren; hinzukommen oberflächliche Bestoßungen und Verreibungen. Dies gilt auch für die linke Schmalseite (Taf. 36 Abb. 153 f.; 37 Abb. 155 f.), die im Unterschied zu der Vorderseite einen Teil der Standfläche und des Sockelornaments erhalten hat. Auf der linken Schmalseite fehlen die linke Figur bis auf Oberschenkelhöhe sowie die rechte untere Ecke samt Teilen eines Stuhls bis auf Wadenhöhe der sitzenden Person. Von der rechten Schmalseite (Taf. 37 Abb. 157-159) fehlt etwa die linke Hälfte der Darstellung; das erhaltene Stück hat Teile der Sockelzone zu bieten. Beschädigungen sind hier weniger zahlreich als auf der Rückseite (Taf. 38 Abb. 160-162), wo Verwitterungsspuren deutlicher zu sehen sind. Bei der Rückseite fehlen die Sockelzone unter der Standleiste bis auf ein kurzes, geglättetes Stück unter der linken Ecke sowie ein Teil des Reliefs auf der rechten Seite. Zwischen der zweiten und dritten erwachsenen Figur nach der linken Ecke ist ein Stück des oberen Kastenabschlusses weggebrochen.

Die Vorderseite (Taf. 35), die linke und die rechte Schmalseite (Taf. 37) präsentieren einen oberen Kastenabschluss, der über einem Rundstab ohne Dekor ein leicht geschwungenes Kyma aus stehenden Akanthusblättern und darüber eine obere Leiste mit Blattranken aufweist. Auf der Rückseite (Taf. 38) wurde auf den Rundstab sowie das Dekor des geschwungenen Profils und der oberen Leiste verzichtet.

Als Sockeldekor wurden für die Vorderseite ${ }^{183}$ (Taf. 35 Abb. 151 f.) und die linke Schmalseite (Taf. 36 Abb. 154; 37 Abb. 155 f.) Akanthusranken gewählt, die sich jeweils aus einem mittig gesetzten Akanthusbüschel zu den Seiten entwickeln. Auf der rechten Schmalseite (Taf. 37 Abb. 157. 159) sind Teile eines Blattstabs aus Eichenblättern erhalten. Die erhaltenen Reste des Sockels der Rückseite (Taf. 38) sind nicht dekoriert.

Aufbau und Dekor des oberen Kastenabschlusses und der Sockelzone bieten wichtige Anhaltspunkte für eine Datierung. Im zweiten Viertel des 3. Jahrhunderts n. Chr. werden die konventionellen Lösungen für den oberen und unteren Kastenabschluss, nämlich die optisch stark untergliederten ornamentierten Profile, aufgegeben. Bei den Profilen wird eine Entwicklung zur Vereinfachung und Verflachung ersichtlich. Die ornamentierten Profile eines ursprünglich tektonischen Gerüsts werden zu rahmenden Elementen, wodurch die Figurenfriese stärker in den Vordergrund treten. Profile wie Perlstab, Eierstab, lesbisches Kyma und Flechtband werden durch vegetabile Schmuckbänder in flachem Relief ersetzt. In aller Regel werden - wie hier auf der Vorder- und der linken Schmalseite - stehende Akanthusblätter oder -ranken als Dekor verwendet.

Gute Parallelen unter den Sarkophagen, die anhand der Porträtköpfe zu datieren sind, bieten die linke Schmalseite eines Amazonomachie-Sarkophags in London ${ }^{184}$, die Vorder- und beide

\footnotetext{
180 Robert 1919, 549 f. Nr. 47 Abb. 47 d; 47’”.

181 s. auch Koch - Sichtermann 1982, Abb. 418; Angelicoussis 1992, 78 Abb. 27; Rogge 1995, Taf. 60, 1.

182 Michaelis 1882, 748-752 Abb. III rechts.

183 Zu Foto und Zeichnung des verschollenen Sockelfragments s. o. Anm. 178 f.

184 British Museum Inv. GR 1846.8-31.1; GR 1846.8-31.2; GR 1846.8-31.3: Robert 1890, 129-132 Nr. 110 Taf. 45 Abb. 110-110 c.; Koch - Sichtermann 1982, 391 mit Anm. 13; 398 mit Anm. 9; 458; Walker 1990, 40 f. Nr. 45
} 
Schmalseiten eines Schlachtsarkophags in Tyros ${ }^{185}$ sowie die Vorderseite und linke Schmalseite eines Achill-Sarkophags in Beirut ${ }^{186}$. Alle Exemplare haben einen oberen Kastenabschluss mit einem Kyma aus stehenden Akanthusblättern. Bei dem Amazonomachie-Sarkophag in London sind nur Reste des Sockeldekors, wohl bestehend aus zwei Ornamentbändern, vorhanden. Zu dem Sarkophag in London gelten zwei Porträtköpfe als zugehörig, da sie mit dem Kasten gefunden wurden; die Porträts werden um 240-250 n. Chr. angesetzt. Der Sockel des Schlachtsarkophags in Tyros ist auf der Vorderseite mit einem Fries aus stehenden Akanthusblättern und auf beiden Schmalseiten mit Akanthusranken geschmückt. Da die Scheitelzopffrisur des erhaltenen weiblichen Porträtkopfs unvollendet blieb, ist nur eine grobe Einordnung in die Mitte des 3. Jahrhunderts n. Chr. möglich. Ebenfalls um die Mitte des 3. Jahrhunderts ist der Achill-Sarkophag in Beirut anzusetzen, bei dem beide Porträts des Ehepaars auf dem Klinendeckel erhalten sind.

Demnach kann für den Achill-Sarkophag in Woburn Abbey eine erste zeitliche Eingrenzung in das zweite Viertel des 3. Jahrhunderts n. Chr. erfolgen, angesichts der flachen Sockelgestaltung dürfte er aber später im zweiten Viertel des 3. Jahrhunderts n. Chr. entstanden sein als bisher angenommen. Auch bei dem Sarkophag in Woburn Abbey fungieren die flachen Blattfriese am oberen Kastenabschluss und Sockel als Rahmung für das mythologisch-dramatische Geschehen. Eine ursprüngliche Funktion des Sarkophagkastens als Klinengestell ist hingegen nicht mehr ersichtlich. Der hier zu ergänzende Klinendeckel mit der repräsentativen Darstellung der Verstorbenen liegt auf einem anspruchsvoll dekorierten Kasten, ohne jegliche Einbindung durch tektonische Glieder oder das Dekor.

Der Figurenfries der Vorderseite (Taf. 35 Abb. 150) beginnt links mit der Schleifung Hektors, wobei der untere Reliefbereich komplett fehlt. Soweit zu erkennen, tragen alle gerüsteten Figuren Stiefel. An der Ecke erscheint ein Gepanzerter, der einen Helm trägt. Auf der linken Schmalseite sind Reste seines Schwerts, das in seinem Arm liegt, zu sehen. Er ist in einer Bewegung nach links gezeigt, blickt aber nach rechts. Es fehlen sein rechter Unterarm, der linke Arm, der dem Ansatz nach erhoben war, und die Beine. Der Bruch, der die Beschädigungen der linken Seite der Figur hervorrief, verursachte auch die des rechts folgenden Pferdes und des darunterliegenden oder sitzenden Trojaners mit >phrygischer Mützeく. Von dieser Füllfigur sind der bestoßene Kopf und Reste des bekleideten Oberkörpers erhalten. Dem Pferd, das vor einen Wagen gespannt ist und sich nach links aufbäumt, fehlen das Maul, das linke Vorderbein und die Hinterbeine. Der Wagendeichsel zufolge müsste zumindest ein zweites Pferd vor den Wagen gespannt gewesen sein, es fehlt aber in der Darstellung. Hinter dem Pferd steht ein Gepanzerter mit Helm in einer Dreiviertelansicht. Sein linker Arm ist bis zum Oberarm verloren, sein rechter ausgestreckt. Es wird nicht deutlich, ob er die Zügel des Pferdes hält. Leicht erhöht und somit im Wagen stehend ist ein unbekleideter Jüngling in Dreiviertelansicht seiner Rückseite abgebildet; sein rechter Arm fehlt, die linke Ellenbogenpartie ist weggebrochen. Über seinen Rücken verläuft ein Schwertgurt und in der Linken hält er einen Schild. Nach Blick und Bewegungsrichtung zu urteilen, will er gerade vom Wagen steigen. Vor dem Wagen liegt der tote Hektor, von dem lediglich die Beine erhalten sind; das rechte Bein ist angewinkelt - im Hintergrund sind Teile des Wagenrads zu erkennen - und am linken zieht ihn der behelmte Gepanzerte nach rechts. Die rechte Hand des Gerüsteten - der Arm fehlt - umfasst den Knöchel Hektors. Über dem Panzer trägt er eine Feldherrenbinde und einen Schild am linken Arm, über den auch eine Gewandbahn gelegt ist. Auf dem heute verschollenen Fragment mit Sockel ${ }^{187}$ (Taf. 35 Abb. 151 f.) sind Gewandreste am Boden und der nach links über den Kopf ausgestreckte rechte Arm Hektors zu erkennen. Zwischen dem Gerüsteten und dem

Taf. 18; Kintrup 2016a, Kap. 3.2.9 Nr. 130.

185 Grabungen, Inv. 3951/3952: Koch - Sichtermann 1982, 405 f. 410 Nr. 66; 459 Abb. 443; Koch 1989a, 197-199 mit Abb. 47-50; Chéhab 1985, 501 f. Taf. 89-92; Rogge 1995, 65 f. 144 f. Nr. 43 Taf. 9; Kintrup 2016a, Kap. 4.2.17 Nr. 260.

186 Nationalmuseum Inv. 607: Koch - Sichtermann 1982, 373 Anm. 68; 377 Anm. 5; 385. 457 f. Abb. 414; Rogge 1995, 48 f. 126 f. Nr. 6 Taf. 52, 2; 53 f. 59, 2; 65, 1.

187 s. o. Anm. 178 f. 
Unbekleideten im Wagen wird eine behelmte, gepanzerte Hintergrundfigur, die einen Rundschild vor sich hält, sichtbar.

Die Schleifung Hektors ist nur auf einem weiteren Exemplar des 3. Jahrhunderts überliefert, auf einem Achill-Sarkophag in Malibu ${ }^{188}$. Dort ist zwar auch eine Biga nach links und unter ihr ein gefallener Trojaner gezeigt, aber die Leiche Hektors liegt mit dem Kopf nach rechts und ist mit Bändern an den Knien am Wagen festgemacht. Der gerüstete Achill besteigt den Wagen nach links und tritt dabei auf Hektors linken Arm. Auf dem Sarkophag in Malibu ist also ein anderer Zeitpunkt festgehalten, nämlich Achills Aufbruch zur Schleifung Hektors um die Mauern Trojas.

Auf der Vorderseite in Woburn Abbey beginnt jenseits des Schilds der mittigen gerüsteten Figur eine zweite Szene: Priamos bittet Achill um Hektors Leiche. In dieser sog. Auslösungsszene steht der bärtige Priamos mit dem Gewand über dem Kopf in Seitenansicht vor Achill. Er ist klein und gebrechlich, mit Stock in der Linken gezeigt; sein rechter Unterarm ist verloren. Priamos fasst Achill mit der Rechten an den Arm, was dieser mit einer abwehrenden Geste quittiert. Hinter Priamos erscheint ein Gepanzerter, einen langen Stab mit seiner Rechten umfassend und einen Rundschild hinter sich. Er scheint sich - den Kopf mit korinthischem Helm gesenkt - nach links abzuwenden. Achill trägt Panzer, Chlamys, aufwendige Fellstiefel ${ }^{189}$ und sein Schwert an einem Gurt an seiner linken Seite. Sein linker Arm fehlt ${ }^{190}$, und neben ihm zeigt sich eine schmale Lücke im Relief, die nach unten fast bis zu seinen Stiefeln reicht. Rechts neben Achill liegt ein Panzer am Boden, dann folgt ein nur mit Chlamys bekleideter Jüngling, der - seinen rechten Arm über den Kopf gelegt - einen korinthischen Helm hält, den er mit seiner Linken von unten stützt; Teile der linken Hand, des Helms sowie die rechte Hand samt Handgelenkspartie fehlen. Dem Jüngling fehlt zudem auch ein Großteil seines linken Beins; der stärker verriebene Kopf ist nach links zu Achill und Priamos gewendet. An der rechten Ecke des Frieses folgt ein behelmter Gepanzerter in Schrittstellung nach rechts, der seinen Blick ebenfalls nach links zurückwendet. Seine Rechte hielt ein Schwert über den Unterarm gelegt; Hand, Handgelenkpartie und der Schwertgriff sind weggebrochen, ebenso wie Großteile seines linken Arms und linken Beins. Zwischen den Beinen des Gepanzerten liegt ein Schild am Boden, dessen Schildband zu erkennen ist.

Durch die Größe der Eckfiguren, ihre Aktionen und die Tatsache, dass die Friesfiguren z. T. bis an die obere Leiste und sogar in diese hineinragen, sind weitere Hinweise für eine Datierung gegeben. Wie oben beschrieben, erfuhr die Gestaltung des oberen und unteren Kastenabschlusses im zweiten Viertel des 3. Jahrhunderts eine Veränderung dahingehend, dass ursprünglich tektonische Glieder zu rahmenden Elementen wurden, wodurch die Figurenfriese stärker in den Vordergrund traten. Dies zeigt sich auch an den Eckfiguren. Betrachtet man zum Vergleich Sarkophage aus dem letzten Viertel des 2. Jahrhunderts n. Chr., wird deutlich, dass nach der Einführung der Klinendeckel bei den attischen Sarkophagen der Kasten als Untergestell der Kline fungiert ${ }^{191}$. Die obere Kastenleiste wird so zum Auflager für die Matratze der Kline. Nahezu realitätsgetreu umgesetzt, erscheinen reliefierte Klinenbeine bei den entsprechend benannten Klinensarkophagen ${ }^{192}$. Aber auch Eckfiguren können formal die Funktion figürlich gestalteter Klinenbeine übernehmen $^{193}$, oder Pilaster können an die Ecken gestellt sein. Bei ausgereiften Exemplaren der frühen

188 J. Paul Getty Museum Inv. 95.AA.80: GettyMusJ 24, 1996, 88 Nr. 3; Towne-Markus 1997, 120 f.; Holtman 1997, 27; Greenberg 2002, 168. Der Sarkophag wurde auch von J. Oakley auf dem Symposium des Sarkophag-Corpus, Marburg, 3.-8. Juli 2006 vorgestellt. Datierung: Mitte des 3. Jhs. n. Chr.

189 Zum mulleus: Rogge 1995, 50. 146; Rudolf 1989, 15 f.; Goette 1988, 401-464. 422 f.; H. Gabelmann, Rez. zu G. Koch, Die antiken Sarkophagreliefs 12, 6. Meleager (Berlin 1975), BJb 179, 1979, 788.

190 Nach den o. in Anm. 178 genannten Zeichnungen war der Unterarm erhoben.

191 Rogge 1993, 117; Rogge 1995, 35 f. 38; Kintrup 2016a, Kap. 3.3 S. 97-100; Kap. 8 S. 208.

192 Grundlegend zu attischen Klinen- und Klinen-Riefel-Sarkophagen s. Rodenwaldt 1930, 116-189, zu dem Klinensarkophag von S. Lorenzo s. Koch - Sichtermann 1982, 446-450; Goette 1991, 309-338 Taf. 89-112. s. auch die Beiträge Cambi 1993, 77-90 Taf. 29-35; Bielefeld 1993, 91-97 Taf. 36-41; Goette 1993, 107-110 Taf. 45.

193 s. z. B. ein Amazonomachie-Fragment in Istanbul, Archäologisches Museum Inv. 63: Robert 1890, 88 Nr. 74 Taf. 30 Abb. 74; Koch - Sichtermann 1982, 391 mit Anm. 6; 458; Kintrup 2016a, Kap. 3.1.1.3 Nr. 101, oder ein Epinausimachie-Fragmente in Tarent, Museo Nazionale Archeologico Inv. 3907-3912: Koch - Sichtermann 1982, 
Sarkophage mit Klinendeckel bilden Sockel, Klinenbeine, Eckfiguren oder Pilaster und oberer Kastenabschluss ein geschlossenes System. Zudem bleibt Reliefgrund sichtbar und die Figuren der Friese bleiben unter den Profilen. Exemplarisch seien die Achill-Sarkophage des 2. Jahrhunderts n. Chr. in Adana ${ }^{194}$ und Ioannina ${ }^{195}$ genannt, bei denen Pilaster die Szene der Lösung Hektors auf der Vorderseite begrenzen. Es bleibt Reliefgrund frei, und nur eine Figur, der Wagenlenker Automedon, bleibt nicht unter den oberen Kastenprofilen ${ }^{196}$.

Bei dem Achill-Sarkophag in Woburn Abbey erscheinen keine Pilaster mehr. Die Figuren des Figurenfrieses sind ebenso groß wie die Eckfiguren, d. h., eine Angleichung von Eckfiguren und Friesfiguren ist formal vollzogen, die Trennung von tektonischem Gerüst und Relieffries ist aufgegeben. Zudem erscheinen die Figuren an den Ecken in die Handlung einbezogen, wodurch ein weiterer kleiner Schritt in der Entwicklung ersichtlich ist. Ein Vergleich mit den zahlenmäßig besser belegten attischen Amazonomachie- und Schlachtsarkophagen zeigt, dass diese Entwicklungsstufen deutlich in das zweite Viertel des 3. Jahrhunderts gehören ${ }^{197}$.

Dass Teile der Figuren oder ihrer Ausrüstung - siehe hier in Woburn Abbey die Helme der linken Eckfigur und besonders des Gerüsteten in der Mitte sowie den Helm, welcher der Jüngling vor der rechten Ecke über dem Kopf hält - bis in die obere Leiste ragen, ist ebenfalls ein Phänomen, das auch auf den späten Achill-Sarkophagen in Tyros, Beirut ${ }^{198}$ und Malibu ${ }^{199}$ sowie den späten Amazonomachie- und Schlachtsarkophagen ab 240 n. Chr. seine Parallelen findet. Auch hierdurch kann für den Achill-Sarkophag in Woburn Abbey die zeitliche Eingrenzung in das zweite Viertel des 3. Jahrhunderts n. Chr. bestätigt werden.

Es ist sehr ungewöhnlich, dass der Fries der Vorderseite mit der Schleifung Hektors und der Auslösung Hektors zwei Szenen nebeneinander zeigt ${ }^{200}$, wodurch die Deutung der zentralen Figur der Vorderseite auch zu hinterfragen ist. Als mögliche Identifizierungen wurden der Wagenlenker Achills, Automedon, ein beliebiger Gefährte Achills oder gar Achill selbst genannt. Auf den ersten Blick scheint eine Identifizierung als Achill aufgrund der prominenten Platzierung in der Mitte und der dargestellten Aktion, Hektor am Bein zu zerren, naheliegend zu sein ${ }^{201}$. Zudem gibt es eine sehr gute Parallele zu der Schleifung auf einem Achill-Sarkophag in Beirut ${ }^{202}$, an dem

411. 412. 413 Nr. 8; 459; Linant de Bellefonds 1985, 102. 118-121. 179 Taf. 38, 1-2; R. Belli Pasqua in: Andreassi 1995, 186 f. 201-205 Nr. VI.11; VI.12.; Kintrup 2016a, Kap. 5.1.1 Nr. 241, oder den >Unterweltsarkophag، in Beirut: Koch - Sichtermann 1982, 417 f. Abb. 436; Oakley 2011, 56-59 mit Abb. 4; 98 f. Kat. 66 Taf. 60, 1; 62, 1; 63, 1.

194 Rogge 1995, 125 Nr. 1 Taf. 2, 1.

195 Rogge 1995, 129 Nr. 12 Taf. 1, 2.

196 Dieses frühe Eingreifen in das tektonische Gerüst ist wohl nicht als Minderung der tektonischen Funktion zu verstehen, sondern eher mit dem Wunsch nach realitätsnaher Darstellung zu erklären: Die im Wagen erhöht stehende Figur ist einfach entsprechend höher ragend dargestellt.

197 Die Entwicklung der Eckfiguren ist besonders gut und detailliert bei attischen Amazonomachie-Sarkophagen belegt. Bei einem Sarkophag in Thessaloniki s. Koch - Sichtermann 1982, 391 mit Anm. 10; 458; StefanidouTiveriou 1997, 166-169 Nr. 134; 380-383 Abb. 336-340; Kintrup 1998, 209 f. 214 f. Taf. 93, 4; Kintrup 2016a, Kap. 3.2.3 Nr. 245, setzt um 220 n. Chr. eine Angleichung des Kopfniveaus der symmetrisch an die Ecken gestellten Eckfiguren und der Friesfiguren ein und so wird auch die tektonische Funktion der Eckfiguren abgebaut. Im 2. Viertel des 3. Jhs. werden weiterhin Niken/Amazonen und Krieger als Eckfiguren auf AmazonomachieSarkophage verwendet, aber sie werden nicht mehr symmetrisch an die Ecken der Vorderseiten positioniert. Ab ca. 240 sind die Eckfiguren von den Friesfiguren nicht mehr in der Größe abgesetzt, womit ihre formale Trennung vom Figurenfries aufgehoben ist. Im letzten Entwicklungsschritt werden die Eckfiguren in das Kampfgeschehen einbezogen und erweisen sich dann auch inhaltlich den Friesfiguren zugehörig. Bei den attischen Schlachtsarkophagen finden sich Hinweise darauf, dass eine inhaltliche Angleichung der Eckfiguren zu kämpfenden Figuren eher einsetzt.

198 Tyros, Nekropole Inv. 328/329: Chéhab 1968, 28-34. 75 f. 82 f. Taf. 13-16; Koch - Sichtermann 1982, 385. 458; Rogge 1995, 45 f. 143 f. Nr. 42 Taf. 52, 1; 55. Zu Beirut, s. o. Anm. 186.

199 s. o. Anm. 188.

200 Zur literarischen und bildlichen Überlieferung, zu möglichen Vorbildern und zur Deutung s. Rudolf 1989, 19-30; Rogge 1995, 98 und auch Grassinger 1999, 50. 52-54.

201 s. z. B. Koch - Sichtermann 1982, 377. 387; Linant de Bellefonds 1985, 68-70; Angelicoussis 1992, 80. 82.

202 Rogge 1995, 126 f. Nr. 6 Taf. 59, 2. 
die Szene auf der rechten Schmalseite abgebildet ist und die entsprechende Figur zweifellos als Achill anzusprechen ist ${ }^{203}$. Da nun aber die rechts folgenden Figuren der Vorderseite in Woburn Abbey eindeutig als Priamos und Achill zu benennen sind, würde dies bedeuten, die Hauptfigur Achill zweimal dargestellt vorzufinden. Das zwei- oder mehrmalige Auftreten einer Figur auf einer Sarkophagseite ist bei attischen Sarkophagen die Ausnahme ${ }^{204}$, es kann neben dem AchillSarkophag nur ein weiterer Beleg angeführt werden, und zwar ein Meleager-Sarkophag in Delphi $^{205}$. Dabei handelt es sich jedoch um ein fragmentiertes und frühes Exemplar noch aus dem 2. Jahrhundert. Allein dadurch ist die zweimalige Darstellung des Helden als unwahrscheinlich abzulehnen ${ }^{206}$. Darüber hinaus sind die Aspekte prominente Platzierung, Aktion, Parallele zur Schmalseite Beirut für eine Identifizierung als Achill nicht zwingend und auch andere Hinweise sprechen dagegen. So sind die Figur im Zentrum der Vorderseite und Achill sehr deutlich in Bekleidung und Bewaffnung unterschieden ${ }^{207}$. Die mittige Figur trägt einen Helm, einen Panzer mit einem geschmückten unteren Abschluss, eine Feldherrenbinde, einen Schild und einfache Stiefel. Achill ist ohne Helm dargestellt, trägt einen Panzer mit schlichtem unterem Abschluss, keine Feldherrenbinde, sondern eine Chlamys um die Schultern, ein Schwert an der Seite und schöne Fellstiefel. Die Wiedergabe ein und derselben Person in so unterschiedlicher Form wäre verstörend und würde verwirrend wirken.

Bezüglich der Position in der Mitte des Frieses als Argument für eine Benennung als Achill ist einzuwenden, dass es zwar einige Achill-Sarkophage, bei denen die Hauptfigur tatsächlich im Zentrum des Vorderseitenfrieses steht, gibt, jedoch handelt es sich um Sarkophage, die z. B. Achills Entdeckung auf Skyros ${ }^{208}$ oder die Rüstung Achills ${ }^{209}$ zeigen $^{210}$. Bei Achill-Sarkophagen mit der Auslösung Hektors ist dies hingegen nicht der Fall. Sowohl auf Vorderseiten von AchillSarkophagen des 2. Jahrhunderts n. Chr., siehe die Exemplare in Adana, Ioannina ${ }^{211}$ und in Beirut $^{212}$, als auch bei Sarkophagen des 3. Jahrhunderts n. Chr., wo die Szene auf Rückseiten erscheint, siehe die Sarkophage in Tyros, Beirut, Paris und Termessos ${ }^{213}$, sind die Hauptfiguren nicht zentral abgebildet. So finden sich Priamos und Achill am rechten Friesende und Hektor ist links liegend abgebildet, während - wenn überhaupt - eine Nebenfigur, nämlich der Wagenlenker Automedon, näher zur Mitte und erhöht stehend dargestellt ist. Demzufolge darf auch für die mittige Figur in Woburn Abbey nicht davon ausgegangen werden, dass sie von besonderer Bedeutung ist.

Auch der Hinweis auf die Aktion der Figur kann ab dem zweiten Viertel des 3. Jahrhunderts nicht überzeugen, denn in dieser Zeit ist eher das Gegenteil der Fall. Es zeigt sich nämlich eine

203 Rogge 1995, 50. 62 f. und 95-99 (zu Vorbildern).

204 Bei stadtrömischen Sarkophagen hingegen ist die sog. kontinuierende Darstellungsweise gängig, ja sogar typisch. Zur kontinuierenden Darstellungsweise bei attischen Sarkophagen und zu den Begriffen s. Himmelmann 1970b, 8 f. mit Anm. 2; Koch 1975, 68; Koch - Sichtermann 1982, 377. 387; Froning 1988, 169-199 (mit Verweisen auf Begriffsentwicklung S. 171 und einschlägiger Lit.); Rudolf 1989, 25-30; Rogge 1995, $21 \mathrm{f.}$

205 Koch 1975, 68. 140 f. Nr. 166 Taf. 131; Koch - Sichtermann 1982, 399 f.

206 So Rogge 1995, 50.

207 s. Anm. 206.

208 s. z. B. die Exemplare in Jerusalem, Ptolemais und Paris: Rogge 1995, Taf. 43, 1-3. s. auch den Sarkophag in Tyros: Die Deutung des Vorderseitenfrieses ist nicht gesichert. Rogge 1995, 45 f. Nr. 42 Taf. 52, 1.

209 s. den Sarkophag in Beirut, dessen Vorderseite sich ebenfalls »als inhaltlich schwer verständliches Gebilde präsentiert«: Rogge 1995, 47-49 Nr. 6 Taf. 52, 2.

210 Und auch innerhalb der Thematik von Achills Entdeckung auf Skyros gibt es einige (frühe) Exemplare, bei denen Achill aus der Mitte nach rechts versetzt erscheint, vgl. z. B. zwei Sarkophage in St. Petersburg und einen in Neapel, s. Rogge 1995, Taf. 26, 1-2; 27.

211 s. o. Anm. $194 \mathrm{f}$.

212 Koch - Sichtermann 1982, Abb. 419; Rogge 1995, 127 f. Nr. 7 Taf. 1, 1. Zu den Genannten und zu einigen Fragmenten s. Rogge 1995, 20-22.

213 Rogge 1995, Taf. 9, 1; 10; 11; 75, 1-2. Zu den Überarbeitungen der Rückseite in Paris s. Rogge 1995, 66 f. 134 Nr. 21. Vgl. auch eine Rückseite in Rom; dort fehlt die Leiche Hektors: Rogge 1995, Taf. 13. Zu den genannten und weiteren - nicht vollständigen - Beispielen s. Rogge 1995, 65-67. 
»Tendenz, die Handlung auf Nebenfiguren zu übertragen « ${ }^{214}$. Kennzeichnete bei frühen Sarkophagen Handlung die Hauptfiguren, ist später eine Deaktivierung der Hauptfiguren zu beobachten ${ }^{215}$. So werden dann Typen aktionsloser Nebenfiguren als Hauptfiguren eingesetzt und umgekehrt die Typen handelnder Hauptfiguren für Nebenfiguren verwendet.

Im Hinblick darauf ist der Vergleich mit der genannten Szene der Schmalseite in Beirut ${ }^{216}$ neu zu bewerten. Er unterstützt nun die These, auch in Woburn Abbey eine Nebenfigur abgebildet zu sehen. Dass der Typus nicht mehr zeitgemäß war, ist durch den Sarkophag in Beirut belegt, denn er wurde hier auf die Schmalseite verbannt, während auf der Vorderseite die aktuellen - nämlich aktionslosen - Typen Verwendung fanden ${ }^{217}$. Wurde der nicht mehr aktuelle handelnde Figurentypus bei dem Sarkophag in Beirut nur noch auf der Schmalseite verwendet, ist er in Woburn Abbey für eine Nebenfigur verwendet. Demzufolge kann die mittige Figur nicht als Achill benannt werden, eine Identifizierung als Automedon ${ }^{218}$ oder als ein beliebiger Gefährte »muss dahingestellt bleiben $\aleph^{219}$.

Typisch für den Umgang mit Figurentypen bei Sarkophagen besonders ab dem zweiten Viertel des 3. Jahrhunderts ist es, Figuren und Gruppen versatzstückartig zu kombinieren. Eine themenspezifische Bindung eines Figurentypus an einen bestimmten Mythos besteht nicht mehr ${ }^{220}$.

214 Wiegartz 1975, 202 und 203 mit Anm. 233 zu dem Folgenden, was sich teilweise explizit auf die Schmalseiten des Sarkophags Woburn Abbey bezieht und teilweise im Hinblick auf späte Hippolytos-Sarkophage konstatiert wird.

215 Diese Entwicklungstendenzen lassen sich sogar bei den attischen Sarkophagen mit Schlachtszenen nachweisen, die naturgemäß aktionsbetonte Szenen bieten. Durch die veränderte Typenwahl bedingt, werden im Laufe der Entwicklung andere Momente eines Kampfes dargestellt. Auf frühen Sarkophagen des 2. Jhs. bis um 230/240 n. Chr. sind dramatische, lebensbedrohliche Kampfsituationen gezeigt, s. z. B. den Amazonomachie-Sarkophag in Paris: Robert 1890, 81-84 Nr. 69 Taf. 30 Abb. 69-69 c; Koch - Sichtermann 1982, 389 f. 391 f. 440 Nr. 36; 456. 458 Abb. 420; Baratte 1985, 256-261 Nr. 166; Kintrup 1998, 206 f. 215 Taf. 92, 1; Kintrup 2016a, Kap. 3.1.1.1 Nr. 156, den Amazonomachie-Sarkophag in Ephesos: hier Kat. 6 Taf. 40-44, den Schlachtsarkophag in Athen: Robert 1890, 131 f.; Koch - Sichtermann 1982, 407. 408 Nr. 14; 458; Kintrup 2016a, Kap. 4.2.5 Nr. 55, oder den Amazonomachie-Sarkophag in Thessaloniki: s. o. Anm. 197. s. dort z. B. stürzende Figuren, in die Knie gezwungene Figuren oder solche, die an den Haaren gerissen werden oder sich gegen den wohl tödlichen Stoß wehren. Die Figuren agieren mit- bzw. gegeneinander in unterschiedlichen Körperansichten; Frontalansichten nehmen dabei im 3. Jh. n. Chr. zu. Bei den späten Exemplaren ab 240 hingegen sind zumeist frontalansichtige Figuren abgebildet, Dramatik begegnet dort kaum noch. Die Kampfszenen haben ihre Aggressivität eingebüßt. Meist werden ein Reiter und ein Fußsoldat als Gegner nebeneinandergesetzt, wobei sich die Gegner nicht einmal mehr direkt berühren. s. hierzu z. B. den Amazonomachie-Sarkophag in Jerusalem: Koch - Sichtermann 1982, 375 f. 391 mit Anm. 12; 445. 458. 467; Gersht - Pearl 1992, 229 Abb. 12-12 b; 240 Nr. 12; Fischer 1998, 208 Nr. 213 ; 225 f. Abb. 213 a-d; Kintrup 1998, 211-213 Taf. 94, 2; Kintrup 2016a, Kap. 3.2.11 Nr. 112, den Schlachtsarkophag in St. Petersburg: Saverkina 1979, 24 f. Nr. 5 Taf. 11-13; Koch - Sichtermann 1982, 407. 409 Nr. 45; 459; Kintrup 2016a, Kap. 4.2.19 Nr. 237, und einen weiteren Amazonomachie-Sarkophag in Thessaloniki: Koch - Sichtermann 1982, 391 mit Anm. 11; 458 Abb. 421; Kintrup 1998, 212 f. Taf. 94, 3; Kintrup 2016a, Kap. 3.2.13 Nr. 247.

216 s. o. Anm. 202.

217 s. Rogge 1995, Taf. 52, 2.

218 So Kossatz-Deissmann 1981, 156 Nr. 706. Eine Deutung als Automedon wäre auch für den unbekleideten Jüngling, der gerade vom Wagen steigen will, möglich, s. Angelicoussis 1992, 80 mit Verweis auf Linant de Bellefonds 1985, 68 f. Nach Angelicoussis 1992, 81 könnte aber auch der nur mit Chlamys bekleidete Jüngling auf der rechten Seite, der einen korinthischen Helm hält, Automedon sein.

219 Robert 1890, 59. In diesem Sinne s. auch Rudolf 1989, 26-30; Rogge 1995, 50.

220 So wurde z. B. bei einem Schlachtsarkophag in Tyros, Grabungen, Inv. 4048/4049: Koch - Sichtermann 1982, 407. 410 Nr. 67; 459. 467; Chéhab 1985, 600 f. Taf. 122-125; Kintrup 2016a, Kap. 4.2.13.2, Nr. 262, der Typus eines Kriegers mit Pferd von den Achill-Sarkophagen, s. Koch - Sichtermann 1982, Abb. 413. 414; Rogge 1995, Taf. 43, 1-3; 44; 48, 1; 49, 1; 52, 2; 54, 1, übernommen, bei einem Schlachtsarkophag in Beirut, Nationalmuseum Inv. 1279: Chéhab 1968, 41-44. 81 Taf. 22-26; Koch - Sichtermann 1982, 407. 408 Nr. 20; 458; Chéhab 1985, 687 f. Taf. 137-139; Kintrup 2016a, Kap. 4.2.15.2 Nr. 72, ebenfalls ein Krieger samt Pferd den Hippolytos-Sarkophagen entlehnt, s. Koch - Sichtermann 1982, Abb. 426; Rogge 1995, Taf. 88, 4; 89, 1-2; 90; 91, 2. Bei einem weiteren Schlachtsarkophag in St. Petersburg Ermitage Inv. A.521: Saverkina 1979, 24 f. Nr. 5 Taf. 11-13; Koch Sichtermann 1982, 407. 409 Nr. 45; 459; Kintrup 2016a, Kap. 4.2.19 Nr. 237, erscheint ein Portalbogen, der häufig bei Achill- und Hippolytos-Szenen, vgl. Koch - Sichtermann 1982, Abb. 419; Rogge 1995, Taf. 1, 1; 7, 1; 14, 2; 14,$5 ; 16,5 ; 37,1 ; 43,1 ; 64,1 ; 69,3 ; 89,3 ; 96$, zu finden ist, die sich in Innenräumen abspielen, unsinnigerweise 
Beispielhaft für diesen >Typentransfer s sind die Figuren der Priamos-Achill-Gruppe in Woburn Abbey. Anstelle der im 2. Jahrhundert üblichen Darstellung des knienden Priamos vor dem sitzenden Achill sind hier zwei stehende Figuren abgebildet. Die seitliche Ansicht und die gebeugte Haltung des Priamos sowie die frontale Darstellung Achills lassen sich eindeutig von der AmmeHippolytos-Gruppe der Hippolytos-Sarkophage des 3. Jahrhunderts ${ }^{221}$ ableiten und in einer weiteren Verwendung wird daraus auf dem Achill-Sarkophag in Beirut ein Diener neben Achill1222.

Der aufgezeigte Typentransfer hat zur Folge, dass die Friese im Hinblick auf den einzelnen Mythos ihre erzählerische Prägnanz ${ }^{223}$ und an mythologischer Substanz verlieren. Doch sind die Kompositionen aus Versatzstücken unter mehr als nur formal-ästhetischen Gesichtspunkten zu betrachten und sollten auch nicht allein als unreflektierte Übernahme - vielleicht mit Blick auf eine rationalisierte Fertigung der Sarkophage - gesehen werden. Vielmehr könnte eine Mehrdeutigkeit beabsichtigt gewesen sein ${ }^{224}$, vielleicht sollte auf verwandte Aspekte angespielt oder auf andere Mythen verwiesen werden. So geben nach E. Rudolf die auf der Vorderseite getragenen Waffen und Rüstungsteile ${ }^{225}$ darauf einen Hinweis ${ }^{226}$ : Im Vergleich zu den Sarkophagen des 2. Jahrhunderts fehlt hier der Geschenkwagen, sodass die Waffen und Rüstungsteile jene zur Auslösung Hektors sein könnten. Doch auch Rudolf möchte sich hier nicht festlegen, sondern es so bewerten, dass "Szenen und Details eine an Andeutungen reiche Vorstellung der Lösung Hektors « geben ${ }^{22}$.

Der sspielerische< Umgang mit Figurentypen kann den Betrachter bereichern, ist er doch vielleicht für ihn tatsächlich mit einer Art `geistreichem Spiel verbunden ${ }^{228}$. Die mit den Versatzstücken verknüpften Anspielungen und Assoziationen dürften durchaus erwünscht und geschätzt worden sein. Das andeutungsreiche Zitieren konnte neue inhaltliche Bezüge herstellen, vielleicht einen Überraschungseffekt hervorrufen, die Bedeutung(en) verdichten, bereichern oder potenzieren ${ }^{229}$.

an der Ecke eines Schlachtgeschehens, das sich naturgemäß unter freiem Himmel abspielt. Weiterhin lässt sich anführen der Transfer einer gelagerten Meeresgöttin, wie sie z. B. auf dem Epinausimachie-Sarkophag in Damaskus, Nationalmuseum Inv. 25662: Koch - Sichtermann 1982, 411. 412. 413 Nr. 4; 459. 467; Koch 1996, 197-207 Taf. 44-49; Kintrup 2000, 125-137 Taf. 26-31; Kintrup 2016a, Kap. 5.2.4.3 Nr. 84, erscheint sowie wohl eine Verteidigerfigur, vgl. den Epinausimachie-Sarkophag in Thessaloniki, Archäologisches Museum Inv. 1246: Koch - Sichtermann 1982, 411. 412. 414 Nr. 18; 416. 459 Abb. 445; Stefanidou-Tiveriou 1997, 169-174 Nr. 135; 384-387 Abb. 341-346; Kintrup 2016a, Kap. 5.2.6.2 Nr. 248, auf die Rückseite eines Hippolytos-Sarkophags in Tarragona, s. Rogge 1995, Taf. 108, 3. Ebenfalls aufschlussreich ist das Beispiel des späten Sarkophags in Pola, Arheološki Muzej Istre Inv. A/426: Zingerle 1907, 157-162 Taf. 5; Koch - Sichtermann 1982, 412.413. 414 Nr. 23; 459; Cambi 2002, 162 f. Abb. 249. Kintrup 2016a, Kap. 5.2.9 Nr. 162, bei dem eine mythologische Figur, nämlich eine Meeresgöttin (s. o.), in die Darstellung einer historischen Schlachtszene (Marathonschlacht) integriert wurde. Offensichtlich ist auch hier eine ursprüngliche Bindung einzelner ikonografischer Typen an eine bestimmte Thematik aufgegeben.

221 Koch - Sichtermann 1982, 389; Rogge 1995, 50. 98; Angelicoussis 1992, 82. Zu Vergleichen s. z. B. Koch Sichtermann 1982, Abb. 426; Rogge 1995, Taf. 88, 4; 89, 1; 89, 2; sowie zwei Schmalseiten Taf. 103, 2; 106, 1 , wo die Amme auf der linken Seiten von Hippolytos steht.

222 Rogge 1995, 47. 50 Taf. 52, 2; 54, 3.

${ }^{223}$ Der Begriff der »erzählerischen Prägnanz« wurde von H. Wiegartz geprägt, s. Wiegartz 1983, 189. 191 f. Vgl. auch Rogge 1995, 39. $119 \mathrm{f}$.

224 s. auch Zanker - Ewald 2004, 27.

225 Die Figur links hinter der mittigen Figur trägt einen Schild, der zweite Jüngling von rechts einen Helm, und ein Panzer liegt bereits zu Füßen Achills.

226 Rudolf 1989, $27 \mathrm{f}$.

227 Rudolf 1989, 27 f. mit Verweis auf Wiegartz 1975, 203. So auch Rogge 1995, 50. »Es werden mehrere Aspekte des Mythos in einem Fries zur Darstellung gebracht, und zwar ohne dass man sich der kontinuierenden Darstellungsweise bediente.« Auch die Deutung anderer später Achill-Sarkophage bereitet Schwierigkeiten, da ihre Darstellungen ähnlich sindifferent‘ sind, s. die Sarkophage in Tyros: Rogge 1995, 45 f. Taf. 52, 1, und in Beirut: Rogge 1995, 47-49 Taf. 52, 2.

228 Mit Dank für den Hinweis s. Amedick 2002, 533.

229 Vgl. Amedick 2002, 527. 532 f. So auch Kintrup 2016a, Kap. 7 S. 206 f., s. dort auch zur sepulkralsymbolischen Bedeutung: Die versatzstückartige Verwendung von Einzelfiguren oder Figurengruppen auf späten attischen Sar- 
Der Verlust erzählerischer Prägnanz ist auch auf beiden Schmalseiten zu beobachten. Auf der bevorzugt gearbeiteten linken Schmalseite (Taf. 37 Abb. 155 f.) sind Achill und seine Gefährten dargestellt, die um Patroklos trauern, wobei der Grund der Trauer, nämlich die Leiche Patroklos', an die linke Ecke gedrängt und ihre frontale Ansicht auf die Rückseite verlagert wurde (Taf. 38) ${ }^{230}$. Hier wie auf der Vorderseite sind die Hauptfiguren Patroklos und Achill am Rand dargestellt, während die mittigen Figuren nicht genauer zu benennen sind. An der linken Ecke steht in seitlicher Ansicht ein Jüngling mit einer Gewandbahn über der linken Schulter, der mit beiden Armen den Brustkorb des toten Patroklos umfasst, den er auf Rücken und Schulter heranträgt. Der Körper Patroklos' ist dabei unnatürlich gekrümmt über dessen rechte Schulter gelegt: Kopf und linker Arm - Ellenbogen und Unteram fehlen - sind auf der Brust des Tragenden nach unten hängend dargestellt, während sein rechter Arm vom Hinterkopf des Tragenden gestützt nach oben zeigt; der Unterarm ist nach links abgewinkelt. Die auf der Rückseite abgebildete frontale Ansicht des toten Körpers ist bis zu den Knien erhalten. Am rechten Ende der linken Schmalseite sitzt Achill, eine Gewandbahn um Hüften und Beine gelegt, auf einem mit Löwenfell bedeckten Hocker. Mit seiner Linken stützt er sich auf den im unteren Teil fehlenden Hocker ab und mit der Rechten fasst er sich in einer verzweifelnden oder resignierenden Trauergeste an den gesenkten Kopf. Er ist umgeben von zwei Gefährten ohne Helm, die ihren Blick nach links auf den toten Patroklos gerichtet haben. Der rechts hinter Achill Stehende trägt eine Chlamys. Er hat seine linke Hand tröstend auf dessen Schulter gelegt und seine rechte verharrt ungläubig und erschrocken vor dem Mund. Links, in Panzer und langer Chlamys, steht der zweite Gefährte mit einem langen Stab in seiner Linken und mit einem eingewinkelten, erhobenen rechten Arm. Der Unterarm fehlt, aber nach Resten der Finger am Kopf haben Arm und Hand auch eine Geste der Trauer oder des Schreckens ausgedrückt. Links daneben folgt ein behelmter Gepanzerter mit Feldherrenbinde und einem aufwärts gestellten Schwert im linken Arm. Seine Rechte ist in einer abwehrenden, erschrocken wirkenden Geste Richtung Mund geführt. Zwischen seinen Beinen liegt ein Panzer am Boden. Wie auf der Vorderseite tragen alle Gerüsteten Stiefel.

Die Szene der Trauer um Patroklos erscheint auch auf zwei weiteren Schmalseiten von AchillSarkophagen in Rom und in Tyros ${ }^{231}$. Beide Darstellungen sind fragmentiert, aber die Hauptpersonen sind vorhanden oder anhand von Resten zu ergänzen. Beide Schmalseiten zeigen den sitzenden Achill rechts ${ }^{232}$ und den toten Patroklos auf der Schulter eines Griechen links. Die Bekleidung Achills ist etwas abgewandelt, und die Figur des Trägers Patroklos' ist in Tyros frontal leicht nach links gewendet gezeigt, sodass die Leiche hinter seinem Körper nach rechts erscheint. Träger und Patroklos lassen sich auf der Schmalseite in Rom in Analogie der Darstellung Woburn Abbey rekonstruieren ${ }^{233}$. Die rechts folgenden Figuren vor Achill sind jedoch, wie im 3. Jahrhundert nicht anders zu erwarten, jeweils verschieden von den beiden anderen Darstellungen in Rom und Tyros gewählt ${ }^{234}$.

Von erzählerischer Prägnanz kann auch auf der erhaltenen rechten Hälfte der vernachlässigt gearbeiteten rechten Schmalseite (Taf. 37 Abb. 158 f.) keine Rede sein. Es zeigen sich zwei frontalansichtige Griechen, beide mit Stiefeln, und ein Pferd. Links steht ein behelmter Gepanzerter mit einem aufwärts gestellten Schwert im linken Arm. Rechts hält ein mit Chlamys bekleideter Jüngling mit der Rechten ein Pferd, das zwischen beiden steht, am Zügel. Er hat einen langen Stab oder einen Speer - die Spitze fehlt - im gesenkten linken Arm. Ausbleibende prägnante Aktionen

kophagen gibt auch einen Hinweis darauf, dass keine konkrete, immanente sepulkralsymbolische Bedeutung mit den einzelnen Figuren oder Gruppen verbunden ist.

230 So bereits Wiegartz 1975, 203 Anm. 235.

231 Rogge 1995, 59-61 Taf. 70, 1-2; 71, 2.

232 In Rom sind zwar nur Teile eines Beins und beide Füße vorhanden, aber eine den Parallelen entsprechende Ergänzung erscheint überzeugend.

233 s. die Rekonstruktionszeichnung bei Rogge 1995, Taf. 70, 3.

234 Zu einem detaillierten Vergleich und Vorbildern s. Rogge 1995, 59-61. 
oder Attribute erschweren die Deutung der Szene ${ }^{235}$. Die meisten Autoren ${ }^{236}$ deuten die Szene als Rüstung Achills mit den neuen Waffen, die ihm Thetis überbringt, vor seinem Kampf mit Hektor, S. Rogge jedoch sieht im Vergleich mit einer Schmalseite in Rom und durch das Fehlen des knienden Dieners eher den Abschied Achills von Lykomedes ${ }^{237}$.

Die zwei Figuren samt Pferd haben ihre engsten Parallelen auf den Schmalseiten von Sarkophagen in Paris, Tyros ${ }^{238}$ und Malibu ${ }^{239}$ sowie auf einem Fragment in Rom ${ }^{240}$. Bei der Schmalseite in Paris handelt es sich um die bevorzugt ausgeführte Schmalseite, so ist die Reliefhöhe größer und die Figuren sind enger aneinander gerückt, wodurch das Pferd mehr im Hintergrund verschwindet. Im Unterschied zu den Figuren der Schmalseite Woburn Abbey hat die zentrale Figur, dort eindeutig Achill, ihre Rechte an den Helm geführt, das Schwert umgehängt und hält einen Schild in der Linken. Ein Diener legt ihr eine Beinschiene an. Wegen der Anwesenheit des Odysseus links neben der Figur des Achill wird diese Szene eher als die Rüstung Achills nach seiner Entdeckung in Skyros gedeutet ${ }^{241}$.

Dies gilt auch für die vernachlässigt ausgeführte Schmalseite in Malibu, wo Odysseus rechts neben Achill stehend dessen Helm zurechtrückt. Achill hat seinen rechten Arm erhoben, den linken Arm vor den Körper geführt, und ein stehender Diener legt ihm die Feldherrenbinde um ${ }^{242}$.

Die vernachlässigt gearbeitete Schmalseite in Tyros zeigt wieder den knienden Diener und Achill, aber mit einem Schwert in der Linken, die Rechte vor dem Körper. Ein Pferd fehlt und die Figur rechts neben ihm trägt ebenfalls eine Rüstung. Da weder Thetis noch Odysseus zugegen sind, ist eine nähere inhaltliche Eingrenzung nicht möglich.

Die beste Parallele bietet das stark beschädigte Fragment in Rom, wo die Figuren in ähnlich vernachlässigter Weise ausgeführt sind wie in Woburn Abbey und auch der Abstand zwischen den Figuren mit einem Pferd dazwischen übereinstimmt. Wie in Malibu hat Achill seinen linken Arm vor den Körper geführt und ein Diener legt ihm die Feldherrenbinde um. Auch hier ist die inhaltliche Eingrenzung auf eine bestimmte Rüstungsszene nicht möglich.

Für die rechte Schmalseite in Woburn Abbey gilt Gleiches: Zwar kann die Ergänzung von Thetis, Odysseus oder eines sitzenden Lykomedes auf der verlorenen Hälfte nicht ausgeschlossen werden, aber es scheint wahrscheinlicher, dass es sich um eine Rüstungsszene handelt als um den Abschied Achills von Lykomedes, denn der Vergleich mit der genannten Schmalseite in Rom ${ }^{243}$ bietet deutlich weniger Übereinstimmungen. Zudem kann das Fehlen des knienden Dieners durch den Bruch bedingt sein; auf der Schmalseite in Tyros ist der Diener mit der Beinschiene auch in einem entsprechenden Abstand zu finden.

Der Sarkophag in Woburn Abbey präsentiert damit auch auf den Schmalseiten bevorzugt frontale Figuren. Sofern es sich bei der gerüsteten Figur, wie angenommen, um Achill handelt, ist auch hier eine aktionslose Hauptfigur gewählt; eine Handlung war - wenn überhaupt - auf eine Nebenfigur beschränkt ${ }^{244}$. Dass diese Vorgehensweise sogar auf der vernachlässigt ausgeführten Schmalseite Anwendung findet, auf der üblicherweise über die längste Zeit ältere Figurentypen

$\overline{235}$ Bei Rogge 1995, 64 f. wird die Schmalseite unter der Überschrift »Inhaltlich nicht genau bestimmbare Schmalseitenfriese« behandelt.

236 So Robert 1890, 60; Wiegartz 1975, 200-205; Koch - Sichtermann 1982, 385 (als nicht sichere Deutung bezeichnet); Linant de Bellefonds 1985, 90; Angelicoussis 1992, 82.

237 Rogge 1995, 64 f. Taf. 68, 1. 3.

238 Rogge 1995, 55-59 Taf. 67, 1-2.

239 s. o. Anm. 188.

240 Rogge 1995, Taf. 67, 1-3.

241 Passend zur Vorderseite in Paris, die besagte Entdeckung zeigt. Zu den verschiedenen möglichen Szenen einer Rüstung Achills s. Kossatz-Deissmann 1981, 65 f. Kap. IId (Rüstung auf Skyros); 69-72 Kap. III (Rüstung in Phthia); 122-128 Kap. XVI (Rüstung vor Troja).

${ }^{242}$ Einen Vergleich dazu bietet auch die Vorderseite des Sarkophags in Beirut, wo der Diener ebenfalls stehend neben Achill erscheint, und zwar wie oben angesprochen in Verwendung der Figurentypen der Amme-HippolytosGruppe, s. o. mit Anm. $221 \mathrm{f}$.

243 s. o. Anm. 240.

244 Zur Frontalität so auch Angelicoussis 1992, 83. 
Verwendung finden, spricht für eine Datierung im fortgeschrittenen zweiten Viertel des 3. Jahrhunderts.

Die Ausführung der Rückseite (Taf. 38 Abb. 160-162) ist im Vergleich zu der rechten Schmalseite noch weiter vernachlässigt, es bleibt mehr Reliefgrund frei und die Figuren sind flacher und weniger sorgfältig ausgeführt. Wie auf der Vorder- sind auch auf der Rückseite zwei Episoden nebeneinander dargestellt. Die Rückseite zeigt links die Wegführung des Astyanax und rechts folgend die Wägung des toten Hektors ${ }^{245}$. Links ist die sitzende Andromache in Chiton und Himation dargestellt; ihre linke Hand scheint den über den Kopf gelegten Mantel in Trauer vor das Gesicht ziehen zu wollen. Daneben steht wohl eine Dienerin, eine Trojanerin mit einer ähnlichen Geste; sie trägt eine >phrygische Mütze` und stützt mit der Rechten ihren linken Arm. Astyanax, langärmelig bekleidet und ebenfalls mit >phrygischer Mützeく, hat seiner Mutter zum Abschied winkend seine Rechte erhoben. An seinem linken Unterarm wird Astyanax von Odysseus, der durch Pilos und Exomis eindeutig zu identifizieren ist, umfasst und nach rechts weggezogen. Odysseus, mit Schwert im linken Arm, schreitet nach rechts, blickt aber auf den Jungen zurück.

Rechts folgt nun die Wägung Hektors. Neben Odysseus steht eine Frau in Seitenansicht, das Gewand in Trauer über den Kopf gezogen. Den eingefurchten Gesichtszügen zufolge, handelt es sich um eine alte Frau, vermutlich Hekabe ${ }^{246}$. Den linken Arm im Gewand verborgen, stützt sie ihren rechten Arm, der aufwärts abgewinkelt ist, mit einer nach oben zeigenden Handfläche. Sie blickt zu Hektor. Der tote, nackte Hektor liegt in einer Waagschale, die Arme eng am Körper, der Kopf hängt herab. Hinter ihm erscheint ein bärtiger Trojaner in einem langärmeligen Oberteil, einer Hose und mit sphrygischer Mützeく. Er trägt einen Panzer auf der Schulter herbei, um ihn in die zweite Waagschale zu legen, denn die rechte Waagschale ist noch höher als die linke, das Gewicht Hektors somit noch nicht ausgeglichen. In der rechten Waagschale liegt bereits ein rechteckiger Gegenstand: es könnte sich um einen Barren aus Edelmetall handeln ${ }^{247}$.

Rechts folgt ein weiterer Trojaner, ebenfalls mit >phrygischer Mütze`, aber gerüstet. Er steht mit einem Schwert im rechten Arm auf einen Stab gestützt; sein Blick ist nach rechts gerichtet, wohl um die jetzt fehlenden Figuren zu beobachten. Erhalten ist vor dem rechts folgenden Bruchrand der Rücken und ein Fußrest einer Gestalt in langem Gewand. Größe und vorgebeugte Haltung lassen - auch im Vergleich zur entsprechenden Gestalt auf der Vorderseite - auf Priamos schließen. Das fehlende Stück dürfte im Wesentlichen zwei Figuren gezeigt haben, nämlich Priamos und Achill ${ }^{248}$. Reste der zweiten Figur sind ebenfalls erhalten. Links neben der rechten Ecke mit dem toten Patroklos, der gekrümmt über der Schulter der Figur auf der linken Schmalseite liegt, sind diese Reste zu erkennen: Die Figur hatte den erhobenen linken Arm um einen langen Stab oder Speer - die Spitze fehlt auch hier - gelegt; auch Reste ihres Panzers sind am Oberarm auszumachen - Achill dürfte nach rechts sitzend mit zurückgewendetem Kopf zu ergänzen sein ${ }^{249}$.

\section{Datierung}

Zusammenfassend lässt sich festhalten, dass Aufbau und Dekor des oberen Kastenabschlusses und der Sockelzone des Sarkophags in Woburn Abbey Anhaltspunkte für eine Datierung in das zweite Viertel des 3. Jahrhunderts n. Chr. bieten. Die Parallelen unter den anhand von Porträtköpfen datierbaren Sarkophagen gehören in die Zeit um 240-250 n. Chr. Auch besonders durch seine flache Sockelgestaltung darf der Sarkophag Woburn Abbey später im zweiten Viertel des 3. Jahrhunderts $\mathrm{n}$. Chr. angesetzt werden als bislang geschehen.

245 Zur literarischen und bildlichen Überlieferung, zu möglichen Vorbildern und zur Deutung s. Rudolf 1989, 19; Rogge 1995, 98 und auch Grassinger 1999, 57.

246 s. Angelicoussis 1992, 81. Rogge 1995, 67 mit Anm. 341; 146, und auch Rudolf 1989, 18 Anm. 44, verweisen auf die Deutungen der Frau durch die älteren Autoren, z. B. Michaelis 1882, 751 und Robert 1890, 61, auf Hekabe.

247 So Rudolf 1989, 18 und bereits Michaelis 1882, 751; Robert 1890, 60.

248 So auch z. B. Rudolf 1989, 19; Rogge 1995, 67 f. 99. 146; Angelicoussis 1992, 81. 82.

249 Zu Vorbildern s. Rudolf 1989, 19; Rogge 1995, 67. 95-99. 
Eine Angleichung der Eck- und der Friesfiguren ist durch ihre Größe formal vollzogen und weiterhin werden die Eckfiguren in die Handlung einbezogen. Vergleichsstücke unter den attischen Amazonomachie- und Schlachtsarkophagen belegen diese Entwicklungsstufen ebenfalls später im zweiten Viertel des 3. Jahrhunderts. Unterstützt wird die spätere Datierung auch dadurch, dass die Friesfiguren teilweise bis an die obere Leiste und in diese hineinragen. Hierdurch und durch die Eckfiguren manifestiert sich eine Entwicklung, die die Funktion des oberen und unteren Kastenabschlusses und der Eckfiguren von ursprünglich tektonischen Gliedern zu rahmenden Elementen und einbezogenen Friesfiguren veränderte, wodurch die Figurenfriese stärker in den Vordergrund rückten.

Die Zusammenstellung der Szenen der Vorder- und auch der Rückseite lässt darauf schließen, dass hier bekannte Szenen variiert und neu kombiniert wurden, um einen neuen Entwurf zu dem Thema beizubringen, der allerdings, den derzeitigen Belegen nach zu urteilen, nicht zu überzeugen wusste und sich somit auch nicht durchsetzen konnte ${ }^{250}$. Die Vorderseite in Woburn Abbey hat durch die mittige bewegte Figur noch nicht die beruhigte Wirkung wie die Vorderseiten der späten Exemplare in Tyros und Beirut, aber die inhaltliche Aussage ist in Teilen ähnlich indifferent wie jene der Vorderseiten dieser Sarkophage ${ }^{251}$, womit sich auch hierdurch eine Datierung näher zu den späten Exemplaren andeutet.

Zunehmend werden frontale Figurentypen eingesetzt. Zudem ist eine Deaktivierung der Hauptfiguren zu beobachten, während für Nebenfiguren handelnde Typen verwendet werden. Einzelne Figuren- und Gruppentypen belegen einen Typentransfer und die versatzstückartige Verwendung von Typen. Dies bedeutet, dass keine Bindung eines Typus an einen bestimmten Mythos intendiert ist. Dadurch gehen die mythologische Substanz sowie die erzählerische Prägnanz der Friese verloren. Durchaus möglich ist aber, dass eine Mehrdeutigkeit angestrebt war, um so dem Betrachter ein an Zitaten, Anspielungen und Assoziationen reiches Bild bieten zu können.

Dass die Verwendung frontaler Figurentypen, der Verlust an erzählerischer Prägnanz und eine Deaktivierung der Hauptfiguren auch an den Schmalseiten - insbesondere auch an der vernachlässigt gearbeiteten - zu beobachten ist, wo in der Regel veraltete Typen ein Nachleben haben, stellt einen weiteren Beleg für die vorgeschlagene spätere Datierung um 240 n. Chr. dar.

Um 240 n. Chr.

\subsubsection{Fragment eines Achill-Sarkophags (Kat. 4 Taf. 39 Abb. 163 f.)}

Woburn Abbey.

Von F. V. J. Arundell 1832 in Selçuk unter dem >Tor der Verfolgung` gefunden. Arundell glaubte ein Fragment des bereits nach Woburn Abbey verbrachten Achill-Sarkophags, der im >Tor der Verfolgung « verbaut gewesen war (hier Kat. 3 Taf. 33-38), gefunden zu haben und schickte das Fragment an den 6. Duke of Bedford. Obwohl das Fragment nicht dem Sarkophag aus dem >Tor der Verfolgung` zugehörig ist, verblieb es in der Sammlung.

\section{H 62; D 13.}

Lit.: Michaelis 1882, 726 Nr. 71; Robert 1890, 54 Nr. 41 (mit älterer Lit.) Taf. 20 Abb. 41; Smith 1900, 45 Nr. 74; Vermeule - Bothmer 1956, 348 f.; Kallipolitis 1958, 22 Nr. 86; Giuliano 1962, 66 Nr. 418; Brommer 1974, 82 Nr. 26; Kemp-Lindemann 1975, 53; Kossatz-Deissmann 1981, 64 Nr. 160; Koch - Sichtermann 1982, 384 Anm. 22; Koch 1991, 819 Nr. 10; Angelicoussis 1992, 96 Nr. 71; 208 Abb. 345; Koch 1999, 555 Anm. 7.

Allseitig gebrochenes Fragment einer Figur in einem doppelt gegürteten, langen Gewand (Taf. 39 Abb. 163 f.). Die Figur ist von oberhalb der Fußknöchel bis auf Höhe der Brust erhalten. Das über

\footnotetext{
250 Vgl. auch Rogge 1995, 51. 68. 98 f.
}

251 s. auch Rogge 1995, 45 f. 47 f. 
dem rechten Bein aufspringende Gewand vermittelt mit seinen tief eingearbeiteten, z. T. gebohrten Falten den Eindruck heftiger Bewegung. Das unter dem Gewand verborgene linke Bein der Figur fehlt in Teilen. Die Ausführung spricht für die Zugehörigkeit des Fragments zu einer bevorzugt gearbeiteten Sarkophagseite.

$\mathrm{Zu}$ der stark bewegten Figur mit aufspringendem Gewand finden sich Vergleiche auf Vorderseiten von Achill-Sarkophagen, die die Entdeckung des Helden auf Skyros darstellen ${ }^{252}$. Als frühe Beispiele aus dem letzten Viertel des 2. Jahrhunderts n. Chr. lassen sich die Exemplare in Neapel $^{253}$ und St. Petersburg ${ }^{254}$ nennen, bei denen Achill nach links bewegt und sein Gewand über das rechte Knie nach oben verrutscht ist. Auf dem Sarkophag um die Mitte des 3. Jahrhunderts n. Chr. in Paris ${ }^{255}$ ist nur noch sein rechter Oberschenkel von einer Gewandbahn bedeckt; die Gewandbahn verläuft hinter dem Körper aufwärts und ist über seine linke Schulter und den Arm wieder nach vorn geführt. Auf dem ebenfalls um die Mitte des 3. Jahrhunderts n. Chr. zu datierenden Sarkophag in Rom ${ }^{256}$ erscheint Achill nun in der Bewegung nach rechts wie auf dem Fragment in Woburn Abbey. Sein Gewand bedeckt nur seine linke Körperseite und das linke Bein.

Sehr ähnlich erscheint Achill auf einem stadtrömischen Achill-Sarkophag im Vatikan²57, bei dem jedoch Ergänzungen und Originalteile kaum noch unterschieden werden können. Zu Bewegungsrichtung und Gewandmotiv sind tatsächlich häufiger Parallelen auf stadtrömischen AchillSarkophagen zu entdecken, wie Beispiele - um nur einige Exemplare mit Datierungen zwischen 150 und 260 n. Chr. zu nennen - in Cambridge ${ }^{258}$, London ${ }^{259}$, Terracina ${ }^{260}$ und auch in Woburn Abbey $^{261}$ belegen $^{262}$. Bei dem Sarkophag in London bedeckt das Gewand beide Beine, bei den Exemplaren in Terracina und Woburn Abbey ist das Gewand nur einmal gegürtet und Achill hat seinen linken Fuß erhöht aufgesetzt. Die Vorderseite in Cambridge bietet die beste Parallele; es fehlt im Vergleich zu dem Fragment in Woburn Abbey nur die zweite Gürtung. Dass Gewand- und Bewegungsmotiv auf zeitgleichen Sarkophagen vorkommen, sichert die thematische Zuordnung zu Achill auf Skyros zusätzlich ab ${ }^{263}$.

Stil und technische Ausführung des Fragments in Woburn Abbey lassen dabei keinen Zweifel an der attischen Provenienz aufkommen und bieten die einzigen Anhaltspunkte für eine Datierung.

252 Eine Durchsicht der dionysischen Sarkophage ergab, dass besonders die Bewegtheit und die muskulöse Gestaltung des freien Beins, auf die z. B. auch Angelicoussis 1992, 96 hinweist, dort keine Parallelen finden.

253 Museo Nazionale Inv. 124325: Koch - Sichtermann 1982, 382-385. 440 Nr. 40; 458 f. Taf. 411; Rogge 1995, 133 Nr. 19 Taf. 26, 2; 31.

254 Ermitage Inv. A 1026: Saverkina 1979, $15-18$ Nr. 1 Taf. 1-5; Koch - Sichtermann 1982, 10. 382-385. 443. 458 f. 584 Anm. 8; Rogge 1995, 138 f. Nr. 28 Taf. 26, 1.

255 Musée du Louvre Inv. Ma 2120: Koch - Sichtermann 1982, 382-385. 458; Baratte 1985, 252-256 Nr. 165; Rogge 1995, 43. 134 Nr. 21 Taf. 43, 3; 48.

256 Museo Capitolino Inv. 218: L’Orange 1933, 9-11 Nr. 2; Wiegartz 1965b, 614; Koch - Sichtermann 1982, 7 f. 366 Anm. 1; 373 Anm. 68; 383-385. 457 f. Abb. 413; Rogge 1995, 44 f. 136-138; Nr. 24 Taf. 44-47; 49 f. 68.

257 Ehemals Belvedere: Koch - Sichtermann 1982, 129 mit Anm. 25; Grassinger 1999, 204 Nr. 26 Taf. 17, 3; $22,2$.

258 Fitzwilliam Museum Inv. Gr 45.1850: Koch - Sichtermann 1982, 128 f. 260; Grassinger 1999, 26-30; 196 Nr. 4 Taf. 4, 1; 13, 1. Um 150.

259 British Museum Inv. GR 1805.7-3.154: Koch - Sichtermann 1982, 128 mit Anm. 20; Walker 1990, 21 Nr. 13 Taf. 5; Grassinger 1999, 27-30; 199 Nr. 13 Taf. 7, 3. Um 200.

260 Museo Civico: Koch - Sichtermann 1982, 128. 276 Anm. 4; Grassinger 1999, 30-34; 201 Nr. 20 Taf. 9, 3. Um 200.

261 Koch - Sichtermann 1982, 129; Angelicoussis 1992, 88-90 Nr. 66 Abb. 36 f.; 277. 322-328; Grassinger 1999, 30-34; 202 f. Nr. 24 Taf. 17, 2; 20, 3; 22, 1. Um 250-260.

262 Zur literarischen und bildlichen Überlieferung, zu möglichen Vorbildern und zur Deutung s. Grassinger 1999, 25 f. 36 f. 38 f. $41-43$.

263 Die Frage nach den Abhängigkeiten der Werkstätten lassen weitere Untersuchungen lohnend erscheinen. 


\section{Datierung}

Die von E. Angelicoussis ${ }^{264}$ vorgeschlagene Datierung um $160 \mathrm{n}$. Chr. erscheint deutlich zu früh. Die genannten Entsprechungen aus dem letzten Viertel des 2. Jahrhunderts n. Chr. in Neapel und St. Petersburg ${ }^{265}$ zeigen bei den Gewändern Achills runder gearbeitete Falten, die den Stoff schwerer wirken lassen, ohne harte Kontraste durch Bohrungen. Das Fragment in Woburn Abbey weist hingegen eine dünner wirkende Stofflichkeit der Gewandbahn, schärfere Faltengrate und tiefe Faltentäler sowie die deutlich sichtbare Verwendung von Bohrungen mit starkem Hell-DunkelKontrast auf. Damit und mit der Bewegungsrichtung nach rechts ${ }^{266}$ steht es dem um die Mitte des 3. Jahrhunderts n. Chr. datierten Sarkophag in Rom²67 näher als Exemplaren des 2. Jahrhunderts. Bezüglich der Faltengestaltung ist auch die Gewandbahn des nach links gewendeten Achills auf dem ebenfalls späten Sarkophag in Paris zu vergleichen ${ }^{268}$. Beide Stücke scheinen stilistisch fortgeschritten - vielleicht auch qualitativ besser - zu sein. Ein Datierungsvorschlag geht daher in das frühe zweite Viertel des 3. Jahrhunderts n. Chr. Dieser Ansatz würde zu der Hypothese passen, dass die Version Achills in Ephesos eine Zwischenstufe der Entwicklung ist von einem im 2. Jahrhundert bekleideten Achill mit der teilweise entblößten Seitenansicht seines linken Beins hin zu einer spiegelbildlichen Version eines fast unbekleideten Achill in der Mitte des 3. Jahrhunderts mit einem nackten, frontal gestellten linken Bein und einem dekorativ bedeckten, seitlich gestellten rechten Bein.

Zweites Viertel des 3. Jahrhunderts n. Chr.

\subsubsection{Eckfragment eines Achill-Sarkophags (Kat. 5 Taf. 39 Abb. 165 f.)}

Efes Müzesi, Selçuk Inv. 2264.

Gefunden in Selçuk, Johannesbasilika (1961), Fund-Nr. St.J. M61/106.

VS: H 60; L 39; DW; 4 Rh 10. - Rechte Ss: H 61; L 38; DW 8,5-9; Rh 6.

Lit.: Koch 1975, 34. 118 Anm. 5; Koch - Sichtermann 1982, 409 Nr. 30; 418 f. Anm. 539; Rudolf 1989, 53 f. »Ephesos K«; Musso 1989/90, 16 mit Anm. 37; N. Gmür Brianza in: E. Berger (Hrsg.), Antike Kunstwerke aus der Sammlung Ludwig 3. Skulpturen, Festschrift Peter Ludwig (Mainz 1990) 406 mit Anm. 10; Koch 1991, 817; Rogge 1995, 52 f. 61 f. 108 f. 128 f. Nr. 11 Taf. 57, 1; 72, 3-4.

Feinkörniger, weißer Marmor mit wenigen Glimmereinschlüssen.

Ecke der Vorderseite (Taf. 39 Abb. 165) und der rechten Schmalseite (Taf. 39 Abb. 166) mit oberem Kastenabschluss erhalten. Die Schmalseite ist nach Reliefhöhe und Ausführung der Figuren sowie durch den frei bleibenden Reliefgrund als vernachlässigte Schmalseite gekennzeichnet. Die Reliefoberfläche weist etliche Verreibungen und Bestoßungen auf. Die Oberseite mit Falz (B $4 \mathrm{~cm}$ ) ist intakt. Die Innenseite der Ecke zeigt eine regelmäßige mittlere Spitzmeißelbearbeitung, wobei $4 \mathrm{~cm}$ vom oberen Rand geglättet sind. Auf der Vorderseite finden sich Bohrungen in der Pferdemähne und eine Punktbohrung im Augenwinkel des Pferdes. Auf der rechten Schmalseite sind die gebohrten Konturlinien gut zu erkennen und die Haare mit Bohrungen versehen. Punktbohrungen finden sich in Augenwinkeln und Nase. Die Mundpartien sind beschädigt, aber die gebohrte Linie bei dem Stehenden ist noch gut zu sehen. Die Augenbrauen und eine Stirnfalte sind eingetieft.

\footnotetext{
264 Angelicoussis 1992, 96.

265 s. o. Anm. 253 f.

266 Vgl. dazu auch die Pferdeführer an der rechten Ecke der Vorderseiten von Achill-Sarkophagen mit der Entdeckung auf Skyros, z. B. in Paris, s. o. Anm. 255, und in Ephesos Inv. 2264 (hier Taf. 39 Abb. 165 f.), s. hier unter Kat. 5 ausführlicher und mit Lit. dazu.

267 s. o. Anm. 256.

268 s. o. Anm. 255.
} 
Von dem Dekor des oberen Kastenabschlusses ist ein Kyma aus stehenden Akanthusblättern erhalten, das auf der rechten Schmalseite hinter dem Kopf des Behelmten nicht gerade, sondern versetzt weitergeführt ist. Das Dekor der oberen Leiste darüber ist auf beiden Seiten verloren. Die Figuren reichen bis an die obere Leiste, der Behelmte auf der Schmalseite ragt vermutlich sogar hinein. Damit ist eine Datierung ab dem zweiten Drittel des 3. Jahrhunderts n. Chr. angezeigt, denn Vergleiche finden sich z. B. auf Achill-Sarkophagen ab 240 n. Chr. wie den Exemplaren in Tyros ${ }^{269}$, Beirut ${ }^{270}$, Woburn Abbey (Kat. 3 Taf. 35-38) und Malibu ${ }^{271}$.

An der rechten Ecke der Vorderseite (Taf. 39 Abb. 165) steht ein unbekleideter Jüngling in Schrittstellung nach rechts. Die Beine fehlen ab den Oberschenkeln, der rechte Arm ist oberhalb des Ellenbogens abgebrochen. Seine linke Hand fehlt; Reste am Oberarm - auf der Ansicht der Schmalseiten (Taf. 39 Abb. 166) zu sehen - belegen, dass er ein Schwert in der Scheide im Arm hielt. Von der Gewandbahn, die über seinen linken Unterarm gelegt ist, verläuft ein Ende hinter seinem Körper nach unten, das andere bauscht sich, seiner Bewegung folgend, links neben ihm. Der behelmte Kopf ist größtenteils verloren, war der Haltung zufolge aber nach links gedreht. Sein ausgestreckter rechter Arm hielt ein Pferd am Zügel, dessen bestoßener Kopf samt Vorderpartie nach links erhalten ist. Vor dem linken Bruchrand sind Reste einer weiteren sitzenden Figur zu erkennen, nämlich die beschädigte linke Körperseite mit dem linken Arm, über den eine Gewandbahn gelegt ist; die linke Hand fehlt.

Die hervorragenden Parallelen auf Vorderseiten einiger Achill-Sarkophage ermöglichen mit einiger Wahrscheinlichkeit Rekonstruktion und Deutung der Szene. Demnach wird es sich um die Entdeckung Achills auf Skyros im Beisein der sitzenden Könige Lykomedes und Agamemnon handeln. So bietet ein Achill-Sarkophag in Paris ${ }^{272}$ den Pferdeführer und den Sitzenden wie das Fragment in Ephesos an der rechten Ecke, aber auch eine spiegelbildliche Version an der linken Ecke. Die spiegelbildliche Version zeigen auch die Achill-Sarkophage in Rom ${ }^{273}$, Jerusalem $^{274}$ und Ptolemais ${ }^{275}$; bei dem Jerusalemer Sarkophag lassen sich die Kopfreste von Pferd und Behelmtem an der rechten Ecke wohl ebenfalls zu dem Pferdeführer ergänzen ${ }^{276}$. Hier in Ephesos dürfte es sich neben dem Pferdeführer um Reste des sitzenden Agamemnon handeln ${ }^{277}$.

Die Sarkophage in Paris, um die Mitte des 3. Jahrhunderts angesetzt, und Ptolemais, mit einer Datierung im zweiten Viertel des 3. Jahrhunderts n. Chr., haben neben den ikonografischen Kriterien auch ornamentale und tektonische gemeinsam. Durch ihren vergleichbaren oberen Kastenabschluss und das weite Hineinragen der Figuren in das Akanthuskyma geben sie mit ihrer chronologischen Stellung weitere Hinweise auf eine ebenfalls späte Datierung für das ephesische Fragment.

269 Nekropole Inv. 328/329: Chéhab 1968, 28-34; 75 f. 82 f. Taf. 13-16; Koch - Sichtermann 1982, 385. 458; Rogge 1995, 45 f. 143 f. Nr. 42 Taf. 52, 1; 55.

270 Nationalmuseum Inv. 607: Koch - Sichtermann 1982, 373 Anm. 68; 377 Anm. 5; 385. 457 f. Abb. 414; Rogge 1995, 48 f. 126 f. Nr. 6 Taf. 52, 2; 53 f. 59, 2; 65, 1.

271 J. Paul Getty Museum Inv. 95.AA.80: GettyMusJ 24, 1996, 88 Nr. 3; Towne-Markus 1997, 120 f.; Holtman 1997, 27; Greenberg 2002, 168. Der Sarkophag wurde zudem von J. Oakley auf dem Symposium des Sarkophag-Corpus, Marburg, 3.-8. Juli 2006 vorgestellt.

272 Musée du Louvre Inv. Ma 2120: Koch - Sichtermann 1982, 382-385. 458; Baratte 1985, 252-256 Nr. 165; Rogge 1995, 43. 134 Nr. 21 Taf. 43, 3; 48, 2.

273 Museo Capitolino Inv. 218: L’Orange 1933, 9-11 Nr. 2; Wiegartz 1965b, 614; Koch - Sichtermann 1982, 7 f. 366 Anm. 1; 373 Anm. 68; 383-385; 457 f. Abb. 413; Rogge 1995, 44 f. 136-138 Nr. 24 Taf. 44-47; 49 f. 68.

274 Koch - Sichtermann 1982, 383-385. 458; Rogge 1995, 40-43. 130 f. Nr. 14 Taf. 43, 1.

275 Koch - Sichtermann 1982, 389; Rogge 1995, 43 f. 135 Nr. 22 Taf. 43, 2.

276 Pferd und Pferdeführer, aber ohne die sitzende Figur, erscheinen ebenfalls an der rechten Ecke der Vorderseite mit der Schleifung Hektors in Malibu, s. o. Anm. 271. Eine spiegelbildliche Version zu dem Eckfragment in Ephesos ist auch auf dem Sarkophag in Beirut, s. o. Anm. 270, abgebildet; der Pferdeführer und der Sitzende sind hier in Verbindung mit einer Rüstungsszene gezeigt, wobei der Sitzende seinen rechten Arm erhoben hat.

$277 \mathrm{Zu}$ Unsicherheiten der Benennung mit Verweisen auf die Forschung und entsprechende Autoren s. Rogge 1995, 41 mit Anm. 158; 52. 129. 
Auf der rechten Schmalseite (Taf. 39 Abb. 166) ist eine Tragegruppe abgebildet. Ein Toter - so wegen der geschlossenen Augen und seines erschlafft herabhängenden rechten Arms zu deuten wird von einem Behelmten, wohl mit einer Tunika bekleidet, getragen. Der Tote hat ein Schwert am Gurt, schräg über die Brust verlaufend, umgehängt. Der Behelmte greift unter dessen Achseln und hat seine Finger vor der Brust des Toten verhakt. Im Hintergrund rechts wird ein T-förmiger Gegenstand sichtbar.

Im Corpus-Band der attischen Achill- und Hippolytos-Sarkophage bietet S. Rogge basierend auf besser erhaltenen Reliefdarstellungen dieser Szene ${ }^{278}$ eine Rekonstruktionszeichnung der Schmalseite in Ephesos ${ }^{279}$. Gezeigt ist der Transport eines toten Jünglings durch zwei Gefährten im Beisein eines älteren Mannes, der einen langen Stock trägt. In Ephesos ist der T-förmige Stockgriff erhalten, während der Alte sowie Unterkörper und Beine des Toten und auch der zweite Gefährte, der die Beine des Toten oberhalb der Knöchel hält, verloren sind. Trotz der überzeugenden Rekonstruktion sind die Benennung der Figuren und die Interpretation der Szene nicht so eindeutig, denn der Typus der Tragegruppe ist für verschiedene Mythen belegt, die - thematisch im trojanischen Mythenkreis angesiedelt - in Frage kämen: die Bergung Achills, die Bergung des Patroklos oder Paris oder der Transport Hektors zur Waage ${ }^{280}$. Einen wie hier prägnanten Tragegruppentypus für verschiedene Figuren und Mythen verwendet zu finden, darf im zweiten Drittel des 3. Jahrhunderts nicht verwundern ${ }^{281}$. Es ist gängige Praxis, Figuren- und Gruppentypen als Versatzstücke zu kombinieren, wobei eine spezifische Bindung eines Figuren- und Gruppentypus an einen bestimmten Mythos verloren gegangen ist ${ }^{282}$.

Eine Deutung ist somit oft nur im Zusammenhang mit den übrigen Sarkophagseiten möglich. Durch die relativ sichere Zuordnung der Vorderseite zu einem Achill-Sarkophag können die Schmalseiten später Achill-Sarkophage dafür herangezogen werden: sie zeigen in aller Regel ebenfalls Szenen, in denen der Held selbst erscheint. Demnach darf man dies auch für dieses Fragment annehmen und in dem Motiv die Bergung Achills erkennen. Der zu ergänzende Alte mit Stock wäre dann als Phoinix anzusprechen.

\section{Datierung}

Die ikonografischen, ornamentalen und tektonischen Kriterien belegen eine späte Datierung um 240-250 n. Chr.

278 Rogge 1995, 61 f. Taf. 72, 4. Zu den Vorbildern einschließlich der Literaturhinweise: Rogge 1995, 61 Anm. 297; s. bes. die Auflistung bei Musso 1989/90, 14-16.

279 Sowie zu Fragmenten in Rom, Catacombe di Pretestato, Museo Inv. 117 und Inv. 364: Rogge 1995, 136 Nr. 23 Taf. 72, 1-2.

280 Zu den Deutungsmöglichkeiten und zu Vorbildern s. Rogge 1995, 61 f. mit Anm. 297-305; 108 f. mit Anm. 164 f.; und s. u. Anm. 282.

281 Zu dem Umgang mit Figuren- und Gruppentypen s. ausführlich auch zum Achill-Sarkophag Woburn Abbey, hier Kat. 3 Taf. 33-38.

282 Vgl. auch eine weitere Variante, nämlich die Heimtragung Meleagers; sie erscheint nicht auf attischen, aber auf stadtrömischen Meleager-Sarkophagen, s. z. B. Koch 1975, 28-38. 106-114 z. B. Nr. 73-77. 81-84. 88. 91.93 Taf. 68. 74. 80 b; 81 c; 85 a-b; 88 b; 89 a, b; 34 f. (zu Vorbildern); LIMC VI (1992) 428 f. Nr. 144-149 Taf. 224 s. v. Meleagros (S. Woodford). Vgl. auch stadtrömische Achill-Sarkophage mit der Heimtragung Hektors, s. z. B. Grassinger 1999, 207 f. Nr. 34. 36. 40 Taf. 34, 1-2; 35, 1; 36, 1; 37, 1 und s. bes. die Exemplare o. Nr. in Basel Taf. 36, 2 und in Syrakus Taf. 36, 4; Touchefeu 1988, 493 Nr. 93 f. Taf. 289. Zu Beispielen, weiteren Deutungen und Vorlagen der Tragegruppen s. ausführlich Grassinger 1999, 57-63, bes. 63-66. - In Abhängigkeit zu dem Typus der Tragegruppe ist auch eine spiegelbildliche Variante auf der Vorderseite eines attischen Sarkophags in Brescia zu sehen: Brescia, Santa Giulia, Museo della città Inv. MR 1: Koch - Sichtermann 1982, 412-414 Nr. 22; 459 Abb. 446; Ciliberto 1996, 57. 100 f. Nr. 78; Kintrup 2016a, Kap. 5.2.9 Nr. 77. Es handelt sich um eine nichtmythologische Schiffskampfdarstellung, die zumeist auf die Schlacht bei Marathon gedeutet wird, s. Kintrup 2016a, Kap. 5.2.9.2. Dort wird ein verwundeter, bärtiger Perser von zwei jüngeren Helfern in ein Schiff gehoben. Zu Reliefs mit Tragegruppen, bei denen der Oberkörper des Toten rechts getragen wird, wie bei dem Vorderseitenfragment in Brescia, s. Musso 1989/90, 9-22. 


\subsection{Sarkophage mit Amazonomachie}

\subsubsection{Fragmentierter Kasten mit Amazonomachie (Kat. 6 Taf. 40-44)}

Selçuk, Efes Müzesi Inv. 260.

1907 in Ephesos in der Nekropole nördlich des Hafenkanals entdeckt, aber erst 1930 ausgegraben $^{283}$. Bei Rudolf 1989, 38 werden 12 Fragmente mit Hinweis auf handschriftliche Notizen F. Eichlers genannt, deren Verbleib unbekannt ist.

L der VS: 262; L der RS: 256; H max. (linke Ss) 104. - L der rechten Ss: 114; L der linken Ss: 115. DW der VS: 6,5-8; DW der RS: 10; max. DW der rechten Ss: 12-13,5; DW der linken Ss: 14-15. Rh der VS: 10; Rh der RS: 8; Rh der rechten Ss: 9; Rh der linken Ss: 8,5.

Lit.: Keil 1914, 133 Anm. 1; Keil 1931, 66; Keil 1932, 68-72 Abb. 48; Redlich 1942, 51 f.; Eichler 1944/45, 129 Nr. 4; Eichler 1946, 89; Andreae 1956a, 32 Nr. 6; 36 Nr. 10; Andreae 1956b, 35; Kallipolitis 1958, Nr. 114; Giuliano 1962, Nr. 251; Giuliano - Palma 1978, 36 Nr. 1 Taf. 36, 88; Devambez - Kauffmann-Samaras 1981, 621 Nr. 530; Koch - Sichtermann 1982, 391 mit Anm. 14; 466; Rudolf 1989, 33-38. 50 Taf. 17-19 Abb. 22-27 (weitere Lit. S. 50); Koch 1991, 816-819; Kintrup 1998, 207-209; 215 Taf. 93, 6; E. Papagianni in: G. Despinis - Th. Stefanidou-Tiveriou - E. Voutiras (Hrsg.), Catalogue of Sculpture in the Archaeological Museum of Thesssaloniki III (Thessaloniki 2010) 319 f. 332 Anm. 5; Russenberger 2015, 351-355 Abb. 167; 530 Anm. 145; Kintrup 2016a, Kap. 3.1.2.1; 3.3 S. 101 f. Nr. 89.

Feinkörniger, heller Marmor mit starken Schichten von Glimmerschiefer.

Auf der Vorderseite (Taf. 41 Abb. 169) und der bevorzugt ausgearbeiteten rechten Schmalseite (Taf. 42 Abb. 171) ist der Kasten zu etwas mehr als der Hälfte des Relieffrieses erhalten, auf der linken Schmalseite (Taf. 42 Abb. 172) bis zum oberen Kastenabschluss, auf der Rückseite (Taf. 41 Abb. 170) verläuft der Bruch von der Halshöhe der rechten Eckherme schräg abfallend zum unteren Teil des Hermenschafts links entlang einer Glimmerschieferschicht. Alle Seiten weisen Verreibungen und Bestoßungen sowie Bruchflächen und Verwitterungsschäden auf, die zu einem großen Teil durch den Anteil an Glimmerschiefer bedingt sind. Bohrungen sind noch als Umrisse in Gewändern und Haaren zu erkennen. Die Innenseite des Kastens zeigt eine mittelgrobe gleichmäßige Spitzmeißelarbeit (ohne Rippen). Im Boden des Kastens finden sich zwei runde Löcher, ein etwas größeres etwa mittig und ein kleineres an der Seite zur Rückwand.

Von dem oberen Kastenabschluss ist nur noch auf der linken Schmalseite ein geringer Teil eines Perlstabs vorhanden. Die Sockelzone ist auf allen Seiten dekoriert, nur auf der Rückseite ist das Dekor nicht von Postamenten eingefasst. Für die selten ornamentierte Sockelzone einer Rückseite lässt sich ein Amazonomachie-Sarkophag in Thessaloniki als Parallele heranziehen ${ }^{284}$. Die Vorder- und die rechte Schmalseite sind mit einem lesbischen Kyma über einem Flechtband dekoriert. Das linke Eckpostament der Vorderseite ist verrieben; zwei Figuren lassen sich erahnen. Das rechte Postament zeigt einen Löwen, der einen Stier reißt. Auch auf der rechten Schmalseite ist das linke Postament zerstört, auf dem rechten ist ein Hund, der einem Reh in den Hals beißt, gezeigt. Die linke Schmal- und die Rückseite sind mit einem Blattstab zwischen zwei geglätteten Leisten geschmückt, dabei treffen die Blattspitzen einander in der Mitte. Der Blattstab der linken Schmalseite weist ein interessantes Detail auf (Taf. 43 Abb. 175): Ein Bruch verursachte einen kleinen Vorsprung, der von der Standfläche durch den Blattstab nach unten verläuft, jedoch ist der Blattstab auch auf dem rückspringenden Teil hinter dem Bruch voll ausgearbeitet erhalten. Demnach war der Bruch schon bei der Ausarbeitung vorhanden, und die mindere Qualität des

283 Zu den jüngsten Forschungen in der Westnekropole vgl. die wissenschaftlichen Jahresberichte des ÖAI 2010-2012 <https://www.oeaw.ac.at/oeai/kommunikation/jahresberichte/> (24. 7. 2017). Die Publikation in den FiE ist in Druckvorbereitung.

284 Archäologisches Museum Inv. 283: Stefanidou-Tiveriou 1997, 166-169 Nr. 134; 382 Abb. 339: Auf der Rückseite ist der Sockel in drei Streifen unterteilt, wobei der mittlere zu zwei Dritteln mit einem Blattstab dekoriert ist. 
Marmors muss den Steinmetzen durchaus bewusst gewesen sein. Auf den Eckpostamenten der linken Schmalseite ist rechts ein Tier abgebildet, das linke ist zerstört.

Auf den Eckpostamenten stehen an allen vier Ecken des Sarkophags Figuren. An den Ecken der Rückseite (Taf. 41 Abb. 170) stehen zwei Hermen über Eck und an der Vorderseite zwei weibliche Figuren im langen Gewand (Taf. 41 Abb. 169). Von der Herme an der linken Ecke der Rückseite ist nur noch das untere Stück des Hermenschafts vorhanden, an der rechten Ecke ist die Herme aber bis auf Halshöhe erhalten. Trotz der verriebenen Oberfläche glaubt man eine Tatze auf der Brust erkennen zu können, wonach es sich um eine Herakles-Herme handeln könnte.

Die Figur an der linken Ecke der Frontseite ist bis zum Oberkörper erhalten, die symmetrisch über die rechte Ecke gestellte Figur bis zur Höhe der Oberschenkel. Die Gewänder sind einseitig offen und lassen den Blick auf die Unterschenkel frei. Die Figur über der linken Ecke hält mit der Rechten ein Schwert senkrecht an ihren rechten Arm gelehnt. Die Figuren sind durch etliche Parallelen wie zwei Sarkophage in Thessaloniki - einen Amazonomachie- und einen Epinausimachie-Sarkophag ${ }^{285}$ - als Niken/Amazonen zu rekonstruieren ${ }^{286}$. Diesen Vergleichen zufolge kann wohl eine Pelta auf der Schulter der Eckfiguren der ephesischen Vorderseite ergänzt werden.

Auf der linken Schmalseite (Taf. 42 Abb. 172) ist zu erkennen, dass sich alle Eckfiguren durch ihre Größe und die ruhige, unbeteiligte Haltung formal vom Kampfgeschehen separieren. Aber mit den Niken/Amazonen sind Eckfiguren gewählt, die inhaltlich eine Beziehung zum Kampfgeschehen aufzuweisen haben. Damit haben sie die Entwicklungsstufe von >figürlich gestalteten Klinenbeinen`, wie sie ihre Vorläufer, z. B. die Karyatiden ${ }^{287}$, repräsentieren, hinter sich gelassen. Dies bedeutet auch, dass die tektonische Funktion der Eckfiguren verloren ging; aus Figuren, die das Klinenauflager stützten, wurden Figuren, die den Kampffries rahmen. In den - hier zu ergänzenden - erhobenen Armen der Niken/Amazonen kann noch eine Reminiszenz an die tektonische Funktion gesehen werden ${ }^{288}$.

285 Amazonomachie: Archäologisches Museum Inv. 283: Koch - Sichtermann 1982, 391 mit Anm. 10. 458; Stefanidou-Tiveriou 1997, 380-382 Abb. 336-339; Kintrup 1998, 209 f. 214 f. Taf. 93, 4; 95, 2. 7; Kintrup 2016a, Kap. 3.2.3 Nr. 245. - Epinausimachie: Archäologisches Museum Inv. 1246: Brenk 1972, 39-46 Abb. 1; Koch - Sichtermann 1982, 411. 412. 414 Nr. 18; 416. 459 Abb. 445; Stefanidou-Tiveriou 1997, 169-174 Nr. 135; 384-387 Abb. 341-346; Kintrup 2007, 181 f. Taf. 63, 1; Kintrup 2016a, Kap. 5.2.6 Nr. 248.

286 Stefanidou-Tiveriou 1997, 166 f. 170 f. benennt die Eckfiguren der beiden Sarkophage in Thessaloniki als »Amazonen-Niken«. Die hier verwendete Bezeichnung als »Niken/Amazonen« wurde gewählt, um so die Gewichtung deutlicher zu machen, denn zu den auf den attischen Sarkophagen an den Ecken dargestellten Figuren finden sich die besten Vergleiche bei »Niken« und »Viktorien«, und zwar zu den Waffen als Attribute, zur Kleidung, die eine Brust und das vorgestellte Bein unbedeckt lässt, zur Haltung der Figuren sowie z. T. zu der Frisur mit Haarschleife. Hingegen sind die amazonenhafte Züge wie die Flügellosigkeit und die Pelta auf der Schulter weniger eindeutig und zudem lässt sich das >Amazonenhafte` der Eckfiguren verstärkt erst im Laufe der späten Entwicklung erkennen, so eine kämpferische Haltung und in wenigen Fällen ein kurzes Gewand. Als Beleg s. die exemplarisch ausgewählten Vergleiche aus klassischer und hellenistischer Zeit: Goulaki-Voutira - Grote 1992, 862 f. Nr. 137 Taf. 572; 866 Nr. 165 Taf. 576 (mit Tropaion); 882 Nr. 383 Taf. 589; 884 Nr. 419 Taf. 591 (mit Schild); 886 Nr. 482 Taf. 594 (mit Haarschleife; ein Arm erhoben). Zu derr Problematik der Nike Apteros s. Goulaki-Voutira - Grote 1992, 902. Besonders s. zu Beispielen römischer Zeit Vollkommer 1997, 244 Nr. 42 Taf. 170 (mit Tropaion; mit Haarschleife); 245 Nr. 69 Taf. 172; 246 Nr. 78 Taf. 172 (mit Schild); 246 Nr. 80 Taf. 172 (mit Tropaion). Zu der häufigen Verwendung in der Sepulkralkunst: Vollkommer 1997, 269. Vgl. auch die stadtrömischen Amazonomachie-Sarkophage in Rom, Museo Capitolino Inv. 726: Grassinger 1999, 237 Nr. 94 Taf. 91, 1; 92, 1 (mit Tropaion; Frisur mit Haarschleife), und San Simeon: Grassinger 1999, 242 f. Nr. 104 Taf. 104. 105, 2 (mit aufwärts gestelltem Schwert und einem erhobenen Arm), die als Vorbilder oder Vermittler in der ikonografischen Tradition für die attischen Amazonomachie-Gruppen I und II von Bedeutung sind, s. Kintrup 2016a, Kap. 6.1.1.

287 Beispielhaft s. Amazonomachie-Sarkophag in Paris (160-170 n. Chr.): Koch - Sichtermann 1982, 389 f. 391 f. 440 Nr. 36; 456. 458 Abb. 420; Kintrup 1998, 206 f. 215 Taf. 92, 1; Kintrup 2016a, Kap. 3.1.1.1 Nr. 156. - Epinausimachie-Fragmente in Tarent (um 180/190 n. Chr.): R. Belli Pasqua in: Andreassi 1995, 186 f. 201-205 Nr. VI.11; Kintrup 2016a, Kap. 5.1.1 Nr. 24. - >Unterweltsarkophag` in Beirut (um 180 n. Chr.): Koch - Sichtermann 1982, 417 f. 459 Abb. 436; Oakley 2011, 56-59 mit Abb. 4; 98 f. Kat. 66 Taf. 60, 1; 62, 1; 63, 1. - Sarkophag »Sieben gegen Theben« in Korinth (um 180 n. Chr.): Koch - Sichtermann 1982, 416 f. 459 Abb. 439; Oakley 2011, 52-54; 87 f. Kat. 50 Taf. 36-38.

288 s. z. B. Rogge 1993, 117 mit Anm. 92-96; Rogge 1995, 38 mit Anm. 147; Kintrup 2016a, Kap. 3.1.2.1.1; 3.3 S. 97-100; Kap. 8 S. 208. 
Anhand der genannten Kriterien der Ornamentik und Tektonik kann der AmazonomachieSarkophag in Ephesos zeitlich in die Nähe des Schlachtsarkophags des Aemilius Aristides (Kat. 1 Taf. 1-25) gesetzt werden. Der Sarkophag, durch zugehörige Inschriften in die ersten Jahre des 3. Jahrhunderts n. Chr. datiert, präsentiert auch eine über Eck gestellte Nike/Amazone. Aufbau und Ornamente der Sockelzone sind gleichartig. Die große Dichte der Figuren - bei dem Aristides-Sarkophag auf der bevorzugten rechten Schmalseite (Taf. 1 Abb. 2; Taf. 2) erhalten - bietet eine gute Parallele. Der Amazonomachie-Sarkophag unterscheidet sich jedoch durch die Hermen an den Ecken der Rückseite vom Schlachtsarkophag, der dort - auch auf rechten Schmalseite erhalten - einen behelmten Krieger präsentiert und damit eine Figur, die im Hinblick auf zunehmende inhaltliche Bezüge der Eckfiguren zu dem Kampfgeschehen schon weiterentwickelt ist. Demzufolge wird für den Amazonomachie-Sarkophag eine Datierung, die vor der des AristidesSarkophags liegt, veranschlagt, nämlich um 190-200 n. Chr.

Für die Beschreibung und Rekonstruktion der Vorderseite und der rechten Schmalseite in Ephesos sind die Fragmente einer Front- und einer linken Schmalseite in den Harvard Art Museums, Arthur M. Sackler Museum²89, von herausragender Bedeutung. Diesen AmazonomachieFragmenten fehlt zwar der untere Abschnitt des Relieffrieses, aber sie bieten genügend Übereinstimmungen, um eine erstaunliche Gleichartigkeit in Bezug auf die Figurenfolge feststellen zu können (Taf. 43 Abb. 173 f.; 44 Abb. 176. 178). Der Sarkophag in Ephesos und die Fragmente in Harvard sind daher die zwei Leitstücke der Amazonomachie-Gruppe II der attischen Amazonomachie-Sarkophage, der sich etliche Fragmente zuordnen lassen ${ }^{290}$.

Im Vergleich mit der Frontseite in Harvard (Taf. 43 Abb. 173) sind die folgenden Figuren- und Gruppentypen einwandfrei zu identifizieren und zu ergänzen: Die Vorderseite in Ephesos (Taf. 43 Abb. 174) beginnt links - neben der Eck-Nike/Amazone - mit einer Sturzgruppe ${ }^{291}$. Der mit dem Rücken zum Betrachter Stürzende hält mit seiner Linken die Zügel seines nach links gewendeten Pferdes, während er versucht, mit der Rechten den Fall zu bremsen ${ }^{292}$. Die nach rechts reitende Amazone, die ihn angegriffen hat, ist hier verloren; nur noch das angehobene rechte Vorderbein ihres Pferdes ist vorhanden. Unten liegen zwei gefallene Figuren: eine Amazone auf dem Bauch und darüber gebeugt ein Grieche, der seinen Kopf, der von hinten zu sehen ist, auf seinen rechten Unterarm aufgestützt hat ${ }^{293}$.

Der nun folgende in Seitenansicht nach rechts ins Knie gebrochene Verwundete gehört zu einer Helfergruppe ${ }^{294}$. Die helfende Figur in Rückenansicht ist hier etwa bis Hüfthöhe vorhan-

289 Harvard Art Museums/Arthur M. Sackler Museum, Gift of Edward W. Forbes, Inv. 1899.9 + 1932.49: Redlich 1942, 49-51 Taf. 3; Koch - Sichtermann 1982, 391 mit Anm. 9; 458; Rudolf 1989, 36 mit Anm. 184; Vermeule - Brauer 1990, 132 f. Nr. 121. mit Abb.; Kintrup 1998, 208 f. 215 Taf. 93, 5; Kintrup 2016a, Kap. 3.1.2.1 Nr. 82.

290 Kintrup 2016a, Kap. 3.1.2. und 3.1.2.2.

291 Kintrup 2016a, 36. 39. 44 f. Typus S I.

292 Rudolf 1989, 35 benennt die Figur des Fallenden als Amazone, vermutlich wegen des Gewands, das auf der linken Schulter geschlossen ist. Allerdings sind etliche Parallelen zu nennen, bei welchen Griechen eine Exomis tragen, die den kurzen Gewändern der Amazonen ähnelt, aber bei den Männern nur einmal gegürtet ist, vgl. z. B. Schlachtsarkophage in Askalon (linke Ecke der Vorderseite und auf der linken Schmalseite), s. Koch - Sichtermann 1982, 407. 408 Nr. 8; 445. 459. 467; Fischer 1998, 205 Nr. 196; 213-215 Abb. 196 a-f; Kintrup 2016a, Kap. 4.2.7 Nr. 3, und in Madrid-Tarragona (Vorderseitenfragment Madrid an der rechten Ecke), s. Koch - Sichtermann 1982, 407. 409 Nr. 49; 459; Massó 1989, 83-108 Abb. 1-6 (mit weiterer Lit.); Kintrup 2016a, Kap. 4.2.9 Nr. 134, oder einen Amazonomachie-Sarkophag in London (Mitte der Vorderseite), s. Koch - Sichtermann 1982, 391 mit Anm. 13; 398 mit Anm. 9; 458; Walker 1990, 40 f. Nr. 45 Taf. 18; Kintrup 1998, 210 f. Taf. 94, 1; Kintrup 2016a, Kap. 3.2.9 Nr. 130. Vgl. auch den Kampfgruppentypus, bei dem ein Kämpfer in Rückenansicht als Gegner einer reitenden Amazone erscheint (Kintrup 2016a, K VII). Diese Kämpfer sind ebenfalls mit einem einfach gegürteten, kurzen Chiton bekleidet, der nur auf der linken Schulter geschlossen ist, s. z. B. hier die linke Schmalseite (Taf. 42 Abb. 172) oder auf einer Schmalseite in Beirut, s. Koch 1989a, 190. 191 mit Abb. 37; 207 f.; Kintrup 2016a, Kap. 3.1.2.2 Nr. 73.

293 Kintrup 2016a, 36. 40. 47 Typus G II.

294 Kintrup 2016a, 36. 39. 45 Typus H I. 
den. Der Vergleich mit der Frontseite in Harvard belegt, dass der Helfende gerüstet, behelmt mit einem Rundschild am linken Arm und Schwert in der Rechten zu ergänzen ist; er verteidigt sich und den Verwundeten gegen eine mit einem Speer bewehrte Amazone, die von links auf ihrem Pferd heranstürmt. Dem Verwundeten der Front in Ephesos fehlt der rechte Arm; unter dem Ansatz seines linken Arms ist ein Stück des untergehakten rechten Arms des Helfers zu erkennen.

Neben der Helfergruppe ist ein sich nach rechts aufbäumendes Pferd etwa zur Hälfte erhalten. Die Frontseite in Harvard zeigt, dass im Hintergrund des Pferdes ein Rossbändiger ${ }^{295}$ zu rekonstruieren ist. Mithilfe dieses Wissens sind in Ephesos kleine Reste des Rossbändigers in Form des unteren Stücks seiner Schwertscheide und seines Schildrandes zwischen der Schulter des Verwundeten der Helfergruppe und dem Hinterteil des Pferdes zu erkennen. Demnach war der ephesische Rossbändiger wahrscheinlich ebenfalls gepanzert.

Am Boden liegen drei gefallene Figuren; davon zwei flach auf dem Rücken, den Kopf nach links, und dazwischen eine Amazone leicht gekrümmt auf dem Bauch ${ }^{296}$ nach rechts. Auf dem angewinkelten rechten Arm liegend, trägt sie ihre Pelta noch am linken Arm; ihr Kopf fehlt. Ohne den Vergleich mit der Vorderseite in Harvard wäre auch das über den Gefallenen dargestellte Kampfpaar nicht einfach zu identifizieren, aber so können die Figuren eindeutig als zur >Fluchtgruppe gehörend angesprochen werden ${ }^{297}$. Eine frontal abgebildete Amazone hat beide Arme ausgebreitet. In der Rechten ein Schwert und in der Linken eine Pelta haltend, flüchtet sie nach links vor einem bekleideten und behelmten Reiter mit zum Schlag erhobener Rechten. Körper und untere Gesichtshälfte des Reiters sind von seinem Rundschild in der Linken verdeckt. Das der Fluchtrichtung entsprechend bewegte Gewand der Amazone ist in Ephesos über der auf dem Bauch liegenden Amazone gut zu erkennen. Der Reiter ist bis über die Hälfte seines Rundschilds erhalten; sein linker Unterschenkel, Fuß und Stiefel sowie das linke Vorderbein seines Pferdes fehlen zu einem großen Teil ${ }^{298}$. Im Hintergrund der fliehenden Amazone ist das Hinterteil eines nach rechts sprengendes Pferdes zu erkennen.

Hier enden die Gemeinsamkeiten zur Frontseite im Arthur M. Sackler Museum und damit auch die Abfolge der Figuren- und Gruppentypen, welche in der genannten Reihenfolge kennzeichnend für die attische Amazonomachie-Gruppe II ist. Hier noch einmal die Abfolge in komprimierter Form: Sturzgruppe mit Fallendem in Rückenansicht und darunter ein kopfüber Gefallener, dessen Hinterkopf zu sehen ist, die Helfergruppe mit Helfer in Rückenansicht, ein Rossbändiger und die Fluchtgruppe mit der auf dem Bauch liegenden Amazone darunter ${ }^{299}$. Einige der Typen finden sich später noch bei Sarkophagen der Amazonomachie-Gruppe III der attischen Sarkophage ${ }^{300}$, aber dann, ab der Jahrhundertwende abnehmend ${ }^{301}$, werden diese frühen Typen in den attischen Werkstätten nicht mehr für Amazonomachie-Sarkophage verwendet - auch nicht in adaptierter Form auf den attischen Schlacht- oder Epinausimachie-Sarkophagen.

In den Harvard Art Museums, Arthur M. Sackler Museum, beenden eine Amazone und ein Tubicen $^{302}$ die Vorderseite, in Ephesos beschließt rechts eine Haarreißergruppe die Kampfszenen

295 Kintrup 2016a, 36. 40. 48 Typus R.

296 Kintrup 2016a, 36. 40. 47 Typus G III.

297 Kintrup 2016a, 36. 38. 43 Typus K X.

298 Durch das Gewand und den Stiefelrest und vor allem ohne den Vergleich mit der Vorderseite in Harvard Art Museums, Arthur M. Sackler Museum, die den Reiter als Gegner der Amazonen zeigt, deutete Rudolf 1989, 36, auch diese Figur als Amazone.

299 Kintrup 2016a, 43-45. 47 f. Typus S I, G II, H I, R, K X mit G III. Besonders bedeutungsvoll für die Frage nach Vorbildern zu diesen Figuren- und Gruppentypen sind die stadtrömischen Amazonomachie-Sarkophage, s. Grassinger 1999, 136-170. Diese zeitlich engsten Vorläufer sind auch ikonografisch die besten Vorbilder. Die stadtrömischen Amazonomachie-Sarkophage bieten exzeptionelle Kongruenzen mit den attischen AmazonomachieGruppen I und II. Zu Vorbildern der frühen Amazonomachie-Gruppen I und II s. Kintrup 2016a, Kap. 6.1.1-6.1.6.

300 s. Kintrup 2016a, Kap. 3.1.3.

301 Die Fragmente in Harvard Art Museums, Arthur M. Sackler Museum erweisen sich schon als >Nachzügler«, s. Kintrup 2016a, Kap. 3.1.2.1.2; 6.4 S. 203 f.

302 Kintrup 2016a, 36. 40. 48 Typus T. 
vor der Nike/Amazone am Eck. Der Angreifer steht links in Frontalansicht und die Amazone kniet rechts von ihm ${ }^{303}$. Kopf und Arme der Amazone sind größtenteils weggebrochen. Anhand der Ansätze zu urteilen, war ihre Rechte gegen ihren Gegner gedrückt und ihre Linke erhoben, wohl um den Griff an ihren Kopf zu lockern. Der Krieger mit einem über den rechten Oberschenkel rutschenden Gewand ist bis zur Hüfte erhalten. Zu dieser Figur gibt es ein sehr gutes Vergleichsstück, nämlich auf der Schmalseite des großartigen frühen Amazonomachie-Sarkophags in Paris ${ }^{304}$. Demzufolge war die Gewandbahn um den linken Arm des Angreifers geschlungen und verlief hinter seinem Körper abwärts; die erhaltenen Reliefbereiche in Ephesos bestätigen das. Der Pariser Sarkophag wird durch die Porträts des gelagerten Ehepaars auf dem Klinendeckel in die Zeit 160-170 n. Chr. datiert. Auf dem Pariser Sarkophag ist die zugehörige Amazone seitlich sitzend abgebildet und zeigt damit eine frühe Variante der Haarreißergruppe ${ }^{305}$. In der attischen Sarkophagkunst werden nämlich im Laufe der Entwicklung zunehmend frontale Ansichten von Figuren verwendet; diese verdrängen oft die Rücken- und Seitenansichten der frühen Figurentypen. Die frontale Ansicht der knienden Amazone der Haarreißergruppe in Ephesos bietet dafür ein gutes Beispiel und einen Beleg für eine Datierung nach dem Sarkophag in Paris, welche sich mit der oben genannten Datierung aufgrund tektonischer und ornamentaler Kriterien deckt. Dies stimmt zudem auch mit der stilistischen Einordnung überein. Die stilistische Entwicklung, besonders der Chitone der Amazonen, geht von einer ausgeprägten Plastizität der Faltengebung hin zu einer grafischeren Gestaltungsweise, wobei die Gewandfalten teilweise flacher und kantiger ausgeführt werden. Der frühe Amazonomachie-Sarkophag in Paris bietet diese schöne Plastizität, während bei dem ephesischen Exemplar die Gewänder der Amazonen bereits etwas flacher gearbeitet sind und damit dünner und enger anliegend erscheinen. Der mit einer Datierung um $220 \mathrm{n}$. Chr. spätere Amazonomachie-Sarkophag in Thessaloniki ${ }^{306}$ zeigt dann deutlichere Ansätze einer grafischen Gestaltungsweise mit flachen und kantigen Falten.

Für die Beschreibung und Rekonstruktion der bevorzugt gearbeiteten rechten Schmalseite mit Amazonomachie in Ephesos (Taf. 42 Abb. 171; 44 Abb. 178) ist das Fragment der linken Schmalseite im Arthur M. Sackler Museum (Taf. 44 Abb. 176) äußerst hilfreich. Beide Schmalseiten bieten eine Kombination zweier Haarreißergruppen. Rechts zu erkennen sind wieder ein Angreifer und eine frontal kniende Amazone einer Haarreißergruppe im Typus, wie er auch am rechten Ende der Vorderseite verwendet wurde. Die Amazone ist hier bis auf Brusthöhe erhalten; von dem Angreifer ist nur sein rechtes Bein und sein linker Fuß, in die Hüfte der Amazone gestemmt, vorhanden. Das zugehörige linke Bein war rundplastisch gearbeitet; durch sein Fehlen ist ein ungehinderter Blick auf die Figuren im Hintergrund frei, wo ein behelmter Gefallener in Rückenansicht, hinter seinem Rundschild auf den rechten Arm gestützt, am Boden liegt ${ }^{307}$. Darüber ist zudem das angewinkelte, gestiefelte Bein einer Figur auf ihrem Pferd nach rechts zu erkennen. Es handelt sich zweifellos um eine Amazone, denn diese Figur gehört zu der zweiten Haarreißergruppe, bei der eine nach rechts reitende Amazone von einem Griechen an den Haaren gepackt wird $^{308}$. Die Parallele auf der Schmalseite in Harvard zeigt, dass die reitende Amazone fast vollständig von dem Angreifer der erstgenannten Haarreißergruppe überdeckt wird, lediglich ihr rechter Arm am Pferdezügel und das Gesicht ihres weit nach hinten gerissenen Kopfes im Profil über dem Angreiferkopf sind dort zu sehen. Der Haarreißer dieser Gruppe ist bis zur Hüfthöhe erhalten. Sein rechter Fuß fehlt und mit seinem linken tritt er auf den Bauch einer Amazone ${ }^{309}$

\footnotetext{
303 Kintrup 2016a, 35. 37. 41 Typus K II.

304 Louvre Inv. Ma 2119: Koch - Sichtermann 1982, 389 f. 391 f. 440 Nr. 36; 456. 458 Abb. 420; Kintrup 1998, 206 f. 215 Taf. 92, 1; Kintrup 2016a, Kap. 3.1.1.1 Nr. 156.

305 Kintrup 2016a, 35. 37. 41 Typus K IIa.

306 s. o. Anm. 285.

307 Kintrup 2016a, 36. 40. 47 Typus G IV (um $180^{\circ}$ in eine Rückenansicht gedreht).

308 Kintrup 2016a, 35. 37. 42 Typus K IV.

309 Kintrup 2016a, 36. 40. 47 Typus G IV.
} 
mit Pelta am linken Arm. Ihr Kopf ist weit nach hinten gesunken, und sie scheint sich nur noch mühsam auf den rechten Unterarm aufzustützen.

Die Kombination der zwei beschriebenen Haarreißergruppen erscheint auf drei weiteren Schmalseiten, auf zwei Amazonomachie-Darstellungen in Side ${ }^{310}$, 200-210 n. Chr., und einer in Thessaloniki ${ }^{311}$ (Taf. 44 Abb. 177), um 220 n. Chr., sowie auf einer Schmalseite in Tyros ${ }^{312}$, um 250 n. Chr., bei der die Amazonen durch Krieger ersetzt wurden. Diese Kombination ist derzeit nicht auf Vorderseiten belegt. Demnach handelt es sich um ein typisches Sujet für Schmalseiten, und zwar bei allen hier herangezogenen Beispielen der Ausführung nach um bevorzugt ausgeführte Schmalseiten. Durch Format und Dichte der Figuren ist die Kombination wie geschaffen dafür.

Auf Amazonomachie-Sarkophagen ist die Kombination der Haarreißergruppen für den Zeitraum zwischen 190/200-220/230 n. Chr. nachgewiesen. Die Verwendung der Gruppenkombination auf dem deutlich jüngeren Schlachtsarkophag in Tyros ist der Beleg für ein Phänomen, das zunehmend bei späten attischen Sarkophagen zu beobachten ist: Mittels Austauschs der Amazonen durch Griechen konnten Figuren- und Gruppentypen - in diesem Fall die zwei Haarreißergruppen $^{313}$ - auch auf Schlachtsarkophagen verwendet werden.

Die vernachlässigt gearbeitete linke Schmalseite in Ephesos bietet ebenfalls eine Amazonomachie-Szene (Taf. 42 Abb. 172). Die Schmalseite ist zwar bis zu Resten des oberen Kastenabschlusses vorhanden, aber die Köpfe einer reitenden Amazone und eines stehenden Griechen mit Helm sind überwiegend verloren. Die Amazone sprengt mit weit erhobenem rechten Arm - die Hand ist weggebrochen - nach rechts; ihr rechter Fuß fehlt. Der Kopf ihres Pferdes ist stark bestoßen; ein Teil des rechten Vorderbeins fehlt. Ihr Gegner in Rückenansicht tritt mit seinem linken Fuß auf den Bauch einer am Boden liegenden Amazone ${ }^{314}$. Der Krieger hält ein Schwert in der gesenkten Rechten und einen erhobenen Rundschild am linken Arm; der rechte Arm ist zu einem großen Teil verloren und das obere Stück des Schilds fehlt auch. Er trägt Stiefel und einen gegürteten, kurzen Chiton, der nur über die linke Schulter verläuft.

Die reitende Amazone und der Grieche rechts in Rückenansicht entsprechen einem gängigen Gruppentypus $^{315}$, der - insofern das zuzuordnen ist - hauptsächlich auf Schmalseiten verwendet wird, siehe nämlich die Schmalseiten der Amazonomachie-Sarkophage Athen-Paris ${ }^{316}$ und in Tyros $^{317}$ sowie ein Schmalseitenfragment in Beirut ${ }^{318}$. Mit einer Datierung um 180/190 n. Chr. ist die ebenfalls vernachlässigte Schmalseite des Sarkophags Athen-Paris das älteste Exemplar. Die Schmalseite in Tyros ist um 200 n. Chr. anzusetzen, obwohl das Kampfpaar ohne Gefallenentypus und mit viel freiem Reliefgrund auf der bevorzugten Schmalseite erscheint, aber die datierenden Kriterien des gesamten Kastens lassen auf diese für die Schmalseite zu spät erscheinende Datierung schließen. Die Schmalseite in Beirut gehört in zeitliche Nähe zu dem Sarkophag in Ephesos, denn Aufbau und Dekor der Sockelzone sind gleich. In Beirut handelt es sich um eine bevorzugt gearbeitete Schmalseite. Dies ist relevant, da sich bei den attischen Sarkophagen eine Entwicklung beobachten lässt, bei der neuere, beispielsweise frontalere Figurentypen die älteren Typen

310 Museum Inv. 72: Wiegartz 1965b, 616 f. Nr. 24; Koch - Sichtermann 1982, 390. 391 mit Anm. 8; 466; Kintrup 2016a, Kap. 3.1.2.2 Nr. 197, dort auch zu der Einordnung als Schmalseite.

311 s. o. Anm. 285.

312 Grabungen, Inv. 3951/3952: Koch - Sichtermann 1982, 378 mit Anm. 2; 388 f. 405. 407. 410 Nr. 66; 459.467 Abb. 443; Chéhab 1985, 501 f. Taf. 89-92; Linant de Bellefonds 1985, 26-28; 43 f. Taf. 2, 3; 4, 2; Rogge 1995, 144 f. Nr. 43; Kintrup 2016a, Kap. 4.2.17 Nr. 260.

313 Kintrup 2016a, 35. 37. 41 f. Typus K II und K IV.

314 Kintrup 2016a, 36. 40. 47 Typus G IV.

315 Kintrup 2016a, 35. 37. 42 f. Typus K VII.

316 Schmalseite in Paris, Louvre Inv. Ma 853: Baratte 1985, 261 f. Nr. 167 (mit weiterer Lit.); Kintrup 2016a, Kap. 3.1.1.2 Nr. 54.

317 Grabungen, Inv. 2772/2773: Chéhab 1968, 36-40. 81 f. Taf. 17-21; Chéhab 1984, 451-453 Taf. 77-79; Koch 1989a, 194. 195 mit Abb. 43; 208; Kintrup 1998, 207-210 Taf. 92, 2; Kintrup 2016a, Kap. 3.2.1.2 Nr. 259.

318 Nationalmuseum: Koch - Sichtermann 1982, 390 Anm. 1; 467; Koch 1989a, 190. 191 mit Abb. 37; 207 f.; Kintrup 2016a, Kap. 3.1.2.2 Nr. 73. 
von den bevorzugt ausgeführten Sarkophagseiten auf die vernachlässigten Seiten verdrängen ${ }^{319}$. Demzufolge ist das Schmalseitenfragment in Beirut in der relativen Chronologie, um 190-200 n. Chr., etwas früher, anzusetzen als unser Sarkophag in Ephesos. Die betonte rechte Schmalseite in Ephesos (Taf. 42 Abb. 171) zeigt ja, wie bereits oben beschrieben, eine dichtere Figurenfüllung und Gruppentypen, die keine Rückansichten mehr zeigen. Die Entwicklung, zunehmend frontale Ansichten von Figuren zu verwenden, ist hier belegt und konnte schon im Hinblick auf die rechte Gruppe der Vorderseite beispielhaft gezeigt werden ${ }^{320}$.

Die Rückseite in Ephesos (Taf. 41 Abb. 170) ist im Hinblick auf Reliefhöhe und -dichte sowie auf die Ikonografie deutlicher vernachlässigt als die linke Schmalseite. Auch die Rückseite bietet Amazonomachie-Szenen. Links reitet eine Amazone gegen einen rechts stehenden Krieger in Frontalansicht, der bis zu den Oberschenkeln erhalten ist, und von rechts sprengt die Amazone gegen einen links stehenden Kämpfer in Frontalansicht, der bis etwa auf Taillenhöhe erhalten ist. Auch diese beiden Kampfgruppen entsprechen üblichen Gruppentypen ${ }^{321}$. Durch die schräg nach rechts ansteigende Bruchlinie sind von der Reiterin rechts nur die Hinterläufe des Pferdes erhalten, während die reitende Amazone vor der rechten Ecke bis zu ihrer rechten Schulter vorhanden ist.

Die beiden Gruppentypen sind symmetrisch gestellt. Hier scheint noch das Dekor früher Rückseiten mit antithetischen Tiermotiven nachzuwirken ${ }^{322}$, denn statt des auf den anderen Sarkophagseiten bevorzugten Variantenreichtums von Figurentypen wurde hier eine einfache Symmetrie bevorzugt. Antithetische Tiermotive sind typisch für Rückseiten im 2. Jahrhundert n. Chr. ${ }^{323}$, werden aber auch um die Mitte des 3. Jahrhunderts n. Chr. des Öfteren abgebildet ${ }^{324}$; in der Zwischenzeit finden sich zumeist Figurenfriese in flacher Ausführung ${ }^{325}$.

\section{Datierung}

Um 190-200 n. Chr.

319 Kintrup 2016a, Kap. 3.1.3.3 mit Anm. 130. s. auch entsprechende Parallelen bei Achill- und Hippolytos-Sarkophagen: z. B. Rogge 1995, 53. 57. 65 (Achill). 75. 83. 87. 89 mit Anm. 101; 90 f. (Hippolytos).

320 Vgl. dazu z. B. Kintrup 2016a, Kap. 3.1.2.1.2 mit Anm. 98.

321 Kintrup 2016a, 36. 38. 43 Typus K VIII und K IX.

322 Zu antithetisch angeordneten Tieren und Tierkampfgruppen: Koch - Sichtermann 1982, $444 \mathrm{f}$.

323 s. z. B. einen Achill-Sarkophag in Adana, s. Rogge 1995, Nr. 1 Taf. 23, 3; einen Hippolytos-Sarkophag in Beirut, Rogge 1995, Nr. 56 Taf. 83, 1; einen Meleager-Sarkophag in Delphi, s. Koch 1975, 141 Nr. 166; sowie einen verschollenen Sarkophag, s. Koch 1975, 138 f. mit Abb. 13 Nr. 161.

324 s. z. B. die Amazonomachie-Sarkophage in Jerusalem: Fischer 1998, 208 Nr. 213; 225 f. Abb. 213 a-d; Kintrup 2016a, Kap. 3.2.11 Nr. 112, und in Thessaloniki, Kintrup 2016a, Kap. 3.2.13 Nr. 247, die Schlachtsarkophage in Antalya, Flagge 1975, 98 Abb. 116 f.; Kintrup 2016a, Kap. 4.2.11 Nr. 4, und St. Petersburg, Saverkina 1979, 24 f. Nr. 5 Taf. 11-13; Kintrup 2016a, Kap. 4.2.19 Nr. 237, und den Epinausimachie-Sarkophag in Tyros, Chéhab 1985, 559 f. Taf. 113-117; Kintrup 2007, 173-186; Kintrup 2016a, Kap. 5.2.8 Nr. 261. Vgl. auch Achill- und Hippolytos-Sarkophage: Rogge 1995, 25 mit Anm. 50; 76.

325 s. z. B. einen Amazonomachie-Sarkophag in Thessaloniki, s. o. Anm. 284, Schlachtsarkophage in Athen, s. Leventopoulou - Sengelin 1997, 712 Nr. 404 f. (RS); Kintrup 2016a, Kap. 4.2.5 Nr. 55, und in Beirut, s. Chéhab 1968, 41-44. 81 Taf. 22-26; Kintrup 2016a, Kap. 4.2.15 Nr. 72, und Epinausimachie-Sarkophage ehemals in Sparta, s. Rogge 1995, 65 Anm. 329; 75. 91. 155 Nr. 65 Taf. 76, 3; 83, 2; Kintrup 2016a, Kap. 5.2.3 Nr. 217, und in Thessaloniki: s. Stefanidou-Tiveriou 1997, 169-174 Nr. 135; 384-387 Abb. 341-346; Kintrup 2016a, Kap. 5.2.6 Nr. 248. Des Weiteren s. z. B. die Achill- und Hippolytos-Sarkophage, s. Rogge 1995, Nr. 39 Taf. 75, 1-2; Nr. 45 Taf. 60, 2-4; Nr. 64 Taf. 110, 1-2. 


\subsubsection{Fragment mit Amazonomachie (Kat. 7 Taf. 45 Abb. 179)}

Selçuk, Efes Müzesi Inv. 14/61/80.

Gefunden in Selçuk, Johannesbasilika, Fund-Nr. StJ 80/40.

H 14; L 29; Rh 6; D 26.

Lit.: Koch 1991, 819 Nachtrag Nr. 8; Kintrup 2016a, 245 Nr. 94.

Feinkristalliner, weißer Marmor. Allseitig gebrochen. Die Rückseite weist Spitzmeißelarbeit auf. Die Oberfläche des Reliefs ist bis auf einige Bestoßungen in gutem Erhaltungszustand; Teile des rechten Ohrs des Pferdes fehlen. Die Figuren sind sorgfältig und mit Liebe zum Detail ausgeführt: Der Amazonenkopf weist Bohrungen in den Haaren, Nasenlöchern, in den Augenund Mundwinkeln auf. Bei dem Pferdekopf ist die Mähne durch Bohrungen untergliedert; die Pupillen sowie Adern sind angegeben. Das Fragment gehörte sicher zu einer bevorzugt gearbeiteten Sarkophagseite.

Auf den nach links gewendeten Kopf einer Amazone folgt ein Pferdekopf nach rechts. Die Amazone wendet sich wohl auf ihrem Pferd nach links zurück. Gute Vergleiche dazu liefern Amazonomachie-Sarkophage in Tyros und Thessaloniki. Auf dem Sarkophag in Tyros, um 200 n. Chr. ${ }^{326}$, bildet die nach rechts reitende Amazone, die sich mit einem erhobenen rechten Arm zurückwendet, den rechten Abschluss der Frontseite. Die Oberfläche der Figuren dort ist leider stark beschädigt, sodass ein stilistischer Vergleich entfallen muss. Auf dem Sarkophag in Thessaloniki mit einer Datierung um 220 n. Chr. ${ }^{327}$ ist eine sich umwendende Amazone in der Mitte der Vorderseite über der zentralen Haarreißergruppe dargestellt und ein weiteres Mal auf der rechten Schmalseite.

\section{Datierung}

Stilistisch und durch die deutliche Verwendung von Bohrungen dürfte das Fragment in Ephesos auch nicht eher als $220 \mathrm{n}$. Chr. zu datieren sein, sodass hier das zweite Viertel des 3. Jahrhunderts n. Chr. vorgeschlagen wird. Erstaunliche Parallelen zur Gestaltung des Pferdekopfes, zur Angabe der Äderung und der Pupillen bieten drei Fragmente in Aquileia, die ab $240 \mathrm{n}$. Chr. anzusetzen $\operatorname{sind}^{328}$.

Zweites Viertel des 3. Jahrhunderts n. Chr.

\subsection{Dionysische Sarkophage}

3.3.1 Fragment eines dionysischen Sarkophags (Kat. 8 Taf. 45 Abb. 180)

Selçuk, Efes Müzesi Inv. 1/23/84.

Fundort: Umgebung von Ephesos; gekauft 1984 (nach Inventarbuch Museum Selçuk).

H 25; L 34; D 12,5; Rh 5.

Lit.: Unpubliziert.

326 s. Chéhab 1968, 36-40; 81 f. Taf. 18. 21 a; Kintrup 1998, 207-210 Taf. 92, 2; Kintrup 2016a, Kap. 3.2.1.2 Nr. 259.

327 Archäologisches Museum Inv. 283: Giuliano - Palma 1978, 36 Nr. 4 Taf. 37, 92-93; 39, 96; Stefanidou-Tiveriou 1997, 166-169 Nr. 134; 380-383 Abb. 336. 338; Kintrup 1998, 209 f. 214 f. Taf. 93, 4. 95, 2; Kintrup 2016a, Kap. 3.2.3 Nr. 245.

328 Scrinari 1972, 145 Nr. 415 Abb. 415; 146 Nr. 417 Abb. 417; 147 Nr. 424 Abb. 421; Ciliberto 1996, 30 f. 82 Nr. 27 Taf. 5 e; 31 f. 82 f. Nr. 28 Taf. 5 f.; 33 f. 84 Nr. 33; Kintrup 2016a, Kap. 4.2.4 Nr. 17. 19 und Kap. 4.2.18 Nr. 30. 
Feinkristalliner, heller Marmor. Allseitig gebrochenes Fragment; Rückseite mit grober Zahneisenbearbeitung. Oberfläche und Faltengrate sind verrieben und teilweise bestoßen. Mehrere Punktbohrungen sind auf dem Fragment oben links angebracht.

Eine Mänade ist mit leicht angewinkeltem rechten Bein in einer Profilansicht nach rechts dargestellt. Ihr Gewand ist nach unten gerutscht. Es entblößt ihr Gesäß zu einem großen Teil, bedeckt aber die Beine, die bis knapp unterhalb der Waden erhalten sind. Links neben der Mänade sind die beschädigten Reste einer Figur zu erkennen, die einen Korb wohl mit Weintrauben auf ihrer linken Schulter trägt; rechts einige Federn eines Flügels.

Vergleiche mit der Mänade bieten die dionysischen Sarkophagen in Boston und Rom, wobei auf dem Bostoner Sarkophag ${ }^{329}$, um 220-230 n. Chr. zu datieren ${ }^{330}$, eine Mänade rechts der Mitte der Vorderseite in einer aufrechteren Haltung abgebildet ist, als es wohl hier der Fall ist. Das Gewand ist noch weiter nach unten geglitten bzw. wird von einem Satyr rechts neben ihr nach unten geschoben. Auch im Museo Capitolino, Rom ${ }^{331}$, um 240 n. Chr. ${ }^{332}$, ist eine Mänade - links der Mitte der Vorderseite - in aufrechter Haltung abgebildet, deren Gewand weiter nach unten gerutscht ist.

Eine interessante Parallele bietet die rechte Schmalseite in Thessaloniki ${ }^{333}$, um 260 n. Chr. ${ }^{334}$, mit der Mänade in einer spiegelbildlichen Version nach links gewandt und einem Eros vor ihr. Diese Parallele macht wahrscheinlich, dass es sich auch bei dem Fragment in Selçuk um Reste eines Erosflügels rechts neben der Mänade handelt.

Für die Figur mit dem Korb finden sich ebenfalls Vergleiche auf den genannten dionysischen Sarkophagen in Boston und Rom. Auf der Bostoner Rückseite trägt ein Knabe einen Früchtekorb auf dem Kopf ${ }^{335}$, auf der Vorderseite in Rom, Museo Capitolino, ein Satyr einen Traubenkorb auf seiner linken Schulter ${ }^{336}$. Weitere Parallelen zu der Figur mit dem Korb bieten zudem die attisch nur seltenen belegten Sarkophage mit Eroten-Weinlese-Darstellungen ${ }^{337}$. Beispielsweise erscheint auf einem Fragment mit Eroten-Vindemia in Triest ebenfalls ein Eros mit einem Korb auf seiner linken Schulter ${ }^{338}$.

Für das Fragment in Selçuk besteht die geringe Wahrscheinlichkeit einer Zugehörigkeit zu einer Eroten-Weinlese-Darstellung. Zwar zeigt auch der Eroten-Weinlese-Sarkophag im >Tor der Verfolgung ${ }^{339}$ (Kat. 10 Taf. 46 Abb. 182 f.) eine weibliche Figur sowie andere Figuren, die Satyrn und Mänaden zitieren oder abwandeln ${ }^{340}$, diese sind aber in der Größe einheitlich gestaltet. Bei den genannten Vergleichsstücken auf den dionysischen Sarkophagen hingegen werden die Knaben und Eroten wie bei dem Fragment in Selçuk im Vergleich zu den Mänaden deutlich kleiner dargestellt.

\section{Datierung}

Da der Aspekt der Weinlese auch bei den dionysischen Sarkophagen auftritt, muss der Knabe mit dem Korb wohl voller Trauben nicht verwundern. Zumal in der späten Gruppe der dionysischen

\footnotetext{
Matz 1968, 106-110 Nr. 9 Taf. 14; Koch - Sichtermann 1982, 419-422. 459.

Wiegartz 1977, 386-388 mit Anm. 90.

1 Matz 1968, 110-112 Nr. 10 Taf. 16, 1; Koch - Sichtermann 1982, 419-422. 459.

32 Wiegartz 1977, 386-388 mit Anm. 90.

Matz 1968, 112-116 Nr. 11 Taf. 19, 2.

4 Wiegartz 1977, 386-388 mit Anm. 90.

35 s. an der rechten Ecke: Matz 1968, 106-110 Nr. 9 Taf. 13, 1.

36 Matz 1968, 110-112 Nr. 10 Taf. 16, 1.

337 Koch - Sichtermann 1982, 425 f. 432 Nr. 51-55; 459 Abb. 451-453 und s. »Zur Ikonographie attischer Sarkophage mit Eroten-Weinlese-Darstellungen«, Bielefeld 1995, 397-404 Taf. 104-107.

338 Bielefeld 1995, 397-400 Taf. 105, 4. s. auch Bielefeld 1995, Taf. 105, 1-2: Eros mit dem Korb auf seiner rechten Schulter (Fragment Foligno).

339 Koch - Sichtermann 1982, 425 f. 432 Nr. 52 Abb. 451; Rudolf 1989, 30-33; 46 Abb. 1. 3.19 f.; Bielefeld 1995, Taf. 104, 2.

340 Bielefeld 1995, $400 \mathrm{f}$.
} 
Sarkophage eine Umdeutung des Themas vom Thiasos zur Weinlese stattgefunden hat, bietet die korbtragende Figur auch einen Hinweis auf die Datierung: es kann sich nicht um ein frühes Stück handeln. Knaben und Eroten, die mit der Weinlese beschäftigt sind, begegnen erst ab dem Fragment in Amman mit einer Datierung um 210-220 n. Chr. ${ }^{341}$. Bei den späten dionysischen Sarkophagen werden Mänaden und Satyrn gedrängt nebeneinander gestellt und erhalten eine große Relieftiefe $^{342}$. Da aufgrund der verriebenen Oberfläche eine stilistische Einordnung für das Fragment in Selçuk erschwert und nicht klar zuzuordnen ist, ob das Fragment zu einer Vorder- oder einer Schmalseite gehörte, die nicht so dicht gedrängte Figuren auswies, ist eine Datierung nicht näher einzugrenzen, als es durch die genannten Parallelen zwischen 220 und 260 n. Chr. möglich ist. Eine Datierung im zweiten Viertel des 3. Jahrhunderts ist dabei wahrscheinlich.

Zweites Viertel des 3. Jahrhunderts n. Chr.

\subsubsection{Fragment eines dionysischen Sarkophags (Kat. 9 Taf. 45 Abb. 181)}

Selçuk, Efes Müzesi Inv. 45/57/79 (mit 45/57/79 ist das Fragment nummeriert, während 45/58/79 im Inventarbuch des Museums Selçuk vermerkt ist).

Fundort: Ephesos, Magnesisches Tor, Ausgrabung 1979, Fund-Nr. MAG 79/3³.

\section{H 41; L 21; DW 10; Rh 11.}

Lit.: Rudolf 1989, 58 Taf. 32 Abb. 54; Koch 1991, 819.

Feinkristalliner, heller Marmor. Allseitig gebrochenes Fragment mit dem Torso einer weiblichen Figur; Rückseite mit grober Zahneisenbearbeitung. Die Umrisse der Figur und der Gewandfalten sind teilweise deutlich gebohrt. Der Oberkörper der Figur weist eine Bruchfläche auf; Oberfläche und Faltengrate sind teilweise bestoßen.

Eine fast rundplastisch erscheinende Mänade ist mit leicht vorgeneigtem Oberkörper in Profilansicht nach links gezeigt. Ihr Gewand ist nach unten gerutscht, entblößt das Gesäß und bedeckt die Beine, die bis zum Oberschenkel erhalten sind. Im Hintergrund oben flattert das Gewand nach rechts. Rechts neben dem Gesäß ist der Pferdeschwanz eines Satyrn erhalten; darunter vermutlich Reste eines Tierfells oder einer Gewandbahn, welche der Satyr trägt.

Nach E. Rudolf ${ }^{344}$ stellen die frühen dionysischen Sarkophage in Istanbul und Athen Vergleiche dar. Auf dem Sarkophag in Istanbul, ca. $160-170$ n. Chr. ${ }^{345}$, erscheint die Mänade mit herabgleitendem Gewand auf der Vorderseite rechts mit einer Kithara und auf dem Vorderseitenfragment in Athen, ca. $150-160$ n. Chr. ${ }^{346}$, mit einer Doppelflöte. Beide Figuren sind jedoch aufrechter dargestellt. Der vermehrt frei bleibende Reliefgrund und die stilistische Einordnung aufgrund der Faltenbildung kennzeichnen die Stücke als die im Vergleich zu dem Fragment in Selçuk älteren Exemplare.

Etwas weniger aufrecht und auch in einer Seitenansicht erscheint je eine Mänade mit herabgleitendem Gewand auf der linken Schmalseite von Sarkophagen in Rom, ca. 240 n. Chr. ${ }^{347}$, und

341 Wiegartz 1977, 387 mit Abb. 63; 388 mit Anm. 90.

342 Koch - Sichtermann 1982, 420.

343 Zu den Grabungen G. Seiterles in den 1970er Jahren vgl. Seiterle 1982, 145-149; zu den jüngeren Untersuchungen Sokolicek 2010, 359-381.

344 Rudolf 1989, 58 mit Anm. 62.

345 Matz 1968, 100 f. Nr. 3 Taf. 4, 1; Koch - Sichtermann 1982, 419-422. 459 Abb. 449. Datierung nach Wiegartz 1977, 386-388 mit Anm. 90.

346 Inv. 1150 aus Patras: Matz 1968, 101 f. Nr. 4 Taf. 5, 1; Giuliano - Palma 1978, Taf. 5, 10. Datierung nach Wiegartz 1977, 386-388 mit Anm. 90.

347 Rom, Museo Capitolino: Matz 1968, 110-112 Nr. 10 Taf. 16, 2; Koch - Sichtermann 1982, 419-422. 459. Datierung nach Wiegartz 1977, 386-388 mit Anm. 90. Auf der Vorderseite, Matz 1968, Taf. 16, 1, ist eine ähnliche Pflückerin abgebildet, die aber - wie die zwei erstgenannten Vergleiche - aufrechter dargestellt ist. 
in Thessaloniki, um $260 \mathrm{n}$. Chr. ${ }^{348}$. Beide zeigen jedoch eine deutlich gedrängtere Figurenfolge als das Fragment in Selçuk ${ }^{349}$.

Weiter nach vorn geneigt und damit dem Fragment in Selçuk noch ähnlicher erscheint eine Mänade an der linken Ecke der Vorderseite des Sarkophags in Kyrene, um $250 \mathrm{n}$. Chr. ${ }^{350}$. Dort sind die Figuren weniger gedrängt, aber aufgrund der leider stark beschädigten Reliefoberfläche wird ein stilistischer Vergleich erschwert. Durch den frei bleibenden Reliefgrund sowie die Relieftiefe der Figur ist auch ein Fragment eines dionysischen Sarkophags in Amman, aus der Zeit um 210-220 n. Chr. ${ }^{351}$, dem Fragment in Selçuk vergleichbar.

\section{Datierung}

Die Parallelen in Kyrene und Amman grenzen eine Datierung für das Fragment in Selçuk in den Zeitraum zwischen 220 und 250 n. Chr. ein, eine Datierung in das zweite Viertel des 3. Jahrhunderts wird vorgeschlagen.

Zweites Viertel des 3. Jahrhunderts n. Chr.

\subsection{Eroten-Weinlese-Sarkophage und/oder dionysische Sarkophage; Erotensarkophage}

\subsubsection{Fragmentierter Kasten eines Eroten-Weinlese-Sarkophags}

(Kat. 10 Taf. 46 Abb. 182 f.)

Gefunden in Selçuk, Johannesbasilika, verbaut im `Tor der Verfolgung` (Taf. 33).

Maße unbekannt.

Lit.: Robert 1890, 57; Benndorf 1906, 108 f.; Eichler 1944/45, 129 Nr. 7; Koch - Sichtermann 1982, 425 f. 432 Nr. 52 (identisch mit 428. 433 Nr. 65 a.) Abb. 451; Rudolf 1989, 11-13; 30-33; 38. 46 »Ephesos D« (mit älterer Lit.) Abb. 1. 3. 19 f.; Koch 1991, 817 f.; Rogge 1993, 115 Anm. 62; Bielefeld 1995, 397-404 Taf. 104, 2; Wohlers-Scharf 1995, 42-44 Abb. 20 f.; Koch 1999, 557; Scherrer 2000, 190 f. Abb. 1; Bevilacqua 2015, 334-336.

Heller Marmor. Erhalten und zu sehen sind ca. drei Viertel der Vorderseite und der mittlere Teil der rechten Schmalseite. Die rechte Seite der Vorderseite ist in einer schrägen Bruchlinie abgebrochen $^{352}$, weitere schräge Brüche verlaufen durch die Vorderseite. Neben den Beschädigungen durch die Brüche erscheint die Oberfläche verrieben, insbesondere die Gesichter.

Die rechte Schmalseite (Taf. 46 Abb. 182) zeigt zwei antithetische Löwen mit einem Kantharos in ihrer Mitte ${ }^{353}$. Von dem Dekor des oberen Kastenabschlusses sind unter der oberen Leiste ein lesbisches Kyma und ein Eierstab vorhanden.

348 Thessaloniki: Matz 1968, 112-116 Nr. 11 Taf. 19, 1; Koch - Sichtermann 1982, 419-422. 459. Datierung nach Wiegartz 1977, 386-388 mit Anm. 90.

349 Zur späten Gruppe der dionysischen Sarkophage, bei der Mänaden und Satyrn eng zusammengedrängt werden und große Relieftiefe erhalten, Weinreben eine stärkere Bedeutung bekommen und aus dem Thiasos eine Weinlese wird, s. Koch - Sichtermann 1982, 420 f. mit Verweisen in Anm. 22.

350 Matz 1968, 89 Nr. 1; 116-118 Nr. 11A Taf. 21, 1. Datierung nach Wiegartz 1977, 386-388 mit Anm. 90. Nach Matz 1968, 89. 117, ist die Figur eine Ableitung vom Typus TH 6 der Doppelflötenbläserin, wobei sich das Mädchen der Variante in Kyrene - wie hier - abwärts wendet.

351 Wiegartz 1977, 387 Abb. 63.

352 Einige Beschädigungen können aus der Zeit um 1810 stammen, als versucht wurde, den Sarkophag aus dem Mauerverband zu lösen (so geschehen bei dem Achill-Sarkophag Woburn Abbey, hier Kat. 3). s. dazu Rudolf 1989, 12 mit Lit. in Anm. 8; 10-14; 30 mit Lit. in Anm. 161. Zur Verbauung der Sarkophage im Tor vgl. zuletzt Bevilacqua 2015, 334-338.

353 Zu dekorativem Schmuck auf Schmalseiten attischer Sarkophage s. Koch - Sichtermann 1982, 445 f. 
Auf der Vorderseite (Taf. 46 Abb. 183) ist unter der Standleiste deutlich zurückspringend das Dekor des Sockels auszumachen: Flechtband und darüber lesbisches Kyma, gerahmt von einem links erhaltenen Eckpostament, das geschmückt ist mit einer Tierkampfgruppe ${ }^{354}$. Im Unterschied zu der klar strukturierten Sockelzone ist der obere Kastenabschluss von vegetabilen Elementen >überwachsen`. Die obere Leiste des Sarkophagkastens ist dabei aber abgesetzt mit einem Rankendekor verziert. Unter der oberen Leiste ist durchaus noch festzustellen, dass die Fläche schräg zu dem eigentlichen Hintergrund abfällt, auf dem sich der Fries entfaltet. Weinstöcke überziehen mit ihren Blättern, Reben und Ranken die Vorderseite und die schräge Fläche bis an die obere Leiste und bilden so den Hintergrund für die Figuren.

An der linken Ecke der Vorderseite steht ein Eros ohne Flügel. Diese und die folgende Figur sind durch eine schräge Bruchlinie betroffen. Die Rechte des Eros an der Ecke stützt ein mit verschiedenen Früchten beladenes Tablett ${ }^{355}$ auf seinem Kopf; die Linke (der Unterarm ist verloren) hält eine um die Hüften geschlungene Gewandbahn. Der Eros hat sein linkes Bein gekreuzt vor das rechte gestellt und den linken Fuß in die Ecke des Kastens gesetzt. Rechts neben der Eckfigur sitzt am Boden ein geflügelter Eros (seine Arme fehlen teilweise) vor einem umgekippten Korb mit Weintrauben. Vornübergebeugt will er den Korb wieder aufrichten, ohne weitere Trauben daraus zu verlieren. Hinter seinem Rücken ragt ein kräftiger Weinstock auf, an den eine weibliche Gestalt (»Psyche ${ }^{356}$ ) gelehnt ist. Sie hat ihr rechtes Bein gekreuzt vor das linke gesetzt und die Arme erhoben. Mit ihrer Rechten (Unterarm und Hand beschädigt) scheint sie Halt in den Ästen gefunden zu haben; ihre Linke ist entspannt über den Kopf gelegt. Eine Gewandbahn flattert über den linken Arm nach rechts, verläuft in ihrem Rücken abwärts und bedeckt die Beine.

Es folgen ein gelagert wirkender $\operatorname{Eros}^{357}$ unter dem Ast eines weiteren Rebstocks sowie ein geflügelter Eros auf dem Ast. Der Eros am Boden liegt jedoch nicht auf seiner linken Seite, sondern hat sein linkes Bein untergeschlagen und kniet weit nach rechts geneigt darauf; er stützt seinen Oberkörper mit der Linken und hat die (größtenteils fehlende) Rechte erhoben, um damit wohl nach einer Rebe zu greifen. Der geflügelte Eros darüber sitzt - ähnlich dem Eros vor dem Korb - weit nach vorn gebeugt auf dem Ast. Mit der Rechten hält er sich an einem kleineren Ast fest; die (verlorene) Linke langt abwärts nach einer Rebe.

Zwei weitere geflügelte Eroten erscheinen nach rechts gewandt vor dem Bruch. Der erste ist von einer Bruchfläche betroffen, ihm fehlen Teile des Oberkörpers, der Kopf und der Korb voller Trauben, den er auf der Schulter trug; dies ist durch die erhaltenen Umrisse und Haltung des Eros zu erschließen. Der zweite Eros ist nach rechts über einen Ziegenbock geneigt, der für den Abtransport der Trauben beladen wird.

Bei der Vorderseite in Selçuk handelt es sich um das auf attischen Sarkophagen selten belegte Sujet der Eroten-Weinlese ${ }^{358}$. D. Bielefeld erkannte, dass die weibliche Gestalt, die sich an den Rebstock lehnt, einen Mänadentypus >zitiert<, der von einem Satyr gestützt wird ${ }^{359}$. Dieser Typus tritt auf den Vorderseiten der dionysischen Sarkophage in Rom, Museo Capitolino ${ }^{360}$, und in Bos-

\footnotetext{
354 Nach Rudolf 1989, 31, reißt ein Löwe eine Hirschkuh; m. E. sind Hörner bei dem gejagten Tier zu erkennen, sodass es sich eher um einen Ziegenbock, eine Antilope oder Ähnliches handeln kann.

355 Bei Matz 1968, 93; Rudolf 1989, 31 als »Korb« bezeichnet. Nach Bielefeld 1995, 400 mit Anm. 30 lanx, s. RE XII (1924) 695 f. s. v. lanx (K. Schneider): »Schüssel oder Platte zum Auftragen von mancherlei Speisen ...«. Zur Darstellung der lanx auf dionysischen Sarkophagen vgl. Salvetti 1993, 64 mit Anm. 4.

356 Rudolf 1989, 32; Bielefeld 1997, 41. Vgl. dort den stadtrömischen Eroten-Weinlese-Sarkophag im Vatikan, Bielefeld 1997, 41. 139 f. Nr. 214 Taf. 28, 2; 32, 2, bei dem die Psyche durch Flügel gekennzeichnet ist. Bei Matz 1968, 91 als »Pflückerin« bezeichnet.

357 Nach Rudolf 1989, 32 »ist ein schon berauschter Amor zu Boden gesunken«.

358 s. Koch - Sichtermann 1982, 425 f. 432 Nr. 51-55; 459 Abb. 451-453; Bielefeld 1995, 397-404 Taf. 104-107. Einführende Lit. zu weinlesenden Eroten (seit hellenistischer Zeit) auf anderen Gattungen (Gemmen, Gemälden, Mosaiken) sowie zur Weiterverfolgung des Motivs in der Spätantike und zur Symbolik ist von Rudolf 1989, 31 in Anm. 164 zusammengestellt.

359 Bielefeld 1995, 400.

360 Matz 1968, 110-112 Nr. 10 Taf. 16, 1; Koch - Sichtermann 1982, 419-422. 459.
} 
ton $^{361}$ auf. Auch die Eckfigur mit dem Früchtetablett hat Parallelen auf den genannten Sarkophagen $^{362}$. Der kniende Eros unter dem Ast und auch der vorgebeugte Eros auf dem Ast in der Mitte der Vorderseite in Selçuk erweisen sich als Abwandlungen von Figuren, die sich ebenfalls auf dem Bostoner Sarkophag, und zwar auf der rechten Schmalseite, finden ${ }^{363}$. Somit geht nach Bielefeld die Szene beider Sarkophage auf einen einzigen Entwurf zurück ${ }^{364}$. Für die Vorderseite in Selçuk werden dabei Satyrn und Mänaden inhaltlich abgewandelt und für die Erotendarstellungen adaptiert - hier werden dann die Eroten durch ihre Größe zu Hauptfiguren gemacht ${ }^{365}$.

Es sind keine eigenständigen Typen oder Motive nachzuweisen, die kennzeichnend für Eroten-Vindemia wären. Die attischen Sarkophage mit Eroten-Weinlese bedienen sich aus dem gleichen Typenrepertoire, das für die dionysischen Sarkophage verwendet wird ${ }^{366}$. Damit sind die dionysischen Sarkophage prädestiniert für die Suche nach Vergleichen, die eine Datierung des Eroten-Vindemia-Sarkophags im >Tor der Verfolgung، erlauben.

Der genannte Bostoner Sarkophag wird um 220-230 n. Chr. datiert ${ }^{367}$. Er gehört im Hinblick auf die tektonischen Elemente - die Eckfiguren, den oberen Kastenabschluss und besonders den Sockel -, die Füllung des Frieses mit Figuren und die Schmalseitendarstellung deutlich in das zweite Viertel des 3. Jahrhunderts. Zu dieser Zeit werden nämlich die bis dahin gängigen Bildungen des oberen und unteren Kastenabschlusses sowie der Eckfiguren verändert; diese Einzelteile eines ursprünglich tektonischen Gerüsts werden zu rahmenden Elementen modifiziert. Die Figurenfriese treten damit stärker in den Vordergrund. Durch die Angleichung des Kopfniveaus der Eck- und der Friesfiguren ist die ehemals >überragende< Position der Eckfiguren gemildert und ihre tektonische Funktion reduziert. In der weiteren Entwicklung werden die Eckfiguren dann in das Geschehen der Friese einbezogen, eine inhaltliche Trennung von den Friesfiguren zu der Eckfigur wird abgebaut. Die späten Eckfiguren erhalten eine `überleitende` Funktion, und der Fries wird ohne Unterbrechung um die Ecken geführt. Die Profile des oberen und unteren Kastenabschlusses werden einfacher und flacher. Die optisch gegliederten ornamentierten Profile - Perlstab, Eierstab, lesbisches Kyma, Flechtband - werden durch einzelne vegetabile Schmuckbänder ausgetauscht ${ }^{368}$. Bei den dionysischen Sarkophagen überzieht das Dekor der Weinstöcke den oberen Kastenabschluss einschließlich der oberen Leiste. All dies trifft auch auf dem Bostoner Sarkophag zu - und damit ist er erheblich weiter entwickelt als der Weinlese-Sarkophag in Selçuk.

Der Sarkophag in Boston bietet außerdem - zu seiner Datierung passend - thematisch auf die Vorderseite abgestimmte dionysische Darstellungen auf beiden Schmalseiten (und sogar auf der Rückseite) ${ }^{369}$. Das heraldische Motiv der Schmalseite in Selçuk (Taf. 46 Abb. 182) hingegen erweist sich als typisches Motiv früherer Exemplare. Auf frühen mythologischen Friessarkophagen sind des Öfteren auf den Schmalseiten Szenen abgebildet, die thematisch gar nicht oder nur

361 Matz 1968, 106-110 Nr. 9 Taf. 14; Koch - Sichtermann 1982, 419-422. 459.

362 In Rom an der rechten Ecke der Vorderseite und in Boston auf beiden Schmalseiten je an der Ecke zur Rückseite, Matz 1968, Taf. 16, 1; 15, 1-2.

363 s. Matz 1968, Taf. 15, 2.

364 Bielefeld 1995, $400 \mathrm{f}$.

365 Ein Vorschlag für eine Ergänzung des fehlenden Bereichs der Vorderseite basiert auf einer Zeichnung nach L. Mayer. Die Zeichnung, s. Rudolf 1989, Frontispiz, 12 f. mit Anm. 14, zeigt drei größere Reliefplatten und links eine etwas kleinere. Die drei größeren lassen sich als Platten eines Achill-Sarkophags (Achill-Sarkophag Woburn Abbey: hier Kat. 3) identifizieren. Und die kleinere linke Platte auf der Abbildung entspricht nach Rudolf 1989, 13, und Koch 1991, 817, dem Eroten-Weinlese-Sarkophag im >Tor der Verfolgung‘. Demnach könnte eine Erotenstützgruppe im heute fehlenden Bereich gestanden haben. Dies widerspricht auch nicht der These Bielefelds, zumal der Bostoner Sarkophag ebenfalls Stützgruppen zu bieten hat, s. zweimal auf der Vorderseite, Matz 1968, Taf. 14.

366 Bielefeld 1995, 402.

367 Wiegartz 1977, 386-388 mit Anm. 90; Matz 1968, 106-110 Nr. 9 Taf. 14; Koch - Sichtermann 1982, 419-422. 459.

368 Kintrup 2016a, Kap. 8 S. 212.

369 Matz 1968, Taf. 13. 15. 
mittelbar mit der Darstellung des Vorderseitenfrieses in einem Zusammenhang stehen ${ }^{370}$. Einen Beleg hierfür findet sich unter den dionysischen Sarkophagen auf dem Stück in Mistra ${ }^{371}$, dessen rechte Schmalseite eine Sphinx mit Tatze auf einem Bockskopf schmückt ${ }^{372}$. Die älteren Motive wurden dann im Laufe der Entwicklung von den bevorzugt gearbeiteten Seiten des Sarkophags auf die vernachlässigten verschoben ${ }^{373}$, während auf der Vorderseite neue Themen und aktuellere Typen vorgestellt werden. Vielleicht wurden einige der vertrauten alten Motive noch von einigen Käufern bestellt, aber es ist wahrscheinlicher, dass bei den frühen Friessarkophagen einfach noch kein Typenschatz zur Verfügung stand, der für die Gestaltung aller Seiten mit passenden Szenen ausreichte ${ }^{374}$.

Der Sarkophag in Mistra wird um 180-190 n. Chr. angesetzt ${ }^{375}$ und ist im Vergleich zu dem Eroten-Weinlese-Sarkophag in Selçuk das ältere Exemplar. Erneut belegen mehrere tektonische Kriterien den zeitlichen Abstand. In den attischen Werkstätten übernimmt mit dem Wechsel von Dach- zu Klinendeckeln um 160-170 n. Chr. der Kasten formal eine Funktion als Klinenuntergestell, und die frühen Eckfiguren können als figürlich gestaltete Klinenbeine verstanden wer$\operatorname{den}^{376}$. Die Eckfiguren in Mistra sind dementsprechend frontal auf die Vorderseite ausgerichtet und haben stützend einen Arm erhoben. Die spiegelsymmetrisch gestalteten Eckfiguren setzen sich durch ihre Standhöhe auf Postamenten und ihre ruhige Haltung deutlich von den Friesfiguren ab. Am oberen Kastenabschluss ist noch ein Eierstab erhalten, der den Figurenfries klar vom Kastenabschluss trennt; die Köpfe der Figuren bleiben dabei erkennbar unter dem Eierstab. Hinzu kommen eine flachere Ausführung der Figuren und mehr frei bleibender Reliefgrund.

Der Eroten-Weinlese-Sarkophag in Selçuk ist anhand des Vergleichs mit dem Bostoner Sarkophag und dem Exemplar in Mistra auf das erste Viertel des 3. Jahrhunderts n. Chr. einzugrenzen. Aufgrund der erhaltenen tektonischen Struktur des Kastens in Selçuk (Taf. 46) mit der Eckfigur über einem Eckpostament ist ein Klinendeckel zu ergänzen. Zudem darf eine dem Eros an der linken Ecke vergleichbare Eckfigur, vielleicht mit einem spiegelbildlichen Standmotiv an die rechten Ecke der Vorderseite gestellt, rekonstruiert werden.

Die Vorderseite mit Eroten-Vindemia zeigt eine inhaltlich angepasste, aber noch nicht in das Geschehen einbezogene, >überleitende` Eckfigur; ein Verständnis als ehemals figürlich gestaltetes Klinenbein wird durch den erhobenen Arm noch zitiert, ist aber bereits erheblich eingeschränkt. Die Sockelzone besteht aus klar abgegrenzten Profilen, eingefasst von Eckpostamenten, die eine gute Basis für die darüberstehenden Eckfiguren bilden, während der obere Kastenabschluss bereits vom Dekor der Weinstöcke überzogen ist. Dabei bleibt die obere Leiste noch abgesetzt und die Köpfe der Figuren bleiben unter der schrägen Fläche, die ehemals orna-

\footnotetext{
370 Vgl. den fragmentierten Schlachtsarkophag in Ptolemais, der um 170 n. Chr. datiert wird, Kintrup 2016a, Kap. 4.1.1.2 Nr. 167, mit einer Erotenszene auf der linken Schmalseite. s. weitere frühe Beispiele auf Schmalseiten, so bei Achill-Sarkophagen in Beirut (Tötung eines Trojaners vor Neoptolemos): Rogge 1995, 23 f. Taf. 22, und in Adana (Sphinx): Rogge 1995, 25 Taf. 17, 2, bei Hippolytos-Sarkophagen in Beirut (Bellerophon mit Pegasos und Sphinx): Rogge 1995, 75 Taf. 82, und in Istanbul (Theseus lässt Ariadne auf Naxos zurück und Sphinx): Rogge 1995, 75 Taf. 80 f., und bei Meleager-Sarkophagen in Athen (Greif, der einen Stier zerfleischt): Koch 1975, 138 Nr. 160, und bei einem verschollenen Exemplar, ehemals in Padua (zwei Kinder und Sphinx): Koch 1975, 138 f. Nr. 161; 139 Abb. 13.

371 Matz 1968, 99 f. Nr. 2 Taf. 2 f.; Wiegartz 1977, 386-388 mit Anm. 90; Koch - Sichtermann 1982, 420 mit Anm. 8; 422; Bielefeld 1995, 400.

372 Matz 1968, Taf. 3, 2.

373 Vgl. dazu z. B. die linke Schmalseite eines Amazonomachie-Sarkophags in Beirut: Kintrup 2016a, Kap. 3.1.2.2 Nr. 73 und die entsprechenden Beispiele auf Achill- und Hippolytos-Sarkophagen: z. B. Rogge 1995, 53. 57. 65 (Achill). 75. 83. 87. 89 mit Anm. 101; 90 f. (Hippolytos).

374 Vgl. Rogge 1995, z. B. 24. 75; Kintrup 2016a, Kap. 8 S. 209.

375 Zur Datierung s. Wiegartz 1977, 386-388 mit Anm. 90; Bielefeld 1995, 400. Frühere Exemplare, z. B. in Istanbul, ebenfalls mit Sphinx (und Widderkopf) auf der rechten Schmalseite, s. Matz 1968, 98 f. Nr. 1 Taf. 1, 3, werden nicht berücksichtigt, da sie die Hintergrunddekorationen aus Weinstöcken, welche für die dem Exemplar in Mistra nachfolgenden Sarkophage obligatorisch sind, noch nicht aufweisen.

376 Rogge 1993, 117 mit Anm. 92-96; Rogge 1995, 38 mit Anm. 147.
} 
mentierte Profile trug. Damit steht der Sarkophag in Selçuk dem Exemplar in Mistra näher als dem Bostoner Sarkophag. Eine gute Parallele zur Sockelgliederung liefert der Schlachtsarkophag des Aemilius Aristides, um 200 n. Chr. (Kat. 1 Taf. 2. 5); thematisch bedingt ist der obere Kastenabschluss der Vorderseite nicht vergleichbar, aber die vernachlässigte Schmalseite des Weinlesesarkophags mit den antithetischen Löwen zeigt ein lesbisches Kyma und einen Eierstab in einer >haptisch ` gearbeiteten Form - im Unterschied zu einer >optischen ২ Auflösung der Ornamente durch eingetiefte Bohrlinien ${ }^{377}$, wie sie z. B. die Vorderseite und die betonte Schmalseite des Aristides-Sarkophags aufweisen. Auch der Aristides-Sarkophag verfügt auf seinen vernachlässigten Seiten über überwiegend shaptisch gearbeitete Formen am oberen Kastenabschluss und am Sockel. Hier ist das Phänomen der Verschiebung älterer Motive von bevorzugten auf vernachlässigte Seiten auch für die Ornamentformen zu beobachten ${ }^{378}$.

\section{Datierung}

Unter Berücksichtigung der thematisch bedingten Unterschiede dürfte der Eroten-Weinlese-Sarkophag in Selçuk in zeitliche Nähe zu dem Aristides-Sarkophag gehören.

200-210 n. Chr.

\subsubsection{Fragment eines dionysischen oder eines Eroten-Weinlese-Sarkophags}

(Kat. 11 Taf. 47 Abb. 184)

Selçuk, Efes Müzesi Inv. 10/65/87.

Gefunden in Selçuk, Johannesbasilika, östliche Stützmauer (1987), Fund-Nr. 87/10.

H 51; L 14; DW 5-7; Rh 5.

Lit.: Unpubliziert.

Feinkörniger, heller Marmor. Bis auf wenige erhaltene Falten ist die Reliefoberfläche verrieben, bestoßen oder abgeplatzt. Ein kleines Stück der Oberseite scheint ebenfalls verrieben vorhanden zu sein. In der Oberseite findet sich eine kleine, rechteckige Eintiefung, die ein Zeichen der Wiederverwendung sein kann, die auch in Form von Mörtelresten Spuren hinterlassen hat. Die Rückseite des Fragments zeigt eine regelmäßige Bearbeitung mit einem mittelgroßen Zahneisen.

Obwohl stark beschädigt, ist eine frontal stehende weibliche Figur zu erkennen, die ihren linken Arm wohl über den Kopf gelegt hatte. Auf der rechten Seite des Kopfes deuten Umrissbohrungen und eine Punktbohrung auf eine Knotenfrisur und einen leicht nach links gewendeten Kopf. Weitere Bohrlinien, die nicht näher zu deuten sind, finden sich links des Kopfes und darüber. Die erhaltenen Falten belegen eine Gewandbahn, die vermutlich über den linken Arm gelegt war und über die linke Hüfte nach vorn über das linke Bein fiel. Der obere Kastenabschluss über der Figur war weder sehr hoch, noch scheint er in verschiedene Profile oder Ornamente unterteilt gewesen zu sein.

Die Haltung und die Gewandreste der Figur lassen an einen dionysischen Kontext denken. Vergleiche bieten beispielsweise zwei Mänaden auf der linken Hälfte der Vorderseite eines dio-

377 Grundlegend zu den Begriffen »haptische - optische« Ornamentbildung, s. Wiegartz 1977, 383 f. An dem Beispiel des Erotensarkophags Athen, Nationalmuseum Inv. 4008 wird schon auf die »Grenzen einer rein stilkritischen Methode« hingewiesen.

378 Bereits Rodenwaldt 1930, 126 macht darauf aufmerksam, dass neue Stilformen oft auf Hauptseiten erscheinen und veraltete Bildungen sich auf Neben-, insbesondere Rückseiten halten. s. auch Rudolf 1989, 38-41. Zu weiteren Beispielen s. Kintrup 2016a, Kap. 3.2.1.1 Nr. 259 (Amazonomachie-Sarkophag in der Nekropole Tyros); Kap. 3.2.4 Nr. 121 (Amazonomachie-Fragment in Korinth); Kap. 4.1.1.1 Nr. 167 (Schlachtsarkophag in Ptolemais). 
nysischen Sarkophags in Boston ${ }^{379}$, datiert um 220-230 n. Chr. ${ }^{380}$. Im Unterschied zu dem ephesischen Fragment hat eine Mänade ihren Kopf nach rechts gewendet und hält ein gefülltes Gefäß in der Linken, die zweite Mänade greift mit ihrem rechten Arm vor der Brust nach rechts oben, um eine Traube zu pflücken. Auf der linken Schmalseite des Sarkophags in Kyrene, um 250 n. Chr. ${ }^{381}$, hat die Mänade den Arm nicht ganz über den Kopf erhoben, die Gewandbahn verläuft hinter dem Rücken über die rechte Hüfte nach vorn und bedeckt die Beine. In Rom, Museo Capitolino ${ }^{382}$, um 240 n. Chr. ${ }^{383}$, erscheint eine Mänade in der linken Hälfte der Vorderseite; sie hat ihren Kopf weiter nach links geneigt und den Arm nicht bis über den Kopf erhoben, sondern greift nach einer Traube. Den über den Kopf erhobenen Arm bildet aber ein ebenfalls spätes Fragment in Athen, gleich zweimal nebeneinander, $\mathrm{ab}^{384}$.

Aufgrund der aufgezählten Vergleiche ist die Figur in Ephesos mit einiger Wahrscheinlichkeit ebenfalls als Mänade zu bezeichnen. Auch die Reste des oberen Kastenabschlusses passen zu der Thematik und bestätigen eine Datierung nicht vor dem zweiten Viertel des 3. Jahrhunderts n. Chr. In dieser Zeit ist eine Verwendung fester Figuren- und Gruppentypen nicht mehr zu erwarten und damit auch nicht, dass direkte Parallelen aufzuzeigen sind. Aber eine weitere - rein zahlenmäßig weniger wahrscheinliche - Möglichkeit einer thematischen Einordnung sei hier auch angesprochen, nämlich die Zuordnung zu einem Eroten-Weinlese-Sarkophag. Die auf attischen Sarkophagen selten erscheinende Thematik der Eroten-Vindemia greift auf das gleiche Typenrepertoire, zurück, das auch für dionysische Sarkophage verwendet wird ${ }^{385}$. Dementsprechend bietet die fragmentierte Vorderseite des Eroten-Weinlese-Sarkophags, verbaut im >Tor der Verfolgung (Kat. 10 Taf. 46), eine weitere gute Parallele, wobei die Gewandbahn hinter dem Rücken der weiblichen Figur verläuft und über ihre rechte Hüfte nach vorn geführt ist, wo sie die Beine bedeckt. Dass das vermauerte Exemplar mit einer Datierung um 200-210 n. Chr. deutlich jünger ist, bestätigt der obere Kastenabschluss, der sich dort noch höher und mit gut abgesetzter oberer Leiste präsentiert, während sich hier trotz der Beschädigungen ein später vorherrschender flacherer, niedrigerer oberer Kastenabschluss abzeichnet.

\section{Datierung}

Zweites Viertel des 3. Jahrhunderts n. Chr.

\subsubsection{Fragment eines dionysischen oder eines Eroten-Weinlese-Sarkophags}

(Kat. 12 Taf. 47 Abb. 185)

Selçuk, Efes Müzesi, Açık Hava Deposu, Etd.Nr. L. 86.

Gefunden in Selçuk, Johannesbasilika, Torbereich ${ }^{386}$.

H 39; L 71; DW 8-10; Rh 10.

Lit.: Rudolf 1989, 33 mit Anm. 172 Abb. 21; Koch 1991, 818.

Feinkörniger, weißer Marmor, von starken Glimmeradern durchzogen. Allseitig gebrochenes Fragment. Die Rückseite zeigt eine unregelmäßige grobe bis mittlere Spitzmeißelarbeit. Die

\footnotetext{
379 Matz 1968, 106-110 Nr. 9 Taf. 14; Koch - Sichtermann 1982, 419-422; 459.

380 Zu den Datierungen dionysischer Sarkophage s. Wiegartz 1977, 386-388 mit Anm. 90.

381 Matz 1968, 89 Nr. 1; 116-118 Nr. 11A Taf. 23, 1.

382 Matz 1968, 110-112 Nr. 10 Taf. 16, 1; Koch - Sichtermann 1982, 419-422. 459.

383 Wiegartz 1977, 386-388 mit Anm. 90.

384 Nationalmuseum: Matz 1968, 119 f. Nr. 18 Fragment A Taf. 25, 3.

385 Dazu ausführlicher Bielefeld 1995, 402. Zu Lit. und weiteren Ausführungen zu Eroten-Vindemia, s. hier Kat. 10.

386 Rudolf 1989, 33 Anm. 172: Das Fragment befand sich bis 1982/1983 im Steindepot bei der Johannesbasilika, danach gelangte es in das Skulpturendepot nach Ephesos.
} 
Oberfläche ist streifig verwittert, weist etliche Bestoßungen und Bruchflächen auf; vom Relief bleibt wenig erkennbar.

$\mathrm{Zu}$ identifizieren sind eine Rebe großer Trauben sowie davor ein Kopf im Profil nach rechts; die weiter links erscheinenden Ritzungen könnten zu einem Flügel gehören, der Kopf würde demnach wohl zu einem Eros passen ${ }^{387}$. Über der Rebe erstrecken sich einige eingetiefte Linien schräg nach links oben, die von gewellten, senkrecht verlaufenden Linien überschnitten werden. Hinter dem (Eros-)Kopf sind mehrere winkelförmige Linien gestaffelt eingetieft. Weitere Linien ziehen sich senkrecht hinter dem (Eros-)Kopf - hier ist nicht klar, ob es sich um Relieflinien handelt: Da keine fühlbaren Vertiefungen vorhanden sind, kann es sich auch um Verwitterungsspuren handeln. Die auf dem zurückspringenden Hintergrund unten zu sehenden Linien hingegen sind eingetieft: vielleicht handelt es sich um Reste eines Gewands.

E. Rudolf schlägt dieses Fragment als Ergänzung für den Fehlbereich der Vorderseite des Eroten-Weinlese-Sarkophags im >Tor der Verfolgung (Kat. 10 Taf. 46) vor, da es auch aus dem Torbereich stammt, die »Art der Aufblätterung des Marmors an die ausgewaschenen Stellen im rechten Abschnitt des Erotensarkophages« erinnert und »die große Traube dort ihr Gegenstück findet $\ll^{388}$.

Ohne die Länge der Vorderseite im >Tor der Verfolgung genau zu kennen, scheint dieses Fragment doch zu lang, um in dem fehlenden Bereich Platz zu finden. Zumindest wären dann ein direkter Anschluss an der linken Seite des Fragments, der nicht zu erkennen ist, sowie Reste einer Eckfigur an der rechten Seite, die für den Eroten-Weinlese-Sarkophag zu rekonstruieren ist, zu erwarten. Die langen, eingetieften Linien und die Größe der Bruchlinien lassen eher auf Figuren schließen, die im Verhältnis größer sind als der (Eros-)Kopf; auch erscheint der Kopf im Vergleich zu der Rebe relativ klein. Demnach wäre eher eine dionysische Darstellung zu vermuten, bei der die Eroten deutlich kleiner dargestellt werden als Satyrn und Mänaden ${ }^{389}$. Eine in manchen Bereichen interessante Parallele bietet eine linke Schmalseite in Jerusalem mit der Darstellung einer gelagerten Leda mit Schwan, eingebettet in ein dionysisches Treiben ${ }^{390}$. Jedoch bleibt bei dem Erhaltungszustand des Reliefs auch diese Zuordnung aber nicht ohne Zweifel.

\section{Datierung}

Auch eine Datierung scheint gewagt. Durch die Reliefhöhe, die Dichte der Bruchlinien und den nicht zu erkennenden freien Reliefgrund könnte jedoch eine Zugehörigkeit in das zweite Viertel des 3. Jahrhunderts angezeigt sein.

Zweites Viertel des 3. Jahrhunderts n. Chr. (?)

\subsubsection{Fragment eines dionysischen oder eines Eroten-Weinlese-Sarkophags}

(Kat. 13 Taf. 47 Abb. 186)

Selçuk, Efes Müzesi, Açık Hava Deposu, Etd.Nr. L. 21.

Gefunden in Ephesos.

H 10; L 42,5; D 23.

Lit.: Unpubliziert.

Feinkörniger, weißer Marmor mit grünlichen Glimmerschiefereinschlüssen. Allseitig gebrochenes Fragment. Rückseite mit gleichmäßiger mittelfeiner Spitzmeißelarbeit. Die Oberfläche ist

\footnotetext{
So Rudolf 1989, 33.

Rudolf 1989, 33.

389 Vgl. die Bemerkungen zu dem Fragment hier Kat. 8 im Museum von Selçuk (Taf. 45 Abb. 180).

390 Oakley 2011, 32-34. 84 f. Nr. 43 Taf. 33, 3: 220-230 n. Chr.
} 
leicht verrieben und teilweise bestoßen. Die Ausrichtung ist nicht gesichert, scheint aber in der hier wiedergegebenen Abbildung am wahrscheinlichsten.

Teil einer oder eher mehrerer Weinreben. Der geknickte Reliefrest in der Mitte kann als Teil einer Ranke oder des Stängels eines Weinstocks gedeutet werden ${ }^{391}$, wie dies z. B. Fragmente dionysischer Sarkophage in Athen ${ }^{392}$ und ehemals in Knin ${ }^{393}$ demonstrieren.

Abgesehen von der Zuordnung zu einem dionysischen Sarkophag kann auch die Möglichkeit einer Zugehörigkeit zu einem Eroten-Weinlese-Sarkophag in Betracht gezogen werden ${ }^{394}$, insbesondere, da mit dem Exemplar im >Tor der Verfolgung` (Kat. 10 Taf. 46) ein prominentes Stück dieser auf attischen Sarkophagen selten belegten Thematik vor Ort existiert. Die Frage einer Zusammengehörigkeit dürfte ohne Steinanalyse aufgrund der Kleinheit des Fragments jedoch nicht zu klären sein. Auch ein Stilvergleich ist durch den Aufbewahrungsort des Eroten-WeinleseSarkophags, der noch im >Tor der Verfolgung verbaut und nur durch dafür unzureichende Fotos dokumentiert ist, nicht aussagekräftig.

\section{Datierung}

Die Trauben sind in unterschiedlicher Reliefhöhe angeordnet und durch sichtbare Bohrkanäle untergliedert, sodass ein plastischer Eindruck entsteht. Die Trauben sind einerseits plastischer und üppiger gestaltet als auf den Sarkophagen in Mistra (um 190-200 n. Chr.) und Sparta (ca. 200-210) mit frühen Darstellungen von Thiasoten zwischen Weinstöcken, aber andererseits nicht durch tiefe, harte Bohrungen unterteilt, wie es bei dem späten Sarkophag in Thessaloniki (um 260 n. Chr.) der Fall ist ${ }^{395}$. Stilistisch gehört das ephesische Fragment demnach am ehesten in die Zeit von 220-240 n. Chr.

Erste Hälfte des 3. Jahrhunderts n. Chr.

\subsubsection{Fragment mit jugendlichem Kopf (Eros [?])}

(Kat. 14 Taf. 48 Abb. 187) $)^{396}$

Selçuk, Efes Müzesi, Inv. nicht bekannt

Gefunden 2010 in Ephesos, Westnekropole, Schnitt 4/10; SE 465. Das Fragment wurde in der Planierung eines Raumes in der Westnekropole gefunden, der zu keinem Grabhaus gehörte, sondern einer sekundären Nutzung diente. Das Fragment war frühestens im 6. Jahrhundert n. Chr. in diese Schicht eingebracht worden ${ }^{397}$.

\section{H 34; L max. 21,4; DW max. 8; Rh 1,4.}

$$
\text { Lit.: Unpubliziert. }
$$

Grobkörniger, weißer Marmor, durchzogen von einer breiten grauen Ader und stark glimmerhaltig. Die stellenweise zu beobachtenden bräunlichen Verfärbungen dürften von Wurzelfasern stammen. Das kleine Fragment mit dem Kopf einer Figur und darüber einem Ornamentband ist dreiseitig gebrochen. Das kleine Stück des intakten oberen Randes bezeugt, dass das Fragment von dem oberen Kastenabschluss eines Sarkophags stammt. Die Rückseite des Fragments ist horizontal grob gespitzt.

391 Die Möglichkeit, dass es sich um ein Vogelbein handelt, ist wegen der Form eher auszuschließen.

392 Matz 1968, 119 f. Nr. 18 (Fragment A) Taf. 25, 4.

393 Matz 1968, 120 f. Nr. 24 (Fragment b) Taf. 27, 2.

394 Koch - Sichtermann 1982, 425 f. 432 Nr. 51-55; 459 Abb. 451-453 und Bielefeld 1995, 397-404 Taf. $104-107$.

395 Zu den Datierungen s. Wiegartz 1977, 386 f. mit Anm. 90.

396 Ich danke dem Ausgräber M. Steskal für die Publikationserlaubnis. Alle Angaben zu dem Fragment werden M. Aurenhammer verdankt.

397 M. Steskal, Die Hafennekropole in Ephesos, FiE 16, 1 (in Druckvorbereitung). 
Die Bruchlinie rechts verläuft bei der Figur entlang der Unterlippe hinab zum Kinn und weiter durch Hals und Brustansatz. Vor der Stirn hat sich ein lanzettförmiger Reliefrest erhalten. Darüber ragt eine längliche Bruchfläche in das Ornament des oberen Kastenabschlusses.

Das Ornamentband ist durch eine tiefe Rille von der Reliefdarstellung getrennt. Es besteht aus Gorgonenhäuptern, die durch vertikale Gliederungselemente getrennt sind. Von der Gorgo haben sich etwas weniger als die rechte Gesichtshälfte mit dem unteren Teil der herabfallenden Locken sowie Haarreste über der Stirn erhalten. Die darüber sichtbaren geringen Reste lassen auf eine dekorierte obere Leiste schließen. Links neben der Gorgo sind der untere vegetabile Teil eines Gliederungselements sowie Haarreste eines weiteren Gorgoneions zu sehen.

Es sind teilweise raue Bearbeitungsspuren am Reliefgrund, im Ornamentband und im Haar der Figur erkennbar. Eine gebohrte Umrisslinie verläuft am Hinterkopf und Profil der Figur entlang. Dagegen sind die Gesichter der Figur und des Gorgoneions schön glatt poliert. Es finden sich zudem feine Punktbohrungen in den Mund- und den inneren Augenwinkeln sowie im Nasenloch der Figur. Tiefere und gröbere Bohrungen im Haar der Figur, des Gorgoneions sowie im Blattwerk des Ornamentbands sorgen für eine ausgeprägte Hell-Dunkel-Wirkung.

Durch Marmor, Stil und das obere Ornamentband sind Fragen nach Provenienz und chronologischer Einordung auch bei diesem kleinen Fragment eindeutig zu beantworten. Eine Zuordnung zu einem späten attischen Sarkophag lässt sich durch Vergleichsstücke gut absichern, von denen zwei ebenfalls in Ephesos gefunden wurden: der Amazonomachie-Sarkophag aus dem Grabhaus der Tatiane (Kat. 2 Taf. 27 Abb. 117-119) und der Hippolytos-Sarkophag »E« (Kat. 15 Taf. 51 Abb. 198). Insbesondere die Gorgo im Gorgonenkyma und z. T. auch die Figuren des HippolytosSarkophags sind ebenfalls so glatt poliert (Taf. 49-51).

Eine dritte Parallele für das Gorgonenkyma ${ }^{398}$ bietet der Achill-Sarkophag in Rom, Museo Capitolino ${ }^{399}$, anhand dessen sich eine plastische Vorstellung für die Ergänzung der Gorgonenhäupter und der vertikalen Gliederungselemente des kleinen ephesischen Fragments gewinnen lässt.

Nach Reliefhöhe und -ausführung wird es sich bei der erhaltenen Figur wohl um eine Nebenoder Hintergrundfigur handeln, während die längliche Bruchfläche, die deutlich in das Gorgoneion des oberen Kastenabschlusses hineinragt, zu einer Hauptfigur im Vordergrund gehören wird.

Die - soweit erhalten - unbekleidete Figur hat ihren Kopf, im Profil nach rechts, mit kinnlangem, gelocktem Haar leicht geneigt. Jugend und Frisur lassen am ehesten an einen Eros denken. Durch den blattförmigen Reliefrest vor dessen Stirn scheint der Gedanke an einen Eroten-Weinlese-Sarkophag berechtigt. Doch weder die fragmentierte Vorderseite des Eroten-Weinlese-Sarkophags, verbaut im >Tor der Verfolgung، (Kat. 10 Taf. 46), noch die Durchsicht anderer attischer Sarkophage mit Eroten-Vindemia ${ }^{400}$ ergeben gute Vergleiche zu Figur und Dekor. Dies gilt auch für die dionysischen Sarkophage, deren Typenrepertoire für die wenig belegte Thematik der Eroten-Vindemia verwendet wird ${ }^{401}$. Bei beiden Sujets sind die oberen Kastenbereiche der späten Sarkophage nahezu überwuchert von Weinranken und Reben.

Für die attischen Erotensarkophage gilt, dass sie »verschiedene Themen zeigen, die ungewöhnlich reich variiert werden, sodaß kein Stück einem anderen gleicht « ${ }^{402}$. Zu dem blattförmigen Reliefrest stellen die Blätter auf Erotensarkophagen beispielsweise in Damaskus ${ }^{403}$ oder Rom ${ }^{404}$ gute Vergleiche dar. Für eine genauere thematische Zuordnung liefert das Fragment wenig Anhaltspunkte.

\footnotetext{
398 Zu weiteren Vergleichen s. Rogge 1995, 68 Anm. 344; 92; Rogge 1993, 120 Anm. 129.

399 Rogge 1995, 136 f. Nr. 24 Taf. 44. 49.

400 s. Bielefeld 1995. Zu Lit. und weiteren Ausführungen zur Eroten-Vindemia, s. hier Kat. 10.

401 Dazu ausführlicher Bielefeld 1995, 402.

402 Koch 1993, 103.

403 Koch - Sichtermann 1982, 425 Abb. 463.

404 Ciliberto 1998, 242 Taf. 100 Abb. 1.
} 


\section{Datierung}

Da der Achill-Sarkophag durch die Porträtköpfe seines Klinendeckels um 250 n. Chr. zu datieren ist, wurden der Amazonomachie-Sarkophag (Kat. 2) und der Hippolytos-Sarkophag »E« (Kat. 15) ebenfalls um 240-250 n. Chr. eingeordnet. Weitere Parallelen mit Gorgonenkyma ${ }^{405}$, die auch in zeitlicher Nähe liegen, bestätigen eine ebensolche Datierung für dieses Fragment, das stilistisch ebenfalls in die Mitte des Jahrhunderts gehört. Das weite Hineinragen von Figuren in den oberen Kastenabschluss gibt einen zusätzlichen Hinweis auf eine späte Datierung für das Fragment $t^{406}$.

240-250 n. Chr.

\subsection{Hippolytos-Sarkophage}

\subsubsection{Kastenfragmente eines Hippolytos-Sarkophags (Kat. 15 Taf. 49-64)}

Selçuk, Efes Müzesi Inv. 111. 114. 115. 138 und weitere Fragmente ohne Inv. im Efes Kapalı Deposu.

Gefunden 1930 in Ephesos, im Schutt neben einem nicht ausgeführten Girlandensarkophag (Halbfabrikat) in einem Grabhaus der Nekropole nördlich des Hafenkanals ${ }^{407}$.

Lit.: Keil 1932, 69; Eichler 1944/45, 129 Nr. 5; Kallipolitis 1958, 31 Nr. 201; Giuliano 1962, 48 Nr. 255; Koch Sichtermann 1982, 396; Rudolf 1989, 46-50 »Ephesos E« Abb. 36-41; Koch 1991, 817. 819; Rogge 1993, 120 Anm. 129; Rogge 1995, 68 Anm. 344; 91 f. 152 Nr. 58 Taf. 112, 3-8.

Feinkörniger, heller Marmor. Nach Lagerung teilweise braun bis rötlich versintert. An einigen Bruchflächen der Fragmente sind Glimmereinschlüsse zu sehen.

In den Aufzeichnungen F. Eichlers werden diese Fragmente unter der Bezeichnung »Sarkophag $\mathrm{E}$ « geführt ${ }^{408}$ und die Figuren als etwa halb lebensgroß beschrieben, womit sie deutlich größer sind als die Figuren des Aristides-Sarkophags (»B«) und des Amazonomachie-Sarkophags (»C«) aus dem Grabhaus der Tatiane (Kat. 1 f.). Somit kann die Größe als Richtlinie für die Zuordnung dienen, zumal die Fragmente des Hippolytos-Sarkophags »E« vermischt mit jenen des AristidesSarkophags und des Amazonomachie-Sarkophags im Efes Kapalı Depot des Efes Müzesi gelagert waren $^{409}$.

Nach den Aufzeichnungen Eichlers gehören die Köpfe 1-4 mit den Inv. 111. 114. 115. 138 in Selçuk, Efes Müzesi, zu dem »Sarkophag E«:

- Kopf 1 (Taf. 49 Abb. 188 f.)

Inv. 111: Jünglingskopf, gelockt (H 14; L 7; T 11).

Etwa ein Viertel des Gesichts des Jünglings ist weggebrochen. Nase und Lippen sind bestoßen; über seiner rechten Augenbraue oberflächliche Beschädigung. Der Halsansatz ist erhalten. Augeninnenwinkel, Nasenlöcher und Philtrum mit Punktbohrungen angegeben; Mundspalte und Ohröffnung gebohrt. Die Haare sind in üppigen, gewellten Strähnen mit deutlichen Bohrkanälen versehen; wenige, feine Spuren der Bearbeitung mit einem Flachmeißel sind zu sehen. Augenbrauen und Oberlider sowie vereinzelte Linien zur Haaruntergliederung sind eingetieft.

405 Zu weiteren Vergleichen s. Rogge 1995, 68 Anm. 344; 92; Rogge 1993, 120 Anm. 129.

406 Dazu mit Vergleichen s. z. B. hier Kat. 3, Achill-Sarkophag in Woburn Abbey (Taf. 34-38) oder hier Kat. 5, Eckfragment eines Achill-Sarkophags (Taf. 39 Abb. 165 f.).

407 Zu den jüngsten Forschungen zur Westnekropole vgl. hier Anm. 283.

408 Die Bezeichnungen »Sarkophag A-D « waren bereits vergeben für die von F. Eichler angenommenen vier Sarkophage des Tatiane-Grabhauses, s. o. Anm. 79.

409 s. auch die Einleitung zu dem Komplex der Sarkophage des Grabhauses der Claudia Antonia Tatiane, o. Kap. 2. Die Einzelmaße der Fragmente sind bei ihrer Beschreibung vermerkt. 
Die nicht vollständige Ausführung des linken Ohrs und der Locken auf der linken hinteren Kopfseite rühren daher, dass der Jüngling hier von weiteren Figuren oder Gegenständen überschnitten wurde. Der Ansatz zum Reliefgrund ist auf seiner verlorenen rechten Kopfseite zu ergänzen. Der Kopf ist für Dreiviertelansicht gemacht und war leicht zu seiner Rechten gewendet. Dies ist der einzige der vier Köpfe, der zwar fein geglättet, aber nicht poliert ist. Weil aber die technische Ausführung und der Stil eine Zusammengehörigkeit zu den folgenden Köpfen bestätigen, kann daraus zumindest ein Hinweis auf die Zugehörigkeit zu der - wohl bevorzugt gearbeiteten - Schmalseite abgeleitet werden, während die anderen drei polierten Köpfe der Vorderseite angehört haben.

- Kopf 2 (Taf. 50 Abb. 192-195)

Inv. 114: Kopf einer Amme (H 12,5; L 13).

Auf dem Hinterkopf ist »E« in rot vermerkt. Der Kopf ist aus zwei Stücken zusammengesetzt; es fehlt die Nase (vielleicht abgemeißelt). Die fein polierte Oberfläche ist auf ihrer linken Gesichtshälfte rau versintert. Entlang der Bruchlinie fehlen kleinere Stücke.

Der Kopf gehört einer Frau, die ein kinnlanges Kopftuch trägt, das über der Stirn umgeschlagen ist. Ihr fast rundplastisch gearbeiteter Kopf war nach rechts gewendet; der Ansatz zum Reliefgrund war auf ihrer verlorenen linken Gesichtsseite. Der Halsansatz ist vorhanden. Augeninnenwinkel, ein breiter Mundspalt und die Ohröffnung sind gebohrt: Punktbohrungen zur Angabe der Nasenlöcher und des Philtrums waren wohl vorhanden. Die Haare der rechten Kopfseite sind durch deutliche Bohrkanäle untergliedert und dazwischen von feineren Meißellinien leicht gewellt gebildet. Augenbrauen und Lidlinien sind schmal und tief eingearbeitet; Gesichtsfalten dagegen etwas flacher und breiter ausgeführt. Die Angabe von Falten auf Stirn, Nase, Wangen und am Kinn kennzeichnen das fortgeschrittene Alter der Frau: es ist das Gesicht der alten Amme Phaidras.

- Kopf 3 (Taf. 49 Abb. 190 f.)

Inv. 115: Jüngling mit Hut (H 15; L 14; T 7).

Aus zwei Teilen zusammengefügter Kopf eines Mannes mit flachkrempigem Hut. Der Spalt verläuft quer über den Petasos und am linken Haaransatz entlang; dort finden sich Fehlstellen. Die gesamte Rückseite des Kopfes ist eine Bruchfläche. Die Nase ist bestoßen, das rechte Ohr fehlt, das linke ist z. T. abgebrochen. Der Halsansatz ist vorhanden. Gesicht und Petasos sind sorgfältig poliert.

Punktbohrungen finden sich in den Augeninnenwinkeln und zwischen Nase und Oberlippe; in dem gebohrten Mundspalt sind Punktbohrungen in den Mundwinkeln sowie zwei in der Oberlippe und eine in der Mitte der Unterlippe auszumachen. Weitere Bohrungen finden sich zur Angabe der Frisur mit kleinteiligen, teilweise eingerollten Löckchen; dort auch Ritzlinien. Augenbrauen und Lidlinien der leicht schräg gestellten Augen sind schmal eingetieft, hinzu kommt eine Stirnfalte. Auf der rechten Gesichtsseite am Rand des Petasos ist ein Reliefansatz zu erkennen, der nicht zu dem Hut gehört. In Analogie zu dem Hippolytos-Sarkophag in Tyros ${ }^{410}$ wird es sich auch hier um einen Jagdgefährten mit Hut des Hippolytos handeln.

- Kopf 4 (Taf. 51 Abb. 196 f.)

Inv. 138: Hundekopf (H 18; L 10,5).

Der Hundekopf wird von F. Eichler als ebenfalls zu dem Sarkophag aus dem Hafenkanal gehörig erwähnt ${ }^{411}$. Erhalten sind Kopf und Hals (mit feinem Riss) eines Hundes mit glänzend polierter Oberfläche. Die Schnauze und die Ohren sind abgebrochen; von dem linken Ohr ist nur noch der Ansatz vorhanden. Hinter dem Kopf, der nach rechts gewendet ist, ragt ein Reliefrest, vielleicht eine Gewandfalte, auf. Die linke Gesichtsseite des Hundes ist stark beschädigt; darunter sind

410 s. Rogge 1995,157 f. Nr. 70 Taf. 88, 4; 91.

411 Eichler 1944/45, 129 Nr. 5: »Unter den figürlichen Resten Jünglingsköpfe, Pferdereste, Hundekopf, Kopf der Amme.« 
am Hals Raspelspuren zu dem Reliefgrund hin zu erkennen. Die Linien zur Angabe der Augen sind schmal eingetieft, ebenso die Schnauzen- und Lefzenlinien. Punktbohrungen wurden für die Pupille und den Augeninnenwinkel verwendet.

- Fragment 5 (Taf. 51 Abb. 198)

An gleicher Stelle wie der Hundekopf wird auch ein Dekor aus Gorgoneia ${ }^{412}$ erwähnt. Bei dem Fragment des oberen Kastenabschlusses mit Gorgoneion ist die Oberseite intakt und auf $10 \mathrm{~cm}$ erhalten (L 7; H 13). Ein kleines Stück der oberen Leiste mit Blattwerk ist ebenfalls vorhanden. Im fein geglätteten Gesicht sind Punktbohrungen in Augenwinkeln, Nasenlöchern, Mundwinkeln, in der Mitte der Unterlippe und über der Oberlippe angebracht sowie in der Ranke und neben der Volute unter dem Gorgoneion. Weitere Bohrungen finden sich in den Haaren. Die Augenbrauen, eine Stirnfalte und Falten unter den Augen und an der Nase ansetzend sind eingetieft.

- Von E. Rudolf ${ }^{413}$ und S. Rogge ${ }^{414}$ wurde ein weiteres Fragment (Taf. 27 Abb. 118) mit oberer Leiste, Resten zweier Gorgonenhäupter sowie der trennenden konsolenartigen Glieder dem Hippolytos-Sarkophag zugeordnet. Das Fragment gehört jedoch nach Stil und Ausführung zu dem erwähnten Amazonomachie-Sarkophag aus dem Grabhaus der Tatiane (Kat. 2) ${ }^{415}$.

Neben den bereits genannten Fragmenten $1-5^{416}$ sind auch die folgenden Fragmente handschriftlich von F. Eichler auf einem Blatt ${ }^{417}$ (Nr. 6-10) und auf zwei Skizzenblättern ${ }^{418}$ (Nr. 11-13) vermerkt und konnten in den Fundkisten des Tatiane-Grabes eindeutig identifiziert werden. Sie lassen sich nicht genauer am Sarkophagkasten positionieren, sind aber wegen ihrer Ausführung den bevorzugten Sarkophagseiten zuzuordnen.

- Fragment 6 (Taf. 52 Abb. 201)

Aus zwei anpassenden Teilen bestehendes Fragment des Unterkörpers und des rechten Oberschenkels eines unbekleideten Mannes (L 18; H 34) ${ }^{419}$; Bruchflächen über und rechts des Bauchnabels sowie entlang seiner linken Leistenlinie und an den Geschlechtsteilen. Die Reliefoberfläche ist poliert. Das rechte Bein war wohl das Standbein. Für das Standmotiv lassen sich die Figuren an den Vorderseiten der Hippolytos-Sarkophage in Agrigent oder in Tarragona ${ }^{420}$ und auch ein Fragment im Vatikan als Vergleiche heranziehen ${ }^{421}$.

- Fragment 7 (Taf. 52 Abb. 202)

Das aus zwei Stücken zusammengesetzte Fragment (L 9; H 18) zeigt ein Gewand aus schön fallenden und sorgfältig gearbeiteten Falten. Unter den Falten erscheint ein Flügel oder eine Hand (? $)^{422}$. Die Oberfläche ist fein geglättet.

- Fragment 8 (Taf. 52 Abb. 203)

Das aus zwei anpassenden Teilen bestehende Fragment zeigt einen erhobenen rechten Oberarm und eine rechte Schulter mit Chlamys, die von einer Scheibenfibel zusammengehalten wird (L 9;

$\overline{412}$ Eichler 1944/45, 129 Nr. 5: »Dekoration wie am kapitolinischen Achilleussarkophag, Robert II Taf. 14, auch mit Gorgoneia wie oben Nr. 2.« Bei Nr. 2 handelt es sich um den attischen Amazonomachie-Sarkophag aus dem Grabhaus der Claudia Antonia Tatiane (Kat. 2 Taf. 26-32). Das Fragment ist zudem auf einer Zeichnung F. Eichlers dem Sarkophag »vom Nordufer des Hafenkanals« zugeordnet.

413 Rudolf 1989, 47 f. Abb. 38.

414 Rogge 1995, 152 Nr. 58 Taf. 112, 7.

415 s. o. Anm. 412.

416 Die vier Köpfe sind bei Rudolf 1989, 47 unter den Nr. 1. 2. 9.13 aufgeführt.

417 So Rudolf 1989, 47, danach = Eichler N.Bl. 299, 1930 ohne genaues Datum.

418 So Rudolf 1989, 47, danach = Eichler N.Bl. 294 f., 1930 ohne genaues Datum.

419 Rudolf 1989, 47 Nr. 4: »Ein Bauch und rechter Oberschenkel«.

420 Rogge 1995, 148 Nr. 47 Taf. 90; 156 Nr. 68 Taf. 89, 3.

421 Rogge 1995, 158 Nr. 71 Taf. 105, 2.

422 Rudolf 1989, 47 Nr. 8: »Ein flatterndes Gewandstück mit Flügel (?).« 
H 24) ${ }^{423}$. Der Haltung mit dem erhobenen Arm zufolge, gehörte das Fragment wahrscheinlich zu einer Eckfigur, wie die Parallelen auf den Hippolytos-Sarkophagen in Beirut ${ }^{424}$ oder in Agrigent ${ }^{425}$ belegen.

- Fragment 9 (Taf. 52 Abb. 204)

Zwei Teile eines rundplastisch gearbeiteten Pferdekopfes nach rechts (L [mit Lücke] 14; H 12) ${ }^{426}$ passen im hinteren Teil aneinander; die Rückseite zeigt Raspelspuren.

- Fragment 10 (Taf. 51 Abb. 199)

Aus zwei anpassenden Stücken bestehendes Fragment des Sockels mit einem Dekor aus Akanthusblättern (L 9; H 16; H der geglätteten Leiste 4,5) ${ }^{427}$. Gute Vergleiche für das Sockeldekor bieten die Hippolytos-Sarkophage in Agrigent ${ }^{428}$, in Tyros ${ }^{429}$ und in Apollonia (Libyen) ${ }^{430}$, die alle an das Ende des zweiten Viertels des 3. Jahrhunderts n. Chr. datiert werden.

- Fragment 11 (Taf. 51 Abb. 200)

Nach rechts liegender Hund (L 10; H 17) ${ }^{431}$. Punktbohrungen an der Pfote und dem Ansatz des Hinterbeins. Der Tierkörper hat eine polierte Oberfläche. Unter der Standleiste ist ein Stück des Sockeldekors, bestehend aus Blattwerk - wohl Akanthusranken - erhalten. Für den liegenden Hund vergleiche beispielsweise den Hippolytos-Sarkophag in Apollonia (Libyen) ${ }^{432}$ und das Blattdekor der Sarkophage in Agrigent und Tyros.

- Fragmente 12 und $13^{433}$ (Taf. 53 Abb. 205 f.)

Zwei nicht anpassende Fragmente einer Keule. Das kürzere Fragment 12 (H ca. 9) war teilweise rundplastisch ausgeführt und zeigt eine Verdickung am Ende, die vermuten lässt, dass hier das obere Ende der Keule folgte.

Das etwas längere Fragment Nr. 13 (H 14) ist deutlicher als Teil einer Keule auszumachen. Keulen sind ein beliebtes Accessoire auf Hippolytos-Sarkophagen, so beispielsweise auf der Vorderseite in Agrigent ${ }^{434}$ oder der Schmalseite in Apollonia (Libyen) ${ }^{435}$.

Des Weiteren sind die folgenden Fragmente handschriftlich von F. Eichler ${ }^{436}$ aufgeführt, konnten aber nicht eindeutig in den Kisten des Tatiane-Grabes identifiziert werden:

Rudolf 1989, 47 Nr. 5: »Ein linkes nacktes Bein (Oberschenkel - Fuß)«.

Rudolf 1989, 47 Nr. 6: »Ein rechtes nacktes Bein«.

Rudolf 1989, 47 Nr. 7: »Eine rechte Hand mit Schwertgriff«.

Rudolf 1989, 47 Nr. 11: »Ein Arm«.

Rudolf 1989, 47: »Der Rest einer Sockelzone«.

\footnotetext{
${ }_{423}$ Rudolf 1989, 47 Nr. 10: »Eine rechte Schulter und Rückenstück mit Chlamys und hoch erhobenen Unterarm.« Hier steht sicher aus Versehen »Unterarm« statt Oberarm.

424 Rogge 1995, 152 Nr. 57 Taf. 86, 1.

425 Rogge 1995, 148 Nr. 47 Taf. 89, 1.

426 Rudolf 1989, 47 Nr. 12: »Zwei Stücke eines Pferdekopfes«.

427 Rudolf 1989, 47 Nr. 14: »Zwei untere Randstücke mit Blattwelle«.

428 Rogge 1995, 148 Nr. 47 Taf. 89, 1; 94, 1; 100, 3.

429 Rogge 1995, 157 f. Nr. 70 Taf. 88, 4; 101, 1.

430 Rogge 1995, 149 Nr. 49 Taf. 97, 2.

431 Rudolf 1989, 47: »Ein Sockelstück mit ornamentiertem Binnenfeld und hockendem Tier nach rechts (Abb. 36)«.

432 Rogge 1995, 149 Nr. 49 Taf. 97, 2.

433 Rudolf 1989, 47: »Zwei Fragmente einer Keule«.

434 Rogge 1995, 148 Nr. 47 Taf. 89, 1; 94, 1.

435 Rogge 1995, 149 Nr. 49 Taf. 103, 1.

436 s. 0. Anm. 417 f.
} 
- Fragment 14 (Taf. 53 Abb. 207)

Relativ wahrscheinlich ist dabei noch die Zuordnung eines Pferdekopfes nach rechts (L 13; H 8) ${ }^{437}$. Die Vorderseite des Fragments ist weggebrochen. Eingeritzte Linien können als Angabe der Augen und vielleicht des Zaumzeugs gedeutet werden. Die Mähne zeigt Bohrungen und Ritzungen.

Weiterhin sind die Fragmente Nr. 15-18 mit der Aufschrift »E« auf der Rückseite versehen:

- Fragment 15 (Taf. 53 Abb. 208)

Fragment einer Pferdemähne (H 8) mit Bohrungen und Ritzlinien zur Untergliederung der Strähnen. Die Rückseite des Fragments trägt die Aufschrift »E« über einem »C« - wurde folglich von Eichler wohl zuerst dem Amazonomachie-Sarkophag zugeordnet.

- Fragment 16 (Taf. 53 Abb. 209)

Ein paar Strähnen vermutlich einer Pferdemähne ragen auf einer nichtdekorierten, schrägen Ablauffläche nahe an eine obere Leiste ebenfalls ohne Dekor (L 5; H 8). Somit gehörte das Fragment zu dem oberen Kastenabschluss einer vernachlässigt gearbeiteten Sarkophagseite. Zu vergleichen sind hier die nicht dekorierten, schrägen Ablaufflächen und oberen Leisten der vernachlässigten Schmalseiten der Hippolytos-Sarkophage in Beirut ${ }^{438}$ und Arles ${ }^{439}$.

- Fragment 17 (Taf. 53 Abb. 210)

Fragment vielleicht eines Oberarms mit einer Gewandsäumung (L 5,5; H 14) in Form einer fein eingetieften Linie; als Rest einer Schwertscheide wäre die Form der Spitze ungewöhnlich und die Scheidenspitze müsste eher nach oben zeigen, hielte die Figur das Schwert im Arm, wie dies etwa bei den Hippolytos-Sarkophagen in St. Petersburg ${ }^{440}$ und Arles ${ }^{441}$ sowie bei dem Fragment im Vatikan ${ }^{442}$ der Fall ist. Eine weitere hypothetische Deutung ist die Identifizierung als Schreibtäfelchen, das die Amme Hippolytos reicht, so auf den Vorderseiten in St. Petersburg ${ }^{443}$ und Arles $^{444}$ oder bei Phaidra auf der Vorderseite in Beirut ${ }^{445}$.

- Fragment 18 (Taf. 53 Abb. 211)

Fragment aus zwei anpassenden Stücken (L 7; H 24). Zwar ist das Fragment mit der Aufschrift »E« auf der Rückseite versehen, und auch die Marmorart und Bearbeitung (Oberfläche poliert) passen dazu, aber die Orientierung des Fragments ist nicht gesichert und die Identifizierung des Dargestellten bereitet Schwierigkeiten. Folgt man der Orientierung der Abbildung sind oben zwei Wülste zu erkennen und ein kleiner Vorsprung sowie auf der rechten Seite Raspelspuren, die darauf deuten, dass hier der Reliefgrund folgte. Vielleicht handelt es sich um eine Körperseite und Chlamysfalten mit Scheibenfibel oder um Finger, vielleicht aber auch um einen Arm. Die Körperproportionen des Fragments sind für eine Zuordnung zu »E « eher zu klein, sodass es wahrscheinlicher dem Schlachtsarkophag des Aristides (»B«) oder dem Amazonomachie-Sarkophag (»C«) zugerechnet werden müsste. Als einzelner Körperteil - z. B. als Arm - wiederum ist das Fragment zu groß für »E« und müsste somit ganz ausgeschieden werden.

- Fragment 19 (Taf. 54 Abb. 212)

Den Größenverhältnissen nach eher zu »E« als $\mathrm{zu} » B$ « oder »C« passend, ist ein Oberkörperfragment, allein sein Marmor erscheint heller als die anderen »E« zugeordneten Fragmente. Das

437 Rudolf 1989, 47 Nr. 3: »Pferdekopf«.

438 Rogge 1995, 152 Nr. 57 Taf. 106, 1.

439 Rogge 1995, 150 Nr. 50 Taf. 108, 1. Zum Hippolytos-Sarkophag in Arles s. auch Gaggadis-Robin 2005, 72-90 mit Abb.

440 Rogge 1995, 154 f. Nr. 64 Taf. 90, 2.

441 Rogge 1995, 150 Nr. 50 Taf. 103, 2.

442 Rogge 1995, 158 Nr. 71 Taf. 105, 2.

443 Rogge 1995, 154 f. Nr. 64 Taf. 90, 1; 93, 1.

444 Rogge 1995, 150 Nr. 50 Taf. 96.

445 Rogge 1995, 152 Nr. 57 Taf. 84, 2. 
allseitig gebrochene Fragment bietet ein Stück eines Schwertgurts (L 22; H 8; Rh ca. 11). Dem Ansatz nach war der rechte Arm der Figur erhoben. Auch die Muskulatur sowie die Bildung der ringförmig angegebenen Brustwarzen unterscheiden sich von jenen der Krieger des Schlachtsarkophags $» \mathrm{~B} \ll$.

- Fragment 20 (Taf. 54 Abb. 213)

Aufgrund der Körpergröße wird auch dieses Fragment »E« zugeordnet. Es handelt sich um das Fragment (L 19,5; H 17) einer linken Brustseite - die Brustwarze ist leicht erhaben angegeben und des linken Oberarms eines Mannes mit plastisch, sorgfältig gearbeitetem Gewandbausch auf seiner linken Schulter. Vergleiche dafür bieten die Hippolytos-Sarkophage in Agrigent ${ }^{446}$ und in Tarragona ${ }^{447}$.

29 weitere Fragmente werden aufgrund der Größe und der Proportionen, der rötlichen Verfärbung des Marmors und der Versinterungen, der Oberflächenglättung sowie des Faltenstils dem Hippolytos-Sarkophag »E« zugeordnet:

- Fragment 21 (Taf. 54 Abb. 214)

Gewandbausch einer Chlamys auf einer linken Schulter; die Chlamys wird von einer Scheibenfibel gehalten (L 9; H 13). Das Fragment passt stilistisch und in allen anderen Kriterien hervorragend zu Fragment 20 und seinen Parallelen.

- Fragment 22 (Taf. 54 Abb. 215)

Erhalten sind die rechte Schulter mit Gewandfalten und ein Stück der rechten Körperflanke einer Figur. Dem Ansatz nach war der rechte Arm leicht vom Körper abgewinkelt. Zu der Vorderseite hin nur Bruchflächen (L 10; H 15), eine lanzenförmige Bruchfläche ist auf der Schulter zu erkennen. Am linken unteren Fragmentrand ist ein Rest des Reliefgrunds erhalten.

- Fragmente 23 und 24 (Taf. 55 Abb. 216. 217)

Bei zwei weiteren Fragmenten könnte es sich, wie bei den Fragmenten 12 und 13 und ihren Parallelen, ebenfalls um ein Stück einer Keule, einer Lanze oder eines Stabs handeln.

Das kürzere und dickere Fragment 23 (H 10) war teilweise rundplastisch ausgeführt und zeigt Raspelspuren auf der Rückseite.

An dem Fragment 24 scheint eine Falte anzusetzen. Es ist schmaler (H 14) als die zwei Keulenfragmente 12 und 13, sodass es sich auch um einen Teil einer Lanze oder eines Stabs handeln könnte. Zu Lanzen oder Stäben, deren Schaft nicht vollkommen gerade ist, sondern wie hier Unregelmäßigkeiten abbildet, die ihre Beschaffenheit aus Holz erkennen lassen, siehe etwa die Hippolytos-Sarkophage in Apollonia (Libyen) ${ }^{448}$, Agrigent ${ }^{449}$ und St. Petersburg ${ }^{450}$ auf der Vorderseite sowie in Beirut ${ }^{451}$ auf einer Schmalseite.

- Fragment 25 (Taf. 55 Abb. 218)

Es wird sich um eine rechte Schulter mit Gewandrest und mit Resten des Reliefgrundes am oberen Fragmentrand handeln (L 6; H 5). Vergleiche für die männlichen Figuren finden sich auf den Hippolytos-Sarkophagen in Rom, Villa Medici ${ }^{452}$, oder in Tarragona ${ }^{453}$; Vergleiche für die weiblichen Figuren bieten die Hippolytos-Fragmente in Paris ${ }^{454}$ und Split ${ }^{455}$. Möglich ist darüber hinaus,

446 Rogge 1995, 148 Nr. 47 Taf. 89, 1; 92, 2.

447 Rogge 1995, 156 Nr. 68 Taf. 89, 3.

448 Rogge 1995, 149 Nr. 49 Taf. 97, 1.

449 Rogge 1995, 148 Nr. 47 Taf. 89, 1; 92.

450 Rogge 1995, 154 f. Nr. 64 Taf. 89, 2; 90.

451 Rogge 1995, 152 Nr. 57 Taf. 106, 1.

452 Rogge 1995, 154 Nr. 63 Taf. 98, 1; 99, 1-2.

453 Rogge 1995, 156 Nr. 68 Taf. 89, 3.

454 Rogge 1995, 154 Nr. 62 Taf. 112, 1.

455 Rogge 1995, 155 f. Nr. 66 Taf. 100, 4; vgl. auch unten Fragment 41 (Taf. 58 Abb. 234). 
dass die linke Schulter eines Stehenden in einer Dreiviertelansicht von hinten abgebildet ist, wie auf dem Hippolytos-Sarkophag in St. Petersburg ${ }^{456}$.

- Fragment 26 (Taf. 55 Abb. 219)

Falten einer Chlamys auf einer Brust und daneben der Ansatz der zugehörigen linken Schulterpartie (L 8,5; H 10). Auch hier ist zu erkennen, dass die Oberfläche poliert ist.

- Fragment 27 (Taf. 55 Abb. 220)

Falten einer Chlamys auf einer Brust aufliegend (L 9,5; H 11).

- Fragment 28 (Taf. 55 Abb. 221)

Vielleicht Oberkörper mit zwei wulstigen Falten (L 13; H 8).

- Fragment 29 (Taf. 55 Abb. 222)

Oberkörper wohl mit dem Faltenrand einer Chlamys (L 7,5; H 13).

- Fragment 30 (Taf. 55 Abb. 223)

Das Fragment (L 14,4; H 8,5) trägt eine Bleistiftaufschrift »L. Brustmuskel (?)«. Dieser Vermutung muss nicht widersprochen werden.

- Fragment 31 (Taf. 56 Abb. 224)

Das Fragment zeigt den linken eingewinkelten Arm einer Figur, die über dem Ellenbogen eine in sorgfältig gearbeiteten, üppigen Falten herabfallende Gewandbahn trägt (L 15; H 20), wofür sich z. B. die Hippolytos-Sarkophage in Agrigen ${ }^{457}$ und in Tarragona ${ }^{458}$ vergleichen lassen. Die Oberfläche ist poliert. Das Fragment der herabfallenden Falten auf der - vom Betrachter gesehen - linken Seite konnte angepasst werden.

- Fragment 32 (Taf. 56 Abb. 225)

Aus zwei anpassenden Stücken bestehendes Fragment (L 11; H 17) aufwendig gearbeiteter Falten mit polierter Oberfläche, die vermutlich über den angewinkelten linken Ellenbogen einer Figur gelegt waren - wie bei Fragment 31 und seinen Parallelen.

- Fragment 33 (Taf. 56 Abb. 226)

Auf den ersten Blick lässt das Fragment (L 13; H 8,5) an eine Hand mit Zügeln denken, aber es handelt sich eher um eine Hand mit Gewand, wie entsprechende Parallelen auf den Hippolytos-Sarkophagen in Woburn Abbey ${ }^{459}$ und in St. Petersburg ${ }^{460}$ bestätigen.

- Fragment 34 (Taf. 56 Abb. 227)

Das kleine, schöne Fragment mit polierter Oberfläche zeigt Falten und Saum eines Gewands (L 7; H 8).

Die Fragmente 35-37 stellen verschiedene Partien mit Unterkörper und Pubis unbekleideter Männerfiguren dar, die aufgrund ihrer Proportionen am ehesten »E« zuzuordnen sind. Sie passen nach Oberflächenbehandlung und Formenbildung dermaßen gut zu Fragment 6 (Taf. 52 Abb. 201), dass bereits F. Eichler sie als zum Hippolytos-Sarkophag »E« gehörig vermerkt. Die für die Vorderseiten von Hippolytos-Sarkophagen zumeist zahlreich zu fordernden Jünglingsfiguren - vergleiche etwa die Sarkophage in Agrigent, St. Petersburg, Tarragona und Tyros ${ }^{461}$ - wären damit wenigstens in kleinen Teilen erhalten:

\footnotetext{
456 Rogge 1995, 154 f. Nr. 64 Taf. 90.

457 Rogge 1995, 148 Nr. 47 Taf. 89, 1.

458 Rogge 1995, 156 Nr. 68 Taf. 89, 3.

459 Rogge 1995, 158 Nr. 73 Taf. 87, 2.

460 Rogge 1995, 154 f. Nr. 64 Taf. 90, 1.

461 Rogge 1995, Nr. 47. 64. 68. 70 Taf. 88, 3; 89, 1-3.
} 
- Fragment 35 (Taf. 57 Abb. 228)

Das Fragment von Bauch mit kleiner Oberkörperpartie, bestoßener Pubis und Ansatz des rechten Beins ist nur in $3 \mathrm{~cm}$ Dicke erhalten (L 8,5; $\mathrm{H} 23$ ).

- Fragment 36 (Taf. 57 Abb. 229)

Fragment der Leistenpartie der rechten Körperflanke mit Beinansatz und Teilen der bestoßenen Pubis (L 11; H 17).

- Fragment 37 (Taf. 57 Abb. 230)

Das kleinste Fragment (L 13 [davon 7 reliefiert]; H 13) mit Bauch, rechtem Beinansatz und bestoßener Pubis ist teilweise stark rötlich braun versintert.

Zwei weitere Fragmente (38. 39) lassen sich hier durch ihren Marmor, die Proportionen, die polierte Oberfläche und ihre Modellierung anschließen. Es handelt sich um Körperpartien, deren Orientierung und Identifizierung aber nicht gesichert sind:

- Fragment 38 (Taf. 57 Abb. 231)

Es könnte sich um die Flanke eines Oberkörpers oder um einen Oberschenkel handeln (L 8; H 20).

- Fragment 39 (Taf. 57 Abb. 232)

Möglicherweise handelt es sich hier um eine Brust-, Schulter- oder Oberarmpartie.

Die nachfolgenden Fragmente 40-44 mit Gewändern präsentieren sehr wahrscheinlich Reste weiblicher Figuren:

- Fragment 40 (Taf. 58 Abb. 233)

Das Fragment zeigt den vom Gewand bedeckten Kniebereich einer Figur (L 11,5; H 15,5). Die Oberfläche ist zwar stark versintert, aber in kleinen Abschnitten noch als poliert zu erkennen. Da der Kniebereich von Kleidung bedeckt ist, wird es sich ohne Zweifel um eine weibliche Figur handeln, für die sich z. B. das Hippolytos-Fragment in Paris' ${ }^{462}$ oder die beschädigte Figur der Amme auf der Vorderseite in Apollonia (Libyen) anbieten ${ }^{463}$.

- Fragment 41 (Taf. 58 Abb. 234)

Aus zwei Stücken zusammengesetztes Fragment. Zu erkennen sind die rechte Schulter und der Oberarmansatz einer Figur, die ein Gewand trägt, dessen flache Falten auf der Schulter geknöpft sind (L 10; H 11). Nach dem Faltenverlauf und der Wölbung zur Brust hin zu urteilen, handelt es sich um eine weibliche Figur in Seitenansicht, was auch die Hippolytos-Fragmente in Paris ${ }^{464}$ und Split ${ }^{465}$ bestätigen.

- Fragment 42 (Taf. 58 Abb. 236)

Aus drei Teilen bestehendes Fragment eines bekleideten Körpers (L 16; H 19). Die Oberfläche ist z. T. verrieben und stärker versintert; ein dunkler Fleck unbekannter Herkunft verunreinigt die Mitte. Über dem Chiton mit flachen Falten verläuft eine geschwungene Gewandbahn vor dem Unterkörper. Dass es sich auch hier um eine weibliche Figur handelt - dem Gewandmotiv zufolge wahrscheinlich um die stehende Amme -, belegen die Parallelen auf den Sarkophagen in Beirut ${ }^{466}$ und St. Petersburg ${ }^{467}$.

462 Rogge 1995, 153 Nr. 61 Taf. 100, 2.

463 Rogge 1995, 149 Nr. 49 Taf. 97, 1-2.

464 Rogge 1995, 154 Nr. 62 Taf. 112, 1.

465 Rogge 1995, 155 f. Nr. 66 Taf. 100, 4.

466 Rogge 1995, 152 Nr. 57 Taf. 86, 2.

467 Rogge 1995, 154 f. Nr. 64 Taf. 90, 1; 100, 1. 
- Fragment 43 (Taf. 58 Abb. 235)

Fragment von Gewandfalten (L 10; H 10,5). Die polierte Oberfläche ist größtenteils von Versinterungen bedeckt. Die Orientierung der flacheren, geschwungenen Falten ist nicht gesichert. Es kann sich vielleicht auch um das Gewand der Amme handeln, das über ihrem Chiton weit über den Rücken abwärts hängt, wie z. B. bei dem Fragment in Triest ${ }^{468}$ und auf den Sarkophagen in Beirut und St. Petersburg. Es könnte sich aber auch um das Gewandstück einer Sitzenden handeln, wie auf den Schmalseiten der Hippolytos-Sarkophage in Agrigent ${ }^{469}$, St. Petersburg ${ }^{470}$ und Tyros ${ }^{471}$. Sofern die Zuordnungen von Fragment 42 und auch diesem Fragment zu der Figur einer Amme richtig sind, muss das zweimalige Erscheinen der Amme nicht verwundern, da bei den drei genannten Parallelen die Amme ebenfalls jeweils auf der Vorder- und einer Schmalseite abgebildet ist.

- Fragment 44 (Taf. 59 Abb. 237)

Allein aufgrund der Größe muss für diese Figur eine Zuordnung zu den Sarkophagen »B« oder »« des Tatiane-Grabes ausscheiden. Aufgrund des Marmors, der Oberflächenglättung sowie des Stils kann das Fragment jedoch zu dem Hippolytos-Sarkophag »E« passen, allerdings wäre die Darstellung ohne direkte Parallele.

Die weibliche Gewandfigur ist aus sieben Stücken zusammengesetzt (L 14; H 44,5). Die Figur ist rundplastisch in Dreiviertelansicht gearbeitet, und auch die Bruchflächen auf der Innenseite deuten darauf, dass es sich um eine Eckfigur handelte. Das unterste Teilstück scheint unorganisch angestückt, passt aber an und steht damit einer Rekonstruktion als Eckfigur mit langem Gewand entgegen, wie sie bei den Hippolytos-Sarkophagen in Beirut ${ }^{472}$ oder in St. Petersburg ${ }^{473}$ belegt sind, während eine Eckfigur im kurzen Gewand ohne Vergleiche bleibt.

Weitere Fragmente lassen sich durch den Marmor, die Proportionen, die polierte Oberfläche und ihre Modellierung anschließen:

- Fragment 45 (Taf. 60 Abb. 238)

Sockelfragment (L 6,5; H 19). Über einem Sockel ohne Dekor (ein Stück der Unterseite ist erhalten) sind eine gebohrte Umrisslinie in rundlicher Form und daneben ein mit dem Flachmeißel bearbeitetes Reliefstück zu sehen. Hier handelt es sich vielleicht um Wellen, Gewand oder Gelände über dem Sockel einer vernachlässigt gearbeiteten Sarkophagseite. Vergleiche bieten etwa die Schmalseiten der Hippolytos-Sarkophage in Agrigent ${ }^{474}$ und Tyros ${ }^{475}$.

- Fragment 46 (Taf. 60 Abb. 239)

Die Orientierung des Fragments ist nicht gesichert (nach Abbildung: L 24; H 5); die polierte Oberfläche ist größtenteils von Versinterungen bedeckt. Neben beschädigten Gewandfalten mit einem kleinen Mantelgewicht sind Strähnen einer Pferdemähne zu erkennen. Die Nähe von Gewandbausch und Pferdemähne lässt sich häufig auf Hippolytos-Sarkophagen nachweisen, so bei den Exemplaren in Beirut ${ }^{476}$, St. Petersburg ${ }^{477}$ oder Arles ${ }^{478}$; eine direkte Parallele fehlt.

\footnotetext{
468 Rogge 1995, 157 Nr. 69 Taf. 98, 2.

469 Rogge 1995, 148 Nr. 47 Taf. 100, 3.

470 Rogge 1995, 154 f. Nr. 64 Taf. 100, 1.

471 Rogge 1995, 157 f. Nr. 70 Taf. 101, 1.

472 Rogge 1995, 152 Nr. 57 Taf. 86, 2.

473 Rogge 1995, 154 f. Nr. 64 Taf. 100, 1.

474 Rogge 1995, 148 Nr. 47 Taf. 104, 1.

475 Rogge 1995, 157 f. Nr. 70 Taf. 105, 1.

476 Rogge 1995, 152 Nr. 57 Taf. 85, 1; 106, 1.

477 Rogge 1995, 154 f. Nr. 64 Taf. 90, 2.

478 Rogge 1995, 150 Nr. 50 Taf. 96, 2; 103, 2.
} 
- Fragment 47 (Taf. 60 Abb. 240)

Gewandfragment (L 15,5; H 3): Die fein eingetiefte Linie, welche die Säumung des Stoffs angibt, lässt an das Fragment 17 (Taf. 37 Abb. 168) denken, bei dem ebenfalls vermutet werden konnte, dass ein Gewandsaum mit eingetiefter Linie abgebildet ist.

- Fragment 48 (Taf. 60 Abb. 241)

Dieses kleine Fragment zeigt vielleicht auch Gewandfalten (L 7; H 6). Die oben liegende, senkrecht verlaufende Bruchfläche ist von fein eingetieften Linien gerahmt.

- Fragment 49 (Taf. 60 Abb. 242)

Reste eines Fußes auf einer geglätteten Standleiste (L 10; H 9). Die Unterseite der Standleiste ist nach hinten abgearbeitet und auf der rechten Seite ist ein kleiner Vorsprung nach unten erhalten, sodass hier eine Ecke zu rekonstruieren ist, bei der auf die Ornamente der Sockelzone unter der Standleiste seitlich ein Eckpostament folgt. Zu vergleichen wären die rechten Ecken der Sockelzonen mit Eckpostament auf der rechten Schmalseite des Schlachtsarkophags des Aemilius Aristides (Kat. 1 Taf. 3) und auf der Vorderseite des Amazonomachie-Sarkophags vom Hafenkanal (Kat. 6 Taf. 41 Abb. 169). Bei beiden scheint der Rücksprung unter der Standleiste größer zu sein als hier.

Ein Vergleich mit dem Fragment 11 (Taf. 51 Abb. 200) könnte Zweifel an der Zugehörigkeit aufkommen lassen. Das Fragment mit dem auf der Standleiste liegenden Hund und einem Stück des Sockeldekors zeigt, dass dort kein Rücksprung unter der Standleiste gearbeitet ist. Allerdings besteht die Möglichkeit, dass das Sockeldekor verschiedener Sarkophagseiten unterschiedlich gearbeitet wurde, wofür der Amazonomachie-Sarkophag Kat. 6, an dem die Standleisten der Vorderseite und der rechten Schmalseite über den Sockelornamenten vorspringen, während dies auf der linken Schmal- und der Rückseite nicht der Fall ist, einen Beleg darstellt.

Letztendlich ist die Zuordnung nicht gesichert. Da das Fragment aus den Kisten stammt, in denen die Fragmente des Hippolytos-Sarkophags vermischt mit jenen des Aristides-Sarkophags lagerten, ist auch eine Zugehörigkeit zu Letztgenanntem möglich.

Bei den nun folgenden Fragmenten 50-57 ist eine Zuordnung zum Hippolytos-Sarkophag »E« zwar möglich, doch sind sie zu klein und ihre Darstellung zu unspezifisch oder nicht näher zu interpretieren, sodass die Zuschreibung schlussendlich hypothetisch bleiben muss:

- Fragment 50 (Taf. 61 Abb. 243)

Nach der Rundung und sorgfältigen Oberflächenbehandlung zu urteilen, handelt es sich hier um ein Fragment von Gliedmaßen.

- Fragment 51 (Taf. 61 Abb. 244)

Vermutlich sind bei diesem Fragment mit weitgehend zerstörter Oberfläche ein Oberarmansatz und Gewandfalten auf der Schulter dargestellt (L 12; H 13).

- Fragment 52 (Taf. 61 Abb. 245)

Auch hier ist eine Deutung auf Gewandfalten am wahrscheinlichsten (L 9; H 13).

- Fragment 53 (Taf. 61 Abb. 246)

Es könnte sich um ein Pferdemaul handeln, aber die Proportionen (L 10; H 11) erscheinen größer als bei dem unter Nr. 9 (Taf. 36 Abb. 162) genannten Pferdekopf.

- Fragment 54 (Taf. 61 Abb. 247)

Das Pferdeknie ist fein geglättet (L 8); es scheint nicht poliert zu sein und könnte somit einer nicht bevorzugt gearbeiteten Sarkophagseite angehört haben.

- Fragment 55 (Taf. 61 Abb. 248)

Der Querschnitt und die Ansicht der >Rückseite` des Fragments zeigen, dass es sich kaum um eine Pferdemähne handeln kann; eine Deutung als Tierschwanz wäre möglich. 
- Fragment 56 (Taf. 61 Abb. 249. 250)

Die Orientierung, die für die Abbildung 249 gewählt wurde, ist nicht gesichert. Die gut modellierten Falten zeigen eine polierte Oberfläche, die auf der linken Seite stark versintert ist. Eine Falte, die zur Mitte hin ausläuft, ist dort bestoßen. Unten biegt eine Falte nach links um, während die zwei folgenden von einem Absatz abgeschlossen werden. Bei der Orientierung von Abbildung 250 wirkt eine Interpretation als Kniebereich einer sitzenden Figur wahrscheinlich.

- Fragment 57 (Taf. 62 Abb. 251)

Eine ähnliche Qualität der Oberflächen- und Faltenbehandlung wie Fragment 56 bietet dieses, welches in der hier gezeigten Orientierung eine Bruchfläche im oberen rechten Teil zeigt (L 6,5; H 6,5). Eine lange Falte verläuft über eine Wölbung, während die übrigen Falten unterhalb der Wölbung ansetzen.

Die Oberfläche der folgenden Fragmente erscheint poliert, aber es fehlen die rötlich braune Färbung und Versinterungen, welche für die sicher dem Hippolytos-Sarkophag »E« zugeordneten Fragmente charakteristisch sind:

- Fragment 58 (Taf. 62 Abb. 252)

Gut zu erkennen ist hier die Knüpfung eines Gewands, wie sie bei halb- bis langärmeligen Frauengewändern über der Schulter und dem Arm (L 8; H 12) typisch ist. Als Vergleich bietet sich das Gewand Aphrodites auf dem Vorderseitenfragment eines Hippolytos-Sarkophags in Antalya $^{479}$ an. Auf dem ephesischen Fragment erscheint über dem dünneren Ärmelchiton eine zweite, etwas dicker gebildete Gewandbahn - vermutlich ein Himation.

- Fragment 59 (Taf. 62 Abb. 253)

In sehr ähnlicher Qualität wie Fragment 58 mit Armelknüpfung präsentiert sich dieses mit scharfgratigeren Falten mit deutlichem Abstand, die darauf schließen lassen, dass eine dünne Stoffqualität dargestellt werden sollte (L 6; H 8,5). Die rechte Falte ist stärker bestoßen.

- Fragment 60 (Taf. 62 Abb. 254)

Gerade Falten (L 6; H 11,5) mit unterem Ende, an dem die Falten - vielleicht auf dem Boden aufstoßen.

- Fragment 61 (Taf. 63 Abb. 263)

Fragment von vier nebeneinanderliegenden Falten (L 8; H 10). Die Orientierung der rundlich gebildeten Falten ist nicht gesichert.

Bei den Fragmenten 62-68 hingegen ist die Reliefoberfläche nicht poliert, aber die rötlich braune Färbung und Versinterung sind vorhanden:

- Fragment 62 (Taf. 62 Abb. 255. 256)

Weit herausgearbeiteter Torso einer Figur mit geglätteter Reliefoberfläche (L 13,5; H 10). Die üppige und bewegte Gewandung suggeriert eine Wendung der Figur nach rechts. Eine Gürtung oder Gewandbahn, die für die Körpermitte anzunehmen ist, schließt die Falten horizontal ab. Auf der linken Seite des Fragments setzte der Reliefgrund an, der den Spuren zufolge durch grobe Meißelhiebe abgeschlagen wurde.

- Fragment 63 (Taf. 62 Abb. 257)

Das Fragment mit geglätteter Oberfläche zeigt hängende Gewandfalten, die von einer zweiten Gewandschicht schräg überlappt werden.

$\overline{479}$ Rogge 1995, 148 f. Nr. 48 Taf. 77, 1. 
- Fragment 64 (Taf. 62 Abb. 258)

Die rechte Seite des Faltenfragments biegt weit nach hinten um, sodass hier der Gewandrand zu vermuten ist. In vergleichbarer Ausführung, aber anderer Form erscheinen die Falten des folgenden Fragments.

- Fragment 65 (Taf. 62 Abb. 259)

Das Faltenfragment (L 3,5; H 7) bietet neben einer geraden seitlichen Falte links zwei ineinander geschachtelte Bogenfalten. Die Qualität des Steins und die Ausführung sind mit Fragment 64 zu vergleichen.

- Fragment 66 (Taf. 63 Abb. 260)

Das Fragment stellt vermutlich den eingewinkelten Arm einer Figur, die eine faltenreiche Gewandbahn über den Arm gelegt hat, dar (L 10; H 8). Der Armstumpf ist auch im Umfang beschädigt (?). Das Motiv entspricht den Fragmenten 31 und 32 (Taf. 56 Abb. 224. 225) und entsprechenden Vergleichen auf Hippolytos-Sarkophagen.

- Fragment 67 (Taf. 63 Abb. 261)

Bei dem in größeren Teilen zerstörten kleinen Fragment (L 9; H 10) könnte es sich um Gewandfalten, die auf einen Absatz stoßen, handeln.

- Fragment 68 (Taf. 63 Abb. 262)

Das aus zwei Stücken bestehende Fragment zeigt zwei relativ glatte Flächen, wobei die obere wohl einen rundlichen Umriss hatte. Die Überlegung, dass es sich um einen Schild handelt, muss wegen des fehlenden Schildrands und einer nicht passenden Wölbung abgelehnt werden. Für die Zuordnung zu einem Körperteil sind die Flächen zu eben, aber für die Identifizierung als Diskus mit dahinter erscheinendem Hermenschaft, wie es auf der Schmalseite des HippolytosSarkophags in Apollonia (Libyen) ${ }^{480}$ belegt ist, scheint die Fläche nicht glatt genug zu sein.

Bei den Fragmenten 69-74 kann eine Zuordnung zu dem Hippolytos-Sarkophag »E« - insbesondere zu den vernachlässigten Sarkophagseiten - nicht ausgeschlossen werden, aber es gibt Indizien, die eine Zuordnung eher zweifelhaft machen: Die Marmorqualität scheint durchaus vergleichbar zu sein, jedoch sind die Fragmente heller. Es fehlen die typischen rötlichen Verfärbungen und Versinterungen und die Oberflächen der Fragmente sind fein geglättet, aber nicht poliert:

- Fragment 69 (Taf. 63 Abb. 264)

Über einen bedeckten Oberkörper fällt ein Gewandbausch abwärts, der wohl auf einer rechten Schulter aufliegt (L 10,5; H 11).

- Fragment 70 (Taf. 63 Abb. 265)

Die leicht fächerig fallenden Gewandfalten haben eine fein geglättete Oberfläche. Der Saum des Gewands ist abgesetzt vom Reliefgrund zu erkennen.

- Fragment 71 (Taf. 64 Abb. 266)

Die sich leicht nach unten verbreiternde Kontur der seitlichen Stege deutet darauf hin, dass es sich um breite und gerade verlaufende Gewandfalten handelt (L 9,5; H 8) und nicht um eine Schwertscheide oder Ähnliches; als Vergleich siehe Fragment 72.

- Fragment 72 (Taf. 64 Abb. 267)

Die Oberfläche des Fragments zeigt einige Kratzer; vermutlich Bearbeitungsspuren eines feinen Zahneisens, die nicht völlig geglättet wurden. Von den - wie bei Fragment 71 - mit deutlichem Abstand verlaufenden Gewandfalten ist die Falte rechts untergeschlagen gebildet.

- Fragment 73 (Taf. 64 Abb. 268)

Schulterpartie mit dick aufliegenden Gewandfalten.

$\overline{480}$ Rogge 1995, 149 Nr. 49 Taf. 108, 2. 
- Fragment 74 (Taf. 64 Abb. 269)

Schulterpartie mit Gewand (L 13; H 5). Im Unterschied zu Fragment 73, aber der flachen Wö1bung der Körperpartien und der Faltengebung entsprechend, ist hier vermutlich eine Hintergrundfigur abgebildet, die ein auf der Schulter zusammengehaltenes Gewand trägt.

Da das folgende Fragment in einer der Kisten aufgefunden wurde, in welcher die Fragmente der Sarkophage des Grabhauses der Claudia Antonia Tatiane vermischt mit jenen des attischen Hippolytos-Sarkophags aus einem Grabhaus nördlich des Hafenkanals gelagert waren, ist die Frage nach der Zugehörigkeit zu stellen:

- Fragment 75 (Taf. 64 Abb. 270. 271)

Es handelt sich um ein Fragment mit dem Kopf eines Kleinkindes (L 9; H 23). Die Reliefoberfläche ist weitgehend verrieben oder zerstört. Die Rückseite hat eine mittlere bis grobe Bearbeitung mit dem Zahneisen erhalten. Vor Gewandfalten im Hintergrund erscheint der rundplastisch gearbeitete Kopf eines Babys, dessen vordere obere Hälfte zerstört ist. Das Kind hat den Kopf weit in den Nacken gelegt und - den Resten der Arme nach zu urteilen - die Arme vorgestreckt. Unter den Armen verlaufen weitere Gewandfalten abwärts bis zu einem kleinen Vorsprung. Der Brustbereich des Kindes ist noch zu erahnen.

Als allem Anschein nach attisches Fragment ist die Zugehörigkeit zu dem kleinasiatischen Säulensarkophag auszuschließen. Eine Zuordnung zu dem attischen Schlachtsarkophag des Aemilius Aristides und dem attischen Amazonomachie-Sarkophag ist im Hinblick auf das Motiv abzulehnen. Auf den attischen Hippolytos-Sarkophagen finden sich zwar Darstellungen von Eroten, ja sogar mit vorgestreckten Armen und vor Gewandfalten, so auf den Vorderseiten der Hippolytos-Sarkophage in Beirut ${ }^{481}$, Istanbul ${ }^{482}$ und Antalya ${ }^{483}$. Es handelt sich in allen drei Fällen um das Gewand Aphrodites, vor dem ein Eros auf einem Podest kniet und mit Pfeil und Bogen auf Phaidra zielt. Allerdings ist der Eros der frühen Sarkophage in Beirut, Istanbul und Antalya ${ }^{484}$ jeweils nach rechts gewendet und blickt in die Zielrichtung und nicht nach oben. Ein Eros mit Blick nach oben ist dann zwar auf späteren Hippolytos-Sarkophagen abgebildet, etwa in Beirut ${ }^{485}$ oder in Agrigent ${ }^{486}$, aber dort fehlt das Gewand im Hintergrund und in Beirut ist zudem ein Arm mit einer Fackel erhoben. Demnach ist eine Zugehörigkeit des ephesischen Fragments zu dem Hippolytos-Sarkophag vom Hafenkanal eher unwahrscheinlich oder zumindest ohne eindeutige Parallele.

\section{Deutung der Darstellung}

Durch die drei aufwendig gearbeiteten und polierten Köpfe (Nr. 2-4), die sehr wahrscheinlich der Vorderseite angehörten, ist die Deutung als Hippolytos-Sarkophag so gut wie gesichert. Die Kombination des charakteristischen Kopfes der Amme, eines Jagdgefährten mit Hut und eines Hundes lässt eine Vorderseitenszene rekonstruieren, wie sie z. B. auf den Hippolytos-Sarkophagen in Agrigent, St. Petersburg, Tarragona und Tyros, die alle in das zweite Viertel des 3. Jahrhunderts $n$. Chr. gehören, zu finden ist ${ }^{487}$ : Die Amme steht nach rechts gewendet neben Hippolytos, der sich in Gesellschaft seiner Jagdgefährten mit den Jagdhunden befindet.

Durch die >Nuda<-Fragmente (6. 35-37) und die verschiedenen Schulter- und Armpartien mit Gewandbausch oder Gewandfalten (8. 20-22. 26. 31. 32) sowie durch die Chlamysfragmente (27-29. 31-34) haben sich etliche Teile der für die Vorderseiten von Hippolytos-Sarkophagen

\footnotetext{
481 Rogge 1995, 151 Nr. 56 Taf. 78, 1.

482 Rogge 1995, 153 Nr. 59 Taf. 79, 1.

483 Rogge 1995, 148 f. Nr. 48 Taf. 77, 1.

484 Alle Sarkophage gehören noch dem 2. Jh. n. Chr. an.

485 Rogge 1995, 152 Nr. 57 Taf. 84, 3.

486 Rogge 1995, 148 Nr. 47 Taf. 100, 3.

487 s. Rogge 1995, Nr. 47. 64. 68. 70 Taf. 88, 4; 89, 1-3.
} 
zumeist zahlreich zu fordernden Jünglingsfiguren erhalten, wie sie auch auf den Sarkophagen in Agrigent, St. Petersburg, Tarragona und Tyros zu finden sind ${ }^{488}$.

Bei den vier Fragmenten 12, 13, 23 und 24 handelt es sich jeweils um Teile einer Keule, einer Lanze oder eines Stabs. Keulen, Lanzen oder Stäbe sind beliebte Ausrüstungsgegenstände auf Hippolytos-Sarkophagen, so auf der Vorderseite in Agrigent ${ }^{489}$ oder der Schmalseite in Apollonia ${ }^{490}$, und komplettieren das Bild.

Durch die Fragmente 40-44, die höchstwahrscheinlich Reste mehrerer weiblicher Figuren präsentieren, sind zudem Hinweise vorhanden, eine Schmalseitenszene zu rekonstruieren, die Phaidra im Frauengemach zeigt. Auch hier sind als Parallelen die Sarkophage in St. Petersburg ${ }^{491}$, Agrigent ${ }^{492}$ oder Tyros zu zitieren ${ }^{493}$.

Für den Hippolytos-Sarkophag muss ein Klinendeckel ergänzt werden, wie beispielsweise bei dem Deckel des Hippolytos-Sarkophags in Tyros ${ }^{494}$. In den Fundkisten ${ }^{495}$ wurden fünf Fragmente von Klinendeckeln aufgefunden (Taf. 25), die alle mit der Aufschrift »TG« (Tatiane-Grab) versehen waren und demnach nicht zum Hippolytos-Sarkophag gehören. Aber nicht alle Fragmente können Teile des Aristides-Sarkophags gewesen sein und aufgrund des Dekors lassen sie sich nicht dem Amazonomachie-Sarkophag (Kat. 2 Taf. 31 f.) zuweisen. Hypothetisch wäre es möglich, sie dem Hippolytos-Sarkophag zuzuschreiben.

\section{Datierung}

Die Vergleiche, aber auch Ausführung und Stil weisen in das zweite Viertel des 3. Jahrhunderts n. Chr. Stilistisch bieten sich besonders für die Fragmente mit Falten (8. 20-22. 26. 27. 31. 32. 34) hervorragende Parallelen auf dem Achill-Sarkophag in Paris ${ }^{496}$ sowie auf den Hippolytos-Sarkophagen in Agrigent ${ }^{497}$ und St. Petersburg ${ }^{498}$.

Wichtig für die Datierung des Sarkophags sind insbesondere die Fragmente 5, 10 und 11 des oberen und unteren Kastenabschlusses (Taf. 51 Abb. 198-200). 10 und 11 zeigen ein Sockeldekor mit Akanthusblättern, wofür die Hippolytos-Sarkophage in Agrigent ${ }^{499}$, Tyros ${ }^{500}$ und in Apollonia ${ }^{501}$, die an das Ende des zweiten Viertels und in die Mitte des 3. Jahrhunderts n. Chr. gehören, Belege bieten.

Mit Fragment 5 hat sich ein Stück des oberen Kastenabschlusses mit Gorgoneion und der oberen Leiste mit Blattwerk erhalten. Da es sich hier um eine selten belegte Dekorform handelt, ist eine Datierung gut einzugrenzen. So bietet neben dem Amazonomachie-Sarkophag aus dem Grabhaus der Tatiane (Kat. 2 Taf. 27 Abb. 116-118) der Achill-Sarkophag in Rom, Museo Capitolino ${ }^{502}$, eine Entsprechung des Gorgonenkymas ${ }^{503}$. Wie dort kann für den Hippolytos-Sarkophag in Ephesos angenommen werden, dass sich vertikale Gliederungselemente zwischen den Gorgonenhäuptern befanden. Der Achill-Sarkophag wird durch die Porträtköpfe seines Klinendeckels um 250 n. Chr. datiert. Der Amazonomachie-Sarkophag (Kat. 2) wurde in Analogie mit dem

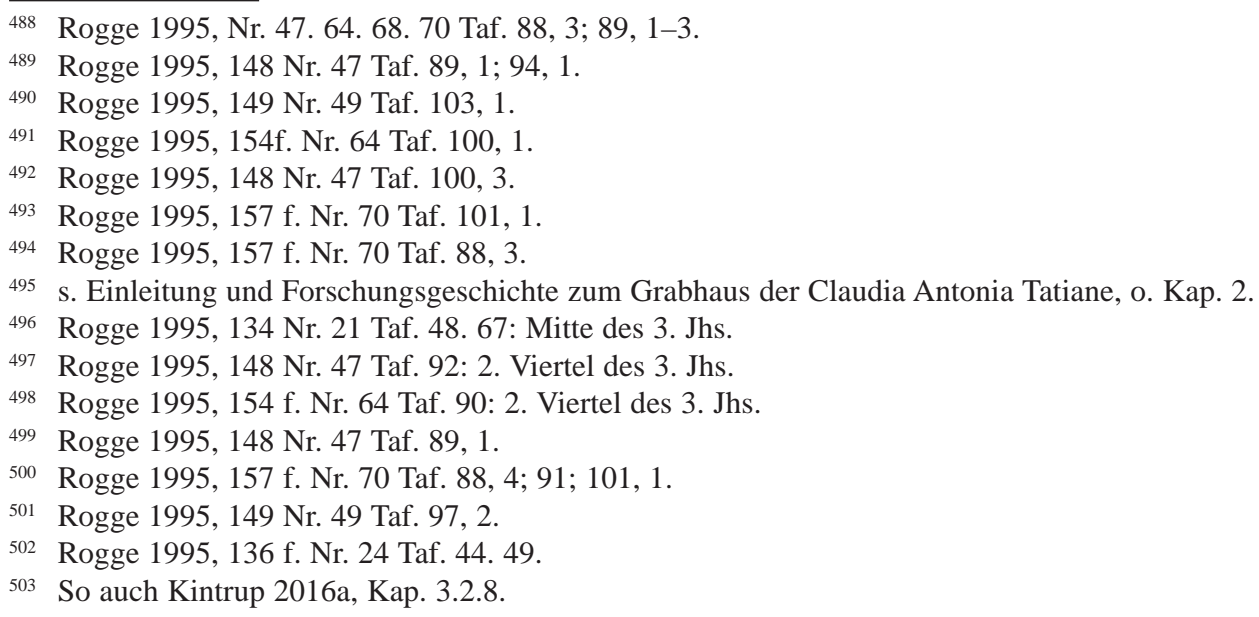


Achill-Sarkophag etwas eher, um 240 n. Chr., angesetzt. Weitere Vergleiche mit Gorgonenkyma ${ }^{504}$ liegen ebenfalls in zeitlicher Nähe um 240 n. Chr., sodass auch der Hippolytos-Sarkophag so eingeordnet werden kann.

240-250 n. Chr.

3.5.2 Eckfragment eines Hippolytos-Sarkophags (Kat. 16 Taf. 65 Abb. 272 f.)

Selçuk, Efes Müzesi Inv. 2268.

Gefunden in Selçuk, Johannesbasilika

VS: H 63; L 16; Rh 13. - Rechte Ss: H 52; L 22; Rh 8.

Lit.: Rudolf 1989, 55 Taf. 30 Abb. 48 f.; Koch 1991, 819.

Feinkristalliner, weißer Marmor. Die geglättete Oberseite des oberen Kastenabschlusses ist erhalten; die obere Leiste jedoch nicht. Die Figuren sind auf beiden Seiten des Fragments weit hinterarbeitet, sodass es sich um die Ecke der bevorzugt gearbeiteten Seiten des Sarkophags handeln muss. Die Seite, auf welche die Eckfigur frontal ausgerichtet ist, wird demnach die Vorderseite sein. Die Eckfigur ist auf der rechten und linken Seite mit groben Spitzmeißelhieben für eine Verbauung zugeschlagen; von einer solchen zeugen auch die Mörtelspuren auf beiden Seiten des Fragments. Die Oberfläche ist größtenteils verrieben; es kommen Bestoßungen im Gesicht und auf dem Oberkörper der Vorderseitenfigur hinzu. Bohrungen in den Augen- und Mundwinkeln sind vorhanden. Tiefe Bohrungen sind für die Haargestaltung der Figur der Vorderseite und für einen Eierstab neben deren Kopf sowie auf der rechten Schmalseite verwendet. In den Bruchkanten über dem Eierstab sind wohl Ansätze des lesbischen Kymas darüber erhalten.

Auf der Schmalseite sind eine rechte Hand um einen Stab (?) und Gewandfalten zu erkennen. Auf der Vorderseite hat ein stehender Jüngling mit Chlamys seinen rechten Arm über den leicht nach rechts geneigten Kopf gelegt. Die tiefen Bohrungen in den langen Locken des Jünglings erzeugen eine ausgeprägte Hell-Dunkel-Wirkung. Stilistisch gehört das Fragment damit nicht mehr zu den frühen Exemplaren, sondern in das 3. Jahrhundert.

Das Motiv einer Figur, die ihren rechten Arm über den Kopf gelegt hat, findet sich auf dionysischen Sarkophagen sowie auf Achill- und Hippolytos-Sarkophagen. Eine Zugehörigkeit zu einem dionysischen Sarkophag ist allerdings so gut wie ausgeschlossen, da Gesicht und Frisur des Jünglings aus Ephesos nicht einem Satyr entsprechen und weitere Hinweise beispielsweise in Form von Blättern, Ranken und Reben zu erwarten wären ${ }^{505}$. Auf Achill-Sarkophagen erscheinen zwar auch Figuren mit dem über den Kopf gelegten rechten Arm, aber die Figuren dort halten einen Helm in der Rechten und sind nicht an einer Ecke positioniert ${ }^{506}$.

Gute Vergleiche finden sich auf Hippolytos-Sarkophagen aus dem zweiten Viertel des 3. Jahrhunderts, so auf den Exemplaren in Beirut ${ }^{507}$, Arles ${ }^{508}$ und Agrigent ${ }^{509}$. Bei dem Hippolytos-Sarkophag in Beirut steht die Figur mit dem rechten Arm über dem Kopf an der linken Ecke der

504 Zu weiteren Vergleichen s. Rogge 1995, 68 Anm. 344; 92; Rogge 1993, 120 Anm. 129.

505 Vgl. z. B. den dionysischen Sarkophag in Boston: Matz 1968, 106-110 Nr. 9 Taf. 14 f.

506 s. z. B. die Achill-Sarkophage in Beirut: Koch - Sichtermann 1982, 385. 457 f. Abb. 414; Rogge 1995, 126 f. Nr. 6 Taf. 52, 2; 63, 3, in Tyros: Rogge 1995, 143 f. Nr. 42 Taf. 52, 1; 63, 1, und in Woburn Abbey: Koch - Sichtermann 1982, 377. 385-389. 458 Abb. 418; Rogge 1995, 145 f. Nr. 45 Taf. 59, 1; 61, 2; 63, 2.

507 Koch - Sichtermann 1982, 395 f. 458; Rogge 1995, 152 Nr. 57 Taf. 84, 1; 86, 1; 106, 1.

508 Koch - Sichtermann 1982, 395 f. 458; Rogge 1995, 150 Nr. 50 Taf. 96, 1; 103, 2; Gaggadis-Robin 2005, 72-90 mit Abb.

509 Koch - Sichtermann 1982, 394 f. 458 Abb. 426; Rogge 1995, 148 Nr. 47 Taf. 89, 1; 100, 3. 
Vorderseite ${ }^{510}$, in Arles an der rechten Ecke der Vorderseite mit dem linken Arm über dem Kopf; dort hält sie auch eine Lanze ${ }^{511}$. Der Sarkophag in Agrigent bietet die beste motivische Parallele zu dem ephesischen Fragment: Die Eckfigur an der rechten Ecke der Vorderseite hat den rechten Arm über den leicht geneigten Kopf gelegt.

Bei der motivischen Übereinstimmung wird der zeitliche Abstand der beiden Stücke umso ersichtlicher. Bei dem Hippolytos-Sarkophag in Agrigent reicht der erhobene Arm der Eckfigur direkt bis an die niedrige obere Leiste, dekoriert mit einer Akanthusranke. Unterhalb dieser findet sich ein Akanthuskyma.

Auch für die Darstellung auf der Schmalseite in Ephesos bieten die genannten HippolytosSarkophage Vergleiche. Auf der rechten Schmalseite des Sarkophags in Agrigent ${ }^{512}$ sind ebenfalls eine rechte Hand und Gewandfalten zu sehen, die zu einer weiblichen Figur der Szene >Phaidra im Frauengemach، gehören.

Handelt es sich bei dem Fragment in Ephesos jedoch nicht nur um eine Gewandfalte in der Hand, sondern um den Rest einer Lanze, finden sich auf den Schmalseiten in Beirut ${ }^{513}$ und Arles ${ }^{514}$ mit den Szenen >Hippolytos vor Theseus` vergleichbare Figuren. In Beirut hält Hippolytos eine Lanze, wobei er nicht direkt an der Ecke steht und seine Chlamys nur um Schultern gelegt ist. In Arles hält Hippolytos in der Mitte der Schmalseite eine Lanze. Sein Mantel bedeckt den Oberkörper, sodass eine Parallele mit den Falten auf dem Fragment in Ephesos gegeben ist ${ }^{515}$.

Die Zugehörigkeit des Eckfragments in Ephesos zu einem Hippolytos-Sarkophag ist sehr wahrscheinlich. Zu einer möglichen Zusammengehörigkeit mit dem Fragment Inv. 2321 siehe unten bei Kat. 17.

\section{Datierung}

Die Verwendung floraler Motive ist charakteristisch für das zweite Viertel des 3. Jahrhunderts n. Chr. Anstelle der Ornamentprofile Perlstab, Eierstab und lesbischem Kyma werden zunehmend flachere vegetabile Schmuckbänder verwendet, auch als Dekor der niedrigeren oberen Leisten. Durch die neuen Schmuckformen wird eine ruhigere, dekorative Rahmung geschaffen, vor der sich die mythologische Szenerie entfalten kann ${ }^{516}$.

Das Fragment in Ephesos mit einer höheren oberen Leiste, den darunter erhaltenen Resten eines Eierstabs und wohl eines lesbischen Kymas, das auf eine komplette Profilfolge von Perlstab, Eierstab und lesbischem Kyma deutet, und dem Arm der Eckfigur, der nur bis unter das lesbische Kyma reicht, ist früher anzusetzen und dürfte in die Zeit zwischen 220 und $240 \mathrm{n}$. Chr. gehören.

220-240 n. Chr.

\footnotetext{
510 Auch an der linken Ecke der linken Schmalseite hat ein Stehender seinen rechten Arm über den Kopf gelegt, Rogge 1995, Taf. 106. Eine Eckfigur mit dem linken Arm über dem Kopf an der linken Ecke der Vorderseite findet sich zudem in Tyros: Rogge 1995, Nr. 70 Taf. 88, 4; 93, 2.

511 Auf der linken Schmalseite hat ebenfalls ein Stehender seinen linken Arm über dem Kopf und hält eine Lanze: Rogge 1995, Taf. 103, 2.

512 Rogge 1995, Taf. 100, 3.

513 Rogge 1995, Taf. 102 (rechte Schmalseite). Auch auf der linken Schmalseite erscheint Hippolytos, wieder mit Lanze, an die auch eine Hintergrundfigur fasst: Rogge 1995, Taf. 106.

514 Rogge 1995, Taf. 103, 2 (linke Schmalseite).

515 s. auch ein Fragment in Paris, Louvre: Rogge 1995, 154 Nr. 62 Taf. 112, 1. Ein Stehender an der Ecke hatte wohl den Arm erhoben und seine Chlamys bedeckte auch den Oberkörper.

516 Zu den Entwicklungen in den Bereichen Tektonik und Ornamentik im 1. und 2. Viertel des 3. Jhs n. Chr. s. Koch 1993, 109; Rogge 1993, 119 f.; Kintrup 1998, 209-213 (zu Amazonomachie-Sarkophagen); Kintrup 2000, 125-137; Kintrup 2016a, Kap. 8 S. 212 (zu Sarkophagen mit Schlachtszenen).
} 


\subsubsection{Fragment eines Hippolytos-Sarkophags (?) (Kat. 17 Taf. 65 Abb. 274)}

Selçuk, Efes Müzesi Inv. 2321.

Gefunden in Selçuk, Johannesbasilika.

H 45,5; L 16; D 22; Rh 11.

Lit.: Rudolf 1989, 54 f. Taf. 29 Abb. 47.

Fein- bis mittelkörniger, weißer Marmor. Die Oberseite des oberen Kastenabschlusses ist mit Falz erhalten. Die Rückseite des Fragments zeigt eine regelmäßige feine bis mittlere Spitzmeißelbearbeitung; die oberen $4 \mathrm{~cm}$ sind geglättet. Die Oberfläche weist einige Bestoßungen an dem oberen Kastenabschluss sowie an der Figur auf. Bohrungen sind für die Umrisslinie der Figur, für die Haargestaltung und im Ohr verwendet. Den oberen Kastenabschluss bilden Perlstab, Eierstab, lesbisches Kyma - alle mit tiefen Bohrungen gearbeitet - und eine obere Leiste mit einem flachen vegetabilen Schmuckband.

Die Ausarbeitung der Profilfolge und der Figur zeigt, dass das Fragment zu einer bevorzugt gearbeiteten Seite des Sarkophags gehörte.

Ein stehender Jüngling mit Chlamys, die auf seiner rechten Schulter geschlossen war, hat seinen Kopf, der mindestens zur Hälfte verloren ist, nach rechts geneigt. Seine rechte Seite wird von einem Reliefrest überdeckt, der am ehesten als Pferdevorderteil zu identifizieren ist ${ }^{517}$.

Nach E. Rudolf zeigt das Fragment eine »ähnliche Form « ${ }^{518}$ wie das Hippolytos-Fragment Kat. 16 (Taf. 65 Abb. 272 f.). Eine Zugehörigkeit zu diesem ist nach der Profilhöhe möglich, auch der Kopf der Figur ragt vergleichbar weit in den oberen Kastenabschluss.

Im Unterschied zu Kat. 16 sind die Haare weniger durch Bohrungen gegliedert und die Falten der Chlamys etwas flacher. Allerdings ist hier eine Kurzhaarfrisur gezeigt und die Figur steht mehr im Hintergrund. Der Marmor erschien hier etwas gröber gekörnt, wobei die zwei Fragmente leider nicht nebeneinander untersucht werden konnten. Die genannten Unterschiede liegen aber noch im Rahmen der möglichen Variationen an einem Sarkophag.

Stehende Figuren mit Chlamys und leicht geneigtem Kopf in Verbindung mit einem Pferd sind thematisch nicht eindeutig festzumachen. Sie sind häufiger anzutreffen auf Achill-, Meleager- und Hippolytos-Sarkophagen. Zwar sind bei den Achill-Sarkophagen ähnliche Figuren und auch Pferde belegt, aber es finden sich keine aussagekräftigen Parallelen; die Jünglinge sind meist behelmt und blicken mehr auf- statt abwärts, als es auf dem Fragment in Ephesos der Fall ist. Bessere Vergleiche bieten die Vorderseiten der Hippolytos-Sarkophage in Agrigent ${ }^{519}$, Beirut ${ }^{520}$, Tyros $^{521}$, St. Petersburg ${ }^{522}$ sowie Vorderseitenfragmente in Woburn Abbey ${ }^{523}$ aus dem zweiten Viertel des 3. Jahrhunderts.

Der abwärts gerichtete Blick passt auch zu Jagdgefährten des Meleager. Hier bieten MeleagerSarkophage, ebenfalls aus dem zweiten Viertel des 3. Jahrhunderts, Entsprechungen: so die Vorderseiten der Sarkophage in Thessaloniki ${ }^{524}$, Liverpool ${ }^{525}$ und Split ${ }^{526}$. Eine direkte Parallele für das Fragment in Ephesos kann jedoch keines der genannten Vergleichsstücke bieten.

517 Vgl. z. B. den Achill-Sarkophag in Beirut: Rogge 1995, Nr. 6 Taf. 52, 2. Für einen alternativ anzunehmenden Oberarm einer im Vordergrund stehenden Figur scheint der Reliefrest etwas zu flach und zu breit zu sein.

518 Rudolf 1989, 55.

519 Koch - Sichtermann 1982, 394 f. 458 Abb. 426; Rogge 1995, 148 Nr. 47 Taf. 89, 1; 92, 1.

520 Koch - Sichtermann 1982, 395 f. 458; Rogge 1995, 152 Nr. 57 Taf. 84, 1; 86, 1; s. auch die linke Schmalseite Rogge 1995, Taf. 106, 1.

521 Koch - Sichtermann 1982, 394. 458; Rogge 1995, Nr. 70 Taf. 88, 4; 91.

522 Koch - Sichtermann 1982, 394. 458; Rogge 1995, Nr. 64 Taf. 89, 2; 90.

523 Zu den stark überarbeiteten Fragmenten s. Rogge 1995, 79 f. 158 Nr. 73 Taf. 87, 1; 88, 3.

524 Koch 1975, 144 Nr. 175 Taf. 138, 1; Koch - Sichtermann 1982, 401 f. 458 Abb. 431.

525 Koch 1975, Nr. 145 Nr. 177 Taf. 138, 3; Koch - Sichtermann 1982, 401 f. 458.

526 Koch 1975, 145 f. Nr. 178 Taf. 139; Koch - Sichtermann 1982, 401 f. 458. 


\section{Datierung}

Auf der Schmalseite eines Meleager-Sarkophags in Chicago mit einer Datierung in das erste Viertel des 3. Jahrhunderts ${ }^{527}$ ragen die Köpfe der Figuren etwas weniger weit in die konventionelle Ornamentfolge, als es bei dem Fragment in Ephesos der Fall ist. Der konventionelle obere Kastenabschluss kann im Verlauf des 3. Jahrhunderts zunehmend von Figuren überschnitten werden. Daher und in Anlehnung an das möglicherweise zugehörige Hippolytos-Fragment Kat. 16 ist auch hier eine Datierung zwischen 220 und 240 n. Chr. vorzuschlagen ${ }^{528}$.

220-240 n. Chr.

\subsection{Sarkophage mit Schlachtszenen}

\subsubsection{Fragment mit einer Schlachtszene (Kat. 18 Taf. 65 Abb. 275)}

Selçuk, Efes Müzesi Inv. 2/34/77.

Gefunden in Selçuk, Johannesbasilika, Baptisterium, Fund-Nr. StJ 77/8.

H 43; L 35; DW 8; Rh 9.

Lit.: Koch 1991, 819 Nachtrag Nr. 4.

Fein- bis mittelkörniger, heller Marmor. Das allseitig gebrochene Fragment hat einige Bestoßungen an der Oberfläche. Ein Großteil der Reliefoberfläche des Fragments zeigt deutliche Raspelspuren. Die Rückseite des Fragments weist eine regelmäßige Spitzmeißelarbeit auf.

Erhalten sind Oberkörper und Beine bis unterhalb der Knie eines nackten, frontal stehenden Kriegers mit einem Schild in der Linken. Als Schildzeichen ist ein Gorgoneion angebracht. Nach dem Ansatz war der rechte Arm erhoben. Ein stark bestoßenes rechtes Pferdevorderbein verläuft vor dem Unterkörper des Kriegers ${ }^{529}$. Hinter den Kriegerbeinen sind Reste eines Rundschilds in Innenansicht und davor ein abgewinkeltes Knie zu erkennen, weiter rechts sind es wohl Teile des Körpers eines gestürzten Pferdes. Die Reliefreste reichen aus, um mit großer Wahrscheinlichkeit einen verbreiteten Kampfgruppentypus und einen ebenso üblichen Gefallenentypus attischer Sarkophage mit Schlachtszenen zu rekonstruieren ${ }^{530}$. Die Kampfgruppe besteht aus einer von links nach rechts reitenden Figur, die eine stehende Figur in Frontalansicht angreift. Vergleiche finden sich z. B. auf Amazonomachie-Sarkophagen, so auf der Vorderseite des Sarkophags in Tyros ${ }^{531}$, auf der Vorder- und der rechten Schmalseite in Thessaloniki ${ }^{532}$ und auf der rechten Schmalseite in Jerusalem ${ }^{533}$. Weitere Parallelen bieten Schlachtsarkophage, etwa auf der Vorderseite des Sarkophags in Askalon ${ }^{534}$, der rechten Schmalseite in Tyros ${ }^{535}$ und auf beiden Schmalseiten in St. Petersburg ${ }^{536}$ sowie jeweils auf der linken Schmalseite der Epinausimachie-Sarkophage in

527 Koch 1975, 142 Nr. 168 Taf. 133, 1; Koch - Sichtermann 1982, 401 f. 458 Abb. 432.

$528 \mathrm{Zu}$ den datierenden Kriterien und Belegen s. bereits unter Kat. 16 mit Anm. 507-516.

529 Das steigende Pferd auf dem Fragment Kat. 33 (Taf. 70 Abb. 293 f.) könnte zwar motivisch hierzu passen, aber die oben beschriebene Oberflächenbehandlung findet sich dort nicht.

530 Kintrup 2016a, 35. 38. 43: Kampfgruppen-Typus K VIII und 36. 40. 47: Gefallenen-Typus G IV.

531 Inv. 2772/2773: Chéhab 1968, 36-40. 81 f. Taf. 18. 21 c; Koch 1989a, 194. 195 mit Abb. 43; 208; Kintrup 1998, 207-210 Taf. 92, 2; Kintrup 2016a, Kap. 3.2.1 Nr. 259.

532 Inv. 283: s. Koch - Sichtermann 1982, 391 mit Anm. 10; 458; Stefanidou-Tiveriou 1997, 166-169 Nr. 134; 380 Abb. 336; 381 Abb. 338; Kintrup 1998, 209 f. 214 f. Taf. 93, 4; Kintrup 2016a, Kap. 3.2.3 Nr. 245.

533 Fischer 1998, 208 Nr. 213; 225 f. Abb. 213 d; Kintrup 2016a, Kap. 3.2.11 Nr. 112.

534 Fischer 1998, 205 Nr. 196; 213-215 Abb. 196 a; Kintrup 2016a, Kap. 4.2.7 Nr. 31.

535 Inv. 4048/4049: Chéhab 1985, 600 f. Taf. 123 b; Kintrup 2016a, Kap. 4.2.13 Nr. 262.

536 Saverkina 1979, 24 f. Nr. 5 Taf. 12; Kintrup 2016a, Kap. 4.2.19 Nr. 237. 
Thessaloniki ${ }^{537}$ und Tyros ${ }^{538}$. Durch den Abstand der Figuren und den Schild mit Gorgoneion in Außenansicht erweist sich die rechten Schmalseite des Amazonomachie-Sarkophags in Thessaloniki ${ }^{339}$ als besonders enge Parallele.

Bei dem Gefallenentypus stützt sich die gefallene Figur zumeist auf den rechten Ellenbogen, ein Fuß ist wie hier aufgestellt, wofür wieder die Schmalseite in Thessaloniki zu vergleichen ist. Bei etlichen Beispielen hat die Figur wie hier in Ephesos einen Schild am linken Arm, so auf beiden Schmalseiten des Amazonomachie-Sarkophags vom Hafenkanal (Kat. 6 Taf. 42) und auf der Vorderseite eines Schlachtsarkophags in Beirut ${ }^{540}$. Da die gefallene Figur einen Rundschild und keine Pelta trägt, wird es sich um einen Krieger, nicht um eine Amazone handeln und damit eher um ein Fragment eines Schlacht- und nicht eines Amazonomachie-Sarkophags.

\section{Datierung}

Der Kampfgruppen- und der Gefallenentypus finden sich - neben der rechten Schmalseite des Amazonomachie-Sarkophags in Thessaloniki - auch bei weiteren Vergleichsstücken wie in Ephesos miteinander kombiniert, etwa auf der rechten Schmalseite des Schlachtsarkophags in St. Petersburg ${ }^{541}$. Aber in Stil und Ikonografie präsentiert die rechte Schmalseite des Amazonomachie-Sarkophags in Thessaloniki ${ }^{52}$ die beste Parallele, sodass eine Datierung ähnlich dieses Sarkophags, der um 220 n. Chr. angesetzt wird, vorzuschlagen ist.

Erstes Drittel des 3. Jahrhunderts n. Chr.

\subsubsection{Fragment mit einer Schlacht bei Schiffen (Kat. 19 Taf. 66 Abb. 276 f.)}

Selçuk, Efes Müzesi Inv. 10/1/95.

Gefunden in Selçuk, Johannesbasilika, Fund-Nr. 92/11 (Karteikarte M. Büyükkolanc1).

H 45; L 27; D 20; DW 9; Rh 11.

Lit.: Unpubliziert.

Feinkristalliner, weißer Marmor. Allseitig gebrochen. Die Rückseite des Fragments trägt regelmäßige mittelgrobe Spitzmeißelarbeit.

Das Fragment zeigt ein nach rechts gerichtetes Schiffsheck auf Wellen. Auf dem Schiffsheck ist Dekor in flachem Relief angegeben. Eine Nereide sitzt auf einem Triton, der in ein Muschelhorn bläst. Sie spielt mit einem Eros, der auf ihren Oberschenkeln steht und den sie an beiden Armen gefasst hat. Darunter hält sich ein Eros an einem Delfin fest und lässt sich von diesem ziehen.

Daneben reitet ein Eros, der eine Schale mit Früchten nach oben hält, auf einem Delfin. Darüber befindet sich eine zweite sitzende Nereide, von der die Beine mit Gewand erhalten sind, auf einem Triton, über dessen Oberkörper die Bruchlinie schräg verläuft. Der gewundene Fischschwanz dieses Tritons erscheint links neben dem Oberkörper des anderen Tritons.

Der obere Rand des Schiffshecks zeigt einen kleinen Absatz, es ist wohl das Auflager für einen Schiffssteg. Zudem ist der Ansatz eines rechts folgenden Schiffshecks vorhanden. Im Schiffsinneren sind tiefe Rillen zur Angabe der Planken und Versteifungen des Hecks zu erkennen sowie

537 Inv. 1246: Stefanidou-Tiveriou 1997, 169-174 Nr. 135; 385 Abb. 342; Kintrup 2016a, Kap. 5.2.6 Nr. 248.

538 Inv. 4038/4039: Chéhab 1985, 559 f. Taf. 113 b; 114 c; Kintrup 2016a, Kap. 5.2.Nr. 261.

539 s. Anm. 532.

540 Koch - Sichtermann 1982, 407. 408 Nr. 20; 458 Abb. 442; Chéhab 1985, 687 f. Taf. 137; Kintrup 2016a, Kap. 4.2.15 Nr. 72.

541 s. o. Anm. 536.

542 s. Anm. 532. 
ein nicht vollständig ausgeführter rechter Fuß. Das zugehörige Bein ist über den Schiffsrand nach innen geführt und bricht oberhalb des gebeugten Knies ab. Darüber erscheint ein angewinkelter linker Ellenbogen.

Die wenigen Reste der Figuren lassen sich analog vollständig erhaltener Exemplare der attischen Sarkophage mit Epinausimachie bestens rekonstruieren: Es handelt sich um zwei Schiffsverteidiger. Ein nackter Jüngling in Rückenansicht erklimmt die Bordwand des Schiffs und hat sein rechtes Bein bereits in das Innere gehoben. Im Schiff steht ein Verteidiger frontal, der wohl mit seiner Linken den rechten Oberarm des Jünglings gefasst hat, um ihm an Bord zu helfen. Die vollständigen Parallelen finden sich auf den Epinausimachie-Sarkophagen in Damaskus ${ }^{543}$ und Tyros $^{544}$; die Fragmente in Athen ${ }^{545}$ und Venedig ${ }^{546}$ haben ebenfalls ausreichend erhalten, um den Kontext abzusichern ${ }^{547}$.

Alle Exemplare gehören der Gruppe I der attischen Epinausimachie-Sarkophage an, d. h., die Schiffe liegen auf der linken Seite der Sarkophagfront ${ }^{548}$. Die beiden Figuren sind als »Typus V I « fassbar $^{549}$. Die Verteidiger in diesem Typus treten immer im linken Schiff auf. Der Typus V I ist jedoch ab dem Beginn des 3. Jahrhunderts bis nach der Jahrhundertmitte belegt ${ }^{550}$ und erlaubt dadurch keine genauere Datierung.

\section{Datierung}

Einen Hinweis auf die Datierung könnte das Dekor des Schiffs geben. Nach den Vergleichen ist ein in zwei Streifen unterteiltes Dekor der Schiffshecks auf Fragmenten in Tarent ${ }^{551}$, Venedig $^{552}$ und Thessaloniki ${ }^{553}$, die etwa zwischen 180 und 220 n. Chr. einzuordnen sind, beschränkt. Bei späteren Sarkophagen (in Damaskus ${ }^{554}$, Tyros ${ }^{555}$ und Thessaloniki ${ }^{556}$ ) ist eine Zweiteilung des Schiffdekors nicht mehr belegt ${ }^{557}$. Demnach dürfte das Fragment in Ephesos nicht zu den frühesten Stücken gehören.

Bei keiner der Parallelen auf den Epinausimachie-Sarkophagen sind unter dem Schiff mit den Verteidigertypen V I Wellen erhalten. Nach den derzeitigen Belegen erscheinen dort ein über

${ }_{543}$ Linant de Bellefonds 1985, 108-111. 119 f. 179 Taf. 39, 2; 40 f.; 43, 1; Touchefeu 1988, 488 Nr. 41 Taf. 285 f.; Koch 1996, 197-207 Taf. 44-49; Kintrup 2016a, Kap. 5.2.4 Nr. 84.

544 Koch - Sichtermann 1982, 373 Anm. 64; 411 f. 413 Nr. 10; 445. 459. 467 Abb. 444; Linant de Bellefonds 1985, 28-30. 99-101. 106-108. 119 f. 179 Taf. 35 f.; 37, 1; Touchefeu 1988, 488 Nr. 42 Taf. 286; Kintrup 2016a, Kap. 5.2.8 Nr. 261.

545 Nationalmuseum Inv. 7353: Robert 1904, 368 Nr. 3 Suppl.-Taf. B Abb. 3; Kintrup 2016a, Kap. 5.2.2 Nr. 69.

546 Museo Archeologico Inv. 154: Linant de Bellefonds 1985, 102-104. 119 f. 179 Taf. 38, 3; Sperti 1988, 158-165 (mit ausführlicher Lit.); Kintrup 2007, 178-181 Taf. 62, 2; Kintrup 2016a, Kap. 5.2.1 Nr. 266.

547 Die Figuren dort blicken jeweils nach rechts.

548 Bei Gruppe II der attischen Epinausimachie-Sarkophage liegen die Schiffe auf der rechten Seite der Sarkophagfront.

549 Kintrup 2016a, 36. 39. 46 Typus V 1.

550 Kintrup 2016a, Kap. 5.3 S. 180.

551 Museo Nazionale Archeologico: Linant de Bellefonds 1985, 102. 118-120. 179 Taf. 38, 1-2; Kintrup 2007, 177180 Taf. 61, 2; Kintrup 2016a, Kap. 5.1.1 Nr. 241.

552 s. o. Anm. 546.

553 Archäologisches Museum Inv. 1209: Despinis u. a. 2003, 251-253 Nr. 331 Abb. 1018 f.; Kintrup 2016a, Kap. 5.2.2 Nr. 246.

554 s. o. Anm. 543.

555 s. o. Anm. 544.

556 Linant de Bellefonds 1985, 112-116. 119 f. 179 Taf. 42, 2; Stefanidou-Tiveriou 1997, 169-174 Nr. 135; 384 Abb. 341; 387 Abb. 346; Kintrup 2016a, Kap. 5.2.6 Nr. 248.

557 Die Zweiteilung des Schiffdekors ist ebenfalls auf zwei weiteren Beispielen aus anderen mythologischen Kontexten belegt, die auch um die Jahrhundertwende datiert werden, s. die rechte Schmalseite eines HippolytosSarkophags mit der Darstellung »Theseus verlässt Ariadne« vom Ende des 2. Jhs n. Chr.: Koch - Sichtermann 1982, 393. 417; Rogge 1995, 153 Nr. 59 Taf. 80, 1, und s. die Fragmente eines Orest-Sarkophags in Theben, Archäologisches Museum, Magazin Inv. 109 (?): Koch - Sichtermann 1982, 402 f. Abb. 434 f.; Giuliano Palma 1978, 47 Nr. 2 Taf. 52, 128; Bonnano Aravantinos 1993, 67-76 Falttaf. 1 Taf. 24, 2-5, aus dem Anfang des 3. Jhs. n. Chr. 
seinem Schild gekrümmt Liegender (Gefallenentypus G VII ${ }^{558}$ ) oder ein Triton. Das Fragment in Ephesos gehört demnach vielleicht in die Übergangszeit des ersten Viertels des 3. Jahrhunderts $n$. Chr., in der ein Flussgott oder Oceanus ${ }^{559}$, gefolgt von dem Gefallenentypus G VII ${ }^{560}$, durch eine Meeresgöttin ${ }^{561}$ mit Triton ersetzt wird ${ }^{562}$. Stimmt dieser zeitliche Ansatz, dann wäre das Fragment in Ephesos ein wichtiger Beleg für eine Phase, in der die Epinausimachie-Sarkophage erhebliche Veränderungen im Figurenrepertoire erfahren.

Alle Hinweise sprechen für eine Datierung in das erste Viertel des 3. Jahrhunderts n. Chr. Das Fragment in Ephesos bereichert das Bild zu Variabilität und Entwicklung der attischen Epinausimachie-Sarkophage, ist aber auch Beleg für deren Kontinuität, zumal für den Zeitraum des ersten Viertels des 3. Jahrhunderts n. Chr. nur wenige Stücke vorhanden sind ${ }^{563}$.

Angesichts dieses Umstands und dadurch, dass es sich bei den Epinausimachie-Sarkophagen insgesamt um eine kleine Gruppe handelt, stellt sich die Frage, ob das folgende Fragment Kat. 20 mit am Boden sitzenden Krieger und Wellen nicht ebenfalls zugehörig ist. Es wäre ein großer Zufall, sollten sich in Ephesos zwei Exemplare mit der Darstellung einer Schlacht bei Schiffen erhalten haben. Einer Zugehörigkeit widersprechen auch nicht Fundort, Marmor, Wandstärke, Reliefhöhe, Ausführung der Wellenlinien oder Datierung.

Datierung

200-220 n. Chr.

3.6.3 Fragment mit einer Schlacht bei Schiffen (Kat. 20 Taf. 66 Abb. 278)

Selçuk, Efes Müzesi Inv. 48.

Gefunden in Selçuk im Bereich der Johannesbasilika (1930).

H 30; L 57; D 19,5; Rh 9,5.

Lit.: Eichler 1944/45, 130 Nr. 9; Kallipolitis 1958, 23 Nr. 108; Giuliano 1962, 48 Nr. 257; Koch - Sichtermann 1982, 409 Nr. 29; Rudolf 1989, 52 Taf. 27 Abb. 44; Koch 1991, 816-819; Koch 1996, 205 Nr. 5; Kintrup 2016a, Kap. 5.2.10 Nr. 88.

Feinkörniger, weißer Marmor. Fragment mit einem Stück der Standleiste; die Unterseite der Standleiste ist von der Vorderkante $9 \mathrm{~cm}$ nach hinten mit dem Flachmeißel abgearbeitet, danach folgt Spitzmeißelarbeit. Die übrigen Seiten sind gebrochen; auf der Rückseite gleichmäßige Spitzmeißelbearbeitung.

Ein am Boden sitzender, nackter Krieger hat seine Beine nach rechts ausgestreckt. Die Füße sowie der Kopf und der rechte Arm fehlen. Knie, Unterschenkel, Pubis und linke Hand sind bestoßen. Über einer Bestoßung in seinem rechten Brustkorb ist eine Wunde plastisch angegeben; unter der Bestoßung sind flache Linien zur Angabe des Bluts eingetieft. Am erschlafft herabhängenden linken Arm hängt ein Schild; Schildband und Reste des Schilds sind hinter seinen Beinen zu erkennen. Rechts neben dem Schildrest und unter den Beinen des Gefallenen sind Wellenlinien angegeben, z. T. tief eingebohrt. Durch die Wellen ist eine Zuordnung zu einem Sarkophag mit der Darstellung einer Schlacht bei Schiffen möglich. Bei attischen Sarkophagen ist die Epinausimachie vor Troja oder die Schlacht bei Marathon belegt. Eine Rekonstruktion, bei der der Gefallene zu einer Helfergruppe gehört, wie sie auf dem Vorderseitenfragment in Brescia

\footnotetext{
558 Kintrup 2016a, 36. 40. 48 Gefallenen-Typus G VII.

559 Zu den Benennungen s. z. B. Kintrup 2016a, Kap. 5.2.1.2.

560 s. das Fragment in Venedig, o. Anm. 546.

$561 \mathrm{Zu}$ den verschiedenen vorgeschlagenen Benennungen s. z. B. Kintrup 2016a, Kap. 5.2.4.3.

562 Kintrup 2016a, Kap. 5.3 S. 179.

563 s. Kintrup 2016a, Kap. 5.2.1; 5.2.2.
} 
(200-220 n. Chr. $)^{564}$ mit der Schlacht bei Marathon vorkommt, ist wahrscheinlich: demnach ist ein hinter dem Gefallenen stehender Krieger zu ergänzen, der den Gefallenen am rechten Arm hält und zu verteidigen sucht. Ähnliche Helfergruppen erscheinen auf der rechten Schmalseite des Schlachtsarkophags des Aemilius Aristides (Kat. 1 Taf. 1 f.) oder auf der Vorderseite eines Amazonomachie-Sarkophags in Tyros ${ }^{565}$, die beide um 200 n. Chr. datiert werden können.

\section{Datierung}

Im Rahmen der attischen Sarkophage mit Schlachtszenen sind diese Helfergruppen gut belegt und zeigen eine Entwicklung ${ }^{566}$, innerhalb derer die hier gezeigte Version mit seitlich ausgestreckten Beinen des Gefallenen eine Datierung in Analogie zu dem Vorderseitenfragment in Brescia in das erste Viertel des 3. Jahrhunderts n. Chr. unterstützt ${ }^{567}$.

200-220 n. Chr.

\footnotetext{
564 s. Koch - Sichtermann 1982, 412. 413. 414 Nr. 22; 459 Abb. 446; Linant de Bellefonds 1985, 121 Taf. 37, 2; Stella 1998, 63 mit Abb.; Kintrup 2016a, Kap. 5.2.9 Nr. 77.

565 s. Chéhab 1968, 36-40. 81 f. Taf. 17-21; Giuliano - Palma 1978, 34 Nr. 9 Taf. 35, 87; Koch - Sichtermann 1982, 390 Anm. 1; 391. 458. 467; Chéhab 1984, 451-453 Taf. 77-79; Koch 1989a, 194. 195 mit Abb. 43; 208; Kintrup 1998, 207-210 Taf. 92, 2; Kintrup 2016a, Kap. 3.2.1 Nr. 259.

566 s. Kintrup 2016a, z. B. Kap. 3.2.1.2 mit Anm. 145 und Kap. 4.2.1.3 mit Anm. 419.

567 Zu einer möglichen Zusammengehörigkeit mit Fragment Kat. 19, s. dort.
} 



\title{
4 Attische Kastenfragmente ohne genaue thematische Zuordnung
}

\author{
4.1 Eckfragment mit Trompeter (Kat. 21 Taf. 67 Abb 279 f.)
}

Oxford, Ashmolean Museum Inv. ANMichaelis.218.a. Von Hyde Clarke 1866 dem Ashmolean Museum geschenkt, gemeinsam mit Kat. 22 (Taf. 67 Abb. 281).

Fundort: Ephesos.

H 35; L 28; H des oberen Kastenabschlusses 21,5; L der anschließenden Seite 17.

Lit.: Michaelis 1882, 590 Nr. 218.1; Robert 1890, 54 Nr. 42 Taf. 20 Abb. 42; Robert 1919, 549; Rodenwaldt 1930, 186; Eichler 1944/45, 130 Nr. 8; Kallipolitis 1958, 23 Nr. 105; Giuliano 1962, 48 Nr. 256; Kossatz-Deissmann 1981, 62 Nr. 142; Koch - Sichtermann 1982, 409 Nr. 50; Rudolf 1989, 50 f. »Ephesos H« Taf. 27 Abb. 42; Koch 1991, 817-819; Kintrup 2016a, Kap. 4.2.4 Nr. 149.

In der Literatur findet sich mehrfach die Annahme einer Zusammengehörigkeit dieses Fragments mit Kat. 22 (Taf. 67 Abb. 281) ${ }^{568}$, aber aufgrund der unterschiedlichen Ornamentausführung, der Maße der Profile und auch der Bearbeitung der Rückseiten ${ }^{569}$ werden die Fragmente hier getrennt besprochen ${ }^{570}$.

Feiner, heller Marmor, bis auf die Oberseite allseitig gebrochen. Auf der Oberseite ist der Falz umbiegend erhalten, sodass die Position an einer Ecke gesichert ist. Von dem Dekor des oberen Kastenrands haben sich der Perlstab und der stark beschädigte Eierstab erhalten, während das zu rekonstruierende lesbische Kyma samt oberer Leiste weggebrochen ist. Bohrungen finden sich im Haar und Ohr eines Trompeters.

Der behelmte Kopf (Nase gebrochen) eines Tubicen im Profil nach links ist samt eines Teils seines Instruments vorhanden. Die Reliefreste der umbiegenden Seite, die wohl nur vernachlässigt gearbeitet war, sind nicht zu identifizieren.

Trompeter sind sehr häufig auf den attischen Sarkophagen mit Schlachtszenen zu finden. Der Kopf des Tubicen ragt in den Eierstab. Undeutliche, gewölbte Reliefreste rechts des Kopfes reichen höher in das Gesims; vermutlich handelt es sich also um eine Eckfigur - vielleicht um den erhobenen Arm einer Nike/Amazone ${ }^{571}$ sowie ein Stück der Pelta auf ihrer Schulter. In diesem Fall würde der Amazonomachie-Sarkophag in Thessaloniki, um 220 n. Chr. ${ }^{572}$, einen guten Vergleich darstellen, denn die Figuren neben der Nike/Amazone ragen ebenfalls in die oberen Profile. Da sie dort aber nicht ganz so weit nach oben ragen, kann das Fragment in Ephesos in einer relativen Reihe nach dem Sarkophag in Thessaloniki eingeordnet werden. In der Regel werden die konventionellen Ornamentfolgen Perlstab, Eierstab und lesbisches Kyma im Zuge der Entwicklung immer mehr von Figuren überschnitten, bis ab dem zweiten Viertel des 3. Jahrhunderts n. Chr. diese optisch stark untergliederten Profile zugunsten einfacher, flacherer vegetabiler Ornamente ${ }^{573}$ schließlich aufgegeben werden. Handelt es sich tatsächlich um eine Nike/Amazone an

568 Dazu und zu den vorgeschlagenen Deutungsmöglichkeiten s. Rudolf 1989, 52 mit Anm. 36.

569 Freundliche Mitteilung nach Autopsie von M. Heinz, 21. 5. 2002.

570 s. auch Koch 1991, 818.

571 Zur Benennung s. Aristides-Sarkophag, Kat. 1, Anm. 126.

572 Koch - Sichtermann 1982, 391 mit Anm. 10; 458; Stefanidou-Tiveriou 1997, 166-169 Nr. 134; 380-383 Abb. 336-340; Kintrup 1998, 209 f. 214 f. Taf. 93, 4; Kintrup 2016a, Kap. 3.2.3 Nr. 245.

573 Vgl. die Ausführungen dazu bei Kat. 1, s. Taf. 2. 10, oder bei Kat. 3, s. z. B. Taf. 35. In der Zeit erscheinen auch einige sexperimentelle`Schmuckformen wie das Gorgonenkyma, die nur selten verwendet wurden, s. z. B. Kat. 2 (Taf. 27 Abb. 117-119). 
der Ecke, wäre damit auch eine Zuordnung des ephesischen Fragments zu einem Amazonomachie-Sarkophag wahrscheinlicher als zu einem Schlachtsarkophag. In aller Regel werden nämlich bei Schlachtsarkophagen männliche Eckfiguren verwendet; eine Nike/Amazone wie sie bei dem Aristides-Sarkophag (Kat. 1 Taf. 2 f.) belegt ist, erweist sich bei den Schlachtsarkophagen als Ausnahme.

Eine weitere Möglichkeit einer thematischen Zuordnung bieten Achill-Sarkophage. Ein Tubicen erscheint auch auf Achill-Sarkophagen, die die Entdeckung des Helden auf Skyros darstellen, etwa auf der Vorderseite in Jerusalem ${ }^{574}$ und in Ptolemais ${ }^{575}$ sowie auf den Schmalseiten der Exemplare in Beirut ${ }^{576}$ und Paris ${ }^{577}$. Die engeren und erheblich häufigeren Parallelen sind jedoch auf Sarkophagen mit Schlachtszenen zu finden.

\section{Datierung}

Um 230 n. Chr.

\subsection{Fragment mit Bärtigem (Kat. 22 Taf. 67 Abb 281)}

Oxford, Ashmolean Museum Inv. ANMichaelis.218b. Von Hyde Clarke 1866 dem Ashmolean Museum geschenkt, zusammen mit Kat. 21 (Taf. 67 Abb 279 f.).

Fundort: Ephesos.

H 27; L 36; D 18; H des oberen Kastenabschlusses 18,5.

Lit.: Michaelis 1882, 590 Nr. 218.2; Robert 1919, 549; Eichler 1944/45, 130 Nr. 8; Kallipolitis 1958, 23 Nr. 105; Giuliano 1962, 48 Nr. 256; Kossatz-Deissmann 1981, 62 Nr. 142; Koch - Sichtermann 1982, 409 Nr. 51; Rudolf 1989, 51 f. »Ephesos I« Taf. 27 Abb. 43; Koch 1991, 817-819; Kintrup 2016a, Kap. 4.2.4 Nr. 150.

Die in der Literatur mehrfach geäußerte Annahme einer Zusammengehörigkeit dieses Fragments mit Kat. 21 (Taf. 67 Abb 279 f.) ${ }^{578}$ kann nicht bestätigt werden. Aufgrund der unterschiedlichen Ornamentausführung, der Maße der Profile und auch der Bearbeitung der Rückseiten ${ }^{579}$ werden die Fragmente getrennt bearbeitet ${ }^{580}$.

Feiner, heller Marmor. Fragment vom oberen Kastenrand. Perlstab, Eierstab, lesbisches Kyma und ein nach links laufendes Tier in Blattwerk auf der oberen Leiste sind trotz starker Beschädigungen zu erkennen.

Am rechten Rand des Fragments erscheint ein Kopf im Profil nach links. Der Bärtige trägt eine Kopfbedeckung, bei der es sich vermutlich um einen korinthischen Helm handelt. Reste unter dem Kinn könnten zu seiner Hand gehören. Die Figur ragt bis nahe an das lesbische Kyma, etwas weiter links reicht eine Bruchfläche in das lesbische Kyma. Bei einem fragmentierten Amazonomachie-Sarkophag in Thessaloniki, der um $230 \mathrm{n}$. Chr. anzusetzen ist ${ }^{581}$, ragen die Figuren ähnlich weit in eine wie hier konventionelle Ornamentabfolge. Wie erwähnt, werden die Ornamentierungen zunehmend von den Figuren überschnitten und bereits ab dem zweiten Viertel des 3. Jahrhunderts n. Chr. durch einfache, flache vegetabile Ornamente ersetzt ${ }^{582}$.

574 Rogge 1995, 130 f. Nr. 14 Taf. 43, 1.

575 Rogge 1995, 135 Nr. 22 Taf. 43, 2.

576 Rogge 1995, 126 f. Nr. 6 Taf. 65, 1.

577 Rogge 1995, 134 Nr. 21 Taf. 64, 1.

578 s. zur Lit. und zu den vorgeschlagenen Möglichkeiten einer Deutung: Rudolf 1989, 52 mit Anm. 36.

579 Freundliche Mitteilung nach Autopsie von M. Heinz, 21. 5. 2002.

580 So auch Koch 1991, 818.

581 Koch - Sichtermann 1982, 391 mit Anm. 14; 458; Kintrup 1998, 210. 214 Taf. 93, 2-3; 95, 6; Kintrup 2016a, Kap. 3.2.5 Nr. 244

582 Vgl. dazu auch das Fragment ebenfalls in Oxford, Kat. 21, mit Anm. 573 zu den Verweisen auf den AristidesSarkophag, Kat. 1, den Achill-Sarkophag in Woburn Abbey, Kat. 3, oder den Amazonomachie-Sarkophag aus dem Tatiane-Grabhaus Kat. 2. 
Bärtige Figuren sind auf den Sarkophagen mit Schlachtszenen die Ausnahme, zudem gibt es keinen Vergleich mit einem Bärtigen mit Hand am Kinn. Diese Geste kann Nachdenklichkeit bis hin zu Trauer ausdrücken. Einen Bärtigen mit Pilos und mit der Hand am Kinn präsentiert der Achill-Sarkophag in Beirut ${ }^{583}$. Bärtige mit korinthischem Helm finden sich beispielsweise auf der Schmalseite eines Achill-Sarkophags in Paris ${ }^{584}$ sowie auf Fragmenten in Paris ${ }^{585}$ und Tyros ${ }^{586}$. Der Achill-Sarkophag in Woburn Abbey (Kat. 3 Taf. 36) zeigt auf der Schmalseite eine Parallele mit einem Bartlosen mit der Hand am Kinn und ebenfalls auf der Schmalseite des Achill-Sarkophags in Tyros ${ }^{587}$ befindet sich ein Bartloser mit attischem Helm und der Hand am Kinn. Insofern ist eine Zuordnung zu einem Achill-Sarkophag gut möglich.

\section{Datierung}

Alle Vergleiche gehören eher in die Nähe der Mitte des 3. Jahrhunderts n. Chr. Einer Datierung des Fragments in Oxford um 230 widersprechen die Parallelen aber nicht, denn die AchillSarkophage zeigen tatsächlich den vereinfachten oberen Kastenabschluss.

Um 230 n. Chr.

\subsection{Eckfragment eines oberen Kastenabschlusses mit Kriegerkopf}

(Kat. 23 Taf. 68 Abb. 282 f.)

Selçuk, Efes Müzesi Inv. 43/1/88.

Gefunden in Selçuk, Johannesbasilika, Fund-Nr. StJ 75/11.

H 21; L der linken Seite 18,5; L der rechten Seite 7,5.

Lit.: Unpubliziert.

Feinkristalliner, heller Marmor. Die geglättete Oberseite des Fragments ist erhalten, die Rückseite gebrochen.

Auf der linken Seite des Fragments ist ein Kriegerkopf nach links gewendet. Die Ohröffnung und eine Konturlinie hinter dem Ohr sind gebohrt. Der Helmstutz der Figur ragt über ein nicht ornamentiertes S-förmiges Profil bis in die breite, geglättete obere Leiste hinauf.

Auf der rechten Seite des Fragments ist die obere Leiste mit einem Eckfeld aus Blattwerk verziert, darunter ist das S-förmige Profil mit einem lesbischen Kyma ornamentiert. Damit ist diese Seite des Fragments als eine bevorzugt gearbeitete Seite des Sarkophags ausgewiesen. Ungewöhnlich ist hier zum einen, dass unter dem lesbischen Kyma kein Eierstab folgt, sondern eine Palmette, und zum anderen, dass diese Seite die Rückansicht des behelmten Kriegerkopfes zeigt.

Glücklicherweise gibt es eine hervorragende Parallele: das Fragment eines AmazonomachieSarkophags in Athen ${ }^{588}$, bei dem es sich ebenfalls um ein Eckfragment des oberen Kastenrands handelt. Die bevorzugt gearbeitete rechte Sarkophagseite bietet dort die Abfolge Perlstab, Eierstab, lesbisches Kyma und eine obere Leiste, die mit einem Eckfeld, das durch Akanthusranken geschmückt, und einem Hakenkreuzmäander, durchsetzt von Rosettenfeldern, verziert ist. An der Ecke zeigt sich, wie im Museum von Ephesos, die Ansicht des behelmten Hinterkopfes eines Kriegers, neben der eine Palmette anstelle des ersten Eis des Eierstabs erscheint; auf der linken

583 s. Rogge 1995, 48 f. 126 f. Nr. 6 Taf. 54, 3; 56, 3.

584 Rogge 1995, 134 Nr. 21 Taf. 67, 1.

585 Rogge 1995, 133 f. Nr. 20 Taf. 66, 1.

586 Rogge 1995, 145 Nr. 44 Taf. 66, 3.

587 Rogge 1995, 143 f. Nr. 42 Taf. 71, 2.

588 Im Depot der 3. Ephorie mit der Inv. M 3028. Orlandos 1962, 12 Abb. 14; Daux 1963, 696 Abb. 13; Kintrup 2016a, Kap. 3.1.3.3 Nr. 46. 
Seite des Fragments sind die Profile und die obere Leiste geglättet. Die Eckfigur ragt hier wie dort weit in das lesbische Kyma.

\section{Datierung}

Für das Hineinragen der Eckfigur in das lesbische Kyma und zu der Profilabfolge mit Metopenmäander bietet der Schlachtsarkophag des Aemilius Aristides (Kat. 1 Taf. 2) einen so guten Vergleich, dass die Fragmente in Athen und in Abhängigkeit dazu das Fragment im Ephesos Museum um 200 n. Chr. angesetzt werden können.

Eine eindeutige Identifizierung der Szene ist anhand des behelmten Kopfes nicht möglich. Wahrscheinlich ist eine Zugehörigkeit zu einem Sarkophag mit Schlachtszene, wie die genannten Vergleiche zeigen. Möglich ist aber auch die Zugehörigkeit zu einem Achill-Sarkophag, wie zwei Beispiele in Rom, Museo Capitolino ${ }^{589}$, und in Woburn Abbey ${ }^{590}$ belegen, die aber beide deutlich jünger anzusetzen sind, nämlich in das zweite Viertel des 3. Jahrhunderts (Woburn Abbey) und gegen Mitte des 3. Jahrhunderts n. Chr. (Rom, Museo Capitolino).

Um 200 n. Chr.

\subsection{Fragment mit oberem Kastenabschluss und Kopf eines Jünglings}

(Kat. 24 Taf. 68 Abb. 284)

Selçuk, Efes Müzesi Inv. 1/8/74591.

Gekauft 1974 in Selçuk.

H 29; L 8; D 15,5; Rh 4.

Lit.: Koch 1991, 819 Nachtrag Nr. 6.

Feinkristalliner, heller Marmor. Die Oberseite des Fragments ist mit Falz erhalten. Die Oberfläche des Reliefs ist z. T. abgeplatzt; die Nase der Figur bestoßen. Die Rückseite zeigt eine gleichmäßige Spitzmeißelarbeit.

Auf dem oberen Kastenabschluss sind keine Ornamente zu erkennen, es dürfte sich aber um ein geschwungenes Profil gehandelt haben. Darunter ist der kurzgelockte Kopf eines Jünglings nach links deutlich abgesetzt. Ein kleiner Reliefrest unter dem Hals links ist nicht genauer zu bestimmen - es könnte sich um Finger einer Hand auf der Schulter handeln oder um Gewandreste. Da keine deutlichen Bohrungen in den Augen- und Mundwinkeln oder in den Haaren vorhanden sind und die Reliefhöhe nicht sehr tief ist, handelt es sich vielleicht um die Hintergrundfigur einer bevorzugt ausgeführten Sarkophagseite, oder aber das Fragment gehörte einer vernachlässigt gearbeiteten Seite des Sarkophags an. Für Letzteres würde auch ein ohne Ornament belassenes, oberes Profil sprechen. Da der Kopf dennoch detailliert ausgeführt wurde - am Hals ist eine fein eingetiefte Falte zu erkennen - , dürfte das Fragment eher einer Schmalseite als einer in der Regel deutlich summarischer gestalteten Rückseite angehört haben.

Ungewöhnlich ist, dass der Kopf vernehmlich unterhalb eines oberen Kastenabschlusses bleibt, der ein geschwungenes Profil aufzuweisen scheint. Die frühen Sarkophage des 2. Jahrhunderts bis ca. 210 n. Chr., bei denen die Figuren unterhalb eines oberen Kastenabschlusses bleiben, weisen in aller Regel eine Ornamentfolge von Perlstab, Eierstab und lesbischem Kyma auf ${ }^{592}$.

\footnotetext{
589 Inv. 218: Koch - Sichtermann 1982, 383-385. 457 f. Abb. 413; Rogge 1995, 136-138 Nr. 24 Taf. 68.

590 Koch - Sichtermann 1982, 385-388. 458 Abb. 418; Rogge 1995, 145 f. Nr. 45 Taf. 71, 1.

591 So auf dem Fragment und im Inventarbuch vermerkt. Bei der von Koch 1991, 819 Nachtrag Nr. 6 angegebenen »Inv. J/9/74 « wird es sich um eine Verlesung handeln.

592 s. z. B. Achill-Sarkophage in Adana: Rogge 1995, 125 Nr. 1 Taf. 2. 17, 1, und in Beirut: Rogge 1995, 127 f. Nr. 7 Taf. 1, 1; 18, oder einen Hippolytos-Sarkophag in Beirut: Rogge 1995, 151 Nr. 56 Taf. 76, 1; 82, 2.
} 
Auch ohne Ornament passt dies nicht zu den Profilresten hier ${ }^{593}$. Bei den deutlich späteren Sarkophagen des zweiten Viertels des 3. Jahrhunderts n. Chr., die ein geschwungenes Profil aufweisen, ragen hingegen die Figuren meist weit in das Profil ${ }^{594}$. Dies und der Erhaltungszustand erlauben keine eindeutige Zuordnung.

Für den gelockten Kopf im Profil sind verschiedene Deutungen denkbar. Abgesehen von einer stehenden Figur könnte möglicherweise auch eine sitzende Figur dargestellt gewesen sein. Parallelen finden sich auf einem Achill-Sarkophag in Beirut ${ }^{595}$, wo auf der rechten Schmalseite der sitzende Neoptolemos mit Blick nach links - allerdings auch unter einer Profilfolge - abgebildet ist. Der Kopf des sitzenden Achill auf der linken Schmalseite des Achill-Sarkophags in Woburn Abbey (Kat. 3 Taf. 36) erscheint etwas mehr nach unten geneigt, man könnte Reste der Hand am Kopf erwarten. Auf der linken Schmalseite des Meleager-Sarkophags in Eleusis ${ }^{596}$ ist die Profilfolge über einem Stehenden unvollendet belassen. Auf der Front des Hippolytos-Sarkophags in Apollonia (Libyen) ${ }^{597}$ ist eine männliche Figur mit Blick nach links auf einen Stock gestützt abgebildet; die Figur ragt nur leicht in das obere geschwungene Profil, das aber auch ornamentiert ist. Ohne bessere Vergleichsstücke sind eine Identifizierung der Darstellung sowie eine genauere Datierung nicht möglich.

\section{Datierung}

Erste Hälfte des 3. Jahrhunderts n. Chr.

4.5 Kopf eines Kriegers (Kat. 25 Taf. 68 Abb. 285)

Selçuk, Efes Müzesi, Inv. nicht bekannt

H 15; L 10.

Lit.: Targaç 2004, 66 f. Nr. 52.

Die bei M. Targaç genannte Inv. 1222 ist laut Inventarbuch leider nicht richtig, sodass der Kopf nicht aufgefunden werden konnte. Die Besprechung konnte nur anhand der Abbildung erfolgen.

Der nach rechts gewendete Kriegerkopf weist im Wesentlichen Bestoßungen an seinem korinthischen Helm sowie an seiner rechten Augenbraue, Nase, Mund und Kinn auf. Die Augen- und Mundwinkel zeigen Punktbohrungen, die Augenbrauen sind als eingetiefte Linien ausgeführt. Ausarbeitung und Stil, Maße sowie ein kleiner Rest vermutlich des Reliefgrundes rechts neben dem Helm machen die Zugehörigkeit zu einem attischen Sarkophag wahrscheinlich.

Vergleiche mit Kriegern mit korinthischem Helm bieten Achill-Sarkophage sowie zahlreiche Amazonomachie- und Schlachtsarkophage und deren Fragmente, etwa die Achill-Sarkophage in Paris $^{598}$ und in Beirut ${ }^{599}$, allerdings ist dort der Kopf nach links gewendet. Mit Blick nach rechts stellt der Achill-Sarkophag in Rom ${ }^{600}$ eine Parallele dar. Die Achill-Sarkophage in Rom und Beirut sind durch die Porträtköpfe ihrer Klinenfiguren um die Mitte des 3. Jahrhunderts n. Chr. zu datieren. Weitere Entsprechungen ${ }^{601}$ bieten die rechte Schmalseite des frühen Amazonomachie-

${ }_{593}$ Vgl. Rogge 1995, Taf. 17, 2; 82, 3.

594 s. z. B. den Achill-Sarkophag in Woburn Abbey Kat. 3 Taf. 35 f., oder Hippolytos-Sarkophage in Beirut: Rogge 1995, 152 Nr. 57 Taf. 102. 106, 1, oder in Arles: Rogge 1995, 150 Nr. 50 Taf. 103, 2.

595 Rogge 1995, 127 f. Nr. 7 Taf. 22.

596 Koch 1975, 142 f. Nr. 170 Taf. 136, 2.

597 Rogge 1995, 149 Nr. 49 Taf. 97, 1.

598 Koch - Sichtermann 1982, 383-385. 457 f. Abb. 413; Rogge 1995, 134 Nr. 21 Taf. $43,3$.

599 Koch - Sichtermann 1982, 385. 457 f. Abb. 414; Rogge 1995, 126 f. Nr. 6 Taf. 52, 2; 54, 1.

600 Rogge 1995, 136-138 Nr. 24 Taf. 44.

601 Etliche Beispiele von Kriegern mit korinthischem Helm sind zudem mit Blick nach links dargestellt. 
Sarkophags in Paris ${ }^{602}$, die linken Schmalseiten der späten Amazonomachie-Sarkophage in Jerusalem $^{603}$ und Thessaloniki ${ }^{604}$, ferner die rechte Schmalseite des Schlachtsarkophags in Athen ${ }^{605}$ sowie die Vorderseiten der Schlachtsarkophage in Askalon ${ }^{606}$, Beirut ${ }^{607}$ und Tyros ${ }^{608}$, die alle nach 230 n. Chr. entstanden sind.

\section{Datierung}

Die eingetieften Augenbrauen sowie die weichen Konturen und das fleischige Gesicht sind Merkmale attischer Sarkophage nach 240 n. Chr., wie beispielsweise der Amazonomachie-Sarkophag in Thessaloniki ${ }^{609}$ oder der Schlachtsarkophag in Antalya belegen ${ }^{610}$. Eine entsprechende Datierung wird somit auch für das ephesische Fragment vorgeschlagen.

Um die Mitte des 3. Jahrhunderts n. Chr.

\subsection{Fragment eines oberen Kastenbereichs mit Ornament und Kopf}

(Kat. 26 Taf. 68 Abb. 286)

Selçuk, Efes Müzesi Inv. 17/8/82.

Gefunden in Selçuk, Johannesbasilika, westliche Stützmauer (1981), Fund-Nr. St.J 81/24.

H der Reliefzone 13,5; H der RS 21; L 8; D am oberen Profil 18; DW 14; Rh 7.

Lit.: Unpubliziert.

Feinkörniger, heller Marmor. Bis auf ein Stück der Oberseite mit abgebrochenem Falz (H 2 cm erhalten) allseitig gebrochen. Auf der Rückseite des Fragments ist eine verriebene, grobe Spitzmeißelbearbeitung vorhanden. Reste der Kontur- und Punktbohrungen in den Augenwinkeln sind zu erkennen; der keulenförmige Reliefrest ist mit dem Flachmeißel gearbeitet.

Fragment des oberen Kastenabschlusses mit stark beschädigten Reliefresten. Auf der oberen Leiste ist ein Ornament aus gerankten Akanthusblättern angebracht. Dem Ornament fehlen ungefähr 1,5 cm bis zur Oberseite des Kastens; die ursprüngliche Höhe des Ornamentbands ist mit etwa $5 \mathrm{~cm}$ zu veranschlagen. Die schräge Ablauffläche darunter blieb ohne Dekor. Ein stark beschädigtes Gesicht blickt schräg nach links oben. Es ist unklar, wie die Reste über dem Gesicht neben dem keulenförmigen Reliefrest zu deuten sind.

Die Bearbeitungsspuren und das sehr flach ausgeführte obere Ornament deuten auf eine vernachlässigte Schmal- oder Rückseite, wobei Rückseiten zumeist keine Ornamente am oberen Kastenabschluss aufweisen. Ohne das erhaltene Stück des Falzes würde man das Fragment eher einer Sockelzone zuordnen, denn ein flaches Akanthusdekor wie hier findet sich häufig am Sockel attischer Sarkophage, so auf der Vorderseite und der bevorzugt gearbeiteten linken Schmalseite eines dionysischen Sarkophags in Boston ${ }^{611}$, um 230 n. Chr. ${ }^{612}$, und eines weiteren dionysischen

602 Baratte 1985, 256-261 Nr. 166; 259 mit Abb.; Kintrup 2016a, Kap. 3.1.1.1 Nr. 156.

603 Fischer 1998, 208 Nr. 213; 225 f. Abb. 213 d.; Kintrup 2016a, Kap. 3.2.11 Nr. 112.

604 Kintrup 2016a, Kap. 3.2.13 Nr. 247.

605 Robert 1890, 131 f.; Koch - Sichtermann 1982, 407. 408 Nr. 14; 458; Kintrup 2016a, Kap. 4.2.5 Nr. 55.

606 Fischer 1998, 205 Nr. 196; 213-215 Abb. 196 a; Kintrup 2016a, Kap. 4.2.7 Nr. 31.

607 Koch - Sichtermann 1982, 407. 408 Nr. 20; 458 Abb. 442; Chéhab 1985, 687 f. Taf. 137; Kintrup 2016a, Kap. 4.2.15 Nr. 72.

608 Koch - Sichtermann 1982, 405 f. 410 Nr. 66; 459 Abb. 443; Rogge 1995, 144 f. Nr. 43 Taf. 9, 2; Kintrup 2016a, Kap. 4.2.17 Nr. 260.

609 s. o. Anm. 604.

610 Giuliano - Palma 1978, 39 Nr. 6 Taf. 44, 107; 45; Linant de Bellefonds 1985, 111 f. Taf. 42, 1; Kintrup 2016a, Kap. 4.2.11 Nr. 4.

611 Matz 1968, 106-110 Nr. 9 Taf. 14; Koch - Sichtermann 1982, 419-422. 459.

612 Zu den Datierungen dionysischer Sarkophage s. Wiegartz 1977, 386-388 mit Anm. 90. 
Sarkophags in Kyrene, dort auch auf der bevorzugten linken Schmalseite, um 250 n. Chr. ${ }^{613}$. In diesem Zusammenhang zu beachten sind auch die Vorderseite eines Hippolytos-Sarkophags in Apollonia ${ }^{614}$ und die Vorderseite sowie die betonte Schmalseite eines Hippolytos-Sarkophags in Tarragona ${ }^{615}$; beide Exemplare gehören an das Ende des zweiten Viertels des 3. Jahrhunderts $n$. Chr. Auf der Vorderseite und bevorzugt gearbeiteten linken Schmalseite eines AmazonomachieSarkophags in Jerusalem ${ }^{616}$ und auf der Vorderseite sowie bevorzugten rechten Schmalseite eines Schlachtsarkophags in Beirut ${ }^{617}$, beide um 250 n. Chr., findet sich das gleiche Ornament am Sockel wie auch auf der Vorderseite und der bevorzugt gearbeiteten linken Schmalseite des Achill-Sarkophags Woburn Abbey, um 240 n. Chr. (Kat. 3 Taf. 35 f.) ${ }^{618}$. Auf dem HippolytosSarkophag in St. Petersburg ${ }^{619}$ kommt das Akanthusdekor zwar ebenfalls am Sockel, aber, wie für das ephesischen Fragment vermutet, auch auf der vernachlässigten Schmalseite - es ist die linke vor. Alle genannten Vergleiche gehören in das zweite Drittel des 3. Jahrhunderts, die meisten an das Ende des zweiten Viertels des 3. Jahrhunderts n. Chr., und grenzen so auch die Datierung des Fragments in Ephesos ein. Aber ein Beleg für ein Dekor des oberen Kastenabschlusses bestehend aus Ranken und Blüten kommt unserem Fragment nahe: es handelt sich um das Fragment eines dionysischen Sarkophags in Gortyn auf Kreta ${ }^{620}$.

Das Dekor von Akanthusranken in flachem Relief tritt zudem auch auf Vorderseiten von Matratzen einiger Klinendeckeln auf, wie Belege ebenfalls aus dem zweiten Drittel des 3. Jahrhunderts bezeugen, so der Deckel des Amazonomachie-Sarkophags aus dem Tatiane-Grab (Kat. 2 Taf. 30 f. $)^{621}$ mit eingestreuten Tieren. Da das Dekor auch auf Klinenmatratzen verwendet wurde, muss es nicht allzu sehr verwundern, es hier als Schmuck einer oberen Leiste zu finden.

Zunächst bleibt jedoch die Frage nach der Deutung der Darstellung offen. Handelt es sich bei dem nicht geglätteten Reliefrest um eine Keule, wäre das ein Hinweis auf eine Kentauromachie, denn Kentauren ${ }^{622}$ sind mit Steinen und Keulen bewaffnet und kommen einige Male auf Rückseiten attischer Sarkophage vor: z. B. auf den Rückseiten der dionysischen Sarkophage in Thessaloniki (um 260 n. Chr.) ${ }^{623}$ und in Kyrene (um 250 n. Chr.) ${ }^{624}$ oder den Rückseiten eines Schlachtsarkophags in Athen (230-240 n. Chr.) ${ }^{625}$, eines Amazonomachie-Sarkophags in London (um 240 n. Chr.) ${ }^{626}$ und auf einem Rückseitenfragment in Split, ebenfalls aus dem zweiten Drittel des 3. Jahrhunderts ${ }^{627}$. Vielleicht sind die Reste über dem Gesicht als Griff eines Gegners in die Haare zu deuten, wie es auf der Rückseite in Kyrene und in frontaler Ansicht in Split der Fall ist.

613 Matz 1968, 116-118 Nr. 11A Taf. 23, 1. Datierung nach Wiegartz 1977, 386-388 mit Anm. 90.

614 Rogge 1995, 149 Nr. 49 Taf. 97, 2.

615 Rogge 1995, 156 Nr. 68 Taf. 89, 3.

616 Fischer 1998, 208 Nr. 213; 225 f. Abb. 213. 213 d.; Kintrup 2016a, Kap. 3.2.11 Nr. 112.

617 Chéhab 1985, 687 f. Taf. 137 f.; Kintrup 2016a, Kap. 4.2.15 Nr. 72.

618 s. dort Ausführungen zu Entwicklung von Aufbau und Dekor des oberen Kastenabschlusses und der Sockelzone, die wichtige Kriterien für eine Datierung liefern.

619 Rogge 1995, 154 f. Nr. 64 Taf. 104, 2.

620 Ghisellini 1985, 283 f. Nr. 9 Abb. 12.

621 s. dort Anm. 174 mit einer Zusammenstellung weiterer Vergleichsstücke.

622 Zu Kentauromachien: Koch - Sichtermann 1982, 398 f.; Leventopoulou - Sengelin 1997, 671-721; 720 (zu möglichen Deutungen); Oakley 2011, 27-32. 78-84 Taf. 24 f. 27-32.

623 Matz 1968, 112-116 Nr. 11 Taf. 17. Zur Datierung s. Wiegartz 1977, 386-388 mit Anm. 90; Oakley 2011, 32.83 f. Nr. 41 Taf. 32, 2. Zwei Kentauren werden von zwei Greifen angegriffen.

624 Matz 1968, 116-118 Nr. 11A Taf. 21, 2; Wiegartz 1977, 386-388 mit Anm. 90; Oakley 2011, 29-31; 79 f. Nr. 31 Taf. 28, 1. Auf der Rückseite Kyrene ist auch der Lapith ganz rechts mit einer Keule bewaffnet.

625 Robert 1890, 131 f.; Koch - Sichtermann 1982, 407. 408 Nr. 14; 458; Oakley 2011, 29-31. 80 Nr. 32 Taf. 28, 2; Kintrup 2016a, Kap. 4.2.5 Nr. 55.

626 Koch - Sichtermann 1982, 391 mit Anm. 13; 398 mit Anm. 9; 458; Walker 1990, 40 f. Nr. 45 Taf. 18; Oakley 2011, 29-31; 82 f. Nr. 38 Taf. 31, 1; Kintrup 2016a, Kap. 3.2.9 Nr. 130.

627 Koch - Sichtermann 1982, 398 f. Abb. 424; Cambi 1988, 124-127 Nr. 30 Taf. 17; Oakley 2011, 29-31. 80 f. Nr. 33 Taf. 29, 1. Hier wie in Kyrene ist ebenfalls ein Lapith rechts mit einer Keule bewaffnet. 
Keulen können aber auch in Jagdszenen erscheinen, so auf den Rückseiten der späten Hippolytos-Sarkophage in Agrigent ${ }^{628}$ und St. Petersburg ${ }^{629}$ oder der Vorderseite eines ebenfalls späten Meleager-Sarkophags in Split ${ }^{630}$ mit den jeweils entsprechenden Eberjagden. Allerdings sind die Köpfe der Jagdteilnehmer nach unten auf den Eber gerichtet, in Ephesos hingegen nach oben.

\section{Datierung}

Die vorgeschlagenen Rekonstruktionsmöglichkeiten bleiben zwar hypothetisch, aber die genannten Vergleiche bestätigen die Datierung.

Ende des zweiten Viertels des 3. Jahrhunderts n. Chr.

\subsection{Fragment des oberen Kastenbereichs mit einem Trompeter}

(Kat. 27 Taf. 69 Abb. 287)

Selçuk, Efes Müzesi Inv. 17/71/78.

Gefunden in Selçuk, Johannesbasilika, Fund-Nr. 78/39.

H 25; L 28; D 21; DW 15; Rh 6.

\section{Lit.: Unpubliziert.}

Feinkörniger, heller Marmor mit rötlichen Einschlüssen. Die geglättete Oberseite des Fragments ist mit Falz (H 2; B 3,5) erhalten. Die Rückseite des Fragments zeigt eine regelmäßige, feine bis mittlere Spitzmeißelbearbeitung, wobei der obere Rand auf $4 \mathrm{~cm}$ geglättet ist. Der Ansatz der Ecke ist auf der rechten Seite der Sarkophaginnenseite erhalten. An der Frontseite des Fragments sind Konturbohrungen gut zu erkennen sowie Bohrungen zur Angabe der Umrisse des Ohrs und der Ohröffnung der Figur, deren Gesicht geglättet, aber nicht poliert ist.

Fragment des oberen Kastenabschlusses mit dem Kopf eines Trompeters. Der Tubicen mit geblähten Wangen ist in einer typischen Haltung mit der linken Hand am Hinterkopf nach links gewendet. Das Mundstück seines Instruments ist erhalten. Durch den Eckansatz auf der Rückseite des Fragments verifiziert, hat der Trompeter eine typische Position an der Ecke einer Darstellung.

Die obere und die schräge Ablauffläche darunter blieben ohne Dekor; eine feine Flacheisenbearbeitung ist zu erkennen. Der schlichte, nichtdekorierte obere Kastenabschluss bietet einen Hinweis auf die Zugehörigkeit zu einer vernachlässigten Schmal- oder Rückseite, da diese oft ohne Ornamentierung belassen wurden. Vergleiche bieten die linke Schmalseite eines Achill-Sarkophags in Paris ${ }^{631}$ (Mitte des 3. Jhs. n. Chr.), die linke Schmalseite eines Hippolytos-Sarkophags in Beirut ${ }^{632}$ (2. Viertel des 3. Jhs. n. Chr.) sowie die Rückseiten eines dionysischen Sarkophags in Kyrene (um 250 n. Chr.) ${ }^{633}$, eines Schlachtsarkophags in Athen (230-240 n. Chr.) ${ }^{634}$ und ein Rückseitenfragment in Split, auch aus dem zweiten Drittel des 3. Jahrhunderts ${ }^{635}$.

Interessant ist, dass auf der oberen Leiste anscheinend die Reste eines leicht vorspringend gearbeiteten Eckfelds zu erkennen sind. Bekannt, aber auch selten sind vorspringend gearbeitete

628 Rogge 1995, Nr. 47 Taf. 109, 1.

629 Rogge 1995, Nr. 64 Taf. 110, 2-3.

630 Koch 1975, 145 f. Nr. 178 Taf. 139, 1; Cambi 1988, 127-129 Nr. 31 Taf. 18.

631 Rogge 1995, 134 Nr. 21 Taf. 64, 1.

632 Rogge 1995, 152 Nr. 57 Taf. 106.

633 Matz 1968, 116-118 Nr. 11A Taf. 21, 2; Wiegartz 1977, 386-388 mit Anm. 90; Oakley 2011, 29-31. 79 f. Nr. 31 Taf. 28, 1.

634 Robert 1890, 131 f.; Koch - Sichtermann 1982, 407. 408 Nr. 14; 458; Oakley 2011, 29-31. 80 Nr. 32 Taf. 28, 2; Kintrup 2016a, Kap. 4.2.5 Nr. 55.

635 Koch - Sichtermann 1982, 398 f. Abb. 424; Cambi 1988, 124-127 Nr. 30 Taf. 17; Oakley 2011, 29-31. 80 f. Nr. 33 Taf. 29, 1. 
Eckpostamente der Sockelzone, wie sie z. B. der Amazonomachie-Sarkophag in London zeigt, dessen Datierung um 240 n. Chr. zu veranschlagen ist ${ }^{636}$.

Der Kopf des Trompeters reicht knapp bis unter die obere Leiste und bestätigt so eine Datierung nach $230 \mathrm{n}$. Chr. Die abwärts verlaufende Rundung rechts scheint eher regelmäßig gebrochen als absichtlich gearbeitet, oder aber es könnte sich um einen Torbogen handeln. Ein Trompeter rechts und ein Torbogen links finden sich auf der linken Schmalseite des Achill-Sarkophags in Paris ${ }^{637}$. Parallelen für eine thematische Zuordnung sind also auf Achill-Sarkophagen zu finden. Ein Tubicen erscheint auf weiteren Achill-Sarkophagen, die die Entdeckung des Helden auf Skyros darstellen, so auch auf der Schmalseite in Beirut ${ }^{638}$. Die häufigste Verwendung finden Trompeter jedoch auf Sarkophagen mit Schlachtszenen.

\section{Datierung}

Zweites Viertel des 3. Jahrhunderts n. Chr.

4.8 Fragment eines Kastens mit Sockelzone (Kat. 28 Taf. 69 Abb. 288)

Selçuk, Efes Müzesi, Açık Hava Deposu, ohne Inv.

Fundort unbekannt.

H 35; L 47; T 30,5; Rh 9.

Lit.: Unpubliziert.

Mittelkörniger, heller Marmor mit Glimmerader. Die Unterseite ist erhalten, sonst allseitig gebrochen. Deutliche Umrissbohrungen. Links verläuft der Bruchrand der Reliefdarstellung entlang einer Glimmerader. Oberhalb der Sockelzone links neben einem Fuß sind Flachmeißelspuren zu erkennen.

Ein kleiner Abschnitt der flachen Sockelzone ist mit Ornamentierung erhalten. Zu sehen sind Blattranken unter einer Standleiste, die einen flachen Zahnschnitt trägt.

Auf der weit zurückspringenden Standleiste erscheint ein linker Fuß leicht nach rechts gewendet, auf seinen Zehen sind kleine Falten eingetieft. Das Bein ist ab dem Knöchel aufwärts gebrochen, etwa in Kniehöhe bricht das Fragment ab. Links neben der verlorenen Wade ist ein leicht vorspringender Reliefrest erhalten. Rechts neben dem Fuß folgen schräg nach oben rechts verlaufende Reliefreste, bei denen es sich um Tierbeine handelt. Im Unterschied zu den Hundepfoten auf den Vorderseiten von Hippolytos-Sarkophagen in Beirut ${ }^{639}$ oder St. Petersburg ${ }^{640}$ und zu Eberfüßen auf den Rückseiten von Hippolytos-Sarkophagen in Agrigent ${ }^{641}$ und St. Petersburg ${ }^{642}$ handelt es sich hier bei den schlanken, behuften Tierbeinen eher um ein Jagdtier, etwa Reh, Hirsch oder Wildziege; hierfür ist die Schmalseite eines Hippolytos-Sarkophags in Arles mit einer Jagdszene heranzuziehen ${ }^{643}$. Bessere Parallelen bieten dafür aber die seltenen nichtmythologischen

\footnotetext{
636 Walker 1990, 40 f. Nr. 45 Taf. 18; Kintrup 2016a, Kap. 3.2 .9 Nr. 130; s. ebenfalls: Schlachtsarkophag in Beirut: Chéhab 1985, 687 f. Taf. 137-139; Wielgosz 2001, 169 f. Abb. 3; Kintrup 2016a, Kap. 4.2.15 Nr. 72, mit einer Datierung um 250 n. Chr. s. auch den Hippolytos-Sarkophag in Apollonia: Linant de Bellefonds 1985, Taf. 59, 2; Rogge 1995, 149 Nr. 49 Taf. 97, 2, ebenfalls um 250 n. Chr.

637 Rogge 1995, 134 Nr. 21 Taf. 64, 1.

638 Rogge 1995, 126 f. Nr. 6 Taf. 65, 1.

639 Rogge 1995, 152 Nr. 57 Taf. 86.

640 Rogge 1995, 154 f. Nr. 64 Taf. 90.

641 Rogge 1995, 148 Nr. 47 Taf. 109, 1.

642 Rogge 1995, 154 f. Nr. 64 Taf. 110, 2-3.

${ }_{643}$ Rogge 1995, 150 Nr. 50 Taf. 108, 1.
} 
attischen Jagdsarkophage ${ }^{644}$, so die Exemplare in Budapest-Split ${ }^{645}$, Kyrene ${ }^{646}$ und Gotha $^{647}$, die alle in das zweite Viertel des 3. Jahrhunderts n. Chr. zu datieren sind. Als weitere Möglichkeit einer thematischen Zuordnung seien dionysische und Sarkophage mit Eroten-Weinlese genannt, die einen Ziegenbock abbilden, der zumeist zum Abtransport der Trauben beladen wird, so auf dem dionysischen Sarkophag in Thessaloniki ${ }^{648}$ und dem Eroten-Weinlese-Sarkophag im >Tor der Verfolgung، (Kat. 10 Taf. 46). Bei beiden Belegen erscheinen die Beine des Ziegenbocks allerdings eher etwas kürzer zu sein, als es bei dem ephesischen Fragment der Fall ist. Eine thematische Zuordnung bleibt hypothetisch.

\section{Datierung}

Mit dem flachen Sockel, dem floralen Ornament und dem Zahnschnitt ist das Fragment wahrscheinlich ab dem zweiten Viertel des 3. Jahrhunderts n. Chr. anzusetzen ${ }^{649}$, vergleiche beispielsweise einen Amazonomachie-Sarkophag in Jerusalem (um 250 n. Chr.) ${ }^{650}$, die Schlachtsarkophage in Athen (230-240 n. Chr. $)^{651}$ und St. Petersburg (250/260 n. Chr.) ${ }^{652}$ sowie einen Hippolytos-Sarkophag in Agrigent aus dem zweiten Viertel des 3. Jahrhunderts n. Chr. ${ }^{653}$.

230-260 n. Chr.

4.9 Fragment eines Kastenreliefs (Kat. 29 Taf. 69 Abb. 289)

Selçuk, Efes Müzesi, Açık Hava Deposu, Etd.Nr. L. 178.

Fundort unbekannt.

H 18; L 44; DW 7,5-8; Rh maximal erhalten 3,5.

Lit.: Unpubliziert.

Feinkörniger, heller Marmor. Allseitig gebrochen. Die Oberfläche ist stark verwittert. An Bearbeitungsspuren sind nur Bohrkanäle, die z. T. um die Reliefteile herumführen, zu erkennen. Die Rückseite des Fragments zeigt eine gleichmäßige mittelgrobe Spitzmeißelbearbeitung.

Die Orientierung des Fragments ist nicht gesichert. In der hier abgebildeten Orientierung (Taf. 69 Abb. 289) erscheint links ein etwas größerer ungeklärter Reliefrest; die Oberfläche ist nicht erhalten. In der Mitte sind flache Gewandfalten erkennbar und rechts am Rand ein Detail, das auf den ersten Blick wie ein rechter Fuß mit Knöchelansatz oder ein Ellenbogen anmutet, aber nicht das entsprechende Volumen dafür hat; zudem verläuft eine fein eingetiefte Linie entlang der Rundung. Es bleibt Reliefgrund frei, sodass ein kleiner Hinweis auf eine nicht späte Datierung oder die Zugehörigkeit zu einer vernachlässigten Sarkophagseite gefunden ist; Letzteres erscheint trotz des beschädigten Zustands aufgrund der erkennbar guten Ausführung aber weniger wahrscheinlich.

644 Dazu und zu wenigen anderen nichtmythologischen Beispielen s. Wiegartz 1975, 177 Anm. 99; 182.196 f. mit Anm. 206-209; 216 mit Anm. 306; Koch - Sichtermann 1982, 379 f. Abb. 406; Rogge 1993, 111 mit Anm. 7.

645 Rodenwaldt 1952, 31-42, bes. Abb. 1 und 6; Koch - Sichtermann 1982, 379 Abb. 427 f.; Cambi 1984, 185-196, bes. Abb. 8; Marin 1992, passim; Rogge 1998, 201-205 Taf. 90, 1-2.

646 Rodenwaldt 1952, Abb. 8 f.; Rogge 1998, 203-205 Taf. 90, 3; 91, 1-2.

647 Rogge 1998, 201-205 Taf. 91, 3.

648 Matz 1968, 112-116 Nr. 11 Taf. 18.

649 Zu Aufbau und Dekor der Sockelzone, die wichtige Anhaltspunkte für eine Datierung bieten, s. z. B. Ausführungen zum Achill-Sarkophag Woburn Abbey Kat. 3 Taf. 35 f. Vgl. auch Rogge 1993, 116.

650 Fischer 1998, 208 Nr. 213; 225 f. Abb. 213 a. d; Kintrup 2016a, Kap. 3.2.11 Nr. 112.

651 Robert 1890, 131 f.; Koch - Sichtermann 1982, 407. 408 Nr. 14; 458; Kintrup 2016, Kap. 4.2 .5 Nr. 55.

652 Saverkina 1979, 24 f. Nr. 5 Taf. 11-13; Kintrup 2016a, Kap. 4.2.19 Nr. 237.

653 Koch - Sichtermann 1982, Abb. 426; Rogge 1995, 148 Nr. 47 Taf. 89, 1. 
Das flatternde Gewand bietet kein eindeutiges Indiz für die Thematik. Vergleiche sind auf frühen dionysischen Sarkophagen in Istanbul (ca. 160-170 n. Chr.) ${ }^{654}$ oder in Ioannina (ca. 170180 n. Chr. ${ }^{655} \mathrm{zu}$ finden, darüber hinaus auf frühen Erotensarkophagen in Istanbul (um $150 \mathrm{n}$. Chr.) ${ }^{656}$ oder Athen (3. Viertel des 2. Jhs. n. Chr.) ${ }^{657}$. Spätere Darstellungen lassen weniger Reliefgrund frei; das gilt auch für bevorzugt gearbeitete Schmalseiten im 3. Jahrhundert.

\section{Datierung}

Zweite Hälfte des 2. Jahrhunderts n. Chr.

\subsection{Kastenfragment mit Kriegerbein (Kat. 30 Taf. 69 Abb. 290) ${ }^{658}$}

Gefunden in Selçuk, sog. İsa Bey-Hamam, Sondage 1 über Ostmauer. Fund-Nr. 24/2001659. Selçuk, Depot des österreichischen Grabungshauses.

\section{H 22,5; L 9.}

Lit.: Unpubliziert.

Grobkörniger, weißer Marmor mit grauem Glimmer. Das allseitig gebrochene Fragment zeigt an der geglätteten Oberfläche Versinterungen und Wurzelfasern. Bohrungen setzen die Pteryges voneinander ab. Aufgrund der Ausarbeitung gehörte das Fragment wohl zu einer bevorzugt gearbeiteten Sarkophagseite.

Das Fragment zeigt ein Knie mit Teilen von Ober- und Unterschenkel. Der Oberschenkel ist von den Pteryges bedeckt. Die angewinkelte Haltung und Muskelangabe verraten die Bewegung eines Stehenden nach links; bei einem Reiter wäre das Knie deutlicher angewinkelt. Die Pteryges zeigen, dass es sich bei der zu ergänzenden Figur um einen Gepanzerten handelte.

Stehende Gepanzerte kommen zahlreich auf attischen Sarkophagen mit Schlachtszenen vor, sind aber auch bei Achill-Sarkophagen häufiger belegt. Bei einem Fragment eines attischen Amazonomachie-Sarkophags in Thessaloniki (um 230-240 n. Chr.) ${ }^{660}$ ist der Unterschenkel des Gepanzerten von einem Pferdekopf verdeckt. Der späte Amazonomachie-Sarkophag ebenfalls in Thessaloniki ${ }^{61}$ bietet auf der linken Schmalseite einen Gepanzerten, der aber mehr nach rechts bewegt ist. Im Hinblick auf die Bewegungsrichtung zeigt die beschädigte Figur an der linken Ecke der Vorderseite des Achill-Sarkophags Woburn Abbey (Kat. 3 Taf. 35) aus dem zweiten Viertel des 3. Jahrhunderts n. Chr. eine gute Parallele.

Einen schönen stilistischen Vergleich zu den durch Bohrungen voneinander abgesetzten Pteryges mit gerundetem unteren Abschluss stellt der Achill-Sarkophag in Beirut auf seiner rechten Schmalseite dar ${ }^{62}$, der anhand der Porträtköpfe auf dem Deckel um die Mitte des 3. Jahrhunderts angesetzt werden kann. Allerdings ist hier wie auch bei weiteren Vergleichen auf Achill-Sarko-

654 Matz 1968, 100 f. Nr. 3 Taf. 4, 1; Koch - Sichtermann 1982, 419-422. 459 Abb. 449. Datierung nach Wiegartz 1977, 386-388 mit Anm. 90.

655 Matz 1968, 104-106 Nr. 8 Taf. 10; Datierung s. Wiegartz 1977, 386-388 mit Anm. 90.

656 Koch - Sichtermann 1982, 424 f. 429 Nr. 2 Abb. 455.

657 Koch - Sichtermann 1982, 424 f. 430 Nr. 9 Abb. 457.

658 Der Hinweis und alle Angaben werden J. Auinger verdankt.

659 Zu diesem Hamam s. Krickl - Pfeiffer-Taş 2002, 221-236.

660 Archäologisches Museum Inv. 229: Giuliano 1962, Nr. 231 f.; Giuliano - Palma 1978, 39 Nr. 2; Koch - Sichtermann 1982, 391 mit Anm. 14; Kintrup 2016a, Kap. 3.2.6 Nr. 243.

661 Archäologisches Museum Inv. 1245: Giuliano - Palma 1978, 39 Nr. 1 Taf. 42, 102; 43; Koch - Sichtermann 1982, 391 mit Anm. 11; 458 Abb. 421; Kintrup 1998, 212 f. Taf. 94, 3; Kintrup 2016a, Kap. 3.2.13 Nr. 247.

662 Nationalmuseum Inv. 607. Koch - Sichtermann 1982, 385 Abb. 414 (VS); Rogge 1995, 48 f. 126 f. Nr. 6 Taf. 59, 2; 62. 
phagen die Bewegungsrichtung des Gepanzerten nach rechts statt nach links gezeigt, mitunter stehen die Gepanzerten ruhig da ${ }^{663}$.

Den bereits genannten Vergleichen zufolge, stellt das Fragment in Ephesos ein rechtes Knie dar. Dies wird durch andere attische Schlachtsarkophage bestätigt: siehe ein Fragment in Umm Qais $^{664}$ (um 230-240 n. Chr.), die Vorderseite des Sarkophags Madrid-Tarragona ${ }^{65}$ (240-250 n. Chr.) sowie eine Vorderseite in Beirut ${ }^{666}$ mit einer Datierung um 250 n. Chr.

Alle zeigen die Bewegungsrichtung des Gepanzerten nach links.

\section{Datierung}

Zwar fehlen tektonische Elemente oder Ornamente bei dem Fragment in Ephesos, aber eine Datierung kann anhand der genannten stilistischen und typologischen Vergleiche, die alle ab dem zweiten Viertel des 3. Jahrhunderts bis $260 \mathrm{n}$. Chr. angesetzt wurden, eingegrenzt werden. Demnach gehört das ephesische Fragment wahrscheinlich ebenfalls in das zweite Drittel des 3. Jahrhunderts n. Chr.

Zweites Drittel des 3. Jahrhunderts n. Chr.

\subsection{Fragment mit oberem Kastenabschluss und Pferdekopf}

(Kat. 31 Taf. 70 Abb. 291)

Selçuk, Efes Müzesi Inv. 5/34/84.

Gefunden in Selçuk, Johannesbasilika, Fund-Nr. StJ 84/5.

H 21,5; L 12; Rh 8.

Lit.: Koch 1991, 819 Nachtrag Nr. 7.

Feinkristalliner, weißer Marmor. Die Oberseite des Fragments ist erhalten, die Oberfläche des Reliefs leicht verrieben mit kleineren Bestoßungen. Die Rückseite des Fragments ist gebrochen.

Eine dekorierte Leiste bildet den oberen Abschluss des Fragments. Darauf ist ein nach rechts laufender Hund zu erkennen, neben ihm findet sich Blattwerk. Darunter ist ein Kyma - ungewöhnlicherweise - aus hängenden statt aus stehenden Akanthusblättern angebracht. Dem schön gearbeiteten Pferdekopf nach rechts fehlt das Maul.

Ein Pferdekopf nach rechts ist nicht nur auf den Schlachtsarkophagen, sondern häufig auch im Kontext von Achill-, Hippolytos- oder Meleager-Sarkophagen zu finden ${ }^{667}$, sodass eine eindeutige thematische Zuordnung nicht möglich ist.

663 s. z. B. die Vorderseite des genannten Achill-Sarkophags in Beirut: Rogge 1995, Taf. 52, 2; 54, 3 sowie die Vorderseiten der Achill-Sarkophage in Tyros: Rogge 1995, Taf. 52, 1; 55, 1; und in Woburn Abbey Kat. 3 Taf. 35. Ferner s. z. B. die Schmalseiten der Achill-Sarkophage in Paris: Rogge 1995, Taf. 67, 1 und wieder in Tyros: Rogge 1995, Taf. 67, 2, die die Rüstung Achills zeigen.

664 Museum, o. Inv.: Piccirillo 1981, 31 Taf. 17-19. 23 (Eckpostament und Deckel); Kerner 1997, 293-295 Abb. 15 (anderes Fragment); Weber 2002) 78. 232 f. 499 SK 1 Taf. 83, A-C; 83, D (Kasten und Deckel); Kintrup 2016a, Kap. 4.2.4 Nr. 263.

665 Museo Arqueológico Nacional Inv. 120: García y Bellido 1948, 97-102 Abb. 8-15 (mit der älteren Lit.); García y Bellido 1949, 224-228 Nr. 253 Taf. 185-187 (mit der älteren Lit.); Sichtermann 1954, 427 f. Abb. 105 f.; 430 f.; Massó 1989, 83-104 Abb. 1-6 (mit weiterer Lit.); Claveria 1998, 140 f. Taf. 72, 7; 73, 2; Kintrup 2016a, Kap. 4.2.9 Nr. 134.

666 Nationalmuseum Inv. 1279: Chéhab 1968, 41-44. 81 Taf. 22-26; Chéhab 1985, 687 f. Taf. 137-139; Wielgosz 2001, 169 f. Abb. 3; Kintrup 2016a, Kap. 4.2.15 Nr. 72.

667 s. z. B. den Achill-Sarkophag in Beirut: Koch - Sichtermann 1982, 385. 457 f. Abb. 414; Rogge 1995, 126 f. Nr. 6 Taf. 52, 2; 54, 1; den Hippolytos-Sarkophag in Agrigent: Koch - Sichtermann 1982, 394 f. 458 Abb. 426; Rogge 1995, 148 Nr. 47 Taf. 89, 1; 92, 2; einen Meleager-Sarkophag in Thessaloniki: Koch 1975, 144 Nr. 175 Taf. 138, 1; 


\section{Datierung}

Der Pferdekopf überdeckt das Kyma bis zur oberen Leiste, womit ein Anhaltspunkt für eine Datierung in das zweite Viertel des 3. Jahrhunderts n. Chr. gegeben ist. Bei dem seltenen Kyma aus hängenden Akanthusblättern handelt es sich um eine Übergangslösung des oberen Kastenabschlusses von der frühen konventionellen Form, bestehend aus mehreren ornamentierten Profilen, hin zu der späten konventionellen Form eines einzelnen S-förmig geschwungenen Profils mit stehenden Akanthusblättern ${ }^{668}$. Konkrete Parallelen bieten Fragmente von Schlachtsarkophagen in Adana, Istanbul und Rom, Palazzo Lazzaroni, die alle um 230-240 n. Chr. eingereiht werden können ${ }^{669}$. Dementsprechend kann auch für das Fragment in Ephesos diese Datierung vorgeschlagen werden.

230-240 n. Chr.

4.12 Kastenfragment mit Pferdehinterteil (Kat. 32 Taf. 70 Abb. 292)

Selçuk, Efes Müzesi Inv. 32/1/95.

Gefunden in Selçuk, Johannesbasilika 1995. Nach dem Inventarbuch lautet die Fund-Nr. StJ 92/35; auf dem Fragment steht »StJ 79«.

H 13; L 31,5; L der linken anschließenden Seite 8.

Lit.: Unpubliziert.

Feinkristalliner, heller Marmor. Die linke Ecke des Fragments ist erhalten. Die Oberfläche weist Bestoßungen und Bruchflächen auf. Die Rückseite des Fragments zeigt eine grobe Spitzmeißelarbeit.

Zu erkennen sind das Hinterteil und Beinansätze eines Pferdes nach rechts. Der Pferdeschweif zeigt tiefe Bohrlinien; auch die Figuren sind von deutlichen Bohrlinien umrissen. Links neben dem Pferdeschweif ist an der Ecke ein gerundeter Reliefrest zu erkennen - eventuell war ein Baum oder Fels dargestellt. Vor dem Pferd erscheint die Kniepartie einer stehenden Figur. Rechts folgt ein Reliefteil mit einem unten gebogenen Umriss. Die links anschließende Seite ist vernachlässigt gearbeitet. An der Ecke könnte ein Pfeiler oder eine Herme gestanden haben.

$\mathrm{Zu}$ Pferdehinterteil und Schweif stellen Fragmente in Gytheion und Istanbul sowie Sarkophage in Athen und Kyrene Vergleiche dar. Bei dem Fragment eines Schlachtsarkophags in Gytheion ${ }^{670}$, um 240/250 n. Chr. datiert, handelt es sich ebenfalls um ein Eckfragment, und zwar jenes der rechten Ecke der Rückseite umbiegend zur linken Schmalseite. Die Zuordnung als Ecke der Rückseite und der linken Schmalseite wäre für das Fragment in Ephesos aufgrund der Ausarbeitung ebenfalls möglich. In Gytheion ist ein Baumstamm über Eck gestellt. Auf der linken Schmalseite ist wie hier ein deutlich umbohrter Pferdeschweif zu sehen.

Bei dem Schlachtfragment in Istanbul ${ }^{671}$ (um 230-240 n. Chr.) handelt es sich hingegen um ein Rückseitenfragment, an dessen linker Ecke ein Pferd mit Reiter nach rechts sprengt. Durchaus typisch für die Ausführung einer Rückseite wurde dort die Ausarbeitung mit Bohrlinien unterlas-

Koch - Sichtermann 1982, 401 f. 458 Abb. 431. Auf den genannten Vergleichsstücken erscheint der Pferdekopf jeweils vor einem konventionellen Kyma aus stehenden Akanthusblättern.

668 Kintrup 2016a, Kap. 4.2.4; 4.3 S. 144 f.

669 Adana: Koch - Sichtermann 1982, 407. 408 Nr. 1; 458. 466. Istanbul: Koch - Sichtermann 1982, 407. 409 Nr. 38 ; 459. 466. Rom: Koch - Sichtermann 1982, 407. 410 Nr. 57; 459; Koch 1982, 180 Nr. 12; 181 Abb. 10. Zu allen: Kintrup 2016a, Kap. 4.2.4 Nr. 1. 107. 183.

670 Koch - Sichtermann 1982, 409 Nr. 32 f.; 464; Kintrup 2016a, Kap. 4.2.6 Nr. 96.

671 Inv. 4015: Koch - Sichtermann 1982, 407. 409 Nr. 38; 459. 466; Kintrup 2016a, Kap. 4.2.4 Nr. 107. 
sen. Dies gilt auch für die Rückseiten eines Schlachtsarkophags in Athen ${ }^{672}$ (um 230-240 n. Chr.) und eines dionysischen Sarkophags in Kyrene ${ }^{673}$ (um die Mitte des 3. Jahrhunderts n. Chr.) ${ }^{674}$. Bei beiden erscheint je ein Kentaur nach rechts an der linken Ecke der Rückseite. Sofern es sich bei dem Fragment in Ephesos tatsächlich um eine Schmalseite handelt, ist die Deutung als Kentaur so gut wie auszuschließen, da bisher keine Parallele für eine Kentauromachie auf einer Schmalseite bekannt ist.

\section{Datierung}

Ohne Anhaltspunkte zur genaueren Datierung kann das Fragment in Ephesos anhand der Vergleiche nur unter Vorbehalt in das zweite Viertel des 3. Jahrhunderts n. Chr. gerückt werden.

Zweites Viertel des 3. Jahrhunderts n. Chr.

\subsection{Unteres Eckfragment unteren Bereichs eines Kastenreliefs mit Pferdehinterteil}

(Kat. 33 Taf. 70 Abb. 293 f.)

Selçuk, Efes Müzesi Inv. 28/13/00.

Fundort unbekannt.

Bevorzugt gearbeitete Seite: H 15; L 27; DW 6; Rh 4.

Vernachlässigt gearbeitete Seite: H 15; L 39; DW 6; Rh 3.

Lit.: Koch 1991, 819 Nachtrag Nr. 3.

Feinkörniger, heller Marmor. Eckfragment des unteren Bereichs des Relieffrieses, innen mit einem Stück des Sarkophagbodens, der eine grobe Spitzmeißelarbeit aufweist. Sockel und Standleiste fehlen; die Unterseite des Fragments ist mit einem kleinen, gerundeten Absatz flach abgearbeitet, was auf eine Wiederverwendung schließen lässt.

Das Pferdehinterteil der bevorzugt gearbeiteten Seite ist von Konturbohrungen umgeben, geglättet und poliert, wobei der Schweif feinere Flachmeißelspuren zeigt. Die Ansicht des Pferdehinterteils auf der vernachlässigt gearbeiteten Seite ist - wie das gesamte erhaltene Stück - mit dem Flachmeißel ausgeführt. Demnach handelt es sich wahrscheinlich um eine Rückseite und das Stück einer bevorzugt gearbeiteten linken Schmalseite. Da es aber auch stark vernachlässigte Schmalseiten gibt, muss zudem mit der Möglichkeit gerechnet werden, dass das Fragment an die linke Ecke der Vorderseite umbiegend zu einer vernachlässigten linken Schmalseite gehörte. Vergleichen lassen sich hierfür die weniger sorgfältigen Schmalseiten der Hippolytos-Sarkophage in Agrigent ${ }^{675}$ und in Arles ${ }^{676}$, eines Amazonomachie-Sarkophags in Jerusalem ${ }^{677}$ oder eines Schlachtsarkophags in Beirut ${ }^{678}$.

Die vernachlässigt gearbeitete Seite zeigt undeutliche Reste und an der Ecke vielleicht einen Baumstamm. Auf der bevorzugt gearbeiteten Seite sind Beine, Hinterteil und Schweif eines Pferdes, das sich nach rechts aufbäumt, erhalten. Die Deutung des kleinen umbohrten Reliefrestes zwischen Schweif und Beinen ist unklar. Das Pferd könnte zu drei gängigen Kampfgruppentypen attischer Sarkophage mit Schlachtszenen gehört haben ${ }^{679}$. Diese Kampfgruppen zeigen alle

672 Koch - Sichtermann 1982, 407. 408 Nr. 14; 458; Oakley 2011, 29-31. 80 Nr. 32 Taf. 28, 2; Kintrup 2016a, Kap. 4.2.5 Nr. 55.

673 Matz 1968, 116-118 Nr. 11A Taf. 21, 2; Oakley 2011, 29-31. 79 f. Nr. 31 Taf. 28, 1.

674 Zur Datierung s. auch Wiegartz 1977, 386-388 mit Anm. 90.

675 Rogge 1995, 148 Nr. 47 Taf. 104, 1.

676 Rogge 1995, 150 Nr. 50 Taf. 108, 1.

677 Fischer 1998, 208 Nr. 213; 225 f. Abb. 213 c.; Kintrup 2016a, Kap. 3.2.11 Nr. 112.

678 Chéhab 1985, 687 f. Taf. 139 b; Kintrup 2016a, Kap. 4.2.15 Nr. 72.

679 Kintrup 2016a, 35 f. 37 f. 42-44; s. die Kampfgruppen-Typen K VII, K VIII, K XII, sog. Dexileos-Gruppe. 
eine reitende Figur, die von links nach rechts sprengt und entweder eine rechts stehende Figur in Rückenansicht ${ }^{680}$, eine rechts stehende Figur in Frontalansicht ${ }^{681}$ oder eine rechts kniende Figur attackiert ${ }^{682}$.

Erwähnt sei eine weitere Möglichkeit, eine motivische Übereinstimmung zu finden, nämlich in den steigenden Pferden der Darstellungen des Sturzes des Hippolytos auf Schmalseiten von Hippolytos-Sarkophagen in Agrigent ${ }^{683}$, St. Petersburg ${ }^{684}$ und Tyros ${ }^{685}$.

\section{Datierung}

Eine dermaßen grobe Vernachlässigung in der Ausführung wie hier ist meistens auf Schmalund Rückseiten später Sarkophage zu finden, sodass eine Datierung in das zweite Viertel des 3. Jahrhunderts n. Chr. vorgeschlagen wird.

Zweites Viertel des 3. Jahrhunderts n. Chr.

4.14 Rückseitenfragment mit Löwen (Kat. 34 Taf. 70 Abb. 295)

Selçuk, Efes Müzesi Inv. 2265.

Fundort Johannesbasilika.

H 37; L 62; D 15; DW 11; Rh 4.

Lit.: Unpubliziert.

Feinkörniger, weißer Marmor mit wenigen Glimmereinschlüssen. Die Oberfläche des allseitig gebrochenen Fragments ist verrieben, entlang der glimmerhaltigen Schichten streifig verwittert und leicht bestoßen. Die Rückseite des Fragments zeigt eine gleichmäßige und dicht gesetzte Spitzmeißelarbeit, wie sie von vielen attischen Sarkophagen bekannt ist. Das Relief ist flach und eher schematisch ausgearbeitet; beides spricht für die Gestaltung einer Rückseite.

Ein Löwe liegt in Profilansicht nach links und hat das Gesicht dem Betrachter zugewendet. Teile der Mähne sowie der Schwanz sind abgebrochen. Die Strähnen der Löwenmähne sind mit dem Flachmeißel gestaltet, wodurch ein holzschnittartiger Charakter entsteht. Bohrungen sind nicht vorhanden. Die Beine des Löwen fehlen größtenteils; das linke Vorderbein war, den bestoßenen Reliefresten nach zu urteilen, nach vorn Richtung Maul gestreckt. Das linke Hinterbein ist oberhalb des Knies abgebrochen.

Das dicke Maul ist durch tiefe Nasolabialfalten, die einander zwischen den Augen treffen, von dem übrigen Gesicht abgesetzt. Die Stirn ist durch eine senkrechte Falte in zwei Hälften unterteilt. Neben den Strähnen der Mähne, die das Gesicht rahmen, ist eine lange Strähne den Rücken entlang geführt und hängt seitlich herab. Unter dem Bauch des Raubtiers ist ein weiterer Reliefrest erhalten; die Kante deutet den Rücken eines Tieres an, auf das der Löwe gesprungen ist.

680 s. z. B. die linke Schmalseite des Amazonomachie-Sarkophags vom Hafenkanal in Ephesos Kat. 6 Taf. 42 Abb. 172, die rechte Schmalseite eines Amazonomachie-Sarkophags in Tyros Inv. 2772/2773: Chéhab 1968, 36-40. 81 f. Taf. 20 b; Kintrup 2016a, Kap. 3.2.1 Nr. 259, oder die Rückseite des Amazonomachie-Sarkophags Thessaloniki Inv. 283: Stefanidou-Tiveriou 1997, 166-169 Nr. 134; 380 Abb. 336; 382 Abb. 339; Kintrup 2016a, Kap. 3.2 .3 Nr. 245.

681 s. etliche Vergleiche, die hier unter Kat. 18 (Taf. 65 Abb. 275) zusammengestellt sind.

682 s. z. B. die Vorderseite und linke Schmalseite eines Amazonomachie-Sarkophags in Jerusalem: Fischer 1998, 208 Nr. 213; 225 f. Abb. 213 a. d; Kintrup 2016a, Kat. 112; Kap. 3.2.11, die rechte Schmalseite eines Schlachtsarkophags in Athen: Robert 1890, 131 f.; Kintrup 2016a, Kap. 4.2.5 Nr. 55, oder die Vorderseite eines Schlachtsarkophags in Tyros Inv. 3951/3952: Koch - Sichtermann 1982, 410 Nr. 66; 459. 467 Abb. 443; Chéhab 1985, 501 f. Taf. 90 a; 91 a; Rogge 1995, 144 f. Nr. 43 Taf. 9, 2; Kintrup 2016a, Kap. 4.2.17 Nr. 260.

683 Rogge 1995, 148 Nr. 47 Taf. 104, 1.

684 Rogge 1995, 154 f. Nr. 64 Taf. 104, 2.

685 Rogge 1995, 157 f. Nr. 70 Taf. 105, 1. 
Unter dem Maul des Löwen sind radial auseinanderlaufende Hautfalten zu erkennen, die zeigen, dass er das Tier bereits gepackt hat.

Nach Reliefhöhe, Ausarbeitung und Motiv handelt es sich um das Fragment einer Rückseite eines attischen Sarkophags, der zwei antithetisch angeordnete Löwenkampfgruppen zeigte. Ein Vergleich mit verwandten Darstellungen belegt dies: So finden sich zwei frühe Parallelen in Antakya, bei denen je zwei Löwen zwei Stiere reißen. Zum einen auf der Rückseite eines Girlandensarkophags ${ }^{686}$, zum anderen auf der Rückseite eines Sarkophags ${ }^{687}$, der auf der Vorderseite Eros und Psyche bei einem Fruchtopfer flankiert von hirschtötenden Niken abbildet. Zwei weitere Parallelen in Beirut und Askalon sind deutlich später entstanden. Bei dem Hippolytos-Sarkophag in Beirut (um 220-230 n. Chr.) ${ }^{688}$ und dem Schlachtsarkophag in Askalon (um 240 n. Chr.) ${ }^{689}$, reißen ebenfalls je zwei Löwen zwei Stiere ${ }^{690}$. Allen gleich ist die Haltung der Raubkatzen, die von hinten auf den Rücken des Stiers gesprungen sind und dem zusammengebrochenen Tier in den Nacken beißen. Dabei haben sie die jeweils sichtbare Vorderpranke in die Seite des Stiers geschlagen, während die Hinterbeine auf dem nach hinten abgestreckten Bein des Stiers zu stehen kommen.

\section{Datierung}

Stilistisch erscheint das Fragment aus Ephesos mit den beiden späteren Sarkophagen in Beirut und Askalon verwandt zu sein.

Zweites Viertel des 3. Jahrhunderts n. Chr.

\subsection{Fragment eines oberen Kastenabschlusses mit Mäander}

(Kat. 35 Taf. 71 Abb. 296)

Selçuk, Efes Müzesi, ohne Inv.

Fundort Selçuk, Johannesbasilika, Fund-Nr. StJ 78/31.

\section{H 21; L 47; D (Oberseite) 14.}

Lit.: Rudolf 1989, 58 Taf. 32 Abb. 54; Koch 1991, 819.

Feinkristalliner, heller Marmor. Oberseite mit Falz erhalten. Rückseite mit gleichmäßiger, grober Spitzmeißelarbeit. Alle Ornamente weisen deutliche Bestoßungen auf.

Das Fragment eines oberen Kastenabschlusses zeigt die Abfolge Perlstab, Eierstab, lesbisches Kyma und eine obere Leiste, die von einem Metopenmäander mit Blütenfüllung geschmückt wird.

\section{Datierung}

$\mathrm{Zu}$ der Profilabfolge mit Metopenmäander ${ }^{691}$ bietet der Schlachtsarkophag des Aemilius Aristides (Kat. 1 Taf. 2) einen so guten Vergleich, dass auch dieses Fragment in Ephesos um 200 n.

\footnotetext{
${ }_{686}$ Inv. 8473: Himmelmann 1970a, H. 9, 12-14. 18 f. Taf. 15. 16 a; Rogge 1993, 112 Anm. 34 Taf. 46, 3 (Schmalseite).

687 Inv. 9576: Himmelmann 1970a, H. 9, 12. 15-19 Taf. 14.

688 Chéhab 1985, 527 f. Taf. 99; Rogge 1995, 91. 152 Nr. 57 Taf. 111, 3.

689 Avi-Yonah 1976, 72-76 Taf. 19, 1; Fischer 1998, 205 Nr. 196; 213-215 Abb. 196 d; Kintrup 2016a, Kap. 4.2.7 Nr. 31.

690 Motivisch nah verwandt sind auch die beiden Löwen-Stier-Kampfgruppen in den Lünetten einer Rückseite mit Girlanden eines Erotensarkophags in Kephissia, s. Koch - Sichtermann 1982, 431 Nr. 43; 435-438. 439 Nr. 33; 445 Anm. 17 Taf. 470; Rogge 1993, 112 Anm. 31; 113. Das Motiv der Löwen-Stier-Kampfgruppen ist bereits von einem Relief des 2. Jhs. v. Chr. aus Pergamon bekannt, auf dem ein Palladion von zwei solchen Gruppen gerahmt wird, s. Hölscher 1972, 85 f. Taf. 11, 3.

691 Zu dem Begriff s. Kat. 1 Anm. 108.
} 
Chr. datiert werden kann. Weitere Vergleiche zu dem oberen Kastenabschluss samt Metopenmäander mit Rosetten sind dementsprechend bereits unter Kat. 1 genannt ${ }^{692}$ und unterstützen die Datierung.

Um 200 n. Chr.

\subsection{Fragment eines Kastenbodens mit Sockel (Kat. 36 Taf. 71 Abb. 297)}

Aufbewahrungsort unbekannt.

Gefunden in Ephesos. Laut Notizen F. Eichlers: beim Magnesischen Tor gefunden, Damianosstoa, Aufnahme vor $1930^{693}$.

Lit.: Rudolf 1989, 56 »Ephesos P« Abb. 50; Koch 1991, 817. 819; Koch 1999, 557 Anm. 21.

Da das Fragment verschollen ist, musste eine Bearbeitung anhand des vorliegenden Fotos (Taf. 71 Abb. 297) erfolgen. Maße fehlen.

Fragment des Kastenbodens. Zu erkennen sind die Sockelornamente einer Schmalseite - die Standleiste darüber fehlt - und das rechte Eckpostament mit Standleiste sowie Reste des Figurenfrieses darüber. Neben einem beschädigten linken Fuß erscheint ein weiterer kleiner Reliefrest, der nicht näher zu identifizieren ist. Das Flechtband läuft von beiden Seiten auf die Mitte zu, die so eine kleine Betonung erfährt; demnach fehlt auf der linken Seite nur ein kleines Stück der Sockelornamente sowie das zu rekonstruierende linke Eckpostament. Das darüberliegende lesbische Kymation ist sorgfältig gearbeitet wie auch das Dekor des Eckpostaments. Dort flieht ein Hirsch nach links, denn er wird von hinten von einem zweiten Tier angesprungen. Der Ausführung nach zu urteilen, war dies die bevorzugt gearbeitete Schmalseite des Sarkophags.

Interessant ist die Notiz F. Eichlers unter einem Foto: »zu Sark. B? « Dies ist insofern nicht zu verifizieren, als die rechte Schmalseite des Aristides-Sarkophags zum Großteil erhalten ist und es sich daher nur um die linke Schmalseite handeln könnte, die dann auch bevorzugt ausgeführt worden wäre. Zudem ist ein kleines Stück des Eckpostaments der linken Schmalseite des Aristides-Sarkophags vorhanden (s. die seitliche Ansicht Taf. 8 Abb. 22), und soweit zu erkennen, ist die Ausarbeitung unterschiedlich, wenn auch das Tierhinterteil des Eckpostaments des AristidesSarkophags motivisch zu den Tieren hier passen könnte.

Vergleiche für den linken Fuß über dem Eckpostament bieten beispielsweise die rechte Schmalseite eines Achill-Sarkophags in Adana ${ }^{694}$ mit der Darstellung der Aufbahrung des Patroklos aus dem letzten Viertel des 2. Jahrhunderts n. Chr. oder die linke Schmalseite eines Hippolytos-Sarkophags in Apollonia (Libyen) ${ }^{695}$, die Hippolytos vor Theseus zeigt, aber um die Mitte des 3. Jahrhunderts $\mathrm{n}$. Chr. anzusetzen ist. Dazu treten die linken Schmalseiten zweier dionysischer Sarkophage, zum einen in Rom, ca. 240 n. Chr. ${ }^{696}$, und zum anderen in Kyrene, um 250 n. Chr. ${ }^{697}$, oder die Rückseite eines ebenso späten Epinausimachie-Sarkophags in Thessaloniki, der Meleager auf der kalydonischen Jagd zeigt ${ }^{698}$. Generell ist keines der Themen den Reliefresten gesichert zuzuordnen.

692 s. dort mit Anm. 109-116.

693 Zu dem Magnesischen Tor s. Anm. 343; zur Damianosstoa und dort geborgenen Sarkophagen vgl. in jüngerer Zeit Steskal u. a. 2003, 241-273.

694 Linant de Bellefonds 1985, Taf. 11, 2; 12, 2; Rogge 1995, 125 Nr. 1 Taf. 17, 1.

695 Rogge 1995, 149 Nr. 49 Taf. 103, 1.

696 Museo Capitolino: Matz 1968, 110-112 Nr. 10 Taf. 16, 2; Koch - Sichtermann 1982, 419-422. 459; Datierung nach Wiegartz 1977, 386-388 mit Anm. 90.

697 Matz 1968, 116-118 Nr. 11A Taf. 23, 1. Datierung nach Wiegartz 1977, 386-388.

698 Koch 1975, 144 Nr. 173 Taf. 136 d; Stefanidou-Tiveriou 1997, 169-174 Nr. 135; 386 Abb. 344; Kintrup 2016a, Kap. 5.2.6 Nr. 248. 


\section{Datierung}

Der gut strukturierte Aufbau der Sockelzone ist mit einem Achill-Sarkophag des letzten Viertels des 2. Jahrhunderts n. Chr. in Beirut ${ }^{699}$ vergleichbar sowie mit dem Amazonomachie-Sarkophag aus der Nekropole nördlich des Hafenkanals von Ephesos (Kat. 6 Taf. 41 f.) mit einer Datierung um 190/200 n. Chr. und mit dem Schlachtsarkophag des Aemilius Aristides (Kat. 1 Taf. 2) mit einer Datierung um 200 n. Chr. Ein Amazonomachie-Sarkophag in Thessaloniki ${ }^{700}$ (um $220 \mathrm{n}$. Chr.) weist zwar auch die hier gezeigten Sockelornamente und dekorierten Eckpostamente auf, aber die Standleiste zwischen den Eckpostamenten ist mit einem Zahnschnitt versehen, was eine Trennung von tektonischem Gerüst und Figurenfries abschwächt und damit schon einen weiteren kleinen Schritt in der Entwicklung markiert. Im zweiten Viertel des 3. Jahrhunderts werden dann die bis dahin konventionellen Sockelornamente Flechtband und lesbisches Kymation zumeist durch vegetabile Schmuckbänder in flachem Relief ersetzt. Bei dem Fragment mit Sockel in Ephesos ist nicht zu entscheiden, ob ein Zahnschnitt vorhanden war. Eine frühe Datierung vor oder um die Jahrhundertwende ist wohl wahrscheinlicher, auch durch die Proportionen und Ausführung der Ornamente, aber eine Datierung in das erste Viertel des 3. Jahrhunderts ist nicht vollkommen auszuschließen.

Viertes Viertel des 2. Jahrhunderts - erstes Viertel des 3. Jahrhunderts n. Chr.

\subsection{Fragment einer Sockelecke (Kat. 37 Taf. 72 Abb. 298)}

Selçuk, Efes Müzesi Inv. 9/13/00.

Gefunden in Selçuk, Johannesbasilika.

Bevorzugt gearbeitete Seite: H 32; L der reliefierten Fläche 21; L rekonstruiert ca. 32.

Rechts anschließende Seite: H 34; L der reliefierten Fläche 9,5.

Lit.: Koch 1991, 819 Nachtrag Nr. 2.

Fein- bis mittelkörniger, heller Marmor mit Glimmereinschlüssen. Allseitig gebrochenes Fragment einer Sockelecke. Auf der Innenseite des Fragments sind keine Ansätze der Ecke oder Bearbeitungsspuren erhalten. Die erhaltene Seite zeigt Bestoßungen und Bruchflächen, auf der rechts anschließenden Seite ist nur ein kleiner reliefierter Rest vorhanden.

Neben einem Flechtband und darüberliegendem lesbischen Kymation folgt rechts ein Eckpostament. Obwohl das lesbische Kymation keine Bohrungen aufweist, scheint es sich eher um eine bevorzugt gearbeitete Sarkophagseite gehandelt zu haben. Dafür sprechen auch Dekor und Ausführung des Eckpostaments: ein Eros mit einem Mäntelchen reitet auf einem Ziegenbock, wobei der Ziegenbock auf dem leicht gewölbten Teil der Rahmung des Bildfeldes läuft. Daneben bricht die Darstellung ab und die Ecke fehlt. Über dem Eckpostament haben sich einige Falten eines langen, auf dem Boden aufliegenden Gewandes erhalten. Der kleine Reliefrest der folgenden Sarkophagseite ist nicht eindeutig zu identifizieren, es könnte sich um eine Tiertatze handeln.

Der Saum des Gewandes über dem Eckpostament ist zu wenig spezifisch, als dass es einem Thema zugeordnet werden könnte. Vergleiche finden sich z. B. auf der linken Schmalseite eines Achill-Sarkophags in Tyros ${ }^{701}$ mit der Darstellung der Trauer um Patroklos, wo ein Gewand von einem Hocker auf den Boden fällt. Auf der rechten Schmalseite eines Hippolytos-Sarkophags

699 Koch - Sichtermann 1982, Abb. 419; Rogge 1995, 127 f. Nr. 7 Taf. 1, 1. Zu den Genannten und zu einigen Fragmenten s. Rogge 1995, 20-22.

700 Archäologisches Museum Inv. 283: Koch - Sichtermann 1982, 391 mit Anm. 10; 458; Stefanidou-Tiveriou 1997, 380-383 Abb. 336-339; Kintrup 1998, 209 f. 214 f. Taf. 93, 4; 95, 2; 95, 7; Kintrup 2016a, Kap. 3.2.3 Nr. 245.

701 Inv. 328/329: Chéhab 1968, 28-34. 75 f. 82 f. Taf. 13-16; Rogge 1995, 143 f. Nr. 42 Taf. 71, 2. 
in St. Petersburg ${ }^{702}$ und der linken Schmalseite eines Hippolytos-Sarkophags in Tyros ${ }^{703}$ fallen Frauengewänder auf den Boden, denn beide Darstellungen zeigen Phaidra mit Amme im Frauengemach. Zudem lässt sich auch die linke Schmalseite des Epinausimachie-Sarkophags in Thessaloniki ${ }^{704}$ vergleichen, wo das Gewand der Eckfigur bodenlang ist. Alle genannten Beispiele sind bereits vom zweiten Viertel bis zur Mitte des 3. Jahrhunderts anzusetzen und zeigen eine dementsprechend weiterentwickelte Sockelgestaltung.

\section{Datierung}

Der Aufbau und die Ornamente Flechtband und lesbisches Kymation der Sockelzone können als typisch für das letzte Viertel des 2. Jahrhunderts und den Beginn des 3. Jahrhunderts n. Chr. angesprochen werden. Beispiele präsentieren etwa ein Achill-Sarkophag in Beirut ${ }^{705}$ aus dem letzten Viertel des 2. Jahrhunderts, ein Amazonomachie-Sarkophag aus Ephesos (Kat. 6 Taf. 41 f.) um 190/200 n. Chr. und der Schlachtsarkophag des Aemilius Aristides (Kat. 1 Taf. 2) mit einer Datierung um 200 n. Chr. Bei einem Amazonomachie-Sarkophag um 220 n. Chr., der sich in Thessaloniki befindet ${ }^{706}$, ist die Standleiste zwischen den Eckpostamenten mit einem Zahnschnitt dekoriert, eine strikte Trennung von tektonischem Elementen und Figurenfries ist so gemildert. In der weiteren Entwicklung im zweiten Viertel des 3. Jahrhunderts werden dann die typischen Sockelornamente Flechtband und lesbisches Kymation durch vegetabile Schmuckbänder zunehmend in flachem Relief ausgetauscht. Bei dem Eckfragment Kat. 37 lässt sich nicht sagen, ob ein Zahnschnitt vorhanden war, sodass eine Datierung vorerst nur auf das letzte Viertel des 2. Jahrhunderts und das erste Viertel des 3. Jahrhunderts n. Chr. einzugrenzen ist. Eine frühe Datierung vor oder um die Jahrhundertwende erscheint durch die Proportionen und die Ausführung der Ornamente sowie des Eckpostaments wahrscheinlicher, aber eine Datierung im ersten Viertel des 3. Jahrhunderts ist nicht völlig auszuschließen.

Viertes Viertel des 2. Jahrhunderts - erstes Viertel des 3. Jahrhunderts n. Chr.

\subsection{Fragment der Oberseite eines Sarkophags mit Falz}

(Kat. 38 Taf. 72 Abb. 299)

Selçuk, österreichisches Grabungshaus.

Gefunden in Ephesos, südlich des Propylons des Vediusgymnasiums ${ }^{707}$.

H 13; L 9; H Falz 1,8; B Falz 4,8-5.

Lit.: Unpubliziert.

Feinkörniger, heller Marmor. Die Rückseite des Fragments, d. h. die Innenseite des Sarkophags, zeigt Spitzmeißelarbeit, wobei der obere Rand auf ca. 2 cm glatter abgearbeitet ist. Die geglättete Oberseite mit Falz ist vorhanden. Die gebrochene Unterseite des Fragments ist stark versintert.

Nach Marmor, Maßen und Bearbeitungsspuren handelt es sich um das Fragment der Oberseite eines attischen Sarkophags mit dem Falz.

$\overline{702}$ Rogge 1995, 154 f. Nr. 64 Taf. 100, 1.

703 s. Rogge 1995, 157 f. Nr. 70 Taf. 101, 1.

704 Stefanidou-Tiveriou 1997, 169-174 Nr. 135; 385 Abb. 342; Kintrup 2016a, Kap. 5.2.6 Nr. 248.

705 Koch - Sichtermann 1982, Abb. 419; Rogge 1995, 127 f. Nr. 7 Taf. 1, 1. Zu den Genannten und zu einigen Fragmenten s. Rogge 1995, 20-22.

706 Archäologisches Museum Inv. 283: Koch - Sichtermann 1982, 391 mit Anm. 10; 458; Stefanidou-Tiveriou 1997, 380 f. Abb. 336-338; Kintrup 1998, 209 f. 214 f. Taf. 93, 4; 95, 2; 95, 7; Kintrup 2016a, Kap. 3.2.3 Nr. 245.

707 Zu dem Vediusgymnasium Steskal - La Torre 2008, zu dem Propylon s. S. 8-11. 



\section{Klinen-Riefel-, Girlanden- und Säulensarkophage}

\subsection{Fragment eines Klinen-Riefel-Sarkophags (Kat. 39 Taf. 72 Abb. 300)}

Selçuk, Efes Müzesi, Efes Kapalı Deposu, ohne Inv.

Fundort unbekannt.

H 35; L 46; D am oberen Profil 17; D unten 11,5.

Lit.: Unpubliziert.

Fein- bis mittelkörniger, heller Marmor mit großen Glimmerschieferschichten.

Die Oberseite mit dem Falz (H 2; B 4) ist erhalten, die übrigen Seiten sind gebrochen. Ober- und Rückseite zeigen eine gleichmäßige und mittelfeine Bearbeitung mit dem Spitzmeißel, wobei auf der Rückseite ein 4,5 cm hoher oberer Rand eine feinere Bearbeitung mit dem Zahneisen erfahren hat. Das Vorderseitenrelief ist nur leicht verwittert, weist aber einige Verreibungen und kleinere Beschädigungen, besonders am Dekor der oberen Leiste sowie an einigen Riefelgraten, auf, was aber auch der schlechten Marmorqualität geschuldet ist.

Über den nach rechts ausgewölbten Riefeln bilden ein lesbisches Kymation und darüber ein beschädigter Fries mit Tieren und Blattwerk den oberen Kastenabschluss. Zu erkennen sind noch ein im gestreckten Lauf nach links fliehendes Tier (Reh [?]) und ein nach rechts gewendetes Tier, das sich, wie zum Sprung ansetzend, vorn auf den Boden duckt (Löwe [?]).

Durch einen kleinen, zurückspringenden Absatz wird das lesbische Kymation unten abgeschlossen. Auf einen schmalen, glatten Streifen folgen die Riefel, die jeweils nur durch einen Grat voneinander getrennt sind.

\section{Datierung}

Der Marmor, die Riefeln und das Dekor des oberen Kastenabschlusses sprechen eindeutig für die Zugehörigkeit dieses Fragments zu der Gruppe der attischen Klinen-Riefel-Sarkophage, die in dem Zeitraum zwischen 180 und 240/250 n. Chr. auftreten ${ }^{708}$. Wegen des Fehlens der Beine und von Tragekonsolen, die an die Schmalseiten gehören, ist eine Zuordnung zu einer Langoder Schmalseite nicht möglich. Damit fehlen auch wichtige Kriterien für eine Datierung, denn die zunehmende Verwendung von Ornamenten an den genannten Teilen und damit verbunden eine »Verunklärung der Möbelform « ${ }^{709}$ lässt eine Entwicklung erkennen, die nur für eine relative Chronologie zu verwenden ist. Doch auch für den oberen Kastenabschluss gilt, dass die schlichter gehaltenen Exemplare die frühe Stufe vertreten, während die reicher ornamentierten Beispiele am Ende des Zeitrahmens anzusiedeln sind. Nur ein Exemplar der Gruppe gibt mit seinem männlichen Porträtkopf einen Hinweis auf eine absolute Datierung: Der Porträtkopf des Klinen-Riefel-Sarkophags im Nationalmuseum Athen wird um 230 n. Chr. datiert ${ }^{710}$. Dieser Sarkophag präsentiert bereits ein im zweiten Viertel des 3. Jahrhunderts übliches Dekor des oberen Kastenabschlusses bestehend aus flachen vegetabilen Ornamenten, während das ephesische Fragment noch das zuvor übliche lesbische Kyma zeigt und somit relativ früher angesetzt werden kann. Der attische Klinen-Riefel-Sarkophag im Kerameikos, Athen, der um 180 n. Chr.

708 s. o. Anm. 192.

709 Goette 1993, 108.

710 Inv. 1497: Koch - Sichtermann 1982, 450 Nr. 2; Goette 1991, 313 f. 323-325 Nr. 4 Taf. 98 f.; Goette 1993, 108; Bielefeld 1993, 93-95 Taf. 41. 
datiert wird ${ }^{711}$, ist mit dem lesbischen Kyma und darüber einer nichtdekorierten Leiste versehen. Damit wäre er in einer relativen Chronologie vor dem Fragment in Ephesos einzuordnen. Lesbisches Kyma und dekorierte Leiste befinden sich auf Fragmenten in Dion (mit kleinem Absatz unter dem lesbischen Kyma) ${ }^{712}$ und in Larissa (mit Perlstab unter dem lesbischen Kyma) ${ }^{713}$ sowie der Sarkophag in der Kathedrale von Salerno ${ }^{714}$, die - z. T. mit Unsicherheiten - um 220-230 n. Chr. datiert werden. Für das Fragment in Ephesos ist demzufolge eine Datierung im ersten Drittel des 3. Jahrhunderts vorzuschlagen.

Aufgrund der Wölbung der Riefeln, ist es wahrscheinlicher, dass sie ursprünglich in einem S-förmigen Schwung die gesamte Fläche überzogen hatten und nicht - wie bei den genannten Exemplaren in Dion und Salerno - in zwei Zonen übereinander mit einem trennenden Mittelstreifen in Form eines Flechtbandes angeordnet waren.

Erstes Drittel des 3. Jahrhunderts n. Chr.

\subsection{Fragment eines Klinen-Riefel-Sarkophags (Kat. 40 Taf. 73) $)^{715}$}

Gefunden südlich des Çukuriçi Höyük, in Richtung Magnesia; der Fund wurde von einer Bäuerin gemeldet $^{716}$.

H 49; L der Ss 118; L der VS 60; L der RS 44.

Lit.: Bammer 2008, 87-93.

Deutliche Verwitterungsspuren, Verreibungen und Bestoßungen, besonders an den Ecken. Erhalten sind die Sockelzone und darüber in etwa die gleiche Höhe der Seitenwände der bevorzugt gearbeiteten rechten Schmalseite mit Stücken von Vorder- und Rückseite eines attischen KlinenRiefel-Sarkophags. Der Sarkophagboden ist grob gespitzt. Die Ansätze der Seitenwände sind zu erkennen.

Die vorspringende Sockelzone besteht auf der Schmalseite aus einem Zahnschnitt, darunter einem lesbischen Kyma, einem Rankenfries und wieder einem lesbischen Kyma, gefolgt von einer flachen Leiste, einem kleinen Rundstab und einem Rankenfries mit Blüten.

Auf der Vorderseite zeigt sich die gleiche Profilierung mit gleicher Ornamentierung, allerdings in einem deutlich verriebeneren Zustand. Lediglich der Zahnschnitt als oberer Abschluss der Sockelzone scheint zu fehlen. Charakteristisch für die vernachlässigte Rückseitenausführung attischer Sarkophage ist dort die Profilierung der Sockelzone ohne Ornament belassen. Über der Sockelzone folgen eingerückt auf der Vorder- und Schmalseite ein größeres lesbisches Kyma und die Ansätze von Riefeln. An den erhaltenen Ecken von Vorder- und Rückseite sind die für attische Klinensarkophage typischen Löwenpfoten der Klinenbeine zu erkennen.

Tektonik, Ornamentik und Maße bezeugen die Zuordnung zu einem attischen Klinen-RiefelSarkophag. Mit Kat. 39 (Taf. 72 Abb. 300) ist bereits ein Fragment mit Riefeln und oberem Kastenabschluss eines Klinen-Riefel-Sarkophags aus Ephesos dokumentiert. Zu Kat. 40 sind keine näheren Angaben über Fundort und Fundumstände bekannt. Die Frage einer möglichen Zusammengehörigkeit dürfte ohne eine Steinanalyse und nur anhand eines Maßvergleichs der Riefel nicht zu klären sein.

711 Goette 1991, 317-321 Nr. 1 Taf. 89-92; Rogge 1993, 119 Taf. 54, 2.

712 Goette 1991, 330 Nr. 11 Taf. 104, 2.

713 Goette 1991, 331 Nr. 13 Taf. 105.

714 Goette 1991, 334 Nr. 17 Taf. 109.

715 Der Hinweis und auch die Zuordnung sind G. Koch zu verdanken.

716 Zu den Forschungen zu diesem Höyük s. die Wissenschaftlichen Jahresberichte des ÖAI 2012-2014 <https://www. oeaw.ac.at/oeai/kommunikation/jahresberichte/> (24. 7. 2017) sowie Horejs 2012, 117-131. Zur Lage des Höyük vgl. hier den Fundortplan Taf. 81. 


\section{Datierung}

Die Gruppe der attischen Klinen-Riefel-Sarkophage ist für den Zeitraum zwischen 180 und 240/250 n. Chr. belegt ${ }^{717}$. Mit der hier reich ornamentierten Sockelzone sind wichtige Kriterien für eine Datierung erhalten, denn die zunehmende Verwendung von Ornamenten und somit eine »Verunklärung der Möbelform « ${ }^{718}$ sind als Entwicklungen zumindest für eine relative Chronologie verwertbar.

So findet sich der flache Zahnschnitt als Dekor der Standleisten attischer Friessarkophage ausschließlich im 3. Jahrhundert n. Chr., vergleiche dazu ein Fragment ebenfalls in Ephesos (Kat. 28 Taf. 69 Abb. 288) ${ }^{719}$. Einen sehr guten Vergleich für Aufbau und Ornamentik der Sockelzone bietet der Klinen-Riefel-Sarkophag im Nationalmuseum Athen ${ }^{720}$. Glücklicherweise gibt dieser Sarkophag durch seinen erhaltenen männlichen Porträtkopf der um 230-240 n. Chr. entstanden ist, einen guten Anhaltspunkt für eine Datierung. Der Sarkophag in Athen zeigt ebenfalls ein größeres lesbisches Kyma, eingerückt über der Sockelzone der Vorderseite und der bevorzugt gearbeiteten Schmalseite. Das ephesische Exemplar dürfte daher in zeitlicher Nähe im zweiten Viertel des 3. Jahrhunderts n. Chr. anzusiedeln sein.

230-240 n. Chr.

\subsection{Fragment eines Girlandensarkophags (Kat. 41 Taf. 74 Abb. 305)}

Selçuk, Efes Müzesi Inv. 346.

Fundort Ephesos.

H 44; L 52; DW 10; D Profil 17; Rh max. 6.

Lit.: Koch 1991, 819 Nachträge Nr. 1; Koch 1999, 557 Anm. 21.

Feinkörniger, heller Marmor, an der Oberfläche grau verwittert. Die Oberseite ist intakt; die übrigen Seiten sind gebrochen. Die Rückseite weist eine mittelgrobe, regelmäßige Spitzmeißelbearbeitung auf. Die Reliefoberfläche ist z. T. bestoßen und Teile sind abgeplatzt. Die Oberfläche der oberen Leiste ist komplett weggebrochen, der darunter folgende Streifen des oberen Kastenabschlusses fehlt größtenteils. Dieser Streifen erscheint leicht geschwungen. Darunter folgen ein etwas breiterer, kaum vorgewölbter Streifen und dann ein Rundstab. Eine Ausarbeitung zu Perlstab, Eierstab und lesbischem Kyma unterblieb.

Zu erkennen sind der bestoßene Kopf eines Eros - die Haare sind auf den Seiten teilweise noch erhalten - und die Reste seiner Schultern unter Teilen einer großen Schleife. Diese gehört zu einer durch Tänien verbundenen Girlande, die der Eros trägt. Die linke Schlaufe ist zum Großteil abgeschlagen. Unter dem wulstförmigen unteren Ende der Manschette setzen die Früchte der Girlande an, die allerdings weitgehend abgebrochen und verwittert sind.

Vergleichsbeispiele in Beirut, Kephissia, Preveza und drei in Athen ${ }^{721}$ gestatten Vermutungen bezüglich der Rekonstruktion. Möglicherweise war, während der rechte Arm eine Tänie umfassend herabhängt, der linke Arm des Eros erhoben, um die Girlande zu stützen; so vermeint man Finger rechts neben seinem Kopf über der Schlaufe zu erkennen. Allerdings ist nur bei dem

17 s. o. Anm. 192.

718 Goette 1993, 108.

719 s. dort weitere Beispiele oder s. eine Aufzählung bei Rogge 1993, 116 mit Anm. 82.

720 Inv. 1497: Koch - Sichtermann 1982, 450 Nr. 2; Goette 1991, 313 f. 323-325 Nr. 4 Taf. 98 f.; Goette 1993, 108; Bielefeld 1993, 93-95 Taf. 41.

721 Koch - Sichtermann 1982, 438 Nr. 8; 439 Nr. 33. 34; 440 Nr. 37; 441 Nr. 83 Abb. 467. 469-472; Rogge 1993, 112 Taf. 47, 1. 
Exemplar in Preveza der rechte Arm des Eros hinter die Girlande geführt und Finger sind nicht zu sehen.

\section{Datierung}

Da die Oberfläche stark in Mitleidenschaft gezogen ist, ist eine zeitliche Einordnung anhand stilistischer Kriterien nicht begründet vorzunehmen. Die nichtornamentierten Profile können ein Kennzeichen für frühe attische Sarkophage vor der Mitte des 2. Jahrhunderts n. Chr. seinn ${ }^{722}$; dies belegen zwei der bereits genannten Beispiele in Athen ${ }^{723}$. Oder das Fragment gehörte zu einer Rückseite von Friessarkophagen. Girlandendekor auf Rückseiten von Sarkophagen mit Figurenfriesen bleibt auf das 2. Jahrhundert n. Chr. beschränkt, gehört aber in die zweite Jahrhunderthälfte. Dafür finden sich Beispiele auf den Rückseiten eines Amazonomachie-Sarkophags in Paris ${ }^{724}$ und eines Schlachtsarkophags in Ptolemais ${ }^{725}$. Weiterhin präsentieren sich Girlanden auf der Rückseite eines Achill-Sarkophags in St. Petersburg726 - auch mit Eros in der Mitte und eines Hippolytos-Sarkophags in Istanbul ${ }^{727}$ - ebenfalls unter nichtornamentierten Profilen. Die genannten Beispiele gehören alle in die Zeit zwischen 160 und 190 n. Chr. Sie geben einen Hinweis darauf, dass wohl noch kein thematisch passendes Typenrepertoire für alle Seiten zur Verfügung stand, und belegen eine Entwicklung, bei der ältere bzw. veraltete Motive nur noch auf vernachlässigten Sarkophagseiten erscheinen ${ }^{728}$.

Da ein Export attischer Sarkophage nach Ephesos durch die übrigen Exemplare bewiesen ist, kann es sich hier um ein vereinzeltes frühes Stück handeln; anhand der genannten Vergleiche erscheint jedoch eine Datierung in das dritte Drittel des 2. Jahrhunderts wahrscheinlicher ${ }^{729}$.

Drittes Drittel des 2. Jahrhunderts n. Chr.

\subsection{Zwei Fragmente eines attischen Säulensarkophags (?)}

(Kat. 42 Taf. 74 f. Abb. 306-309)

Selçuk, Efes Müzesi Inv. 29/13/00.

Fundort unbekannt.

Fragment A: H (inkl. Falz) 31; L 72; DW 4,5-5,5; D oben am Profil 21.

Fragment B: H 26; L 33; DW 4,5-6; D oben am Profil 20.

Lit.: Kintrup - Heinz 2012, 195-197 Taf. 87.

Beide Fragmente bestehen aus fein- bis mittelkörnigem, hellen, leicht gräulichen Marmor mit Glimmer, der bei Fragment A bräunlich versintert und bei Fragment B teilweise mit rostroten Flechten besetzt ist, was durch eine Lagerung im Freien zu erklären ist. Beide Fragmente zeigen auf der Rückseite eine regelmäßige, recht feine Spitzmeißelbearbeitung und am oberen Rand einen $3 \mathrm{~cm}$ breiten Streifen, der geglättet wurde. Diese Bearbeitung auf der Innenseite, der z. T.

722 s. Wiegartz 1975, 172-176; Koch - Sichtermann 1982, 435-441; Rogge 1993, 112 f.

${ }_{723}$ Koch - Sichtermann 1982, 438 Nr. 8 Abb. 467; Rogge 1993, Taf. 47, 1.

724 Robert 1890, 81-84 Nr. 69 Taf. 30 Abb. 69 c; Baratte 1985, 256-261 Nr. 166; 258 mit Abb.; Kintrup 2016a, Kap. 3.1.1.1 Nr. 156.

725 Pietrogrande 1930, 108-111 Nr. 1 f. Abb. 3 f.; Kintrup 2016a, Kap. 4.1.1.2 Nr. 167. Zu der Zusammengehörigkeit des Eckfragments der Rück- und linken Schmalseite mit dem Schlachtfragment der Vorderseite und der rechten Schmalseite in Ptolemais, s. Kintrup 2016a, Kap. 4.1.1.1. So auch Rogge 1995, 24 Anm. 44; ebenfalls vermutet von Rudolf 1989, 39 f. Anm. 204.

726 Rogge 1995, 33 f. 139 f. Nr. 29 Taf. 41, 3-4.

727 Rogge 1995, 76. 153 Nr. 59 Taf. 80, 2.

728 s. Rogge 1995, 24. 75 zu diesem Phänomen bei Achill- und Hippolytos-Sarkophagen und vgl. Kintrup 2016a, Kap. 3.1.1.1.3; 4.1.1.2; 4.3 S. 147 zu Sarkophagen mit Schlachtszenen.

729 So auch Koch 1991, 819. 
erhaltene Falz auf der Oberseite beider Fragmente und der an der Ecke von Fragment B erhaltene Umbruch der Wandung bezeugen die Zugehörigkeit zu einem Sarkophag.

Bei Fragment A kann es sich bei dem Pilaster um die Verstärkung der Ecke handeln, die abgehende Wandung ist allerdings wegen des schrägen Bruchs auf der Rückseite nicht erhalten; sie müsste entsprechend dem kleineren Fragment B etwa in der Mitte des Pfeilers ansetzen.

Fragment A bietet eine Sarkophagseite mit vorgesetzter Säule. Die Sarkophagwand zeigt eine reliefiert dargestellte Quaderwand samt einem oben abschließenden lesbischen Kymation sowie eine Pilasterdekoration am linken Bruchrand. Das erhaltene Stück eines kannelierten Pilasters wird von einem ionischen Kapitell in Seitenansicht bekrönt. Die rundplastisch vorgesetzte ionische Säule stützt ein ungewöhnlich weit vorkragendes $(14 \mathrm{~cm})$ und hohes $(12,5 \mathrm{~cm})>G e b a ̈ l k$ r. Das ionische Kapitell zeigt einen zweiteiligen Abakus, einen mit einem Eierstab dekorierten Echinus samt Voluten. Der nur im Ansatz erhaltene Säulenschaft ist durch einen vorgewölbten Ring von dem Kapitell abgesetzt. Das obere Abschlussprofil in Form eines Gebälks präsentiert drei Dekorstreifen in flachem Relief: einen schmalen Zahnschnitt mit annähernd quadratischen Zähnen, ein lesbisches Kymation und einen Akanthusrankenfries.

Fragment B bietet mit reliefierter Quaderwand samt lesbischem Kymation und Pilasterdekoration den gleichen Aufbau. Eine Säule unter dem vorkragenden, hohen oberen Abschluss ist nicht erhalten. Die Ornamentierung ist flacher und sparsamer: der Pilaster ist facettiert statt kanneliert. Der Zahnschnitt fehlt und das untere Ornament ist schmaler.

Die beiden Fragmente passen nicht aneinander, gehören aber wegen des Materials, der Bearbeitung, Maßgleichheit und außergewöhnlichen Gestaltung mit hoher Wahrscheinlichkeit zu demselben Sarkophag. Fragment A wird einer Hauptansichtsseite angehört haben, Fragment B wird wegen der leicht vereinfachten Ornamentierung einer Nebenseite des Sarkophags zuzuordnen sein. Für eine vorläufige Rekonstruktion ist ein Sarkophagkasten mit vorgesetzter ionischer Säulenreihe vorzuschlagen. Die umlaufende, frei stehende Säulenreihe stützt ein schweres Gebälk und steht vor einer Quaderwand, die an den Ecken durch Pilaster verstärkt ist.

Einem ersten Eindruck folgend, könnte man vermuten, dass die beiden ephesischen Fragmente zu einem Einzelstück gehörten, das in der Nachfolge des sog. Klagefrauensarkophags ${ }^{730}$ und der hellenistischen Holzsarkophage aus Kertsch ${ }^{731}$ am ehesten dem Hellenismus zuzuschreiben wäre. Die genaue Überprüfung der Details bietet jedoch ein vollkommen anderes Bild. Die Ornamente entsprechen denen der attischen Sarkophage des 3. Jahrhunderts n. Chr., wenn sie auch ungewöhnlich im Hinblick auf ihre Kombination und Position sind.

Aufgrund der beschriebenen Ornamentik und der vorläufigen Beurteilung des Marmors mit bloßem Auge ${ }^{732}$ ist eine attische Herkunft dieses Sarkophags nicht unwahrscheinlich. Dazu passt auch die angesprochene Bearbeitung der Sarkophaginnenseite, die typisch für attische Sarkophage ist. Somit kann davon ausgegangen werden, dass es sich bei den beiden Fragmenten aus Ephesos um einen rattischen Säulensarkophag، handelt. Gestützt wird diese These durch zwei ebenfalls exzeptionelle Fragmente aus Salona, die wahrscheinlich einem vergleichbaren Objekt zuzuordnen sind. Auch bei den zwei Fragmenten in Split stehen Säulen vor einer reliefierten Quaderwand. Aufgrund der Ornamente auf der Sockelzone des einen Fragments - nämlich wie in Ephesos Zahnschnitt und Blattranke - und der Aussage, dass, »der Marmor sicher pentelisch ist«, wurden sie von N. Cambi der attischen Produktion des mittleren 3. Jahrhunderts n. Chr. zugewiesen $^{733}$.

730 Fleischer 1983, passim.

731 Watzinger 1984, passim, bes. 48 Abb. 89. 90; 54 Abb. 116. 117; G. Zimmer in: W.-D. Heilmeyer (Hrsg.), Antikenmuseum Berlin. Die ausgestellten Werke. Staatliche Museen Preußischer Kulturbesitz (Berlin 1988) 174 f.; vgl. auch zwei späthellenistische Sarkophage aus Cefalù: Tullio 1984, 598-610 Taf. 85.

732 Eine naturwissenschaftliche Untersuchung des Marmors steht noch aus.

733 Cambi 2007, 170 Taf. 59, 1. 2. Ich bedanke mich hiermit bei Prof. N. Cambi für die bereits vor der Publikation zur Verfügung gestellten Fotos. 
Der Typus der Säulensarkophage war bislang für die attischen Werkstätten nicht bekannt, wohingegen die Säulensarkophage kleinasiatischer Produktion bereits ab der Mitte des 2. Jahrhunderts n. Chr. den in Kleinasien führenden Typus darstellen. Prinzipiell erinnert die architektonische Form der Kastenfragmente aus Ephesos und Salona an die kleinasiatischen Säulensarkophage. N. Cambi vermutet daher, dass »das Vorkommen der Säulensarkophage in der attischen Produktion ist sehr wahrscheinlich auf kleinasiatischen Einfluss zurückzuführen sei « ${ }^{734}$.

Kann es sich also bei diesen Sarkophagen um den Versuch attischer Werkstätten - beeindruckt von dem Typus der kleinasiatischen Säulensarkophage und auch von deren Erfolg angespornt Säulensarkophage herzustellen? Waren sie als >Konkurrenzprodukt im attischen Stil gedacht, das aber letztendlich keinen Absatzmarkt fand? Oder handelt es sich, wie bei derart exzeptionellen Stücken zu vermuten, um individuelle Auftragsarbeiten? In unserem Fall beispielsweise der Auftrag eines Ephesiers oder auch eines Atheners in Ephesos an eine attische Werkstatt, den in Kleinasien beliebten Typus des Säulensarkophags im attischen Stil herzustellen?

Offenbar war ein Austausch nicht nur von Athen nach Kleinasien ${ }^{735}$, sondern durchaus auch umgekehrt möglich, wenn auch auf Einzelfälle beschränkt.

\section{Datierung}

Der flache Zahnschnitt findet sich als Verzierung der Standleisten attischer Friessarkophage ausschließlich im 3. Jahrhundert n. Chr., so auf einem Amazonomachie-Sarkophag in Jerusalem (um 250 n. Chr.) ${ }^{736}$, einem Schlachtsarkophag in Athen (230-240 n. Chr.) ${ }^{737}$ oder auch auf einem kleinen Fragment eines Kastens mit Sockelzone, ebenfalls in Ephesos (Kat. 28 Taf. 69 Abb. 288 ${ }^{738}$. In außerordentlicher Position findet sich ein umgekehrter Zahnschnitt unter einem Akanthusfries am Sockel einer erst 1998 in Brescia entdeckten Amazonomachie-Vorderseite mit einer Datierung um $230 \mathrm{n}$. Chr. ${ }^{739}$.

Der flachreliefierte Akanthusrankenfries erscheint auf attischen Sarkophagen häufig in der ersten Hälfte des 3. Jahrhunderts n. Chr., sowohl am oberen Kastenabschluss, beispielsweise an den Achill-Sarkophagen in Tyros ${ }^{740}$ und Woburn-Abbey (Kat. 3 Taf. 34-38), als auch am Sockel, so an den Achill-Sarkophagen in Rom, Museo Capitolino ${ }^{741}$, und wiederum in Woburn Abbey ${ }^{742}$.

Das lesbische Kymation findet häufig Verwendung am oberen Kastenabschluss und an der Sockelzone attischer Sarkophage, vermag daher eine Datierung nicht näher einzugrenzen. Die oben genannten Parallelen legen jedoch eine Datierung in das zweite Viertel des 3. Jahrhunderts n. Chr. nahe.

Zweites Viertel des 3. Jahrhunderts n. Chr.

734 s. Anm 733

735 s. im Folgenden z. B. die lokalen Stücke Kat. L1-L4. L7-L9.

736 Fischer 1998, 208 Nr. 213; 225 f. Abb. 213 a. d; Kintrup 2016a, Kap. 3.2.11 Nr. 112.

737 Robert 1890, 131 f.; Koch - Sichtermann 1982, 407. 408 Nr. 14; 458; Kintrup 2016a, Kap. 4.2 .5 Nr. 55.

738 s. dort weitere Beispiele oder s. eine Aufzählung bei Rogge 1993, 116 mit Anm. 82.

739 Quattrocchi 1999, 93 mit Abb. (seitenverkehrt); F. Morandini in: C. Bertelli - G. P. Brogiolo (Hrsg.), Il futuro dei Longobardi. (Ausstellungskatalog Brescia) (Mailand 2000) 525 f. Nr. 499 Abb. 373; Morandini 2000, 184-190 Abb. 4; Morandini 2007, 39-42 Taf. 19, 5; Kintrup 2016a, Kap. 3.2.7 Nr. 78.

740 Rogge 1995, Taf. 9, 2.

741 Rogge 1995, Taf. 44.

742 s. zudem zu flachreliefierten Akanthusrankenfries auf Matratzen attischer Klinendeckel: Liste bei Rogge 1993, 119 mit Anm. 118. 


\section{Attische Sarkophagdeckelfragmente}

\subsection{Großes Fragment eines Klinendeckels (Kat. 43 Taf. 76 Abb. 311 f.)}

Selçuk, Efes Müzesi Inv. 21/13/00.

Gefunden in Ephesos, in der Nähe der Damianosstoa (1999) $)^{743}$.

Gesamt: H 37; L 156; T 66. - Rechte Ss: L 44,5.

Liegende: H 15,5. - Matratze: H nimmt zum Ende mit den Relieffeldern zu von 19-26.

Reliefbilder: H 16,5; Rahmen 2,3.

Lit.: Unpubliziert.

Fein- bis mittelkörniger, weißer Marmor. Die Oberfläche ist braun versintert. Bis auf Teile einer Klinenaußenseite allseitig gebrochen. Reste der Klinenfiguren - üblicherweise zwei Gelagerte sind auf der Kline rudimentär erhalten. Auf deren Rückseite finden sich ein kleiner Absatz und darüber einige unregelmäßig gesetzte Bohrungen. Die Oberfläche der Matratze ist nur wenig bestoßen; sie zeigt eine regelmäßige, feine bis mittlere Spitzmeißelarbeit. Auf der Klinenunterseite sind sehr grobe Meißelspuren und $8 \mathrm{~cm}$ Falz erhalten.

Bearbeitungsspuren und der Umriss der Reste der Gelagerten zeigen, dass hier der hintere Teil der Kline erhalten ist, wobei die Rückseite der Kline fehlt und nur ein Teil der rechten Klinenlehne vorhanden ist; vergleichen lässt sich damit der Deckel des Amazonomachie-Sarkophags aus dem Tatiane-Grabbau (Kat. 2 Taf. 31 f.). Der erhaltene Teil der Klinenlehne zeigt eine übliche Aufteilung in gerahmte Felder mit zwei gegenläufig geschwungenen klammerförmigen Linien dazwischen. Außergewöhnlich ist das Dekor der zwei - leider beschädigt - erhaltenen Felder, die jeweils geflügelte Eroten bei der Weinlese darstellen.

Im linken Feld steht links ein Eros mit einem Henkelkorb in der gesenkten rechten Hand. Er greift mit seiner Linken in den Korb eines etwas kleineren Gefährten, der von rechts auf ihn zukommt und seinen Korb in den nach vorn erhobenen Armen trägt. Die Szene wird von einem Weinstock gerahmt, der rechts aus dem Boden emporwächst und von dem oben Trauben und Weinblätter herabhängen. Ein zweiter Rebstock erscheint zwischen den beiden Eroten. Bei dem bestoßenen Reliefrest am linken Rand wird es sich mit großer Wahrscheinlichkeit ebenfalls um einen Weinstock handeln. Im rechten Bildfeld neigt sich ein mit Trauben und Blättern bestückter Weinstock von der Mitte nach links. Ein Eros hat den Stamm von rechts bestiegen. Unter dem Weinstock links betrachtet ein zweiter Eros seinen mit Trauben prall gefüllten Henkelkorb, den er gerade vor sich auf den Boden zu stellen scheint. Der Rest des Bildes ist abgeplatzt.

Darstellungen von >Eroten-Vindemia treten auf einigen Sarkophagen als Relieffriese des Kastens auf. Das Thema ist zwar auf attischen Sarkophagen selten belegt ${ }^{744}$, aber mit Kat. 10 (Taf. 46) gibt es sogar ein Exemplar, das noch heute im >Tor der Verfolgung « verbaut ist. Des Weiteren kennen wir einige kleine Fragmente ${ }^{745}$ sowie die beiden großen Eroten-Weinlese-Sarkophage in Klinenform in Rom, San Lorenzo ${ }^{746}$, und in Split ${ }^{747}$, die den Bildfeldern auf dem ephesischen Kli-

\footnotetext{
743 Zur Damianosstoa Anm. 693.

744 s. Koch - Sichtermann 1982, 425 f. 432 Nr. 51-55; 459 Abb. 451-453; Bielefeld 1995, 397-404. Einführende Lit. zu Wein lesenden Eroten (seit hellenistischer Zeit) auf weiteren Gattungen wie Gemmen, Gemälden und Mosaiken sowie »zur Weiterverfolgung des Motivs in der Spätantike« und zur Symbolik s. Rudolf 1989, 31 in Anm. 164.

745 Bielefeld 1995, 397-404.

746 Rodenwaldt 1930, 116-189; Koch - Sichtermann 1982, 425 f. 432 Nr. 53; 459 Abb. 452 f.; Bielefeld 1993, 91-97 Taf. 36-39; Bielefeld 1995, 397-404 Taf. 107, 2; Bielefeld 2000, 44 Taf. 10, 1.

747 Cambi 1993, 77-85 Taf. 29-33; Bielefeld 1993, 91; Bielefeld 1995, 397.
} 
nenfragment durch das flache Relief eher verwandt scheinen. Die Eroten tummeln sich dort sehr ähnlich in und unter den Weinstöcken, wenn auch vollständig übereinstimmende Motive fehlen.

Motivische Übereinstimmungen lassen sich jedoch bei den stadtrömischen Eroten-VindemiaSarkophagen nachweisen, die in erheblich größerer Anzahl vorhanden sind ${ }^{748}$. Demnach scheinen bei dem Klinenfragment in Ephesos verschiedene Typen aus dem stadtrömischen Repertoire verwendet und - mehr oder weniger willkürlich - zusammengestellt worden zu sein. So ist der auf den Weinstock steigende Eros in ähnlicher Form auf einem Sarkophag im römischen Palazzo Venezia dargestelltt ${ }^{74}$. Der Eros, der den Korb in den ausgestreckten Armen vor sich emporhält, gehörte wohl zu einer Gruppe, bei welcher der Eros mit den beiden erhobenen Armen einen vollen Korb in Empfang nimmt; der Korb wird ihm nämlich von einem zweiten Eros, der erhöht auf einem Rebstock oder auf einer Leiter steht, heruntergereicht ${ }^{750}$. Der Eros, der den Korb vor sich auf den Boden stellt, ist mit kleinen Variationen häufiger zu finden ${ }^{751}$.

\section{Datierung}

Es kann demnach in Betracht gezogen werden, dass das Repertoire der stadtrömischen Sarkophage als Vorlage genutzt wurde, oder aber, dass die seltenen attischen Sarkophage mit Eroten-Vindemia keine entsprechenden Motive überliefert haben. In beiden Fällen sind keine Hinweise auf eine genauere Datierung zu gewinnen. Zudem ist die Eroten-Weinlese hier ja nicht als Kastenfries, sondern als Dekor der Klinenaußenseite angebracht. Da dies derzeit nur hier und wohl auch bei dem folgenden Fragment Kat. 44 (Taf. 76 Abb. 310), das ebenfalls aus Ephesos stammt, belegt ist ${ }^{752}$, ist keine Vergleichbarkeit gegeben. Stilistische Kriterien greifen nur bedingt: tendenziell sind wohl die Bildfelder früher Klinendeckel sorgfältiger und mit mehr Plastizität gestaltet als Bildfelder später Exemplare, die flacher, teilweise grafischer ausgeführt scheinen $^{753}$. Die flache Reliefbildung hier lässt eher auf eine späte Datierung schließen und auch die motivische Nähe zu den späten Klinensarkophagen in Rom, San Lorenzo, und in Split legt eine späte Datierung nahe.

Datierungsvorschlag: ab dem zweiten Viertel des 3. Jahrhunderts n. Chr.

6.2 Eckfragment eines Klinendeckels (Kat. 44 Taf. 76 Abb. 310)

Selçuk, österreichisches Grabungshaus, ohne Inv.

Gefunden in Ephesos, eingemauert in die Westwand der >Stiegengasse`2, welche östlich des Hanghauses 1 verläuft ${ }^{754}$; 1984 von E. Rudolf aus der Wand entnommen.

Rechte Ss: H 26,5; L 13,5. - RS: H 30; L 24.

Reliefbild: H 16; Rahmen 2,5.

Lit.: Rudolf 1989, 57 »Ephesos T« Abb. 53; Koch 1991, 819; Rogge 1993, 119 Anm. 124.

Feinkörniger, weißer Marmor. Fragment eines Klinendeckels. Erhalten ist die Ecke der rechten Schmal- und der Rückseite. Rückseite und rechter Rand der Schmalseite sind teilweise versintert.

748 Bielefeld 1995, 397 nennt »mehr als 150 stadtrömische Exemplare, Deckel und Nebenseitendarstellungen eingeschlossen«.

749 Bielefeld 1997, 129 Nr. 162 Taf. 1, 1; 3, 1. Um 150 n. Chr. Ähnlich s. auch Eroten auf einer Leiter, z. B. Sarkophag in Rom, Museo Nazionale Romano Inv. 708: Bielefeld 1997, 121 Nr. 121 Taf. 4, 1; 6, 1; 7, 1. Um 160 n. Chr.

750 s. z. B. einen Sarkophag im Vatikan, Museo Gregoriano Profano Inv. 10435: Bielefeld 1997, 138 Nr. 212 Taf. 6, 2; 7, 2. Um 160 n. Chr.

751 So z. B. Bielefeld 1997, Taf. 14, 1; 15, 1. 2; 55, 4.

${ }^{752}$ Zu bislang ebenfalls einmaligen Darstellungen von Erotenwagenrennen auf Fragmenten der Klinenaußenseite im Archäologischen Museum von Heraklion s. Ghisellini 1985, 286 f. Nr. 6 Abb. 9 a-b.

753 Dazu und zu Belegen mit Meeresthiasos-Szenen s. Kat. 45 mit Anm. 765 f.

754 Zu dem Hanghaus 1: Lang-Auinger 1996. 
Wenige Reste der Oberseite des Deckels und der Ansätze der Klinenlehnen sowie ein kleines Stück der geglätteten Rückenlehne sind vorhanden. Die Rückseite zeigt eine mittlere Spitzmeißelbearbeitung, wobei der Rand und die untere Rundung zum Kasten hin geglättet wurden.

Auf der rechten Schmalseite ist der rechte Teil des gerahmten hinteren Bildfelds erhalten sowie dahinter die typische doppelklammerförmige Dekoration, die auch zwischen den Bildfeldern zu ergänzen ist (vgl. Kat. 43 Taf. 76 Abb. 311 f.). Im Reliefbild ist ein pausbäckiger Eros nach links zu erkennen, hinter dem ein Stamm aufragt. Ein Vergleich mit dem Klinendeckelfragment Kat. 43 hilft hier weiter, denn dieses zeigt auf der Außenseite der rechten Klinenlehne Bildfelder mit Eroten-Weinlese. In Analogie dazu dürfte es sich auch bei Kat. 44 wohl um einen Weinstock handeln; über dem Eros erscheinen die zugehörigen Ranken samt Blatt ${ }^{755}$. Eine Zusammengehörigkeit der beiden Bruchstücke ist aufgrund der Maße und der überlappend erhaltenen Teile jedoch auszuschließen ${ }^{756}$.

6.3 Fragment der Vorderseite eines Klinendeckels (Kat. 45 Taf. 76 Abb. 313)

Selçuk, Efes Müzesi Inv. 2322

Gefunden in Selçuk, Johannesbasilika (1970).

H 17,5; L 36,5; T 34,5.

Lit.: Unpubliziert.

Feinkörniger, heller Marmor. Die Oberseite ist abgebrochen. Auf der Vorderseite sind kleine Teile der Deckelrundung nach unten umbiegend erhalten; auf der grob gepickten Unterseite ist der Falz mit ca. $8 \mathrm{~cm}$ bestoßen vorhanden. Das flache Relief der Vorderseite weist nur kleinere Verreibungen und Bestoßungen auf. Von der Verbauung in der Johannesbasilika finden sich noch wenige Mörtelspuren.

Auf diesem Fragment der Vorderseite einer Klinenmatratze ist der größere Teil eines Bildfelds und ein Teil der die Bildfelder trennenden Gurte erhalten. Das Bildfeld zeigt einen Triton nach rechts, der mit seinem rechten Arm einen langen, dünnen Gegenstand - vielleicht ein Ruder - hält. Der Triton ist bis zur Brusthöhe erhalten, sein gewundener Fischschwanz ist verloren. Unter ihm erscheint ein Eros, der mit ausgestreckten Armen nach rechts fliegt. Auf dem Rücken des Fischleibes des Tritons sitzt eine Nereide, bis in Hüfthöhe erhalten und ebenfalls nach rechts gewendet. Ihre Beine sind mit Gewand bedeckt. Sie spielt wahrscheinlich mit einem zweiten Eros (Kopf fehlt), der auf Zehenspitzen weit nach links vorgebeugt vor ihr steht und ihr die Arme (Umriss erhalten) entgegenstreckt, wie dies eine ähnliche Szene auf dem Epinausimachie-Fragment in Selçuk (Kat. 19 Taf. 66 Abb. 276) abbildet.

Zwischen den drei rechts folgenden flachen Gurten sind zwei breitere Streifen mit Blattwerk und Vögeln eingearbeitet; im linken Streifen ist im oberen Bereich wohl ein Kranich (Kopf fehlt) dargestellt, im rechten Streifen sind ein Storch und neben dessen Kopf ein hängender Blütenkelch zwischen den Blättern zu erkennen. Dem Erhaltenen zufolge handelt es sich um eine häufig belegte Form des Frontdekors der Klinenmatratze. In aller Regel wird die Klinenmatratze auf der Front durch fünf gestreifte Gurte und vier rechteckige Bildfelder dazwischen unterteilt, so auf dem Sarkophag des Aemilius Aristides (Kat. 1 Taf. 4 Abb. 8; Taf. 24) ${ }^{757}$. Für den Meeresthiasos

755 Nach Rogge 1993, 119 Anm. 124 zeigen Fragmente eines Klinendeckels in Herakleion, Archäologisches Museum Inv. 167-169, s. Ghisellini 1985, 268 f. Abb. 9 a. b. Wagen fahrende Eroten und unser Fragment hier »dürfte ähnlich dekoriert gewesen sein«.

756 Zu Vergleichen zu Darstellungen von Eroten-Weinlese als Kastenfriese von Sarkophagen, zur Seltenheit der Darstellung als Dekor der Klinenaußenseite sowie zu den Schwierigkeiten einer Datierung s. unter Kat. 43.

757 Zu Variationen im Dekor der Kline und der Matratze sowie zu möglichen Vorbildern s. Ghisellini 1985, 268-271 mit Anm. 155-159. 
lässt sich das kleine Fragment in Wien Kat. 46 (Taf. 77 Abb. 314) vergleichen. Neben Szenen des Meeresthiasos, wie hier abgebildet, erscheinen auch Tiere ${ }^{758}$ und Jagdszenen in den Bildfeldern $^{759}$. Die Klinenmatratzen können zudem ein vegetabiles Dekor aufweisen, wie dies auf dem Amazonomachie-Sarkophag, ebenfalls aus dem Grabhaus der Tatiane (Kat. 2 Taf. 30-32) der Fall ist $^{760}$. Motive sowie das flache Relief der Dekorationen dürfen als Nachbildungen der gewebten Stoffe, die für Matratzenbezüge verwendet wurden, interpretiert werden ${ }^{761}$.

\section{Datierung}

Vegetabiles Dekor der Matratzenfront lässt sich auf eine Datierung ab 230 n. Chr. eingrenzen ${ }^{762}$. Bei der Einteilung der Matratzenfront in Gurte und Bildfelder mit Meeresthiasosszenen ist eine Eingrenzung der Datierung nicht so einfach möglich, denn diese Dekoration ist sowohl auf frühen Klinendeckeln des vierten Viertels des 2. Jahrhunderts als auch auf späten Exemplaren aus der Mitte des 3. Jahrhunderts n. Chr. nachzuweisen. Lediglich einige der frühesten Klinendeckel sind z. T. ohne Dekor geblieben ${ }^{763}$, oder es wurden nur die Gurte angegeben ${ }^{764}$. Als Tendenz lässt sich beobachten, dass das Dekor bei frühen Klinendeckeln plastischer, sorgfältiger und >liebevoller ausgearbeitet ist ${ }^{765}$, während bei späten das Bild- und Gurtdekor eher einfacher, flacher, weniger plastisch, teilweise grafischer gestaltet ist ${ }^{766}$. Demnach wäre für das ephesische Fragment eine frühe Datierung noch im 2. Jahrhundert n. Chr. zu veranschlagen. Nach S. Rogge ${ }^{767}$ setzen sich bei frühen Klinendeckeln die nichtdekorierten schmalen Bänder deutlich von den dekorierten breiteren ab, was die vorgeschlagene frühe Datierung stützen würde. Leider sind bei Rogge keine konkreten Vergleichsstücke genannt und auch die Beobachtungen zum Stil können ohne Untersuchungen auf einer größeren Materialbasis nicht als gesichert und verbindlich gelten.

Datierungsvorschlag: viertes Viertel des 2. Jahrhunderts.

\subsection{Fragment der Vorderseite eines Klinendeckels (Kat. 46 Taf. 77 Abb. 314)}

Wien, Kunsthistorisches Museum, Antikensammlung Inv. I 929.

Selçuk, Ayasoluk; 1911 den kaiserlichen Sammlungen geschenkt, 1914 inventarisiert ${ }^{768}$.

$\overline{758}$ s. den Eroten-Weinlese-Sarkophag in Split: Cambi 1993, 77-85 Taf. 30.

759 Dazu: Rogge 1993, 118 f. mit gesammelten Beispielen in Anm. 116.

760 s. dort auch etliche Beispiele in Anm. 172.

761 Eichler 1946, 93 (zu dem folgenden Wiener Fragment, hier Kat. 46). 95. s. auch Keil 1929, 48; Rodenwaldt 1930, 135. 167. 178-180. 184; Linant de Bellefonds 1985, 29 Anm. 2; Rogge 1993, 118 f.; Ciliberto 1998, 245-247.

762 s. dazu ausführlicher unter dem Amazonomachie-Sarkophag aus dem Tatiane-Grab, hier Kat. 2.

763 s. z. B. den Amazonomachie-Sarkophag in Paris, Louvre Inv. Ma 2119: Koch - Sichtermann 1982, 389 f. 391 f. 440 Nr. 36; 456. 458 Abb. 420; Kintrup 1998, 206 f. 215 Taf. 92, 1; Kintrup 2016a, Kap. 3.1.1.1 Nr. 156.

764 s. z. B. den Achill-Sarkophag in St. Petersburg: Rogge 1995, 139 f. Nr. 29 Taf. 27. 28, 2, den Schlachtsarkophag in Ptolemais: Pietrogrande 1930, 108-111 Nr. 1 f. Abb. 6; Kraeling 1962, 185 f. 206 f. Nr. 69 f. Taf. 51 A; Kintrup 2016a, Kap. 4.1.1 mit Anm. 361 Nr. 167, und den >Unterweltsarkophag in Beirut: Koch - Sichtermann 1982, 417 Abb. 436; Oakley 2011, 56-59 mit Abb. 4; 98 f. Kat. 66 Taf. 59, 2; 60, 1.

765 s. z. B. einen Achill-Sarkophag in Ioannina: Rogge 1995, 129 Nr. 12 Taf. 1, 2; 24, 3-4.

766 s. z. B. einen Achill-Sarkophag in Rom, Museo Capitolino: Rogge 1995, 136 f. Nr. 24 Taf. 45; EpinausimachieSarkophage in Damaskus: Koch 1996, 197-207 Taf. 44-49; Kintrup 2016a, Kap. 5.2.4 Nr. 84, in Thessaloniki: Linant de Bellefonds 1985, 112-116. 119 f. 179 Taf. 42, 2; Stefanidou-Tiveriou 1997, 169-174 Nr. 135; 384 Abb. 341; Kintrup 2016a, Kap. 5.2.6 Nr. 248, und in Tyros: Linant de Bellefonds 1985, 28-30. 99-101. 106-108. 119 f. 179 Taf. 35; Chéhab 1985, 559 f. Taf. 114 a-b; 116 b; Kintrup 2016a, Kap. 5.2.8 Nr. 261, einen Schlachtsarkophag in Tyros: Chéhab 1985, 501 f. Taf. 91 b; 92 a; Kintrup 2016a, Kap. 4.2.17 Nr. 260.

767 Rogge 1993, 118.

768 Angabe zu dem Fundort Ayasoluk (= Burgberg in Selçuk) nach Eichler 1946, 92 Nr. 4; zur Schenkung an das Museum freundliche Auskunft G. A. Plattner. 
H 28,5; L 48,5; L des Bildfelds 29,5.

Lit.: Eichler 1944/45, 130 Nr. 10; Eichler 1946, 92-96 Nr. 4 Abb. 23; Kallipolitis 1958, 35 Nr. 252; Giuliano 1962, 48 Nr. 258; Fabbricotti 1975, 44 Anm. 19; Rudolf 1989, 56 f. »Ephesos R«; Icard-Gianolio - Szabados 1992, 798 Nr. 178.

Heller, fein- bis mittelkörniger Marmor. Vorderseitenfragment eines Klinendeckels. Zu beiden Seiten Bruch. Die Unterseite vorhanden; sie ist grob gemeißelt mit einem feiner bearbeiteten Falz von 6,5 cm Breite. Auf der Oberseite des Fragments ist ein Dübelloch über dem linken verzierten Gurtstreifen vorhanden, dessen Zweck vielleicht mit einer Wiederverwendung in Zusammenhang steht ${ }^{769}$.

Die Oberseite zeigt kleine Reste der antiken Oberfläche, die wahrscheinlich zu dem Kissen einer gelagerten Klinenfigur gehören. Die Umrisse der Reste lassen darauf schließen, dass es sich um das Kissen der gelagerten Frau gehandelt hat, da das Kissen des Mannes, an die seitliche Klinenlehne anstoßend, nicht den Umriss wie hier zeigt, der sich rechts wieder auf die Matratze absenkt ${ }^{770}$. Demnach wird es sich bei der Matratzenfront um das zweite Bildfeld von rechts handeln; es ist anzunehmen, dass hier die übliche Einteilung vorhanden war, bei der die Matratzenfront fünf gestreifte Gurte und dazwischen vier rechteckige Bildfelder aufwies (vgl. Kat. 1 Taf. 4 Abb. 8; Taf. 24). Der größte Teil eines Bildfelds sowie rechts und links Teile der die Bildfelder trennenden Gurte sind erhalten. Zwischen je zwei flachen Gurtstreifen ist je ein Streifen mit Blattwerk und Tieren verziert. Im ornamentierten Streifen links des Bildfelds ist eine sich aufwärts windende Schlange zu erkennen; im verzierten Streifen rechts des Bildfelds sind ein Adler mit nach rechts zurückgewendetem Kopf und darüber ein kleiner Hase nach rechts eingearbeitet.

Das Bildfeld zeigt einen Triton nach links, der eine Nereide mit dem üblichen Hüftmantel auf dem Rücken seines Fischleibes trägt. Unter ihnen schwimmen zwei Delfine nach rechts. Der Triton hält eine Kanne in seiner gesenkten Rechten und einen Ketos ${ }^{771}$ in der ausgestreckten Linken. Mit dem Seedrachen scheint er einen Eros und die Nereide erschrecken zu wollen. Der Eros ist im Ausfallschritt nach rechts mit einem Früchtekorb in der Linken dargestellt; er hat seine Rechte in einer abwehrenden Geste erhoben, während die Nereide, auf ihren linken Arm gestützt, mit der Rechten zum >Gegenschlag a ausgeholt hat. Der Gegenstand in ihrer Hand ist nicht mit Sicherheit zu identifizieren ${ }^{772}$. Für den Meeresthiasos lassen sich die ephesischen Beispiele Kat. 1 (Taf. 4 Abb. 8; Taf. 24) ${ }^{773}$ und Kat. 45 (Taf. 76 Abb. 313) heranziehen ${ }^{774}$.

\section{Datierung}

Da ein Dekor der Matratzenfront mit gestreiften Gurten und Szenen des Meeresthiasos auf frühen Klinendeckeln des letzten Viertels des 2. Jahrhunderts bis hin zu späten Klinendeckeln der Mitte des 3. Jahrhunderts n. Chr. zu belegen ist, ist eine nähere Eingrenzung der Datierung schwierig ${ }^{775}$. Hinweise auf die Datierung finden sich - unter Vorbehalt - nach stilistischen Kriterien. So scheinen die Bildfelder früher Klinendeckel sorgfältiger und mit größerer Plastizität gestaltet zu sein als späte, welche flachere, teilweise grafischer ausgeführte Bildfelder bieten ${ }^{776}$. Demzufolge wird es sich hier wohl nicht um ein spätes Exemplar handeln.

769 Eichler 1946, 93.

770 Eichler 1946, 94.

771 LIMC VIII Suppl. (1997) 731-736 s. v. Ketos (J. Boardman).

772 Eichler 1946, 94: »... sinngemäß wahrscheinlich ein Fisch oder junger Delphin, dessen Kieme sich im Relief von der Fläche abhebt«. Nach Autopsie handelt es sich eher um eine Sandale.

$773 \mathrm{Zu}$ Variationen im Dekor der Kline und der Matratze sowie zu möglichen Vorbildern s. hier Kat. 1 mit Anm. 158-160.

774 s. Eichler 1946, 94 f., dort auch zu Bildfeldern mit einem anderen Dekor von Jagdszenen und Tieren.

775 s. dazu ausführlicher auch bereits hier Kat. 45.

776 Zu Belegen s. auch Kat. 45 mit Anm. 765 f. 
Datierungsvorschlag: viertes Viertel des 2. Jahrhunderts - erstes Viertel des 3. Jahrhunderts n. Chr.

\subsection{Linke Ecke eines Klinendeckels (Kat. 47 Taf. 77 Abb. 315 f.)}

Selçuk, Efes Müzesi, Açık Hava Deposu, Etd.Nr. L. 84.

Fundort unbekannt.

VS.: H 25; L 24; Ss: H 25; L 37.

Lit.: Rudolf 1989, 56 »Ephesos Q« Abb. 51; Koch 1991, 817. 819; Rogge 1993, 119 mit Anm. 118 und 126.

Feinkörniger, weißer Marmor. Eckfragment eines Klinendeckels. Erhalten ist die linke Ecke der Vorderseite und ein Stück der linken Schmalseite. Die Oberseite der Klinenecke ist geglättet. Die Unterseite bietet regelmäßig gearbeitete Falze (B max. 8,5). Das linke Fulcrum der Vorderseite endet in einem Entenkopf, dessen Schnabelspitze fehlt; der aufsteigende Teil des Fulcrums ist mit Blattwerk verziert, dessen oberes Ende ebenfalls weggebrochen ist. Auf der linken Schmalseite ist im unteren Teil ein Kyma aus stehenden Akanthusblättern erhalten. Es fehlt der obere Bereich einschließlich der Klinenlehne und auf der linken Seite zunehmend das Dekor.

\section{Datierung}

Zu dem Dekor beider Seiten bietet der Amazonomachie-Sarkophag aus dem Tatiane-Grabhaus (Kat. 2 Taf. 31 f.) eine gute Parallele, und es finden sich etliche weitere Vergleiche auf weiteren Sarkophagdeckeln ${ }^{777}$. Da alle Vergleichsstücke eine Datierung im zweiten Drittel des 3. Jahrhunderts haben, wird auch für dieses Eckfragment eine entsprechende Einordnung vorgeschlagen.

Zweites Drittel des 3. Jahrhunderts n. Chr.

\subsection{Fragment der Schmalseite eines Klinendeckels (Kat. 48 Taf. 77 Abb. 317 f.)}

Selçuk, in der nördlichen Seite - nahe der Ecke zur Ostseite - der Stützmauer des Atriums der Johannesbasilika verbaut (Taf. 77 Abb. 317).

»Im Zuge der Restaurierungsarbeiten an der Johannesbasilika in den achtziger Jahren ... eingebaut« (Rudolf 1989, 57).

H 38; L 51; D (erhalten) 4,5; Rautenfeld mit Rahmen H 16; L 26.

Lit.: Rudolf 1989, 57 »Ephesos S« Abb. 52; Koch 1991, 819.

Fein- bis mittelkörniger, heller Marmor. Die Oberfläche ist rechts stärker verrieben als links. Trotz der Bruchflächen im oberen Teil sind die Ansätze der nach außen gewölbten Teile der Kline und kleine Reste der geglätteten Oberseite der Klinenlehne vorhanden. Als Dekor der Außenseite der Kline erscheinen zwei ineinander geschachtelte Rhomben und fünf Blüten in zweifach gerahmten, rechteckigen Feldern. Die zwei flachen Rahmen sind oben und unten von leicht S-förmig geschwungenen Profilen eingefasst, die zwischen den Rhombenfeldern einen klammerförmigen Mittelteil bilden. Nach der mehrfachen Rahmung und deren teilweiser Profilierung zu urteilen, gehörte das Fragment einer bevorzugt gearbeiteten Sarkophagseite an. Die Rückseiten der Außenseiten der Klinendeckel waren zumeist vernachlässigt oder gar nicht dekoriert, während auf den Schmalseiten oft auch für den Deckel eine bevorzugte und eine vernachlässigte Ausführung nachzuweisen ist. Am linken Rand des Fragments sind kleine Ansätze

777 s. Rogge 1993, 119 Anm. 118. Anm. 126 oder unter Kat. 2 in Anm. 174. 
der klammerförmigen Zwischenglieder zu erkennen. Die linke Seite des Fragments erscheint stark verrieben, aber nicht gebrochen. Zudem gibt der nach oben gerundete Verlauf einen Hinweis darauf, dass hier das rechte Fulcrum der Vorderseite zu finden war, wie bei zwei Sarkophagen in Thessaloniki, einem Amazonomachie- und einem Epinausimachie-Sarkophag ${ }^{778}$, deren Fulcra ähnlich gebrochen sind. Das Fragment gehörte damit zur rechten Schmalseite.

\section{Datierung}

Für dieses typische Dekor der Außenseiten einer Kline im späten 2. und in der ersten Hälfte des 3. Jahrhunderts n. Chr. ist wiederum der Sarkophag des Aemilius Aristides (Kat. 1 Taf. 21-24) zu vergleichen ${ }^{779}$. Da das Kassettendekor mit Rhomben und Blüten so häufig belegt und zeitlich nicht genauer zu fassen ist, kann eine Datierung nur sehr schwer eingegrenzt werden. Im Allgemeinen sind die rechteckigen Felder bei früheren Klinendeckeln höher ${ }^{780}$, bei späteren niedriger ${ }^{781}$ und haben damit eine länglichere Form ${ }^{782}$, sodass eine frühe Datierung anzunehmen wäre. Allerdings sind auch Ausnahmen zu finden, wie der Eroten-Weinlese-Sarkophag in Klinenform in Split ${ }^{783}$ oder der Epinausimachie-Sarkophag in Thessaloniki ${ }^{784}$, die um die Mitte des 3. Jahrhunderts n. Chr. anzusetzen sind und fast quadratische Kassettenfelder außen auf den seitlichen Klinenlehnen aufweisen. Dies muss zur Vorsicht bei der Datierung mahnen - die frühe Datierung kann nur ein Vorschlag sein, eine späte Datierung ist aufgrund der Vergleiche zumindest als unwahrscheinlicher anzusehen.

Datierungsvorschlag: viertes Viertel des 2. Jahrhunderts - erstes Viertel des 3. Jahrhunderts n. Chr.

778 Amazonomachie: Archäologisches Museum Inv. 283: Koch - Sichtermann 1982, 391 mit Anm. 10; 458; Stefanidou-Tiveriou 1997, 380-383 Abb. 336-340; Kintrup 2016a, Kap. 3.2 .3 Nr. 245. - Epinausimachie: Archäologisches Museum Inv. 1246: Brenk 1972, 39-46 Abb. 1 f.; Koch - Sichtermann 1982, 411. 412. 414 Nr. 18 ; 416. 459 Abb. 445; Stefanidou-Tiveriou 1997, 169-174 Nr. 135; 384 f. Abb. 341 f.; Kintrup 2007, 181 f. Taf. 63, 1; Kintrup 2016a, Kap. 5.2.6 Nr. 248.

779 Zu möglichen Vorbildern s. hier Kat. 1 Anm. 160.

780 s. z. B. die Achill-Sarkophage in St. Petersburg: Rogge 1995, 139 f. Nr. 29 Taf. 39, 2; und in Ioannina: Rogge 1995, 129 Nr. 12 Taf. 19, 1; 20.

781 s. z. B. einen Hippolytos-Sarkophag in Tyros: Rogge 1995, 157 f. Nr. 70 Taf. 101, 1; 105, 1; und drei Schlachtsarkophage, zwei in Tyros, nämlich Inv. 4048/4049: Chéhab 1985, 600 f. Taf. 123 a; Kintrup 2016a, Kap. 4.2.13 Nr. 262 sowie Inv. 3951/3952: Chéhab 1985, 501 f. Taf. 90 b; Kintrup 2016a, Kap. 4.2.17 Nr. 260 und einen in Beirut: Chéhab 1985, 687 f. Taf. 136 c; Kintrup 2016a, Kap. 4.2.15 Nr. 72.

782 So Rogge 1993, 119.

783 Cambi 1993, 77-85 Taf. $32 \mathrm{f}$.

784 Stefanidou-Tiveriou 1997, 169-174 Nr. 135; 384 Abb. 342 f.; Kintrup 2016a, Kap. 5.2.6 Nr. 248. 



\section{$7 \quad$ Lokale Sarkophagfragmente ${ }^{785}$}

\subsection{Einleitung}

1970 wurde von N. Himmelmann ${ }^{786}$ ein ephesisches Fragment mit Amazone als attisches Stück erwähnt, das dann auch 1989 in der Publikation von E. Rudolf ${ }^{787}$ besprochen wurde. Da sich das Fragment (Kat. L1 Taf. 78 Abb. 319 f.) in technischer, stilistischer und typologischer Hinsicht von attischen Exemplaren unterscheidet ${ }^{788}$, wurde eine attische Herkunft jedoch angezweifelt. Auch der Marmor ließ Skepsis an einer attischen Provenienz aufkommen, was auch durch die Steinanalysen bestätigt wurde. Im Hinblick auf die erstgenannten Kriterien ist eine Zugehörigkeit zu den stadtrömischen oder kleinasiatischen Amazonomachie-Sarkophagen ebenfalls auszuschließen, sodass als Möglichkeit eine Fertigung in einer lokalen Werkstatt anzunehmen war.

Die Marmoranalyse ergab eine Herkunft aus Dokimeion/Afyon ${ }^{789}$. Zudem zeigte sich, dass einige weitere Fragmente sehr ähnlicher Qualität und Ausführung in Ephesos vorhanden sind. Eine Untersuchung hinsichtlich einer möglichen Zuordnung an eine lokale Werkstatt erschien damit umso lohnender - insbesondere auch unter dem Aspekt übergeordneter Fragestellungen zu Lokalisierung provinzieller Werkstätten, zu Kriterien, Kopien und zu Nachahmungen in den Provinzen, um diese Denkmäler von den Exemplaren der Produktionszentren unterscheiden zu können ${ }^{790}$.

Zunächst sicherten die Autopsien, besonders auch der Rückseiten, die Einordnung der fraglichen Exemplare als Sarkophagfragmente. Leider sind bei den mutmaßlichen lokalen Fragmenten keine Reste des oberen Kastenabschlusses, der Sockelzone oder einer seitlichen Rahmung erhalten. Die dann folgenden Untersuchungen bestätigten die ersten Einschätzungen: die hier zusammengestellten Fragmente der Sarkophage Kat. L1-L9 (Taf. 78-80) können einer lokalen Werkstatt zugeordnet werden.

\subsection{Kastenfragment mit fallender Amazone (Kat. L1 Taf. 78 Abb. 319 f.)}

Selçuk, Efes Müzesi Inv. 1883.

Selçuk, im Bereich des Saadet Hatun-Hamams, der Teil des Museums ist (1968) ${ }^{791}$.

\section{H 53; L 41; DW 6; Rh 9.}

Lit.: Himmelmann 1970a, H. 9, 23 mit Abb. 15; Rudolf 1989, 50 »Ephesos G«; Koch 1991, 817 f.; Kintrup - Heinz 2012, 189-191 Taf. 85, 1; Russenberger 2015, 616 Anm. 100; 620 Anm. 145; Kintrup 2016a, Kap. 3.2.10 Nr. 92.

Feinkörniger, heller Marmor aus Dokimeion/Afyon; so auch Kat. L4 (Taf. 79 Abb. 323). Allseitig gebrochen. Die Rückseite erscheint recht flach, ist - wohl von einer Wiederverwendung - abgetreten und zeigt weiße Farbspuren. Die Oberfläche des Reliefs ist in den vorstehen-

785 Vgl. dazu u. Kap. 8 zu den Marmoranalysen (W. Prochaska).

786 Himmelmann 1970a, H. 9, 23.

787 Rudolf 1989, 50 »Ephesos G«. Rezension zu Rudolf: Koch 1991, 816-819.

788 Die Verf. beschäftigte sich bereits im Rahmen der Untersuchungen für den Corpus-Band über die attischen Sarkophage mit Schlachtszenen ausführlicher mit dem Fragment: Kintrup 2016a, Kap. 3.2.12 Nr. 92.

789 s. u. Kap. 8.1.2; 8.3.1; 8.4.

790 Diese Fragestellungen standen auch im Zentrum des internationalen Kolloquiums »Les sarcophages romains: centres et périphéries« 2005 in Paris, auf dem erste Ergebnisse zu den folgenden Friesfragmenten vorgestellt wurden: Kintrup - Heinz 2012. Ferner: Kintrup 2016b.

791 Vgl. zu diesem Hamam A. Zülkadıroğlu in: Scherrer 2000, 220. 
den Bereichen verrieben; hinzukommen einige Bestoßungen an der Brust und besonders dem Gesicht einer Amazone. Deutliche Bohrlinien finden sich in der Pferdemähne. Tiefe und breite Bohrkanäle umranden die Konturen der Figuren und des Gewands, während die Binnengliederung des Chitons durch Meißelarbeit gestaltet ist. Aufgrund der Reliefhöhe gehörte das Fragment zu einer bevorzugt gearbeiteten Sarkophagseite ${ }^{792}$.

Das Fragment zeigt eine kopfüber vom Pferd stürzende Amazone in einem typischen kurzen Chiton, der ihre rechte Brust unbedeckt lässt. Ihre Arme hängen herab und die Hände sind über dem Kopf gefasst. Von dem nach links steigenden Pferd ist ein Teil des Pferdekörpers mit Hals, Mähne und dem Ansatz des linken Vorderlaufs erhalten. Links neben der Amazone ist ein Stück einer Pelta zu erkennen. Rechts neben ihr wird das Pferd von einer weiteren Figur überschnitten. Es bleibt geglätteter Reliefgrund sichtbar.

Zwar zeigt sich bei dem Fragment in Ephesos durch die Bohrkonturen und durch die Bildung des Kolpos der Amazone eine Anlehnung an attische Vorlagen. So ist der Kolpos in einer besonders den reitenden Amazonen auf attischen Sarkophagen verwandten Art kurz und gebauscht dargestellt, etwa auf den attischen Amazonomachie-Sarkophagen im Athener Nationalmuseum (Inv. $1147^{793}$ und 2716 ${ }^{794}$ ) oder auf zwei Exemplaren (Inv. 283 $3^{795}$ und 276 $6^{796}$ ) im Archäologischen Museum von Thessaloniki ${ }^{797}$.

Die sehr breiten Bohrkanäle des Chitons jedoch scheinen das für attische Sarkophage typische Merkmal der gebohrten Umrisslinien ${ }^{798}$ betont, ja geradezu übertrieben abzubilden. Der Verlauf der Bohrkanäle wirkt dabei schematisch gewellt und nicht adäquat für das Sturzmotiv. Die MeiBelarbeit der Binnengliederung ist nicht ungeschickt, aber die flache Faltengestaltung und der Faltenverlauf können im Vergleich zu den genannten attischen Exemplaren nicht überzeugen. Eine interessante Parallele findet sich auf einem ebenfalls provinziellen Sarkophag in Tunis ${ }^{799}$ aus dem zweiten Viertel des 3. Jahrhunderts n. Chr., wo die flache Faltengebung sowie die gewellte Konturlinie des Kolpos einer reitenden Amazone ähnlich unattisch wirken.

Einen wichtigen Beleg für eine lokale Herstellung des Fragments in Ephesos liefert zudem das Sturzmotiv der Amazone, denn es hat keine Parallelen auf attischen Exemplaren; ein typisches Sturzmotiv zeigt der bereits genannte Sarkophag in Thessaloniki Inv. 283800. Ein Vergleich zu Kat. L1 findet sich wiederum auf einem lokal gearbeiteten Amazonomachie-Sarkophag; auf einem Exemplar in Annaba ${ }^{801}$, um die Mitte des 3. Jahrhunderts n. Chr., handelt es sich allerdings um einen stürzenden Griechen ${ }^{802}$.

792 Zur Forschungsgeschichte s. o. in der Einleitung.

793 Robert 1890, 85 f. Nr. 70 Taf. 30 Abb. 70-70 d; Baratte 1985, 261 f. Nr. 167 (mit weiterer Lit. zu dem zugehörigen Schmalseitenfragment in Paris); Kintrup 1998, 207 mit Abb. 1; 215; Kintrup 2016a, Kap. 3.1.1.2 Nr. 54.

794 Datsouli-Stavridi 1984, 185 Taf. 26 a; Kintrup 2016a, Kap. 3.1.3 und 3.1.3.1 Nr. 60.

795 Stefanidou-Tiveriou 1997, 166-169 Nr. 134; 380-383 Abb. 336-340; Kintrup 1998, 209 f. 214 f. Taf. 93, 4; 95, 2. 7; Kintrup 2016a, Kap. 3.2.3 Nr. 245.

796 Giuliano - Palma 1978, 36 Nr. 2 Taf. 34, 90-91; Kintrup 1998, 210. 214 Taf. 93, 2-3; 95, 6; Kintrup 2016a, Kap. 3.2.5 Nr. 244.

$797 \mathrm{Zu}$ längeren, wenig gebauschten Kolpoi und zur Gewandbehandlung auf stadtrömischen Amazonomachie-Sarkophagen vgl. hingegen z. B. zwei Sarkophage im Vatikan, Belvedere s. Grassinger 1999, 250 f. Nr. 125.127 Taf. 111, 2-3 oder das Exemplar Mazara del Vallo, Grassinger 1999, 246 Nr. 116 Taf. 110, 1. Zur Gewandbehandlung auf kleinasiatischen Amazonomachie-Sarkophagen s. z. B. das Exemplar in Aizanoi, Rheidt 1997, 487 Abb. 17. Hier wie dort fehlen zudem die gebohrten Umrisslinien.

798 Vgl. u. Anm. 916.

799 Robert 1890, 128 Nr. 107; Koch - Sichtermann 1982, 311 Anm. 10; 472; Grassinger 1999, 187. 256 f. Taf. 120 , 3; Kintrup 2016a, Kap. 3.2.10 Nr. 258.

800 s. o. Anm. 795.

801 Koch - Sichtermann 1982, 471 mit Anm. 12; 472 Abb. 336; Grassinger 1999, 186 f. mit Anm. 405; 256 Nr. 142 Taf. 113, 3; 128, 4-5.

802 Für den Sarkophag Annaba wurde festgestellt, dass er zwar stilistisch Parallelen zu attischen Sarkophagen aufweist, typologisch aber eindeutig von stadtrömischen Sarkophagen abhängig ist, s. Koch - Sichtermann 1982, 471 mit Anm. 12; 472 Abb. 336; so auch Grassinger 1999, 186 f. 256 Nr. 142 Taf. 113, 3; 128, 4-5, die dies detailliert belegt. 
Weitere vergleichbare Motive finden sich auf stadtrömischen Sarkophagen. Ein stadtrömischer dionysischer Sarkophag mit Inderschlacht in Rom ${ }^{803}$ zeigt einen fallenden Inder, wobei dessen Kopf bereits den Boden berührt und das Pferd unter ihm nach rechts gestürzt ist. Bessere Vergleiche in Bezug auf die Armhaltung der Amazone bieten interessanterweise stadtrömische Phaethon-Sarkophage, so der Phaethon-Sarkophag in Kopenhagen ${ }^{804}$, dessen Datierungen zwischen der Mitte des 2. Jahrhunderts und dem späten 3. Jahrhundert n. Chr. schwanken, oder jener in Rom, Villa Borghese ${ }^{805}$, um 300 n. Chr. Zudem kann ein Phaethon-Sarkophag in Florenz ${ }^{806}$, um 170 n. Chr., als enge Parallele herangezogen werden. Das Sturzmotiv lässt sich jedoch deutlich länger zurückverfolgen. Es erscheint in Kopien der Amazonomachie von dem Schild der Athena Parthenos (447-438 v. Chr.) aus dem 3. nachchristlichen Jahrhundert ${ }^{807}$.

\section{Datierung}

Da datierende Kriterien wie tektonische Elemente oder Ornamentik bei dem Fragment in Ephesos fehlen und auch stilistische und typologische Kriterien im Vergleich zu attischen Exemplaren und zu den anderen genannten Parallelen zu unterschiedlich sind, ist eine fundierte Datierung derzeit nicht möglich. Keines der Vergleichsexemplare hat ausreichende Übereinstimmungen aufzuweisen, die für das Fragment in Ephesos eine zeitliche Einordnung in Analogie rechtfertigen würden. Der frei bleibende Reliefgrund des Fragments in Ephesos lässt aber auf eine frühe Datierung schließen.

\subsection{Kastenfragment mit Leda und dem Schwan (Kat. L2 Taf. 78 Abb. 321)}

Selçuk, Efes Müzesi Inv. 1839.

Gefunden in der Gegend der İsa Bey-Moschee und der Johannesbasilika (1967).

H 45; L 48; DW 9; Rh 5.

Lit.: Kintrup - Heinz 2012, 191 f. Taf. 85, 2-3.

Grobkörniger, grauer Marmor aus Thasos ${ }^{808}$. Allseitig gebrochenes Fragment. Die Oberfläche ist porös verwittert, besonders betroffen sind der Kopf und die gesamte Rückenseite Ledas sowie die Brust des Schwans.

Die Rückseite zeigt Bearbeitungsspuren durch ein mittelgroßes Zahneisen. Zudem ist ein kleiner Absatz eingearbeitet, der auch auf anderen Exemplaren, z. B. Kat. L3 (Taf. 78 Abb. 322) oder dem Riefelsarkophag in dem Coemeterium der Siebenschläfer in Ephesos, vorkommt. Vielleicht handelt es sich um eine Möglichkeit, einen Trennboden für eine Wieder- oder Mehrfachbelegung anzubringen.

Dargestellt ist der Liebesakt zwischen Zeus in Gestalt des Schwans und Leda. Der Figur Ledas fehlen die Schädelkalotte und die Beine ab den Waden abwärts; dem Schwan ein Teil des Halses, die Spitzen der Schwanzfedern, der untere Bereich seines rechten Flügels und die Flügelspitzen

${ }_{803}$ Museo Capitolino Inv. 1347, s. Matz 1969, 428-430 Nr. 238 Taf. 259, 1 Beil. 111, 1; 112.

804 Ny Carlsberg Glyptotek: Zanker - Ewald 2004, 87 f. mit Abb. 70; 373 f. Nr. 34.

805 LIMC VII (1994) 352 Nr. 18 Taf. 313 s. v. Phaeton I (F. Baratte) und LIMC a. O. 352 Nr. 15; Koch - Sichtermann 1982, 182 f. Abb. 213.

806 Uffizien Inv. 181: Koch - Sichtermann 1982, 181-183 Abb. 212; Zanker - Ewald 2004, 26 f. mit Abb. 18.

807 s. die Marmorreplik >Strangford`, London, British Museum Inv. 302: Bothmer 1957, 210 Nr. 3 Taf. 87, 1; Harrison 1966, 107-133 Taf. 37 a; Devambez - Kauffmann-Samaras 1981, 603 Nr. 246 f. Taf. 473, 230-250 n. Chr.; s. auch die Statuette Athena Lenormant, Athen, Nationalmuseum Inv. 128; s. Bothmer 1957, 210 Nr. 4 Taf. 87, 2; Devambez - Kauffmann-Samaras 1981, 603 Nr. 246e Taf. 473. Listen der Schildkopien und einzelner Gruppen des Schilds finden sich bei Bothmer 1957, 210 f.; Devambez - Kauffmann-Samaras 1981, 603 f. Nr. 246 a-g Taf. $472 \mathrm{f}$.

808 s. u. Kap. 8.1; 8.3.1; 8.4. 
des linken, die Bruchkante verläuft wohl den linken Flügelrand entlang. Von der Frisur Ledas ist noch der Haarknoten zu erkennen. Zwischen den Figuren bleibt geglätteter Reliefgrund frei. Beide Figuren sind seitenansichtig dargestellt. Der Schwan hat auf dem eingewinkelten linken Oberschenkel Ledas Halt gefunden und küsst sie. Sein linker Flügel ist in einer umarmenden Geste um ihre rechte Schulter geführt. Ledas linke Hand ist vor ihre Scham gelegt. Sie hält dabei vielleicht das Gewandstück, das vor ihrem Knie in senkrechten Falten fällt und hinter dem Knie in mehr oder weniger horizontalen Falten in Erscheinung tritt; es scheint, als wäre es um ihren rechten Oberschenkel geschlungen, allerdings wäre das Bein dann fast durchgedrückt, was nicht zu der etwas gebückten Haltung Ledas passt. So ist der Verlauf des Gewandes unklar. Ledas rechter Arm bleibt dem Blick verborgen.

Tiefe und recht breite Bohrkanäle setzen den linken Arm Ledas von dem Körper des Schwans und ihrem eigenen Körper ab, den rechten Schwanenfuß von ihrem linken Oberschenkel. Bohrkanäle sind auch für die Faltenangabe bei dem Gewandstück verwendet, die Binnenzeichnung des Schwanengefieders hingegen ist nur mit dem Meißel gearbeitet.

Der nichtattische Marmor sowie die Kombination von tiefen, breiten Bohrkanälen und einer in flacher Meißelarbeit gestalteten Binnenzeichnung weist das Fragment als lokales Exemplar aus. Im Unterschied zu den übrigen lokalen Fragmenten ist aber bei diesem die Frage nach möglichen Vorbildern der Darstellung einfacher zu beantworten, zumal es Parallelen auf zwei Schmalseiten attischer Sarkophage gibt ${ }^{809}$. Dadurch liegt die Vermutung nahe, dass auch dieses Fragment einer Schmalseite angehörte. Bei den attischen Exemplaren handelt es sich zum einen um die linke Schmalseite eines Sarkophags in Kephissia ${ }^{810}$, um 160-170 n. Chr. ${ }^{811}$, der auf der Frontseite Helena und die Dioskuren und damit den Nachwuchs aus der Verbindung Ledas mit dem Schwan zeigt, zum anderen um die linke Schmalseite eines Achill-Sarkophags in Jerusalem ${ }^{812}$, der um 210 n. Chr. angesetzt werden kann ${ }^{813}$.

Auf dem Fragment in Ephesos finden sich - mit kleineren Abweichungen - Elemente beider Darstellungen. Die Größe des Schwans und das Motiv des Vogels, der sich an der Gestalt Ledas festhält ${ }^{814}$, entspricht besser der Schmalseite in Kephissia, während auf der Schmalseite in Jerusalem der Schwan, dessen Größe fast ins Groteske gesteigert ist ${ }^{815}$, vor Leda steht. Die zum Kuss zugeneigten Köpfe und die Haltung des linken Arms Ledas jedoch entsprechen wiederum eher dem Sarkophag in Jerusalem, wohingegen in Kephissia der linke Arm Ledas versucht, den Schwan zurückzudrängen. Das in Jerusalem um den linken Unterarm Ledas gewickelte Gewand mit horizontalen und darunter vertikalen Falten klärt zwar den Faltenverlauf nicht befriedigend ${ }^{816}$,

$809 \mathrm{Zu}$ weiteren Verwendungen von »Leda und der Schwan in der kaiserzeitlichen attischen Plastik«, s. Wiegartz 1983, 168-196; 172 f. zu Vorläufern aus dem späten Hellenismus.

810 Koch - Sichtermann 1982, 415 mit Anm. 10. 13. 15; Wiegartz 1983, 168-172 Abb. 1 Taf. 24, 1; Linant de Bellefonds 1992, 239 f. Nr. 79 mit Abb.; Trunk 2000, 307 Anm. 12; Oakley 2011, 15-17. 72 f. Nr. 11 Taf. 12.

811 Das Exemplar ist eines der frühesten mit Klinendeckel. Der Wechsel von Dach- zu Klinendeckeln dürfte innerhalb der attischen Werkstatt früher stattgefunden haben als bisher angenommen: Kintrup 2016a, Kap. 1 mit Anm. 20; Kap. 8 S. 208 mit Anm. 1156. Zu einer Datierung um 180 n. Chr.: Koch - Sichtermann 1982, 415; Wiegartz 1983, 171; Wiegartz 1977, 386.

812 Avi-Yonah 1967, 143-148 (hebräischer Text). 73* (English Summary) Taf. 25, 1; Avi-Yonah 1972, 9-21; Koch - Sichtermann 1982, 415 mit Anm. 14 f.; Wiegartz 1983, 177 Taf. 24, 2; Linant de Bellefonds 1992, 240 Nr. 80 ; Rogge 1995, 63 f. 130 f. Nr. 14 (mit weiterer Lit.) Taf. 73, 2; Fischer 1998, 206 Nr. 199a-b; 219 Abb. 199 b; Trunk 2000, 308 mit Anm. 20; Oakley 2011, 32-34. 84 Nr. 42 Taf. 33, 1-2.

813 Nach Avi-Yonah 1967; Wiegartz 1983, 177; Rogge 1995, 63 f. 130 f. Nr. 14 und Oakley 2011, 84 Nr. 42 um/kurz nach 200 n. Chr. Nach Koch - Sichtermann 1982, 415 und Trunk 2000, 308: um 220/230 n. Chr.

814 In Kephissia hat der Schwan seinen linken Fuß auf den rechten Arm Ledas gesetzt und den rechten Fuß auf ihr Gewand, das sie vor sich ziehen will.

815 So auch Wiegartz 1983, 177, wobei sich die Größe des Schwans als Ausdruck seiner Göttlichkeit verstehen ließe.

816 Die Schmalseite in Jerusalem weist weitere >Ungereimtheiten ‘ auf: So erscheinen einige bewegte Gewandfalten ohne Verbindung hinter dem Rücken Ledas. Darunter ist ein gerundeter Umriss gezeigt; hier ist offensichtlich der ursprünglich umarmende linke Flügel des Schwans falsch gedeutet oder umgedeutet, während der rechte Arm Ledas hinter Federn des linken Flügel des Schwans verschwindet, wobei der Verlauf des Flügels unorganisch wirkt und unklar bleibt. Aus dem Vergleich mit der Darstellung z. B. eines Tonreliefs aus Knidos, s. Anm. 820, und 
gibt aber vielleicht einen Hinweis, wie das nicht geglückte Motiv auf der lokalen Kopie entstanden sein konnte.

Möglich ist aber auch eine andere Erklärung: So zeigen Marmorreliefs in London ${ }^{817}$, im Athener Nationalmuseum ${ }^{818}$ und in Sevilla ${ }^{819}$, ein Tonrelief aus Knidos ${ }^{820}$, eine Tonlampe in London ${ }^{821}$ sowie eine Statuengruppe in Venedig ${ }^{822}$ die Zudringlichkeit des Gottes in Schwanengestalt erheblich deutlicher ${ }^{823}$. Er hat seinen Unterkörper zwischen die Beine Ledas gedrängt, sodass auf den genannten Belegen die Schwanzfedern ${ }^{824}$ oder diese von Gewand verdeckt zwischen den Beinen Ledas dargestellt sind. Dies trifft jedoch auf das ephesische Fragment nicht zu, denn hier sind die abwärts gerichteten Schwanzfedern noch gut zu erkennen ${ }^{825}$. Damit und mit den zum Kuss zugeneigten Köpfen stellt das Fragment eine weniger deutliche Variante dar, trotzdem könnte der unbefriedigend wirkende Faltenverlauf seine Vorbilder in den expliziten Darstellungen haben.

\section{Datierung}

Bei den attischen Sarkophagen ist das Motiv zeitgleich nach dem Exemplar in Jerusalem nicht mehr belegt. Zweifigurige Motive und singuläre Themen, die mit den Sujets der Vorderseite nicht in Verbindung stehen, werden im ersten Viertel des 3. Jahrhunderts seltener und anschließend aufgegeben ${ }^{826}$, sodass eine spätere Datierung sehr unwahrscheinlich ist. In welchem zeitlichen Abstand die Fertigung in der lokalen Werkstatt erfolgte, ist zwar nicht zu sagen, aber nach den konkret zu benennenden attischen Vorbildern ist auch für das lokale Fragment eine solche Eingrenzung wahrscheinlich, und es darf wohl angenommen werden, dass die lokale Werkstatt saktueller Motive verwenden wollte und sollte.

Vor 200 n. Chr.

\subsection{Kastenfragment mit Leda (?) (Kat. L3 Taf. 78 Abb. 322)}

Selçuk, Efes Müzesi, Efes Kapalı Deposu, Etd.Nr. L. 168.

Fundort unbekannt.

H 27,5; L 35; DW 6; Rh 7.

Lit.: Kintrup - Heinz 2012, 192 f. Taf. 85, 4.

einer Statuengruppe in Venedig, s. Anm. 824, geht hervor, dass wohl auch dieses Motiv auf dem Sarkophag falsch wiedergegeben wurde. Bei den genannten Vergleichen hatte Leda nämlich ihren rechten Arm in einer Abwehrgeste gegen den Hals des Schwans ausgestreckt.

817 British Museum Inv. 2199: Wiegartz 1983, 171 f. mit Anm. 14 Abb. 2; Linant de Bellefonds 1992, 233 Nr. 15 Taf. 110 .

818 Inv. 1499: Wiegartz 1983, 172 mit Anm. 14; Linant de Bellefonds 1992, 241 Nr. 100 Taf. 122.

819 >Casa de Pilatos`, zwischenzeitlich in Madrid s. Wiegartz 1983, 172 mit Anm. 16. 18; Trunk 2000, 305-311 Taf. $67,1$.

820 Wiegartz 1983, 174 mit Anm. 22 Abb. 3.

821 LIMC III (1986) 961 Nr. 24 Taf. 680 s. v. Eros/Amor, Cupido (N. Blank - F. Gury).

822 Wiegartz 1983, 174-177 Abb. 4; Linant de Bellefonds 1992, 241 Nr. 96 Taf. 122.

823 Auf den Reliefs in London und Sevilla drückt der Schwan zudem mit dem Schnabel in Ledas Nacken ihren Kopf nieder.

824 Zur Möglichkeit, dass der Schwanenschwanz bei der Statuengruppe in Venedig überarbeitet und verfälscht sein könnte, s. Wiegartz 1983, 175 f.

825 Erwähnenswert ist hier auch eine seitenverkehrte Version z. B. auf einem Relief, ehemals in römischen Privatbesitz, s. Trunk 2000, 309 f. (mit Repliken) Taf. 68, 1, das die Kusshaltung, den >Stand « des Schwans auf dem Oberschenkel und die abwärts gerichteten Schwanzfedern wie auf dem ephesischen Fragment wiedergibt.

826 s. die Ausführungen und Beispiele zum Eroten-Weinlese-Sarkophag im >Tor der Verfolgung ‘ Kat. 10 Taf. 46, mit Anm. 370; Wiegartz 1983, 190 f. 193 zu zweifigurigen Schmalseitengruppen. 
Grobkörniger, grauer Marmor aus Thasos ${ }^{827}$. Allseitig gebrochen. Die Rückseite ist in regelmäßiger, feiner Spitzmeißelarbeit ausgeführt, in der ein kleiner Absatz eingearbeitet ist (DW dort $5 \mathrm{~cm}$ ), der wie bei Kat. L2 (Taf. 78 Abb. 321) vielleicht einen Hinweis auf eine Wieder- oder Mehrfachbelegung geben kann.

Die Reliefoberfläche ist in allen vorstehenden Bereichen verrieben; hinzu kommen Bestoßungen an der Brust und den Händen der dargestellten Figur. Tiefe und breite Bohrkanäle umranden die rechte Kontur der Figur und sind für die Binnengliederung des Gewandes im Hintergrund und am linken Arm verwendet. Durch die Reliefhöhe ist das Fragment einer bevorzugt gearbeiteten Sarkophagseite zuzuordnen.

Eine leicht nach rechts geneigt stehende weibliche Figur ist vom Hals bis zu den Oberschenkeln erhalten. Der Oberkörper ist nackt, die Beine sind bedeckt, wobei Gewandfalten vor ihrem linken Bein abwärts verlaufen. Sie hat ein Gewand um die Schultern gelegt, das ihren linken Arm weitgehend verdeckt. Ihr rechter Arm ist verloren, während die bestoßene linke Hand unter der Gewandbahn verborgen zu sein scheint, die vor ihrem Körper von der linken Hand gehalten, schräg aufwärts geführt ist. Unter dieser Gewandbahn und neben ihrem rechten Bein bleibt geglätteter Reliefgrund frei.

Auch dieses Fragment weist die charakteristischen Merkmale der lokalen Werkstatt auf, nämlich die nichtattische Marmorsorte, die tiefen, breiten Bohrkonturen und den frei bleibenden geglätteten Reliefgrund. Die halb nackte, stehende weibliche Figur lässt an eine Mänade denken, allerdings ist eine Figur in entsprechender Haltung und mit diesem Gewandmotiv nicht auf attischen dionysischen Sarkophagen zu finden ${ }^{828}$, was einen weiteren Beleg für eine lokale Herstellung des Fragments in Ephesos darstellt.

Den Schlüssel zur wahrscheinlichen Deutung ${ }^{829}$ liefert eine Silberplatte aus dem Trésor de Graincourt-lès-Havricourt in Paris, Louvre Bj 2213830. Diese zeigt als Mittelmotiv Leda, die eine Gewandbahn vor sich hält, wobei der Schwan versucht, ihr diese am unteren Ende zu entreißen. Der Oberkörper der Leda der Silberplatte ist nach links tordiert wie auch ein Gewand vor ihrem Unterkörper fehlt, jedoch ist durch die lange Gewandbahn in den ausgebreiteten Armen diese Darstellung die nächste motivische Parallele.

\section{Datierung}

Ohne datierende Kriterien der Tektonik oder Ornamentik und ohne stilistische und typologische Vergleiche bei attischen Exemplaren fehlen für das ephesische Fragment konkrete Anhaltspunkte für eine Datierung.

\subsection{Kastenfragment eines Eroten-Weinlese-Sarkophags (?) (Kat. L4 Taf. 79 Abb. 323)}

Selçuk, Efes Müzesi Inv. 4/13/00.

Gefunden in Ephesos.

H 16,5; L 36; DW 11,5; Rh 5.

Lit.: Kintrup - Heinz 2012, 193 f. Taf. 86, 1.

\footnotetext{
827 s. u. Kap. 8.1.2.4.

828 Ebensowenig waren gute ikonografische Vergleiche unter weiteren möglichen Stichworten wie z. B. unter Amymone, Aphrodite/Venus, Ariadne, Daphne, Grazien, Mainaden, Nereiden, Tyche/Fortuna oder im Umfeld von Dionysos und Poseidon im LIMC oder in ASR-Bänden zu finden.

829 Der Dank für diesen wichtigen Hinweis gebührt R. Amedick.

830 Baratte 1989, 141 f. Nr. 88; Linant de Bellefonds 1992, 237 Nr. 56 mit Abb.
} 
Fein- bis mittelkörniger, heller Marmor aus Dokimeion/Afyon ${ }^{831}$. Allseitig gebrochen, die Brüche sind neueren Datums. Von der Rückseite ist nur ein kleines Stück erhalten, das eine flache Spitzmeißelarbeit zeigt. Die Oberfläche ist bräunlich versintert, Verreibungen und kleinere Bestoßungen finden sich an den vorspringenden Reliefteilen, besonders an den Trauben einer Rebe. Nach Ausführung und Relieftiefe gehörte das Fragment einer bevorzugt gearbeiteten Sarkophagseite an.

Erhalten sind der Torso eines Eros, sein rechtes Bein bis zum Oberschenkel, sein linkes bis unterhalb des Knies. Das linke Bein ist leicht angehoben, als hätte der Eros seinen Fuß auf etwas gestellt. Kopf, Schultern und Arme des Eros fehlen. Eine breite, tiefe Bohrrille setzt seinen Körper rechts von einer Rebe aus großen Trauben sowie von Hals und Flügel des Vogels ab. Links neben einem kleinen, nicht zu deutendem Reliefrest am Fragmentrand bleibt geglätteter Reliefgrund frei; es folgt ein großer Vogel in Seitenansicht nach links mit aufgestellten Flügeln, dessen Kopf, Hals, oberer Flügelbereich sowie Schwanzfedern fehlen. Punktbohrungen sind zwischen den Krallen des Vogels und beiderseits seines Beins zu erkennen, während im Übrigen nur mit dem Meißel gearbeitet wurde. Möglicherweise hält der Eros die Traube in seiner linken Hand und der Pfau, davon angelockt, fliegt herbei, um davon zu naschen.

Eros und Trauben lassen zuerst an einen dionysischen Sarkophag denken. Aber die Durchsicht der dionysischen Sarkophage ergibt, dass selten Vögel abgebildet sind. Es finden sich ein Schwan ${ }^{832}$, ein Hahn ${ }^{833}$ und ein Kranich (? ${ }^{834}$, die aber alle keine engen Parallelen zu dem Vogel auf dem Fragment in Ephesos darstellen. Erheblich mehr Vögel und bessere Vergleiche liefern die Eroten-Weinlese-Sarkophage in Klinenform in Rom, San Lorenzo ${ }^{835}$, und in Split ${ }^{836}$. Auf der Rückseite in Split erscheint ein vergleichbarer Vogel nach rechts gewandt, und auf dem Exemplar in San Lorenzo ist ein Vogel wie hier in Profilansicht nach links und ebenfalls mit aufgestellten Flügeln dargestellt. In beiden Fällen handelt es sich um Pfauen ${ }^{837}$.

Auf den attischen Sarkophagen in Rom und Split unterscheiden sich die Pfauen von den anderen Vögeln durch das Federkrönchen auf dem Scheitel und durch ihre langen Schwanzfedern; in San Lorenzo sind auf diesen sogar die Augenflecken zu erkennen. Leider sind bei dem ephesischen Fragment Kopf und Schwanzfedern weggebrochen, sodass eine eindeutige Identifizierung nicht möglich ist. Da das Fragment in Ephesos auch nicht das für die Eroten-Weinlese-Sarkophage in Klinenform typische flache Relief zeigt, kann eine Zugehörigkeit zu dieser Gruppe ausgeschlossen werden. Zwar sind die attischen Sarkophage mit Eroten-Vindemia auch als Friessarkophage belegt ${ }^{838}$, eine motivische Übereinstimmung ist bei den derzeitigen Belegen aber nicht zu finden.

Zudem fallen bei dem Fragment in Ephesos etliche stilistische Unsicherheiten auf, womit eine attische oder stadtrömische Provenienz unwahrscheinlich wird: Der Vogelfuß, besonders die Krallen, erscheinen im Vergleich zu den attischen Belegen zu groß und recht plump. Der Körper des Eros ist im Verhältnis zu den Beinen recht schmal dargestellt. Die Trauben sind in Proportion zu dem Eros und dem >Pfau < andererseits recht groß gestaltet und zudem tropfenförmig statt rund gebildet; die für attische Stücke häufig verwendete Binnengliederung durch feinere eingetiefte Bohrlinien fehlt.

Vg1. dazu Kat. L1, s. u. Kap. 8.1.2.4.

832 So auf der Rückseite in Boston: Matz 1968, 106-110 Nr. 9 Taf. 13, 1 Beil. 4, 2.

833 s. die Mitte der Vorderseite in Rom, Museo Capitolino: Matz 1968, 110-112 Nr. 10 Taf. 16, 1.

834 s. die linke Ecke der Vorderseite in Thessaloniki: Matz 1968, 112-116 Nr. 11 Taf. 18. Nach Wiegartz 1983, 193, handelt es sich ebenfalls um einen Schwan. Zur Deutung und ihrer überzeugenden Herleitung s. Wiegartz 1983, $192 \mathrm{f}$.

835 Rodenwaldt 1930, 116-189; Koch - Sichtermann 1982, 425 f. 432 Nr. 53; 459 Abb. 452 f.; Bielefeld 1993, 91-97 Taf. 36-39; Bielefeld 1995, 397-404 Taf. 107, 2; Bielefeld 2000, 44 Taf. 10, 1.

836 Cambi 1993, 77-85 Taf. 29-33; Bielefeld, 1993, 91; Bielefeld 1995, 397.

837 RE XIX (1938) 1414-1421 s. v. Pfau (Steier); Toynbee 1983, 240-243; Bielefeld 2000, 39 mit Anm. 2.

838 Koch - Sichtermann 1982, 425 f. 432 Nr. 51-55; 459 Abb. 451-453; Bielefeld 1995, 397-404 Taf. 104-107. s. ausführlicher Kat. 10 Taf. 46: Eroten-Weinlese-Sarkophag im >Tor der Verfolgung، in Selçuk. 
Auch bei der Durchsicht der stadtrömischen dionysischen Sarkophage und Eroten-WeinleseSarkophage sind keine besseren Parallelen zu finden; so erscheinen Pfauen lediglich auf einem späten Porphyrsarkophag aus dem Mausoleum der Constantina, heute im Vatikan ${ }^{839}$. Die Kombination von Eros mit angehobenem linken Bein, Vogel (Pfau [?]) und Trauben ist zwar auf einem dionysischen Sarkophag in Rom zu finden ${ }^{840}$, doch hält dort der Eros die Trauben vor seinem Körper in der Rechten und der Vogel ist nach links gewendet, um Trauben zu picken.

Dennoch erscheint für eine thematische Zuordnung die Deutung als Eroten-Weinlese weiterhin als nächstliegende Möglichkeit, denn für die Zusammenstellung von Eros, einem Pfau ähnlichem Vogel und Weinrebe finden sich derzeit keine überzeugenderen Parallelen.

Technisch-stilistische Merkmale, nämlich die breite, tiefe Bohrrille, die den Eroskörper von der Rebe trennt, sowie die Binnengliederung ausschließlich in Meißelarbeit, hier besonders die Binnenzeichnung des Gefieders mit kurzen sicheren Meißelhieben, haben ihre Entsprechungen auf den Fragmenten lokaler Herstellung, sodass durch die Ähnlichkeit in Qualität und Ausführung ebenfalls eine Provenienz aus einer lokalen Werkstatt zu postulieren ist.

\section{Datierung}

Weil zu datierende Kriterien wie auch stilistische und typologische Vergleiche fehlen, ist eine zeitliche Eingrenzung nicht möglich.

\subsection{Fragment eines Kastens: Fliehende (?) und Kniender mit Kind}

(Kat. L5 Taf. 79 Abb. 324)

Selçuk, Efes Müzesi Inv. 12/61/80.

Gefunden in Selçuk, Johannesbasilika, Fund-Nr. 80/25.

H 31; L 60; DW 11; Rh 5,5.

Lit.: Kintrup - Heinz 2012, 194 f. Taf. 86, 2.

Grobkörniger, grauer Marmor aus Thasos ${ }^{841}$. Die Reliefoberfläche ist versintert und in den vorragenden Reliefteilen bestoßen. Die Rückseite zeigt eine Bearbeitung mit einem Zahneisen. Auf dem allseitig gebrochenen Fragment ist ein kleines Stück der Standleiste für den Figurenfries vorhanden.

Weder das Motiv noch die nicht geglückte, ungelenke frontale Darstellung des Knienden haben Parallelen auf attischen oder anderen Sarkophagen. Der Marmor sowie die flache Faltengestaltung und der Faltenverlauf passen zu den anderen Exemplaren aus der lokalen Werkstatt. Von der dafür typischen breiten und tiefen Umrissbohrung hat sich ein Stück über dem rechten Arm des Knienden erhalten.

Eine männliche nackte Figur, deren Kopf verloren ist, kniet auf ihrem rechten Knie und hat den linken Fuß aufgestellt. Sie hält ein offensichtlich totes Kind in den Armen; der Kopf - nur teilweise in Kontur erhalten - und die Arme des kleinen Kindes hängen erschlafft herunter. Der Mann hat seine Linke unter dem Rücken des Kindes durchgeschoben und hält dessen Bauch mit seiner (bestoßenen) Rechten. Im Hintergrund zeigen sich zwei lange Gewänder mit bewegtem Faltenverlauf; die linke Gestalt war nach links gewendet, die rechte nach rechts. Vor der linken Figur erscheint ein langer Stab.

Die nackte männliche Gestalt, bewegte Gewänder - vielleicht von Tanzenden - und möglicherweise ein Thyrsosstab lassen eine dionysische Darstellung vermuten, doch passt ein wohl

\footnotetext{
839 Koch - Sichtermann 1982, 578 Abb. 598; Bielefeld 1997, 69. 134 f. Nr. 192 (mit ausführlicher Lit.) Taf. 95, 1.

840 Thermenmuseum Inv. 124711, s. Matz 1969, 327 f. Nr. 178 Taf. 202; LIMC III (1986) 548 Nr. 94 Taf. 435 s. v. Dionysos/Bacchus (C. Gasparri); Zanker - Ewald 2004, 156 f. mit Abb. 141.

841 s. u. Kap. 8.1.2.4.
} 
totes Kind nicht in die Szenerie ${ }^{842}$. Die erschlafften Arme und der hängende Kopf bieten aber deutliche Chiffren für den >Tod`, wie ein Vergleich mit Niobiden-Sarkophagen belegt ${ }^{843}$. Eine Interpretation als ein totes Kind in den Armen eines Erwachsenen, bewegte Gewänder - von Fliehenden - sowie vielleicht der Stab eines Pädagogen könnte auch an die Tötung der Niobiden denken lassen, doch fügt sich dann die nackte männliche Gestalt nicht in die bekannte Motivik ${ }^{844}$. Eine thematische Einordnung bleibt somit ungesichert.

\section{Datierung}

Weil zu datierende Kriterien wie auch stilistische und typologische Vergleiche fehlen, ist eine zeitliche Eingrenzung nicht möglich.

\subsection{Fragment mit Löwenprotom (Kat. L6 Taf. 79 Abb. 325)}

Selçuk, Efes Müzesi, Efes Kapalı Deposu, Etd.Nr. L. 170.

Fundort unbekannt.

H 25; L 35,3; D 10; Rh 6.

Lit.: Unpubliziert.

Grobkörniger, grauer Marmor aus Prokonnesos ${ }^{845}$. Allseitig gebrochen. Die Reliefoberfläche ist stark verrieben, sodass Aussagen über die Ausführung nur eingeschränkt zu treffen sind. Die Rückseite des Fragments ist glatt geschliffen, eventuell für eine Wiederverwendung.

Auf dem geglätteten Reliefgrund ist ein frontaler Löwenkopf zu erkennen. Das Maul scheint regelmäßig abgearbeitet, kann aber auch abgestoßen sein. Die gerundeten Reste seitlich des leicht geöffneten Mauls könnten zu einem Ring gehören.

Vergleiche präsentieren die attischen Girlandensarkophage ${ }^{846}$, die häufig Löwenköpfe in den Girlandenbögen abbilden, wie Beispiele in Athen ${ }^{847}$, Antakya ${ }^{848}$ und Herakleion ${ }^{849}$ belegen $^{850}$, die

${ }_{842}$ An der rechten Ecke der Vorderseite eines dionysischen Sarkophags in Rom, Palazzo Mattei, Matz 1968, 260 f. Nr. 120 Taf. 142, 2, hat zwar ein stehender Satyr mit einem Kind über dem Knie seines aufgestellten linken Beins Ähnlichkeiten, aber Teile des Satyrs und der Oberkörper des Kindes ab den Hüften sind falsch ergänzt; es wird anhand von Vergleichen, Matz 1968, 260 f., eine Ergänzung des Satyrs, Flöte in der Rechten, mit dem Kleinen spielend vorgeschlagen.

${ }_{843}$ Vgl. z. B. die Sarkophage um die Mitte des 2. Jhs. n. Chr. in München, im Vatikan und in Venedig. München, Glyptothek, s. Robert 1919, Nr. 312 Taf. 99 Abb. 312; Koch - Sichtermann 1982, 169. Vatikan, Galleria dei Candelabri Inv. 2635, s. Robert 1919, 379 f. Nr. 313b mit Abb. 313 b’ Taf. 99 Abb. 313 b; Bielefeld 1951, 70 Nr. d; Sichtermann - Koch 1975, 49 Nr. 47 Taf. 123 (r. Ss). Bei diesen beiden sind auch besonders auf den Deckeln viele erschlafft Liegende abgebildet. Und s. Vatikan, Museo Gregoriano Profano Inv. 10437, früher Lateran: Robert 1919, 381-383 Nr. 315 Taf. 100 Abb. 315; Koch - Sichtermann 1982, 169 Abb. 189; Krierer 1995, 39 f. Taf. 4, 16. Venedig, Mus. Arch., s. Robert 1919, 383 Nr. 316 Taf. 100 Abb. 316; Sichtermann - Koch 1975, Nr. 49 Taf. 122, 1; Koch - Sichtermann 1982, 169 (140-160 n. Chr.).

844 s. Anm. 843 oder vgl. den Iliupersis-Sarkophag in Mantua, um 180 n. Chr., Palazzo Ducale: Robert 1890, 71-73 Nr. 63 Taf. 26 Abb. 63 a; Sichtermann - Koch 1975, 37 f. Nr. 32 Taf. 72 f.; Koch - Sichtermann 1982, 154 f. Abb. 165 (VS): Ein gebückt Stehender hält dort einen Toten in den Armen.

845 s. u. Kap. 8.2.1; 8.3.1; 8.4.

${ }^{846}$ Bei den römischen und kleinasiatischen Girlandensarkophagen sind im Handbuch keine Löwenköpfe in den Girlandenbögen erwähnt, s. Koch - Sichtermann 1982, 226. 499, und auch die Durchsicht der römischen Löwensarkophage, s. Stroszeck 1998, passim, zeigt, dass diese stilistisch sehr verschieden sind von unserem Exemplar.

847 Koch - Sichtermann 1982, 436 f. 438 Nr. 8 (Athen, Nationalmuseum Inv. 1180) und Nr. 10 (Athen, Römische Agora) Taf. $467 \mathrm{f}$.

848 Archäologisches Museum Inv. 8473: Rogge 1993, 112 f. Taf. 46, 3; Gaggadis-Robin 1998, 271 Taf. 108, 1.

849 Archäologisches Museum Inv. 387, aus Mallia: Rogge 1993, Taf. 46, 1; 47, 2; Gaggadis-Robin 1998, Taf. $108,3$.

850 s. auch die Liste Koch - Sichtermann 1982, 438-441. 
in der zeitlichen Abfolge von ca. 150-190 n. Chr. angesetzt werden ${ }^{851}$. Der Girlandensarkophag in Herakleion zeigt dabei den bei attischen Exemplaren seltenen Ring im Maul des Löwen ${ }^{852}$.

Bei dem Fragment in Ephesos fällt nun auf, dass die Ohren des Löwen zugunsten eines gefälligen Strähnenkranzes unterschlagen wurden. In stilistischer Hinsicht ist die sichere, aber im Vergleich zu attischen Exemplaren flacher wirkende Meißelbearbeitung zur Binnengliederung der Mähne bemerkenswert ${ }^{853}$. Dadurch und auch insbesondere durch die Marmorart unterscheidet sich das ephesische Fragment von attischen Originalen und steht den lokalen Fragmenten nahe.

\section{Datierung}

Da die ephesischen Werkstätten Girlandensarkophage in großer Zahl herstellten, muss es nicht verwundern, dass für das Dekor in den Girlandenbögen auch Anregungen von außerhalb aufgegriffen wurden. In Anlehnung an die erwähnten möglichen Vorbilder wird eine Datierung vor 200 n. Chr. vorgeschlagen.

Zweite Hälfte des 2. Jahrhunderts n. Chr.

7.8 Fragment eines Dachdeckels (Kat. L7 Taf. 80 Abb. 326 f.)

Selçuk, Efes Müzesi Inv. 24/13/00.

Fundort unbekannt.

H 19; L 92; T 47.

Lit.: Unpubliziert.

Mittelkörniger, leicht grauer Marmor: Ephesos I ${ }^{854}$. Erhalten sind Teile der Vorder- und der rechten Giebelseite eines Dachdeckels mit Blattziegeln und Resten eines Akroters.

Die Oberfläche zeigt fleckige Verwitterungsspuren sowie kleinere Risse und Bestoßungen. Die Innenseite ist mit grobem Spitzmeißel bearbeitet. Am größtenteils weggebrochenen Eckakroter zeigen sich breite und tiefe Bohrkanäle; diese finden sich auch bei der Ausführung des Kymas aus stehenden Akanthusblättern, die das leicht geschwungene untere Abschlussprofil schmücken. Darunter ist in Teilen ein Perlstab erhalten. Eine umlaufende glatte Leiste $(2,5 \mathrm{~cm}$ hoch) trennt das Akanthuskyma von der Dachschräge, die blattförmige Ziegel mit erhabenem Mittelgrat zeigt. Die Ziegel sind durch deutliche Bohrkanäle voneinander abgesetzt. Die Zwischenräume der Ziegel am unteren Rand der Dachschräge wurden mit lanzettförmigen Blättern gefüllt.

Das ephesische Deckelfragment entspricht nach der Form seiner Ziegel und ihrer Anordnung den typischen attischen Giebeldachdeckeln aus versetzten, überlappenden Reihen aus Blattziegeln $^{855}$; bei kleinasiatischen Dachdeckeln sind hingegen nebeneinanderliegende eckige Platten und Stirnziegel abgebildet ${ }^{856}$.

\footnotetext{
851 So Koch - Sichtermann 1982, 436 f.; Gaggadis-Robin 1998, 271; Rogge 1993, 112 f. Die attischen Sarkophage mit allseitigem Girlandendekor enden wohl schon vor 200 n. Chr., so Koch - Sichtermann 1982, 438.

852 Koch - Sichtermann 1982, 436: Löwenköpfe in den Girlandenbögen sind häufig, aber selten mit Ring.

853 Vgl. z. B. auch den Löwenkopf des attischen Rückseitenfragments mit Löwenkampfgruppe, ebenfalls in Ephesos, hier Kat. 34 (Taf. 70 Abb. 295).

854 s. u. Kap. 8.1.2; 8.3.1; 8.4.

855 Vgl. Wiegartz 1975, 208 f.; Koch - Sichtermann 1982, 371; Rogge 1993, 112.

856 Zu Dachdeckeln attischer und kleinasiatischer Sarkophage s. auch Wiegartz 1965a, 36 f.
} 
Vor dem Wechsel von Dach- zu Klinendeckeln, der um 160 n. Chr. beginnt ${ }^{857}$, sind diese Dachdeckel kanonisch für attische Sarkophage ${ }^{858}$. Zahlreiche Belege mit Dachdeckeln finden sich unter den dekorativen und unter thematisch vielfältigen attischen Sarkophagen. Dazu gehören Girlandensarkophage in Antakya ${ }^{859}$ und Herakleion ${ }^{860}$, die zwischen ca. 150 und 170/180 n. Chr. datiert werden $^{861}$. Dionysische Sarkophage aus Beirut und heute in Istanbul ${ }^{862}$, in Athen ${ }^{863}$, aus Thessaloniki, heute ebenfalls in Istanbul ${ }^{864}$, und in Ioannina ${ }^{865}$ werden in der genannten Reihenfolge von etwa 140-180 n. Chr. datiert ${ }^{866}$. Drei Erotensarkophage in Athen ${ }^{867}$ und einer in Kephissia ${ }^{868}$ gehören in die zweite Hälfte des 2. Jahrhunderts n. Chr. wie auch ein Jagdsarkophag in Athen ${ }^{869}$. Achill-Sarkophage mit Dachdeckeln aus dem letzten Viertel des 2. Jahrhunderts n. Chr. befinden sich in St. Petersburg ${ }^{870}$ und in London ${ }^{871}$. Darüber hinaus trägt ein Hippolytos-Sarkophag in Beirut $^{872}$ ebenso wie ein Meleager-Sarkophag in Athen ${ }^{873}$ einen Dachdeckel. Der Dachdeckel auf einem Amazonomachie-Sarkophag in Tyros ${ }^{874}$ ist eine Besonderheit, weil der heute aufsitzende Dachdeckel nicht mit der Erstbelegung in Verbindung zu bringen ist, da der Kasten eindeutig für das Tragen eines Klinendeckels ausgelegt ist. Der Dachdeckel wurde vermutlich bei einer Wiederbelegung mit dem Kasten kombiniert; dies lassen auch zwei nachträglich angebrachte Inschriften auf der Vorder- und der rechten Schmalseite vermuten ${ }^{875}$.

Die attischen Dachdeckel haben zumeist kleine Eckakrotere, die gelegentlich mit Palmetten verziert sein können ${ }^{876}$. Kennzeichnend für frühe Deckel sind dabei niedrige Giebel mit glatten, unteren Abschlussprofilen ohne Ornamente, während sich spätere Exemplare durch wachsende

857 Kintrup 2016a, Kap. 1 mit Anm. 20; Kap. 8 S. 208 mit Anm. 1156. Später veranschlagt wurde der Wechsel zu Klinendeckeln bei Wiegartz 1975, 188 f.; Wiegartz 1977, 386; Koch - Sichtermann 1982, 371 f.; Rogge 1993, $112 \mathrm{f} .116 \mathrm{f}$.

858 Zu Übergangsformen mit attikaförmigen Aufbauten an Front- und Schmalseiten, s. Koch - Sichtermann 1982, 371; Rogge 1993, $112 \mathrm{f}$.

859 Archäologisches Museum Inv. 8473: Rogge 1993, 112 f. Taf. 46, 3; Gaggadis-Robin 1998, 271 Taf. 108, 1.

860 Archäologisches Museum Inv. 387, aus Mallia: Rogge 1993, Taf. 46, 1; 47, 2; Gaggadis-Robin 1998, Taf. 108, 2-3.

861 Koch - Sichtermann 1982, 436 f.; Gaggadis-Robin 1998, 271; Rogge 1993, 112 f. Zu attischen Girlandensarkophagen s. hier unter Kat. L6 (Taf. 79 Abb. 325).

862 Archäologisches Museum Inv. 1417: Matz 1968, 98 f. Nr. 1 Taf. 1 (ca. 140-150).

863 Sarkophag des Magnos Eryades: Matz 1968, 103 f. Nr. 7 Taf. 7, 1; 8 f. (etwa 150-160).

864 Archäologisches Museum Inv. 366: Matz 1968, 100 f. Nr. 3 Beil. 2, 1 (ca. 160-170).

865 Archäologisches Museum Inv. 412: Matz 1968, 104-106 Nr. 8 Taf. 10 f.; 11, 1 Beil. 3, 1 (ca. 170-180); Rogge 1993, 113. 115 Taf. 51, 2 (linke Schmalseite).

866 Zu den Datierungen s. Wiegartz 1977, 388 mit Anm. 90.

867 Akademie Platons: Koch - Sichtermann 1982, 424-429. 432 Nr. 56 Abb. 460; Rogge 1993, 112 Anm. 31; 114 Taf. 49, 2 (4. Viertel 2. Jh. n. Chr.). - Athen, Nationalmuseum Inv. 1187: Koch - Sichtermann 1982, 371. 424-429 Nr. 1 Abb. 454; Rogge 1993, 112 Taf. 51, 1 (um 150 n. Chr.). - Athen, Nationalmuseum Inv. 4008: Koch - Sichtermann 1982, 424-429. 432 Nr. 46; Rogge 1993, 115 Taf. 52, 1 (3. Viertel 2. Jh. n. Chr.).

868 Koch - Sichtermann 1982, 424-429. 431 Nr. 43; Rogge 1993, 112 Anm. 31; 113 f. Taf. 49, 1 (4. Viertel 2. Jh. n. Chr.).

869 Nationalmuseum Inv. 1177: Koch - Sichtermann 1982, 379 f.; Rogge 1993, 114 Taf. 50, 3 (frühes 3. Viertel 2. Jh. n. Chr.).

870 Ermitage Inv. A 1026: Rogge 1995, 138 f. Nr. 28 Taf. 26, 1; 28, 1; 38, 1-2; 40 (letztes Viertel des 2. Jhs. n. Chr.).

871 British Museum Inv. GR 1861.2-20.3: Rogge 1995, 131 f. Nr. 17 Taf. 32, 2-3 (Ende 2. Jh. n. Chr.).

872 Rogge 1995, 151 f. Nr. 56 Taf. 76, 1; 83, 1 (letztes Viertel des 2. Jhs. n. Chr.).

873 Nationalmuseum Inv. 1186: Koch 1975, 138 Nr. 160 Taf. 128, 1; Koch - Sichtermann 1982, 371 Abb. 429; Koch 1993, 100. 103 Abb. 58 (3. Viertel 2. Jh. n. Chr.).

874 Grabungen, Inv. 2772/2773: Chéhab 1968, 36-40; 81 f. Taf. 17-21; Koch - Sichtermann 1982, 390 Anm. 1; 391. 458. 467; Chéhab 1984, 451-453 Taf. 77-79; Kintrup 1998, 207-210 Taf. 92, 2; Kintrup 2016a, Kap. 3.2.1 Nr. 259.

875 Zu den Inschriften: Rey-Coquais 1977, 68 f. Nr. 118; 145 f. 148. 150. 158 f. 166. 171 Taf. 19, 4; Rey-Coquais 1979, 282. 284. 286 f. 289 Taf. 1, 2; Rogge 1993, 111 mit Anm. 4; 122 mit Anm. 153.

876 Koch - Sichtermann 1982, 371. Mit Palmetten: Dionysischer Sarkophag in Istanbul, Archäologisches Museum Inv. 1417, aus Beirut: Matz 1968, 98 f. Nr. 1 Taf. 1 (s. Anm. 862). Achill-Sarkophag in St. Petersburg, Ermitage Inv. A 1026: Rogge 1995, Taf. 26, 1; 28, 1; 38, 1-2 (s. Anm. 870). 
Giebelhöhe, eingetieftes Giebelfeld - z. T. mit Relief - und durch meist geschwungene untere Abschlussprofile, die ornamentiert sein können, auszeichnen ${ }^{877}$.

So zeigt der Erotensarkophag in der Akademie Platons in Athen einen Palmettenfries auf dem unteren Abschlussprofili ${ }^{878}$. Auf dem Achill-Sarkophag in St. Petersburg ist das untere Abschlussprofil auf drei Seiten durch Ranken, die sich um Blüten legen und aus einem mittigen Akanthusbüschel entspringen, geschmückt ${ }^{879}$. Schließlich präsentieren der Girlandensarkophag in Herakleion ${ }^{880}$, der dionysische Sarkophag in Ioannina ${ }^{881}$ und der nicht zugehörige Dachdeckel auf dem Amazonomachie-Sarkophag in Tyros ${ }^{882}$ ein Kyma aus stehenden Akanthusblättern unter Dachschrägen und Giebeln, wie es auch bei dem ephesischen Deckelfragment der Fall ist.

Im direkten Vergleich sind die stilistischen Unterschiede besonders markant: Die breiten und tiefen Bohrkanäle, die bei dem ephesischen Fragment zur Ausführung des Akanthuskymas verwendet wurden, unterscheiden sich deutlich von der flachen Meißelarbeit ${ }^{883}$ der attischen Beispiele. Die deutlichen Bohrlinien, die die Blattziegel hier voneinander trennen, fehlen dort. Weiterhin finden sich für Form und Ausführung der erhaltenen Reste des Akroters in Ephesos keine attischen Parallelen.

Die beschriebenen Beobachtungen und die verwendete Marmorsorte liefern die Belege dafür, dass es sich hier um eine lokale Arbeit handelt. Einen guten Vergleich dazu bietet zudem der Dachdeckel mit Blattziegeln des >Unterweltsarkophags « in Istanbul aus der Mitte des 2. Jahrhunderts, der ja vermutlich auch aus Ephesos stammt ${ }^{884}$, und für den bereits $\mathrm{H}$. Wiegartz ${ }^{885}$ attischen Einfluss besonders bei der Form des Deckels geltend machte.

\section{Datierung}

Eine Datierung wird in Anlehnung an die aufgezeigten Parallelen vor 200 n. Chr. im wahrscheinlich dritten Viertel des 2. Jahrhunderts vorgeschlagen.

Drittes Viertel des 2. Jahrhunderts n. Chr.

\subsection{Fragment eines Dachdeckels (Kat. L8 Taf. 80 Abb. 328)}

Selçuk, Efes Müzesi, Açık Hava Deposu, Etd.Nr. L. 120.

Fundort unbekannt.

\section{H 22; L 85,5; T 41.}

Lit.: Unpubliziert.

Grobkörniger, hellgrauer Marmor: Ephesos I ${ }^{886}$. Das allseitig gebrochene Fragment hat ein Stück des Firstes und der Unterseite erhalten. Die Oberfläche zeigt dunkle Verwitterungsspuren sowie Risse und kleinere Bestoßungen.

\footnotetext{
877 s. zur Entwicklung attischer Dachdeckel grundlegend Wiegartz 1975, 208 f. Vgl. auch Koch - Sichtermann 1982, 371; Rogge 1993, 113.

878 Rogge 1993, Taf. 49, 2 (s. o. Anm. 867). Ebenfalls mit Palmettenfries: Fragment, gefunden in der Nikolaoskirche, Myra, s. Wiegartz 1975, 205-210 mit Abb. 36 Taf. 91 A.

879 Inv. A 1026, Rogge 1995, Taf. 26, 1; 28, 1; 38, 1-2; 40 (s. Anm. 870).

880 Archäologisches Museum Inv. 387, aus Mallia: Rogge 1993, Taf. 46, 1; 47, 2; Gaggadis-Robin 1998, Taf. 108, 3 (s. Anm. 860).

881 Matz 1968, 104-106 Nr. 8 Taf. 10 f.; 12, 1 Beil. 3, 1 (s. Anm. 865).

882 s. o. mit Anm. $874 \mathrm{f}$.

883 s. z. B. die Detailaufnahmen Matz 1968, Beil. 3, 1 und Chéhab 1968, Taf. 19 a.

${ }^{884}$ Keil 1914, 133-144 Abb. 18-21 Taf. 2; Wiegartz 1965a, 40 f. 44.50 .179 Nr. 36 Taf. 8 b; 14 b; Wiegartz 1975, 208 f. mit Anm. 252; Koch - Sichtermann 1982, 522 Taf. 511; Koch 1999, 561.

885 Wiegartz 1965a, 44.

886 s. u. Kap. 8.1.2.4.
} 
Das Deckelfragment entspricht wie Kat. L7 nach Form und Anordnung der Ziegel den attischen Dachdeckeln ${ }^{887}$. Im Vergleich zu Kat. L7 sind die Mittelgrate der Blattziegel feiner und weniger erhaben und auch die Zwischenräume der Blattziegel sind schmaler und feiner gebildet.

Hier ist es vor allem der ephesische Marmor, der eine attische Provenienz ausschließt. Es fällt zudem auf, dass die Ziegelreihen am First nicht genau gegenüberliegend ausgeführt sind, sondern unschön versetzt aufeinander treffen.

Der Dachdeckel eines attischen Achill-Sarkophags in London ${ }^{888}$ und ein Fragment eines attischen Dachdeckels, gefunden in der Nikolaoskirche in Myra ${ }^{889}$, zeigen hingegen am First versetzt beginnende Ziegelreihen. Ob dies die Regel ist, oder ob attische Dachdeckel versetzte oder gegenüberliegende Ziegelreihen am First aufzuweisen haben, ist aufgrund fehlender Dokumentation der Oberseiten der Dachdeckel derzeit nicht zu klären.

\section{Datierung}

Eine Datierung kann nur in Analogie zu Fragment Kat. L7 auf vor 200 n. Chr. eingegrenzt werden.

Zweite Hälfte des 2. Jahrhunderts n. Chr.

7.10 Fragment eines Dachdeckels (Kat. L9 Taf. 80 Abb. 329)

Selçuk, Johannesbasilika, Freiluftdepot, Etd.Nr. StJ 177.

Gefunden in Selçuk, Johannesbasilika.

\section{H 26; L 23.}

Lit.: Unpubliziert.

Grobkörniger, grauer Marmor ${ }^{890}$. Die Oberfläche des allseitig gebrochenen Fragments ist verwittert und z. T. bestoßen; die Innenseite des Deckels ist nicht erhalten. Die Blattziegel haben einen leicht erhabenen Mittelgrat.

Das Deckelfragment ist wie Kat. L7 und L8 in Form und Anordnung der Blattziegel attischen Dachdeckeln ${ }^{891}$ nachgebildet. Durch den nichtattischen Marmor ist eine lokale Fertigung angezeigt. Zudem sind ähnlich wie bei Kat. L7 die Blattziegel durch deutliche Bohrkanäle voneinander getrennt; allerdings sind die Ziegel hier wie nebeneinanderliegend gearbeitet und nicht überlappend. Deshalb und auch wegen der Größe der Ziegel kann dieses Fragment nicht zu den Fragmenten Kat. L7 oder L8 gehören, sondern ist Teil eines weiteren lokalen Dachdeckels.

\section{Datierung}

Das kleine Fragment liefert keine weiteren Anhaltspunkte für eine Datierung; es kann nur in Anlehnung an die vorgenannten Exemplare eingeordnet werden.

Zweite Hälfte des 2. Jahrhunderts n. Chr.

887 Dazu s. Kat. L7 und dort auch zu etlichen Beispielen und der Entwicklung attischer Dachdeckel.

888 British Museum Inv. GR 1861.2-20.3: Rogge 1995, 131 f. Nr. 17 Taf. 32, 2-3.

889 Eines von vier zusammengehörigen Fragmenten: Wiegartz 1975, 205-210 mit Abb. 36 Taf. 91 A.

890 Der Marmor dieses Fragments wurde nicht beprobt.

891 Zur Entwicklung attischer Dachdeckel und etlichen Beispielen s. Kat. L7. 



\title{
8 Die Marmore der Sarkophagfragmente L1-L8
}

\author{
(Walter Prochaska)
}

\subsection{Die untersuchten Proben}

Im Jahr 2014 konnten acht Fragmente von Sarkophagen beprobt werden. Die Proben waren generell sehr klein, was naturgemäß ein Problem darstellt, da hier oft die notwendige Homogenität nicht in befriedigendem Maß gegeben ist. Aufgrund der geringen Probengröße konnten auch nicht von allen Proben mikroskopische Präparate angefertigt werden. Vor der Analyse wurden die Proben einer umfangreichen Reinigung unterzogen, wodurch die Oberflächenkontaminationen weitgehend beseitigt werden konnten.

Alle acht Proben sind aus weißem oder hellgrauem Marmor. Der Marmor von zwei Proben (L1 und L4) ist feinkörnig, bei den restlichen sechs (L2. L3. L5. L6. L7 und L8) liegen mittel- bis grobkörnige Marmore vor.

\subsection{Die Untersuchungsmethoden}

Für die Untersuchungen zur Herkunft der Marmore wurde eine Kombination verschiedener analytischer Methoden angewendet. Alle Untersuchungen einschließlich der Isotopenanalysen wurden am Department Angewandte Geowissenschaften und Geophysik der Montanuniversität Leoben durchgeführt.

In jenen Fällen, bei denen die Probengröße die Herstellung von mikroskopischen Präparaten erlaubte, wurden zur petrografischen Charakterisierung der Marmore mikroskopische Untersuchungen mithilfe des Polarisationsmikroskops vorgenommen.

Die Analyse der stabilen Isotope von Kohlenstoff und Sauerstoff ist die Standardmethode bei der Provenienzuntersuchung antiker Marmore. Für die Analyse der Zusammensetzung der stabilen Isotope von Kohlenstoff und Sauerstoff wurde ein ThermoFisher DELTA V Massenspektrometer (ThermoFisher, Bremen, Germany) mit einer Onlineverbindung zu einer ThermoFisher GasBench II und einem CTC Combi-Pal-Probengeber (bzw. Aufschlusseinheit) verwendet. Für den Aufschluss der fein gemahlenen Proben (ca. 0,2 mg) wurde $\mathrm{H}_{3} \mathrm{PO}_{4 \text { conc. }}$ in einer He-gefluteten Atmosphäre bei einer Temperatur von $70^{\circ} \mathrm{C}$ verwendet. Die Ergebnisse werden relativ zum PDB-Standard in der üblichen $\delta$-Angabe $\left(\delta^{13} \mathrm{C}\right.$ und $\left.\delta^{18} \mathrm{O}\right)$ wiedergegeben. Die Langzeit-Präzision beträgt 0,06 \% für Sauerstoff und 0,05 \% für Kohlenstoff.

Das fein gemahlene Probenpulver wurde einer chemischen Analyse unterzogen. Gemessen wurden die Gehalte an Mg, Sr, Mn, Fe und Zn, weil diese Elemente an die Karbonatphase gebunden und im Kristallgitter eingebaut sind und daher deutlich geringere Schwankungen aufweisen als solche Elemente, die an Spurenminerale gebunden und infolgedessen üblicherweise inhomogen im Gestein verteilt vorkommen.

Um eine bessere Trennung der Felder der Zusammensetzung der einzelnen Marmortypen zu erlangen, wurde zusätzlich zu den konventionellen analytischen Methoden die Analyse der Flüssigkeitseinschlüsse der Marmore zu ihrer Charakterisierung verwendet. Hier werden mikroskopisch kleine, mit Gas und Flüssigkeit gefüllte Hohlräume in den Kristallen, die in allen Marmoren vorkommen, mechanisch extrahiert und mittels Ionenchromatografie auf ihre chemischen Bestandteile untersucht. Diese Methode wird seit einigen Jahren in der Lagerstättenkunde für die Untersuchung mineralisierender Erzlösungen routinemäßig herangezogen ${ }^{892}$ und wurde hier

892 z. B. Prochaska 1999, 175-183. 
mit geringen Adaptionen für die Charakterisierung und in weiterer Folge für die Bestimmung der Provenienz von Marmoren verwendet. Bei der Charakterisierung von Marmoren und ihrer Herkunftsanalyse wurde diese Methode in den letzten Jahren mit Erfolg angewendet ${ }^{893}$. Für einen Vergleich der ermittelten analytischen Daten der jeweiligen Proben wurde in den letzten Jahren eine Datenbank von Steinbruchproben von Marmorlagerstätten aus der gesamten antiken Welt aufgebaut ${ }^{894}$.

\subsubsection{Petrografische Beschreibung}

Die Größe der einzelnen Proben erlaubte nicht in jedem Fall die Herstellung eines mikroskopischen Präparats, es konnte jedoch von jeder Probengruppe zumindest ein Präparat angefertigt werden. In der Folge wird eine zusammenfassende petrografische Charakterisierung der einzelnen Probengruppen gegeben.

Von den feinkörnigen Marmoren konnte von der Probe L1 ein Dünnschliff angefertigt werden (Abb. 1). Es handelt sich um einen sehr reinen Kalzitmarmor mit einer äußerst leichten Schieferung. Die maximale Korngröße beträgt hier 0,8 mm. Das Gefüge ist deutlich heteroblastisch mit verzahnten Korngrenzen. Diese Texturen sind für die Marmore aus Dokimeion/Afyon charakteristisch.

Bei der Probe L7 (Abb. 2) handelt es sich um einen mittelkörnigen Marmor mit einer maximalen Korngröße von 1,8 mm. Charakteristisch ist hier das Auftreten kleiner, gelängter Cluster von Dolomitkristallen in einer generell gleichkörnigen Kalzitmatrix. Derartige Gefüge weisen die Marmore vom Typ Ephesos I auf.

Ein weiterer mittelkörniger Marmor tritt bei der Probe L6 (Abb. 3) auf. Hier beträgt die maximale Korngröße 1,6 mm, das Gefüge ist heteroblastisch. Dolomit tritt hier nicht auf.

Die Probe L2 (Abb. 4) ist ein sehr grobkörniger Marmor mit einer maximalen Korngröße von $6 \mathrm{~mm}$. Es handelt sich um ein Kalzitkorngefüge mit leicht verzahnten Korngrenzen. Deformationsspuren sind nicht zu erkennen.
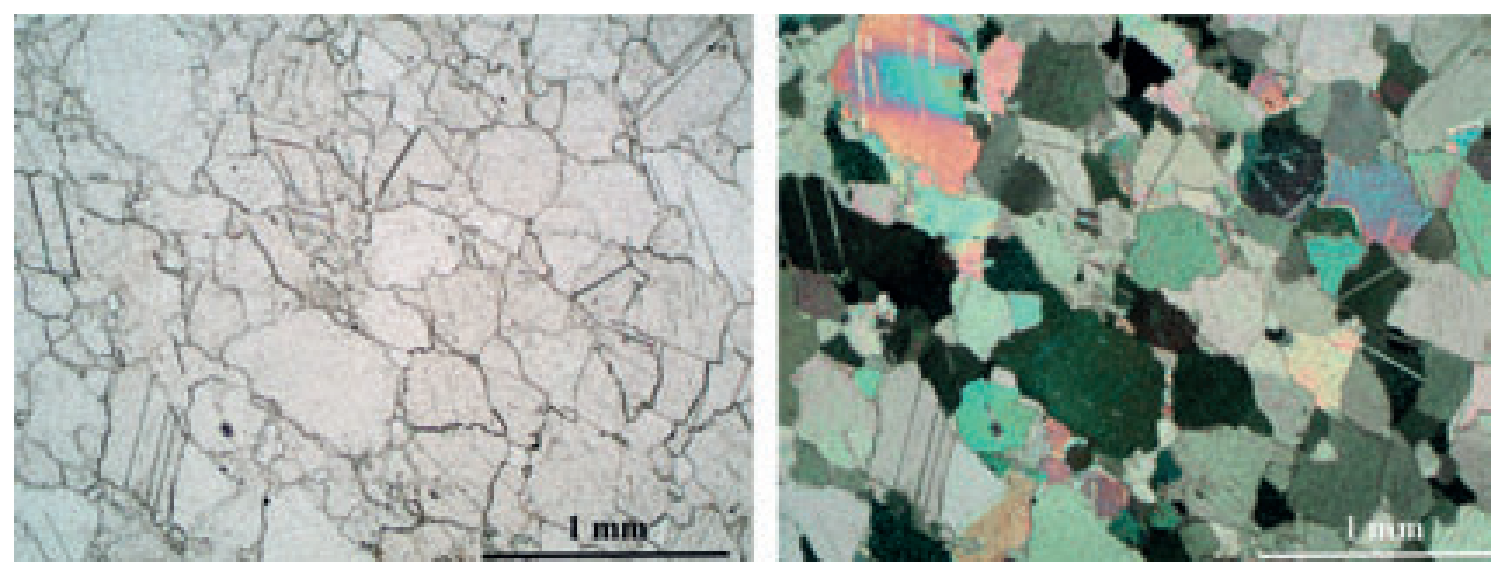

Abb. 1 Mikrofoto des feinkörnigen Marmors der Probe L1

893 Eine ausführliche Schilderung der Methode und ein Anwendungsbeispiel bei der Provenienzanalyse der Marmore des Mausoleums von Belevi sind zu finden bei W. Prochaska - S. M. Grillo - P. Ruggendorfer, Chemical analysis of inclusion fluids - a new method to pinpoint the origin of white marbles, illustrated at the Mausoleum at Belevi, Forum Archaeologiae 45/XII/2007 <http://farch.net> (24. 7. 2017).

${ }^{894}$ Unsere Datenbank umfasst zurzeit mehr als 2800 Steinbruchproben mit den entsprechenden isotopischen und chemischen Daten. 

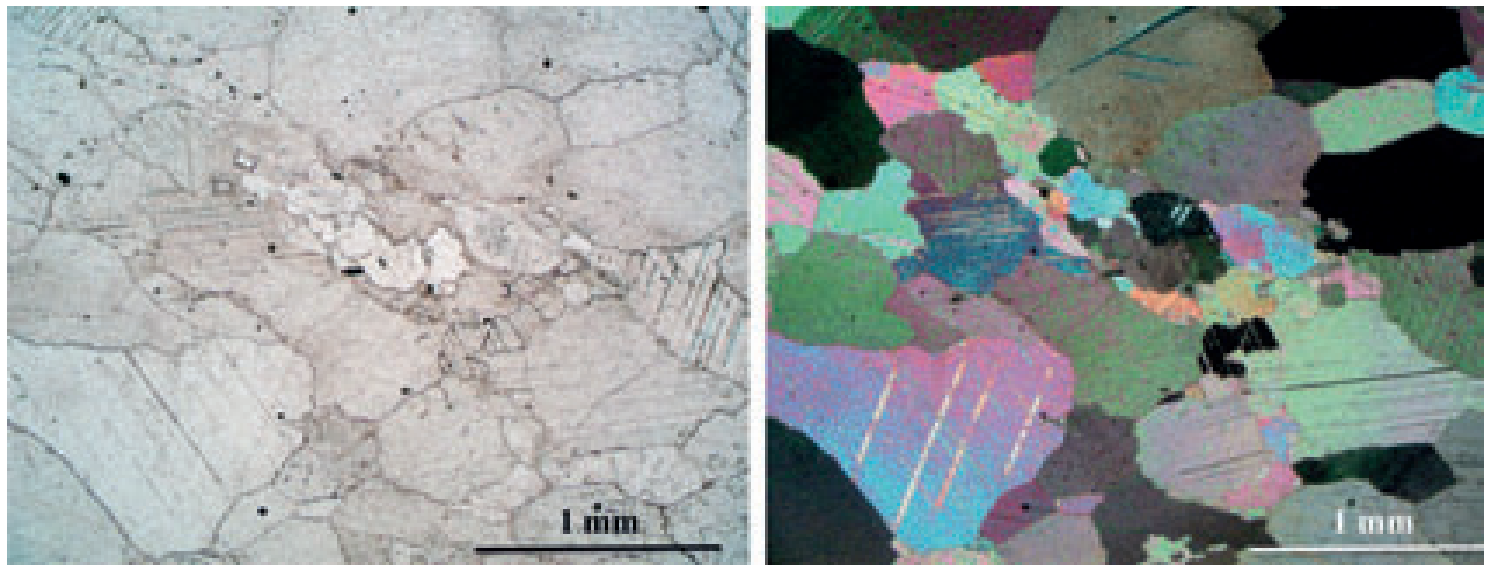

Abb. 2 Mikrofoto des mittelkörnigen Marmors der Probe L7
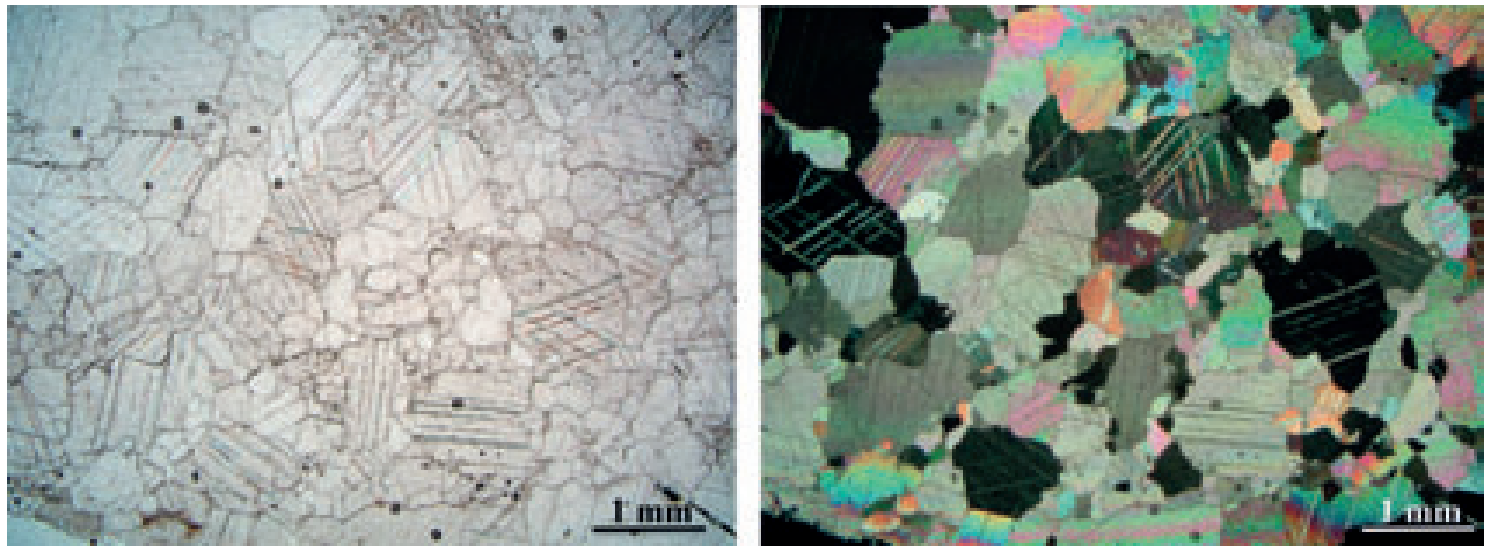

Abb. 3 Mikrofoto des mittelkörnigen Marmors der Probe L6
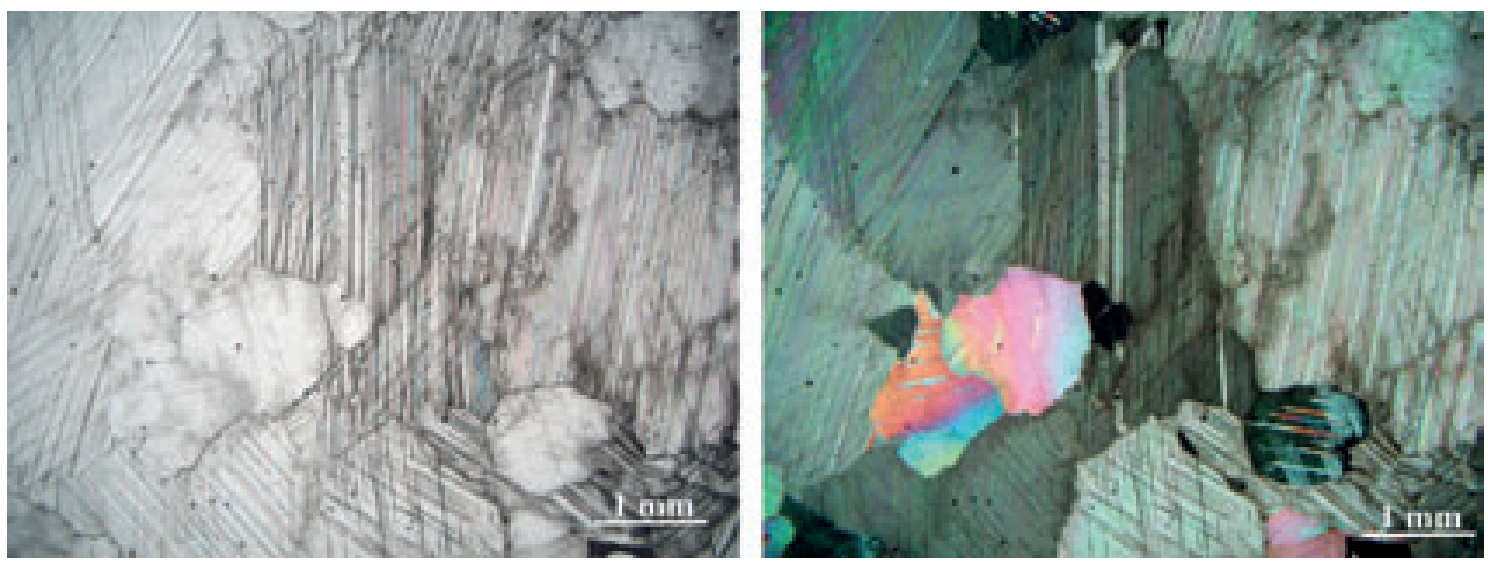

Abb. 4 Mikrofoto des grobkörnigen Marmors der Probe L2 


\subsection{Die analytischen Ergebnisse}

\subsubsection{Mittel- bis grobkörnige Marmore}

Die Ergebnisse der Analysen der stabilen Isotope und der chemischen Zusammensetzung der Marmore sowie der Einschlussfluide sind in Tabelle 1 aufgelistet.

Tab. 1 Die analytischen Ergebnisse der untersuchten grobkörnigen Marmore

\begin{tabular}{|l|l|c|c|c|c|c|c|c|c|c|c|c|c|}
\hline Probe & $\mathrm{DS}$ & $\mathrm{MgCO}_{3}$ & $\mathrm{Fe} p \mathrm{ppm}$ & $\mathrm{Mn} \mathrm{ppm}$ & $\mathrm{Sr} \mathrm{ppm}$ & $\mathrm{Li} / \mathrm{Na}$ & $\mathrm{Cl} / \mathrm{Na}$ & $\mathrm{K} / \mathrm{Na}$ & $\mathrm{Br} / \mathrm{Na}$ & $\mathrm{I} / \mathrm{Na}$ & $\mathrm{SO}_{4} / \mathrm{Na}^{1}$ & $\partial^{18} \mathrm{O}_{(\mathrm{PDB})}$ & $\partial^{13} \mathrm{C}_{(\mathrm{PDB})}$ \\
\hline L2 & 6902 & 1,97 & 80 & 47 & 127 & 1,247 & 1730 & 712 & 7,0 & 128,4 & 323,1 & $-0,40$ & 3,11 \\
L3 & 3200 & 1,00 & 67 & 33 & 119 & 2,138 & 1363 & 611 & 3,6 & 72,3 & 587,5 & 0,12 & 3,06 \\
L5 & 4955 & 1,24 & 75 & 34 & 128 & 1,342 & 1720 & 605 & 5,5 & 40,7 & 715,6 & $-0,02$ & 3,07 \\
L6 & 9887 & 1,60 & 86 & 20 & 192 & 1,238 & 1604 & 242 & 7,6 & 57,9 & 376,1 & $-1,94$ & 2,58 \\
L7 & 6028 & 2,68 & 201 & 32 & 118 & 1,657 & 1867 & 577 & 5,1 & 7,5 & 327,3 & $-3,68$ & 4,34 \\
L8 & 3100 & 1,42 & 126 & 19 & 147 & 0,998 & 1904 & 961 & 4,1 & 8,4 & 541,1 & $-3,31$ & 4,57 \\
\hline
\end{tabular}

Für die Untersuchung der Herkunft der mittel- bis grobkörnigen Marmore der beprobten Sarkophagfragmente wurden aus petrografischen Gründen und wegen der Ähnlichkeit der isotopischen Zusammensetzung die folgenden Marmore zum Vergleich mittels Diskriminanzanalyse ausgewählt:

Aus der Region von Ephesos wurden die Marmore Ephesos I und Tavşantepe ausgewählt. Ephesos I ist der am häufigsten verwendete Marmor in der antiken Stadt, und die Marmore des kleinen Steinbruchs von Tavşantepe (ca. 4 km von der Ruinenstätte entfernt) wurden für die Herstellung von Sarkophagen verwendet. Weiters wurden die Marmore von Prokonnesos (mittelkörnig) und die grobkörnigen, weißen Marmore der Insel Thasos bei den Berechnungen berücksichtigt, da es sich hier um Marmore handelt, für die eine Verwendung bei der Sarkophagproduktion nachgewiesen wurde ${ }^{895}$.

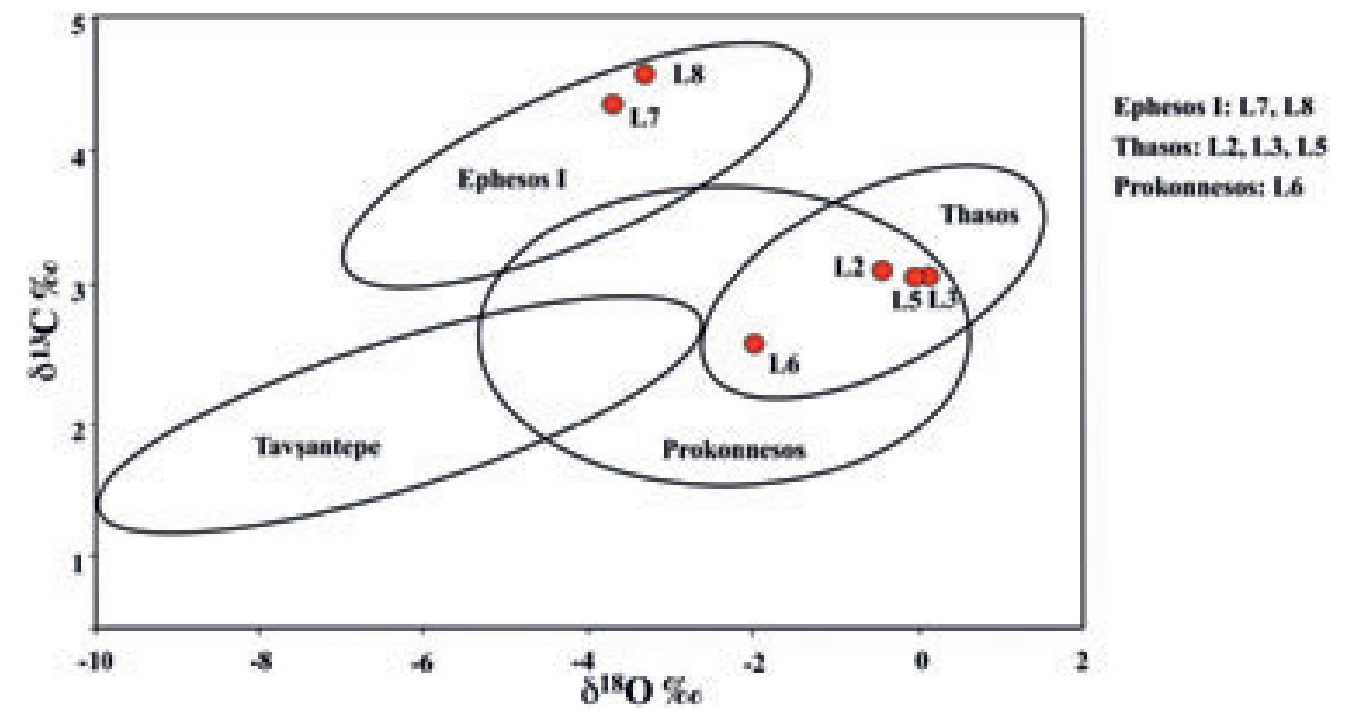

Abb. 5 Isotopendiagramm der untersuchten mittel- bis grobkörnigen Marmore und der Isotopenfelder der zum Vergleich herangezogenen Weißmarmore

895 z. B. Maniatis u. a. 2010, 45-58. 
Es besteht im Isotopendiagramm (Abb. 5) eine unterschiedlich starke Überlappung der einzelnen Felder, daher ist eine sichere Zuordnung der einzelnen Proben allein auf Basis der Isotopenzusammensetzung nur bedingt möglich. Im Isotopendiagramm existiert die bekannte Überlagerung der Felder von Prokonnesos und Thasos. Allerdings lässt auch schon hier die zentrumsnahe Position der Probe L6 eine Zugehörigkeit zu Prokonnesos vermuten. Die Einbeziehung weiterer chemischer Parameter ergibt ein besser abgesichertes Bild der Marmorherkunft.

Die Ergebnisse der multivariaten Diskriminationsanalyse sind in Abbildung 6 grafisch dargestellt. Hier sind die einzelnen Proben relativ eindeutig zugeordnet, die Probe $\mathbf{L} 6$ weist eine zentrale Lage im Prokonnesos-Feld auf und hat nur noch eine Randlage im Thasos-Feld. Die hier gewählte bivariate Darstellung eines multidimensionalen Systems ist nur eine approximative Angleichung, die exakten Parameter der Zuordnung sind in Tabelle 2 nummerisch wiedergegeben.

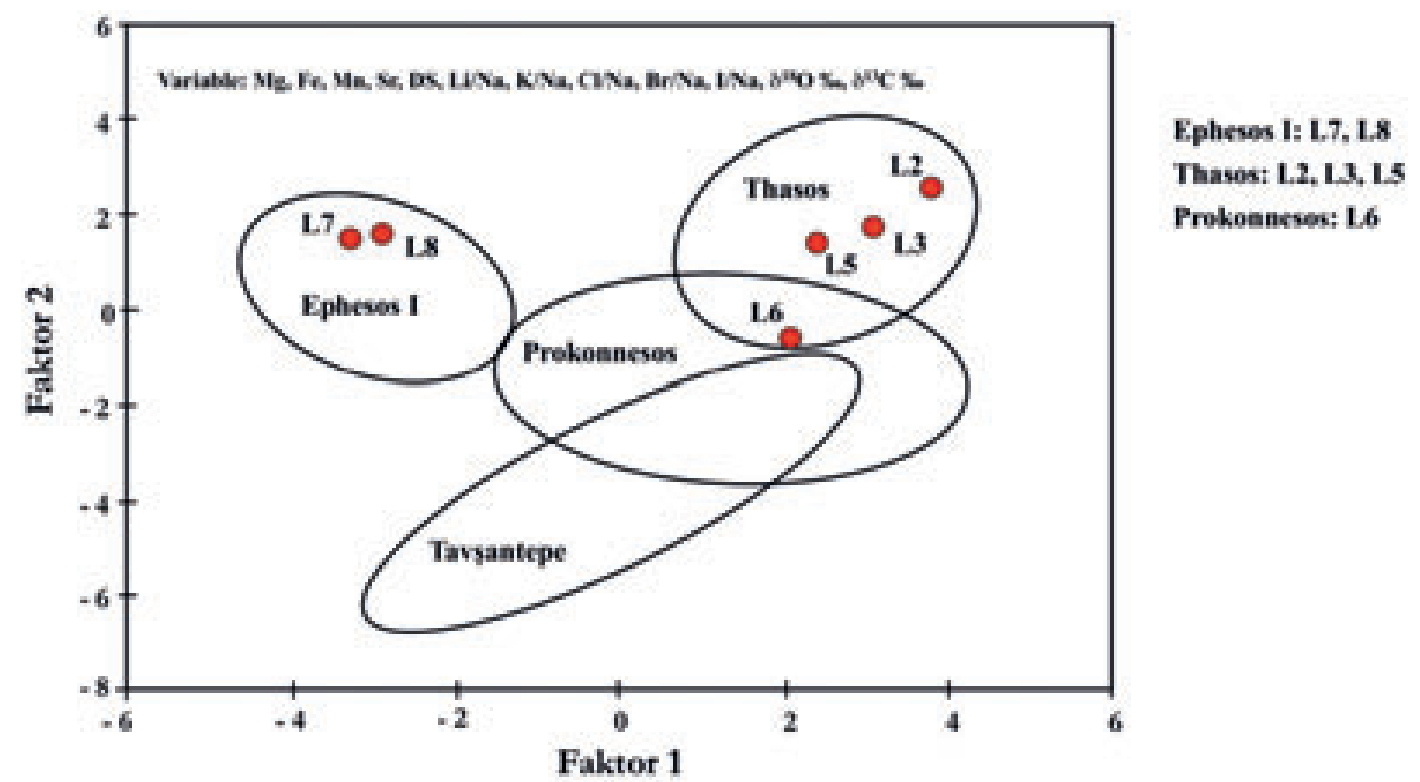

Abb. 6 Bivariates Diagramm der beiden wichtigsten Faktoren der multivariaten Analyse der Marmore der untersuchten Sarkophage und ihre Zuordnung zu den jeweiligen Herkunftsgebieten

Zur multivariaten Berechnung wurden die Variablen Mg, Fe, Mn, Sr, DS, Li/Na, Cl/Na, K/Na, $\mathrm{Br} / \mathrm{Na}, \mathrm{I} / \mathrm{Na}, \partial^{18} \mathrm{O}, \partial^{13} \mathrm{C}$ herangezogen. Die Ergebnisse sind in Tabelle 2 wiedergegeben.

Die relative Wahrscheinlichkeit bezeichnet die Wahrscheinlichkeit der Zuordnung einer Probe zu einem Vorkommen innerhalb der für die statistische Auswertung in Betracht gezogenen Marmorvorkommen (in diesem Fall fünf Vorkommen, vier dokimeische Steinbruchbereiche und Prokonnesos). Bei der zweiten Wahl sind die relativen Wahrscheinlichkeiten natürlich geringer als bei der ersten Wahl. Die Summe der relativen Wahrscheinlichkeiten aller betrachteten Vorkommen muss $100 \%$ ergeben.

Die absolute Wahrscheinlichkeit bezeichnet die Wahrscheinlichkeit, mit der die Probe einer bestimmten Gruppe zugehörig ist. Im gegenständlichen Fall sind das die ausgewählten Marmore Ephesos I und II, Aphrodisias, Prokonnesos und die parischen Lychnites. Die absolute Wahrscheinlichkeit ist ein distanzabhängiger Parameter. In einem zweidimensionalen Diagramm können die multivariaten Probencluster dargestellt werden, und die jeweiligen Probengruppen werden durch Wahrscheinlichkeitsellipsen definiert (Abb. 6). Hier wurden 90 \%-Ellipsen gewählt, der Schwellenwert für Proben am Rand der Ellipse ist 10 \%. Das Zentrum der Wahrscheinlichkeitsellipse ist 100 \%, je weiter vom Zentrum die Probe liegt, umso geringer ist der Wert. Eine Probe im Zentrum weist in allen Parametern eine für diese Gruppe durchschnittliche Zusammensetzung auf. 
Die Distanz ist die Entfernung vom Ellipsenmittelpunkt. Je größer diese Distanz vom Mittelpunkt einer Population ist, umso geringer ist die absolute Wahrscheinlichkeit der Zugehörigkeit der Probe zu der betrachteten Probengruppe.

Tab. 2 Die nummerischen Ergebnisse der Diskriminationsanalyse der grobkörnigen Marmore

\begin{tabular}{|c|c|c|c|c|c|c|c|}
\hline Probe & $\begin{array}{l}\text { verwendete } \\
\text { Varible }\end{array}$ & Distanz & $\begin{array}{l}\text { absolute Wahr- } \\
\text { scheinlichkeit }\end{array}$ & $\begin{array}{l}\text { relative Wahr- } \\
\text { scheinlichkeit }\end{array}$ & Herkunft & $\begin{array}{l}\text { relative Wahr- } \\
\text { scheinlichkeit }\end{array}$ & Herkunft \\
\hline & & \multicolumn{4}{|c|}{ 1. Wahl } & \multicolumn{2}{|c|}{ 2. Wahl } \\
\hline $\mathbf{L 2}$ & $\begin{array}{l}\mathrm{Mg}, \mathrm{Fe}, \\
\mathrm{Mn}, \mathrm{Sr}, \\
\mathrm{DS}, \mathrm{Li} / \mathrm{Na}, \\
\mathrm{Cl} / \mathrm{Na}, \mathrm{K} / \\
\mathrm{Na}, \mathrm{Br} / \mathrm{Na}, \\
\mathrm{I} / \mathrm{Na}, \partial^{18} \mathrm{O}, \\
\partial^{13} \mathrm{C}\end{array}$ & 2,81 & 42,2 & 100 & Thasos & - & - \\
\hline $\mathbf{L 3}$ & $\begin{array}{l}\text { Mg, Fe, } \\
\mathrm{Mn}, \mathrm{Sr}, \\
\mathrm{DS}, \mathrm{Li} / \mathrm{Na}, \\
\mathrm{Cl} / \mathrm{Na}, \mathrm{K} / \\
\mathrm{Na}, \mathrm{Br} / \mathrm{Na}, \\
\mathrm{I} / \mathrm{Na}, \partial^{18} \mathrm{O}, \\
\partial^{13} \mathrm{C}\end{array}$ & 0,85 & 83,7 & 99,9 & Thasos & 0,1 & Prokonnesos \\
\hline L5 & $\begin{array}{l}\text { Mg, Fe, } \\
\mathrm{Mn}, \mathrm{Sr}, \\
\mathrm{DS}, \mathrm{Li} / \mathrm{Na}, \\
\mathrm{Cl} / \mathrm{Na}, \mathrm{K} / \\
\mathrm{Na}, \mathrm{Br} / \mathrm{Na}, \\
\mathrm{I} / \mathrm{Na}, \partial^{18} \mathrm{O}, \\
\partial^{13} \mathrm{C}\end{array}$ & 1,10 & 77,6 & 98,5 & Thasos & 1,5 & Prokonnesos \\
\hline L6 & $\begin{array}{l}\mathrm{Mg}, \mathrm{Fe}, \\
\mathrm{Mn}, \mathrm{Sr}, \\
\mathrm{DS}, \mathrm{Li} / \mathrm{Na} \text {, } \\
\mathrm{Cl} / \mathrm{Na}, \mathrm{K} / \\
\mathrm{Na}, \mathrm{Br} / \mathrm{Na}, \\
\mathrm{I} / \mathrm{Na}, \partial^{18} \mathrm{O}, \\
\partial^{13} \mathrm{C}\end{array}$ & 1,63 & 65,2 & 89,3 & $\begin{array}{l}\text { Prokon- } \\
\text { nesos }\end{array}$ & 10,7 & Thasos \\
\hline L7 & $\begin{array}{l}\text { Mg, Fe, } \\
\mathrm{Mn}, \mathrm{Sr}, \\
\mathrm{DS}, \mathrm{Li} / \mathrm{Na}, \\
\mathrm{Cl} / \mathrm{Na}, \mathrm{K} / \\
\mathrm{Na}, \mathrm{Br} / \mathrm{Na}, \\
\mathrm{I} / \mathrm{Na}, \partial^{18} \mathrm{O}, \\
\partial^{13} \mathrm{C}\end{array}$ & 1,18 & 75,8 & 100 & Ephesos I & - & - \\
\hline $\mathbf{L 8}$ & $\begin{array}{l}\mathrm{Mg}, \mathrm{Fe}, \\
\mathrm{Mn}, \mathrm{Sr}, \\
\mathrm{DS}, \mathrm{Li} / \mathrm{Na} \text {, } \\
\mathrm{Cl} / \mathrm{Na}, \mathrm{K} / \\
\mathrm{Na}, \mathrm{Br} / \mathrm{Na}, \\
\mathrm{I} / \mathrm{Na}, \partial^{18} \mathrm{O}, \\
\partial^{13} \mathrm{C}\end{array}$ & 1,62 & 65,4 & 100 & Ephesos I & - & - \\
\hline
\end{tabular}




\subsubsection{Feinkörnige Marmore}

Zwei der untersuchten Sarkophagfragmente bestehen aus feinkörnigem Marmor. Für die nachstehenden Untersuchungen wurden daher die attischen Marmore (pentelischer Marmor), die Marmore von Carrara und Göktepe und die Marmore der kaiserlichen Steinbrüche von Dokimeion/ Afyon in Betracht gezogen. Für die letztgenannten Marmore wird der gesamte Datensatz der Datenbank in Betracht gezogen und nicht die Einteilung in einzelne Untergruppen nach der Originalarbeit von J. Röder ${ }^{896}$ verwendet, da die verschiedenen Marmore von Dokimeion kaum voneinander zu unterscheiden sind.

Tab. 3 Die analytischen Daten der beiden feinkörnigen Marmore L1 und L4

\begin{tabular}{|c|l|c|c|c|c|c|c|c|c|c|c|c|c|}
\hline Probe & $\mathrm{DS}$ & $\mathrm{MgCO}_{3}$ & $\mathrm{Fe} \mathrm{ppm}$ & $\mathrm{Mn} \mathrm{ppm}$ & $\mathrm{Sr} \mathrm{ppm}$ & $\mathrm{Li} / \mathrm{Na}$ & $\mathrm{Cl} / \mathrm{Na}$ & $\mathrm{K} / \mathrm{Na}$ & $\mathrm{Br} / \mathrm{Na}$ & $\mathrm{I} / \mathrm{Na}$ & $\mathrm{SO}_{4} / \mathrm{Na}$ & $\partial^{18} \mathrm{O}_{(\mathrm{PDB})}$ & $\partial^{13} \mathrm{C}_{(\mathrm{PDB})}$ \\
\hline $\mathbf{L 1}$ & 7995 & 1,48 & 268 & 77 & 194 & 1,665 & 2397 & 637 & 5,0 & 6,3 & 182,8 & $-4,05$ & 2,50 \\
$\mathbf{L 4}$ & 4253 & 0,40 & 77 & 19 & 140 & 0,917 & 1316 & 934 & 2,4 & 4,4 & 481,7 & $-4,04$ & 2,07 \\
\hline
\end{tabular}

In Tabelle 3 sind die Ergebnisse der Isotopenanalysen und der chemischen Analysen aufgelistet. Die O-Isotopenzusammensetzung von ca. -4 \%o schließt eine Herkunft dieser Marmore aus den attischen Steinbrüchen aus (Abb. 7). Auch die Carraramarmore kommen schon alleine aufgrund ihrer isotopischen Zusammensetzung nicht als Quelle für die gegenständlichen Marmore in Frage. Die Isotopenwerte der Steinbrüche von Dokimeion streuen relativ stark und bilden ein entsprechend großes Feld. Die beiden untersuchten Proben liegen sehr zentrumsnah in diesem Isotopenfeld.

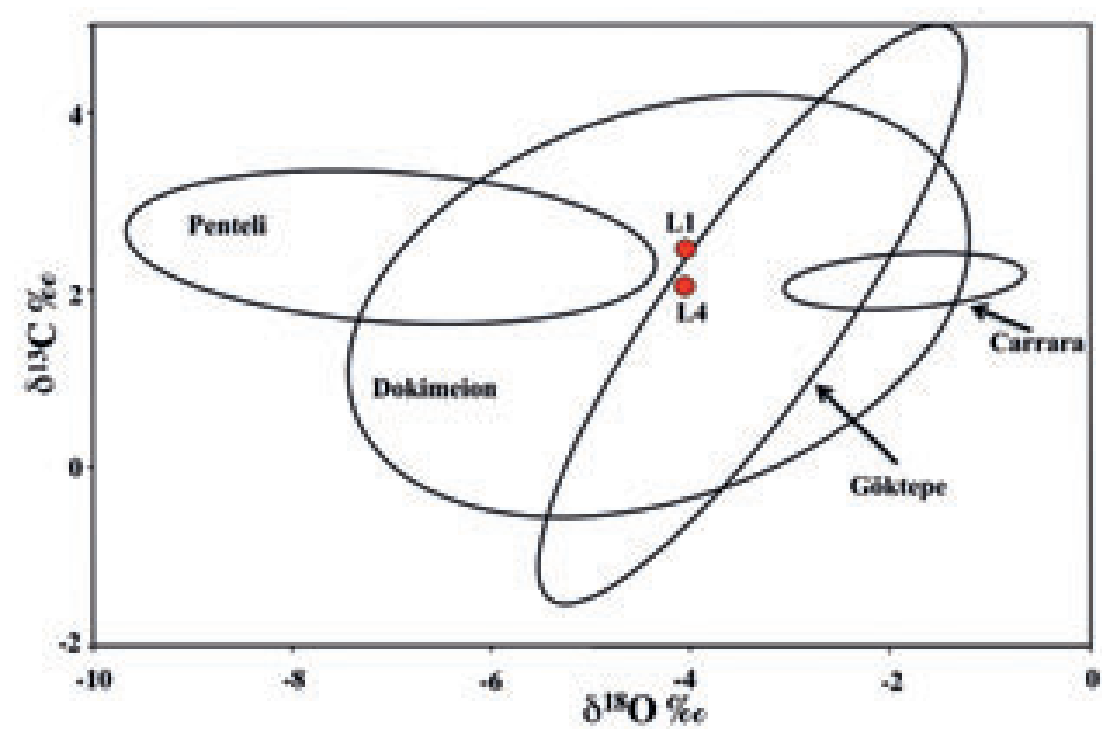

Abb. 7 Isotopendiagramm der feinkörnigen Marmore der zum Vergleich herangezogenen Weißmarmore von Mt. Pentelikon bei Athen und der verschiedenen Steinbrüche von Dokimeion

Die multivariate Analyse, grafisch in Abbildung 8 dargestellt, zeigt das gleiche Ergebnis. Aufgrund dieser eindeutigen Zuordnung der feinkörnigen Marmore zu den Steinbrüchen von Dokimeion anhand der petrografischen, chemischen und isotopischen Untersuchungen wurde hier auf eine nummerische statistische Kalkulation verzichtet.

896 Röder 1971, 251-321. 


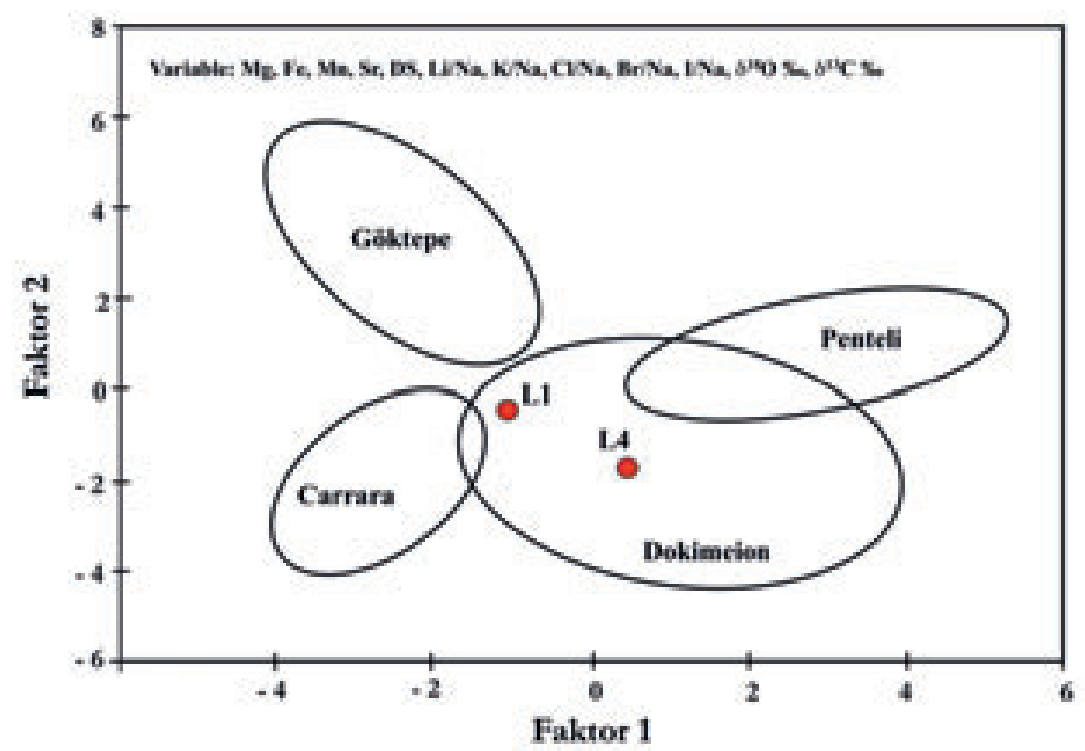

Abb. 8 Bivariates Diagramm der beiden wichtigsten Faktoren der multivariaten Analyse der beiden feinkörnigen Marmore der untersuchten Sarkophage und ihre Zuordnung zu den jeweiligen Herkunftsgebieten

\subsection{Zusammenfassung}

Für die vorliegende Untersuchung wurden 2014 acht Fragmente von Sarkophagen ${ }^{897}$ beprobt und einer Kombination verschiedener Analysemethoden mit dem Ziel einer Herkunftsanalyse der entsprechenden Marmore unterzogen. Entsprechend der multivariaten Diskriminationsanalyse sind die Marmore der Sarkophage unterschiedlicher Herkunft:

L1 und L4: Dokimeion/Afyon; L2, L3 und L5: Thasos; L6: Prokonnesos; L7 und L8: Ephesos I.

897 Das Fragment L9 konnte nicht beprobt werden. 


\section{Ergebnisse zu den attischen Sarkophagen und den lokalen Fragmenten aus Ephesos}

\subsection{Attische Sarkophage}

Die Zahl der bisher bekannten 32 attischen Exemplare aus Ephesos ${ }^{898}$ konnte mit dem vorliegenden Band auf 48 Katalognummern erhöht werden. Die Einschränkung, dass die meisten Exemplare als »Gelegenheits- oder Oberflächenfunde zu werten « sind ${ }^{899}$ und damit nur ein Bruchteil der Gesamtzahl erhalten ist ${ }^{900}$, muss natürlich weiterhin gelten.

Die mit anderen Skulpturen vermischt gelagerten Fragmente der Sarkophage des Grabhauses der Claudia Antonia Tatiane und des attischen Hippolytos-Sarkophags aus einem Grabhaus der Nekropole nördlich des Hafenkanals wurden so gut wie möglich sortiert. Unter Kat. 1, Kat. 2 sowie Kat. 15 verbergen sich daher zahlreiche zugeordnete Fragmente. Unter Kat. 1 ließen sich zu dem Schlachtsarkophag des [Quintus] Aemilius Aristides (Taf. 1-25) weit über 70 Fragmente zuordnen, unter Kat. 2, Amazonomachie-Sarkophag aus dem Tatiane-Grab (Taf. 25-32), sind über 20 Fragmente eingeordnet und bei Kat. 15, dem Hippolytos-Sarkophag (Taf. 49-64), sind wieder über 70 Fragmente aufgeführt, die teilweise als nicht gesicherte Zuordnungen gekennzeichnet sind. Unter Kat. 1, 2 und 15 finden sich die entsprechenden Zuordnungen und ihre Kriterien.

Als weiterer Schritt konnte hier auch der Grad der > Verstreuung « der Sarkophage auf verschiedene Aufbewahrungsorte dokumentiert werden. Dies gilt besonders für den Schlachtsarkophag des Aemilius Aristides, dem durch seine Inschriften und den erhaltenen Porträtkopf archäologisch und historisch eine herausragende Bedeutung zukommt. In einem nächsten Schritt wäre es wünschenswert, die zusammengehörigen Fragmente des Kastens und den Deckel wieder zusammenzuführen.

Auch dem Amazonomachie-Sarkophag aus der Nekropole nördlich des Hafenkanals, Kat. 6, kommt eine besondere Bedeutung zu, und zwar im Hinblick auf die Ikonografie. Der Sarkophag in Ephesos ist neben Fragmenten in den Harvard Art Museums, Arthur M. Sackler Museum, eines der beiden Leitstücke der sog. Amazonomachie-Gruppe II der attischen AmazonomachieSarkophage, die sich durch eine verbindliche Typenabfolge definiert ${ }^{901}$. Zu Beginn der Produktion wird das Typenrepertoire der zwei frühen attischen Amazonomachie-Gruppen I und II von den beiden frühen stadtrömischen Amazonomachie-Gruppen übernommen ${ }^{902}$. Die Typenabfolge der frühen attischen Vorderseiten bleibt dabei anfangs weitgehend gleich ${ }^{903}$. Bei AmazonomachieGruppe II, also auch bei dem Leitstück in Ephesos, sind dies eine Sturzgruppe mit fallendem Griechen in Rückenansicht und darunter ein kopfüber Gefallener, dessen Hinterkopf zu sehen ist, eine Helfergruppe mit dem Helfer in Rückenansicht, ein Rossbändiger und eine Fluchtgruppe mit einer auf dem Bauch liegenden Amazone darunter ${ }^{904}$.

898 Zuletzt: Koch 1999, 557.

899 Rudolf 1989 in der Einleitung.

900 Koch 1999, 557: „Wir haben also ursprünglich mit vielen Hunderten an attischen Sarkophagen in Ephesos zu rechnen.«

901 Kintrup 2016a, Kap. 3.1.2. Der Gruppe II lassen sich etliche weitere Fragmente zuordnen, s. Kintrup 2016a, 3.1.2.2.

902 s. dazu kurz unter Kat. 6 mit Anm. 299.

903 Dies ist ebenfalls für die attischen Achill- und Hippolytos-Sarkophage zu belegen, s. Rogge 1995, 119. 121.

904 Zur weiteren Verwendung dieser Typen s. Kat. 6 mit Anm. 300 f. 
Bei der Bearbeitung der erwähnten attischen Sarkophage und an etlichen weiteren Exemplaren aus Ephesos ließen sich grundlegende Entwicklungen in Bezug auf Tektonik, Ornamentik, Ikonografie und Stil aufzeigen.

Der Aristides-Sarkophag Kat. 1 und der Amazonomachie-Sarkophag Kat. 6 präsentieren eine Anordnung der Friesfiguren in mehreren Reliefebenen und eine Figurendichte - Letzteres zunehmend bis ca. 240 n. Chr. -, die typisch für die Sarkophage um die Jahrhundertwende sind. Bei den beiden Sarkophagen zeigt sich - soweit erhalten - auf den Hauptansichtsseiten ein ebenso typischer Aufbau des tektonischen Gerüsts im letzten Viertel des 2. Jahrhunderts bis zum Anfang des 3. Jahrhunderts n. Chr. Sockelzone und oberer Kastenabschluss sind gut gegliedert. Die Sockelzone bietet zwischen den Eckpostamenten ein Flechtband, darüber ein lesbisches Kyma und eine Standleiste für die Figuren. Der obere Kastenabschluss ist in Perlstab, Eierstab, lesbisches Kyma und obere Leiste unterteilt.

Die Eckfiguren sind durch ihre Größe und Teilnahmslosigkeit formal von dem Kampffries getrennt. Aber mit den Niken/Amazonen und dem Krieger sind Eckfiguren ausgesucht, die inhaltlich bereits Bezüge zu den dargestellten Kämpfen herstellen. Somit sind sie in der Entwicklung einen Schritt weiter als ihre Vorläufer, die ১figürlich gestalteten Klinenbeine`, etwa in Form von Karyatiden oder Attisfiguren, an den Ecken aufweisen. Damit büßten die Eckfiguren ihre tektonische Funktion, das Klinenauflager zu stützen, ein und wurden zu Figuren, welche die Kampfdarstellungen einrahmten.

In zeitliche Nähe zum Aristides-Sarkophag (Kat. 1) gehört aufgrund seiner erhaltenen tektonischen Struktur des Kastens mit dessen klar strukturierter Sockelzone samt Eckfigur über einem Eckpostament der Eroten-Weinlese-Sarkophag Kat. 10 im >Tor der Verfolgung〈. Die Eckfigur ist der Eroten-Vindemia inhaltlich angepasst, aber nicht in das Geschehen eingebunden. Der obere Kastenabschluss der Vorderseite ist - ebenfalls an das Thema angepasst - mit vegetabilem Dekor verziert. Im Vergleich zu dem Aristides-Sarkophag erscheint der Eroten-Weinlese-Sarkophag in Selçuk durch Einbeziehung der thematisch bedingten Adaptionen als das fortgeschrittenere Exemplar.

Der Achill-Sarkophag in Woburn Abbey, Kat. 3, demonstriert dann eine deutlich fortgeschrittene Entwicklungsstufe, die im zweiten Viertel des 3. Jahrhunderts n. Chr. anzusetzen ist. Die optisch gut gegliederten und ornamentierten Profile des oberen Kastenabschlusses und der Sockelzone weichen vegetabilen Schmuckbändern in flachem Relief. Wie hier werden auf den Hauptansichtsseiten bevorzugt stehende Akanthusblätter oder -ranken als Dekor angebracht. Die flachen Blattfriese oben und unten fungieren als Rahmung für das mythologische Geschehen. Ein typisches Phänomen später attischer Sarkophage ist zudem, dass die Friesfiguren oder Teile ihrer Ausrüstung, wie bei Kat. 3, bis in die obere Kastenleiste ragen. Die Aufmerksamkeit wurde stärker auf die Figurenfriese gelenkt. Dies wird auch von den Eckfiguren unterstützt, die ebenso groß sind wie die Friesfiguren - es hat eine formale Anpassung stattgefunden. Eine ehemals tektonische Funktion ist auch dadurch verloren gegangen, indem die Figuren an den Ecken in das Geschehen des Frieses eingebunden wurden ${ }^{905}$.

Die beiden stark fragmentierten Exemplare Kat. 2 und Kat. 15, der Amazonomachie- und der Hippolytos-Sarkophag, zeigen am Sockel ebenfalls die üblichen flachen Blattfriese, bieten aber am oberen Kastenabschluss eine seltene Schmuckform: Das dort erhaltene Gorgonenkyma gehört zu den experimentellen Schmuckformen und ist nur im zweiten Drittel des 3. Jahrhunderts n. Chr. belegt ${ }^{906}$.

Der Hippolytos-Sarkophag (Kat. 15) präsentiert sich nach Ausführung und Stil als exzellente Arbeit später attischer Sarkophagbildhauer. Insbesondere die erhaltenen Köpfe, fein geglättet oder poliert, und die Fragmente mit Gewandfalten belegen dies ${ }^{907}$.

905 Zur Entwicklung der Eckfiguren s. Kat. 3 mit Anm. 197.

906 Zu Vergleichen s. Kat. 2 und Kat. 15 mit Anm. 176 und 398.

$907 \mathrm{Zu}$ ausgezeichneten Vergleichen s. Kat. 15 mit Anm. 496-498. 
Während die Qualität der Bildhauerarbeit z. T. hervorragend ist, wie etwa bei Kat. 15 oder Kat. 1, ist die Qualität des Marmors teilweise minderwertig oder gar schlecht. So zeigt etwa Kat. 2, der Amazonomachie-Sarkophag aus dem Tatiane-Grabbau, starke Glimmerschiefereinschlüsse, Kat. 12 ist von starken Glimmeradern durchzogen und bei Kat. 28 verläuft der Bruchrand der Reliefdarstellung links entlang einer Glimmerader. Kat. 6, der AmazonomachieSarkophag aus der Nekropole nördlich des Hafenkanals, weist etliche Beschädigungen und Verwitterungsschäden auf, die zu einem Großteil aus dem Anteil an Glimmerschiefer resultieren. Die Ausarbeitung über einer Bruchstelle belegt zudem, dass den Bildhauern die minderwertige Marmorqualität bewusst war. Ähnlich verhält es sich mit Kat. 39: das Fragment eines Klinen-RiefelSarkophags zeigt ebenfalls Verreibungen und Beschädigungen, die auf die schlechte Steinqualität zurückzuführen sind.

Der Achill-Sarkophag in Woburn Abbey, Kat. 3, bietet neben den erwähnten charakteristischen Elementen der Tektonik und Ornamentik des späten zweiten Viertels des 3. Jahrhunderts n. Chr. auch im Hinblick auf die Ikonografie Kennzeichnendes für seine Zeit: Es werden verstärkt ruhige, frontale Figurentypen abgebildet und zugunsten handelnder Nebenfigurentypen hat eine Deaktivierung der Hauptfiguren eingesetz ${ }^{908}$. An einigen Figuren- und Gruppentypen lässt sich eine versatzstückartige Verwendung von Typen nachweisen. Ein solcher Typentransfer als übliche Praxis belegt den Verlust an mythologischer Substanz und erzählerischer Prägnanz ${ }^{909}$. Eine signifikante Verknüpfung bestimmter Figuren- oder Gruppentypen mit einem spezifischen Mythos ist nicht mehr angestrebt. Dabei ist durchaus denkbar, dass eine Mehrdeutigkeit beabsichtigt war, um dem Betrachter ein an Anspielungen und Verknüpfungen reiches Bild präsentieren zu können.

Andererseits dürften unter Berücksichtigung der Wirtschaftskrise des 3. Jahrhunderts n. Chr. praktische Erwägungen bezüglich Wirtschaftlichkeit und Fertigung auf Vorrat eine Rolle gespielt haben. Gegebenenfalls war dadurch die Produktion von Sarkophagen angezeigt, die weniger arbeitsaufwendig und kostengünstiger waren. Je populärer und weniger individuell die Darstellungen waren, desto größer war der potenzielle Käuferkreis: »In Zeiten des wirtschaftlichen Niederganges wie im 3. Jahrhundert mochten sie ein geringeres Absatzrisiko bilden und sich auch auf Vorrat arbeiten lassen. «110.

Die attischen Sarkophage aus Ephesos sind durch die belegte Auswahl der dargestellten Themen als repräsentativ zu bezeichnen. Die gesicherten thematischen Zuordnungen verteilen sich wie folgt:

Achill
Amazonomachie
Dionysisches oder Eroten-Weinlese
Hippolytos
Schlacht
Schlacht bei Schiffen

\author{
Kat. 3. 4. 5 \\ Kat. 2. 6.7 \\ Kat. 8. 9. 10. 11. 12.13. 14 \\ Kat. 15. 16. 17 \\ Kat. 1.18 \\ Kat. 19. 20
}

Damit waren alle gängigen Themen der attischen Sarkophage auch in Ephesos vertreten; allein eine eindeutige Zuweisung auf eine Meleager-Szene fehlt. Auch die Fragmente ohne eindeutige thematische Zuordnung zeigen mit Trompeter, Kriegern, Jünglingen und Pferden alle Ausschnitte, die in das angesprochene Repertoire passen. Zahlenmäßig überdurchschnittlich sind dabei die dionysischen und die Erotendarstellungen erhalten ${ }^{911}$.

\footnotetext{
908 s. ausführlicher Kat. 3 mit Anm. 214 f.

909 Vgl. z. B. auch das Eckfragment eines Achill-Sarkophags (Kat. 5). Weitere Beispiele s. in Anm. 282. Zu dem Begriff »erzählerische Prägnanz« s. Wiegartz 1983, 189. 191 f. Vgl. auch Rogge 1995, 39. 119 f.

910 So Brandenburg 1967, 210 Anm. 50 zu Meerwesendarstellungen auf Sarkophagen. Zu dem Themenbereich der Wirtschaftskrise des 3. Jhs. n. Chr. und Überlegungen im Hinblick auf attische Sarkophage s. z. B. Kintrup 2016a, Kap. 8 S. 215 mit Anm. 1208.

911 Zudem sind sogar bei zwei Fragmenten von Klinendeckeln (Kat. 43 Taf. 76 Abb. 311 f. und Kat. 44 Taf. 76 Abb. 310) als außergewöhnliches Dekor der Klinenaußenseite Eroten-Weinlese-Darstellungen ausgeführt.
} 
Einzigartig sind hingegen die zwei Fragmente eines attischen Säulensarkophags (?) (Kat. 42 Taf. 74 f. Abb. 306-309) ${ }^{912}$. Der Typus der Säulensarkophage war bislang für die attischen Werkstätten nicht bekannt, wohingegen die Säulensarkophage kleinasiatischer Produktion bereits ab der Mitte des 2. Jahrhunderts n. Chr. den führenden Typus in Kleinasien darstellen. Gründe für die Herstellung dieses Einzelstücks mögen spekulativ bleiben, doch offenbar war der Austausch nicht nur von Athen nach Kleinasien, sondern durchaus auch in umgekehrter Richtung möglich, wenn es sich auch um Einzelfälle handelte.

Aus den Untersuchungen der attischen Sarkophage aus Ephesos ergaben sich vielfältige Kriterien und Entwicklungen für die Erstellung einer relativen Chronologie. Damit bildeten die untersuchten Merkmale und Charakteristika die Grundlage für die Datierung der einzelnen Objekte und für die Erstellung einer Chronologie der Gattung vor Ort. Die im Einzelnen erzielten Resultate gewinnen an Bedeutung, weil sie mit chronologisch >fixierten` Eckdaten korreliert werden können ${ }^{913}$. Die Ergebnisse können mit anderen attischen Sarkophagen verglichen werden und werden übertragbar auf andere Gattungen der kaiserzeitlichen attischen Plastik.

Die folgenden Übersichten in tabellarischer Form bieten recht genaue Datierungen, sollen aber auch nicht verhehlen, dass die einzelnen Datierungen z. T. nur ungenau auf ein Drittel oder eine Hälfte eines Jahrhunderts festzulegen sind.

Attische Friessarkophage lassen sich ab dem Ende des 2. Jahrhunderts n. Chr. nachweisen. Ihre Zahl nimmt bereits im ersten Drittel des 3. Jahrhunderts zu und erreicht im zweiten Drittel des 3. Jahrhunderts ihren Höhepunkt - in dieser Zeit verdrängen die attischen Sarkophage alle >Konkurrenzprodukte ${ }^{914}$. Die attischen Sarkophage aus Ephesos sind in Bezug auf die erhaltene chronologische Verteilung als charakteristisch zu bezeichnen ${ }^{915}$.

\begin{tabular}{|c|c|c|c|c|c|c|}
\hline \multirow[t]{2}{*}{190 n. Chr. } & 200 n. Chr. & 210 n. Chr. & 220 n. Chr. & 230 n. Chr. & 240 n. Chr. & 250 n. Chr. \\
\hline & $\begin{array}{l}\text { Kat. } 1 \\
\text { (Schlacht, } \\
\text { Aristides) }\end{array}$ & & \multicolumn{3}{|c|}{ Kat. 15 (Hippolytos) } & \\
\hline \multicolumn{2}{|c|}{ Kat. 6 (Amazonen) } & & \multicolumn{3}{|c|}{ Kat. 17 (Hippolytos [?]) } & \\
\hline & \multicolumn{2}{|c|}{ Kat. 10 (Eroten-Weinlese) } & & $\begin{array}{l}\text { Kat. } 21 \\
\text { (Schlacht [?]) }\end{array}$ & $\begin{array}{l}\text { Kat. } 2 \\
\text { (Amazonen, } \\
\text { Tatiane) }\end{array}$ & \\
\hline & \multicolumn{3}{|c|}{ Kat. 19 Schiffskampf } & $\begin{array}{l}\text { Kat. } 22 \\
\text { (Achill [?]) }\end{array}$ & \multicolumn{2}{|c|}{$\begin{array}{l}\text { Kat. } 14 \text { (Eros [?]) } \\
\text { Kat. } 15 \text { (Hippolytos) }\end{array}$} \\
\hline & \multicolumn{3}{|c|}{ Kat. 20 Schiffskampf } & \multicolumn{2}{|c|}{$\begin{array}{l}\text { Kat. } 31 \text { (Pferd) } \\
\text { Kat. } 40 \text { (Klinen-Riefel) }\end{array}$} & \\
\hline & $\begin{array}{l}\text { Kat. } 23 \\
\text { (Krieger) } \\
\text { Kat. } 35 \\
\text { (Mäander) }\end{array}$ & & & & Kat. 3 (Achill) & $\begin{array}{l}\text { Kat. } 25 \\
\text { (Krieger) }\end{array}$ \\
\hline & & & & & \multicolumn{2}{|l|}{ Kat. 5 (Achill) } \\
\hline
\end{tabular}

\footnotetext{
${ }_{912}$ Zu möglicherweise zwei vergleichbaren Fragmenten aus Salona/Split und den spekulativen Gründen der Schaffung dieses exzeptionellen Exemplars s. Kat. 42.

913 s. in der Einleitung mit Anm. 50-57 und die dort aufgezählten Exemplare mit Anm. 58-70.

914 So auch Koch 1999, 557. 563. Nach Koch 1993, 111, war Ephesos »Hauptabnehmer« in Kleinasien.

915 So bereits Koch 1993, 112; Koch 1999, 557 mit Vergleichen, »in denen die Fundlage günstig ist, also beispielsweise Tyrus, Thessaloniki, Salona, Aquileia oder Rom«.
} 


\begin{tabular}{|c|c|c|c|}
\hline 3. Viertel 2. Jh. n. Chr. & 4. Viertel 2. Jh. n. Chr. & 1. Viertel 3. Jh. n. Chr. & 2. Viertel 3. Jh. n. Chr. \\
\hline & & & Kat. 4 (Achill) \\
\hline & & & Kat. 7 (Amazonen) \\
\hline & & & Kat. 8 (dionysisch) \\
\hline & & & Kat. 9 (dionysisch) \\
\hline & & & $\begin{array}{l}\text { Kat. } 11 \text { (dionysisch oder } \\
\text { Eroten-Weinlese) }\end{array}$ \\
\hline & & & $\begin{array}{l}\text { Kat. } 12 \text { (dionysisch oder } \\
\text { Eroten-Weinlese) }\end{array}$ \\
\hline & & Kat. 18 (Schlacht) & \\
\hline & & & $\begin{array}{l}\text { Kat. } 26 \text { (unsichere Datie- } \\
\text { rung) bis Ende 2. Viertel }\end{array}$ \\
\hline & & & Kat. 27 (Trompeter) \\
\hline & & & Kat. 32 (Pferd) \\
\hline & & & Kat. 33 (Pferd) \\
\hline & & & Kat. 34 (Löwe, Rückseite) \\
\hline & \multicolumn{2}{|c|}{ Kat. 36 (Sockel) 4. Viertel - 1. Viertel } & \\
\hline & \multicolumn{2}{|c|}{ Kat. 37 (Sockelecke) 4. Viertel - 1. Viertel } & \\
\hline & & & $\begin{array}{l}\text { Kat. } 42 \text { (attischer Säu- } \\
\text { lensarkophag) }\end{array}$ \\
\hline & & & Kat. 43 (Klinendeckel) \\
\hline & Kat. 45 (Klinendeckel) & & \\
\hline & \multicolumn{2}{|l|}{ Kat. 46 (Klinendeckel) } & \\
\hline & \multicolumn{2}{|l|}{ Kat. 48 (Klinendeckel) } & \\
\hline
\end{tabular}

\begin{tabular}{|l|l|l|}
\hline 3. Drittel 2. Jh. n. Chr. & 1. Drittel 3. Jh. n. Chr. & 2. Drittel 3. Jh. n. Chr. \\
\hline Kat. 41 (Girlande) & $\begin{array}{l}\text { Kat. } 13 \text { (dionysisch oder Eroten- } \\
\text { Weinlese) }\end{array}$ & $\begin{array}{l}\text { Kat. } 28 \text { (Sockelzone) 230-260 n. } \\
\text { Chr. }\end{array}$ \\
\hline & Kat. 39 (Klinen-Riefel) & Kat. 30 (Krieger) 230-260 n. Chr. \\
\hline & Kat. 47 (Klinendeckel) & \\
\hline
\end{tabular}

\begin{tabular}{|l|l|}
\hline 2. Hälfte 2. Jh. n. Chr. & 1. Hälfte 3. Jh. n. Chr. \\
\hline Kat. 29 (unsichere Datierung) & Kat. 24 (Jüngling) \\
\hline
\end{tabular}

\subsection{Lokale Fragmente}

Die unter dieser Überschrift katalogisierten Exemplare zeigen eine ähnliche Qualität und Ausführung. Kat. L1 und Kat. L4 sind dabei aus Marmor aus Dokimeion/Afyon gefertigt; der Marmor der anderen Fragmente wurde auf Thasos (Kat. L2. L3 und L5), in Prokonnesos (Kat. L6) und in Ephesos selbst gebrochen (Kat. L7 und L8). Charakteristisch für die ephesischen Sarkophagfriesfragmente sind im Besonderen die technische Ausführung durch tiefe, breite Bohrkonturen der Figuren ${ }^{916}$ in Kombination mit einer in flacher Meißelarbeit gestalteten Binnengliederung. Aufgrund dessen und aufgrund der Marmorsorten sowie des ungewöhnlichen

916 Dass Umrissbohrungen weder ein ausschließlich attisches Phänomen sind noch allein als chronologisches Kriterium verwendet werden können, belegte ausführlicher zuletzt Gaggadis-Robin an den Sarkophagen in Arles: Gaggadis-Robin 2003, 79-90. 
Motivschatzes wurde die Zuordnung zu einer lokalen Werkstatt vorgenommen. Das Fragment wohl eines Girlandensarkophags, Kat. L6, bietet keine deutlichen Bohrlinien, ist aber anhand stilistischer und typologischer Kriterien der lokalen Werkstatt zugeordnet, was wiederum durch die nichtattische Marmorsorte (Prokonnesos) bestätigt wird.

Aus dem typischen groben grauen Marmor sind drei Fragmente von Dachdeckeln angefertigt (Kat. L7-L8; wohl auch Kat. L9; die Marmoranalyse der Fragmente L7-L8 erbrachte die Bestimmung `Ephesos I ). Zwei der drei Exemplare zeigen deutliche Bohrlinien zur Untergliederung des Blattziegeldekors; bei Kat. L7 sind auch die Ornamente auf dem unteren Abschlussprofil durch breite und tiefe Bohrkanäle ausgeführt. Als Vorbilder lassen sich die attischen Dachdeckel bestimmen.

Der Motivschatz der Friesfragmente der lokalen Werkstatt schöpft aus attischen und stadtrömischen Quellen, teilweise waren jedoch keine Vorbilder zu finden. Allein die Darstellungen der fallenden Amazone (Kat. L1 Taf. 78 Abb. 319 f.) und jene der Leda mit dem Schwan (Kat. L2 Taf. 78 Abb. 321) haben klar festzumachende Vorbilder, wobei nur zu ১Leda mit dem Schwan direkte Parallelen auf attischen Sarkophagen aufzuzeigen waren. Durch die Amazone, die >Leda ohne Schwan< (Kat. L3 Taf. 78 Abb. 322), die sog. Eroten-Weinlese (Kat. L4 Taf. 79 Abb. 323) und den Knienden mit Kind (Kat. L5 Taf. 79 Abb. 324) zeigt sich, dass die Bildhauer der lokalen Werkstatt durchaus das Selbstbewusstsein hatten, nicht nur Motive zu adaptieren, sondern auch eigene neue Typen für Figuren und Gruppen zu entwerfen und umzusetzen.

Ein lange bekanntes und prominentes Beispiel für eine einzigartige Darstellung auf einem Sarkophag aus Ephesos zeigt der >Unterweltsarkophag « in Istanbul ${ }^{917}$. Der >Unterweltsarkophag bot durch seinen Dachdeckel mit Blattziegeln einen Grund, attischen Einfluss besonders bei der Form des Deckels zu konstatieren ${ }^{918}$, und konnte hier als wichtige Parallele für die lokalen Dachdeckelfragmente angeführt werden ${ }^{919}$. Der >Unterweltsarkophag ‘ hat nun aber auch deutliche Umrissbohrungen aufzuweisen ${ }^{920}$, zudem scheinen die Faltengebung der Gewänder und der frei bleibende Reliefgrund den hier vorgestellten Fragmenten durchaus vergleichbar zu sein. So bestätigt der >Unterweltsarkophag ` die lokale Herstellung der hier genannten Friesfragmente und erhält selbst eine Bestätigung als ephesisches Werkstück.

Mit einer Datierung vor bis um die Mitte des 2. Jahrhunderts n. Chr..$^{921}$ ist der >Unterweltsarkophag später entstanden als die frühesten attischen Friessarkophage ${ }^{922}$, ein Umstand, der wiederum Anlass gab, seine Entstehung ebenfalls auf attischen Einfluss zurückzuführen ${ }^{923}$. Demnach hätten die eingeführten attischen Sarkophage zwar die Entstehung der ephesischen Friessarkophage der Form nach angeregt, eine Vorbildfunktion für die Motive und Darstellungen blieb aber begrenzt ${ }^{924}$.

Es ist nicht verwunderlich, dass eine oder mehrere lokale Werkstätten, die Girlandensarkophage produzierten, auf speziellen Wunsch eines Käufers oder in Konkurrenz zu den attischen Sarkophagen oder generell den importierten Exemplaren Friessarkophage herstellten. Wertschät-

917 Keil 1914, 133-144 Abb. 18-21 Taf. 2; Wiegartz 1965a, 40 f. 43 Anm. 54; 44. 50. 61 f. 64.179 Nr. 36 Taf. 8 b; 14, b; Wiegartz 1975, 208 f. mit Anm. 252; Koch - Sichtermann 1982, 522 Taf. 511; Koch 1999, 561.

918 Wiegartz 1965a, 40. 44.

919 s. unter Kat. L7 (Taf. 80 Abb. 326 f.).

920 s. z. B. Wiegartz 1965a, Taf. 8, b.

921 s. o. Anm. 917.

922 Die Produktion attischer Friessarkophage beginnt um 140 n. Chr., s. Wiegartz 1974, 361; Wiegartz 1977, 385; Koch - Sichtermann 1982, 369. 456; Koch 1993, 97. 108. Zu dem Beginn der Produktion attischer Sarkophage in spättrajanisch-frühhadrianischer Zeit: Himmelmann-Wildschütz 1959, 25; F. Matz, Gnomon 31, 1959, 697 (Rez. zu Kallipolitis 1958); Wiegartz 1965b, 614.

923 Wiegartz 1965a, 43 mit Anm. 54; 44.

924 s. Koch - Sichtermann 1982, 522 mit dem Hinweis, dass allerdings »aus so früher Zeit attische Beispiele in Ephesos bisher nicht nachweisbar sind«. 
zung und Verbreitungsgrad attischer Sarkophage sowie die erheblichen Kosten für Herstellung und Transport machen eine Kopiertätigkeit lokaler Werkstätten nachvollziehbar ${ }^{925}$.

In Ephesos ist bislang aber keine bedeutende Produktion heimischer Friessarkophage nachzuweisen. Die hier angeführten Exemplare können als Einzelstücke angesprochen werden, die zeitlich begrenzt bleiben ${ }^{926}$. Da datierende Kriterien wie tektonische Elemente oder Ornamentik bei den ephesischen Fragmenten fehlen und auch stilistische und typologische Kriterien im Vergleich zu Exemplaren der Zentren zu verschieden sind, ist eine fundierte Datierung derzeit nicht möglich. Jedoch ist in Anlehnung an den >Unterweltsarkophag durch den frei bleibenden Reliefgrund und durch die teilweise festzustellenden motivischen Parallelen auch für die lokalen Fragmente eine zeitliche Eingrenzung um die Mitte bis zum letzten Viertel des 2. Jahrhunderts n. Chr. vorzuschlagen.

Mit Einführung der Klinendeckel und der zunehmenden Füllung mit Figuren bei attischen und stadtrömischen Sarkophagen waren vielleicht die Grenzen der technischen Möglichkeiten der lokalen Werkstatt erreicht, oder die Produktion von Friessarkophagen wurde eingestellt, da sie zu arbeitsaufwendig und im Vergleich zu den Importen nicht konkurrenzfähig waren ${ }^{927}$. >Originale wie die attischen Friessarkophage oder auch kleinasiatische Säulensarkophage hatten demnach einen besonderen Stellenwert und waren durch Kopien nicht adäquat zu ersetzen.

\subsection{Die Fundorte der attischen Sarkophage und lokalen Fragmente}

$$
\text { (Carola Kintrup - Maria Aurenhammer) })^{928}
$$

Eine Übersicht über die Fundorte der attischen Sarkophage und die lokalen Fragmente bietet folgendes Bild ${ }^{929}$ :

Westnekropole: Kat. 6. 14. 15

>Stiegengasse 2 (= östlich von Hanghaus 1, verbaut in Westwand der Gasse): Kat. 44

Vediusgymnasium, südlich des Propylons: Kat. 38

Magnesisches Tor: Kat. 9

Damianosstoa: Kat. 36 (beim Magnesischen Tor). 43 (genauer Fundort unbekannt)

Grabhaus der Tatiane, südöstlich des Magnesischen Tors: Kat. 1. 2

Südlich des Çukuriçi Höyük, Richtung Magnesia: Kat. 40

Ephesos: Kat. 13. 21. 22. 25 (?). 41. L4

Umgebung von Ephesos: Kat. 8

>Tor der Verfolgung ‘: Kat. $\mathbf{3}$ und $\mathbf{1 0}$ (verbaut). $\mathbf{4}$ (unterhalb des Tors gefunden)

Bereich İsa Bey-Moschee/Johannesbasilika: Kat. L2

Johannesbasilika: Kat. 5. 7. 11 (verbaut). 12 (Torbereich). 16. 17. 18 (Baptisterium). 19. 20.

23. 26 (verbaut). 27. 31. 32. 34. 35. 37. 45.48 (in den 1980er Jahren verbaut). L5. L9

Ayasoluk: Kat. 46 (genauer Fundort unbekannt)

925 Zur Kopiertätigkeit in den Provinzen des Römischen Reiches s. Koch - Sichtermann 1982, 470-475. Für attische Sarkophage z. B. gilt, dass lokale Werkstätten auf das Kopieren attischer Stücke spezialisiert waren - so z. B. für Sparta und Aquileia nachgewiesen: Kintrup 2016a, Kap. 1 mit Anm. 21 f. mit Verweisen. s. z. B. auch Papagianni 2007, 187-192, bes. 191 mit Anm. 33. Der derzeitigen Fundlage entsprechend nahmen die Kopien im 3. Jh. n. Chr. wieder ab, ein Phänomen, das im Zusammenhang mit den steigenden Exportzahlen attischer Sarkophage zu sehen sein mag: Koch - Sichtermann 1982, 475; Koch 1993, 112.

926 s. auch Koch 1999, 555. 563.

927 Die lokalen Girlandensarkophage und Halbfabrikate blieben jedoch - wahrscheinlich auch durch die Abdeckung eines deutlich kleineren Preissegments - konkurrenzfähig.

928 Alle Informationen und Erkenntnisse werden M. Aurenhammer verdankt.

929 Im Fundortplan Taf. 81 wird zwischen gesicherten Fundorten und Fundortbereichen unterschieden. 
Selçuk, sog. İsa Bey-Hamam: Kat. 30

Selçuk, Saadet Hatun-Hamam: Kat. L1

Selçuk, Ankauf des Museums: Kat. 24

Fundort unbekannt: Kat. 28. 29. 33. 39. 42. 47. L3. L6. L7. L8

Die Verteilung der Fundorte ist signifikant. Aus der Westnekropole stammen zwei Sarkophage aus den frühen Grabungen (der Amazonomachie-Sarkophag Kat. 6 und die Fragmente des Hippolytos-Sarkophags Kat. 15) sowie ein Sarkophagfragment sekundärer Verwendung aus den jüngeren Grabungen (Kat. 14). Aus dem Bereich des Magnesischen Tors bzw. der Ostnekropole stammen die folgenden Fragmente: Bei den Grabungen der 1970er Jahre im Bereich des Tors wurde das Sarkophagfragment Kat. 9 mit der Darstellung einer Mänade entdeckt. In der Spätantike wurde die Südseite von Vor- und Torhof für die Aufstellung von Sarkophagen verwendet ${ }^{930}$. Kat. 36, der Altfund eines Kastenbodenfragments, stammt aus der Nähe des Magnesischen Tors an der Damianosstoa; für das Fragment eines Klinendeckels Kat. 43 ist nur der allgemeine Bereich »Damianosstoa« angegeben. Das Grabhaus der Tatiane mit dem Aristides-Sarkophag Kat. 1 und dem Amazonomachie-Sarkophag Kat. 2 befand sich vor der Stadtmauer südöstlich des Magnesischen Tors. Aus dem Areal südlich des prähistorischen Çukuriçi Höyük (in Richtung Magnesia) wurde der Fund des Fragments eines Klinen-Riefel-Sarkophags Kat. 40 gemeldet.

Im Stadtgebiet von Ephesos wurden nur zwei Fragmente gefunden: das Eckfragment eines Klinendeckels, Kat. 44, verbaut in die Westwand der >Stiegengasse`2, und das kleine Fragment der Oberseite eines Sarkophags, Kat. 38, aus den jüngeren Grabungen im Vediusgymnasium (Fundort südlich des Propylons).

Für etwa ein halbes Dutzend Fragmente ist nur der Fundort »Ephesos« oder »Umgebung von Ephesos « überliefert.

Demgegenüber fällt die Konzentration der Funde im Bereich des Burghügels Ayasoluk und besonders der Johannesbasilika auf ${ }^{931}$ - es handelt sich um verbaute Sarkophage und Sarkophagfragmente oder Denkmäler, die im Zuge der Grabungs- und Restaurierungsarbeiten in diesem Areal angetroffen wurden. Diese Objekte wurden, wie auch Grabreliefs, Architekturfragmente und Inschriften aus dem Areal der antiken Stadt und ihren Nekropolen sowie aus dem Artemision, als Baumaterial auf dem Burghügel wiederverwendet ${ }^{932}$. Hier sind besonders die Sarkophagkästen hervorzuheben, die zusammen mit Akanthusrankenfriesen ostentativ über dem Torbogen des südlichen Eingangstors der Festungsmauer, dem sog. Tor der Verfolgung, als Spolien eingebaut worden waren und noch heute dort zu sehen sind: die Platten des nach Woburn Abbey transportierten Achill-Sarkophags Kat. 3 und der noch an Ort und Stelle befindliche fragmentierte Kasten des Eroten-Weinlese-Sarkophags Kat. 10. Die neuzeitliche Bezeichnung >Tor der Verfolgung geht auf die interpretatio christiana der Szenenfolge des Achill-Sarkophags in Woburn Abbey durch Reisende des 17. und 18. Jahrhunderts zurück ${ }^{933}$. Das Fragment des Achill-Sarkophags Kat. 4 wurde von F. V. J. Arundell unter dem >Tor der Verfolgung، entdeckt. Die Erweiterung der aus Spolien errichteten Festungsmauer am Ayasoluk mit dem umgebauten >Tor der Verfolgung s wird zumeist als Reaktion auf die Arabereinfälle gesehen und in das 7.-8. Jahrhundert $\mathrm{n}$. Chr. datiert ${ }^{934}$. Die Verwendung von Spolien mit figürlichen Darstellungen an spätantiken und byzantinischen Toranlagen ist ein verbreitetes Phänomen ${ }^{935}$, das L. Bevilacqua derzeit in einem

930 Seiterle 1982, 147 Abb. 2 Taf. 26, 1.

931 Zu diesem Hügel und seiner Bezeichnung vgl. in jüngerer Zeit Daim - Drauschke 2010, 516 (S. Ladstätter). 524 (A. Külzer). 567 f. (A. Pülz). Zu Ayasoluk und Johannesbasilika: Thiel 2005.

932 Zur Verwendung von Spolien in Bauten auf dem Burghügel vgl. u. a. Leggio 2003, 366 f. 375. 378.

933 Vgl. dazu Rudolf 1989, 11-14; Angelicoussis 1992, 79 f.; Wohlers-Scharf 1995, 42-44; Bevilacqua 2015 , 336 f. und hier unter Kat. 3 mit weiterer Lit.

934 Zur Datierung von Mauer und Tor vgl. u. a. Müller-Wiener 1961, 91-97. 108 f. (S. 95. 108 zu einem Kernbau schon im 6. Jh.); Foss 1979, 107. 113; Carile 1999, 136; Thiel 2005, 103; Jacobs 2009, 199 (mid-6 ${ }^{\text {th }}$ century [?]); Bevilacqua 2015, 335: Einbau der Sarkophagreliefs wohl anlässlich der Befestigung des 7.-8. Jhs.

935 Jacobs 2009, 202-204. 206-209; Niewöhner 2010, 247-249; Niewöhner 2011, 114-118. 
Forschungsprojekt für die byzantinische Epoche untersucht. In einem einleitenden Artikel zu dem Reliefschmuck des >Tors der Verfolgung` unterstreicht sie die Bedeutung der sicher mit Bedacht gewählten Sarkophagreliefs an diesem Haupteingang des Pilgerziels und weist darauf hin, dass jedenfalls das Motiv der Eroten-Weinlese auf dem noch im Tor verbauten Sarkophag in christlichem Sinn interpretiert werden konnte ${ }^{936}$.

Schließlich stammen zwei Sarkophagfragmente aus mittelalterlichen bzw. neuzeitlichen Bädern im Bereich der Siedlung Ayasoluk: Kat. 30 aus dem sog. İsa Bey-Hamam südlich der İsa Bey-Moschee, dessen Nutzungsbeginn derzeit mit der Regentschaft des İsa Bey ab etwa 1360 angenommen wird, und das lokal gefertigte Fragment Kat. L1 aus dem Bereich des im 16. Jahrhundert errichteten Saadet Hatun-Hamams (Kat. L1), welches heute in das Efes Müzesi inkorporiert ist ${ }^{937}$.

936 Bevilacqua 2015, 334-338.

937 Zur Datierung der Bäder Krickl - Pfeiffer-Taş 2002, 235 f.; A. Zülkadıroğlu in: Scherrer 2000, 220. 



\section{Zusammenfassung - Summary - Özet}

\subsection{Zusammenfassung}

In der Einleitung werden die Besonderheiten der attischen Sarkophage und ihre Abgrenzung gegenüber den zwei weiteren großen Gruppen der kaiserzeitlichen Sarkophagplastik, nämlich den stadtrömischen und den kleinasiatischen Sarkophagen, dargestellt.

Der Bedeutung für die attischen Sarkophage Rechnung tragend, wurde bei der Bearbeitung mit den Sarkophagen aus dem Grabhaus der Claudia Antonia Tatiane Kat. 1 und $\mathbf{2}$ begonnen. Die übrigen Sarkophage und Fragmente wurden thematisch und typologisch geordnet und datiert. Die Zahl der vorher bekannten 32 attischen Exemplare aus Ephesos konnte auf 48 Katalognummern erhöht werden. Die Einschränkung, dass damit wohl nur ein Bruchteil der Gesamtzahl erhalten ist, hat aber weiterhin Gültigkeit.

Neun Fragmente von Sarkophagen konnten nach Material, Technik und Motivschatz einer lokalen Werkstatt zugeordnet werden. Walter Prochaska unterzog die Fragmente einer Marmoranalyse (Kap. 8). Diese Fragmente wurden in den Band aufgenommen im Hinblick auf die übergeordneten Fragestellungen zu Lokalisierung provinzieller Werkstätten und zu Kriterien, Kopien und Nachahmungen in den Provinzen, um diese Denkmäler von den Exemplaren aus den Produktionszentren zu unterscheiden.

Bei der Bearbeitung der attischen Sarkophage vor Ort und an etlichen weiteren Exemplaren aus Ephesos ließen sich grundlegende Entwicklungen in Bezug auf Tektonik, Ornamentik, Ikonografie und Stil aufzeigen. Zudem ließen sich Aussagen zu Auswahl und Anzahl der Themen treffen.

Die vermischt gelagerten Fragmente der Sarkophage des Grabhauses der Claudia Antonia Tatiane (Kat. 1 und 2) und des attischen Hippolytos-Sarkophags aus einem Grabhaus der Westnekropole nördlich des Hafenkanals (Kat. 15) wurden neu aufgenommen und weitest möglich sortiert. Unter diesen Katalognummern verbergen sich daher zahlreiche zugeordnete Fragmente.

Dem Amazonomachie-Sarkophag aus der Nekropole nördlich des Hafenkanals, Kat. 6, kommt eine besondere Bedeutung im Hinblick auf die Ikonografie zu. Der Sarkophag ist neben Fragmenten in den Harvard Art Museums, Arthur M. Sackler Museum, eines der beiden Leitstücke der sog. Amazonomachie-Gruppe II der attischen Amazonomachie-Sarkophage, die sich durch eine verbindliche Typenabfolge definiert.

Der Aristides-Sarkophag (Kat. 1) und der Amazonomachie-Sarkophag (Kat. 6) präsentieren eine Anordnung der Friesfiguren in mehreren Reliefebenen und eine Figurendichte, die typisch für die Sarkophage um die Jahrhundertwende (um 200 n. Chr.) ist. Bei Kat. 6 und Kat. 1 zeigt sich auf den beiden Hauptansichtsseiten ein für das letzte Viertel des 2. Jahrhunderts bis zum Anfang des 3. Jahrhunderts n. Chr. ebenso typischer Aufbau des tektonischen Gerüsts - Sockelzone und oberer Kastenabschluss sind gut gegliedert. Die Eckfiguren sind durch ihre Größe und Teilnahmslosigkeit formal von dem Kampffries getrennt. Aber mit den Niken/Amazonen und dem Krieger sind Eckfiguren ausgesucht, die inhaltlich doch Bezüge zu den abgebildeten Kämpfen herstellen. Somit sind sie in der Entwicklung einen Schritt weiter als ihre Vorläufer, die figürlich gestalteten Klinenbeine.

Der Achill-Sarkophag in Woburn Abbey, Kat. 3, präsentiert dann eine deutlich fortgeschrittene Entwicklungsstufe, die im zweiten Viertel des 3. Jahrhunderts n. Chr. anzusetzen ist. Die optisch gut gegliederten und ornamentierten Profile des oberen Kastenabschlusses und der Sockelzone weichen vegetabilen Schmuckbändern in flachem Relief. Die Aufmerksamkeit wurde stärker auf die Figurenfriese gelenkt. Dies wird auch von den Eckfiguren unterstützt, deren Größe sich nicht 
mehr von den Friesfiguren unterscheidet - es hat eine formale Anpassung stattgefunden. Eine ehemals tektonische Funktion geht auch dadurch verloren, dass die Figuren an den Ecken in das Geschehen des Frieses eingebunden werden.

Kat. 3 bietet zudem auch im Hinblick auf die Ikonografie Typisches für seine Zeit, denn es werden verstärkt ruhige frontale Figurentypen abgebildet. Es hat eine Deaktivierung der Hauptfiguren zugunsten handelnder Nebenfigurentypen eingesetzt. An einigen Figuren- und Gruppentypen lässt sich eine versatzstückartige Verwendung von Typen nachweisen. Ein solcher Typentransfer als gängige Praxis belegt den Verlust an mythologischer Substanz und erzählerischer Prägnanz.

Der Hippolytos-Sarkophag Kat. 15 präsentiert sich nach Ausführung und Stil als exzellente Arbeit später attischer Sarkophagbildhauer. Insbesondere die erhaltenen Köpfe, fein geglättet oder poliert, und die Fragmente mit Gewandfalten unterstreichen dies.

Die attischen Sarkophage aus Ephesos sind bezüglich der dargestellten Themen als repräsentativ zu bezeichnen. Das Themenspektrum setzt sich zusammen aus: Achill, Amazonomachie, Dionysisches oder Eroten-Weinlese, Hippolytos, Schlacht sowie Schlacht bei Schiffen. Lediglich eine eindeutige Zuweisung einer Meleager-Szene fehlt. Hervorzuheben ist die überdurchschnittlich hohe Anzahl an erhaltenen Fragmenten mit dionysischen Darstellungen und Erotenmotiven.

Die Produktion attischer Sarkophage mit figürlichen Friesen setzt um 140 n. Chr. ein; ihr Ende wird nach der Mitte des 3. Jahrhunderts veranschlagt. Die attischen Sarkophage aus Ephesos sind in Bezug auf die erhaltene chronologische Verteilung als charakteristisch zu bezeichnen. Aus den Untersuchungen der attischen Sarkophage aus Ephesos ergaben sich vielfältige Kriterien für die Erstellung einer relativen Chronologie. Die im Einzelnen erzielten Resultate gewinnen an Bedeutung, weil sie mit chronologisch `fixierten Eckdaten - siehe den Aristides-Sarkophag mit Porträtkopf und zugehöriger Inschrift am Sarkophagsockel - korreliert werden können. Die Ergebnisse können so mit anderen attischen Sarkophagen verglichen und übertragbar auf andere Gattungen der kaiserzeitlichen attischen Plastik eingesetzt werden.

Signifikant ist die Verteilung der (bekannten) Fundorte der attischen und der lokal produzierten Sarkophage (s. den Fundortplan). Fast ein Dutzend Exemplare stammt aus Nekropolen, nur zwei Fragmente wurden im Stadtbereich gefunden. Der Großteil der Sarkophage und der Fragmente wurde jedoch in byzantinischer Zeit im Bereich der Johannesbasilika und in der Fortifikation des Ayasoluk-Hügels verbaut.

\subsection{Summary}

In the Introduction, the characteristic features of Attic sarcophagi and their differences compared to the two other large groups of sculpted sarcophagi of the imperial period, namely the Asia Minor sarcophagi and those from the city of Rome, are outlined.

Taking account of their significance for the Attic sarcophagi, the analysis begins with the sarcophagi from the tomb building of Claudia Antonia Tatiane, Cat. 1 and 2. The remaining sarcophagi and fragments are thematically and typologically classified and dated. The number of 32 Attic examples from Ephesos known previously could be increased to 48. The reservation is still valid, however, that this figure probably represents only a fraction of the original number.

Nine fragments of sarcophagi could be assigned to a local workshop according to material, technique and inventory of motifs. Walter Prochaska subjected the fragments to a marble analysis (Chap. 8). These fragments have been included in the volume with regard to the overriding issues of the localisation of provincial workshops, and on the criteria of copies and imitations in the provinces, in order to differentiate these monuments from the examples from the centres of production. 
For the workmanship of the Attic sarcophagi on site, and for a number of further examples from Ephesos, fundamental developments with regard to tectonics, ornamentation, iconography and style could be identified. In addition, statements regarding the selection and number of themes could also be made.

The fragments of the sarcophagi, stored in intermingled manner, from the tomb building of Clauda Antonia Tatiane (Cat. 1 and 2) and of the Attic Hippolytus sarcophagus from a tomb in the west necropolis to the north of the harbour channel (Cat. 15) were newly recorded, and as far as possible re-sorted. Therefore numerous associated fragments are included under these catalogue numbers.

The Amazonomachy sarcophagus, Cat. 6, from the necropolis to the north of the harbour channel, could be assigned particular importance on account of its iconography. In addition to fragments in the Harvard Art Museums' Arthur M. Sackler Museum, the sarcophagus is one of the two leading pieces of the so-called Amazonomachy Group II of the Attic Amazonomachy sarcophagi, which are defined by a binding sequence of types.

The Aristides sarcophagus Cat. 1 and the Amazonomachy sarcophagus Cat. 6 present an arrangement of the frieze figures in a number of relief levels and a density of figures which is typical for the sarcophagi of the turn of the century (ca. 200 A.D.). On Cat. 6 and Cat. 1 on both of the main visible sides the construction of the tectonic framework is also typical for the last quarter of the $2^{\text {nd }}$ century up until the beginning of the $3^{\text {rd }}$ century - the socle zone and upper termination of the chest are well articulated. The corner figures are formally separated from the battle frieze due to their scale and lack of participation. Yet with the Nikai/Amazons and the warriors, corner figures have been selected that establish a connection to the battle scenes depicted. In this regard they represent a developmental step forward compared to their predecessors, the figurally designed kline legs.

The Achilles sarcophagus in Woburn Abbey, Cat. 3, then illustrates a clearly advanced stage in the development that can be placed in the second quarter of the $3^{\text {rd }}$ century A.D. The optically well articulated and ornamented profiles of the upper termination of the chest and of the socle zone give way to vegetal decorative bands in flat relief. The viewer's attention is more strongly directed to the figural frieze. This is also supported by the corner figures, whose size is no longer distinguished from that of the frieze figures: a formal adaptation has taken place. A previously tectonic function is also thereby lost, so that the figures at the corners are integrated into the events of the frieze.

In addition, Cat. 3 also offers characteristics typical for its time with regard to the iconography: increasingly, calm frontally-posed figural types are depicted. A deactivation of the main figures in favour of active secondary characters has been introduced. For certain figures and types of groups, an employment of types as set pieces can be demonstrated. Such a transfer of types as common practice attests to the loss of mythological substance and narrative incisiveness.

The Hippolytos sarcophagus Cat. 15 can be viewed, due to its execution and style, as an excellent work by sculptors of later Attic sarcophagi. This is underscored in particular by the preserved heads, which are finely smoothed or polished, and the fragments with drapery folds.

The Attic sarcophagi from Ephesos can be described as representative with regard to the themes depicted. The spectrum of themes is composed of the following: Achilles, Amazonomachy, Dionysiac or Erotes vintaging, Hippolytos, battles, and marine battles. Only an unambiguous attribution to a Meleager scene is missing. The greater than average number of preserved fragments with Dionysiac imagery should be emphasised.

The production of Attic sarcophagi with figural friezes began in around 140 A.D.; its end is estimated after the middle of the $3^{\text {rd }}$ century A.D. The Attic sarcophagi from Ephesos can be assessed as characteristic with regard to their preserved chronological distribution. Diverse criteria for the creation of a relative chronology have resulted from the investigation of the Attic sarcophagi from Ephesos. The individual results achieved increase in significance because they can be correlated with chronologically ১fixed benchmark dates - for example the Aristides sar- 
cophagus with its portrait head and accompanying inscription on the sarcophagus socle. It is therefore possible to compare the results with other Attic sarcophagi, and, in a transferable sense, these results can be applied to other genres of Attic sculpture of the imperial period.

The distribution of the (known) find sites of the Attic and of the locally produced sarcophagi is significant (cf. map of find sites). Almost a dozen examples originate from necropoleis, while only two fragments were found in the urban area. The majority of the sarcophagi and fragments were, however, reused as building material in the Byzantine period in the region of the Basilica of St. John and in the fortifications of the Ayasoluk hill.

Translation: Sarah Cormack

\section{3 Özet}

Giriş bölümünde Attika Lahitlerinin özellikleri ve bunların Roma İmparatorluk Dönemi lahit plastiğinin diğer iki büyük grubunu oluşturan Roma kent lahitleri ile Küçük Asya lahitlerinden olan ayrımları ortaya konulacaktır.

Değerlendirme, Attik Lahitlerin önemine itafen Claudia Antonia Tatiane'nin mezar evinden gelen lahitlerle (Kat. 1 ve Kat. 2) başlamaktadır. Diğer lahitler ve parçalar konularına ve tipolojilerine göre düzenlenmiş ve tarihlendirilmişlerdir. Efes'te daha önceden bilinen 32 Attika örnek 48 katalog sayısına yükseltilebilmiştir. Bununla birlikte toplam sayının sadece çok küçük bir parçasının korunmuş olduğu kısıtlaması hala geçerliliğini korumaktadır.

Dokuz lahit parçasının malzemelerine, teknik özelliklerine ve motif zenginliklerine bakılarak yerel bir atölyeye ait oldukları tespit edilebilmiştir. Walter Prochaska parçalar üzerinde bir mermer analizi yapmıştır (Bölüm 8). Bu parçalar, eyalet atölyelerinin lokalizasyonu ve eyaletlerdeki kriterler, kopyalar ve taklitler ile ilgili geniş kapsamlı konular bakımından ve bu anıtları üretim merkezlerinden gelen örneklerden ayırabilmek amacıyla yayına dahil edilmişlerdir.

Attika Lahitleri üzerinde yerinde yapılan ve Efes'ten gelen çok sayıdaki diğer örnekler üzerinde gerçekleştirilen çalışmalarda tektonik, süsleme, ikonografik ve stil bakımından temel oluşturabilecek gelişimler ortaya konulabilmiştir. Ayrıca konuların seçimi ve sayısı ile ilgili bilgi sahibi olunabilmiştir.

Claudia Antonia'nın Mezarevi lahitlerinin (Kat. 1 ve 2) ve Liman Kanalının kuzeyinde yer alan Batı Nekropolü'ndeki bir mezarevinde bulunan Attika Hippolytos Lahdi'nin (Kat. 15) karışık olarak depolanan parçaları tekrar düzenlenmiş ve mümkün olduğunca sınıflandırılmışlardır. Bu nedenle bu katalog numaraları altında çok sayıda bağlantı kurularak eklenmiş parça yer almaktadir.

Liman Kanalının kuzeyindeki nekropolden gelen Amazonomakhia Lahdi'nin (Kat. 6) ikonografik bakımdan özel bir önemi vardır. Lahit, Harvard Art Müzesi ve Arthur M. Sackler Müzesi'ndeki parçaların yanında Attika Amazonomakhia Lahidleri'nin birbiriyle bağlantılı figür sıralaması ile kendini gösteren ve II. Amazonomakhia Grubu olarak adlandırılan grubunun iki öncü örneğinden biridir.

Aristides Lahdi Kat. 1 ve Amazonomakhia Lahdi Kat. 6 friz figürlerinin bir çok farklı kabartma alanlarında düzenlemesini ve yüzyılın değiştiği dönem (MS. 200 civarı) için tipik olan bir figür yoğunluğunu sunar. Kat. 6 ve Kat. 1 'in iki ana yüzünde MS. 2. Yüzy1lın son çeyreğinden 3. Yüzyılın başına kadar olan dönemde aynı şekilde tipik olan tektonik yapı düzenlemesi görülür. Taban bölümü ve sandukanın üst bitimi iyi bir şekilde düzenlenmiştir.

Köşe figürleri büyüklüklerinden ve konuyla ilgisiz olmalarından dolayı biçimsel olarak savaş frizinden ayrılırlar. Ancak Nike/Amazon ve savaş̧̧ı figürleri ile tasvir edilen savaşla konu bakımından bağlantılı köşe figürleri seçilmiştir. Bununla birlikte figürlü kline bacaklarından oluşan öncü örneklerinden gelişim bakımından bir adım daha ileridedir. 
Woburn Abbey’deki Achilleus-Lahdi (Kat. 3) belirgin olarak MS. 3. Yüzyılın ikinci çeyreğinde başlayan ileri bir gelişim evresini gösterir. Üst sandık bitimi ve taban kısmının görsel açıdan iyi düzenlenmiş ve süslenmiş profilleri, alçak kabartma şeklindeki bitkisel süsleme bandlarına yerlerini bırakır. İlgi daha kuvvetli bir biçimde figürlü frize yöneltilmiştir. Bu durum, artık boyutları bakımından friz figürlerinden farklı olmayan köşe figürleri ile de desteklenir: Biçimsel bir uydurma yapılmıştır. Köşelerdeki figürlerin frizdeki olayla bağlantılı hale getirilmesiyle eskiden var olan tektonik işlevin kaybolmasına katkı sağlanmış olur. Ayrıca Kat. 3, daha çok sakin duran ve önden görünen figürlerin tasvir edilmesiyle dönem için ikonografik bakımdan tipik bir özelliğini sunar. Ana figürlerin etkinliği hareket eden yan figürlerin yararına azaltılmaya başlamıştır. Bazı figürler ve grup tiplerinde, tiplerin yerleri değiştirilebilir parçalar şeklindeki kullanımı kanıtlanabilmiştir. Alışılagelmiş bir uygulama olan bu tür tip transferleri mitolojik yapının ve anlatımsal doğruluğun kaybını belgeler.

Hippolytos Lahdi Kat. 15, stili ve yapılışı bakımından geç dönem Attika lahit heykeltraşlarının mükemmel bir çalışmasını sunar. Özellikle çok iyi bir şekilde düzleştirilmiş veya perdahlanmış korunmuş halde ele geçen başlar ve kıyafet kıvrımlarının görüldüğü parçalar bu durumu vurgular niteliktedir.

Efes'ten gelen Attika Lahidleri tasvir edilen konular itibariyle karakteristik olarak nitelendirelebilir. Konu çeşitliliği Achilleus, Amazonomakhia, Dionysos ya da Erosların Bağbozumu, Hippolytos, savaş ve gemi savaşlarından oluşur. Sadece belirli bir şekilde Meleagros'a tahsis edilmiş bir sahne eksiktir. Ele geçen Dionysos ile ilgili tasvirlere ve Eros motiflerine sahip parçaların ortalamanın üstünde yüksek bir sayıya sahip olması dikkat çekicidir.

Figürlü frize sahip Attika Lahitlerinin üretimi MS. 140 civarlarından başlamıştır ve MS. 3. Yüzyılın ortalarından sonra ise sona erdiği tahmin edilmektedir. Efes’ten gelen Attika lahitleri elde edilen kronolojik dağılımlarına bakıldığında karateristik olarak nitelendirilebilir. Efes'ten gelen Attika Lahitlerinin incelemelerinden göreli bir kronoloji oluşturmaya yarayacak çeşitli kriterler ortaya çıkmıştır. Ayrı ayrı elde edilen sonuçlar, kronolojik açıdan kesin olarak saptanmış dayanak verilerle (bkz. Portre başlı Aristides Lahdi ve buna ait lahdin tabanındaki yazıt) bağlantıları kurulabildiğinden önem kazanmaktadır. Böylece sonuçlar diğer Attika Lahitleri ile karşılaştırlabilirler ve Roma İmparatorluk Dönemi Attika Plastiğinin diğer türlerine aktarılarak kullanılabilirler.

Attika üretimi ve lokal üretim lahitlerin (bilinen) buluntu yerlerinin dağılımı (bkz. Buluntu yeri planı) dikkate değer niteliktedir. Neredeyse bir düzine örnek nekropollerden gelmektedir ve sadece iki parça şehir alanında bulunmuştur. Ancak lahitlerin ve parçaların büyük bir kısmı Bizans Dönemi'nde Aziz Johannes Bazilika'sının bulunduğu alanda ve Ayasoluk Tepesi'deki kalenin inşaasında kullanılmışlardır. 



\section{Abkürzungen und abgekürzt zitierte Literatur}

Die in diesem Band verwendeten Abkürzungen und Zitierweisen folgen den Richtlinien des ÖAI <https://www.oeaw. ac.at/oeai/publikationen/fuer-autorinnen-und-autoren/hinweise/> (2. 10. 2017).

Zusätzlich kommen folgende Abkürzungen und Kurzzitate zur Anwendung:

$\begin{array}{ll}\text { DW } & \text { Wanddicke } \\ \text { Etd. } & \text { Etüdlük (Studienobjekt) } \\ \text { Rh } & \text { Reliefhöhe } \\ \text { RS } & \text { Rückseite } \\ \text { SE } & \text { Stratigrafische Einheit } \\ \text { Skizzenbuch } & \text { Skizzenbuch der ephesischen Inschriften (Archiv, ÖAI) } \\ \text { Ss } & \text { Schmalseite(n) } \\ \text { VS } & \text { Vorderseite }\end{array}$

Alle Maße sind in cm angegeben.

\begin{tabular}{|c|c|}
\hline \multicolumn{2}{|r|}{ Abgekürzt zitierte Literatur } \\
\hline Altmann 1902 & W. Altmann, Architektur und Ornamentik der antiken Sarkophage (Berlin 1902). \\
\hline Alzinger 1955 & W. Alzinger, Zwei spätantike Porträts aus Ephesos, ÖJh 42, 1955, 27-42. \\
\hline Alzinger 1962 & W. Alzinger, Die Stadt des siebenten Weltwunders (Wien 1962). \\
\hline Amedick 1991 & $\begin{array}{l}\text { R. Amedick, Die Sarkophage mit Darstellungen aus dem Menschenleben. Vita privata, } \\
\text { ASR I } 4 \text { (Berlin 1994). }\end{array}$ \\
\hline Amedick 2002 & $\begin{array}{l}\text { R. Amedick, Die Schöne, das Seeungeheuer und der Held. Antike Bildbeschreibungen } \\
\text { und die Ikonographie mythologischer Bilder, AW 33, 5, 2002, 527-538. }\end{array}$ \\
\hline Andreae 1956a & $\begin{array}{l}\text { B. Andreae, Motivgeschichtliche Untersuchungen zu römischen Schlachtsarkophagen } \\
\text { (Berlin 1956). }\end{array}$ \\
\hline Andreae 1956b & B. Andreae, Ein Amazonengemälde, RM 63, 1956, 32-45. \\
\hline Andreassi 1995 & $\begin{array}{l}\text { C. Andreassi (Hrsg.), Catalogo del Museo Nazionale Archeologico di Taranto 4, 1. Ta- } \\
\text { ranto. La scultura in marmot e pietra (Tarent 1995). }\end{array}$ \\
\hline Angelicoussis 1992 & $\begin{array}{l}\text { E. Angelicoussis, The Woburn Abbey Collection of Classical Antiquities, MAR } 20 \\
\text { (Mainz 1992). }\end{array}$ \\
\hline Aurenhammer 1983 & M. Aurenhammer, Römische Porträts aus Ephesos, ÖJh 54, 1983, Beibl. 105-146. \\
\hline Avi-Yonah 1967 & M. Avi-Yonah, The Leda Coffin from Beth-She'arim, Eretz-Israel 8, 1967, 143-148. \\
\hline Avi-Yonah 1972 & M. Avi-Yonah, The Leda Sarcophagus from Beth She'arim, ScrHieros 24, 1972, 9-21. \\
\hline Avi-Yonah 1976 & $\begin{array}{l}\text { M. Avi-Yonah, Recently Discovered Sarcophagi from Ashkelon, Atiqot, English Series } \\
\text { 11, 1976, 72-76. }\end{array}$ \\
\hline Bammer u. a. 1974 & $\begin{array}{l}\text { A. Bammer - R. Fleischer - D. Knibbe, Führer durch das Archäologische Museum in } \\
\text { Selçuk (Wien 1974). }\end{array}$ \\
\hline Bammer 2008 & A. Bammer, Ein hellenistischer Grabthron in Kleinasien, AnatA 16, 2008, 87-93. \\
\hline Baratte 1985 & $\begin{array}{l}\text { F. Baratte in: F. Baratte - C. Metzger, Musée du Louvre. Sarcophages en pierre d'épo- } \\
\text { ques romaine et paléochrétienne (Paris 1985). }\end{array}$ \\
\hline Baratte 1989 & F. Baratte, Trésors d’ofevrerie gallo-romains (Ausstellungskatalog Paris 1989). \\
\hline Benndorf 1906 & O. Benndorf, Forschungen in Ephesos, FiE 1 (Wien 1906). \\
\hline Bergmann 1977 & M. Bergmann, Studien zum römischen Porträt des 3. Jahrhunderts n. Chr. (Bonn 1977). \\
\hline Bevilacqua 2015 & $\begin{array}{l}\text { L. Bevilacqua, Recycling Myths in Byzantine Art. Spolia on the Gate of Persecution in } \\
\text { Ephesus, in: A. Nascimento Pena - M. C. Relvas - R. C. Fonseca - T. Casal (Hrsg.), } \\
\text { Revisitar o Mito. Myths Revisited (Lissabon 2015) 331-341. }\end{array}$ \\
\hline Bielefeld 1951 & $\begin{array}{l}\text { E. Bielefeld, Amazonomachia. Beiträge zur Motivwanderung in der antiken Kunst, } \\
\text { Hallische Monographien } 21 \text { (Halle 1951). }\end{array}$ \\
\hline Bielefeld 1993 & $\begin{array}{l}\text { D. Bielefeld, Zum Klinensarkophag von S. Lorenzo, in: G. Koch (Hrsg.), Grabeskunst } \\
\text { der römischen Kaiserzeit (Mainz 1993) 91-97. }\end{array}$ \\
\hline Bielefeld 1995 & $\begin{array}{l}\text { D. Bielefeld, Zur Ikonographie attischer Sarkophage mit Eroten-Weinlese-Darstellun- } \\
\text { gen, RM 102, 1995, 397-404. }\end{array}$ \\
\hline
\end{tabular}


Bielefeld 1997

Bielefeld 2000

Bonnano Aravantinos 1993

Bothmer 1957

Brandenburg 1967

Brenk 1972

Brommer 1974

Budde 1964

Calza 1940

Cambi 1984

Cambi 1988

Cambi 1993

Cambi 2002

Cambi 2007

Carile 1999

Castritius 1970

Chéhab 1968

Chéhab 1984

Chéhab 1985

Choiseul-Gouffier 1782

Christof 2010

Ciliberto 1996

Ciliberto 1998

Claveria 1998

Coupel - Demargne 1976

Daim - Drauschke 2010

Datsouli-Stavridi 1984

Daux 1963

Daux 1964

Degrassi 1952

Demargne 1966

Despinis u. a. 2003

Devambez - KauffmannSamaras 1981

Eichler 1944/45

Eichler 1946
D. Bielefeld, Die stadtrömischen Eroten-Sarkophage. Weinlese- und Ernteszenen, ASR V 2, 2 (Berlin 1997).

D. Bielefeld, »Schönblumiger als eine Wiese ...«. Pfauendarstellungen auf paganen Sarkophagen, in: T. Mattern (Hrsg.), Munus. Festschrift Hans Wiegartz (Münster 2000) 39-45.

M. Bonnano Aravantinos, Il mito di Ifigenia in Tauride sui sarcofagi attici di età romana, in: G. Koch (Hrsg.), Grabeskunst der römischen Kaiserzeit (Mainz 1993) 67-76.

D. v. Bothmer, Amazons in Greek Art (Oxford 1957).

H. Brandenburg, Meerwesensarkophage und Clipeusmotiv. Beiträge zur Interpretation römischer Sarkophagreliefs, JdI 82, 1967, 195-245.

B. Brenk, Spätantiker attischer Sarkophag in Saloniki, JbÖByz 21, 1972, 39-46.

F. Brommer, Denkmälerlisten zur griechischen Heldensage II (Marburg 1974).

L. Budde, Ein Achilleus-Sarkophag aus Tarsus in Adana, in: E. Homann-Wedeking -

B. Segall (Hrsg.), Festschrift Eugen v. Mercklin (Waldsassen 1964) 9-31.

G. Calza, La necropoli del Porto di Roma nell’Isola Sacra (Rom 1940).

N. Cambi, Die Rekonstruktion des attischen Jagdsarkophags Budapest-Salona, MarbWPr, 1984, 185-196.

N. Cambi, Atički Sarkofazi u Dalmaciji, Biblioteka Znanstvenih Djela 27, 1988.

N. Cambi, New Attic Sarcophagi from Dalmatia, in: G. Koch (Hrsg.), Grabeskunst der römischen Kaiserzeit (Mainz 1993) 77-90.

N. Cambi, Antika (Zagreb 2002).

N. Cambi, Neue attische Sarkophag-Fragmente aus Dalmatien, in: G. Koch (Hrsg.), Akten des Symposiums des Sarkophag-Corpus, Marburg 2.-7. Juli 2001, SarkophagStudien 3 (Mainz 2007) 165-171.

A. Carile, Efeso da polis a kastron, in: R. Pillinger - O. Kresten - F. Krinzinger E. Russo (Hrsg.), Efeso paleocristiana e bizantina. Frühchristliches und byzantinisches Ephesos, DenkschrWien 282 = AForsch 3 (Wien 1999) 133-145.

H. Castritius, Die Sockelinschrift eines attischen Sarkophags in Saloniki, AA 1970, 93-110.

M. Chéhab, Sarcophages à relief de Tyr, BMusBeyrouth 21 (Paris 1968).

M. Chéhab, Fouilles de Tyr. La nécropole II, BMusBeyrouth 34 (Paris 1984).

M. Chéhab, Fouilles de Tyr. La nécropole III, BMusBeyrouth 35 (Paris 1985).

M. G. Choiseul-Gouffier, Voyage pittoresque de la Grèce I (Paris 1782).

E. Christof, Skulpturen, in: F. Krinzinger (Hrsg.), Hanghaus 2 in Ephesos. Die Wohneinheiten 1 und 2. Baubefund, Ausstattung, Funde, FiE 8, 8 (Wien 2010) 656-676.

F. Ciliberto, I sarcofagi attici nell' Italia settentrionale, HASB Beih. 3 (Bern 1996).

F. Ciliberto, Attische Sarkophage in Oberitalien: Importe und Nachahmungen, in:

G. Koch (Hrsg.), 125 Jahre Sarkophag-Corpus, Akten des Symposiums, Marburg 4.-7. Oktober 1995, Sarkophag-Studien 1 (Mainz 1998) 240-248.

M. Claveria, Roman Sarcophagi in Tarragona, in: G. Koch (Hrsg.), 125 Jahre Sarkophag-Corpus, Akten des Symposiums, Marburg 4.-7. Oktober 1995, Sarkophag-Studien 1 (Mainz 1998) 138-149.

P. Coupel - P. Demargne (Hrsg.), Melanges d'histoire ancienne et d'archeologie offerts à Paul Collart (Lausanne 1976).

F. Daim - J. Drauschke (Hrsg.), Byzanz - Das Römerreich im Mittelalter. Teil 2, 2. Schauplätze. Ephesos, Monographien des RGZM 84, 2, 2 (Mainz 2010).

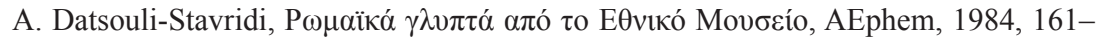
190.

G. Daux, Chronique des fouilles et découvertes archéologiques en Grèce en 1962, BCH 87, 1963, 689-878.

G. Daux, Chronique des fouilles et découvertes archéologiques en Grèce en 1963, BCH 88, 1964, 690-915.

A. Degrassi, I fasti consolari dell'Imperio Romano (Rom 1952).

P. Demargne, Un sarcophage attique à Xanthos, in: R. Chevallier (Hrsg.), Mélanges d'archéologie et d'histoire offerts à André Piganiol (Paris 1966) 451-461.

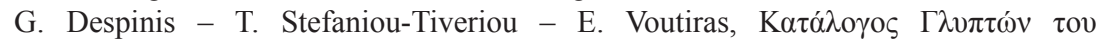

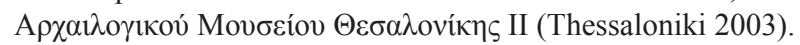

LIMC I (1981) 586-653 s. v. Amazones (P. Devambez - A. Kauffmann-Samaras).

F. Eichler, Zwei kleinasiatische Säulensarkophage, JdI 59/60, 1944/1945, 125-136.

F. Eichler, Fragmente attischer Sarkophage in Wien, ÖJh 36, 1946, 82-96. 
Fabbricotti 1975

Faust 1989

Ferrari 1966

Fischer 1998

Fittschen - Zanker 1994

Flagge 1975

Fleischer 1983

Foss 1979

Friesinger - Krinzinger 1999

Froning 1988

Gabelmann 1977

Gaggadis-Robin 1998

Gaggadis-Robin 2003

Gaggadis-Robin 2005 Ganzert 1984

García y Bellido 1948

García y Bellido 1949

Gasparri 1974/75

Gersht - Pearl 1992

Ghisellini 1985

Giuliano 1962

Giuliano - Palma 1978

Goette 1988

Goette 1991

Goette 1993

Goltz - Hartmann 2008

Goulaki-Voutira - Grote 1992

Grassinger 1999

Greenberg 2002

Groh 2006

Haas 1959

Hanfmann 1975

Harter-Uibopuu 2014
E. Fabbricotti, Un nuovo frammento di sarcofago attico a kline, ArchCl 27, 1975, 4145.

S. Faust, Fulcra. Figürlicher und ornamentaler Schmuck an antiken Betten, RM Ergh. 30 (Mainz 1989).

G. Ferrari, Il commercio dei sarcofagi asiatici (Rom 1966).

M. L. Fischer, Marble Studies. Roman Palestine and the Marble Trade, Xenia 40 (Konstanz 1998).

K. Fittschen - P. Zanker, Katalog der römischen Porträts in den Capitolinischen Museen und den anderen kommunalen Sammlungen der Stadt Rom 1. Kaiser- und Prinzenbildnisse ${ }^{2}$ (Mainz 1994).

I. Flagge, Untersuchungen zur Bedeutung der Greifen (Sankt Augustin 1975).

R. Fleischer, Der Klagefrauensarkophag aus Sidon, IstForsch 34 (Tübingen 1983).

C. Foss, Ephesus after Antiquity: A Late Antique, Byzantine and Turkish City (Cambridge 1979).

H. Friesinger - F. Krinzinger (Hrsg.), 100 Jahre Österreichische Forschungen in Ephesos, Akten des Symposiums Wien 1995, DenkschrWien 260 = AForsch 1 (Wien 1999).

H. Froning, Anfänge der kontinuierenden Bilderzählung in der griechischen Kunst, JdI 103, 1988, 169-199.

H. Gabelmann, Zur Tektonik oberitalischer Sarkophage, Altäre und Stelen, BJb 177, 1977, 199-244.

V. Gaggadis-Robin, Sarcophages d'Arles: Art attique et influences micrasiatiques, in: G. Koch (Hrsg.), 125 Jahre Sarkophag-Corpus. Akten des Symposiums, Marburg 4.-7. Oktober 1995, Sarkophag-Studien 1 (Mainz 1998) 262-277.

V. Gaggadis-Robin, La technique du »relief cerné«: un marqueur chronologique?, BAParis 30, 2003, 79-90.

V. Gaggadis-Robin, Les sarcophages païens du Musée de l'Arles antique (Arles 2005). J. Ganzert, Das Kenotaph für Gaius Caesar in Limyra. Architektur und Ornamentik, IstForsch 35 (Tübingen 1984).

A. García y Bellido, Sarcófagos romanos de tipo oriental hallados en la Península Ibérica, AEspA 21, 1948, 95-109.

A. García y Bellido, Esulturas romanas de España y Portugal (Madrid 1949).

C. Gasparri, Lo stadio Panatenaico, ASAtene 52-53, 1974/1975, 313-392.

R. Gersht - Z. Pearl, Decoration and Marble Sources of Sarcophagi from Caesarea, in: R. L. Vann (Hrsg.), Caesarea Papers 5. Straton's Tower, Herod's Harbour, and Roman and Byzantine Caesarea, JRA Suppl. 5 (Ann Arbor, MI 1992), 222-243.

E. Ghisellini, Sarcofagi romani di Gortina, ASAtene 47, 1985, 249-335.

A. Giuliano, Il commercio dei sarcofagi attici (Rom 1962).

A. Giuliano - B. Palma, La maniera ateniese di età romana. I maestri dei sarcofagi attici, Studi Miscellanei 24, 1975/1976 (Rom 1978).

H. R. Goette, Mulleus, Embas und Calceus - Ikonographische Studien zu römischem Schuhwerk, JdI 103, 1988, 401-464.

H. R. Goette, Attische Klinen-Riefel-Sarkophage, AM 106, 1991, 309-338.

H. R. Goette, Attische Klinen-Riefel-Sarophage, in: G. Koch (Hrsg.), Grabeskunst der römischen Kaiserzeit (Mainz 1993) 107-110.

A. Goltz - U. Hartmann, Valerianus und Gallienus, in: K.-P. Johne (Hrsg.), Die Zeit der Soldatenkaiser (Berlin 2008) 223-295.

LIMC VI (1992) 850-904 s. v. Nike (A. Goulaki-Voutira - U. Grote).

D. Grassinger, Die mythologischen Sarkophage. Achill bis Amazonen, ASR XII 1 (Berlin 1999).

M. Greenberg, The J. Paul Getty Museum. Handbook of the Antiquities Collection (Los Angeles 2002).

S. Groh, Neue Forschungen zur Stadtplanung in Ephesos, ÖJh 75, 2006, 47-116.

C. Haas, Zur Ornamentik der attischen Sarkophage der römischen Kaiserzeit (unpubl. Diss. Universität Wien 1959).

G. M. A. Hanfmann, From Croesus to Constantine (Michigan 1975).

K. Harter-Uibopuu, Tote soll man ruhen lassen ... Verbote und Strafen zur Sicherung von Gräbern am Beispiel von Inschriften aus Ephesos, in: J. Fischer (Hrsg.), Der Beitrag Kleinasiens zur Kultur- und Geistesgeschichte der griechisch-römischen Antike. Akten des internationalen Kolloquiums Wien 2010, DenkschrWien 469 (Wien 2014) 159-161. 
Harrison 1966

Himmelmann 1970a

Himmelmann 1970b

Himmelmann-Wildschütz 1959

Holtman 1997

Horejs 2012

Icard-Gianolio -

Szabados 1992

İnan - Rosenbaum 1966

İnan - Alföldi-Rosenbaum 1979

İplikçioğlu 1993

IvE

Jacobs 2009

Kallipolitis 1958

Keil 1914

Keil 1929

Keil 1930

Keil 1931

Keil 1932

Keil 1964

Kemp-Lindemann 1975

Kerner 1997

Kintrup 1998

Kintrup 2000

Kintrup 2007

Kintrup 2016a

Kintrup 2016b

Kintrup - Heinz 2012

Koch 1980

Koch 1982

Koch 1989a
E. B. Harrison, The composition of the amazonomachy on the shield of Athena Promachos, Hesperia 35, 1966, 107-133.

N. Himmelmann, Sarkophage in Antakya, AbhMainz (Mainz 1970).

N. Himmelmann, Der >Sarkophag، aus Megiste (Mainz 1970).

N. Himmelmann-Wildschütz, Fragment eines attischen Sarkophags, MarbWPr 1959, 25-40.

M. Holtman, The J. Paul Getty Museum. Handbook of the Collections (Los Angeles 1997).

B. Horejs, Cukurici Höyük. A Neolithic and Bronze Age Settlement in the Region of Ephesos, in: M. Özdogan (Hrsg.), The Neolithic in Turkey. New Excavations and New Research. Western Turkey (Istanbul 2012) 117-131.

LIMC VI (1992) 785-824 s. v. Nereides (N. Icard-Gianolio - A.-V. Szabados).

J. İnan - E. Rosenbaum, Roman and Early Byzantine Portrait Sculpture in Asia Minor (London 1966).

J. İnan - E. Alföldi-Rosenbaum, Römische und frühbyzantinische Porträtplastik aus der Türkei. Neue Funde (Mainz 1979).

B. İplikçioğlu, Der Ritterstand und seine Tätigkeit im kaiserlichen Reichsdienst in Asia (Ankara 1993).

Die Inschriften von Ephesos, IK 11-17,4 (Bonn 1979-1984).

I. Jacobs, Gates in Late Antiquity in the Eastern Mediterranean, BABesch 84, 2009, 197-213.

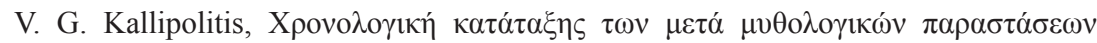

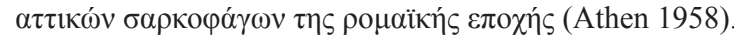

J. Keil, Grabbau mit Unterweltsarkophag aus Ephesos, ÖJh 17, 1914, 133-144.

J. Keil, XIV. Vorläufiger Bericht über die Ausgrabungen in Ephesos, ÖJh 25, 1929, Beibl. 5-51.

J. Keil, XV. Vorläufiger Bericht über die Ausgrabungen in Ephesos, ÖJh 26, 1930, Beibl. 5-66.

J. Keil, Die Ausgrabungen in Ephesos, FuF 7, 1931, 65 f.

J. Keil, XVI. Vorläufiger Bericht über die Ausgrabungen in Ephesos, ÖJh 27, 1932, Beibl. 5-72.

J. Keil, Ephesos. Ein Führer durch die Ruinenstätte und ihre Geschichte ${ }^{5}$ (Wien 1964). D. Kemp-Lindemann, Darstellungen des Achilleus in griechischer und römischer Kunst (Frankfurt am Main 1975).

S. Kerner, Umm Qays-Gadara: A Preliminary Report 1993-1995, AAJ 41, 1997, 283 302.

C. Kintrup, Chronologie der attischen Amazonomachie-Sarkophage, in: G. Koch (Hrsg.), 125 Jahre Sarkophag-Corpus. Akten des Symposiums, Marburg 4.-7. Oktober 1995, Sarkophag-Studien 1 (Mainz 1998) 206-215.

C. Kintrup, Zum Porträtkopf des attischen Schiffskampf-Sarkophags in Damaskus, in: T. Mattern (Hrsg.), Munus. Festschrift Hans Wiegartz (Münster 2000) 125-137.

C. Kintrup, Tod bei den Schiffen. Der Epinausimachie-Sarkophag aus Tyros, in: G. Koch (Hrsg.), Akten des Symposiums des Sarkophag-Corpus, Marburg 2.-7. Juli 2001, Sarkophag-Studien 3 (Mainz 2007) 173-186.

C. Kintrup, Die Sarkophage Griechenlands und der Donauprovinzen. Die attischen Sarkophage. Amazonomachie - Schlacht - Epinausimachie, ASR IX 1, 2 (Berlin 2016).

C. Kintrup, Weitere lokale Sarkophagfragmente aus Ephesos, in: G. Koch (Hrsg.), Akten des Symposiums Römische Sarkophage. Marburg 2.-8. Juli 2006, Marburger Beiträge zur Archäologie 3 (Marburg 2016) 165-169.

C. Kintrup - M. Heinz, Abgeschaut und nachgemacht? Wechselbeziehungen zwischen Athen und Kleinasien anhand von Sarkophag-Fragmenten aus Ephesos, in: G. Koch F. Baratte (Hrsg.), Akten des Symposiums »Sarkophage der römischen Kaiserzeit: Produktion in den Zentren - Kopien in den Provinzen«, Paris 2.-5. November 2005 (Ruhpolding 2012) 189-198

G. Koch, Stadtrömisch oder östlich? Probleme einiger kaiserzeitlicher Sarkophage in Rom, BJb 180, 1980, 56-104.

G. Koch, Östliche Sarkophage in Rom, BJb 182, 1982, 167-208.

G. Koch, Der Import kaiserzeitlicher Sarkophage in den römischen Provinzen Syria, Palaestina und Arabia, BJb 189, 1989, 161-211. 
Koch 1989b

Koch 1991

Koch 1993

Koch 1996

Koch 1999

Koch 2010

Koch 2012

Koch - Sichtermann 1982

Kossatz-Deissmann 1981

Kraeling 1962

Krickl - Pfeiffer-Taş 2002

Krierer 1995

Lang-Auinger 1996

Leggio 2003

Leon 1971

Leventopoulou - Sengelin 1997

Linant de Bellefonds 1985

Linant de Bellefonds 1992

L’Orange 1933

Maniatis u. a. 2010

Marin 1992

Martin - Gruskova 2014

Massó 1989

Mateev 1982

Matz 1873

Matz 1968

Matz 1969

Meischner 1982

Michaelis 1882

Morandini 2000

Morandini 2007

Müller-Wiener 1961

Musso 1989/90

Niewöhner 2010
G. Koch, Sarkophage der römischen Kaiserzeit im Nationalmuseum in Damaskus, DaM 4, 1989, 163-179.

G. Koch, BJb 191, 1991, 816-819 (Rezension zu Rudolf 1989).

G. Koch, Sarkophage der römischen Kaiserzeit (Darmstadt 1993).

G. Koch, Ein attischer Schiffskampf-Sarkophag aus Arethousa in Damaskus, DaM 9, 1996, 197-207.

G. Koch, Kaiserzeitliche Sarkophage in Ephesos, in: H. Friesinger - F. Krinzinger (Hrsg.), 100 Jahre Österreichische Forschungen in Ephesos. Akten des Symposions Wien 1995, DenkschrWien 260 = AForsch 1 (Wien 1999) 555-563.

G. Koch, Sarkophage der römischen Kaiserzeit in der Türkei. Ein Überblick (mit einer Bibliographie), Adalya 13, 2010, 111-182.

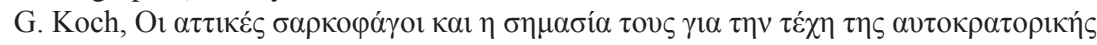

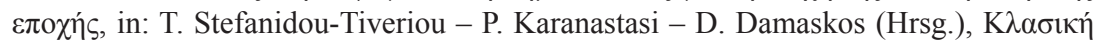

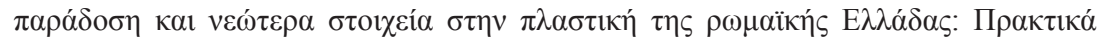

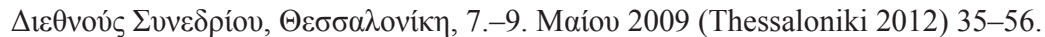

G. Koch - H. Sichtermann, Römische Sarkophage, HdArch (München 1982). LIMC I (1981) 37-200 s. v. Achilleus (A. Kossatz-Deissmann).

C. Kraeling, Ptolemais. City of the Libyan Pentapolis (Chicago 1962).

A. Krickl - S. Pfeiffer-Taş, Zur Nutzungs- und Zerstörungsgeschichte des sog. İsa Bey Hamamı, ÖJh 71, 2002, 221-236.

K. R. Krierer, Sieg und Niederlage. Untersuchungen physiognomischer und mimischer Phänomene in Kampfdarstellungen der römischen Plastik, WForsch 1 (Wien 1995).

C. Lang-Auinger, Hanghaus 1 in Ephesos. Der Baubefund, FiE 8, 3 (Wien 1996).

I. Leggio, Valenza del reimpiego: il caso di Efeso, in: L. Lavan - W. Bowden (Hrsg.), Theory and Practice in Late Antique Archaeology, Late Antique Archaeology 1 (Leiden 2003) 359-381.

C. F. Leon, Die Bauornamentik des Trajansforums und ihre Stellung in der früh- und mittelkaiserzeitlichen Architekturdekoration Roms (Wien 1971).

LIMC VIII Suppl. (1997) 671-721 s. v. Kentauroi et Kentaurides (M. Leventopoulou T. Sengelin).

P. Linant de Bellefonds, Sarcophages attiques de la nécropole de Tyr (Paris 1985).

LIMC VI (1992) 231-246 s. v. Leda (P. Linant de Bellefonds).

H. P. L’Orange, Studien zur Geschichte des spätantiken Porträts (Oslo 1933).

Y. Maniatis - D. Tambakopoulos - E. Dotsika, Marble provenance investigation of Roman sarcophagi from Thessaloniki, Archaeometry 52, 1, 2010, 45-58.

E. Marin (Hrsg.), Der attische Jagdsarkophag Budapest-Split (Split 1992).

G. Martin - J. Gruskova, »Dexipus Vindobonensis« (?). Ein neues Handschriftenfragment zum sog. Herulereinfall der Jahre 267/268, WSt 127, 2014, 101-120.

J. Massó, Notes sobre escultures i inscripcions romanes a la Tarragona dels segles XVI, XVIII i XIX, Faventia 11, 1, 1989, 83-108.

M. Mateev, Ein Bild der Seeschlacht auf einem Sarkophag aus Philippopolis, Pulpudeva 5, 1982, 258-260.

F. Matz, Sarkophag aus Patras, AZ 30, 1873, 11-18.

F. Matz, Die dionysischen Sarkophage, ASR IV 1 (Berlin 1968).

F. Matz, Die dionysischen Sarkophage, ASR IV 3 (Berlin 1969).

J. Meischner, Privatporträts der Jahre 195 bis 220 n. Chr., JdI 97, 1982, 401-439.

A. Michaelis, Ancient Marbles in Great Britain (Cambridge 1882).

F. Morandini, Osservazioni su quattro sarcofagi romani inediti dal monastero di Santa Giulia in Brescia, QuadAVen 16, 2000, 184-190.

F. Morandini, Frammenti di sarcofagi della chiesa di San Salvatore di Brescia, in: G. Koch (Hrsg.), Akten des Symposiums des Sarkophag-Corpus. Marburg 2.-7. Juli 2001, Sarkophag-Studien 3 (Mainz 2007) 37-42.

W. Müller-Wiener, Mittelalterliche Befestigungen im südlichen Ionien, IstMitt 11, 1961, 5-122.

L. Musso, Il trasporto funebre di Achille sul rilievo Colonna-Grottaferrata: una nota iconografia, BCom 93, 1989/1990, 9-22.

P. Niewöhner, Byzantinische Stadtmauern in Anatolien. Vom Statussymbol zum Bollwerk gegen die Araber, in: J. Lorentzen - F. Pirson - P. Schneider - U. Wulf-Rheidt (Hrsg.), Aktuelle Forschungen zur Konstruktion, Funktion und Semantik antiker Stadtbefestigungen. Kolloquium Istanbul 9.-10. Februar 2007, Byzas 10 (Istanbul 2010) 239-260. 
Niewöhner 2011

Oakley 2011

Orlandos 1962

Orlandos 1963

Papagianni 2007

Pflaum 1960

Piccirillo 1981

Pietrogrande 1930

Pietsch 1999

Pitton de Tournefort 1717 Prochaska 1999

Quattrocchi 1999

Redlich 1942

Rheidt 1997

Reinach 1912

Rey-Coquais 1977

Rey-Coquais 1979

Reynolds 1999

Reynolds - Ward-Perkins 1952

Robert 1890

Robert 1904

Robert 1919

Rodenwaldt 1930

Rodenwaldt 1933

Rodenwaldt 1952

Röder 1971

Rogge 1993

Rogge 1995

Rogge 1998

Rogge 2008

Rudolf 1989

Rudolf 1992

Rüsch 1969
P. Niewöhner, The Riddle of the Market Gate: Miletus and the Character and Date of Earlier Byzantine Fortifications in Anatolia, in: O. Dally - C. Ratté (Hrsg.), Archaeology and the Cities of Asia Minor in Late Antiquity, Kelsey Museum Publication 6 (Ann Arbor 2011) 103-122.

J. H. Oakley, Die Sarkophage Griechenlands und der Donauprovinzen. Die attischen Sarkophage. Andere Mythen, ASR IX 1, 3 (Berlin 2011).

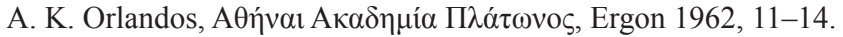

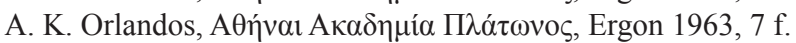

E. Papagianni, Der Eroten-Sarkophag Inv. 1248 des Archäologischen Museums in Thessaloniki, in: G. Koch (Hrsg.), Akten des Symposiums des Sarkophag-Corpus. Marburg 2.-7. Juli 2001, Sarkophag-Studien 3 (Mainz 2007) 187-192.

H.-G. Pflaum, Les carrières procuratoriennes équestres sous le haut-empire romain (Paris 1960).

M. Piccirillo, Chiese e Mosaici della Giordania Settentrionale (Jerusalem 1981).

A. L. Pietrogrande, Sarcofagi provenienti da Tolmetta, Africa Italiana 3, 1930, 107-140. W. Pietsch, Außerstädtische Grabanlagen von Ephesos, in: H. Friesinger - F. Krinzinger (Hrsg.), 100 Jahre Österreichische Forschungen in Ephesos. Akten des Symposiums Wien 1995, DenkschrWien 260 = AForsch 1 (Wien 1999) 455-464.

J. Pitton de Tournefort, Relation d'un voyage du Levant III (Paris 1717).

W. Prochaska, Die Bedeutung der chemischen Zusammensetzung von Einschlussfluiden und laufbaren Salzen für die Genese von hydrothermalen und sedimentären Karbonatgesteinen der Ostalpen, Mitteilungen der Österreichischen Geologischen Gesellschaft 90, 1999, 175-183.

G. Quattrocchi, Un museo tutto case e chiese, Archeo 15, Nr. 6 (172), Juni 1999, 93.

R. Redlich, Die Amazonensarkophage des 2. und 3. Jahrhunderts n. Chr. (Berlin 1942).

K. Rheidt, Römischer Luxus - Anatolisches Erbe. Aizanoi in Phrygien - Entdeckung, Ausgrabung und neue Forschungsergebnisse, AW 28, 1997, 479-499.

S. Reinach, Répertoire de reliefs grecs et romains 2. Afrique - Iles Britanniques (Paris 1912).

J.-P. Rey-Coquais, Inscriptions greques et latines découvertes dans les fouilles de Tyr (1963-1974) I. Inscriptions de la nécropole, BMusBeyrouth 29 (Paris 1977).

J. P. Rey-Coquais, Fortune et rang social des gens de métiers de Tyr au Bas Empire, Ktema 4, 1979, 281-292.

J. Reynolds, Ephesus in the Inscriptions of Aphrodisias and Aphrodisians, in: H. Friesinger - F. Krinzinger (Hrsg.), 100 Jahre Österreichische Forschungen in Ephesos. Akten des Symposiums Wien 1995, DenkschrWien 260 = AForsch 1 (Wien 1999) 133-137. J. Reynolds - J. B. Ward-Perkins, Inscriptions of Roman Tripolitania (Rom 1952).

C. Robert, Die mythologischen Sarkophage, ASR II (Berlin 1890).

C. Robert, Die mythologischen Sarkophage, ASR III 2 (Berlin 1904).

C. Robert, Die mythologischen Sarkophage, ASR III 3 (Berlin 1919).

G. Rodenwaldt, Der Klinensarkophag von S. Lorenzo, JdI 45, 1930, 116-189.

G. Rodenwaldt, Sarcophagi from Xanthos, JHS 53, 1933, 181-213.

G. Rodenwaldt, Ein attischer Jagdsarkophag in Budapest, JdI 67, 1952, 31-42.

J. Röder, Marmor Phrygium. Die antiken Marmorbrüche von Iscehisar in Westanatolien, JdI 86, 1971, 251-321.

S. Rogge, Tektonik und Ornamentik attischer Sarkophage. Studie zur Chronologie dieser Denkmälergattung, in: G. Koch (Hrsg.), Grabeskunst der römischen Kaiserzeit (Mainz 1993) 111-132.

S. Rogge, Die Sarkophage Griechenlands und der Donauprovinzen. Die attischen Sarkophage. Achill und Hippolytos, ASR IX 1, 1 (Berlin 1995).

S. Rogge, Waidmannsheil auf attischen Sarkophagen: ... nochmals zum attischen JagdSarkophag Budapest-Split und verwandten Stücken, in: G. Koch (Hrsg.), 125 Jahre Sarkophag-Corpus. Akten des Symposiums. Marburg 4.-7. Oktober 1995, SarkophagStudien 1 (Mainz 1998) 201-205.

S. Rogge, Achill in Side. Ein fragmentierter attischer Sarkophag im Museum in Side, in: E. Winter (Hrsg.), Vom Euphrat bis zum Bosporus. Kleinasien in der Antike. Festschrift Elmar Schwertheim, AMS 65, 2 (Bonn 2008) 581-595.

E. Rudolf, Attische Sarkophage aus Ephesos, DenkschrWien 209 (Wien 1989).

E. Rudolf, Der Sarkophag des Quintus Aemilius Aristides, DenkschrWien 230 (Wien 1992).

A. Rüsch, Das kaiserzeitliche Porträt in Makedonien, JdI 84, 1969, 59-196. 
Russenberger 2015

Salvetti 1993

Saverkina 1979

Scherrer 2000

Schwarz 2008

Scrinari 1972

Seiterle 1982

Sichtermann 1954

Sichtermann - Koch 1975

Smith 1900

Sokolicek 2010

Sperti 1988

Spon - Wheler 1678

Stefanidou-Tiveriou 1993

Stefanidou-Tiveriou 1997

Stefanidou-Tiveriou 2007

Stefanidou-Tiveriou 2014

Stella 1998

Stella 2003

Steskal - La Torre 2008

Steskal u. a. 2003

Stroszeck 1998

Targaç 2004

Themelis 1998

Thiel 2005

Touchefeu 1988

Towne-Markus 1997

Toynbee 1983

Trunk 2000

Tullio 1984

Vanderpool 1964

Vermeule - Bothmer 1956

Vermeule - Brauer 1990
C. Russenberger, Der Tod und die Mädchen. Amazonen auf römischen Sarkophagen, Image and Context 13 (Berlin 2015).

C. Salvetti, Su alcuni frammenti di sarcofagi nella basilica di S. Silvestro a Priscilla, RACr 69, 1993, 63-88.

I. I. Saverkina, Römische Sarkophage in der Ermitage (Berlin 1979).

P. Scherrer (Hrsg.), Ephesus. The New Guide (Istanbul 2000).

G. Schwarz, Priam's großer Heldenstamm verdirbt ... Zur Rückseite des Sarkophags Woburn Abbey, in: P. Mauritsch (Hrsg.), Antike Lebenswelten. Konstanz - Wandel Wirkungsmacht. Festschrift Ingomar Weiler, Philippika. Marburger altertumskundliche Abhandlungen 32 (Wiesbaden 2008) 737-748.

V. S. M. Scrinari, Museo Archeologico di Aquileia. Catalogo delle sculture romane (Rom 1972).

G. Seiterle, Das Hauptstadttor von Ephesos, AntK 25, 1982, 145-157.

H. Sichtermann, Archäologische Funde und Forschungen in Spanien von 1940-1953, AA 1954, 313-465.

H. Sichtermann - Koch, Griechische Mythen auf römischen Sarkophagen (Tübingen 1975).

A. H. Smith, Catalogue of Sculpture at Woburn Abbey (London 1900).

A. Sokolicek, Chronologie und Nutzung des Magnesischen Tores von Ephesos, ÖJh 79, 2010, 359-381.

L. Sperti, Rilievi Greci e Romani del Museo Archeologico di Venezia (Rom 1988).

J. Spon - G. Wheler, Voyage d'Italie, de Dalmatie, de Grèce et du Levant fait aux années 1675 et 1676 (Amsterdam 1678).

T. Stefanidou-Tiveriou, Späte attische Sarkophage und das Ende der attischen Werkstätten, in: G. Koch (Hrsg.), Grabeskunst der römischen Kaiserzeit (Mainz 1993) 133-139. G. Despinis - T. Stefanidou-Tiveriou - E. Voutiras, Catalogue of Sculpture in the Archaeological Museum of Thessaloniki I (Thessaloniki 1997).

T. Stefanidou-Tiveriou, Klinensarkophage in Thessaloniki, in: G. Koch (Hrsg.), Akten des Symposiums des Sarkophag-Corpus, Marburg 2.-7. Juli 2001, Sarkophag-Studien 3 (Mainz 2007) 263-270.

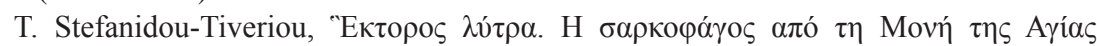

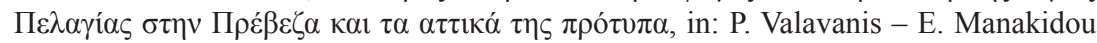
(Hrsg.), ЕГРАФ $\Sigma$ EN KAI ЕПOIE $\Sigma E N$. Essays on Greek Pottery and Iconography in Honour of Michalis Tiverios (Thessaloniki 2014) 511-524.

C. Stella in: Santa Giulia. Museo della Città. L'età romana (1998).

C. Stella (Hrsg.), Santa Giulia. Museo della Città. Brixia. Scoperte e riscoperte (Mailand 2003).

M. Steskal - M. La Torre, Das Vediusgymnasium in Ephesos, FiE 14, 1 (Wien 2008).

M. Steskal - K. Grossschmidt - M. Heinz - F. Kanz - H. Taeuber, Die Damianosstoa in Ephesos. Bericht über die Ausgrabung 2002 im Abschnitt Kathodos III, ÖJh 72, 2003, 241-273.

J. Stroszeck, Die dekorativen römischen Sarkophage. Löwen-Sarkophage, ASR VI 1 (Berlin 1998).

M. İ. Targaç (Hrsg.), Anadolu medeniyetlerinden kültür yansımaları. Yavuz Tatış Koleksiyonu (Izmir 2003). Tarih İncelemeleri Dergisi 19, 1, 2004, 66 f.

P. Themelis, Ancient Messene. Site and Monuments (Athen 1998).

A. Thiel, Die Johanneskirche in Ephesos. Spätantike - Frühes Christentum - Byzanz. Kunst im ersten Jahrtausend, Reihe B, Band 16 (Wiesbaden 2005).

LIMC IV (1988) 482-498 s. v. Hektor (O. Touchefeu).

E. Towne-Markus, Masterpieces of the J. Paul Getty Museum. Antiquities (Los Angeles 1997).

J. M. C. Toynbee, Tierwelt der Antike (Mainz 1983).

M. Trunk, Leda in Sevilla, in: T. Mattern (Hrsg.), Munus. Festschrift Hans Wiegartz (Münster 2000) 305-311.

A. Tullio, Due sarcofagi tardo-ellenistici da Cefalù, in: N. Bonacasa (Hrsg.), Alessandria e il mondo ellenistico-romano: studi in onore di Achille Adriani (Rom 1984) 598-610.

E. Vanderpool, News Letter from Greece, AJA 68, 1964, 293-295.

C. C. Vermeule - D. v. Bothmer, Notes on a New Edition of Michaelis: Ancient Marbles in Great Britain. Part Two, AJA 60, 1956, 321-350.

C. C. Vermeule - A. Brauer, Stone Sculptures. The Greek, Roman, and Etruscan Collections of the Havard University Art Museums (Cambridge 1990). 
Vollkommer 1997

Walker 1990

Watzinger 1984

Weber 2002

Wenger 1929

Wiegartz 1965a

Wiegartz 1965b

Wiegartz 1971

Wiegartz 1974

Wiegartz 1975

Wiegartz 1977

Wiegartz 1978

Wiegartz 1983

Wielgosz 2001

Wiplinger - Wlach 1995

Wohlers-Scharf 1995

Wrede 1977

Wrede 1990

Zanker - Ewald 2004

Zingerle 1907
LIMC VIII (1997) 237-269 s. v. Victoria (R. Vollkommer).

S. Walker, Catalogue of Roman Sarcophagi in The British Museum, CSIR Great Britain II 2 (Oxford 1990).

C. Watzinger, Griechische Holzsarkophage aus der Zeit Alexanders des Großen (Leipzig 1905; Nachdr. Leipzig 1984).

T. M. Weber, Gadara Decapolitana. Untersuchungen zur Topographie, Geschichte, Architektur und der Bildenden Kunst einer »Polis Hellenis« im Ostjordanland = Gadara - Umm Qes 1, Abhandlungen des Deutschen Palästina-Vereins 30 (Wiesbaden 2002).

L. Wenger, Griechische Inschriften zum Kaiserkult und zum Grabrecht, ZSav 49, 1929, 308-344.

H. Wiegartz, Kleinasiatische Säulensarkophage, IstForsch 26 (Berlin 1965).

H. Wiegartz, Gnomon 37, 1965, 612-617 (Rezension zu Giuliano 1962).

H. Wiegartz und Mitarbeiter, Symposium über die antiken Sarkophagreliefs, AA 1971, 86-92.

H. Wiegartz, Marmorhandel, Sarkophagherstellung und Lokalisierung der kleinasiatischen Säulensarkophage, in: Mansel'e armăgan = Mélanges A. M. Mansel (Ankara 1974) 345-383.

H. Wiegartz, Kaiserzeitliche Reliefsarkophage in der Nikolaoskirche, in: J. Borchhardt (Hrsg.), Myra. Eine lykische Metropole in antiker und byzantinischer Zeit, IstForsch 30 (Berlin 1975) 161-251.

H. Wiegartz, Zu Problemen einer Chronologie der attischen Sarkophage, AA 1977, 383-388.

H. Wiegartz, Das Sarkophagcorpus und die Erforschung der antiken Sarkophage Kleinasiens, in: E. Akurgal (Hrsg.), Proceedings of the $\mathrm{X}^{\text {th }}$ International Congress of Classical Archaeology, Ankara - Izmir 23.-30.9. 1973 (Ankara 1978) 667-676.

H. Wiegartz, Leda und der Schwan in der kaiserzeitlichen attischen Plastik, Boreas 6, 1983, 168-196.

D. Wielgosz, Sarcofagi attici a Palmira, RdA 25, 2001, 167-176.

G. Wiplinger - G. Wlach, Ephesos - 100 Jahre österreichische Forschungen (Wien 1995).

T. Wohlers-Scharf, Die Forschungsgeschichte von Ephesos. Entdeckungen, Grabungen und Persönlichkeiten, Europäische Hochschulschriften Reihe 38, Archäologie Band 54 (Frankfurt a. M. 1995).

H. Wrede, Stadtrömische Monumente, Urnen und Sarkophage des Klinentypus in den ersten beiden Jahrhunderten n. Chr., AA 1977, 395-431.

H. Wrede, Der Sarkophagdeckel eines Mädchens in Malibu und die frühen Klinensarkophage Roms, Athens und Kleinasiens, in: G. Koch (Hrsg.), Roman Funerary Monuments in The J. Paul Getty Museum 1, Occasional Papers on Antiquities 6 (Malibu 1990) 15-46.

P. Zanker - B. C. Ewald, Mit Mythen leben. Die Bilderwelt der römischen Sarkophage (München 2004).

J. Zingerle, Relief in Pola, ÖJh 10, 1907, 157-168. 


\section{Abbildungsnachweis}

Alle Fotos stammen von N. Gail @ ÖAW-ÖAI mit Ausnahme der folgenden:

Abb. 1

Abb. 2

Abb. 3

Abb. 6

Abb. 9

Abb. 12

Abb. 13

Abb. 20

Abb. 22. 63. 76-79

112. 171. 178. 205-206.

280. 294. 299. 307-309.

311-312

Abb. 23

Abb. 24

Abb. 91

Abb. 98. 100-101.

138-141. 317-318

Abb. 99

Abb. 113

Abb. 114

Abb. 142

Abb. 143-145

Abb. 147

Abb. 148

Abb. 149

Abb. 150. 155-157.

160-161. 163

Abb. 151

Abb. 152

Abb. 153. 158

Abb. 154

Abb. 159

Abb. 162

Abb. 164

Abb. 167

Abb. 168

Abb. 173. 176

Abb. 177

Abb. 279. 281

Abb. 285

Abb. 297

Abb. 301-304

Abb. 314

Abb. 330 aus Rudolf 1992, Taf. 1 Abb. 1

aus Rudolf 1992, Taf. 2 Abb. 3

ÖAI Neg. Bl. 374/2

ÖAI Neg. Nr. II 398

aus Rudolf 1992, Taf. 29 Abb. 51

aus Rudolf 1992, Taf. 25 Abb. 46 (Ausschnitt)

aus Rudolf 1992, Taf. 27 Abb. 49

ÖAI Neg. Nr. II 263

M. Heinz

ÖAI Neg. Nr. II 382

aus E. Rudolf (Rudolf 1992, Taf. 5 Abb. 7) nach einer Skizze von F. Eichler

nach E. Rudolf, Ausschnitt (aus Rudolf 1992, Taf. 4 Abb. 5)

C. Kintrup

aus Rudolf 1992, Taf. 24 Abb. 45.

ÖAI Neg. Bl. 66/4 (F. X. Prascaits)

ÖAI Neg. Nr. II 455

ÖAI Neg. Nr. II 251

E. Rudolf

aus Robert 1890, Taf. 23 Abb. 47’. 47’ a

aus Robert 1890, Taf. 23 Abb. 47' c

aus Robert 1890, Taf. 23 Abb. 47”

$<$ http://arachne.uni-koeln.de/arachne/index.php?view[layout]=marbilder_ item\&search[constraints][marbilder][searchSeriennummer] $=456388>\langle\ldots$ 456386 $>$ $<\ldots 456392><\ldots 456384><\ldots 456389><\ldots 456422><\ldots$ 7705958> aus Robert 1919, 549 Nr. 47 Abb. 47 d

aus Robert 1919, 550 Abb. 47'”

The Warburg Institute, London

aus Robert 1890, Taf. 22 Abb. 47 a

aus Robert 1890, Taf. 22 Abb. 47 b

aus Robert 1890, Taf. 22 Abb. 47 c

aus Robert 1890, Taf. 20 Abb. 41

ÖAI Neg. Nr. II 1182

aus Rudolf 1989, Taf. 17 Abb. 23.

Imaging Department (C) President and Fellows of Harvard College

aus Stefanidou-Tiveriou 1997, Abb. 337

Image (C) Ashmolean Museum, University of Oxford

aus Targaç 2004, 66 f. Nr. 52 mit Abb.

ÖAI Neg. Nr. I 261

G. A. Plattner

(C) Kunsthistorisches Museum, Wien

Fundortplan C. Kurtze, (C) ÖAW-ÖAI 

TAFELN 



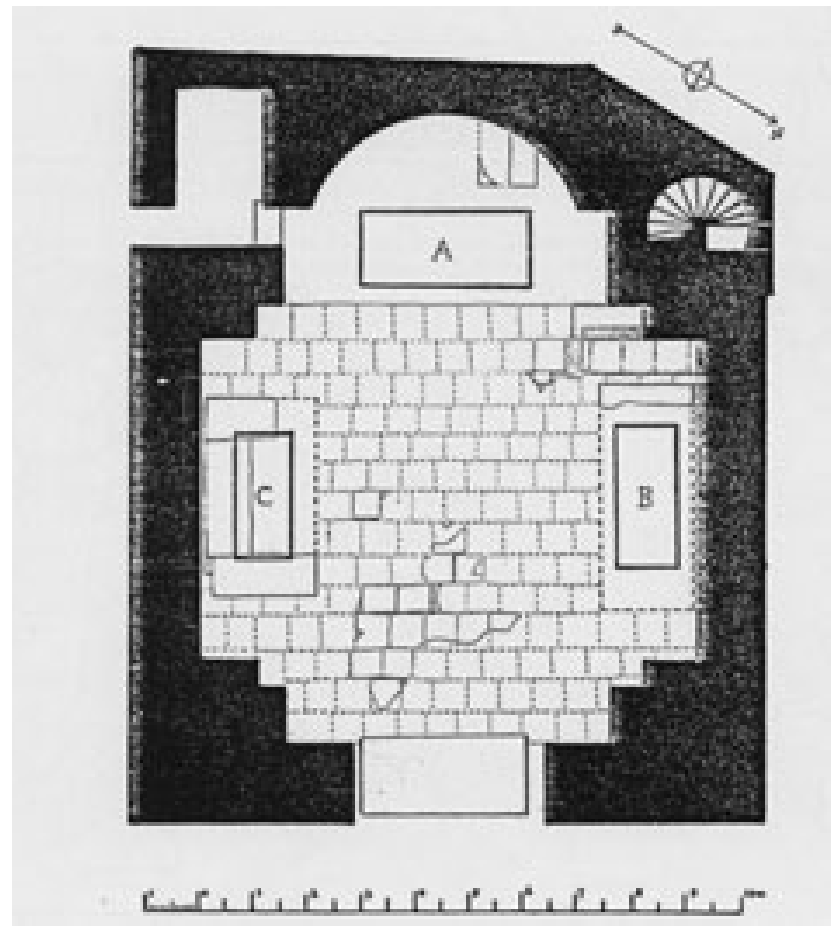

Abb. 1 Grundriss des Grabhauses der Claudia Antonia Tatiane (nach F. Eichler)

A Kleinasiatischer Säulensarkophag der Claudia Antonia Tatiane

B Attischer Schlachtsarkophag des [Quintus] Aemilius Aristides, Kat. 1

C Attischer Amazonomachie-Sarkophag, Kat. 2

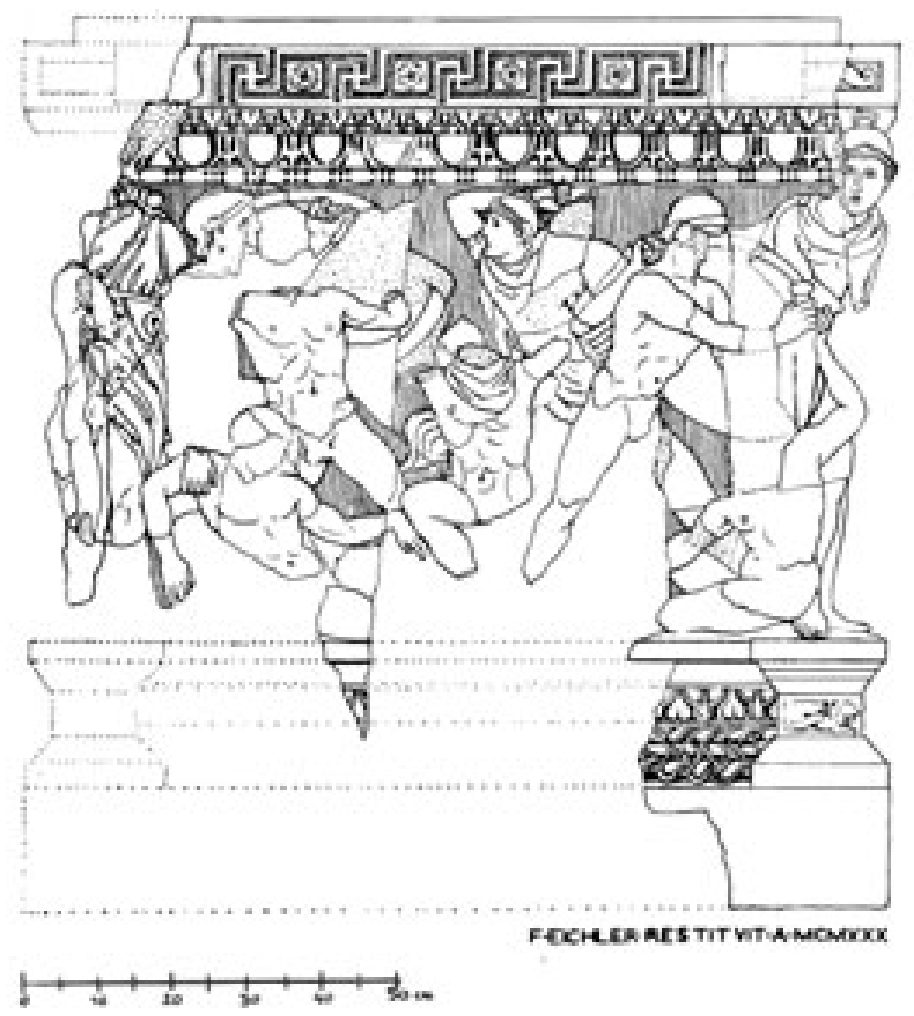

Abb. 2 Rechte Schmalseite. Rekonstruktion F. Eichler (1930)

Kat. 1 Schlachtsarkophag des [Quintus] Aemilius Aristides 
Tafel 2

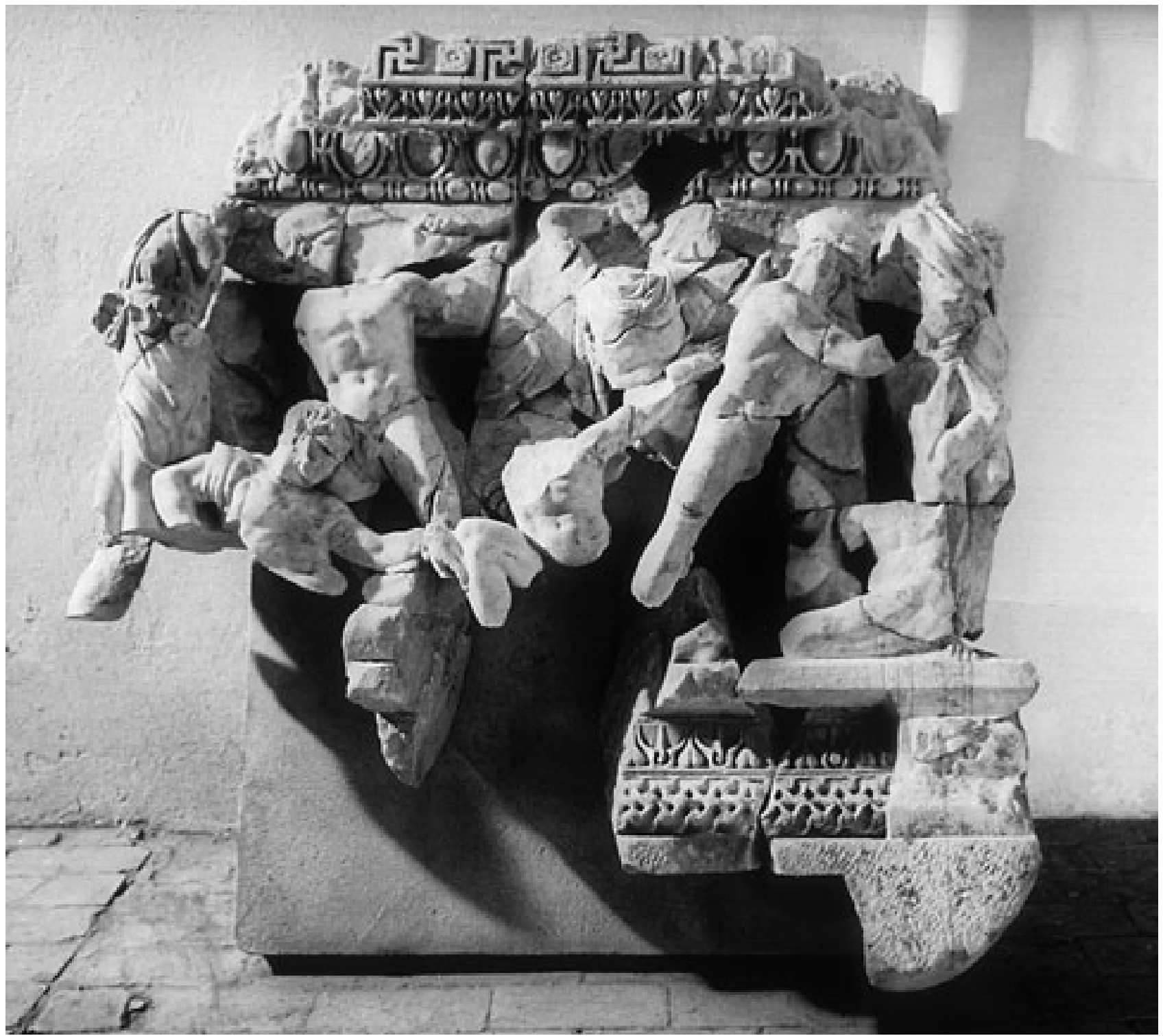

Abb. 3 Rechte Schmalseite. Selçuk, Efes Müzesi Inv. 12

Kat. 1 Schlachtsarkophag des [Quintus] Aemilius Aristides 
Tafel 3
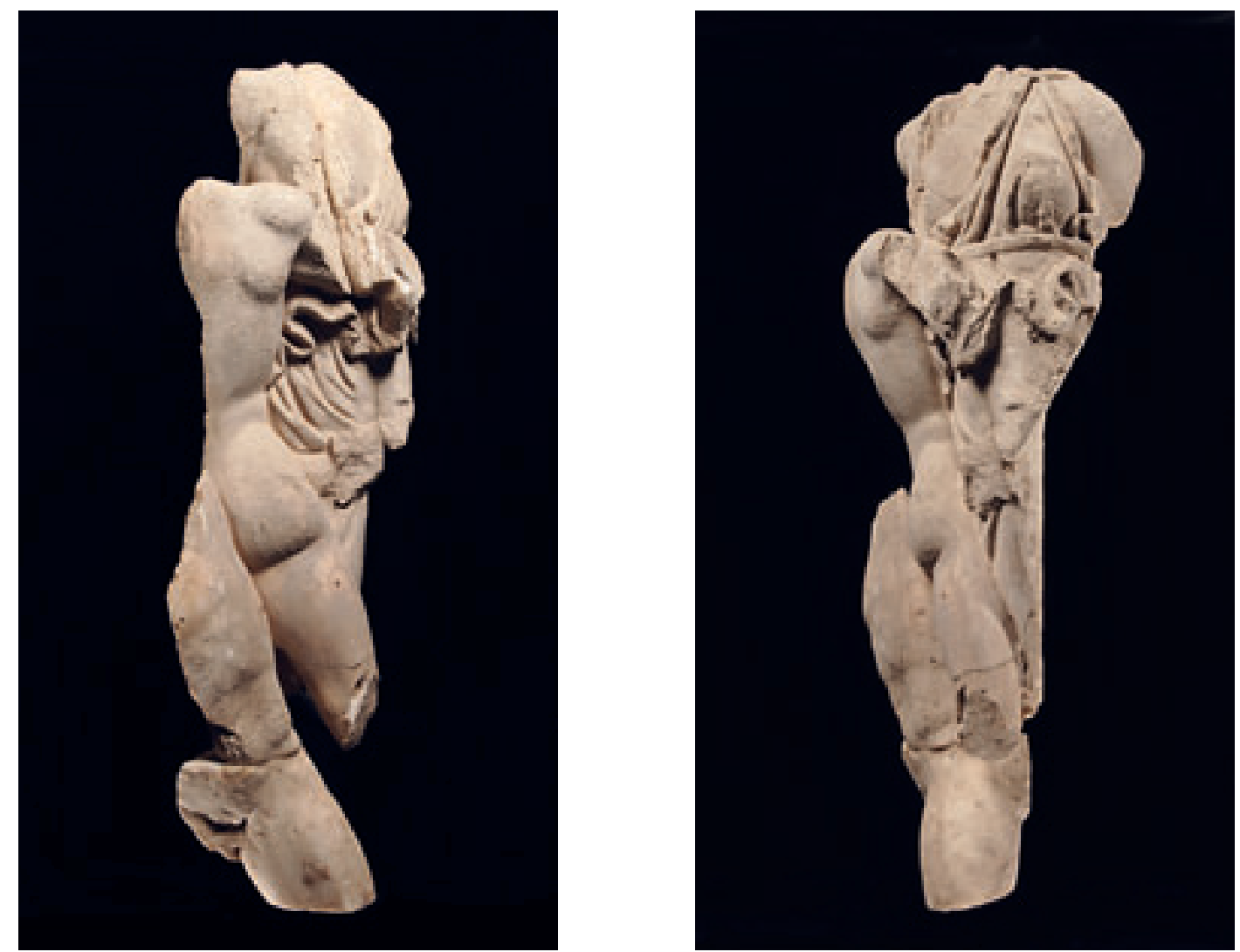

Abb. 4-5 Rechte Ecke der Vorderseite
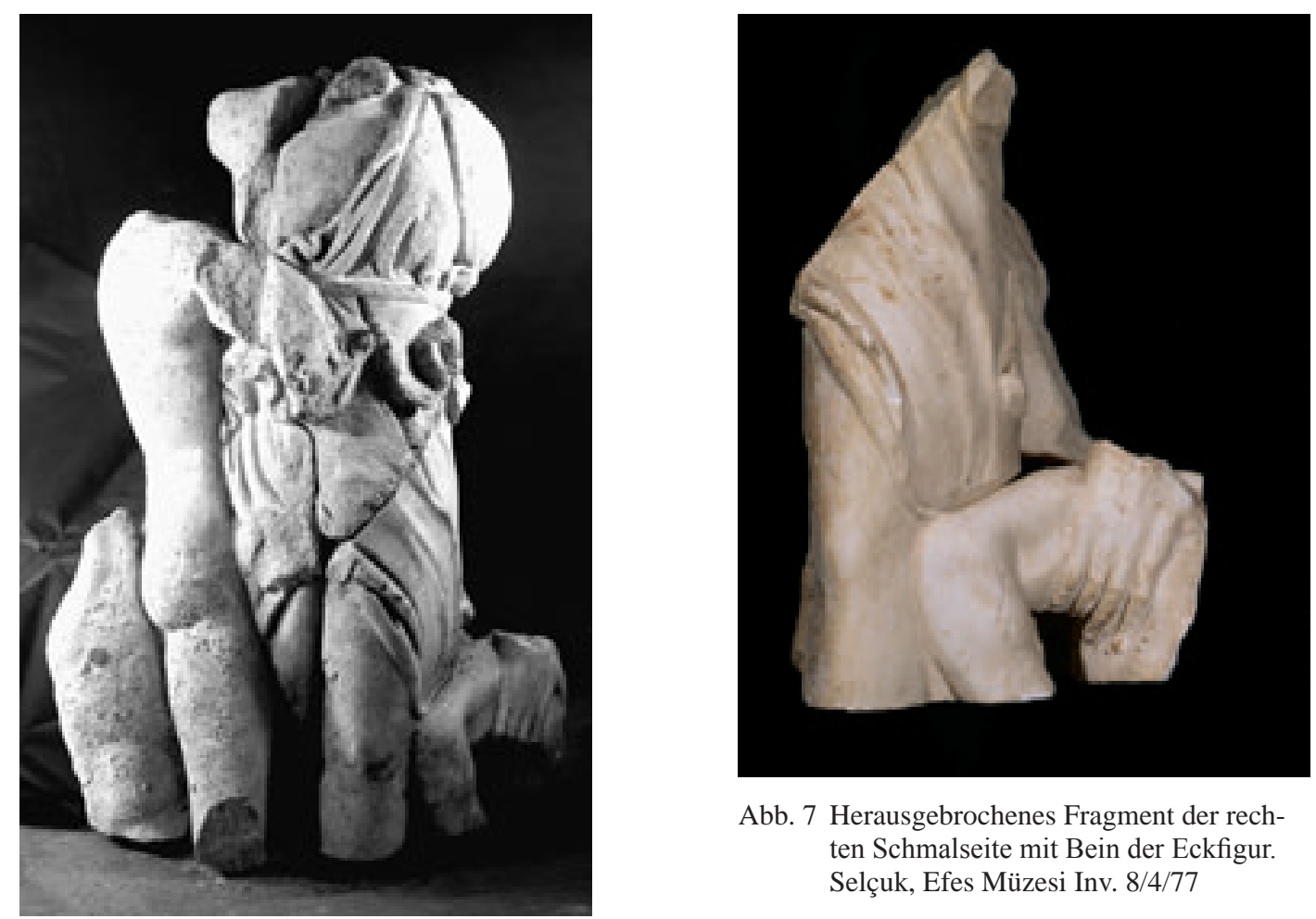

Abb. 7 Herausgebrochenes Fragment der rechten Schmalseite mit Bein der Eckfigur. Selçuk, Efes Müzesi Inv. 8/4/77

Abb. 6 Rechte Ecke der Vorderseite mit anpassendem Fragment der rechten Schmalseite

Kat. 1 Schlachtsarkophag des [Quintus] Aemilius Aristides 
Tafel 4

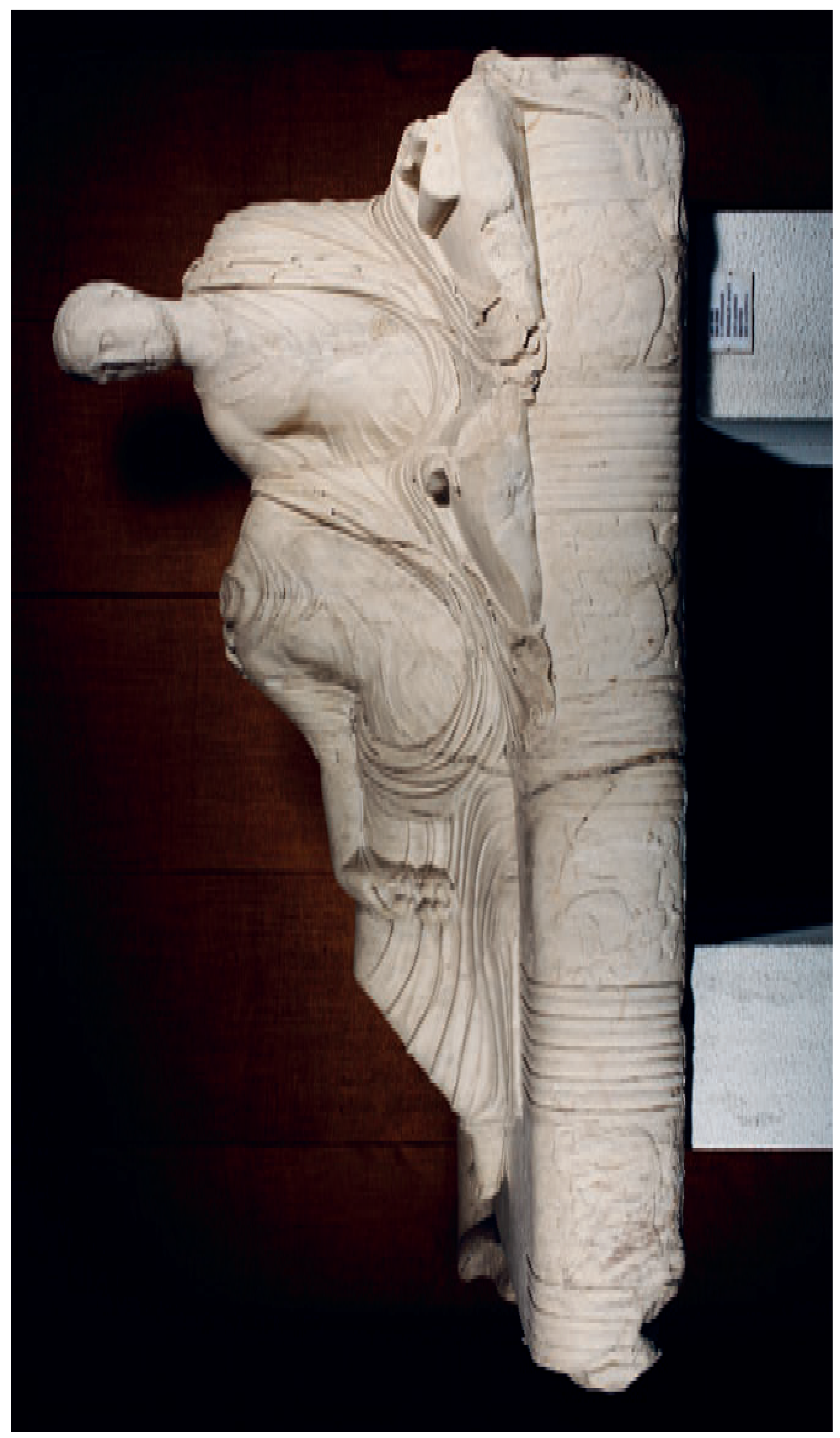

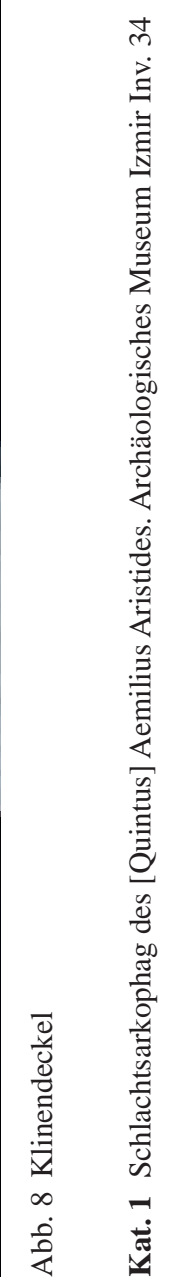


Tafel 5
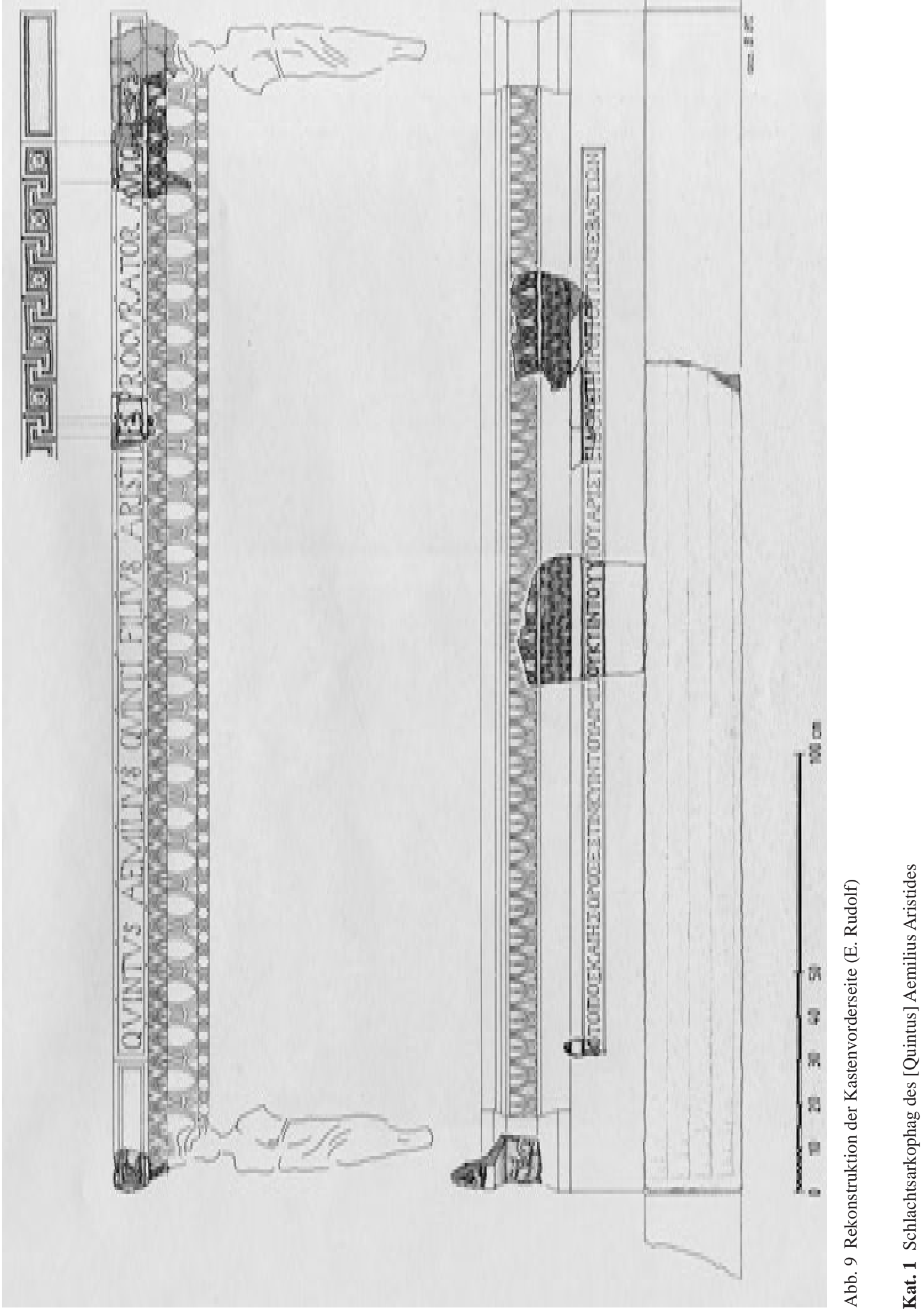
Tafel 6

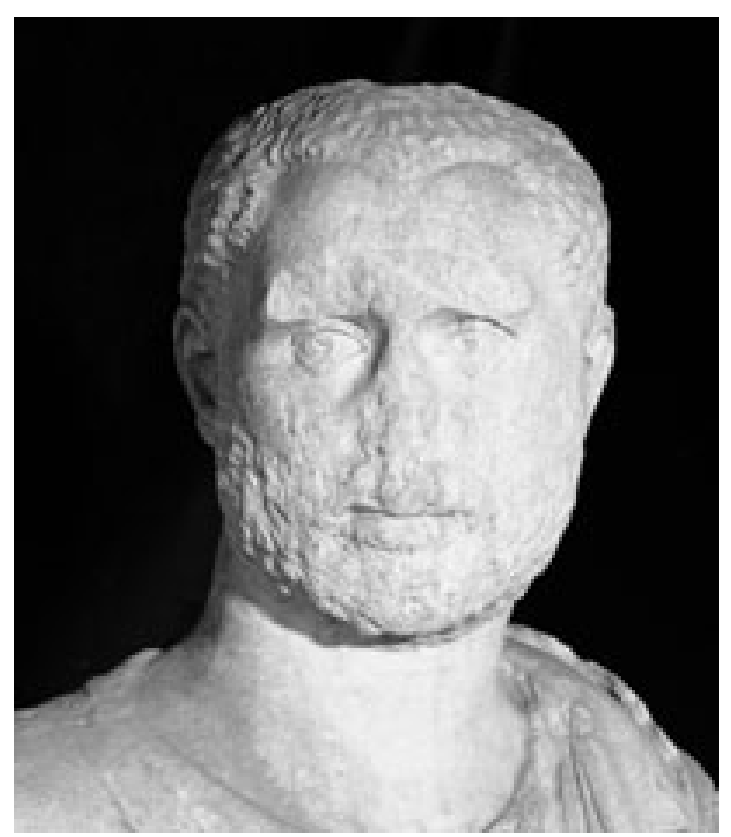

Abb. 10

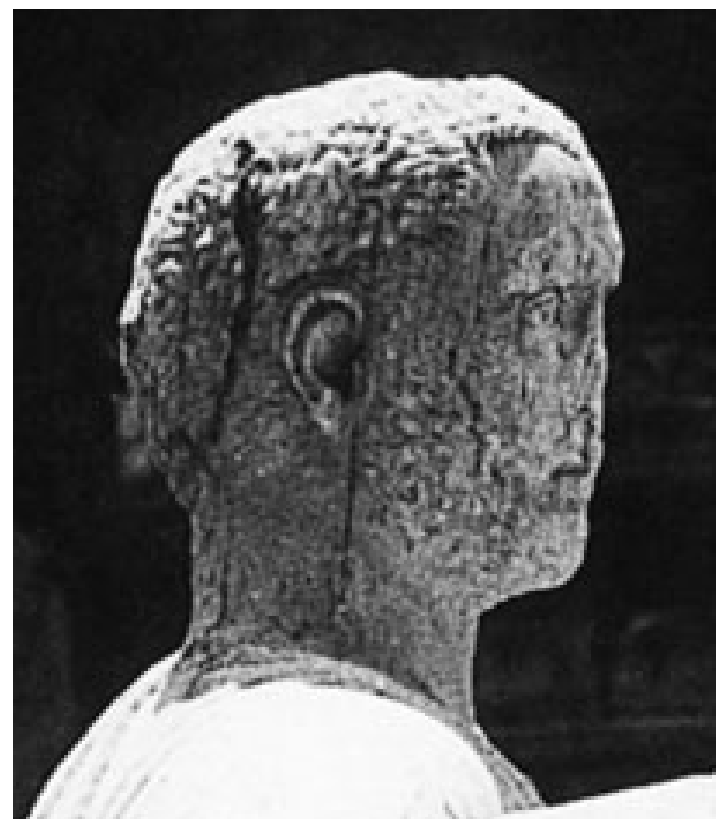

Abb. 12

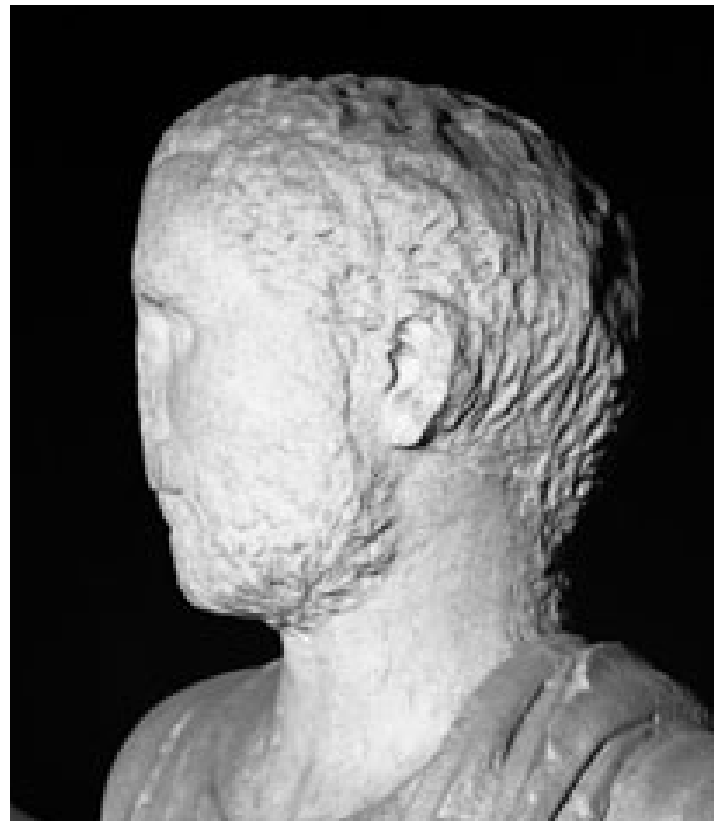

Abb. 11

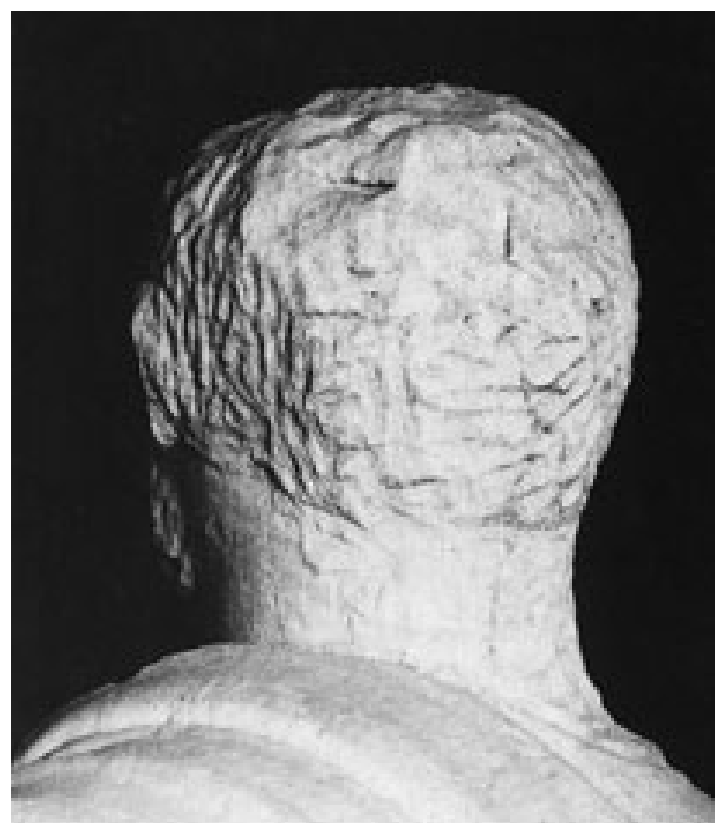

Abb. 13

Kat. 1 Schlachtsarkophag des [Quintus] Aemilius Aristides Abb. 10-13 Deckelporträt 


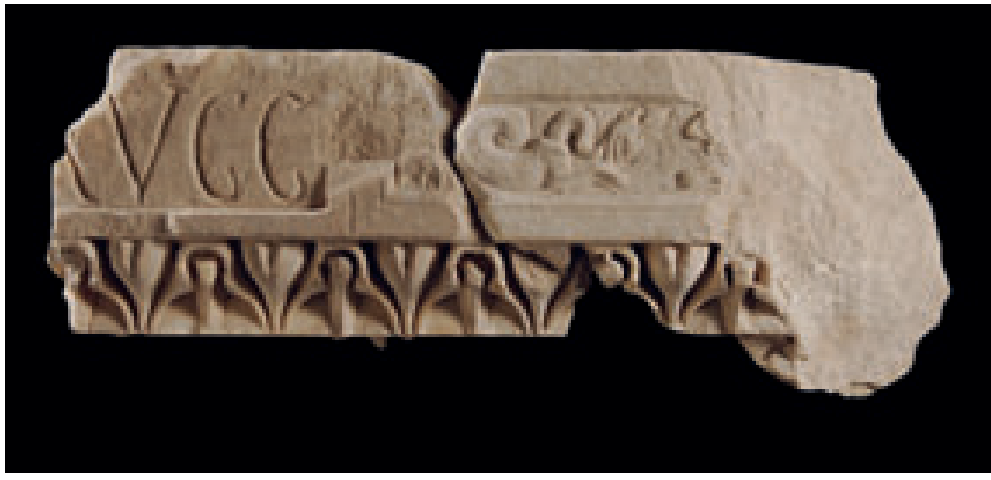

Abb. 14 Fragment 1: rechtes Ende der lateinischen Inschrift mit anschließendem rechten oberen Eckfeld

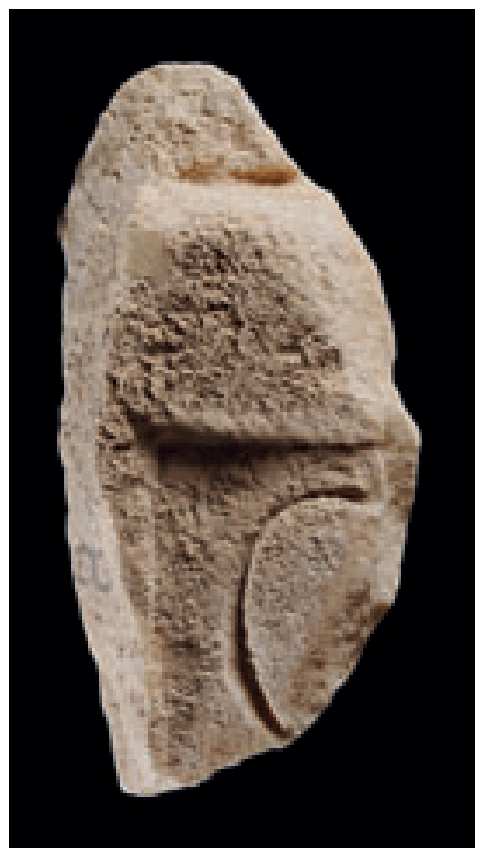

Abb. 16 Fragment 3 mit dem Beginn der griechischen Inschrift

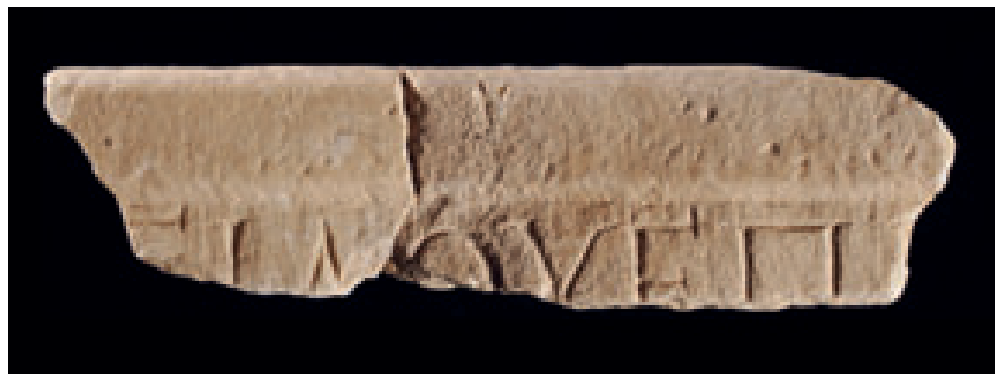

Abb. 18 Sockelfragment 5 der griechischen Inschrift

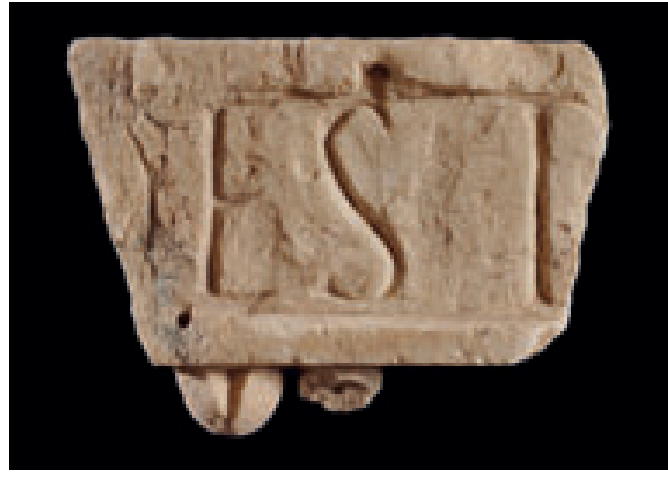

Abb. 15 Fragment 2 der lateinischen Inschrift

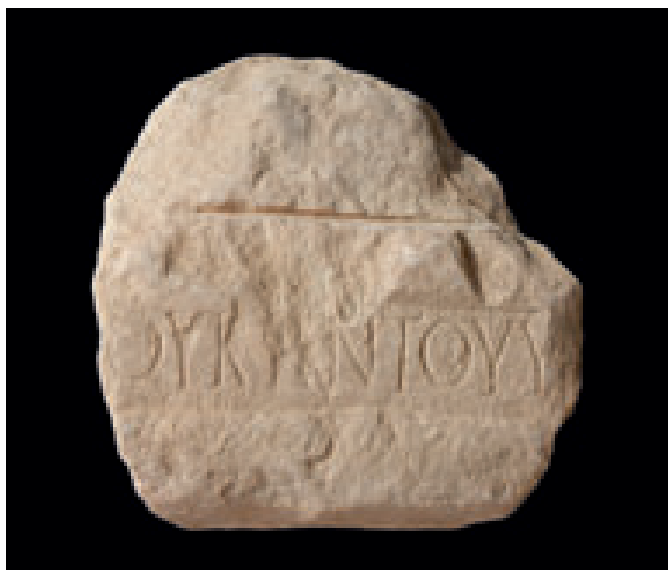

Abb. 17 Wiederentdecktes Fragment (Fragment 4) der griechischen Inschrift

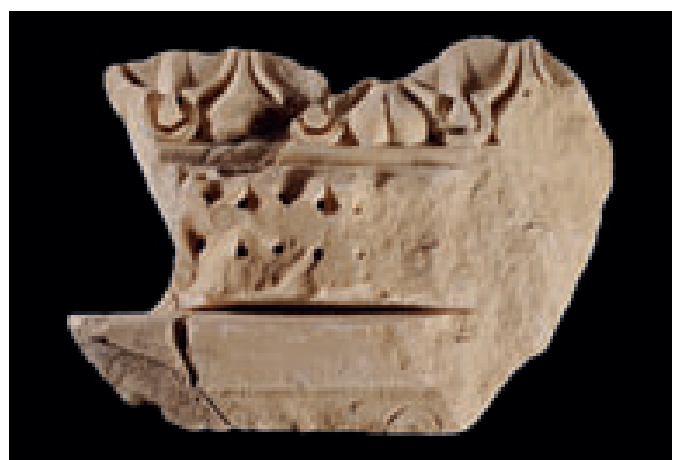

Abb. 19 Sockelfragment 6 der griechischen Inschrift

Kat. 1 Schlachtsarkophag des [Quintus] Aemilius Aristides 
Tafel 8

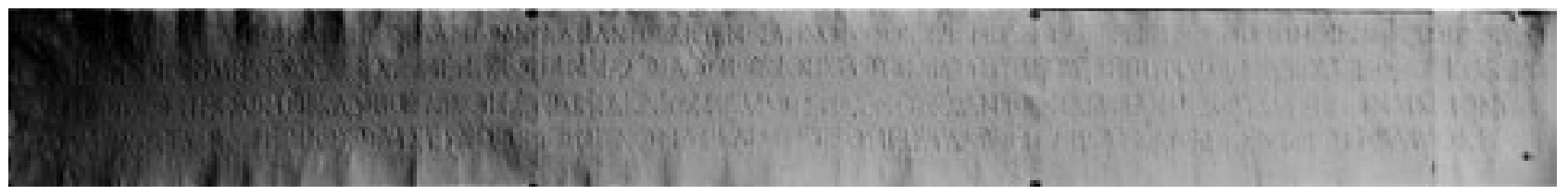

Abb. 20 Griechische Inschrift auf dem Postament unter dem Schlachtsarkophag

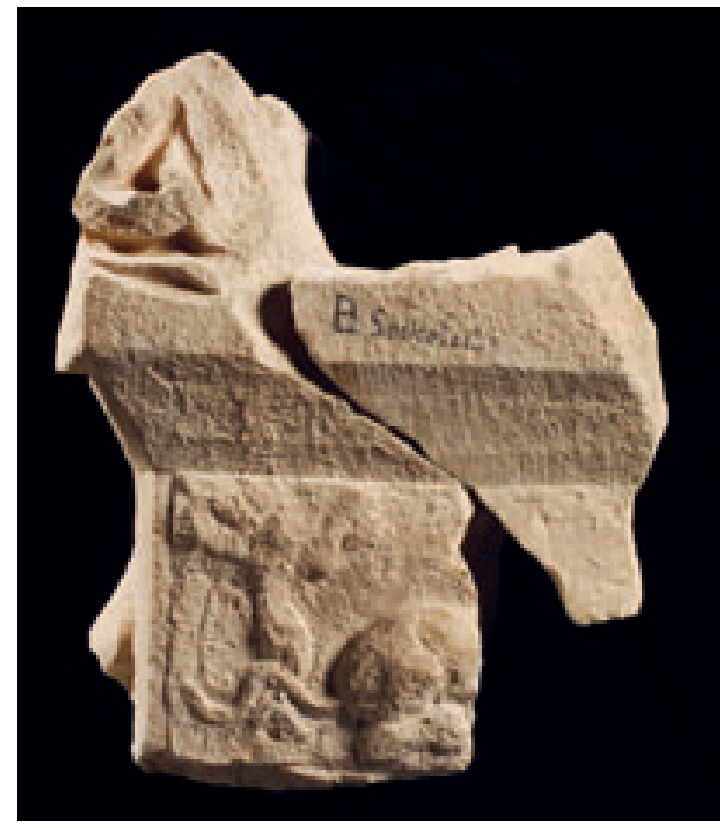

Abb. 21 Eckpostament Fragment 21 und 22: Ansicht der Vorderseite

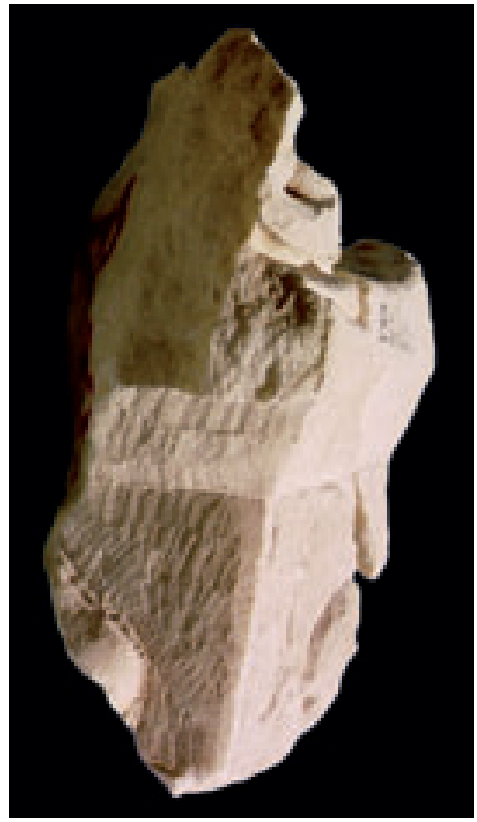

Abb. 22 Eckpostament Fragment 21 und 22: Ansicht der linken Schmalseite

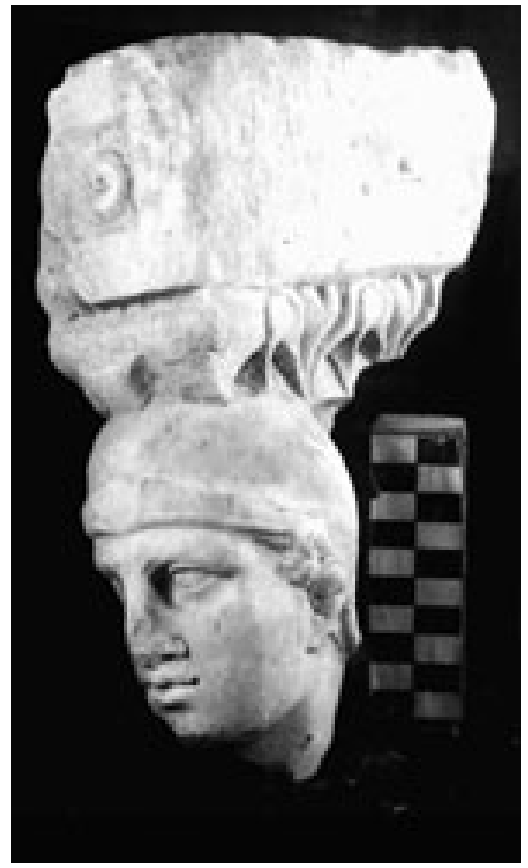

Abb. 23 Verschollenes Fragment der rechten oberen Ecke der rechten Schmalseite

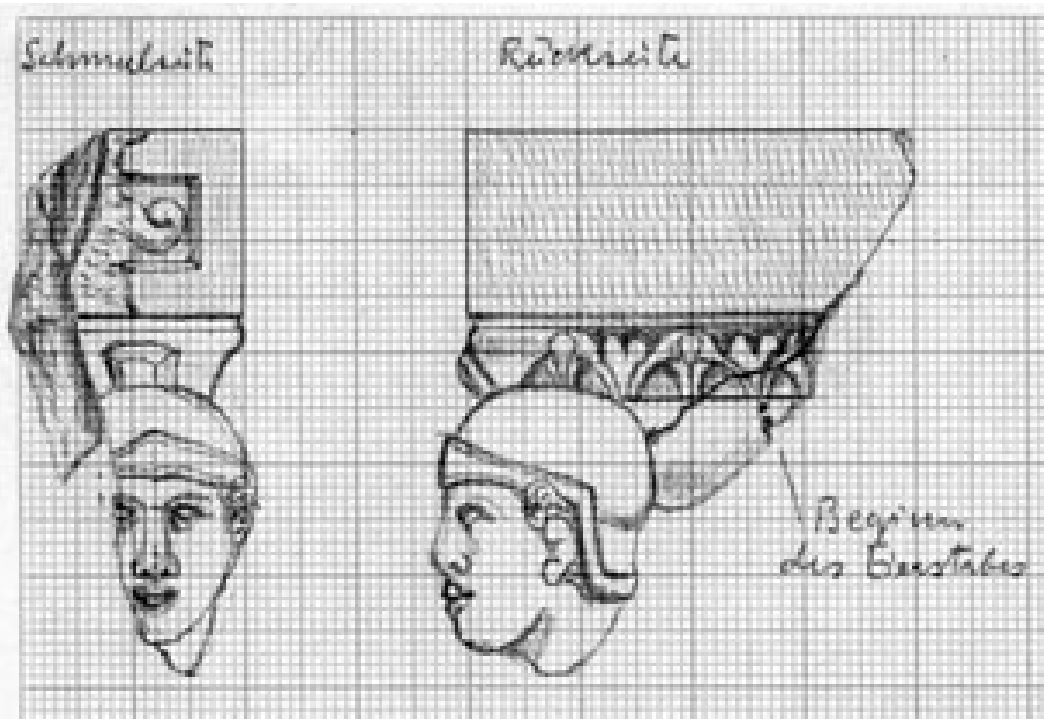

Abb. 24 Skizze F. Eichlers des verschollenen Fragments Abb. 23

Kat. 1 Schlachtsarkophag des [Quintus] Aemilius Aristides 
Tafel 9

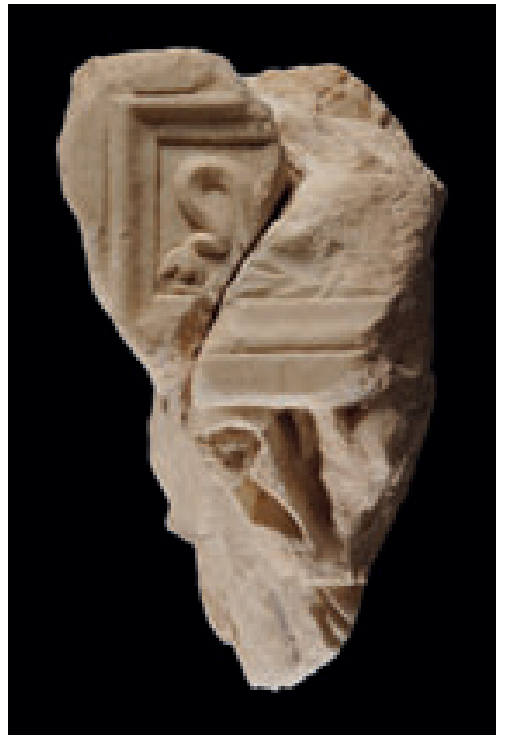

Abb. 25 Zwei anpassende Fragmente des oberen linken Eckfeldes der Vorderseite (Fragment 8)

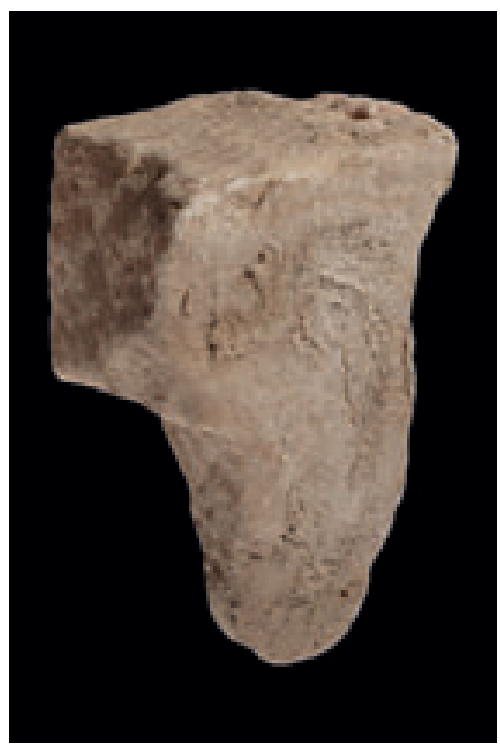

Abb. 28 Fragment 11: keilförmiges Bruchstück mit Falz, Oberseite des Kastens

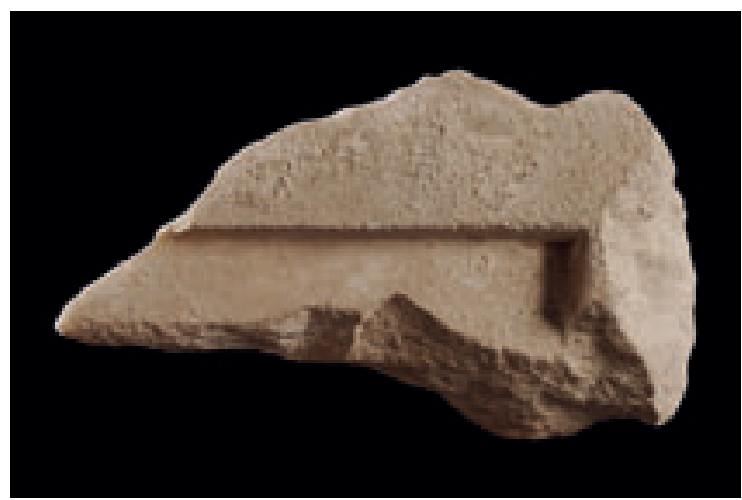

Abb. 30 Fragment 13 eines Eckfeldes

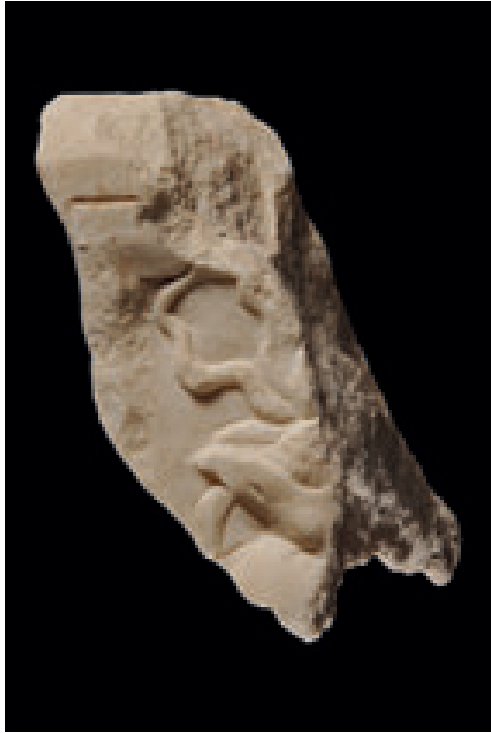

Abb. 26 Fragment 9 eines Eckfeldes

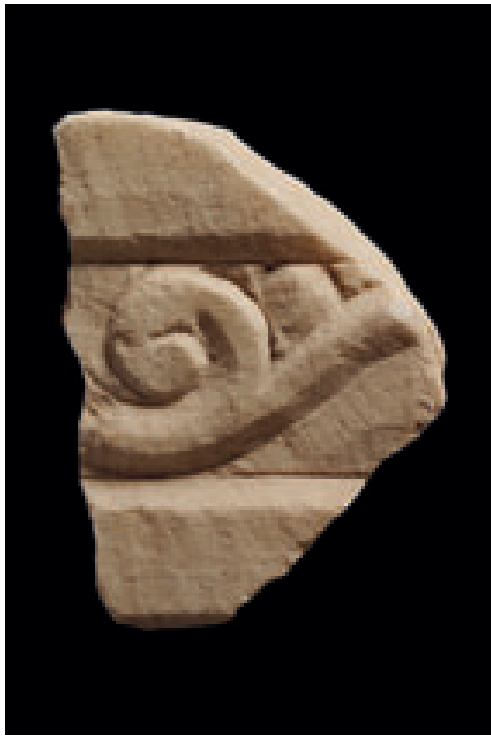

Abb. 27 Fragment 10 eines oberen Eckfeldes

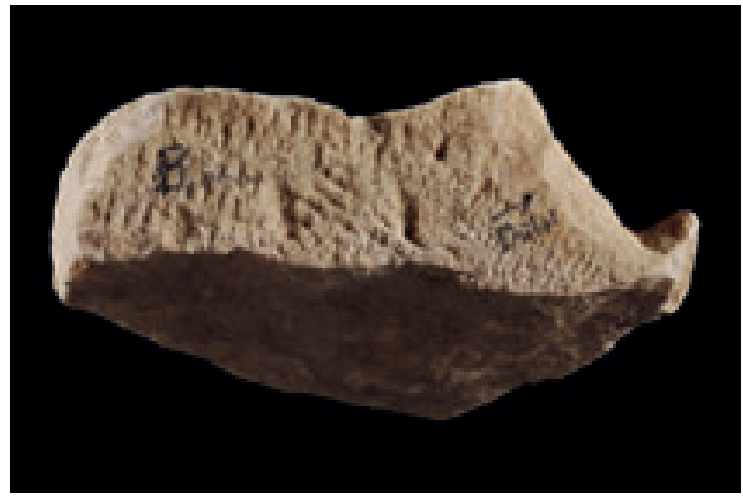

Abb. 29 Fragment 12 mit Klammerloch

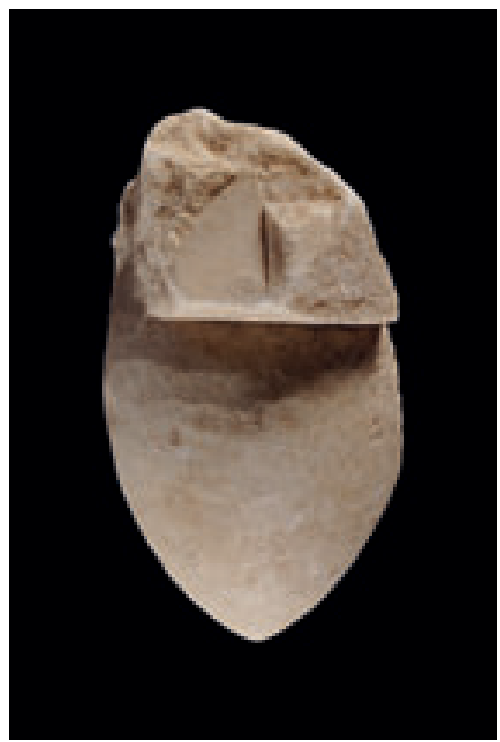

Abb. 31 Fragment 14: Eierstab

Kat. 1 Schlachtsarkophag des [Quintus] Aemilius Aristides 
Tafel 10

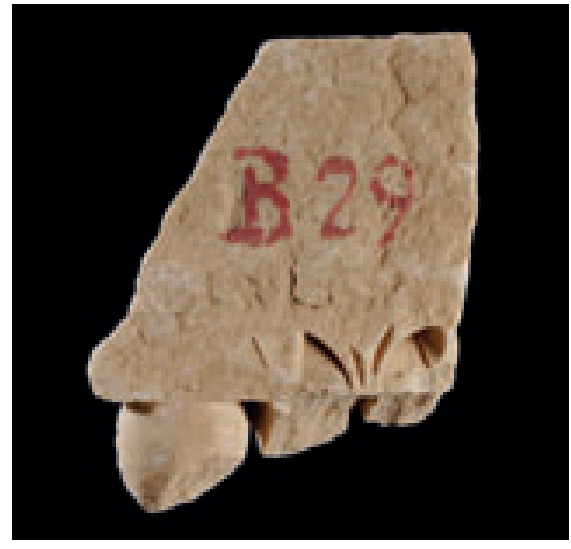

Abb. 32 Fragment 15

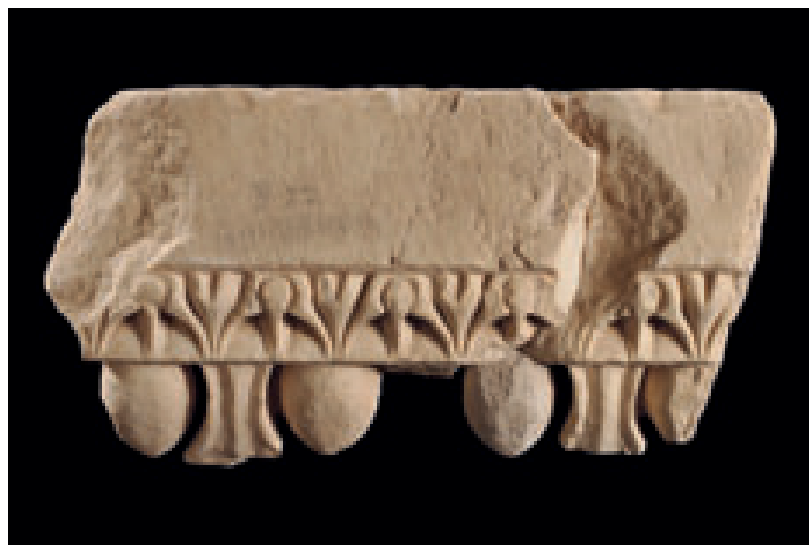

Abb. 34 Fragment 17

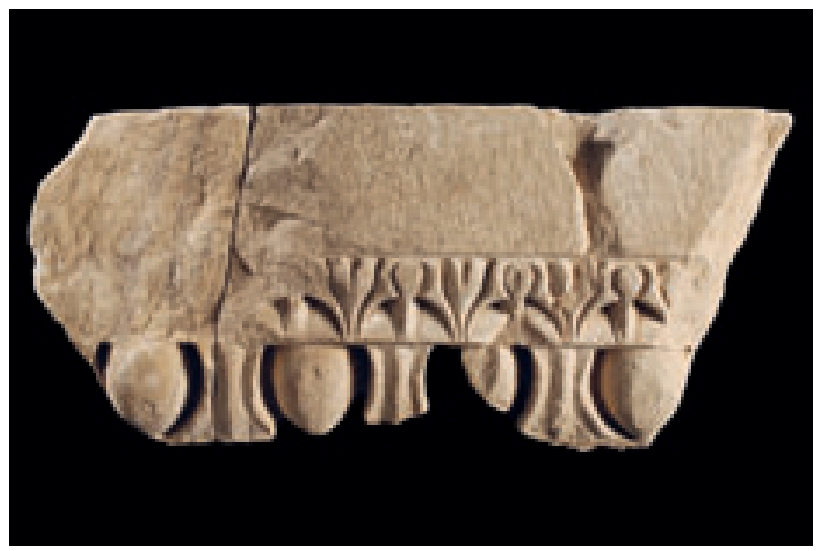

Abb. 36 Fragment 19

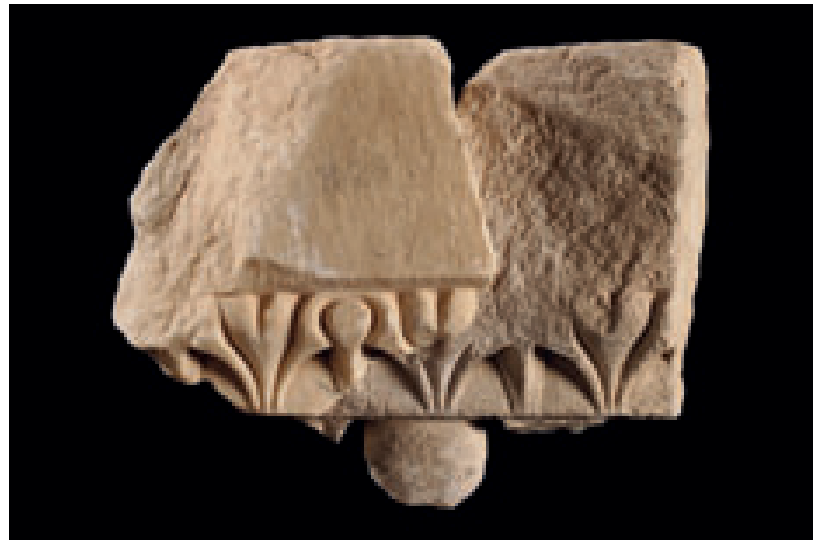

Abb. 33 Fragment 16

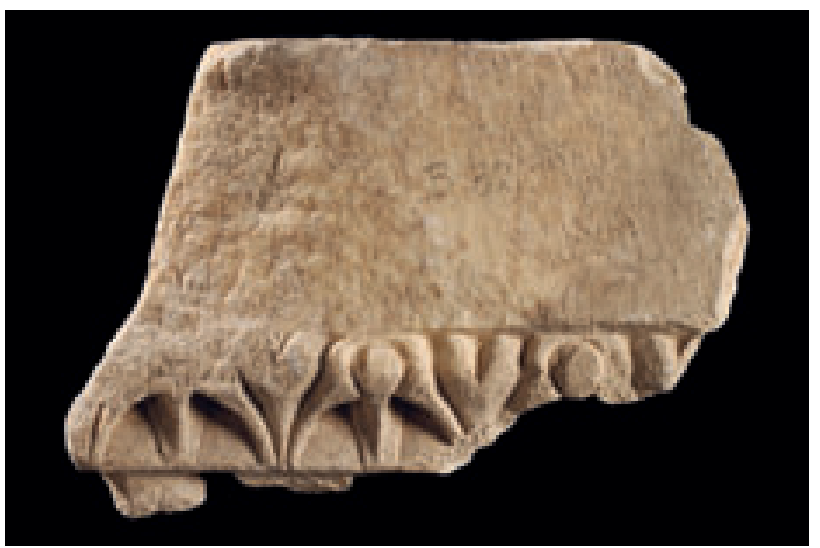

Abb. 35 Fragment 18

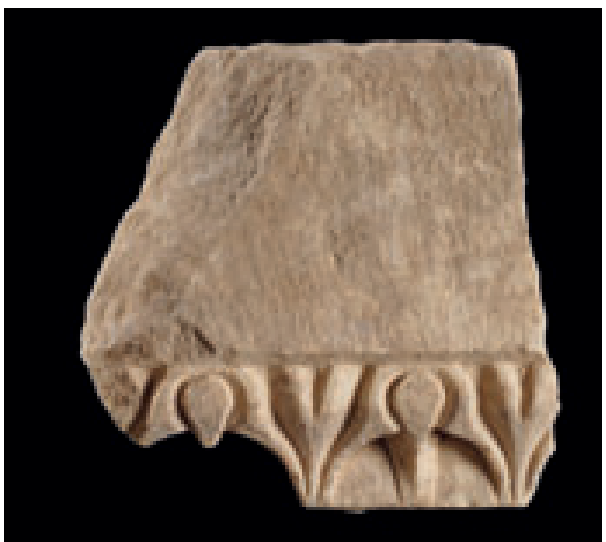

Abb. 37 Fragment 20

Kat. 1 Schlachtsarkophag des [Quintus] Aemilius Aristides, Fragmente des oberen Kastenabschlusses 
Tafel 11

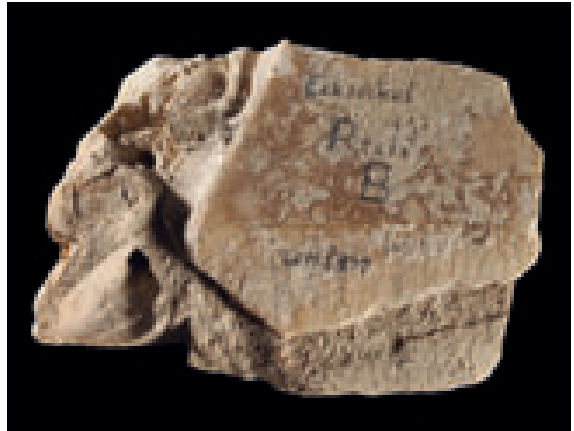

Abb. 38 Fragment 23: Fragment des rechten Eckpostaments der Vorderseite

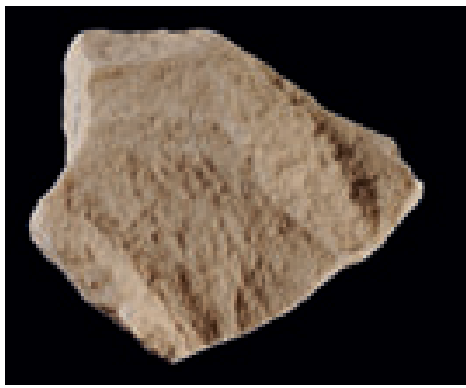

Abb. 41 Fragment 45: Sockelfragment
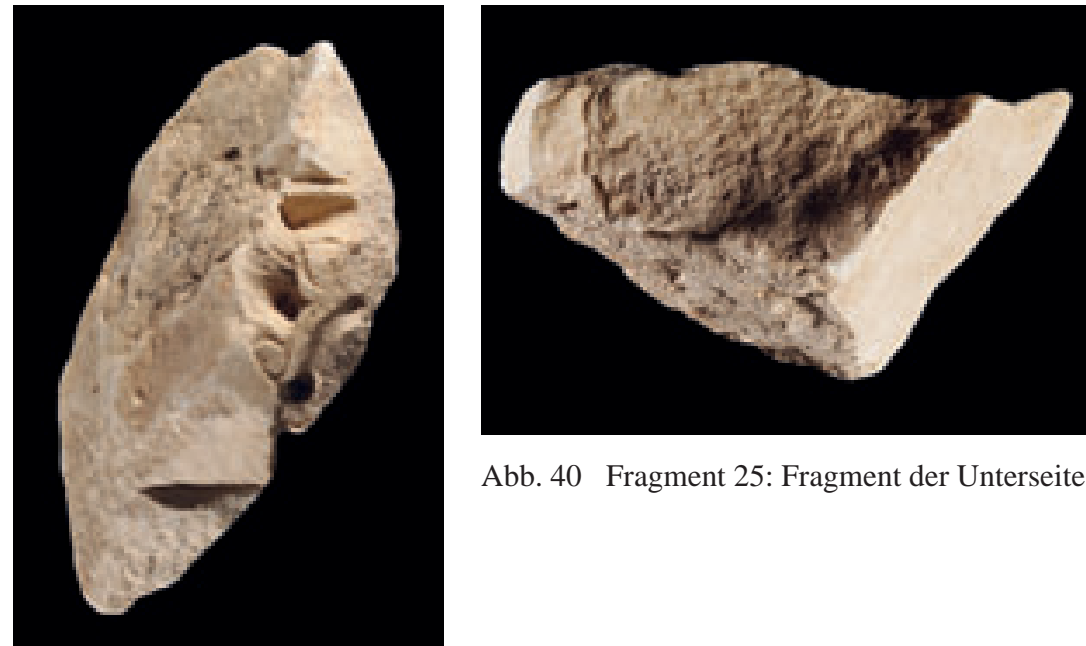

Abb. 40 Fragment 25: Fragment der Unterseite

Abb. 39 Fragment 24: linkes Ende des Flechtbands

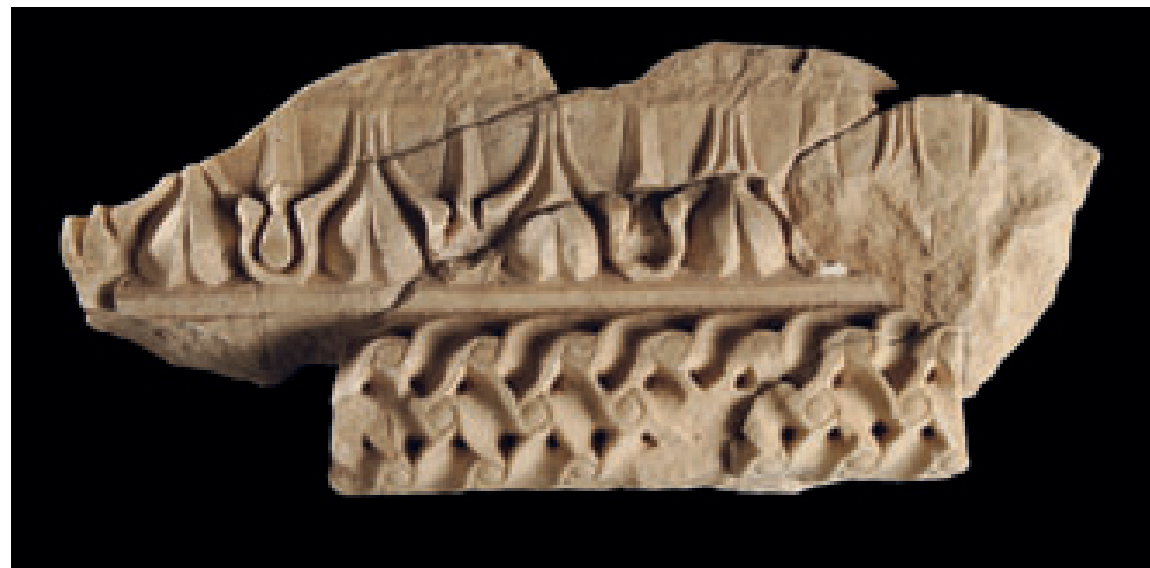

Abb. 42 Fragment 26: Sockelfragment

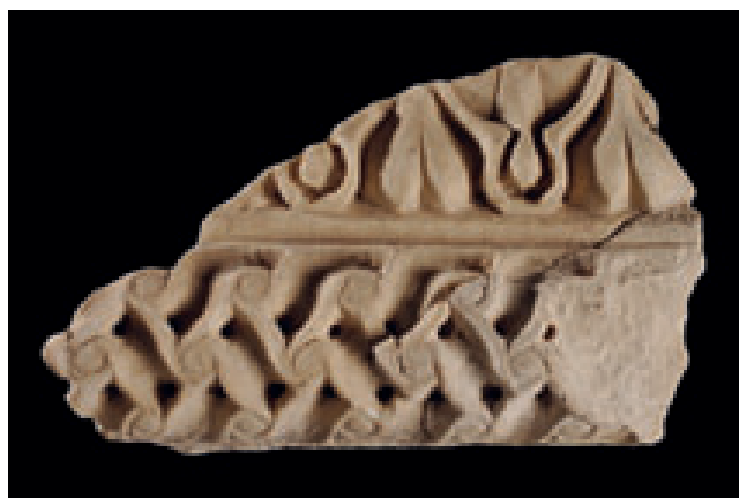

Abb. 43 Fragment 27: Sockelfragment

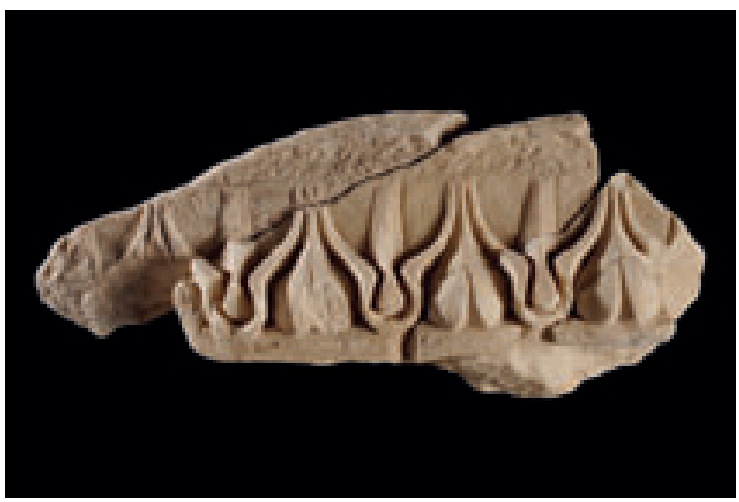

Abb. 44 Fragment 28: Sockelfragment 
Tafel 12

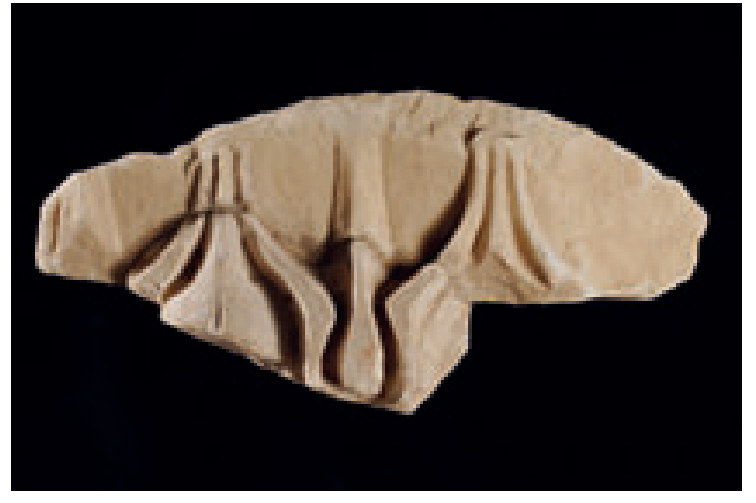

Abb. 45 Fragment 29

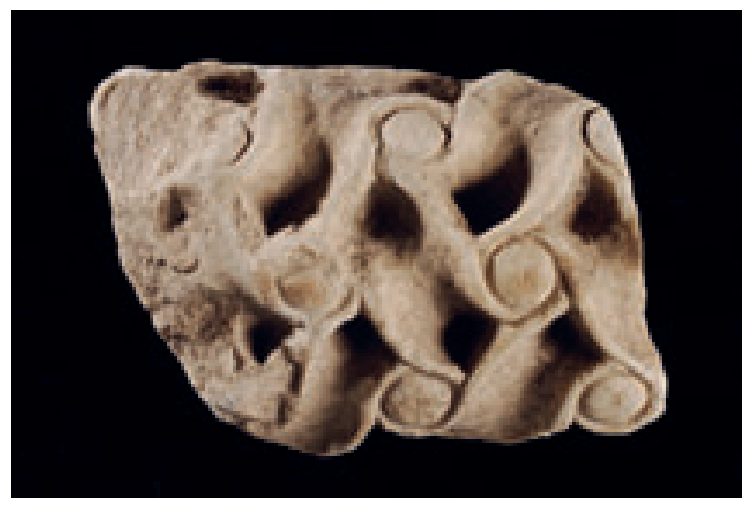

Abb. 47 Fragment 31

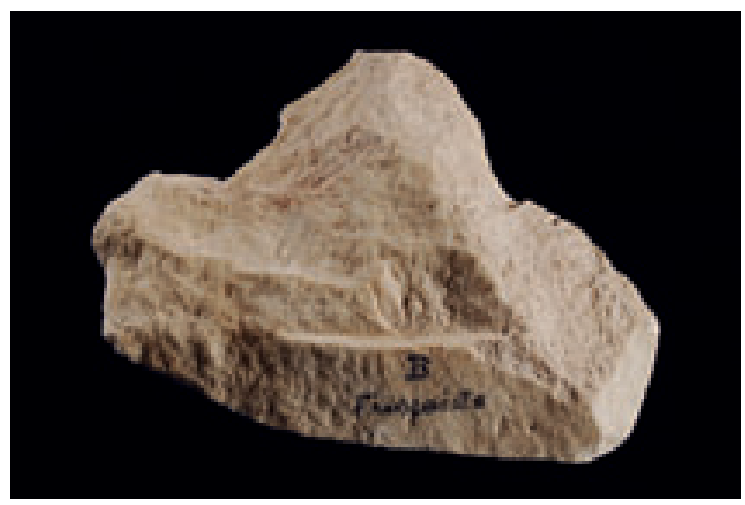

Abb. 49 Fragment 33

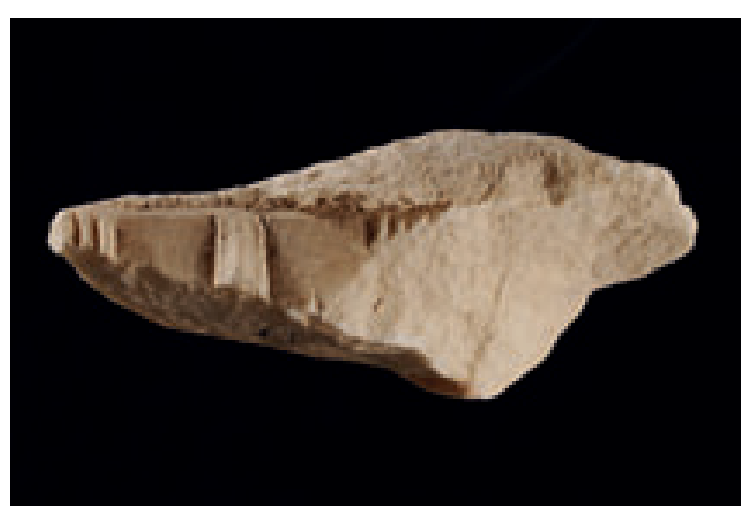

Abb. 51 Fragment 35

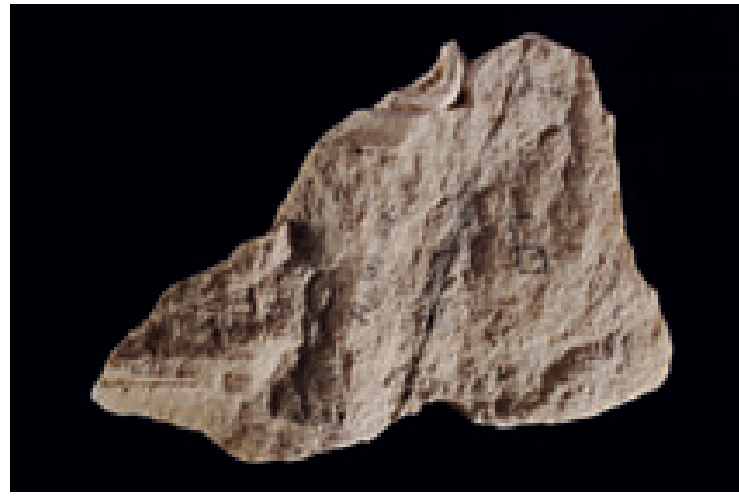

Abb. 46 Fragment 30

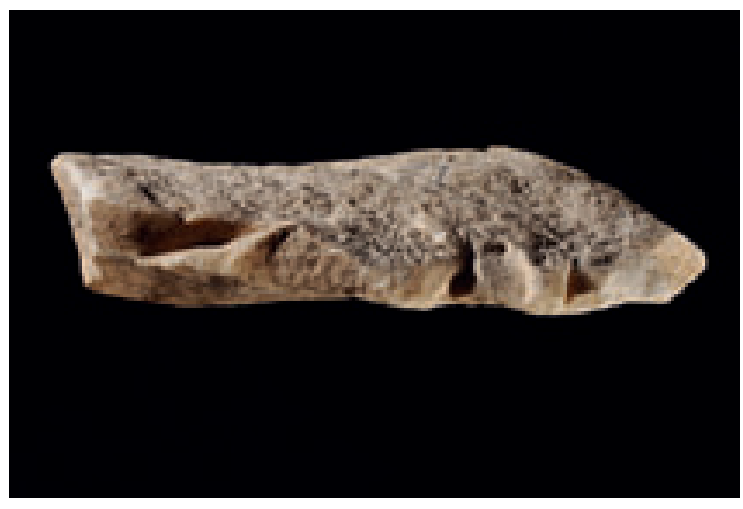

Abb. 48 Fragment 32

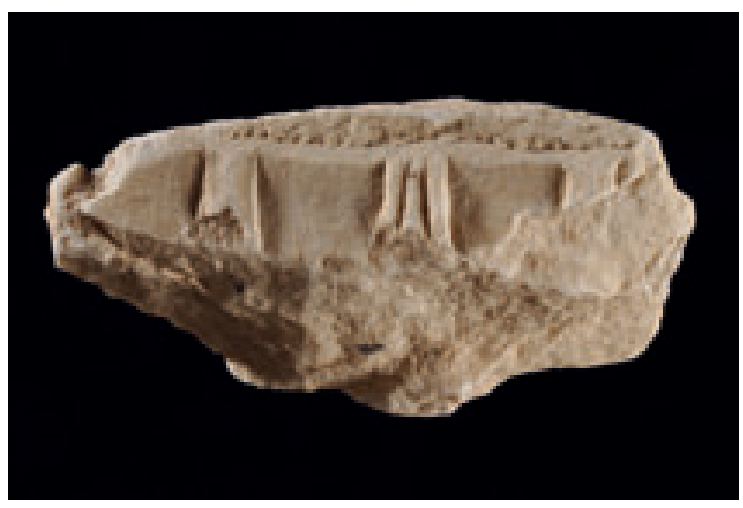

Abb. 50 Fragment 34

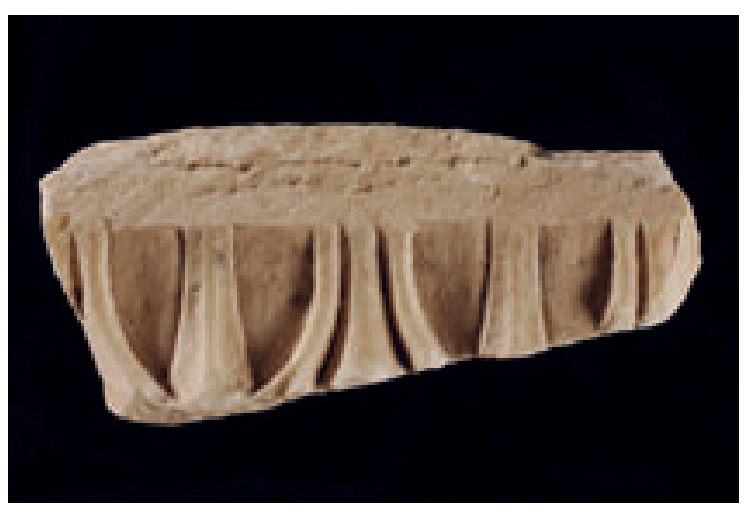

Abb. 52 Fragment 36

Kat. 1 Schlachtsarkophag des [Quintus] Aemilius Aristides, Sockelfragmente 
Tafel 13

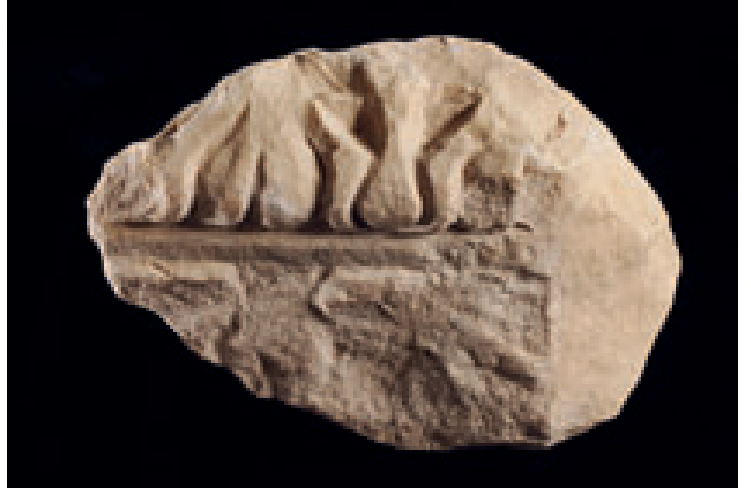

Abb. 53 Fragment 37

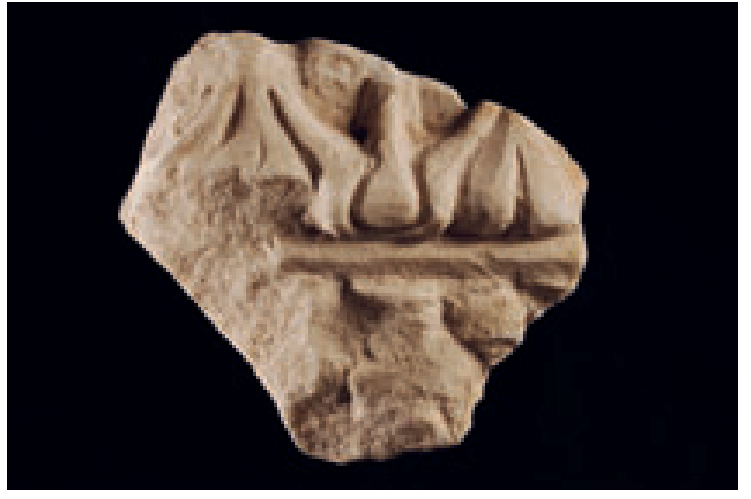

Abb. 55 Fragment 39

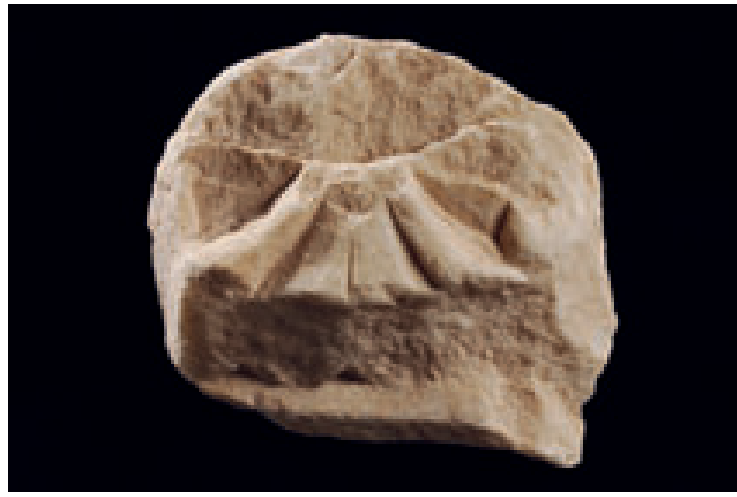

Abb. 57 Fragment 41

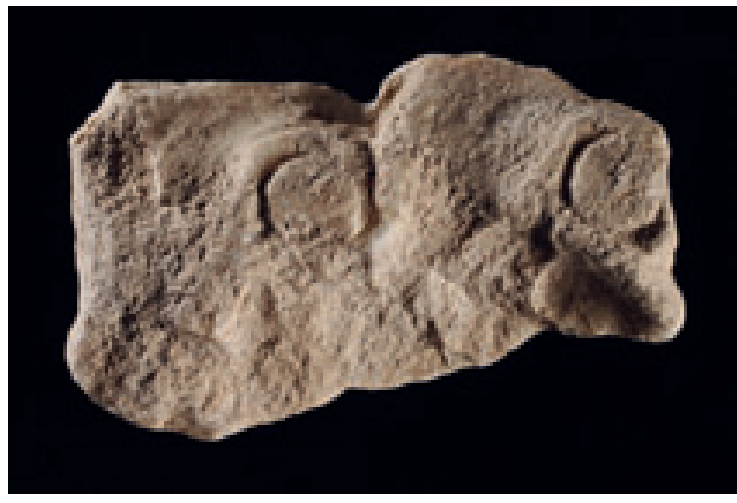

Abb. 59 Fragment 43

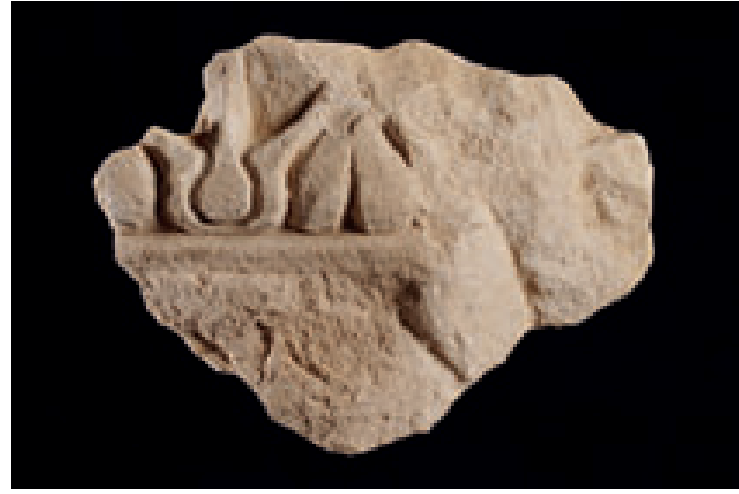

Abb. 54 Fragment 38

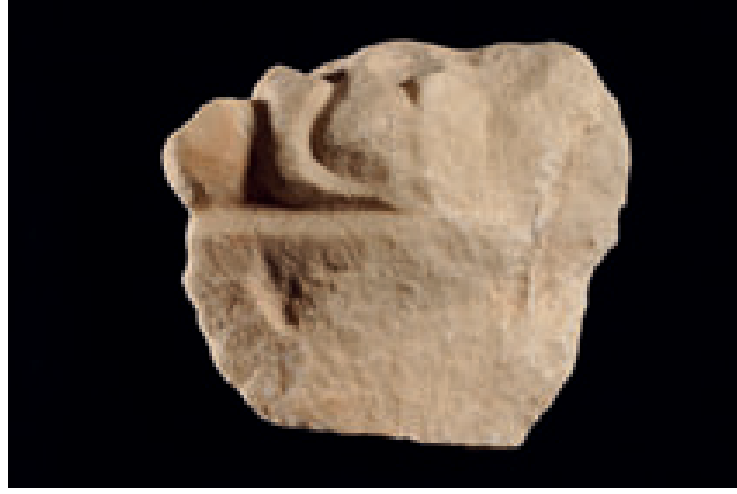

Abb. 56 Fragment 40

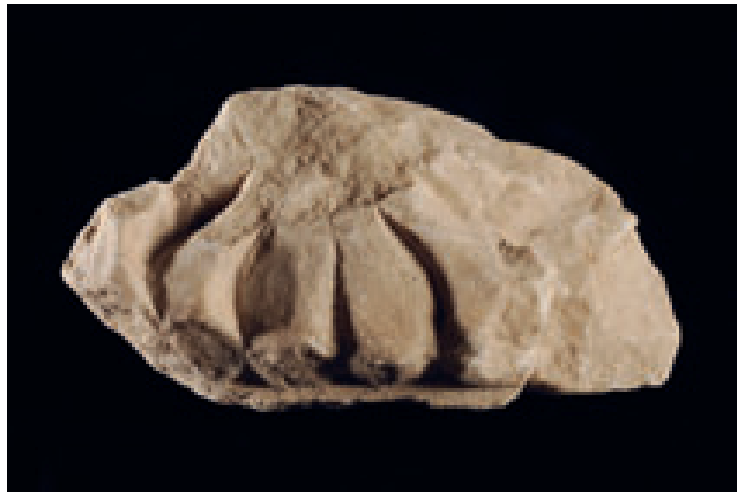

Abb. 58 Fragment 42

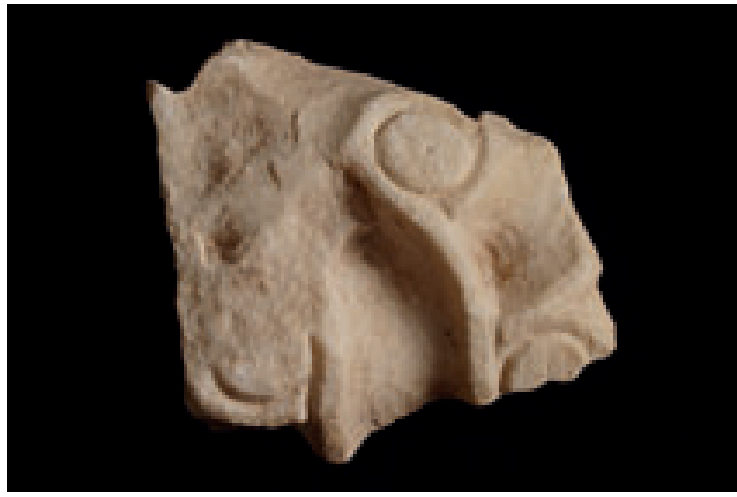

Abb. 60 Fragment 44

Kat. 1 Schlachtsarkophag des [Quintus] Aemilius Aristides, Sockelfragmente 
Tafel 14

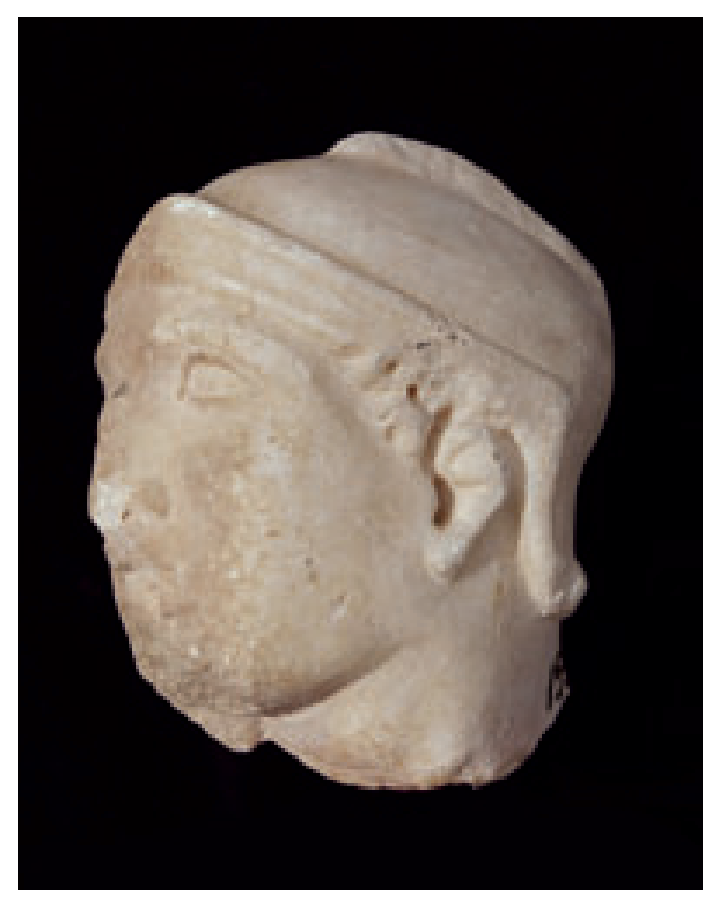

Abb. 61 Kopf des Reiters der rechten Schmalseite. Izmir, Historisches und Kunsthistorisches Museum Inv. 1555

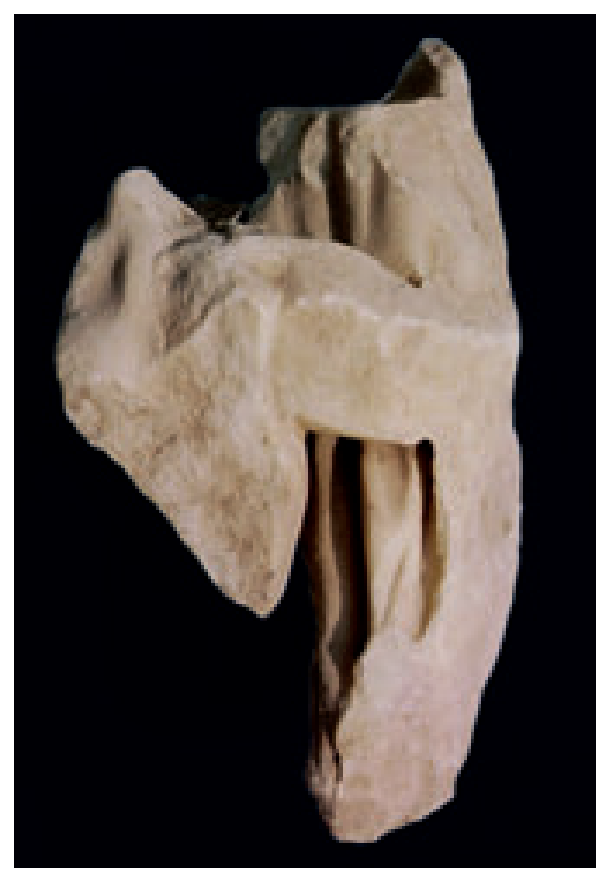

Abb. 63 Fragment 47

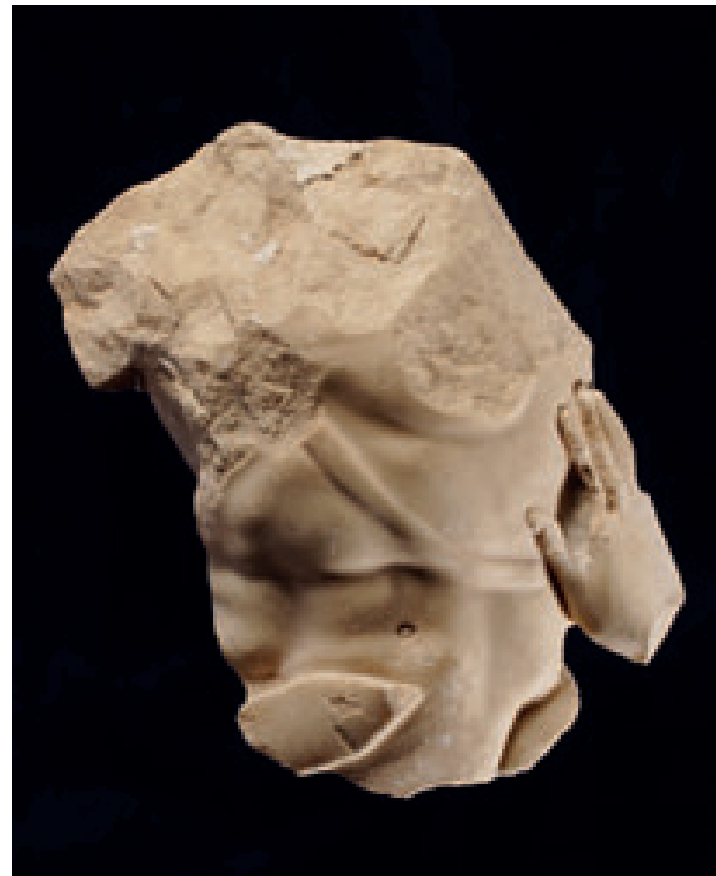

Abb. 62 Fragment 46

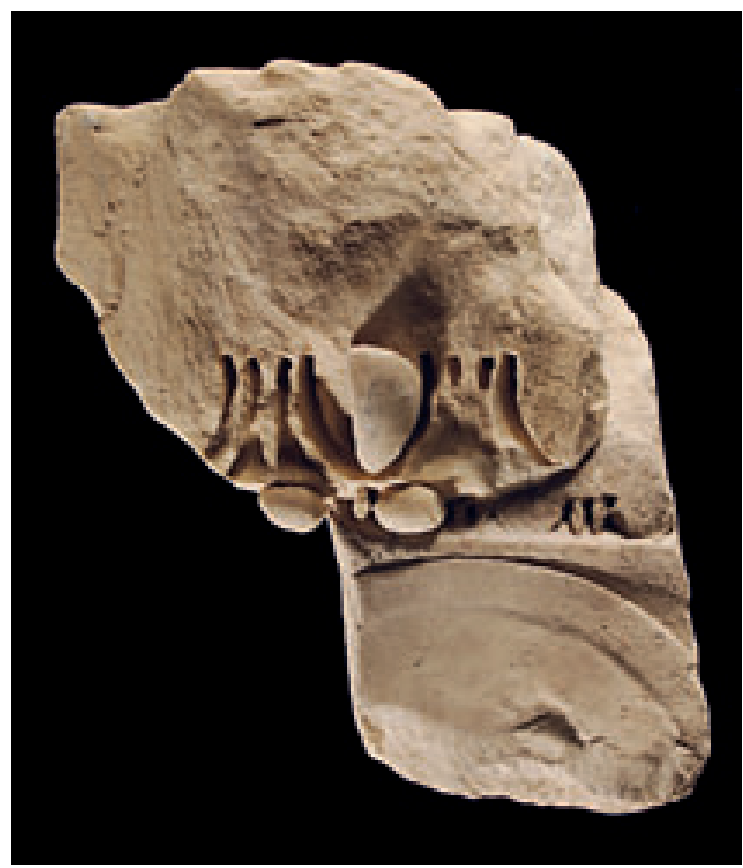

Abb. 64 Fragment 48

Kat. 1 Schlachtsarkophag des [Quintus] Aemilius Aristides, Friesfragmente 
Tafel 15

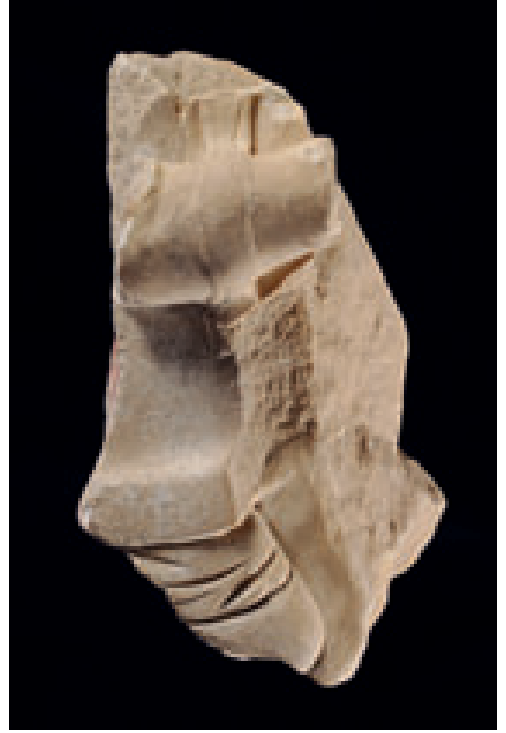

Abb. 65 Fragment 49

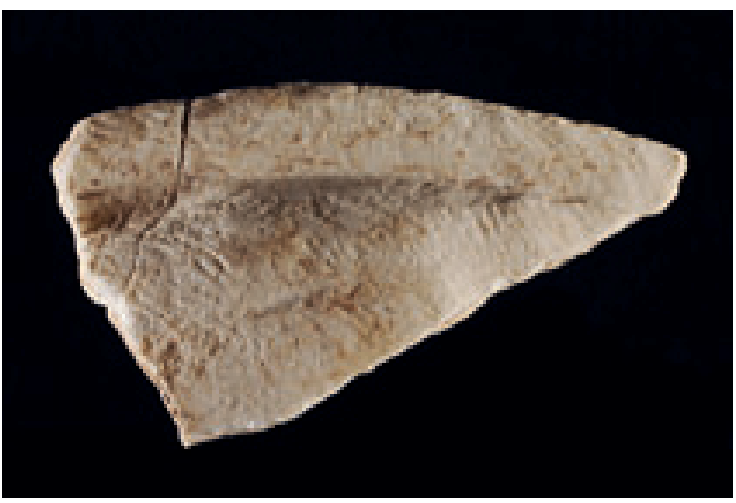

Abb. 67 Fragment 51

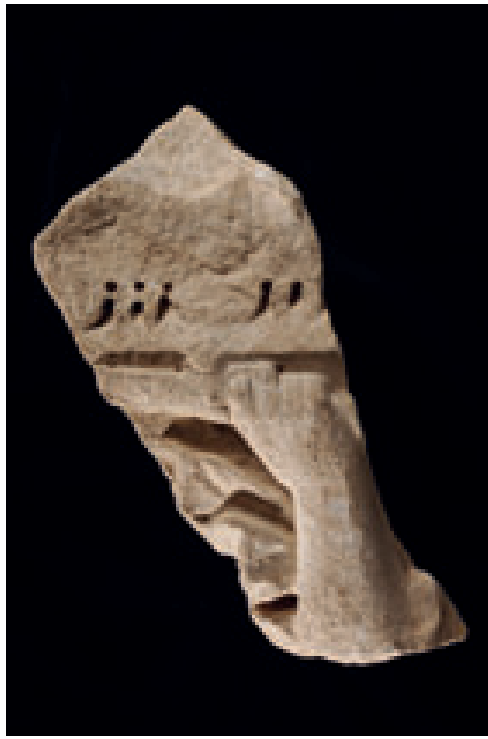

Abb. 69 Fragment 53

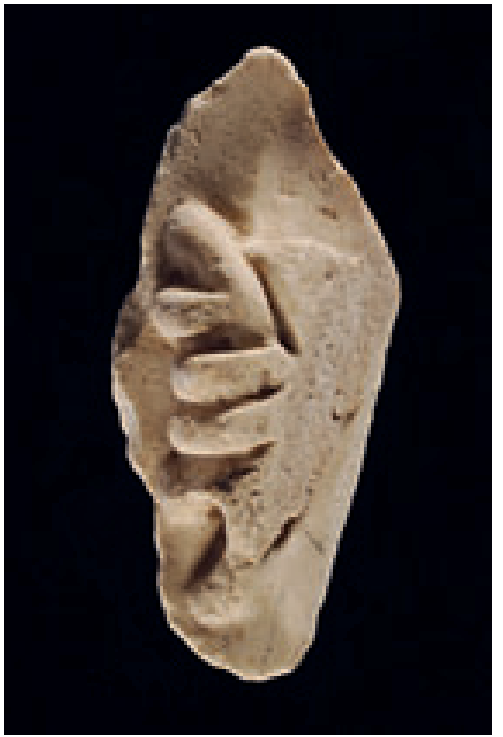

Abb. 66 Fragment 50

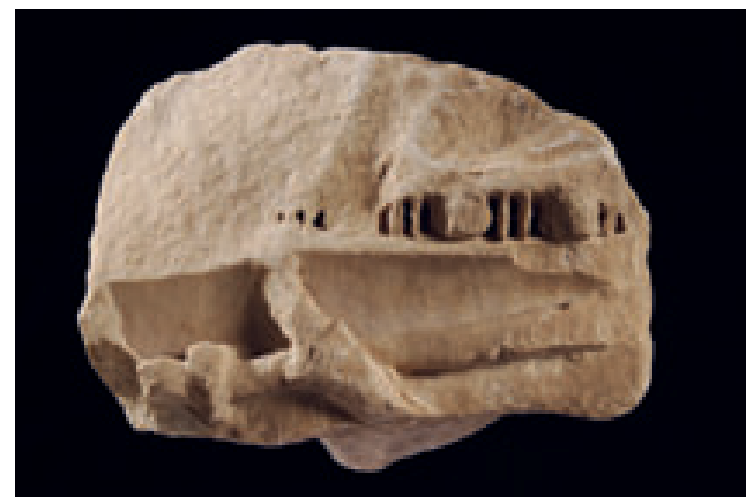

Abb. 68 Fragment 52

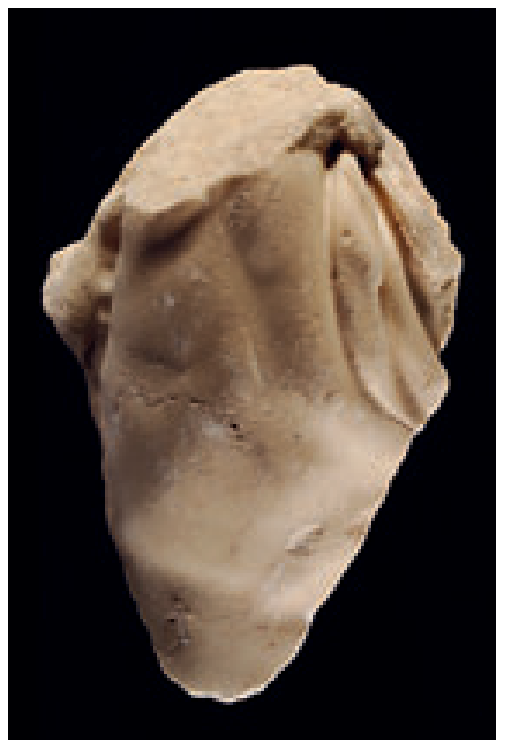

Abb. 70 Fragment 54

Kat. 1 Schlachtsarkophag des [Quintus] Aemilius Aristides, Friesfragmente 
Tafel 16

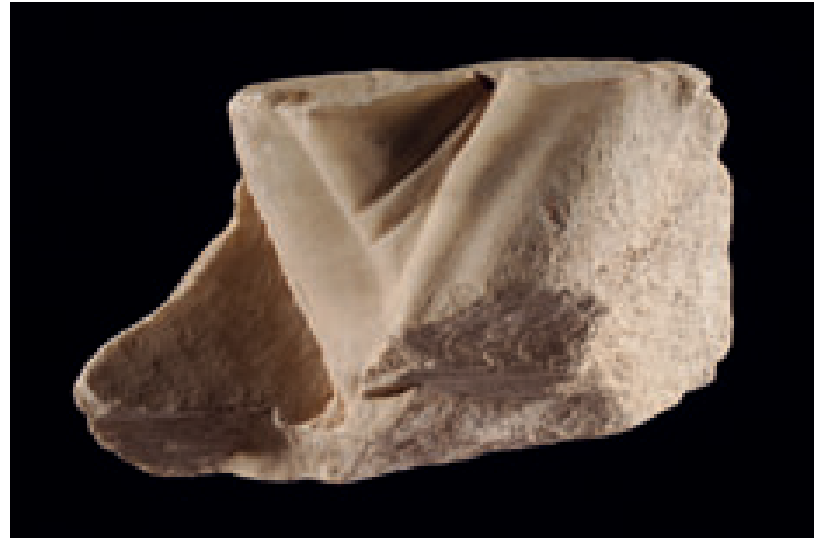

Abb. 71 Fragment 55

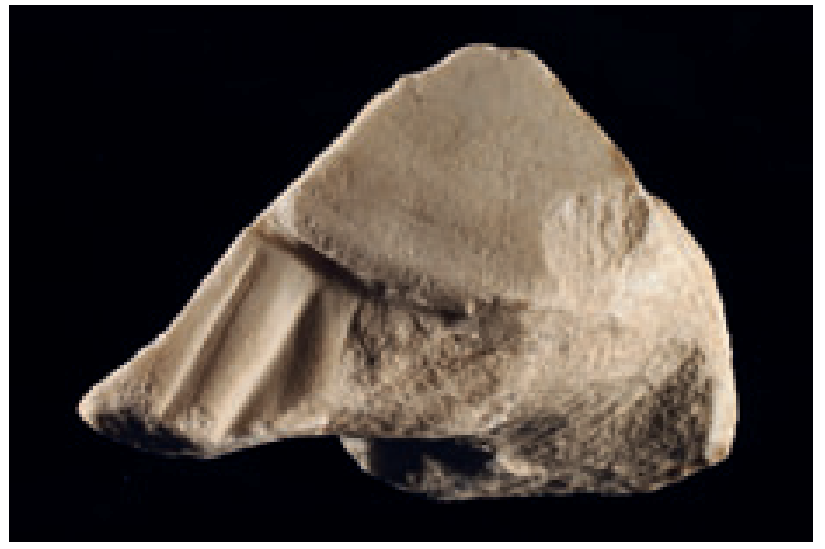

Abb. 73 Fragment 57

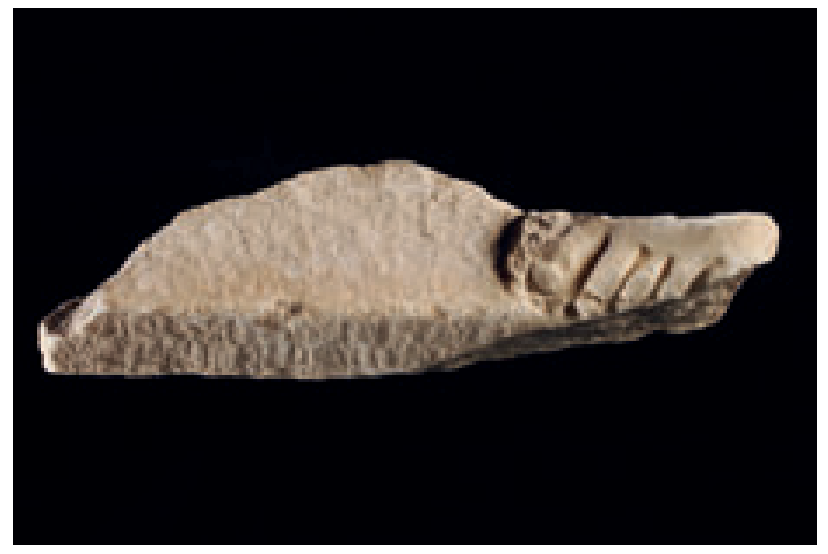

Abb. 75 Fragment 59

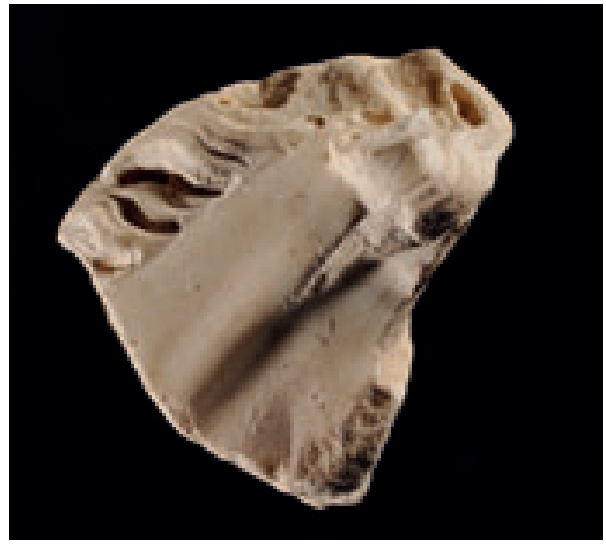

Abb. 72 Fragment 56

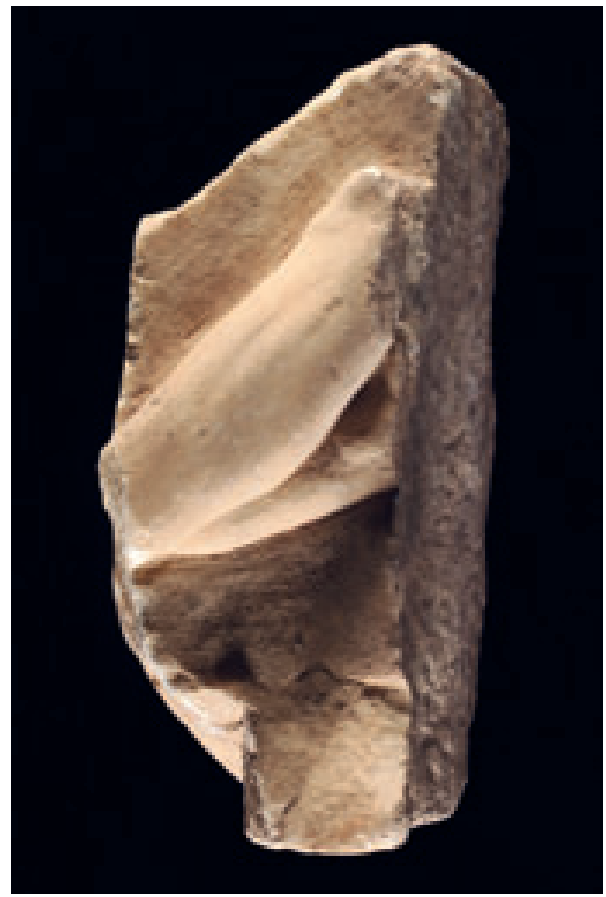

Abb. 74 Fragment 58

Kat. 1 Schlachtsarkophag des [Quintus] Aemilius Aristides, Friesfragmente 
Tafel 17

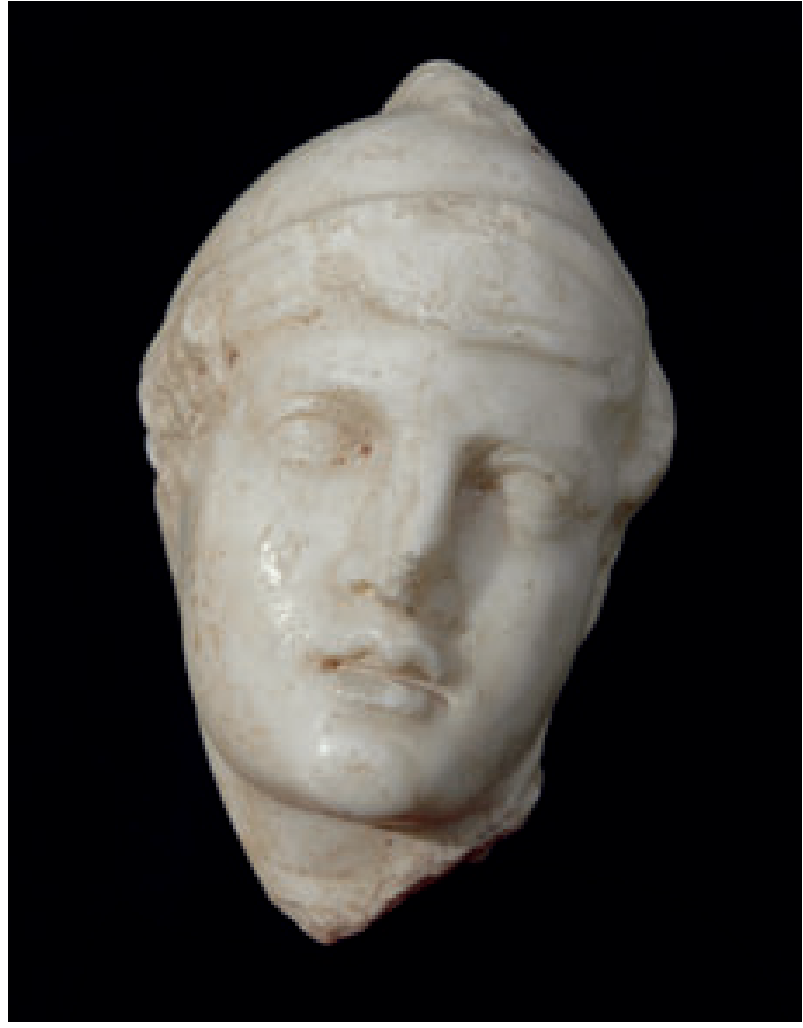

Abb. 76 Kriegerkopf. Historisches und Kunsthistorisches Museum Izmir Inv. 1556

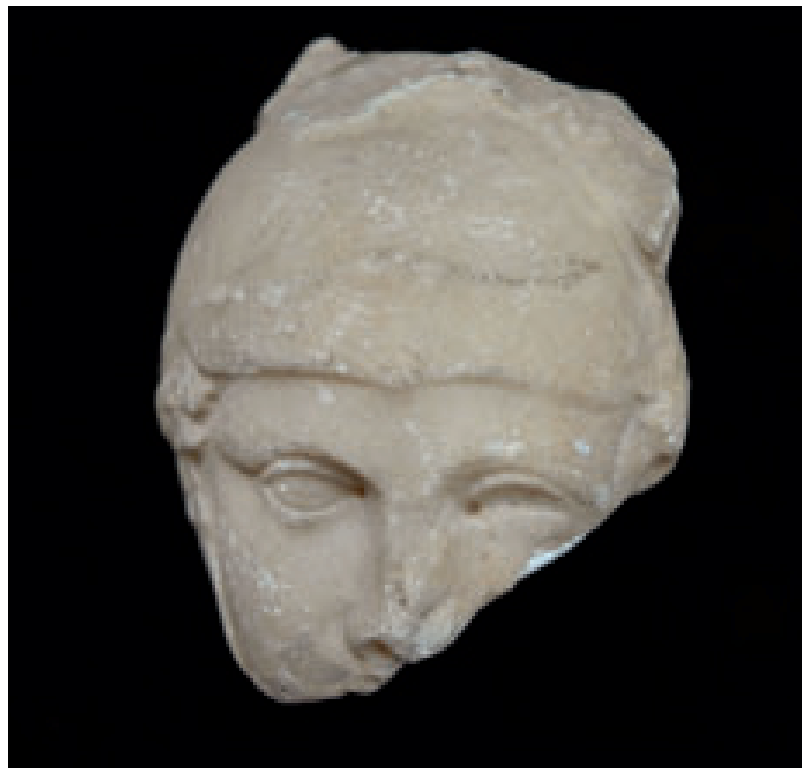

Abb. 78 Kriegerkopf. Historisches und Kunsthistorisches Museum Izmir Inv. 1013

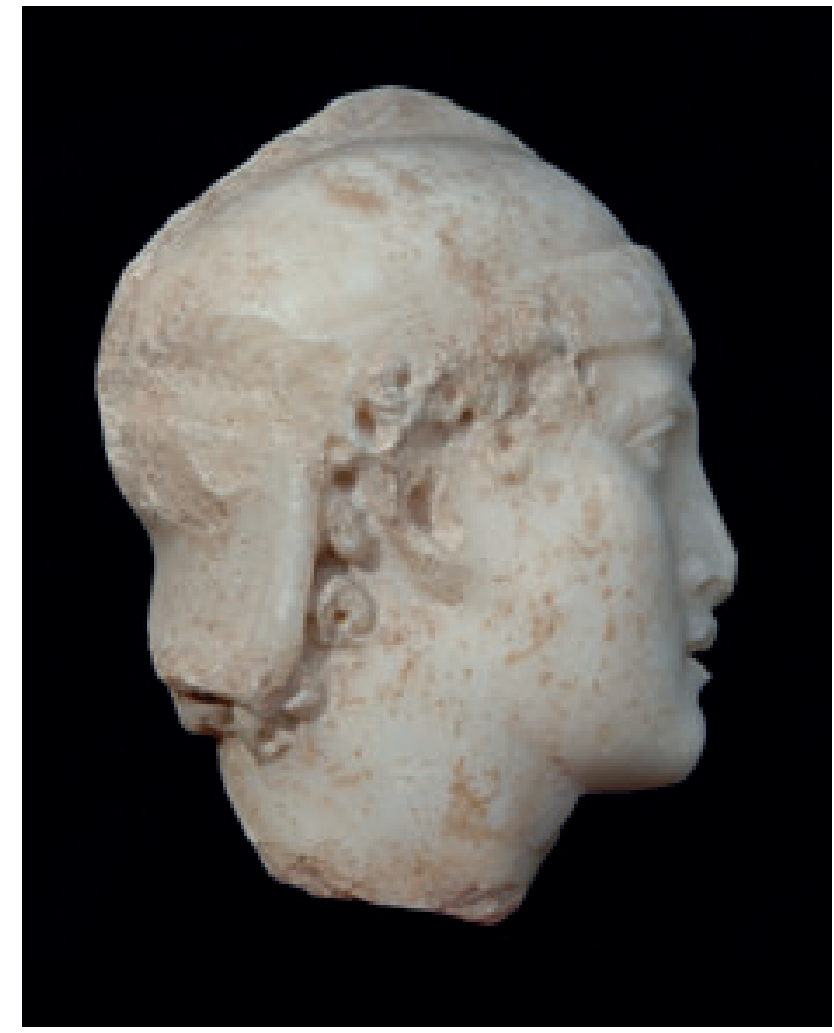

Abb. 77 Kriegerkopf. Historisches und Kunsthistorisches Museum Izmir Inv. 1556

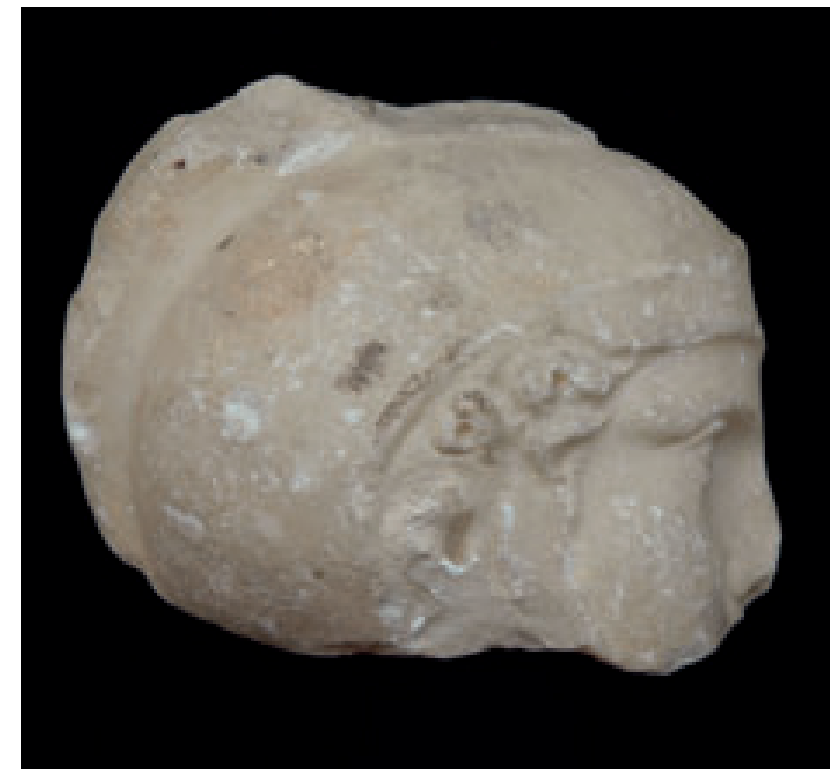

Abb. 79 Kriegerkopf. Historisches und Kunsthistorisches Museum Izmir Inv. 1013

Kat. 1 Schlachtsarkophag des [Quintus] Aemilius Aristides, Friesfragmente 
Tafel 18
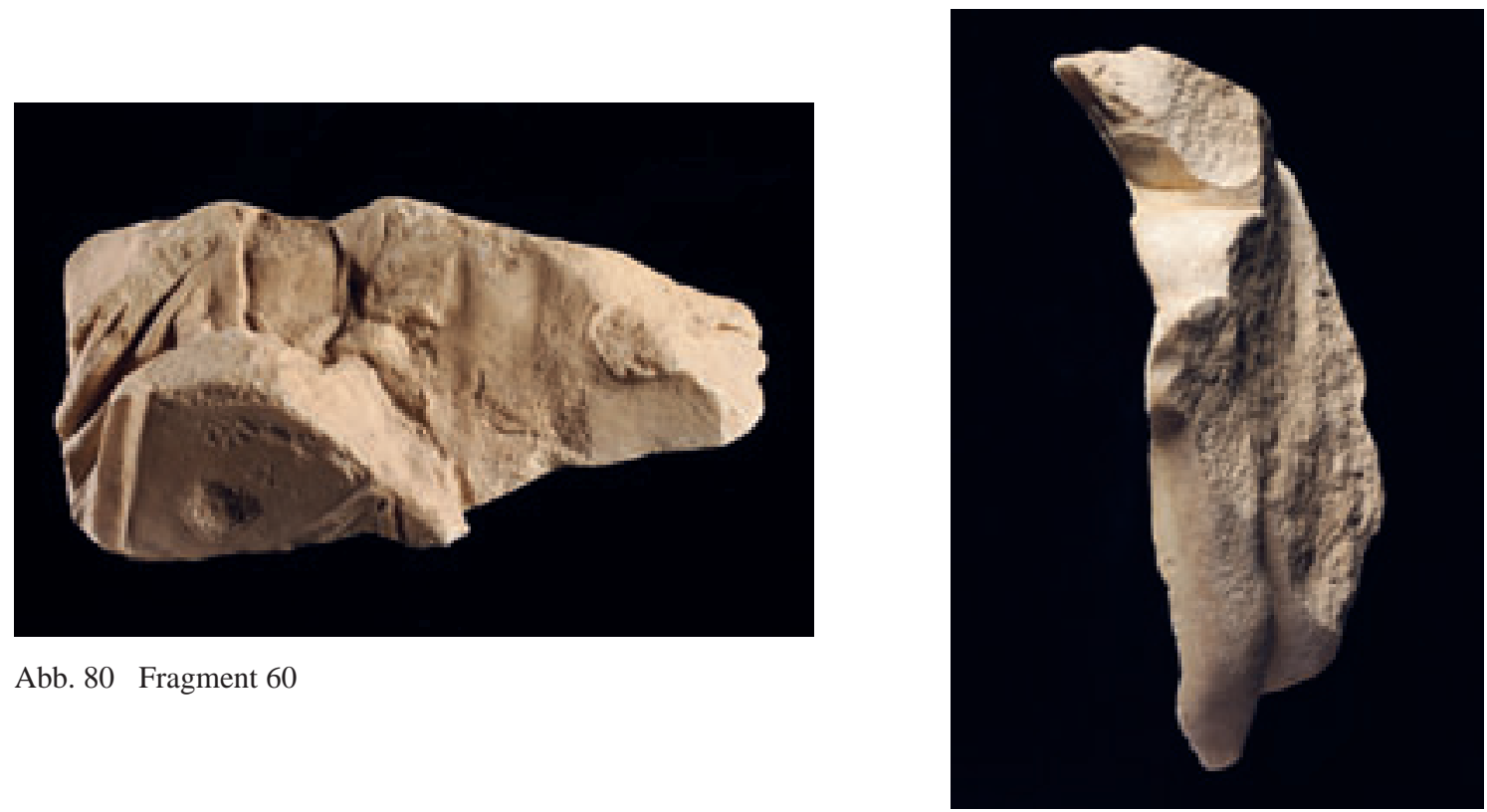

Abb. 81 Fragment 61
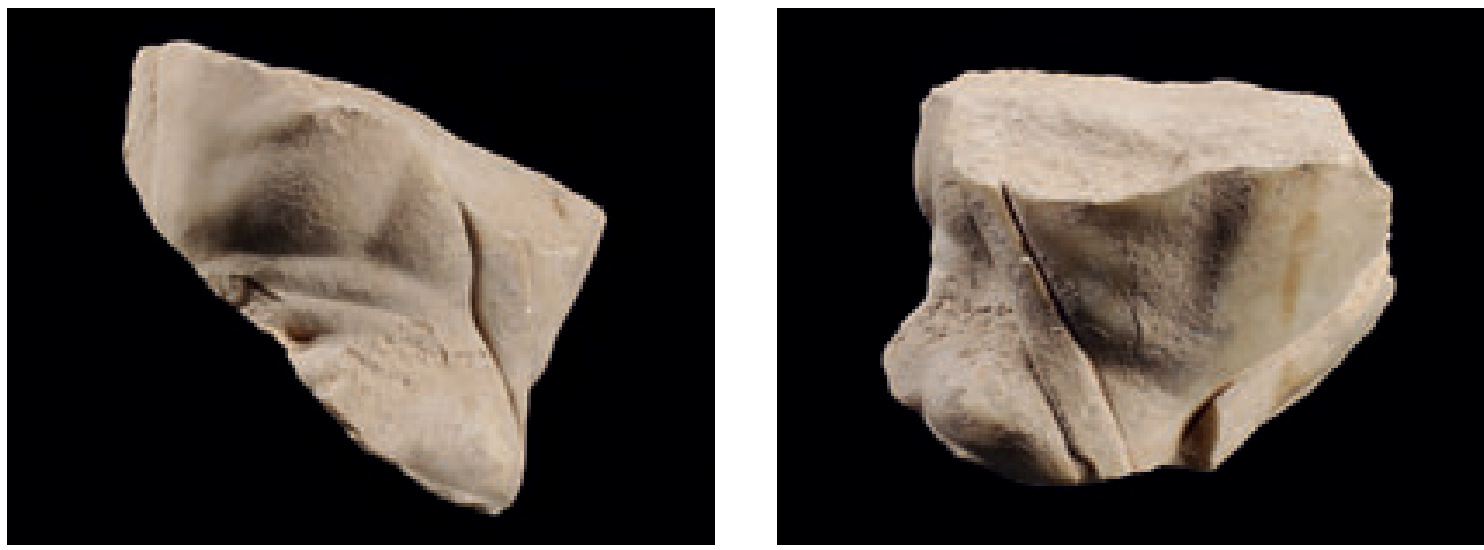

Abb. 82 Fragment 62

Abb. 83 Fragment 62

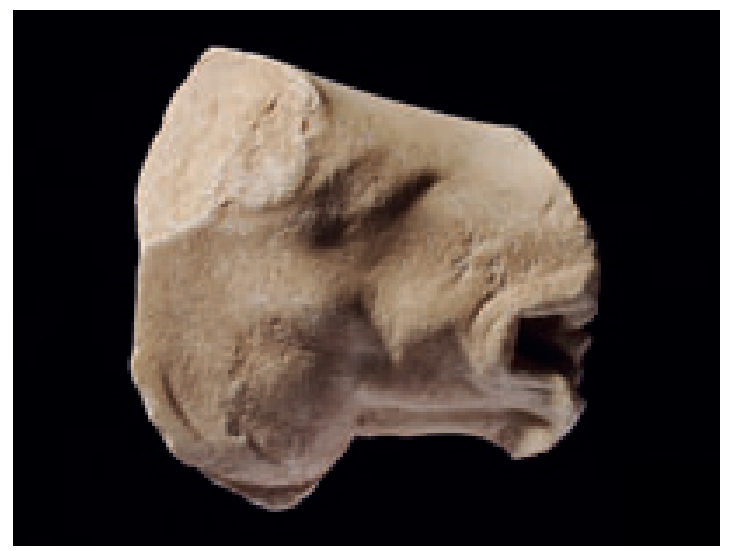

Abb. 84 Fragment 63

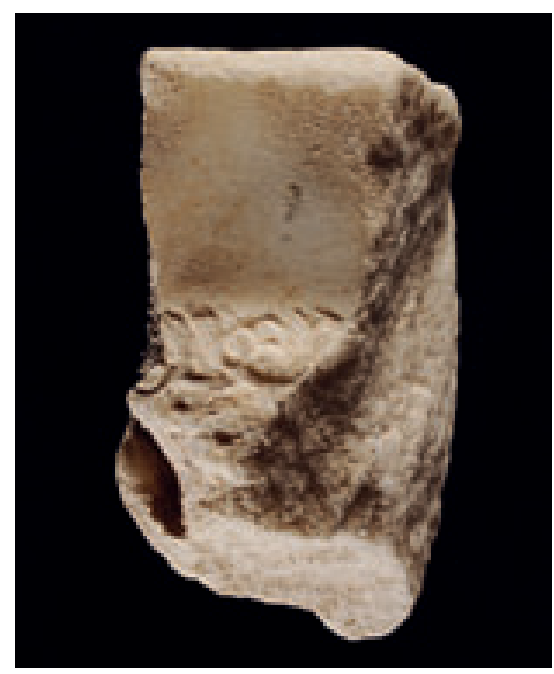

Abb. 85 Fragment 64

Kat. 1 Schlachtsarkophag des [Quintus] Aemilius Aristides, Friesfragmente 
Tafel 19

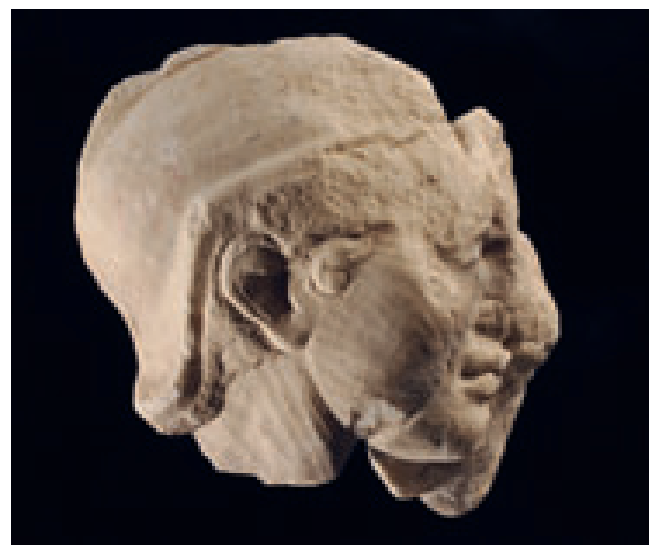

Abb. 86 Fragment 65

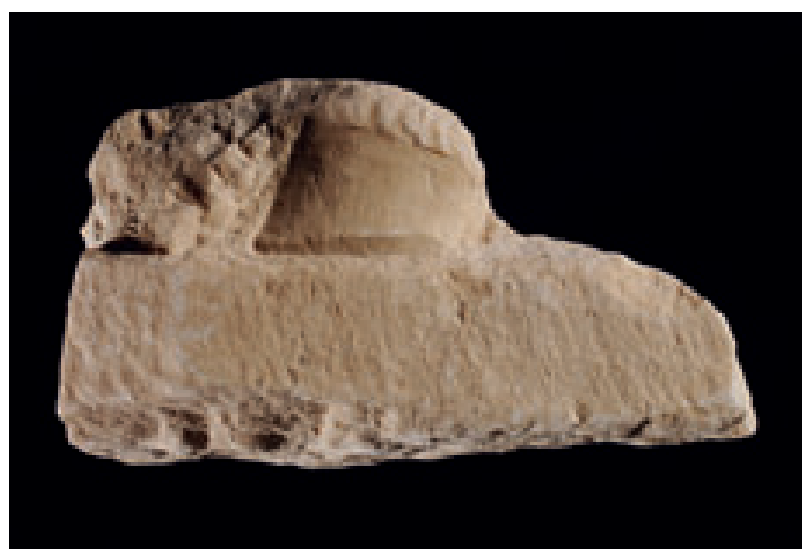

Abb. 88 Fragment 66

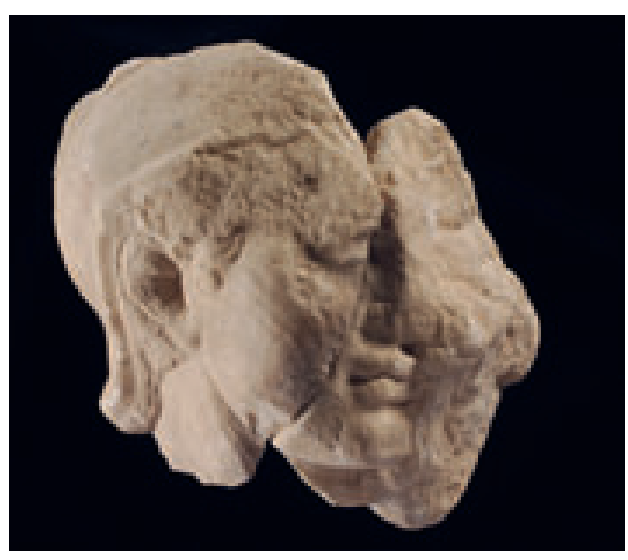

Abb. 87 Fragment 65

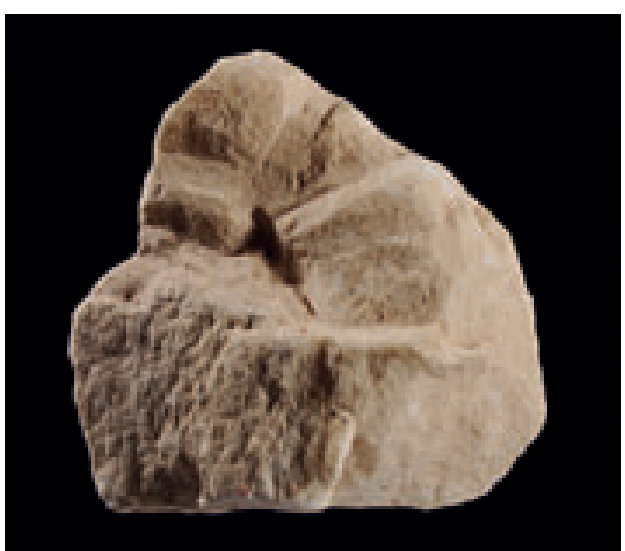

Abb. 89 Fragment 67

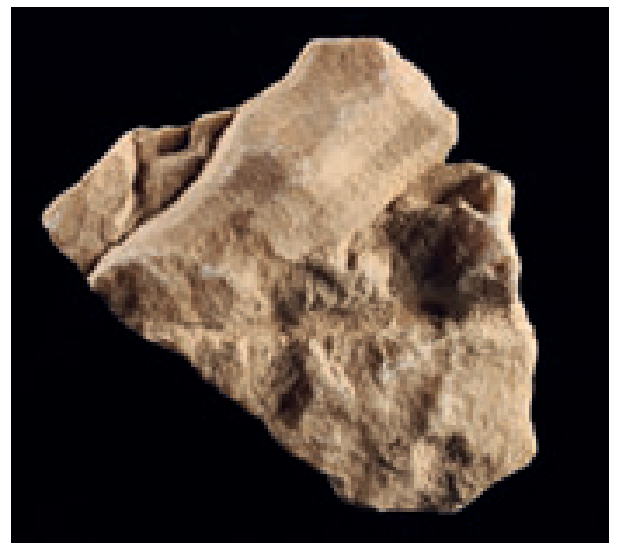

Abb. 90 Fragment 68

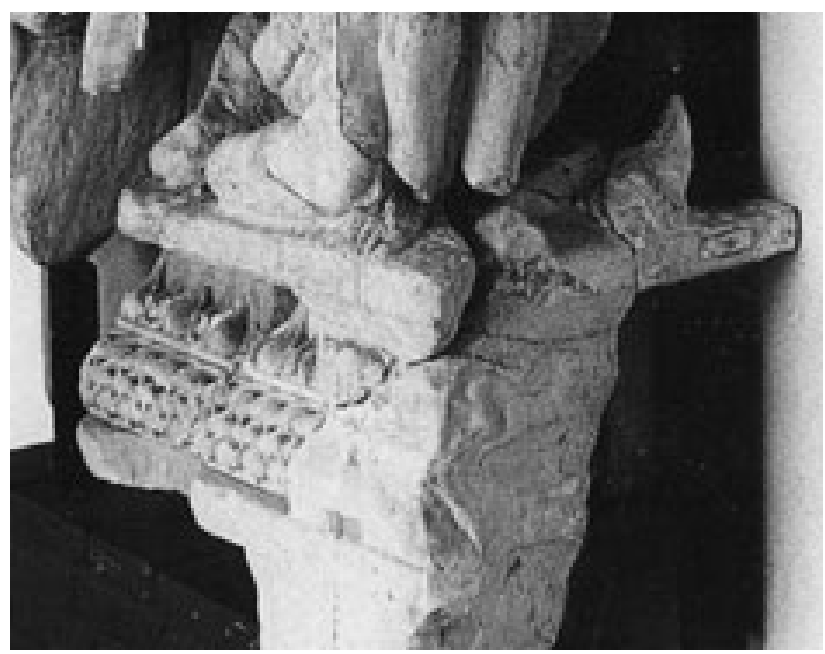

Abb. 91 Untere Ecke der rechten Schmalseite und Rückseite. Selçuk, Efes Müzesi Inv. 12 (alte Inv. 1589)

Kat. 1 Schlachtsarkophag des [Quintus] Aemilius Aristides, Rückseitenfragmente 
Tafel 20

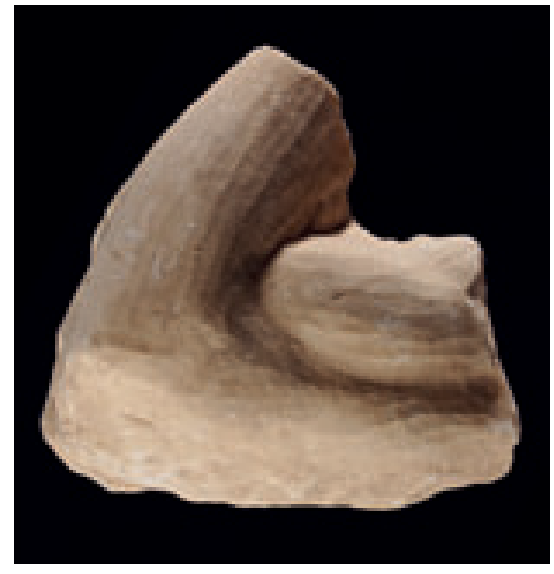

Abb. 92 Fragment 69

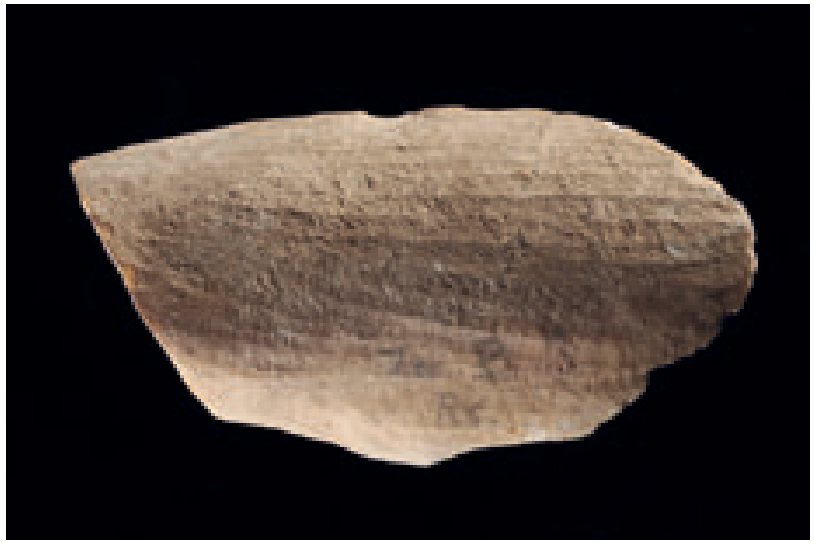

Abb. 93 Fragment 70

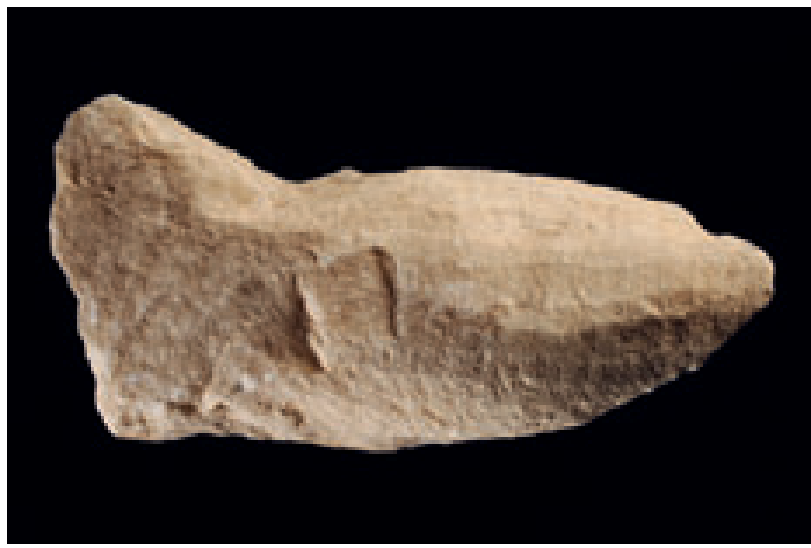

Abb. 94 Fragment 71

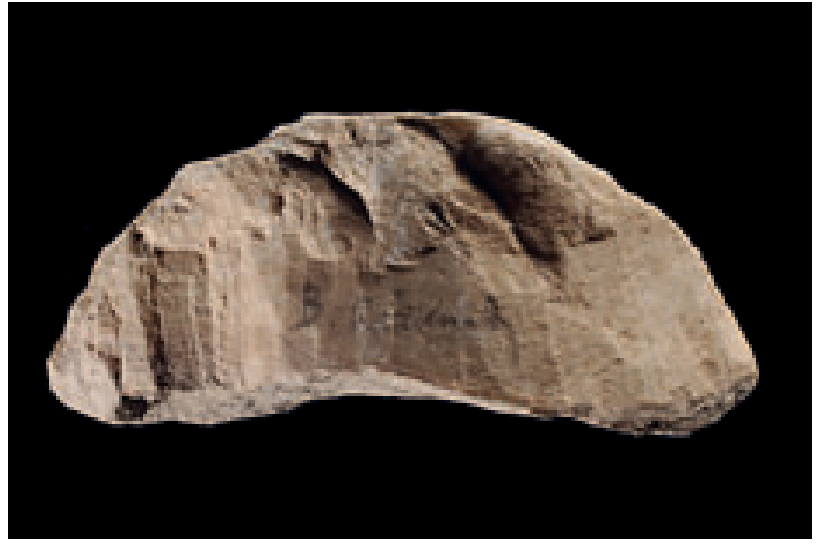

Abb. 95 Fragment 72

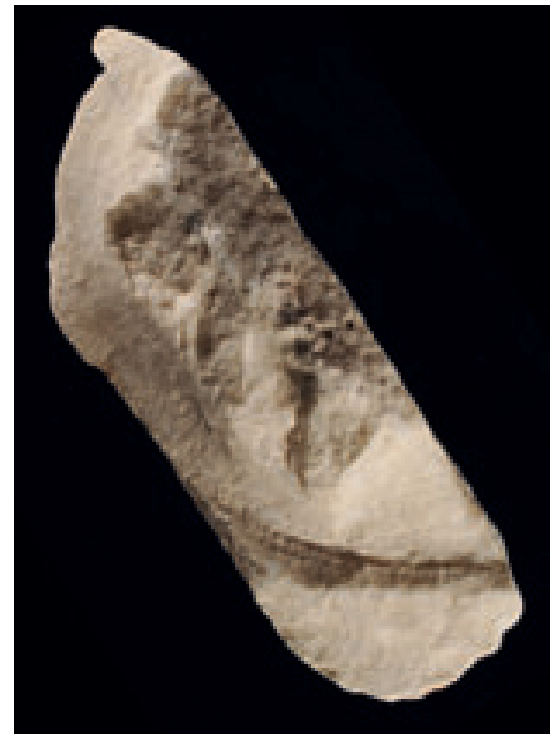

Abb. 96 Fragment 73

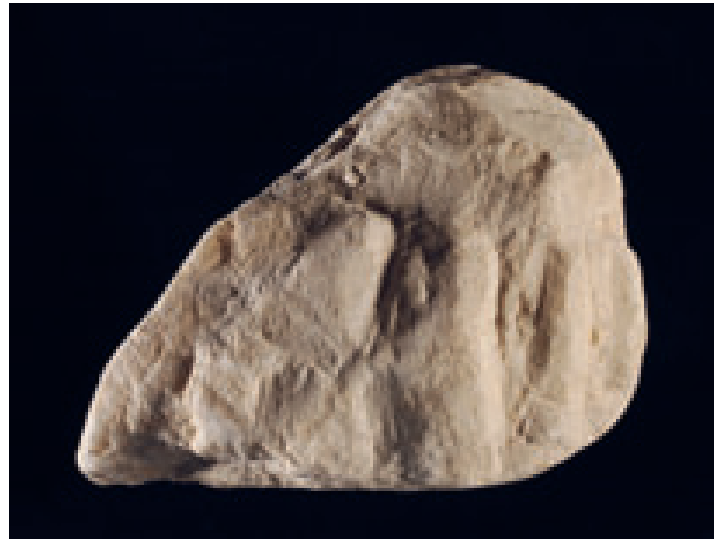

Abb. 97 Fragment 74

Kat. 1 Schlachtsarkophag des [Quintus] Aemilius Aristides, Rückseitenfragmente 
Tafel 21

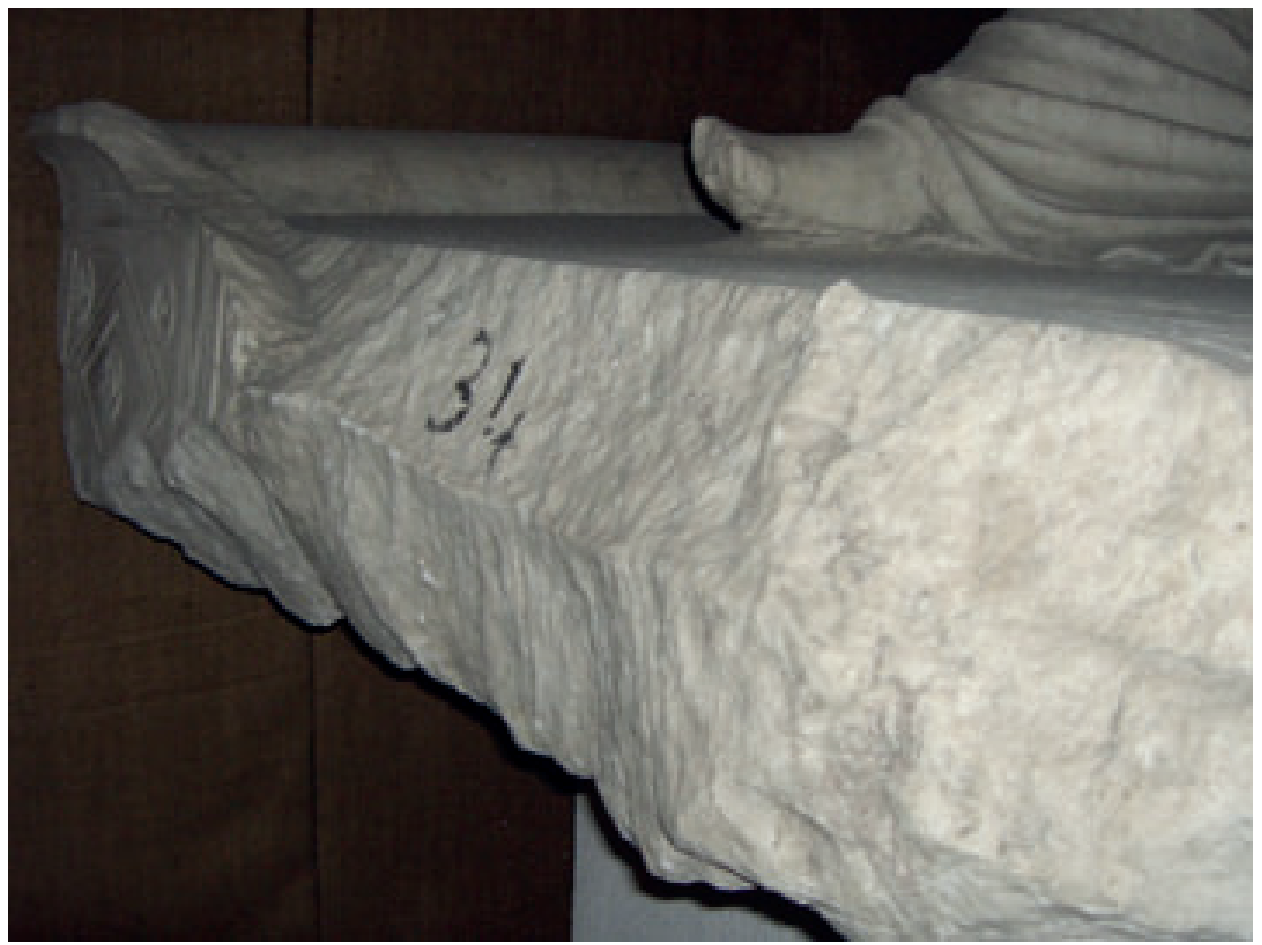

Abb. 98 Klinendeckel, linke Schmalseite. Izmir, Archäologisches Museum Inv. 34

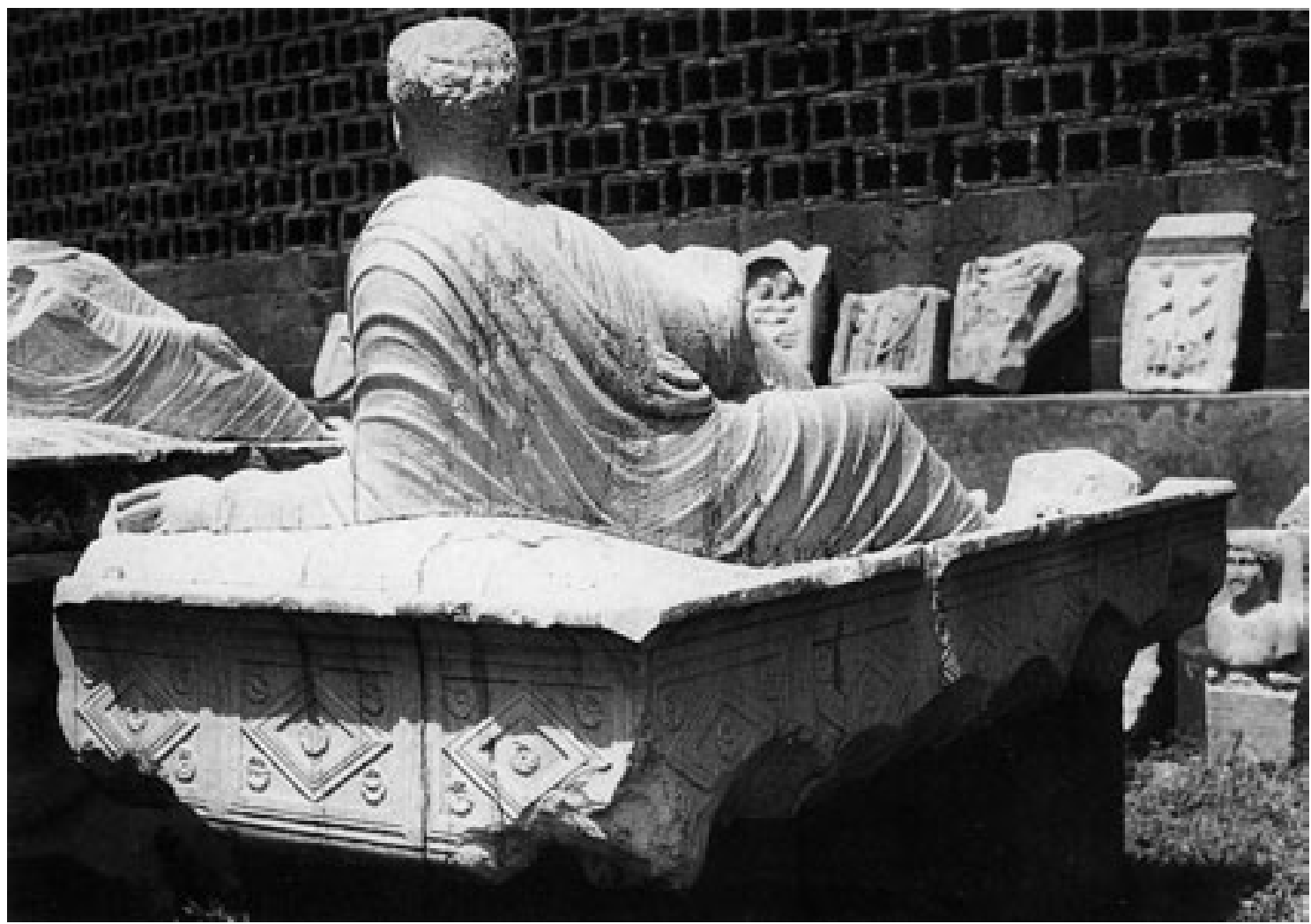

Abb. 99 Klinendeckel, rechte Schmal- und Rückseite. Izmir, Archäologisches Museum Inv. 34

Kat. 1 Schlachtsarkophag des [Quintus] Aemilius Aristides 
Tafel 22

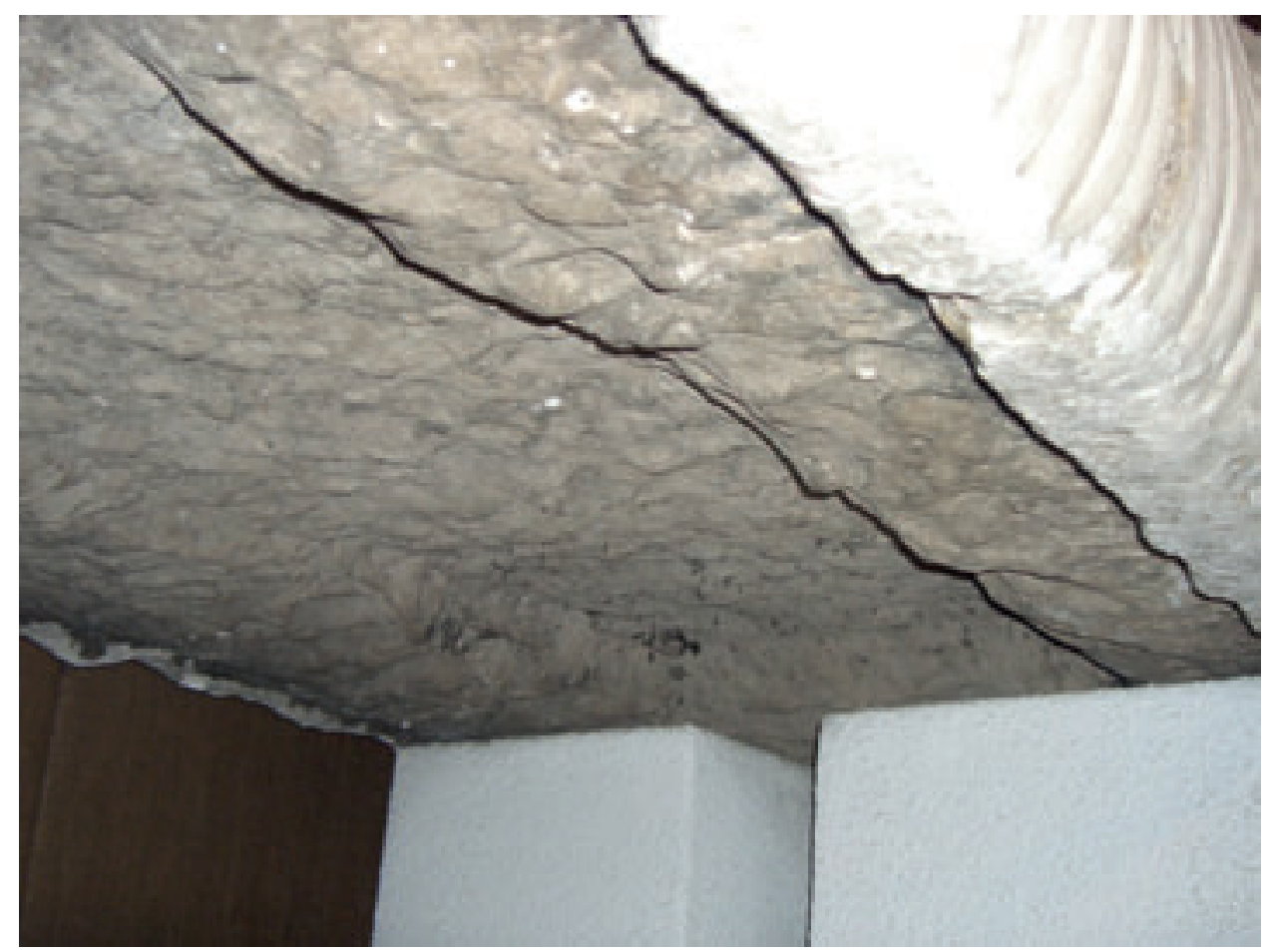

Abb. 100 Klinendeckel, Unterseite. Izmir, Archäologisches Museum Inv. 34

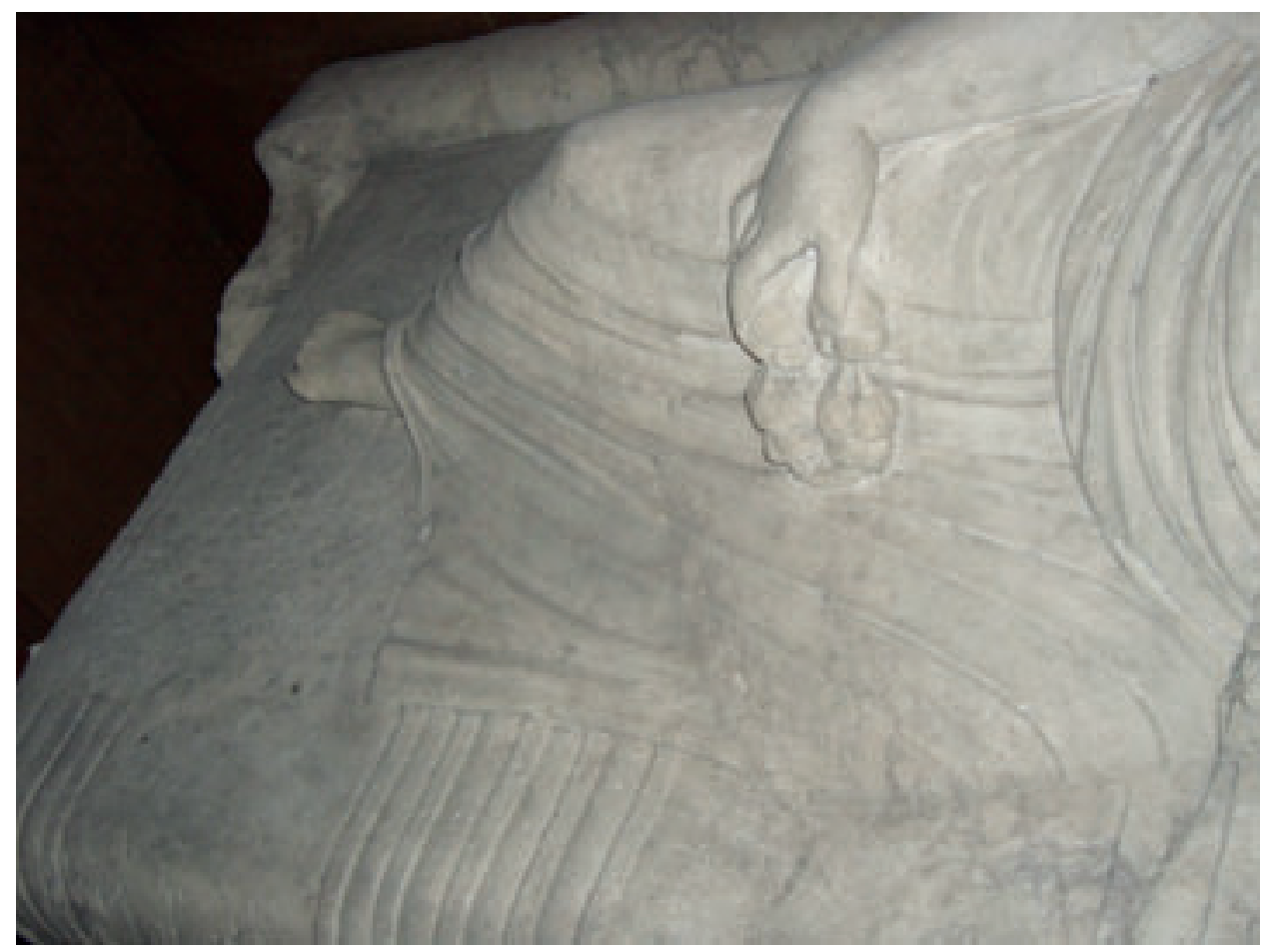

Abb. 101 Klinendeckel, Oberseite des Fußendes. Izmir, Archäologisches Museum Inv. 34

Kat. 1 Schlachtsarkophag des [Quintus] Aemilius Aristides 
Tafel 23

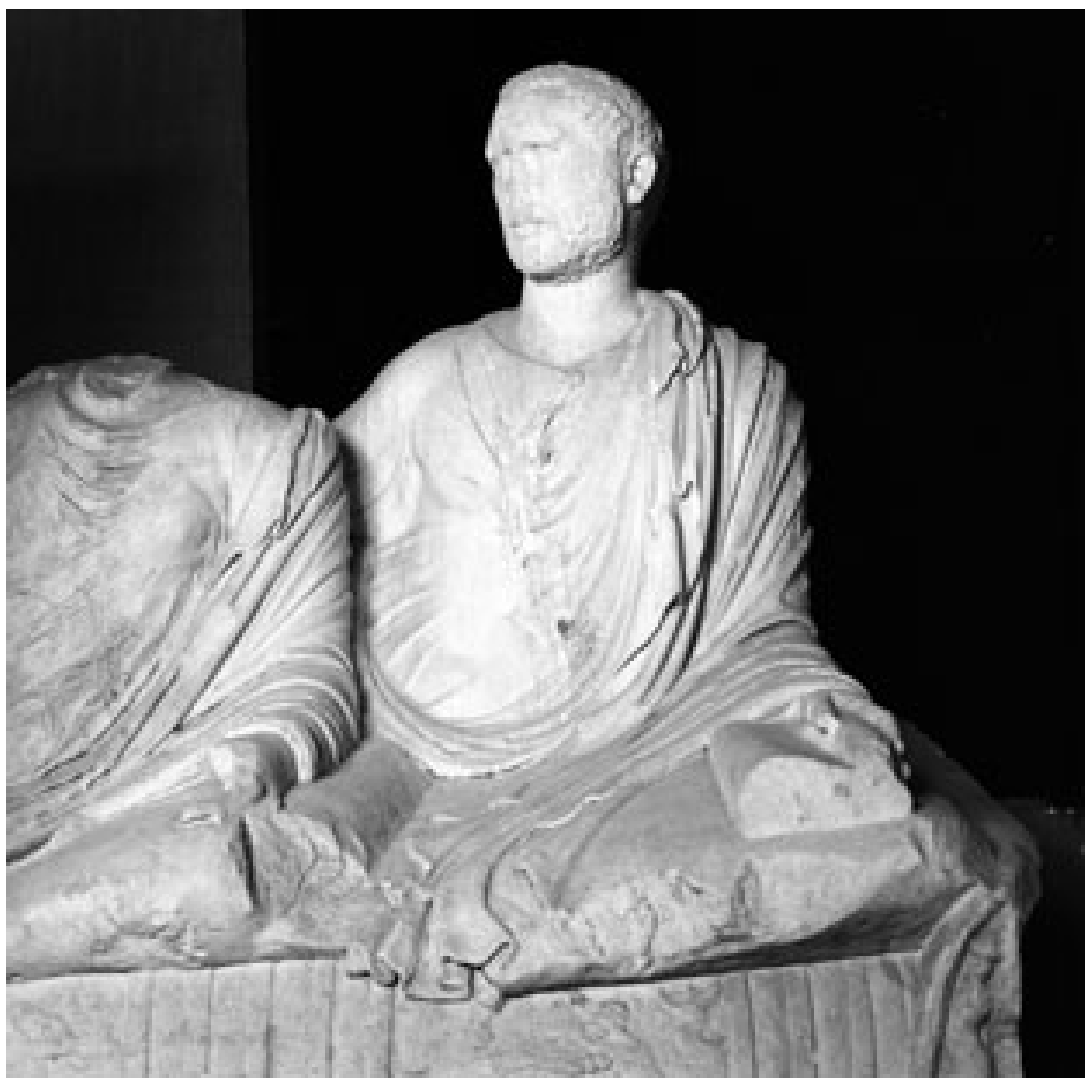

Abb. 102 Klinendeckelfiguren. Izmir, Archäologisches Museum Inv. 34

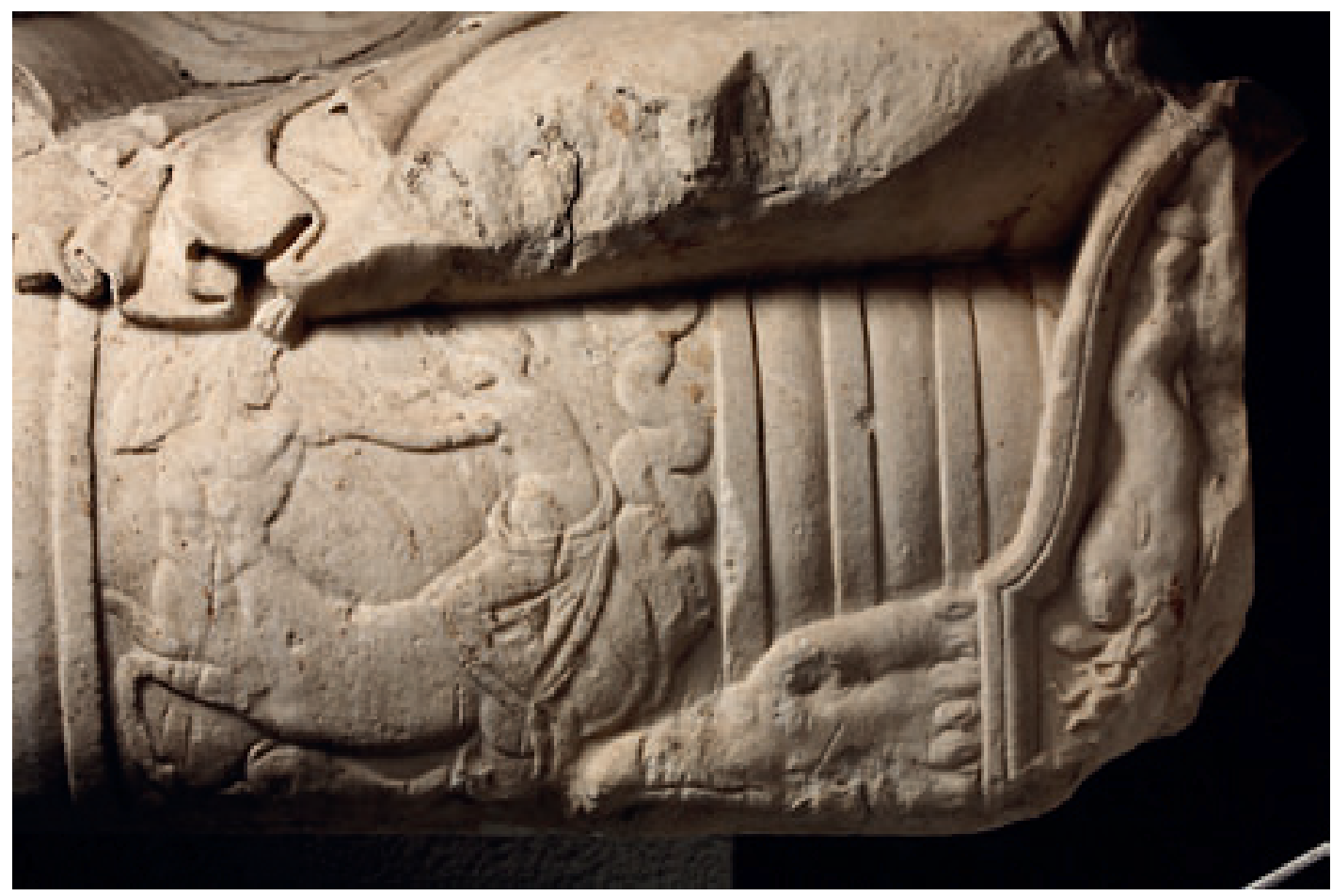

Abb. 103 Rechtes Fulcrum der Matratzenfront. Izmir, Archäologisches Museum Inv. 34

Kat. 1 Schlachtsarkophag des [Quintus] Aemilius Aristides 
Tafel 24
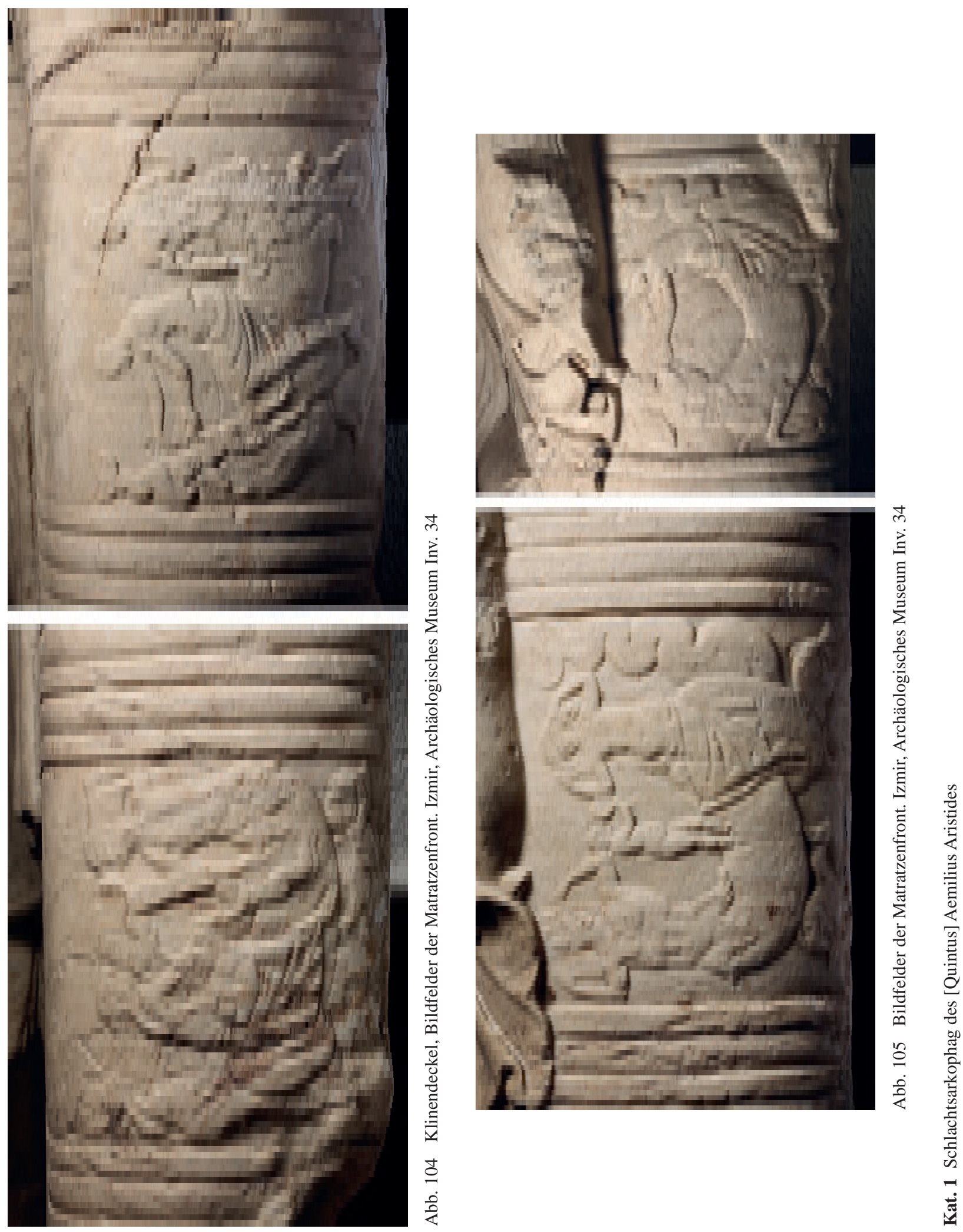
Tafel 25

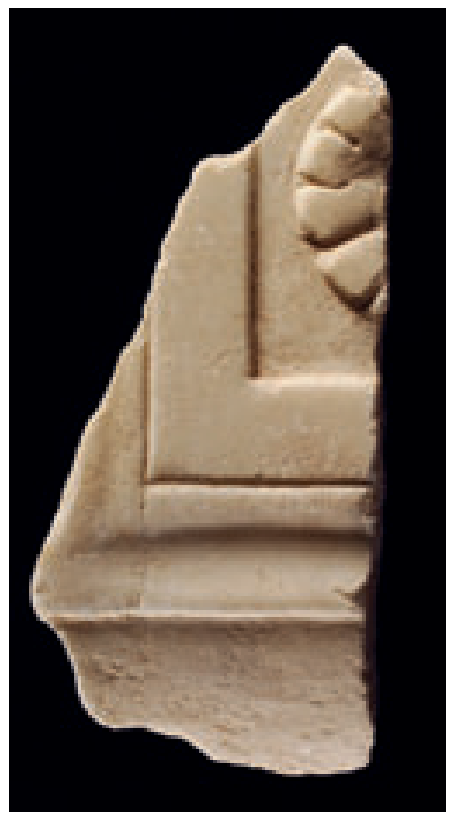

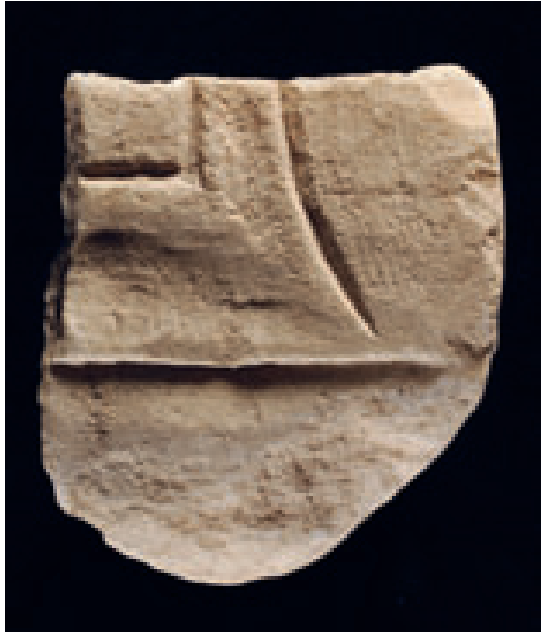

Abb. 107 Fragment 76

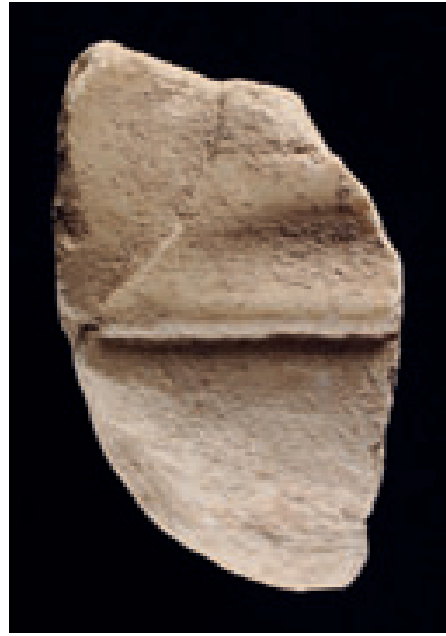

Abb. 108 Fragment 76

Abb. 106 Fragment 75

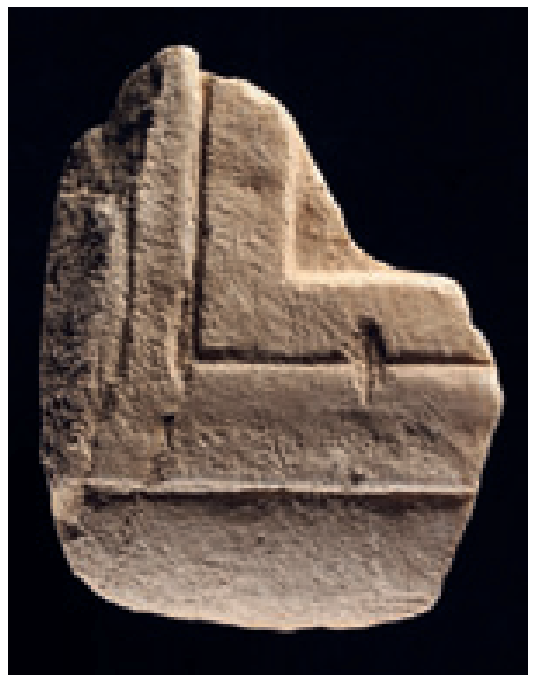

Abb. 109 Fragment 77

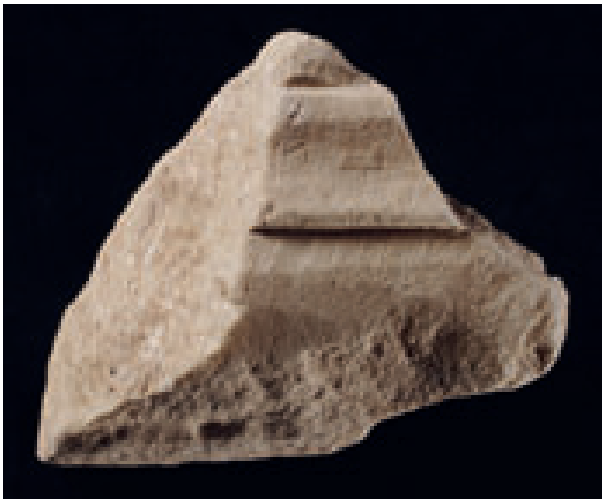

Abb. 110 Fragment 78

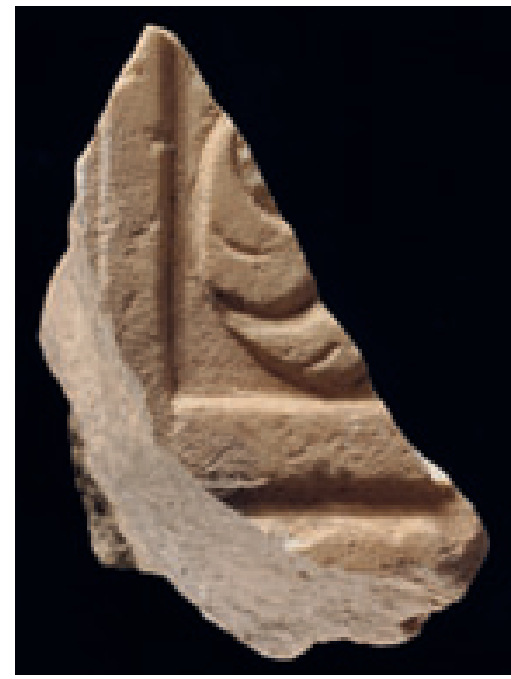

Abb. 111 Fragment 79

Fragmente von Klinendeckeln 
Tafel 26

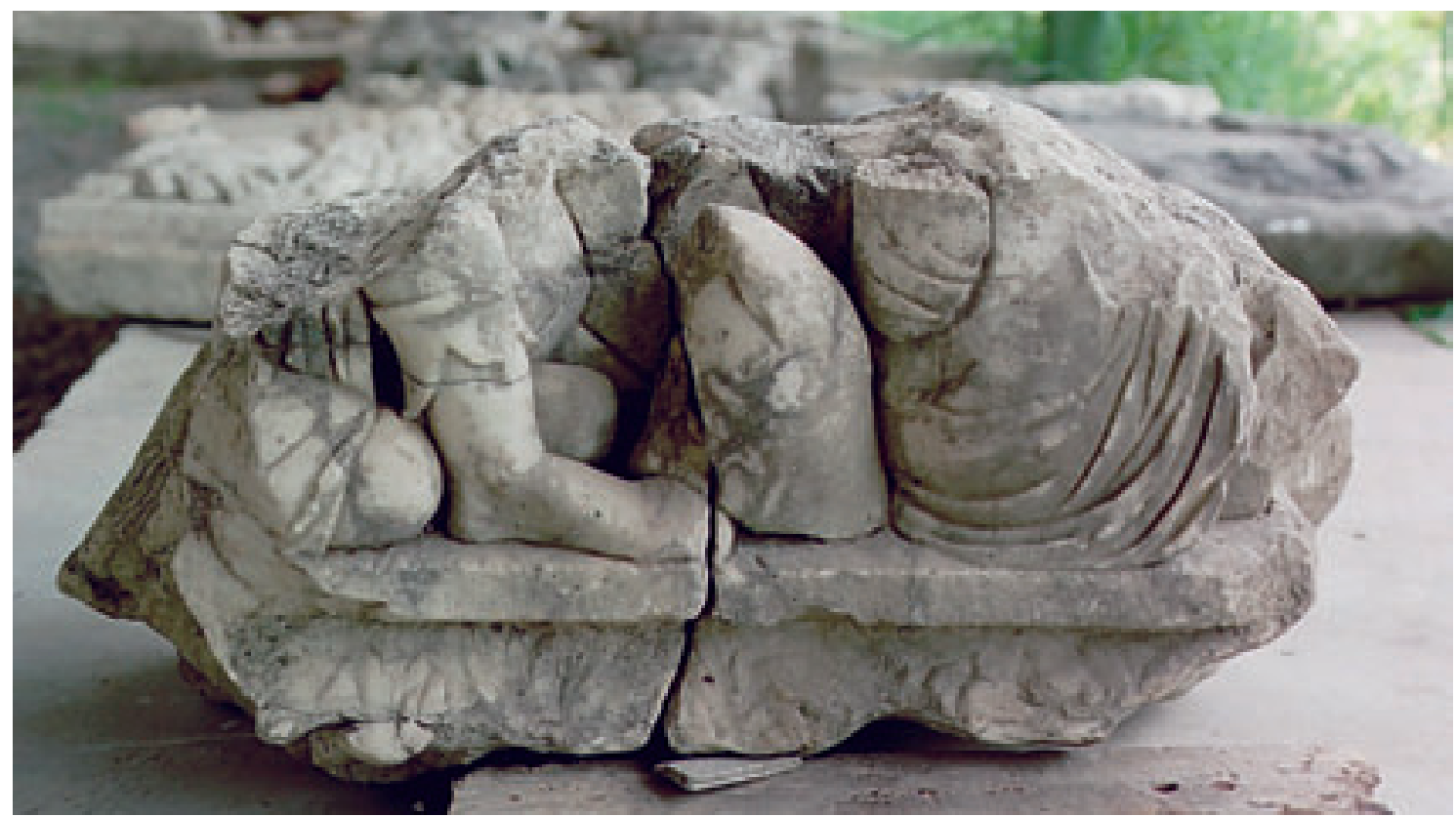

Abb. 112 Fragment. Selçuk, Efes Müzesi Inv. 352

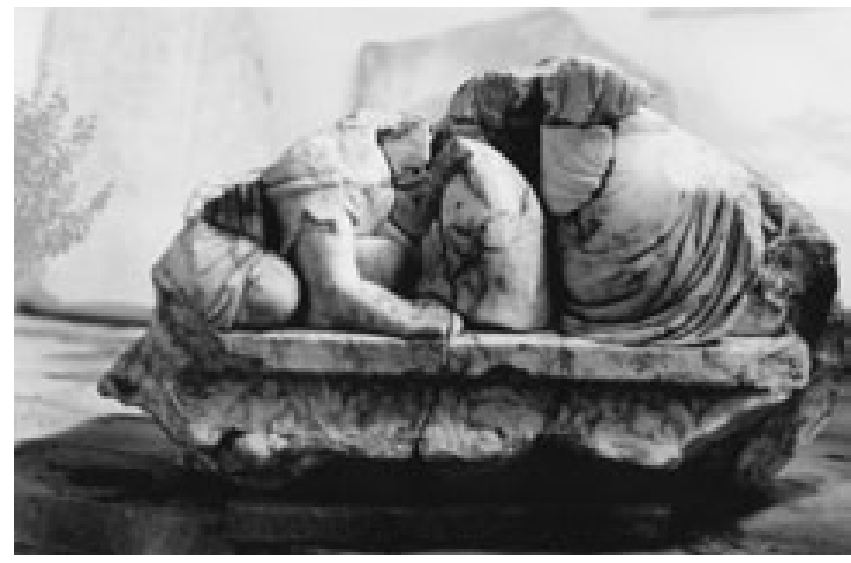

Abb. 113 Fragment. Selçuk, Efes Müzesi Inv. 352 mit

kleinem anpassenden Fragment bei Rudolf 1989, Taf. 22 Abb. 31

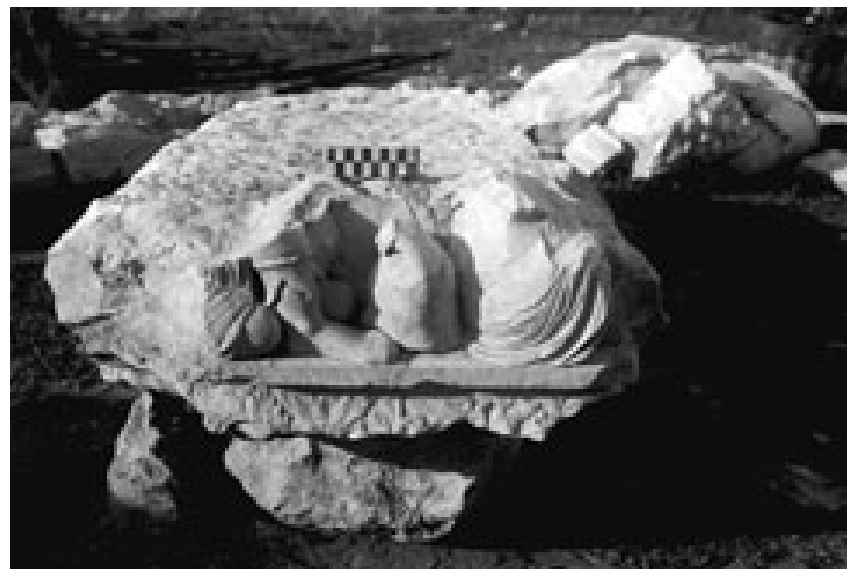

Abb. 114 Fragment. Selçuk, Efes Müzesi Inv. 352, ungebrochener Zustand

Kat. 2 Amazonomachie-Sarkophag aus dem Grabhaus der Claudia Antonia Tatiane 
Tafel 27
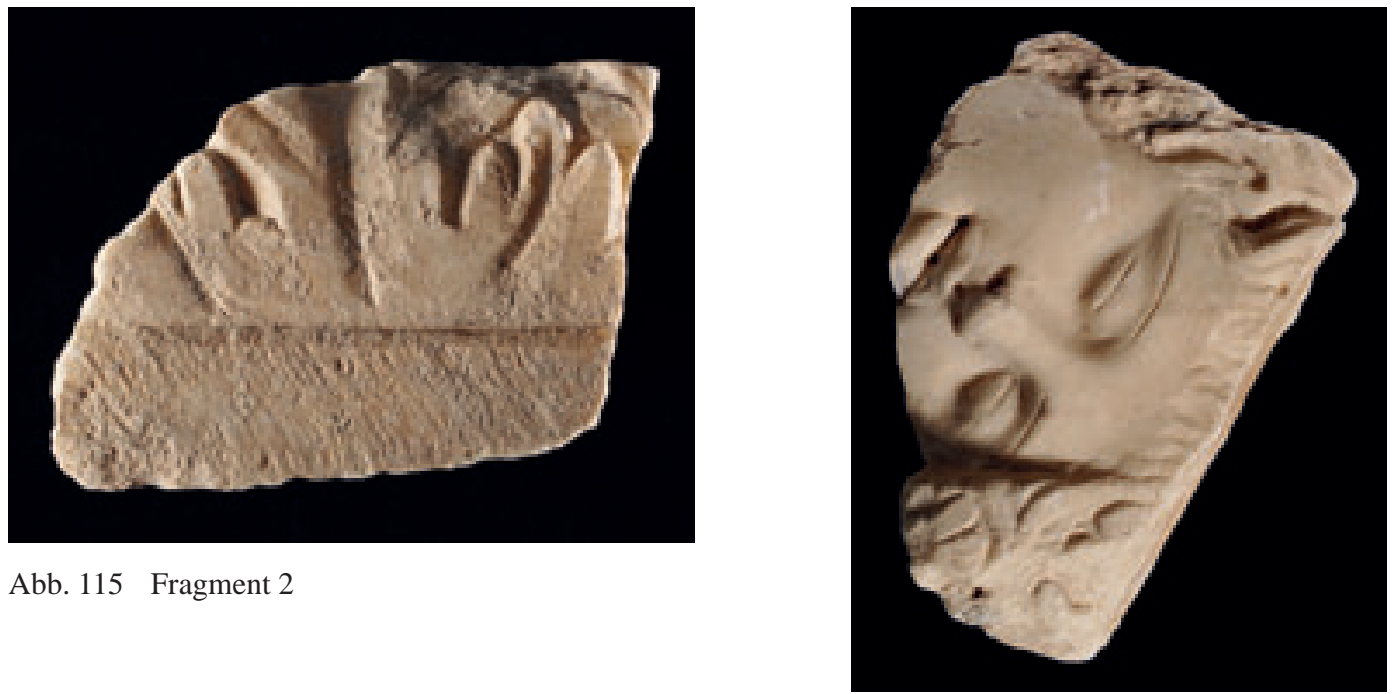

Abb. 116 Fragment 3
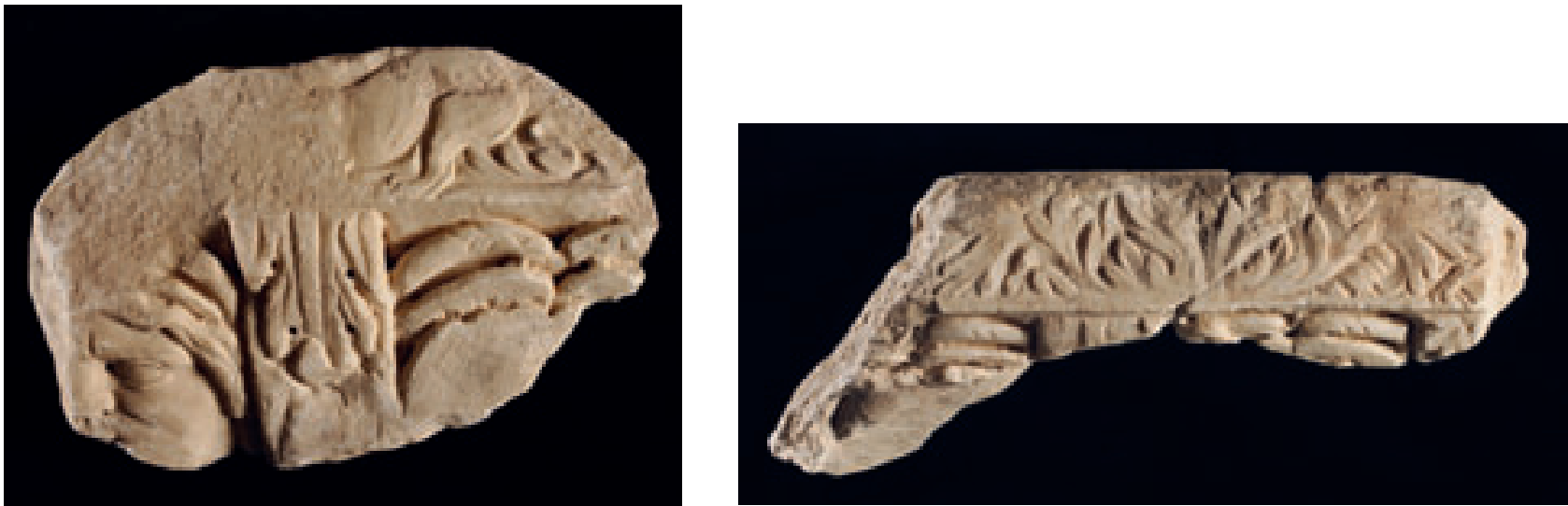

Abb. 117 Fragment 4

Abb. 118 Fragment 5

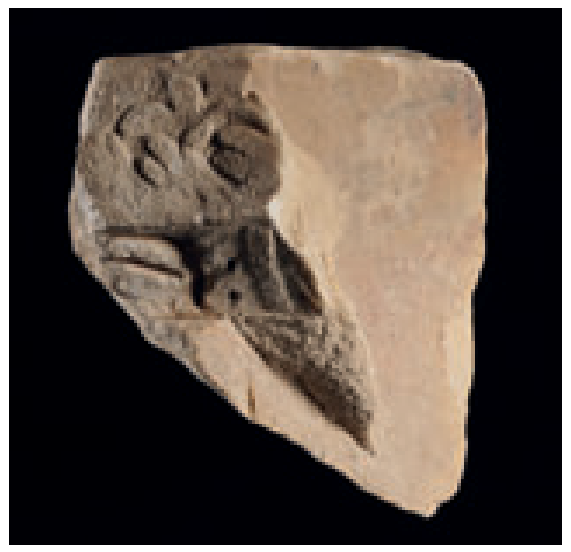

Abb. 119 Fragment 6

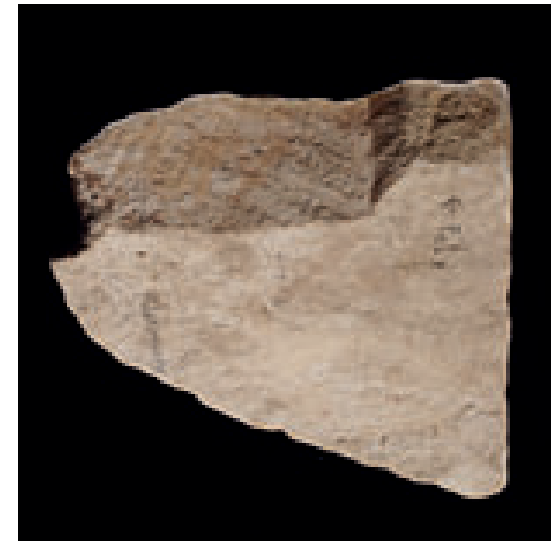

Abb. 120 Fragment 7

Kat. 2 Amazonomachie-Sarkophag aus dem Grabhaus der Claudia Antonia Tatiane, Kastenfragmente des Sockelbereichs und des oberen Kastenabschlusses 
Tafel 28

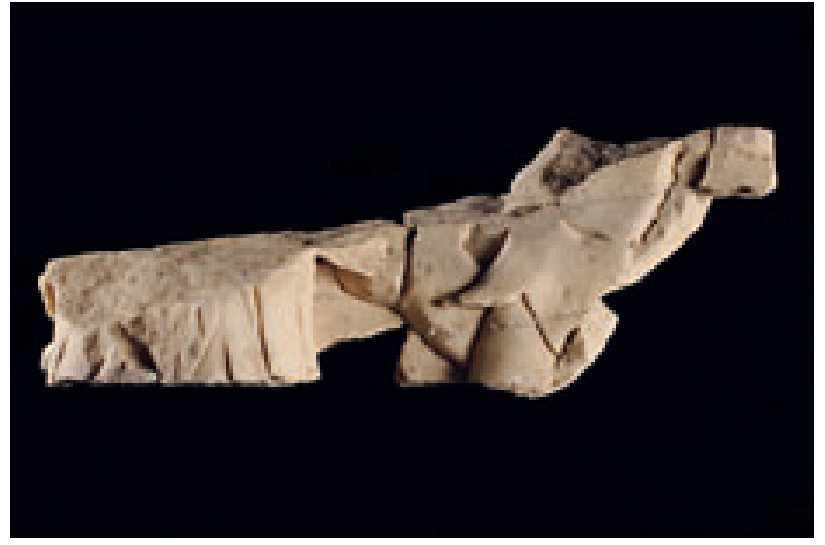

Abb. 121 Fragment 8

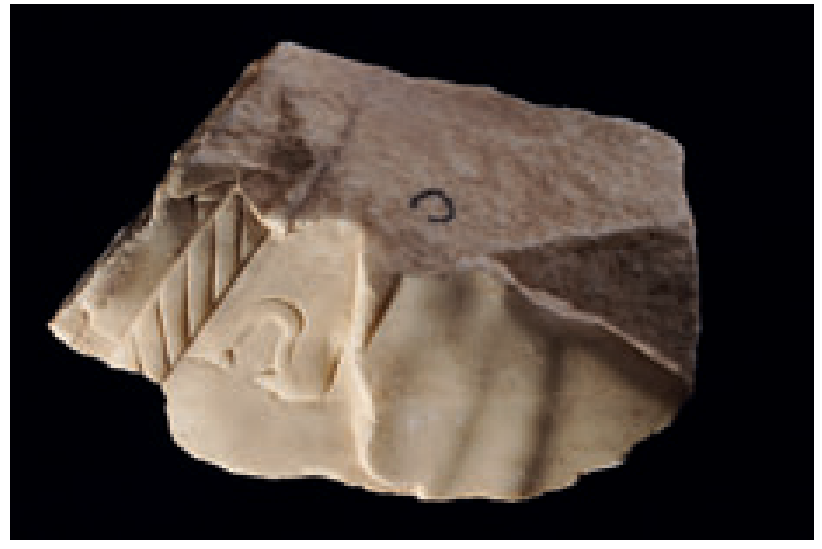

Abb. 122 Fragment 9

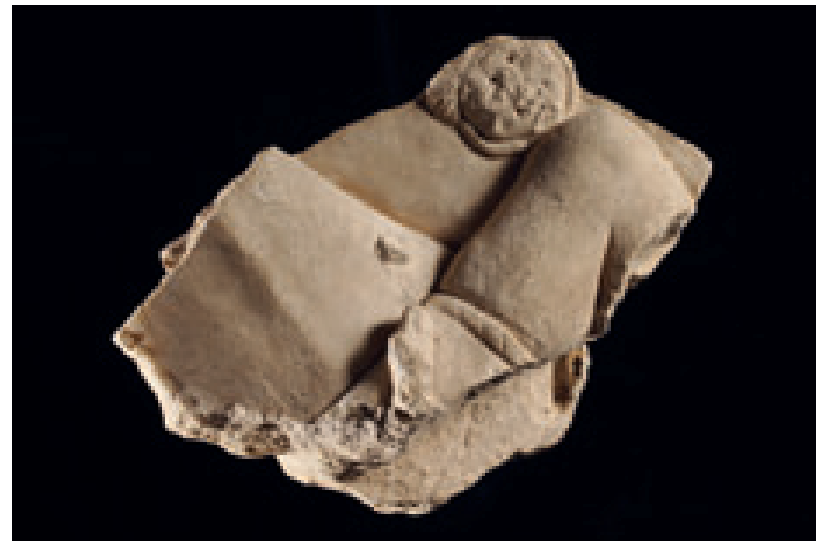

Abb. 123 Fragment 10

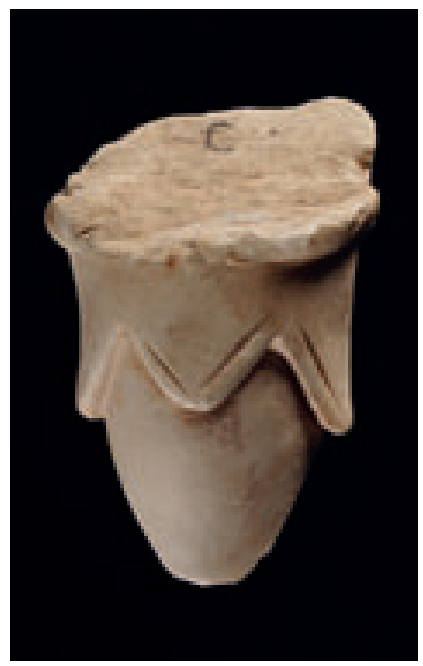

Abb. 124 Fragment 11

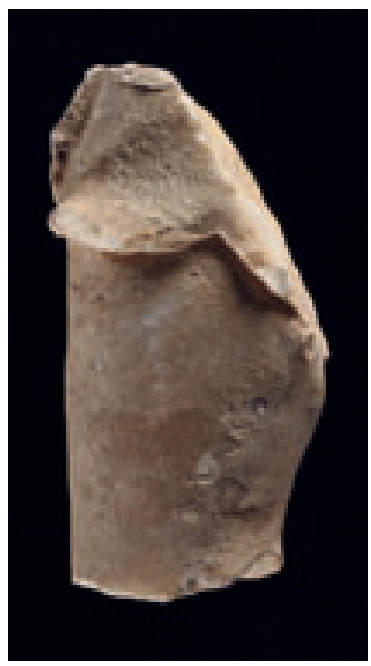

Abb. 125 Fragment 12

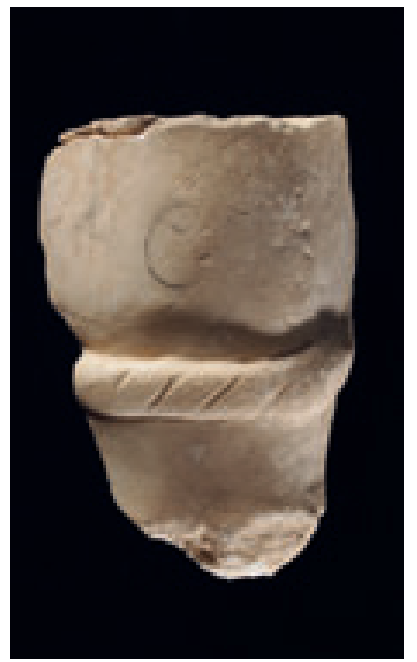

Abb. 126 Fragment 13

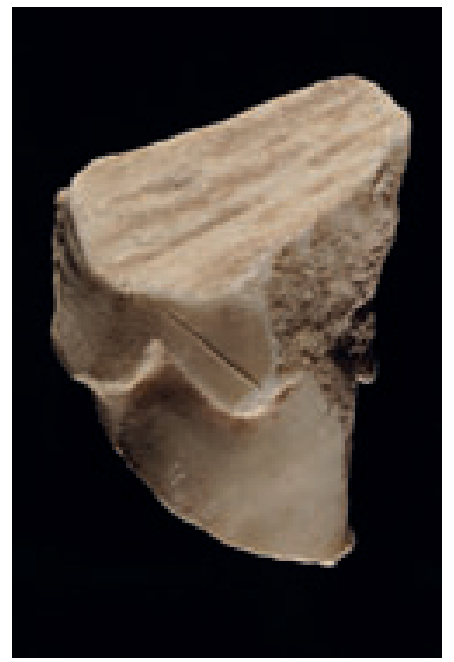

Abb. 127 Fragment 14 
Tafel 29

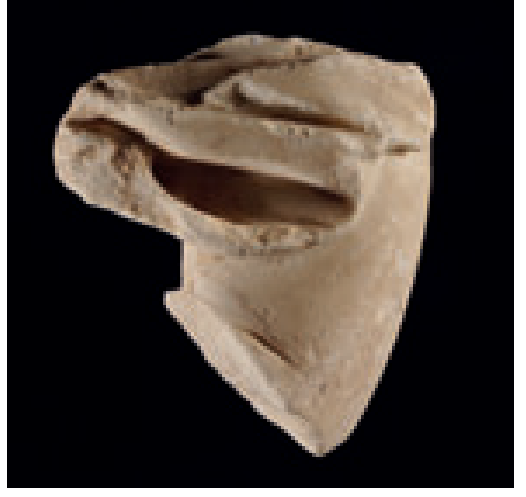

Abb. 128 Fragment 15

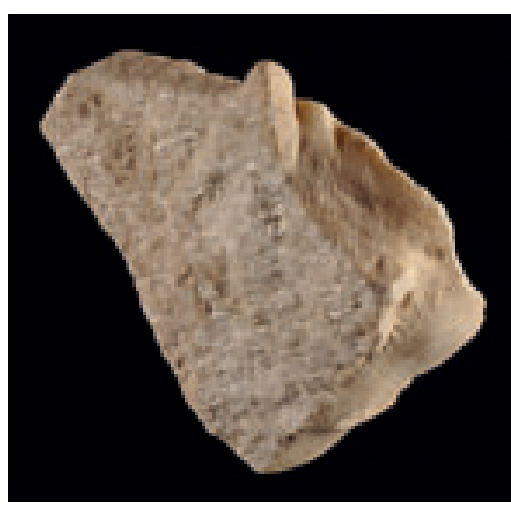

Abb. 130 Fragment 17

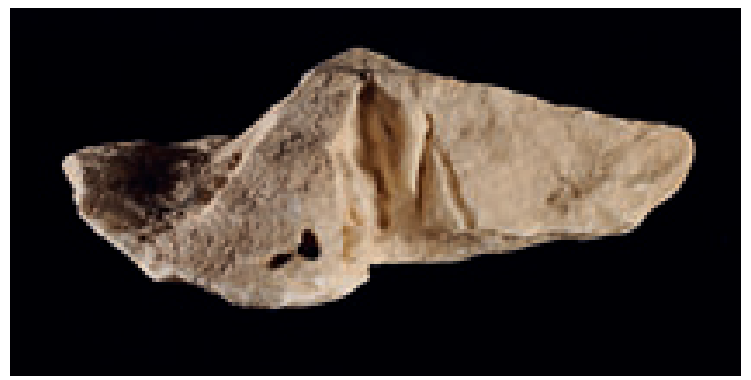

Abb. 132 Fragment 19

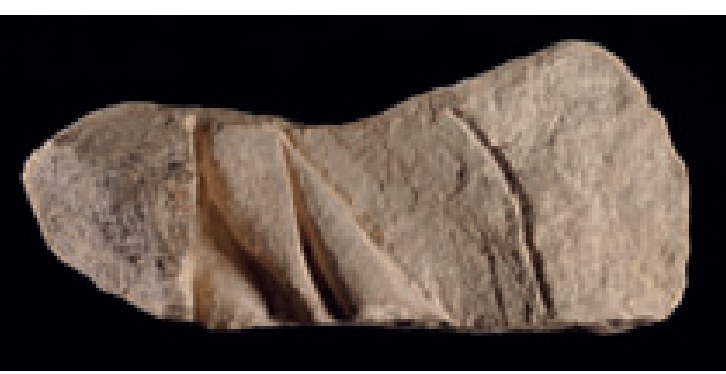

Abb. 134 Fragment 21

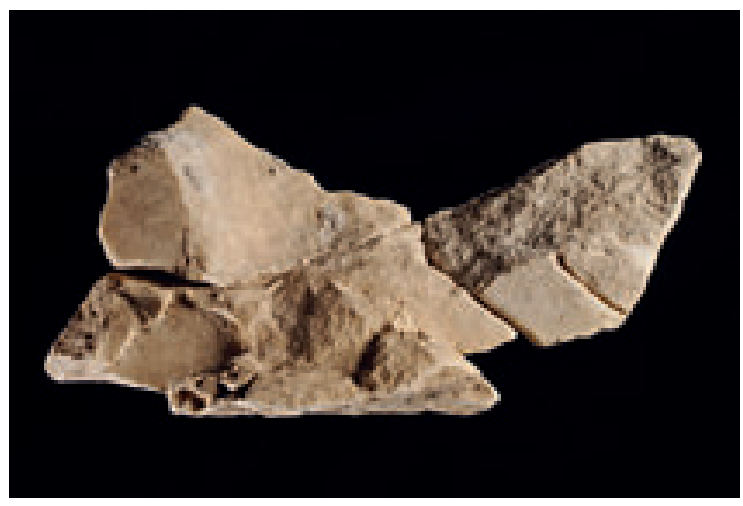

Abb. 129 Fragment 16

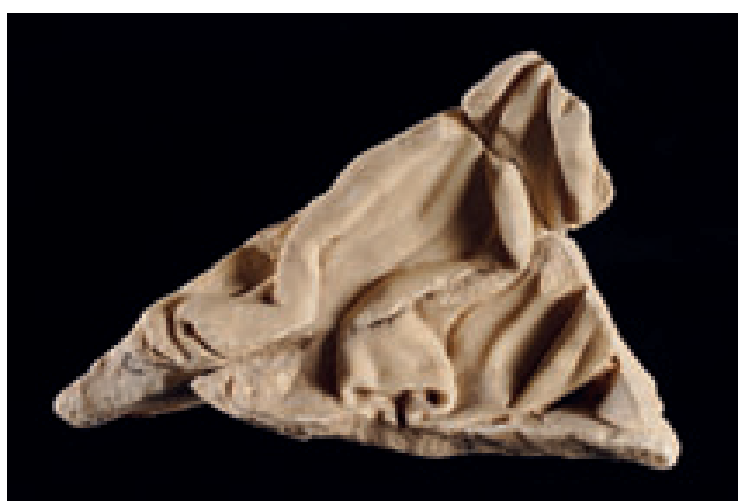

Abb. 131 Fragment 18

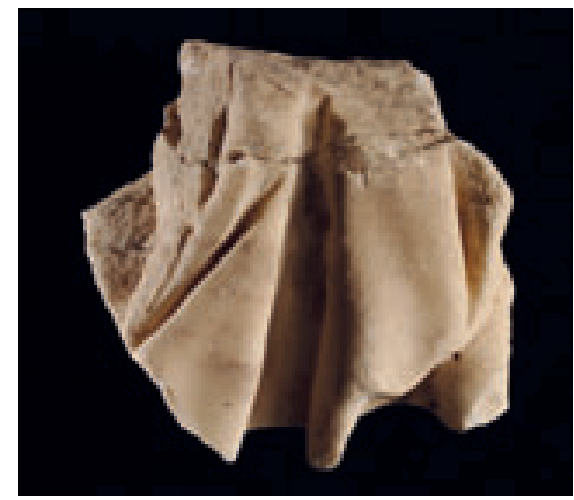

Abb. 133 Fragment 20

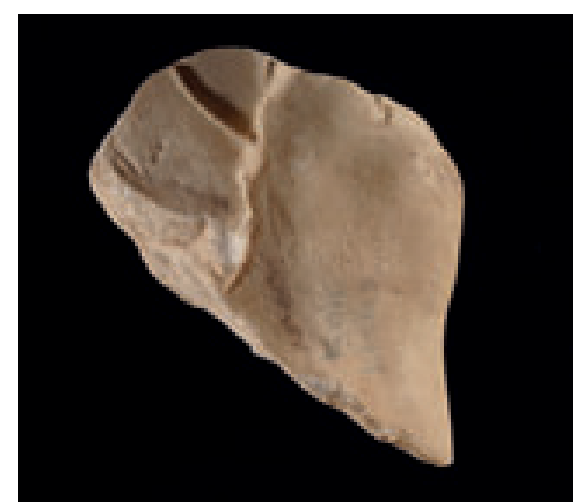

Abb. 135 Fragment 22

Kat. 2 Amazonomachie-Sarkophag aus dem Grabhaus der Tatiane, Friesfragmente 
Tafel 30
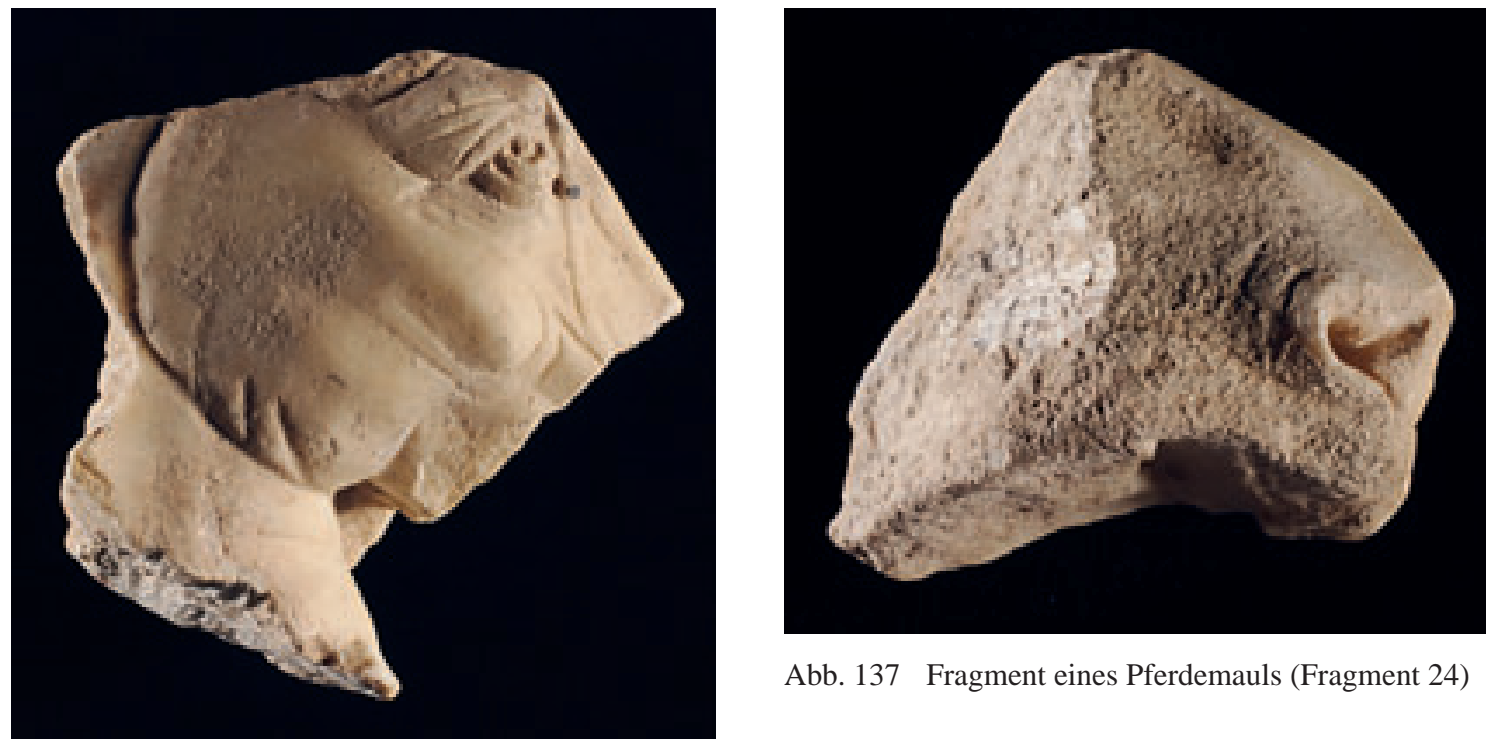

Abb. 137 Fragment eines Pferdemauls (Fragment 24)

Abb. 136 Fragment eines Pferdekopfes (Fragment 23)

Kat. 2 Amazonomachie-Sarkophag aus dem Grabhaus der Tatiane, Friesfragmente

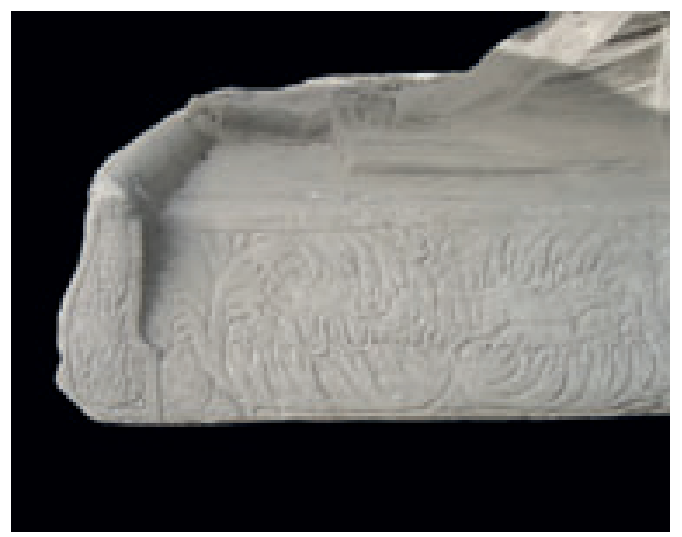

Abb. 138 Linkes Fulcrum gefolgt von Akanthusranken mit Tieren

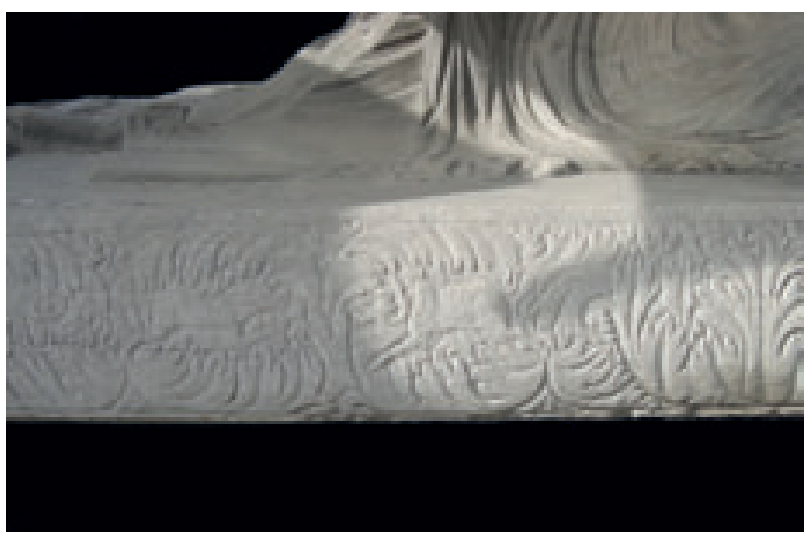

Abb. 139 Akanthusranken mit Tieren

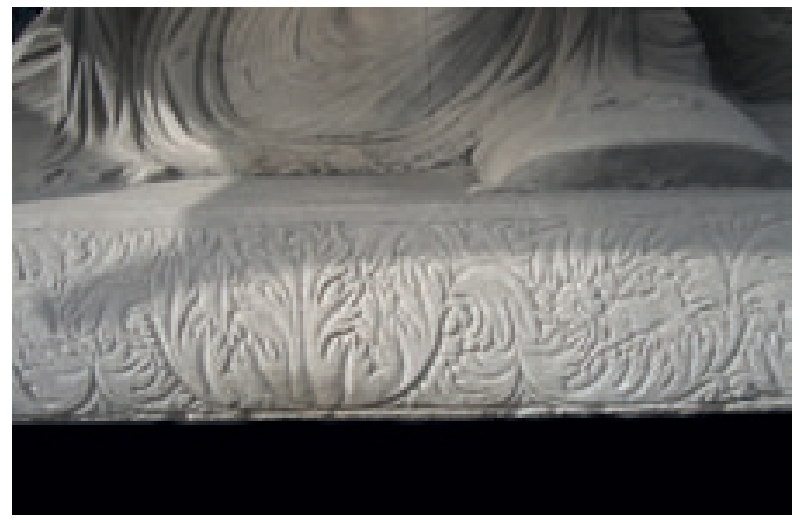

Abb. 140 Akanthusbüschel in der Mitte

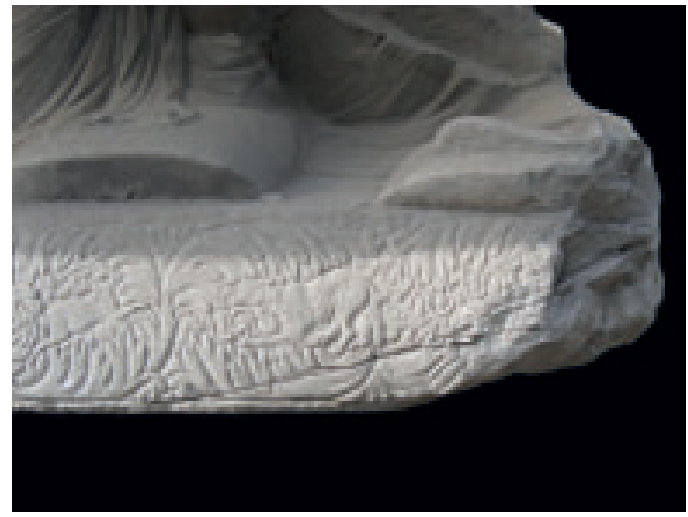

Abb. 141 Akanthusranken mit Tieren, rechtes Fulcrum verloren

Kat. 2 Amazonomachie-Sarkophag aus dem Grabhaus der Tatiane, Klinendeckel, Vorderseite der Klinenmatratze. Izmir, Garten des Archäologischen Museums Inv. 2 
Tafel 31

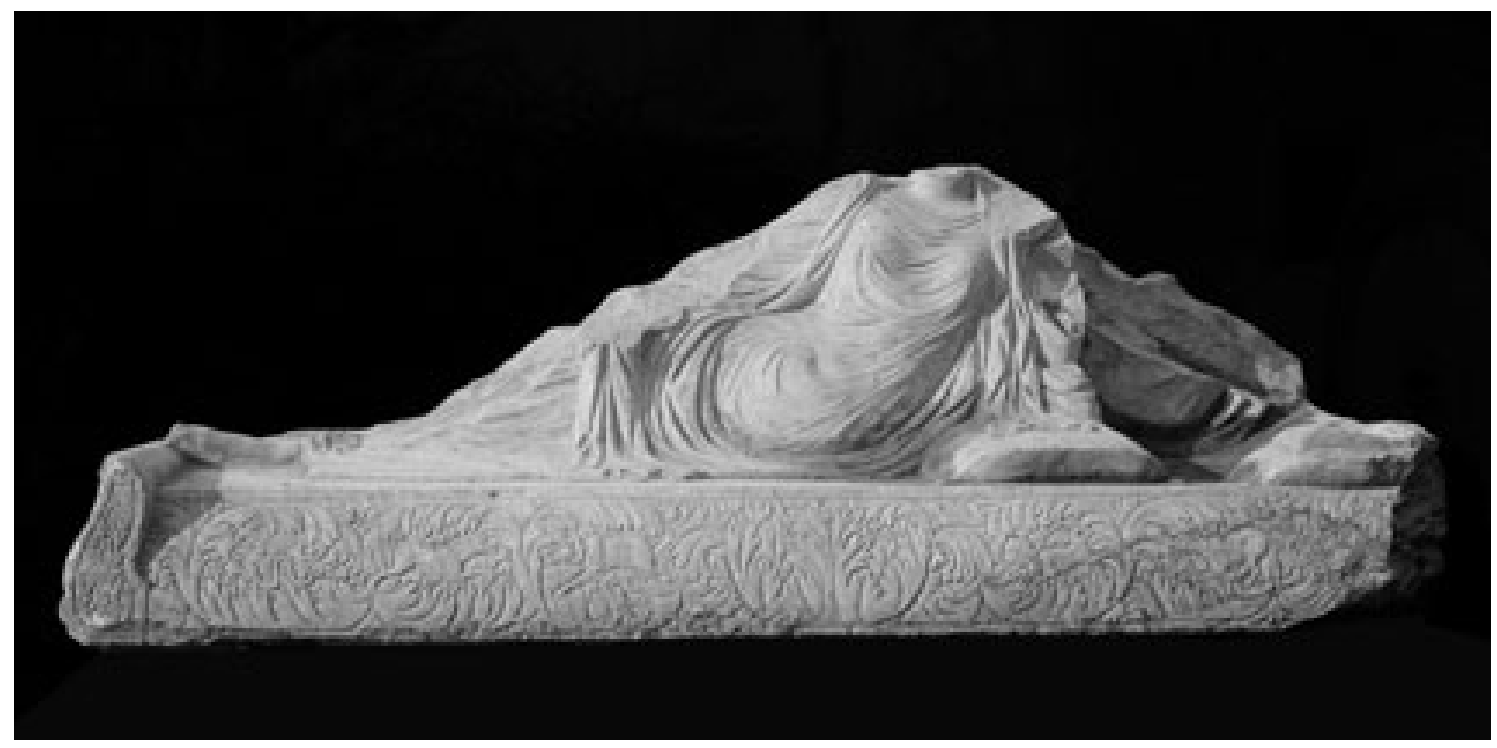

Abb. 142 Vorderseite

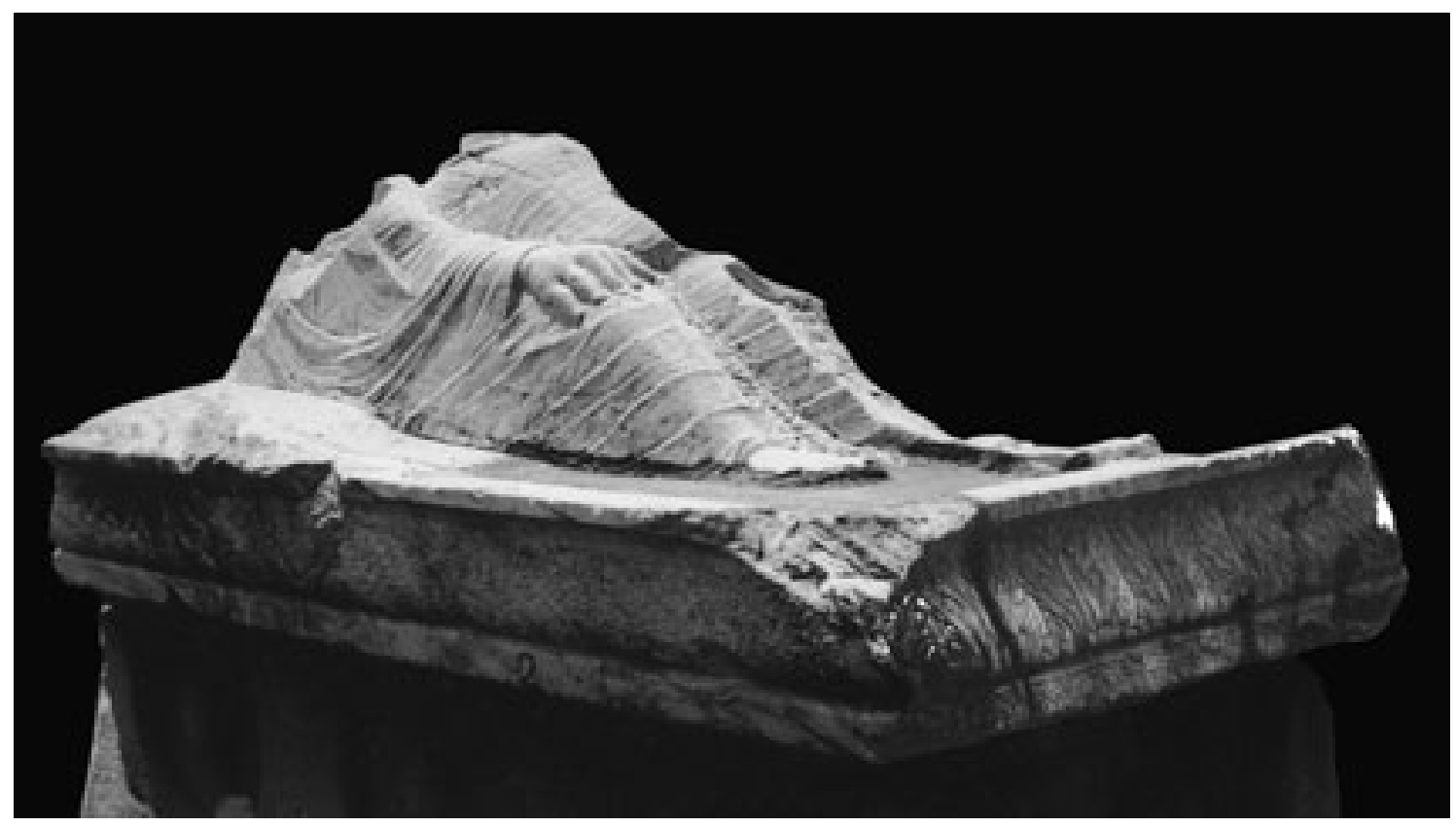

Abb. 143 Rückseite mit linker Schmalseite

Kat. 2 Amazonomachie-Sarkophag aus dem Grabhaus der Tatiane, Klinendeckel. Izmir, Garten des Archäologischen Museums Inv. 2 
Tafel 32

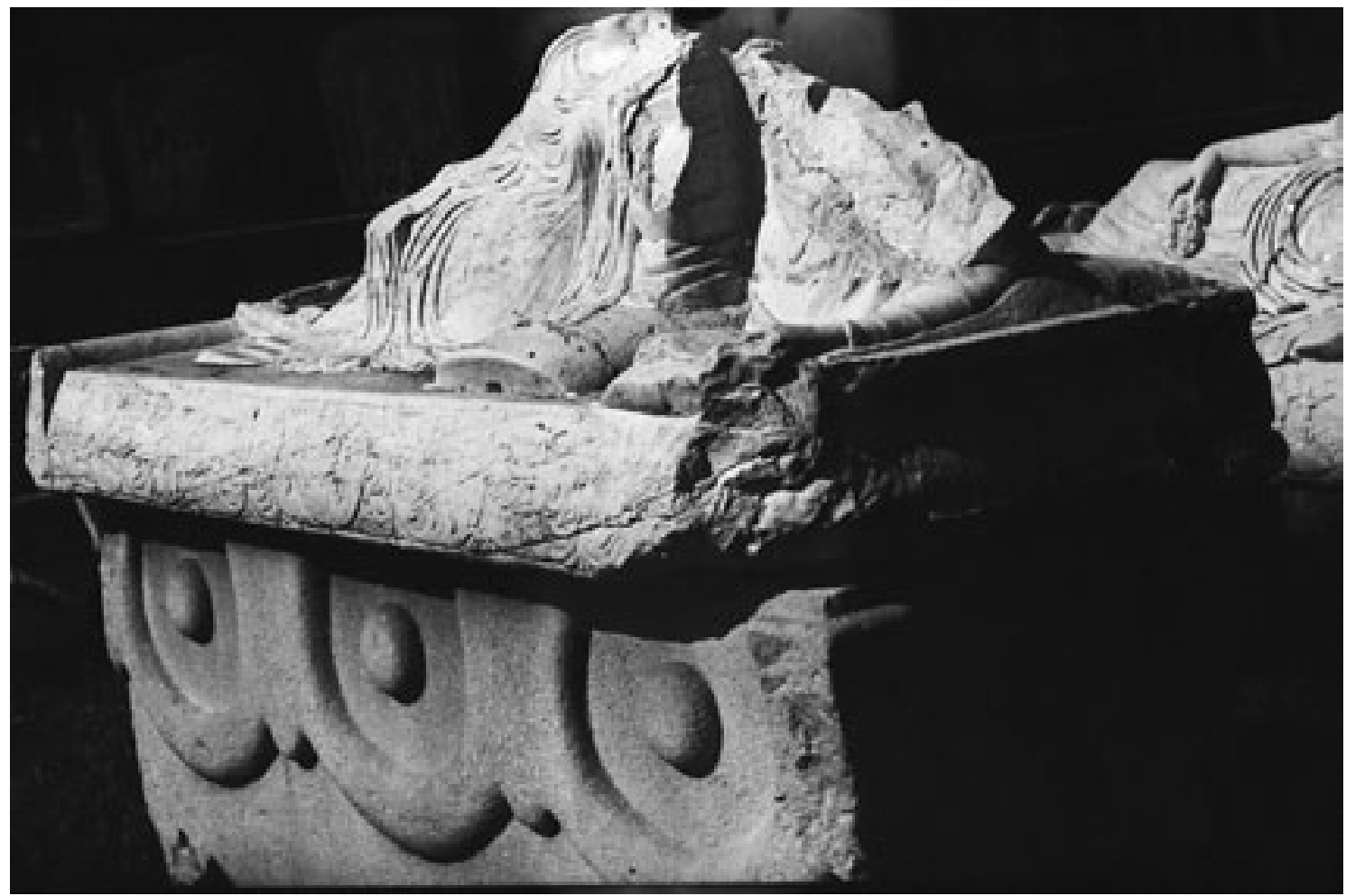

Abb. 144 Rechte Schmalseite

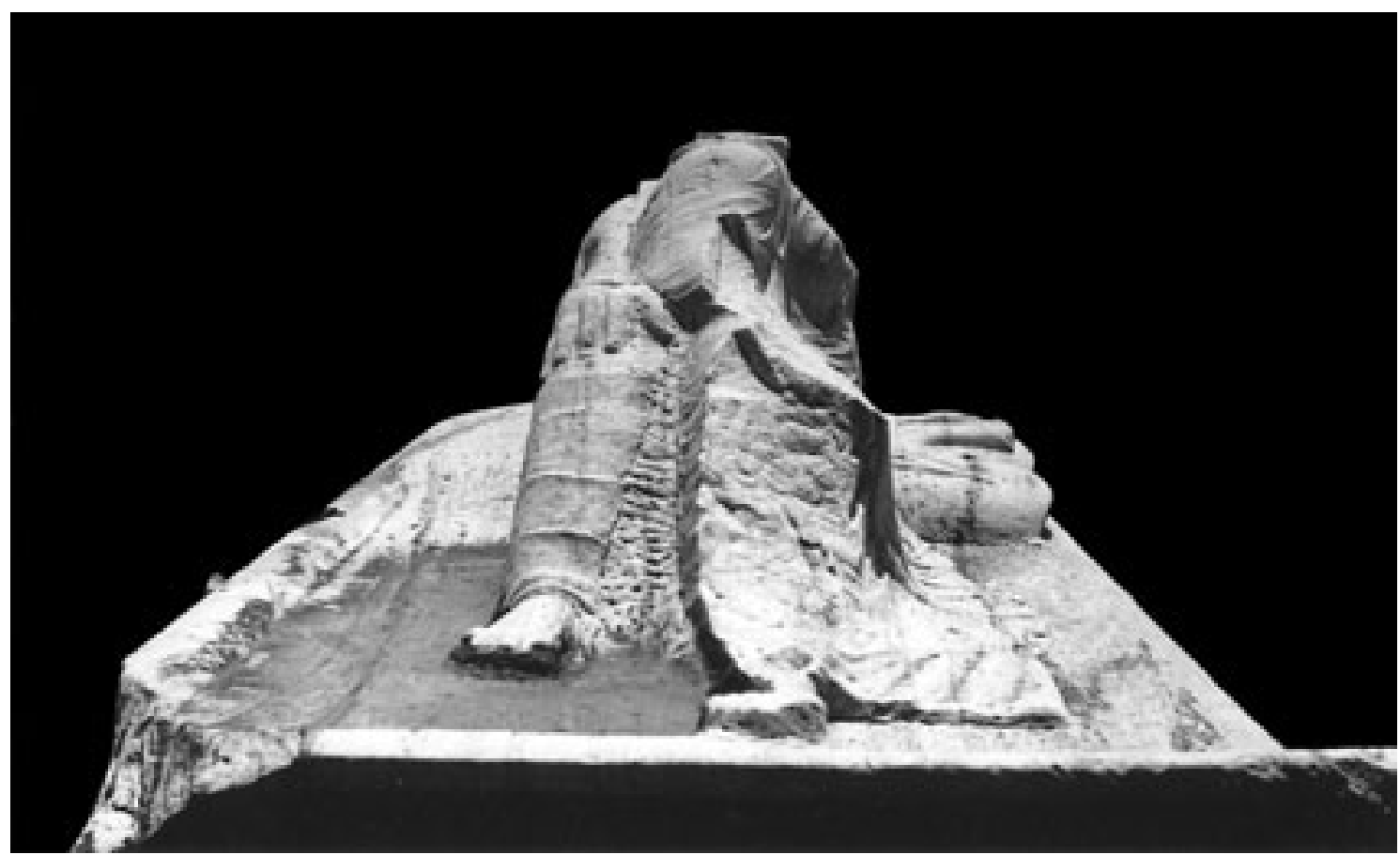

Abb. 145 Linke Schmalseite

Kat. 2 Amazonomachie-Sarkophag aus dem Grabhaus der Tatiane, Klinendeckel. Izmir, Garten des Archäologischen Museums Inv. 2 
Tafel 33




Tafel 34

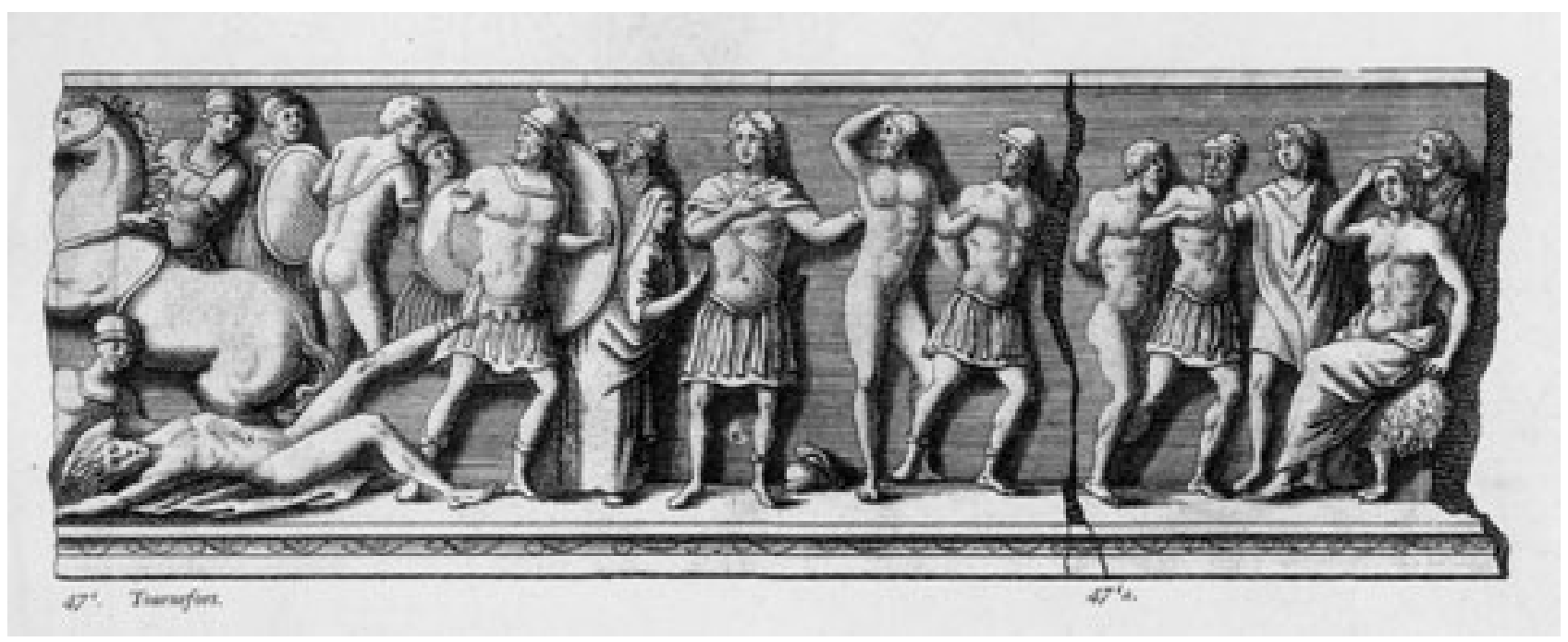

Abb. 147 Vorderseite und linke Schmalseite (Zeichnung J. Pitton de Tournefort)

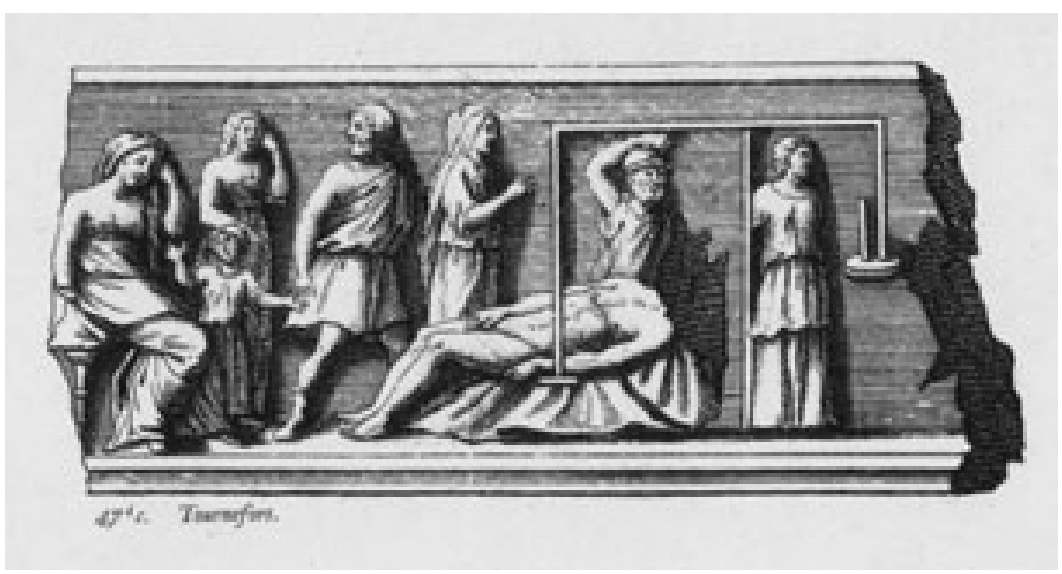

Abb. 148 Rückseite (Zeichnung J. Pitton de Tournefort)

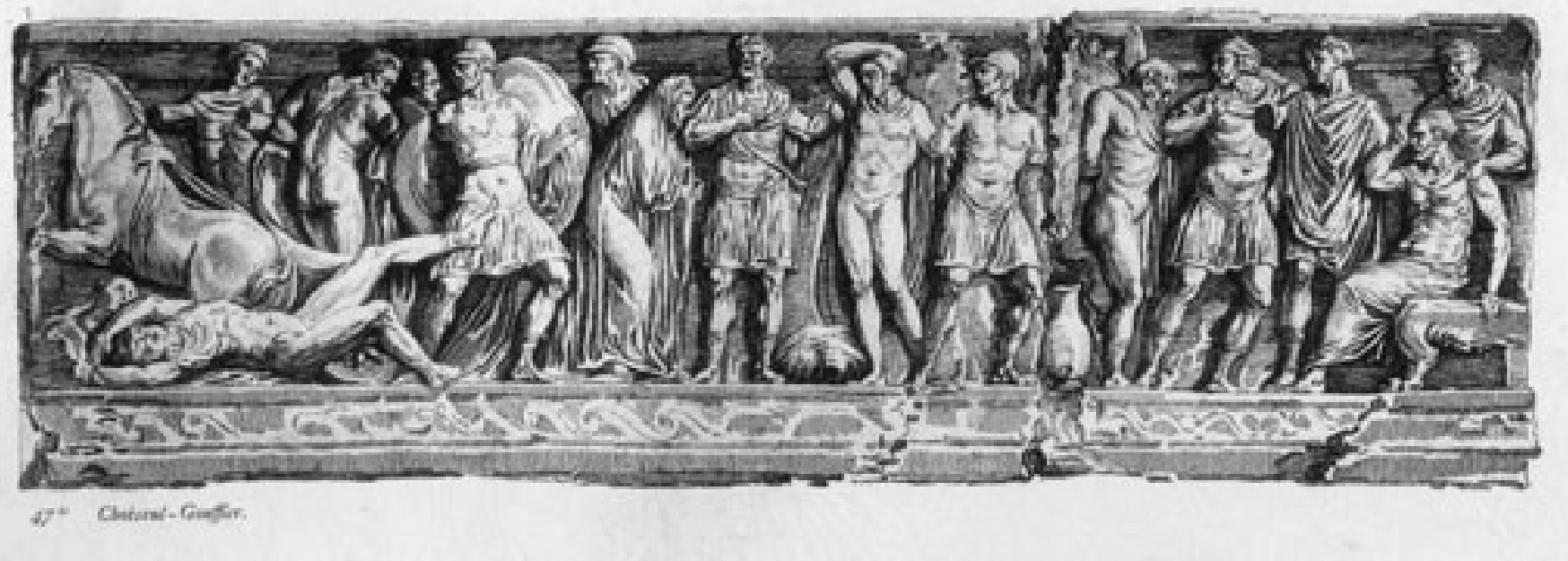

Abb. 149 Vorderseite und linke Schmalseite (Zeichnung M. G. Choiseul-Gouffier)

Kat. 3 Achill-Sarkophag in Woburn Abbey 
Tafel 35

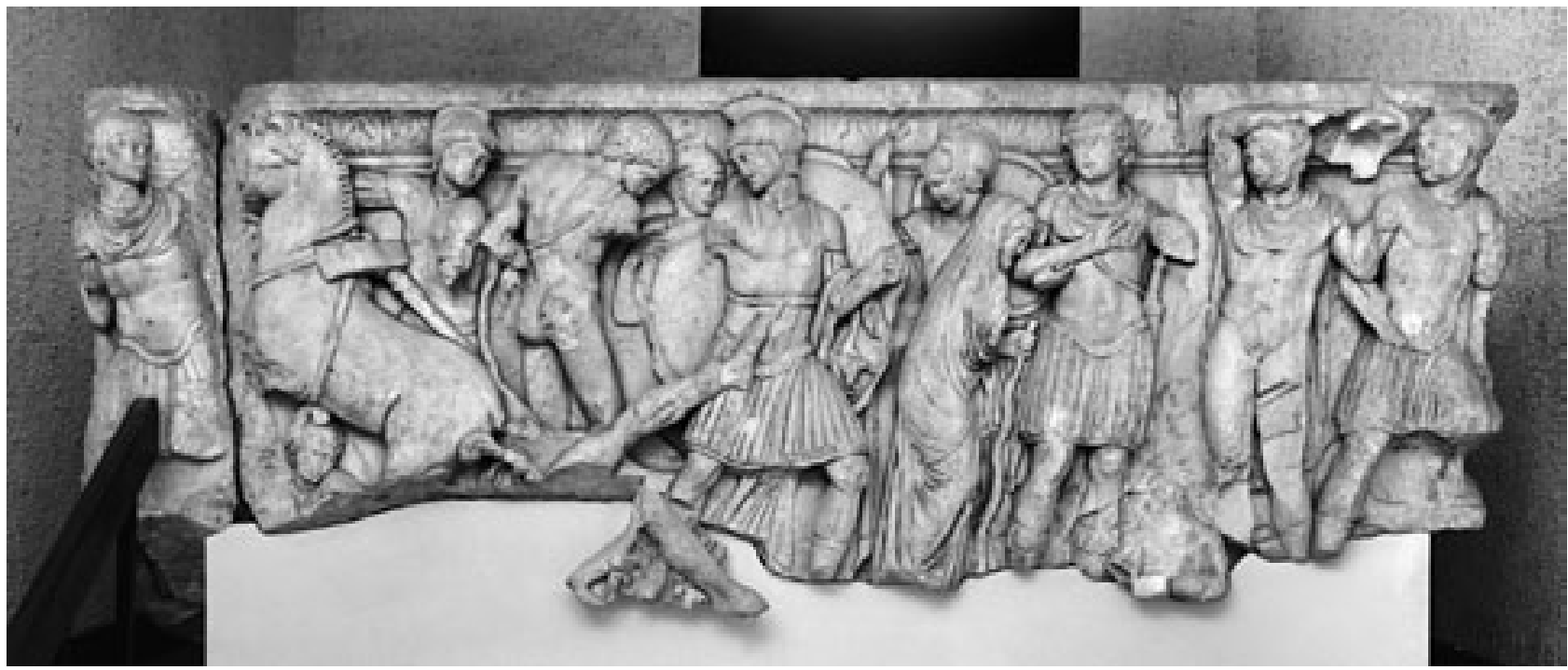

Abb. 150 Vorderseite

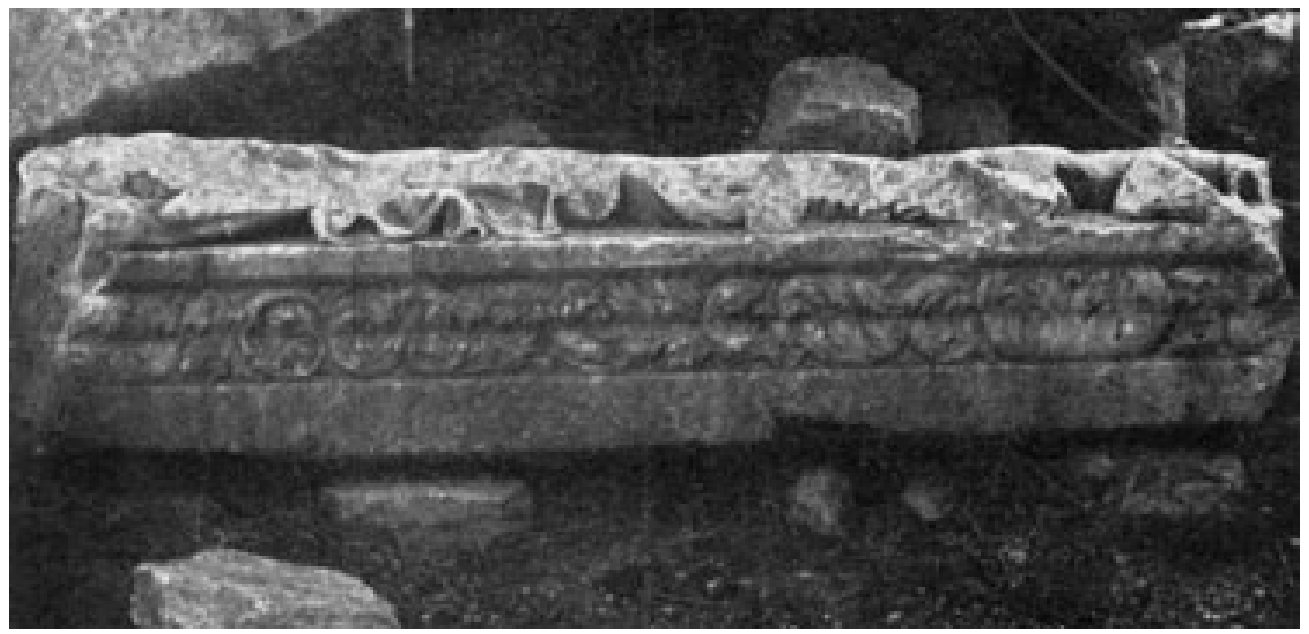

Abb. 151 Verschollenes Sockelfragment der Vorderseite

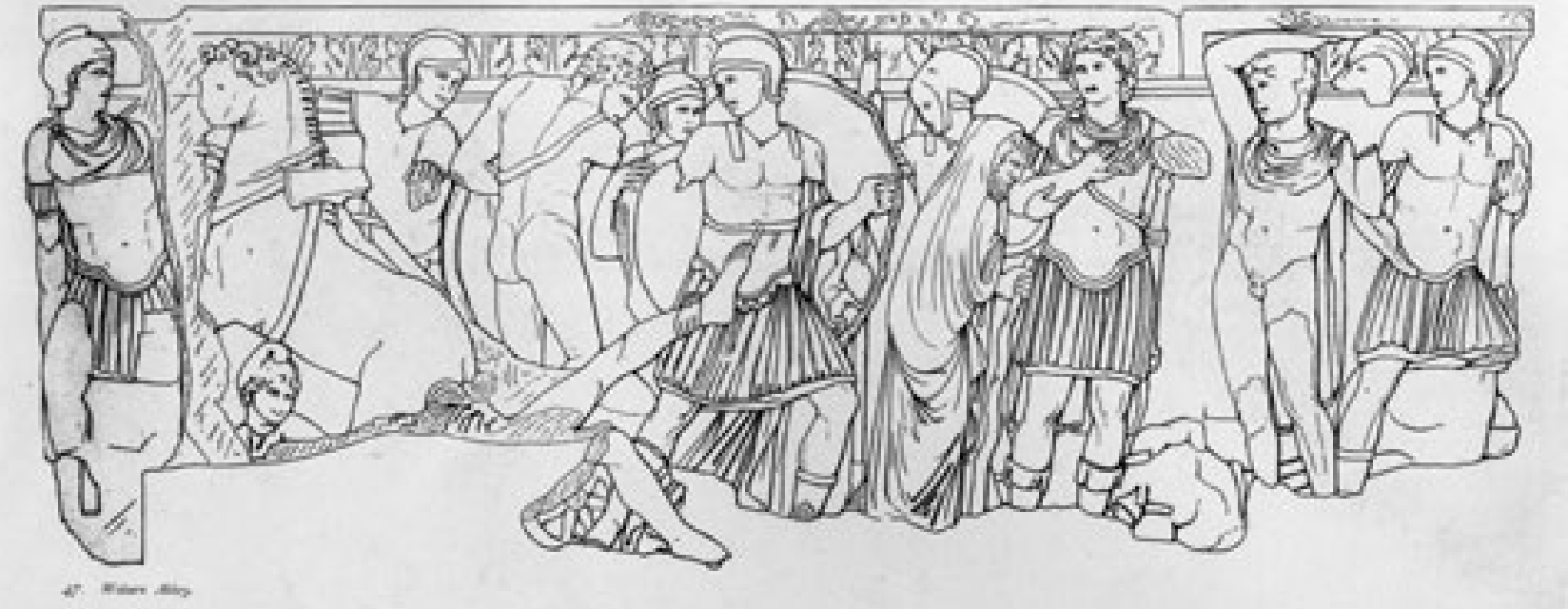

Abb. 152 Zeichnerische Rekonstruktion der Vorderseite und des verschollenen Sockelfragments (nach C. Robert)

Kat. 3 Achill-Sarkophag in Woburn Abbey 
Tafel 36

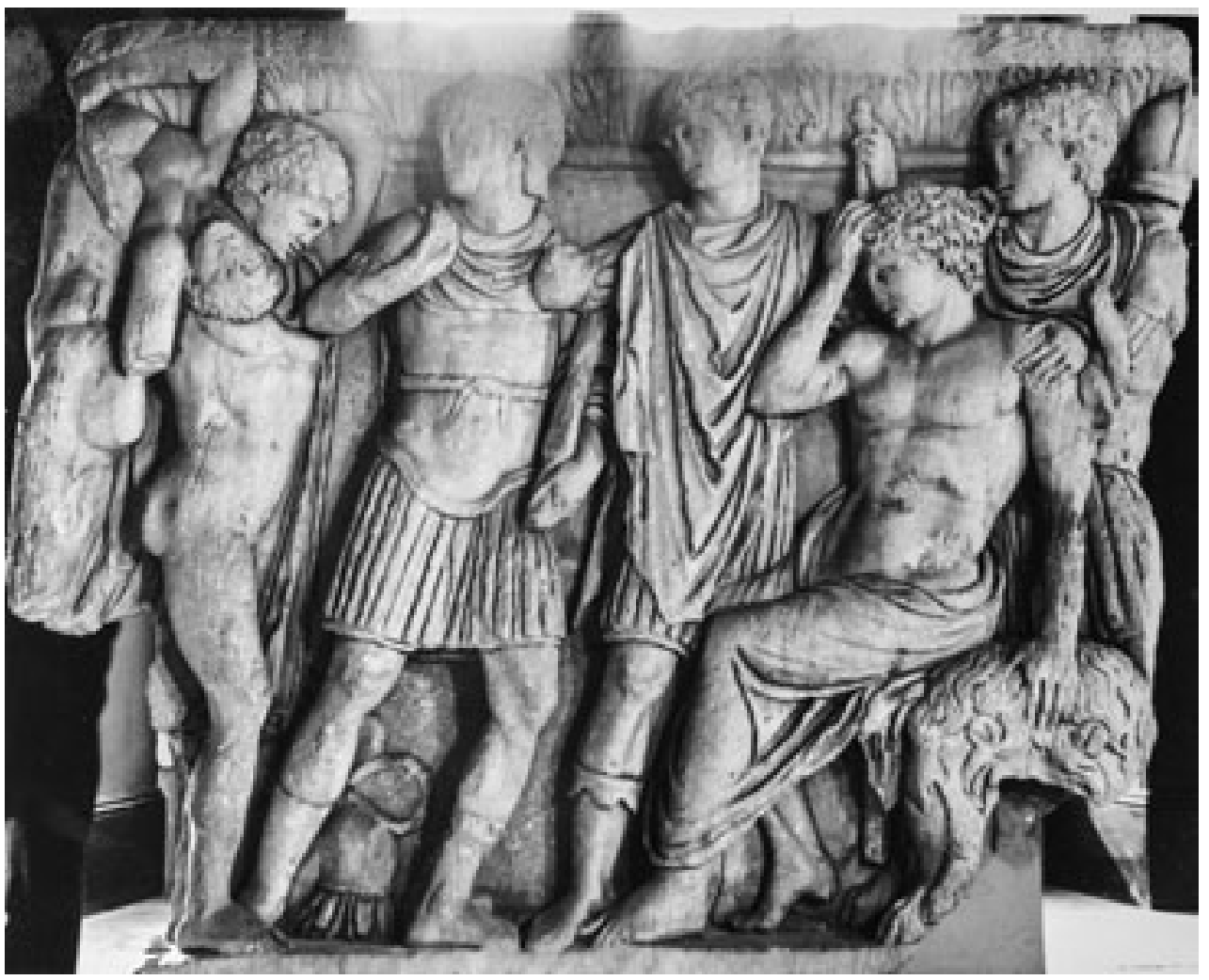

Abb. 153 Linke Schmalseite

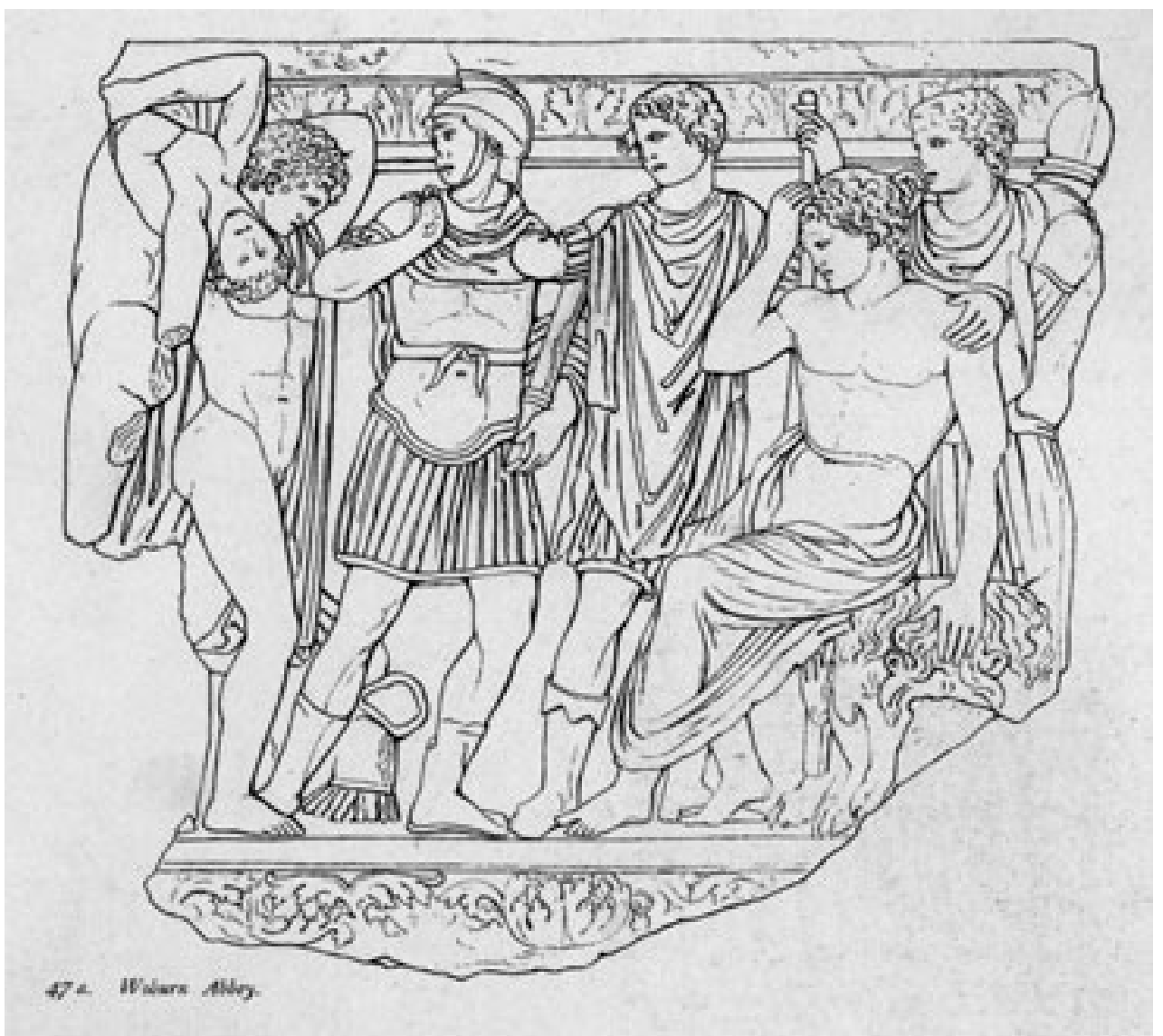

Abb. 154 Linke Schmalseite, Zeichnung (nach C. Robert)

Kat. 3 Achill-Sarkophag in Woburn Abbey 
Tafel 37

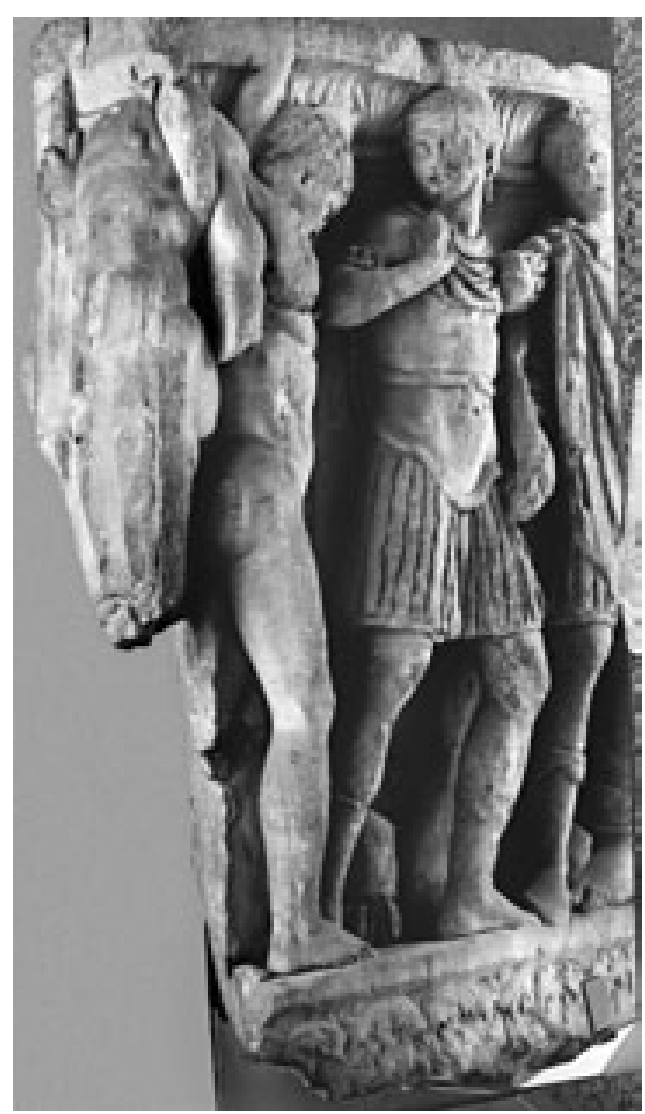

Abb. 155 Linke Schmalseite mit der Ecke zur Rückseite

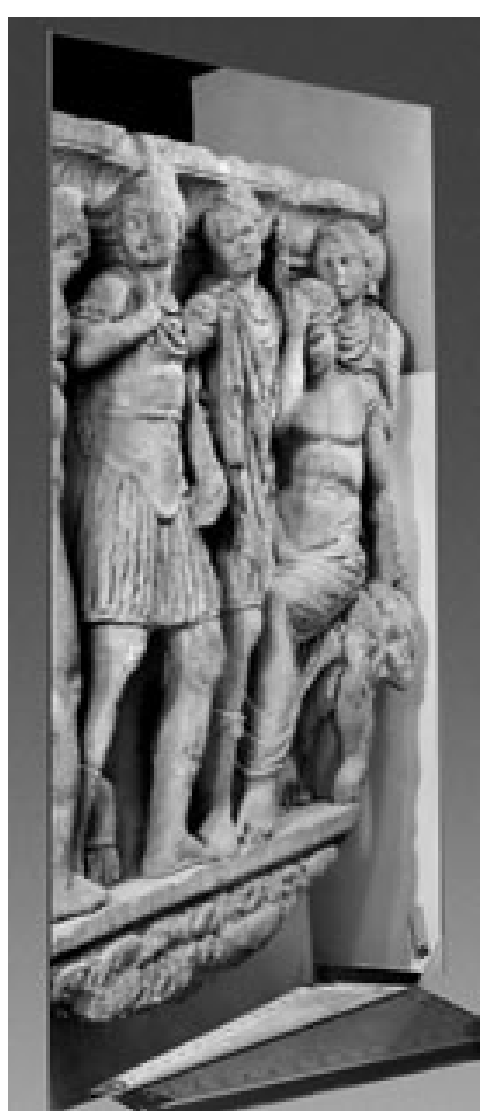

Abb. 156 Linke Schmalseite

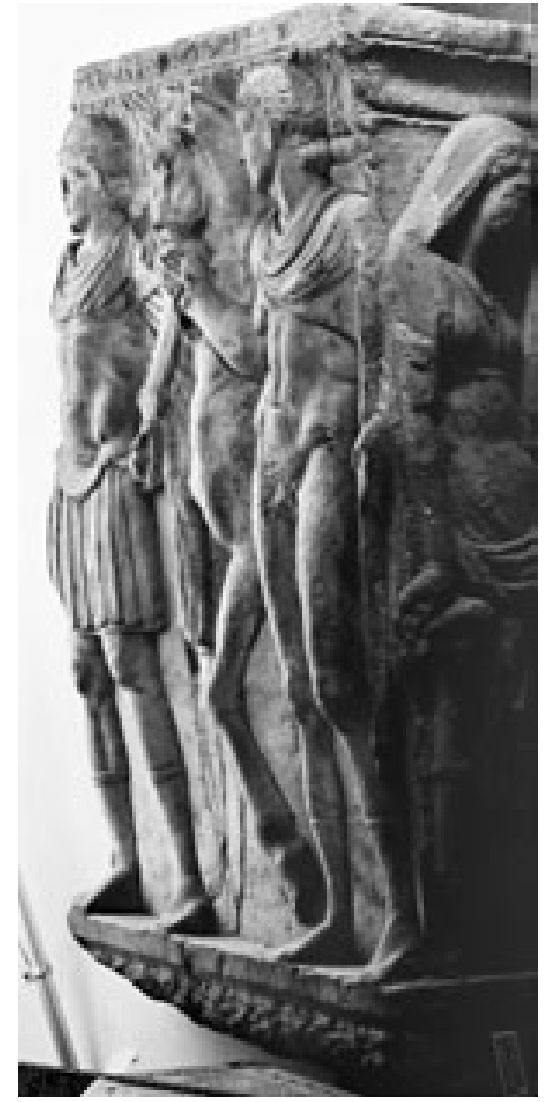

Abb. 157 Rechte Schmalseite mit der Ecke zur Rückseite

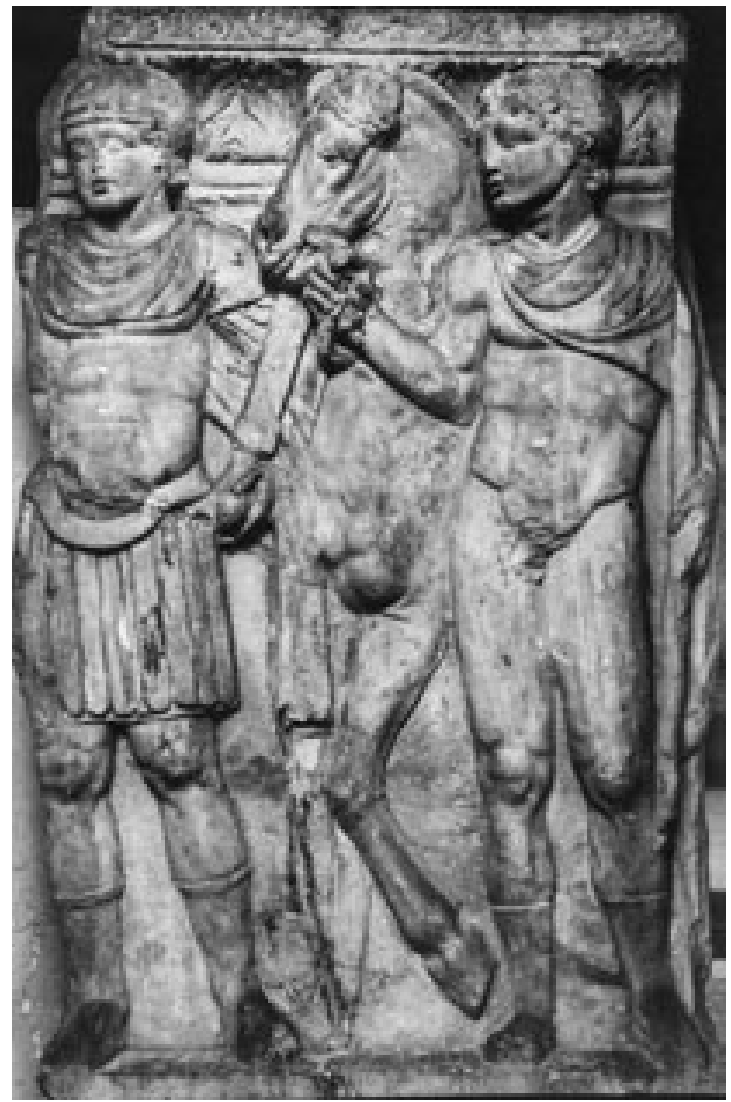

Abb. 158 Rechte Schmalseite

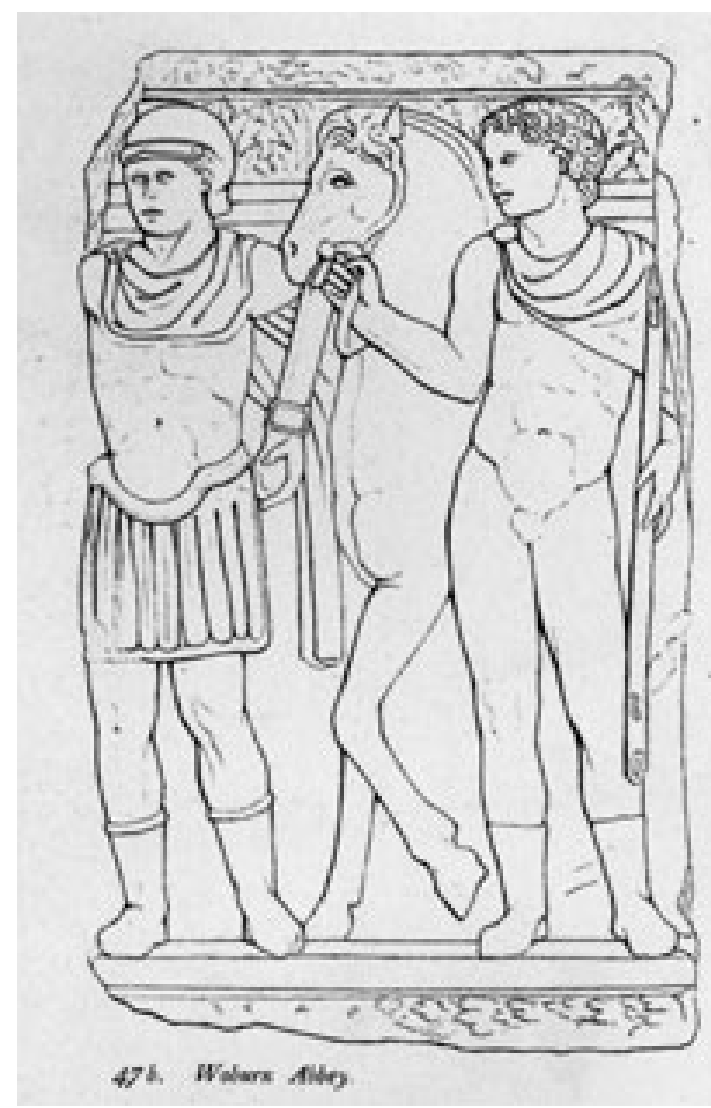

Abb. 159 Rechte Schmalseite, Zeichnung (nach C. Robert) 
Tafel 38

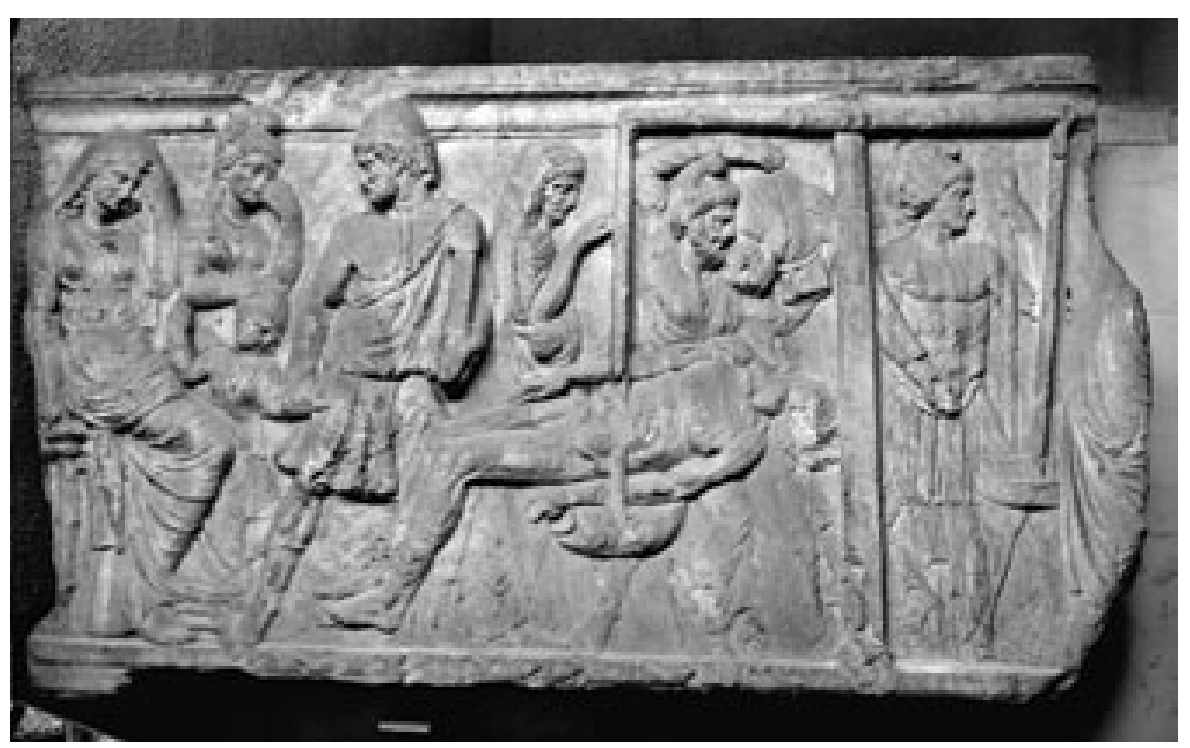

Abb. 160 Rückseite

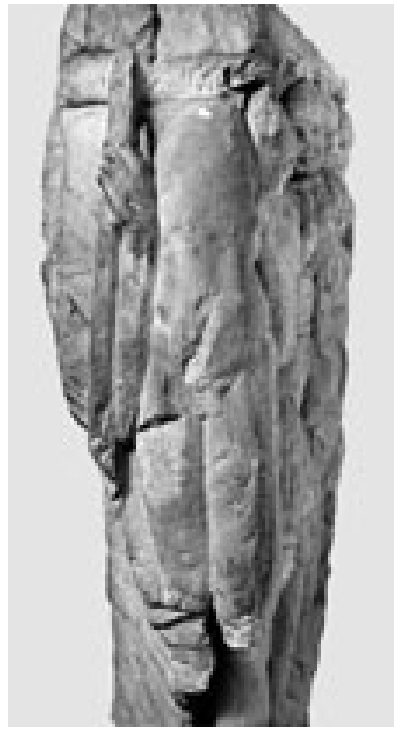

Abb. 161 Rechte Ecke der Rückseite

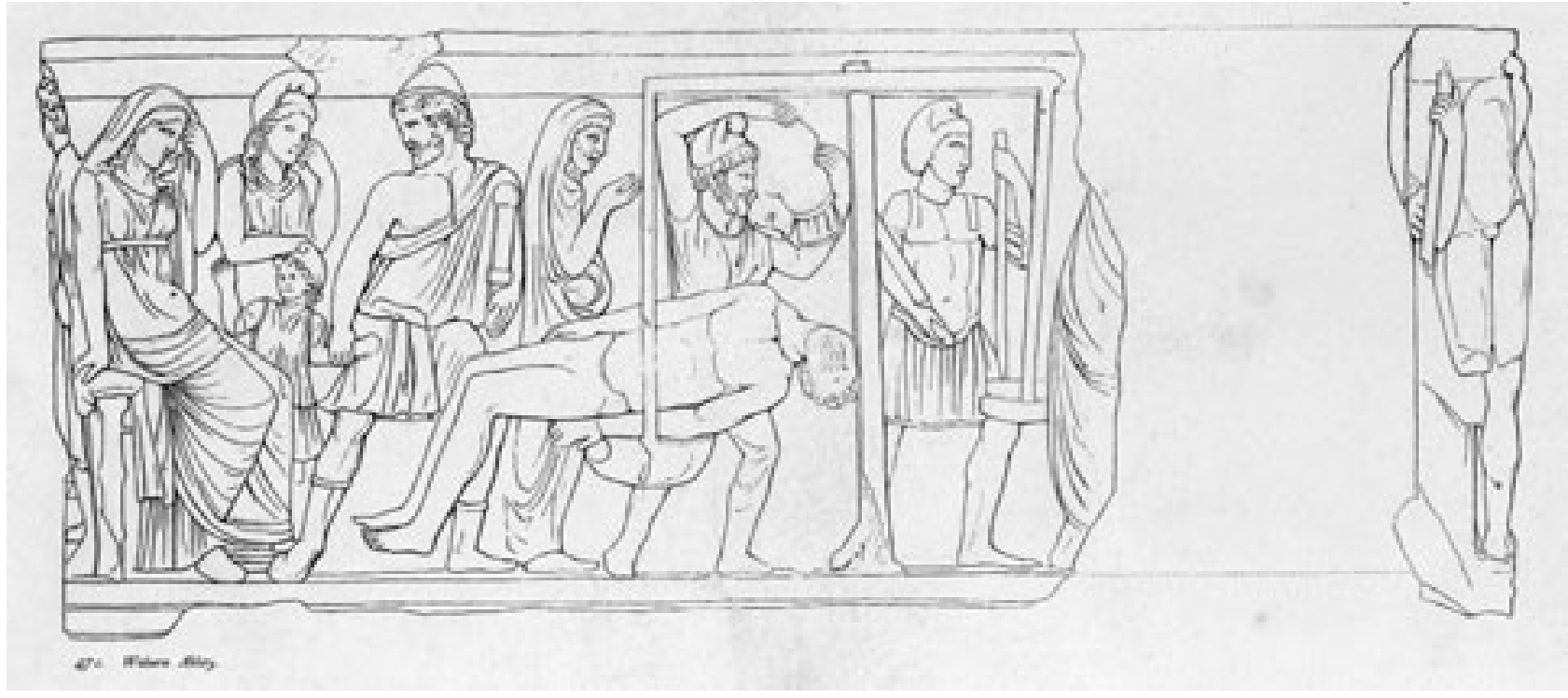

Abb. 162 Rückseite, Zeichnung (nach C. Robert)

Kat. 3 Achill-Sarkophag in Woburn Abbey 
Tafel 39

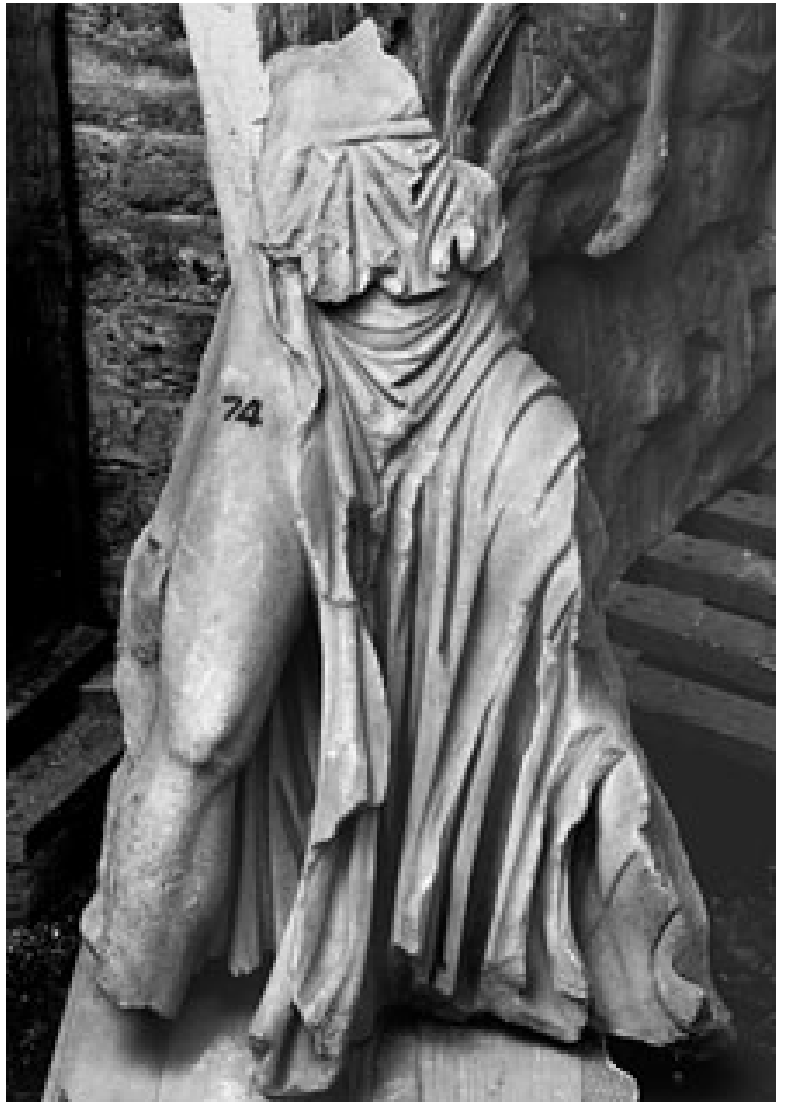

Abb. 163 Fragment

Kat. 4 Fragment eines Achill-Sarkophags in Woburn Abbey

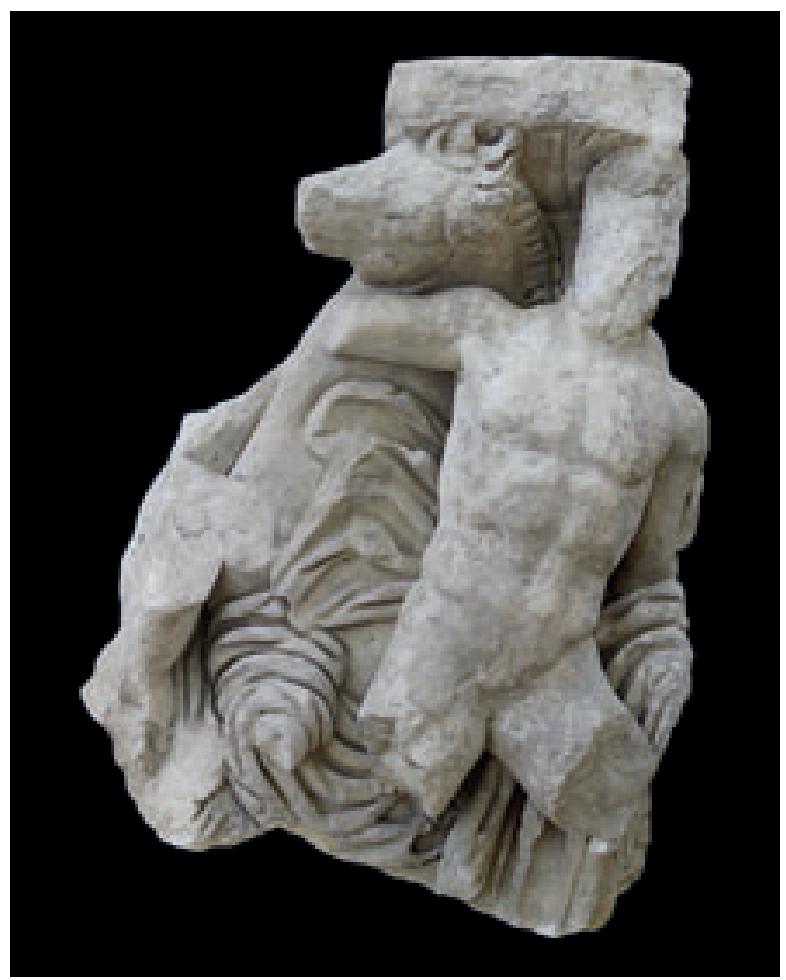

Abb. 165 Eckfragment

Kat. 5 Achill-Sarkophag. Selçuk, Efes Müzesi Inv. 2264

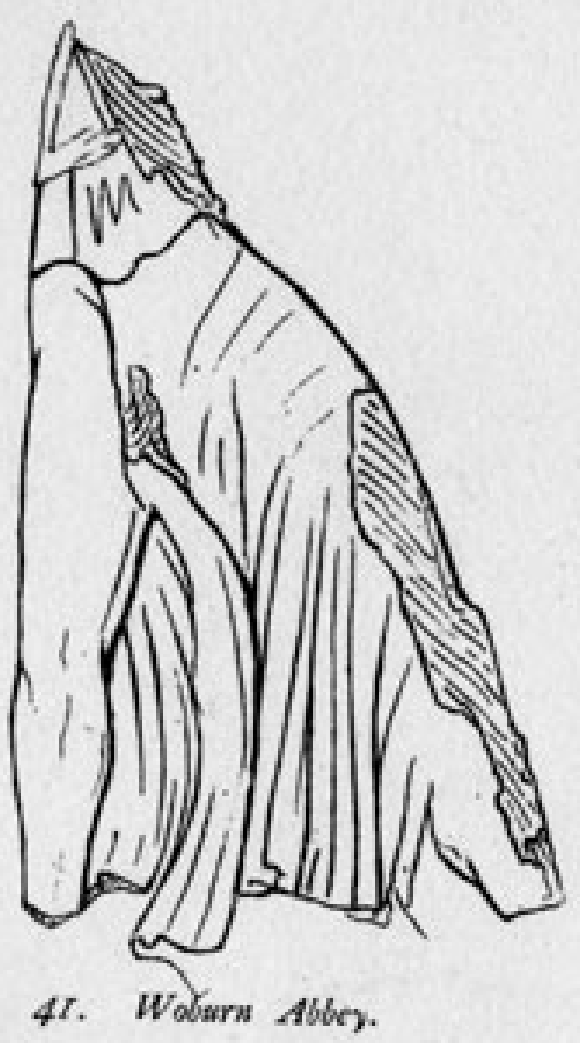

Abb. 164 Zeichnung (nach C. Robert)

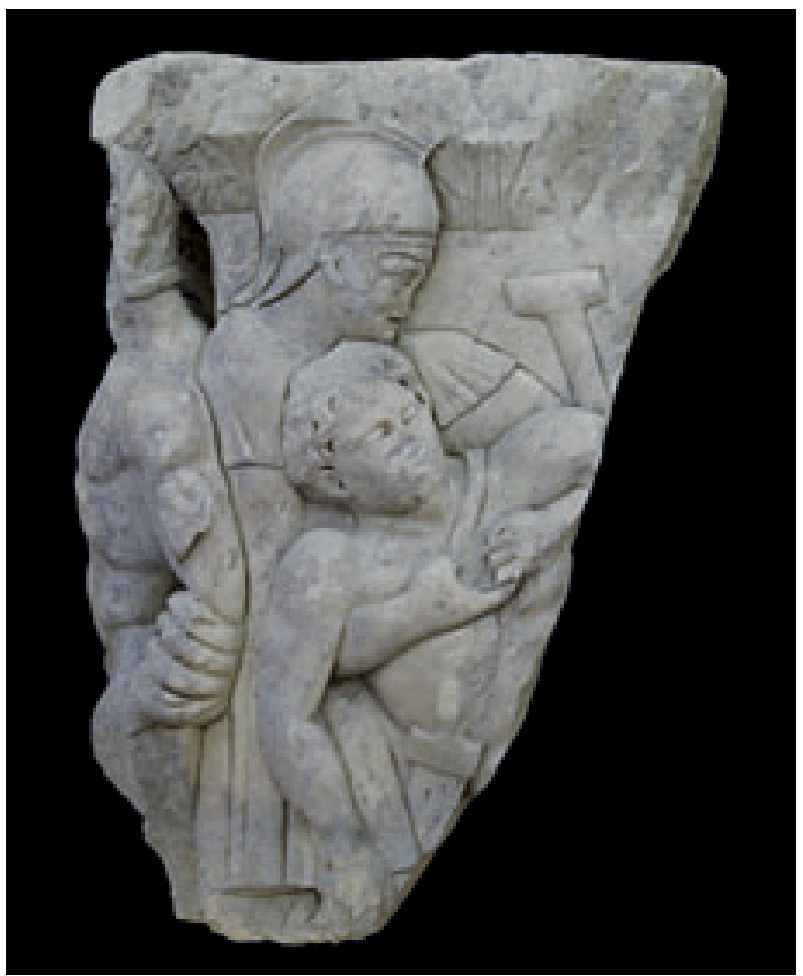

Abb. 166 Rechte Schmalseite 
Tafel 40

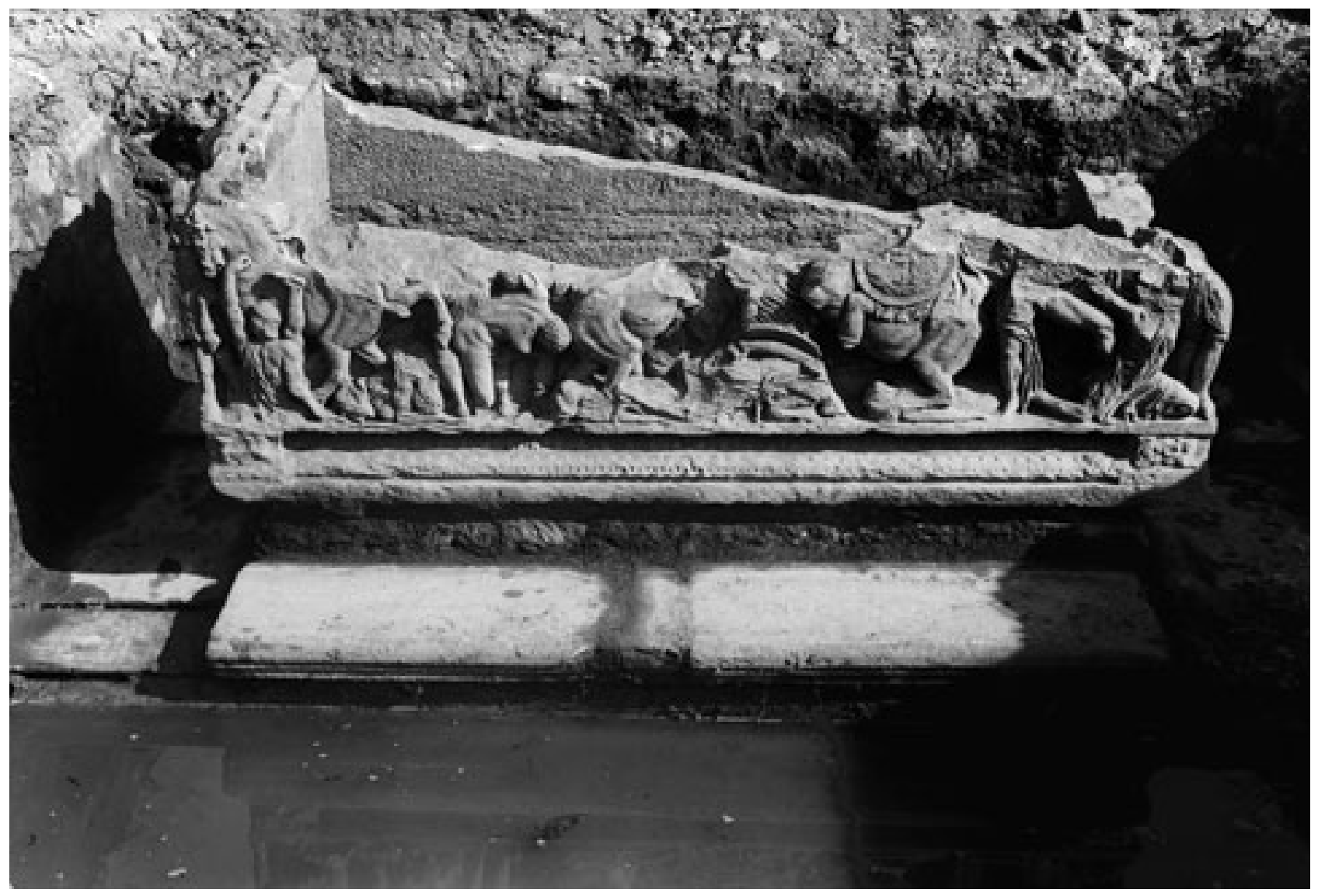

Abb. 167 Grabungssituation

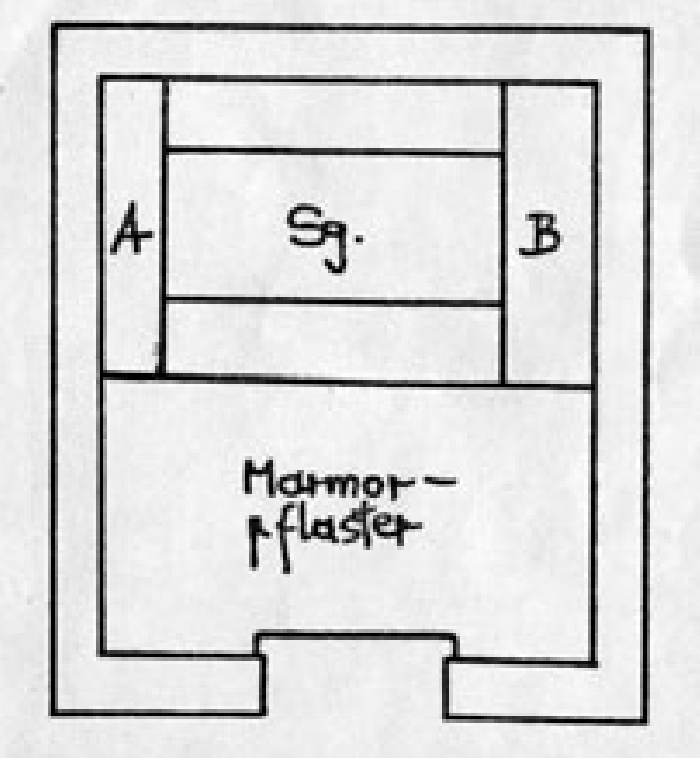

Abb. 168 Grundrissskizze des Grabbaus (J. Keil/ E. Rudolf)

Kat. 6 Fragmentierter Amazonomachie-Sarkophag aus einem Grabhaus der Nekropole nördlich des Hafenkanals in Ephesos. Selçuk, Efes Müzesi Inv. 260 
Tafel 41

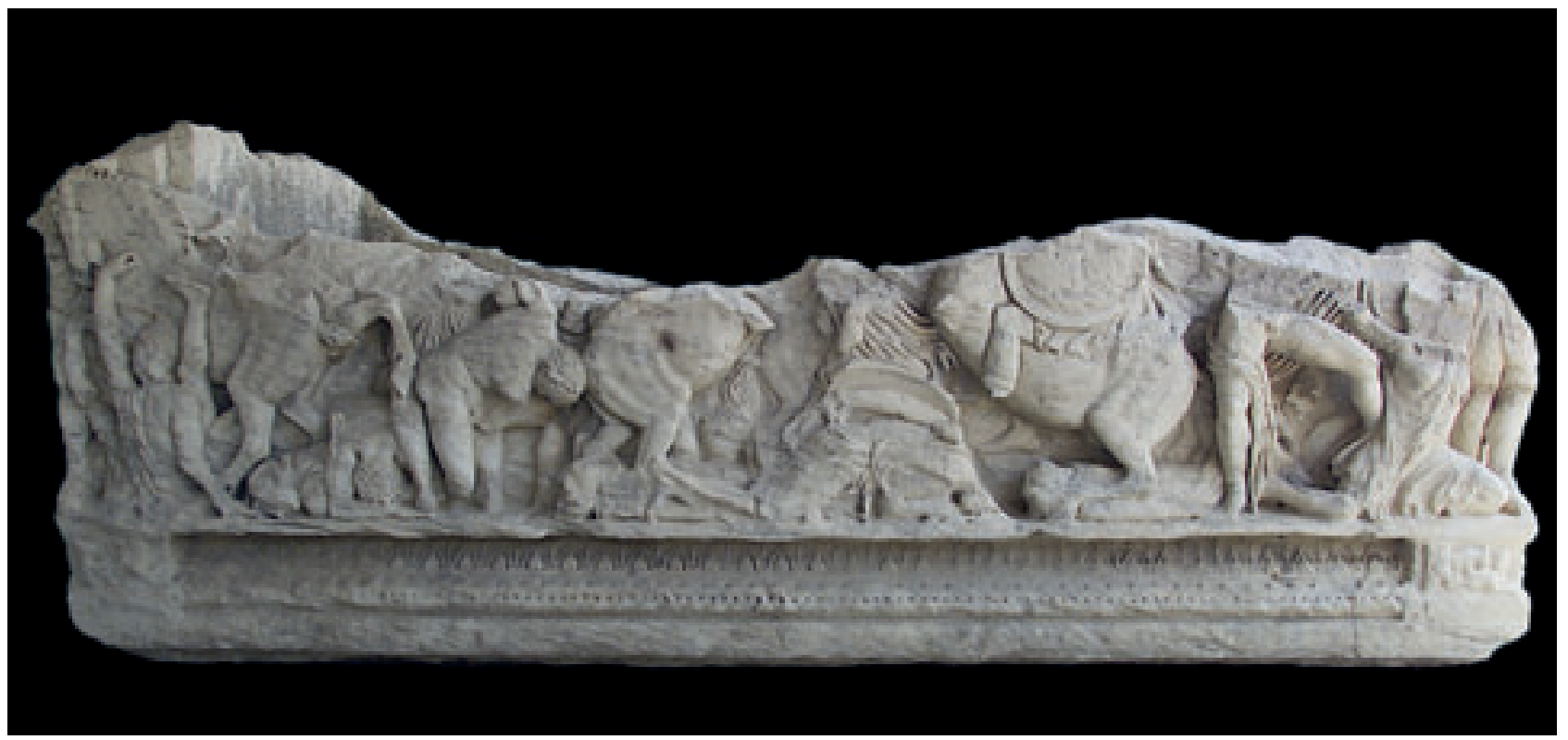

Abb. 169 Vorderseite

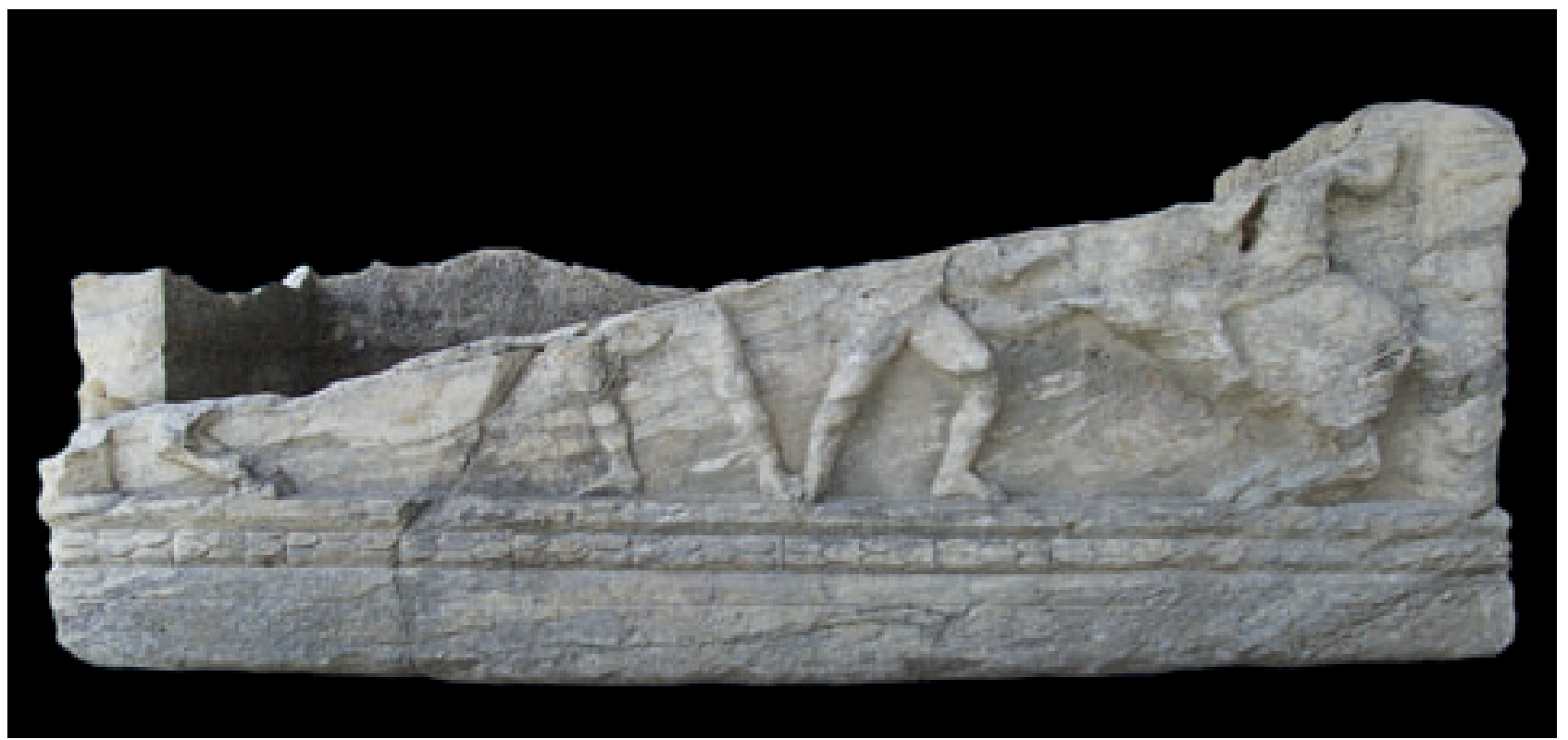

Abb. 170 Rückseite

Kat. 6 Fragmentierter Amazonomachie-Sarkophag aus einem Grabhaus der Nekropole nördlich des Hafenkanals in Ephesos. Selçuk, Efes Müzesi Inv. 260 
Tafel 42

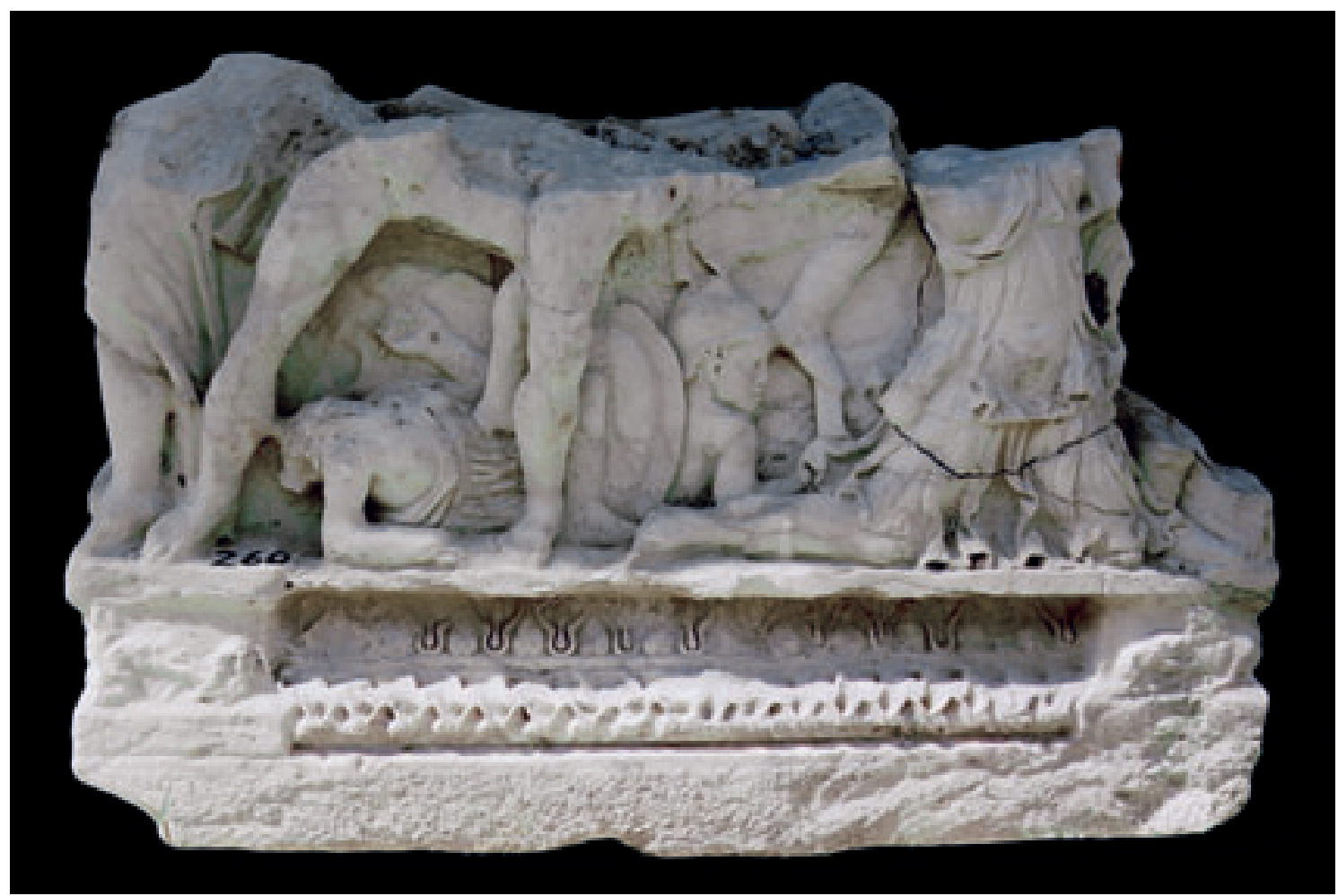

Abb. 171 Rechte Schmalseite

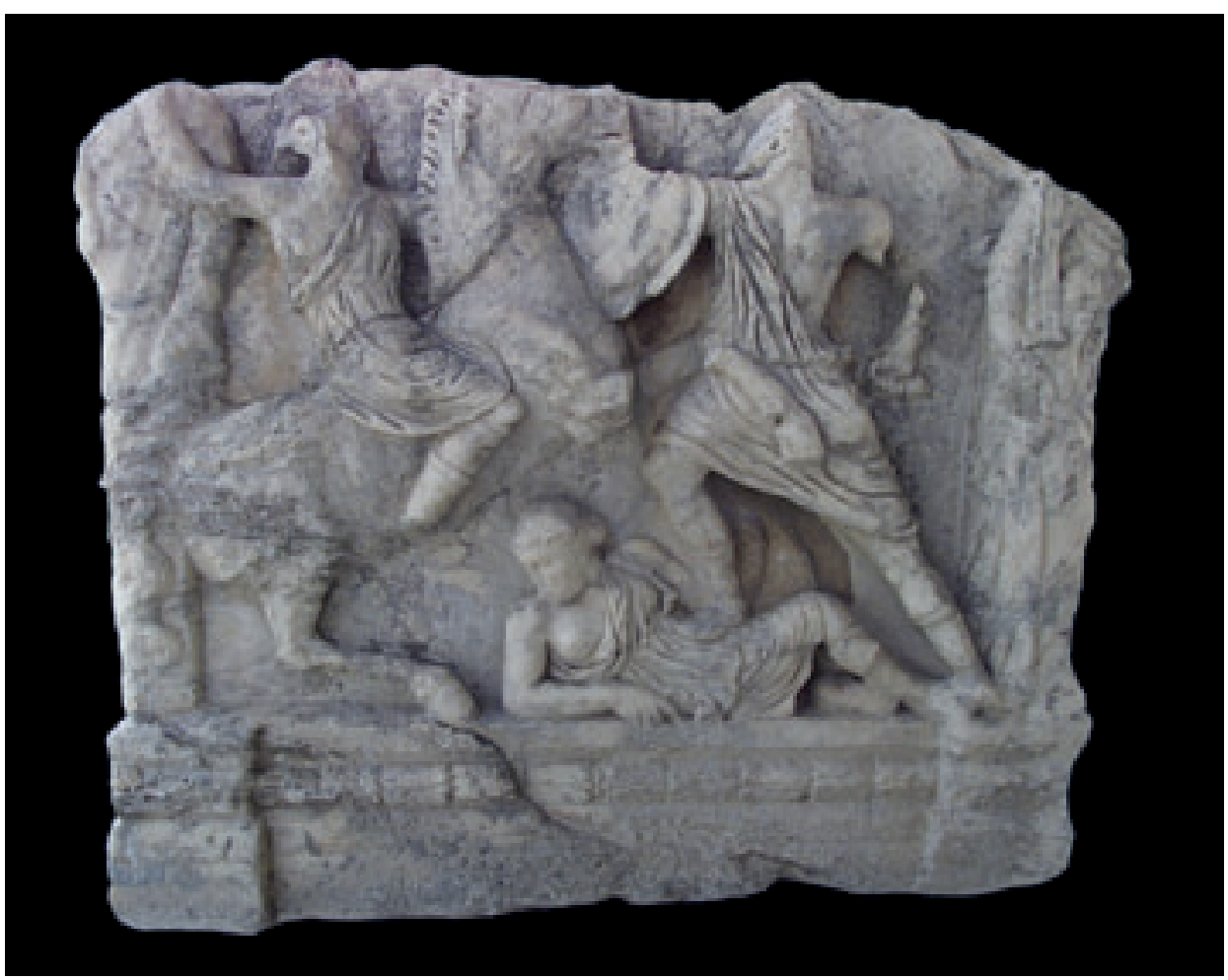

Abb. 172 Linke Schmalseite

Kat. 6 Fragmentierter Amazonomachie-Sarkophag aus einem Grabhaus der Nekropole nördlich des Hafenkanals in Ephesos. Selçuk, Efes Müzesi Inv. 260 
Tafel 43

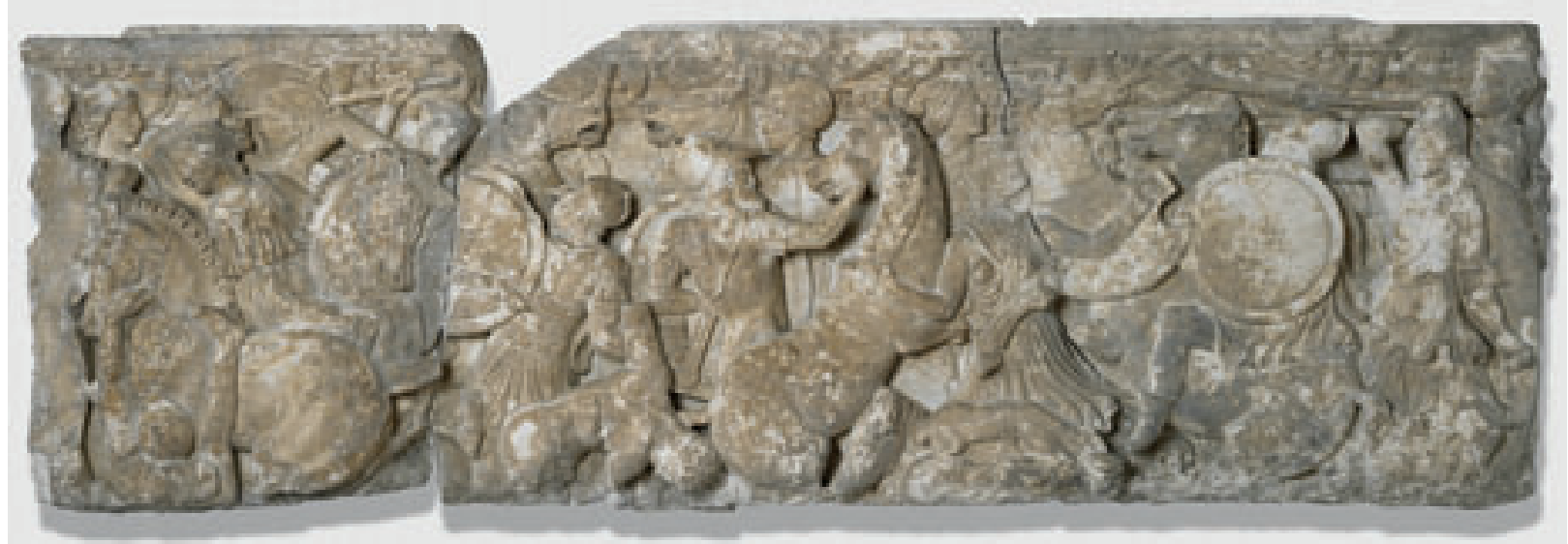

Abb. 173 Vorderseite eines Amazonomachie-Sarkophags. Harvard Art Museums/Arthur M. Sackler Museum, Gift of Edward W. Forbes Inv. 1899.9+1932.49

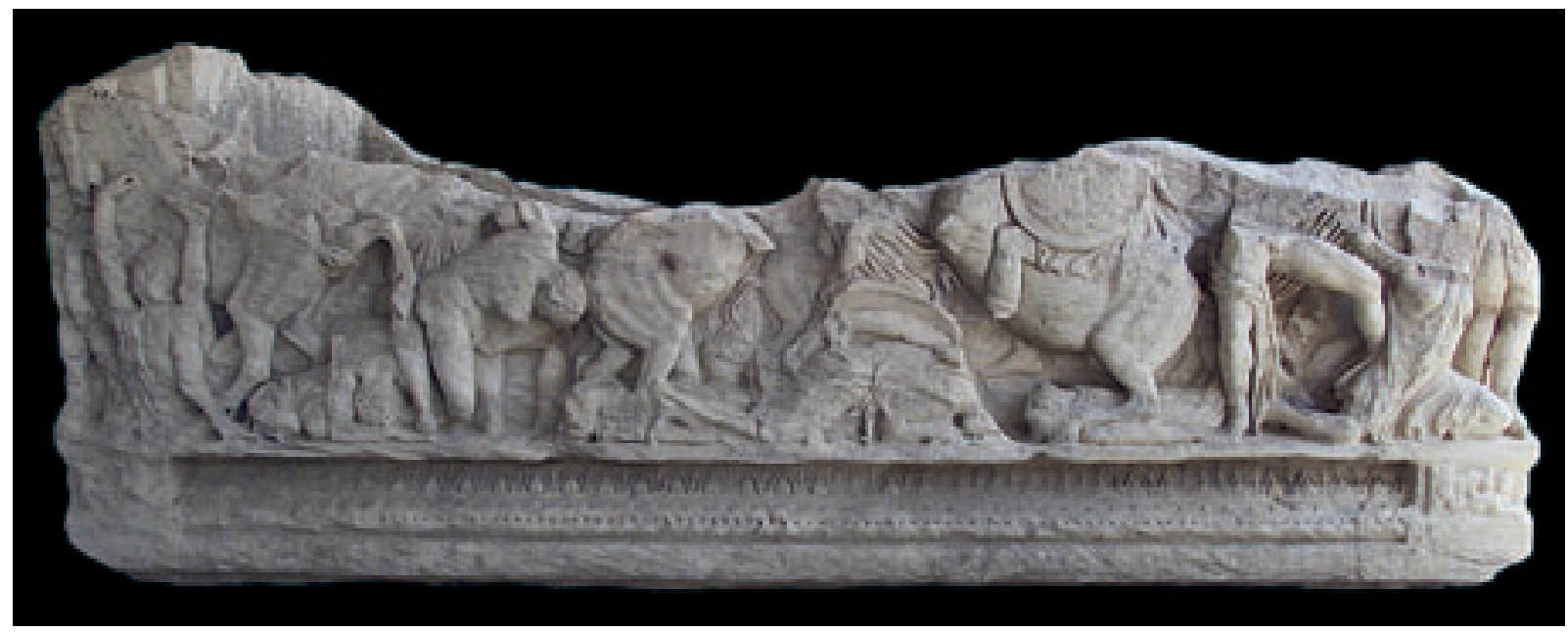

Abb. 174 Vorderseite

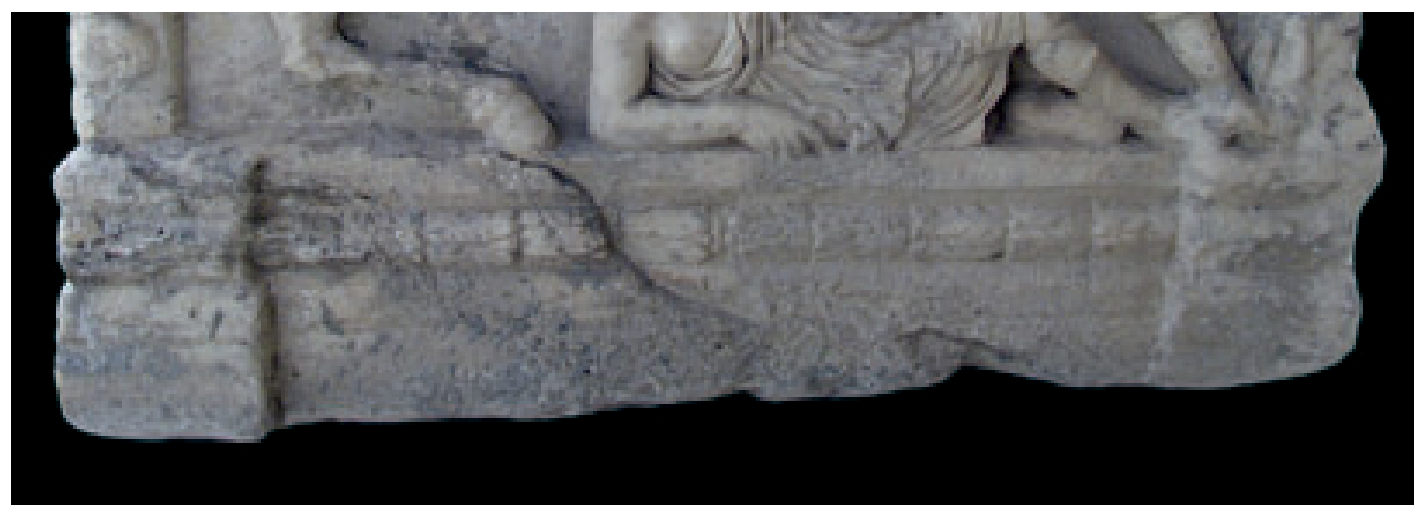

Abb. 175 Sockelzone der linken Schmalseite

Kat. 6 Amazonomachie-Sarkophags. Selçuk, Efes Müzesi Inv. 260 
Tafel 44

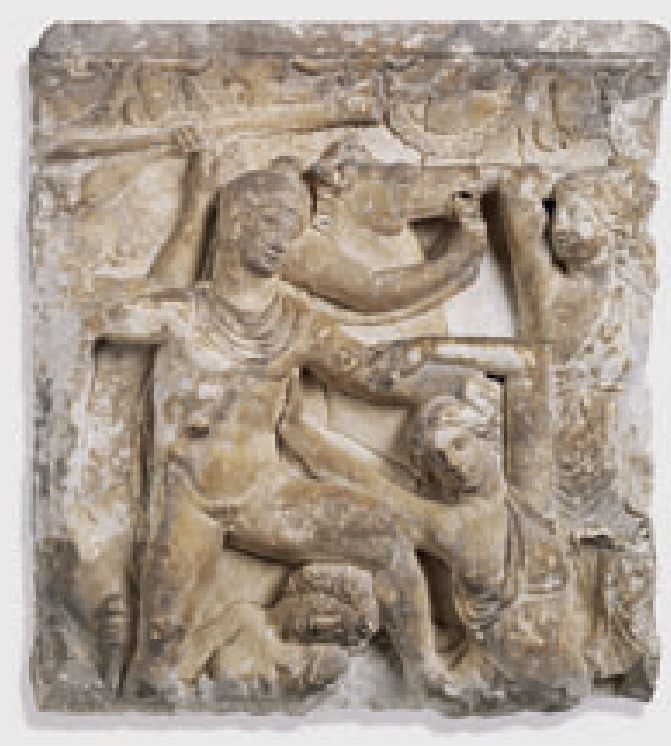

Abb. 176 Linke Schmalseite eines AmazonomachieSarkophags. Harvard Art Museums/

Arthur M. Sackler Museum, Gift of Edward W. Forbes Inv. 1899.9+1932.49

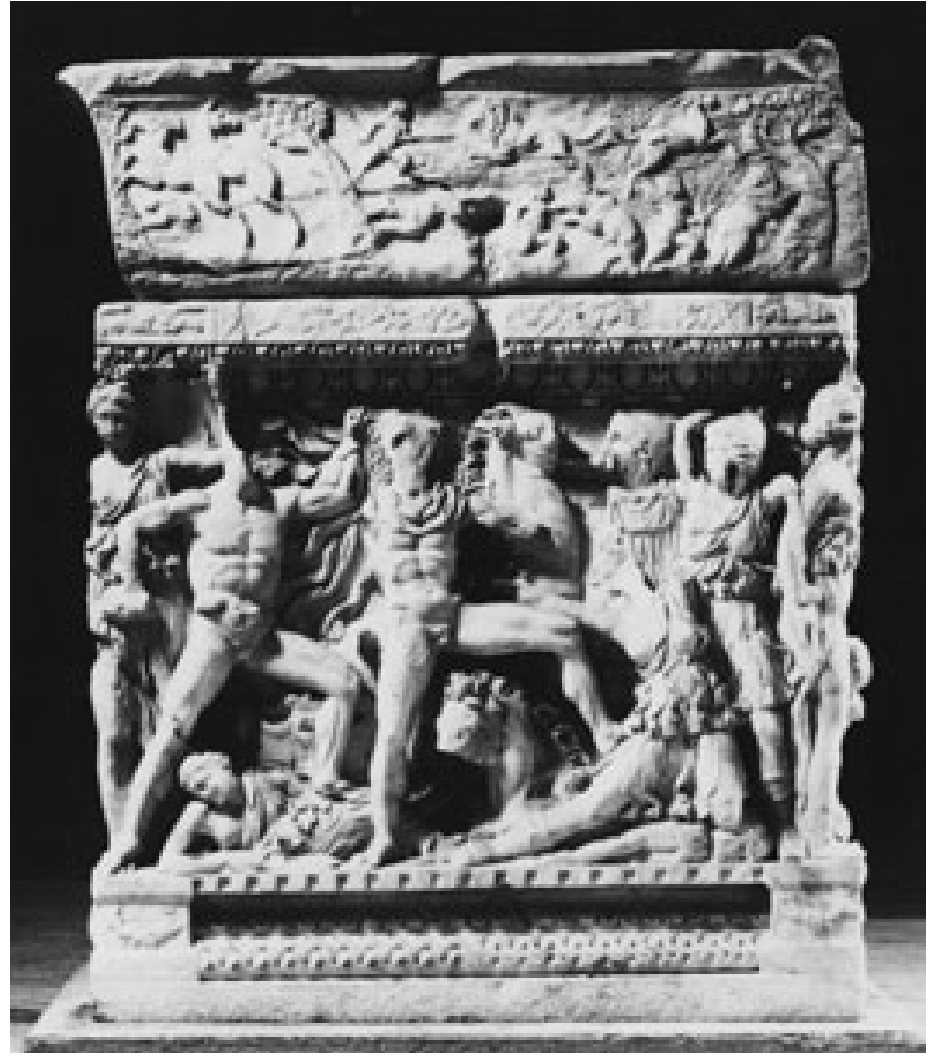

Abb. 177 Linke Schmalseite eines Amazonomachie-Sarkophags. Thessaloniki, Archäologisches Museum Inv. 283

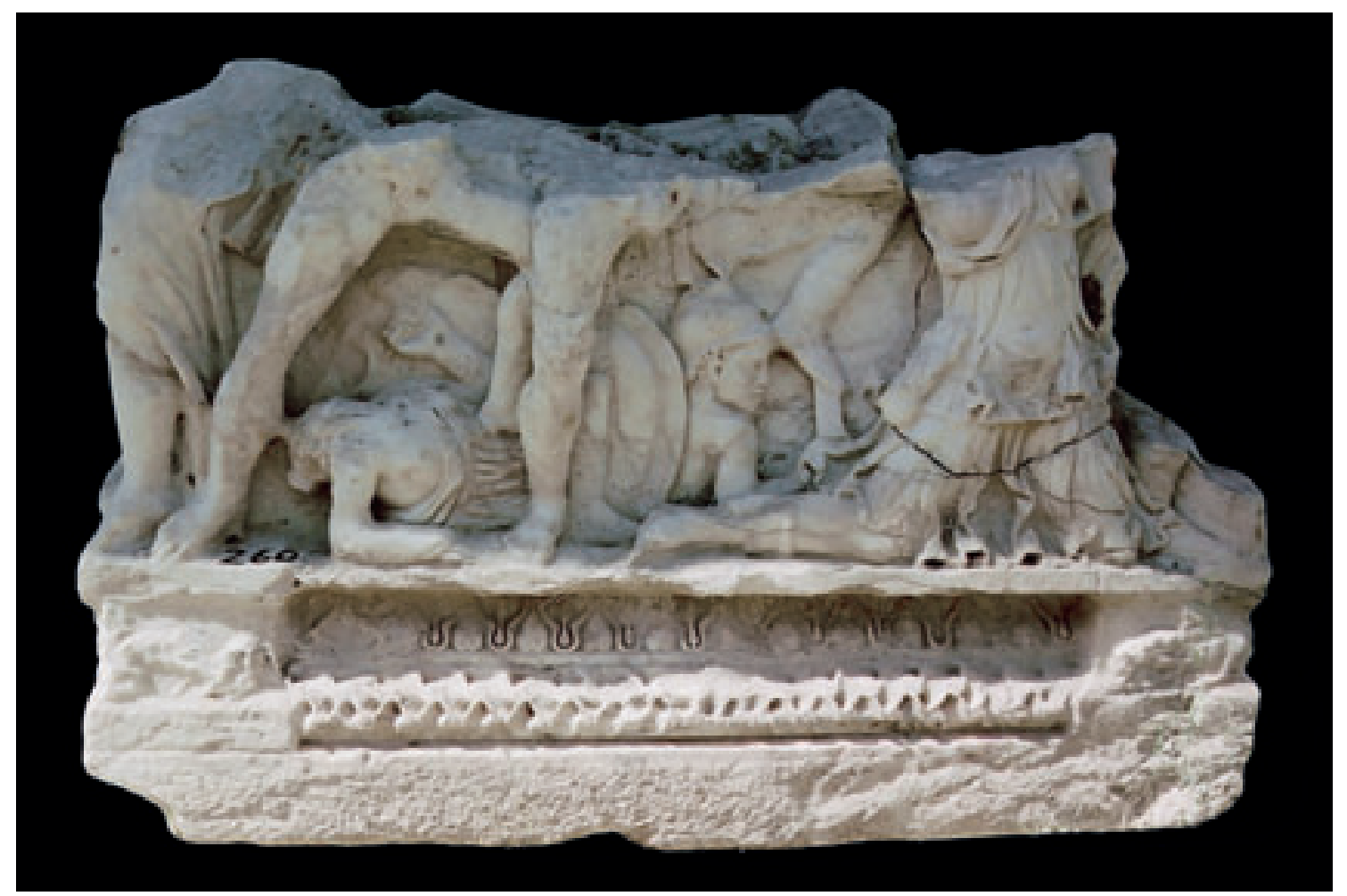

Abb. 178 Kat. 6, rechte Schmalseite des Amazonomachie-Sarkophags. Selçuk, Efes Müzesi Inv. 260 
Tafel 45

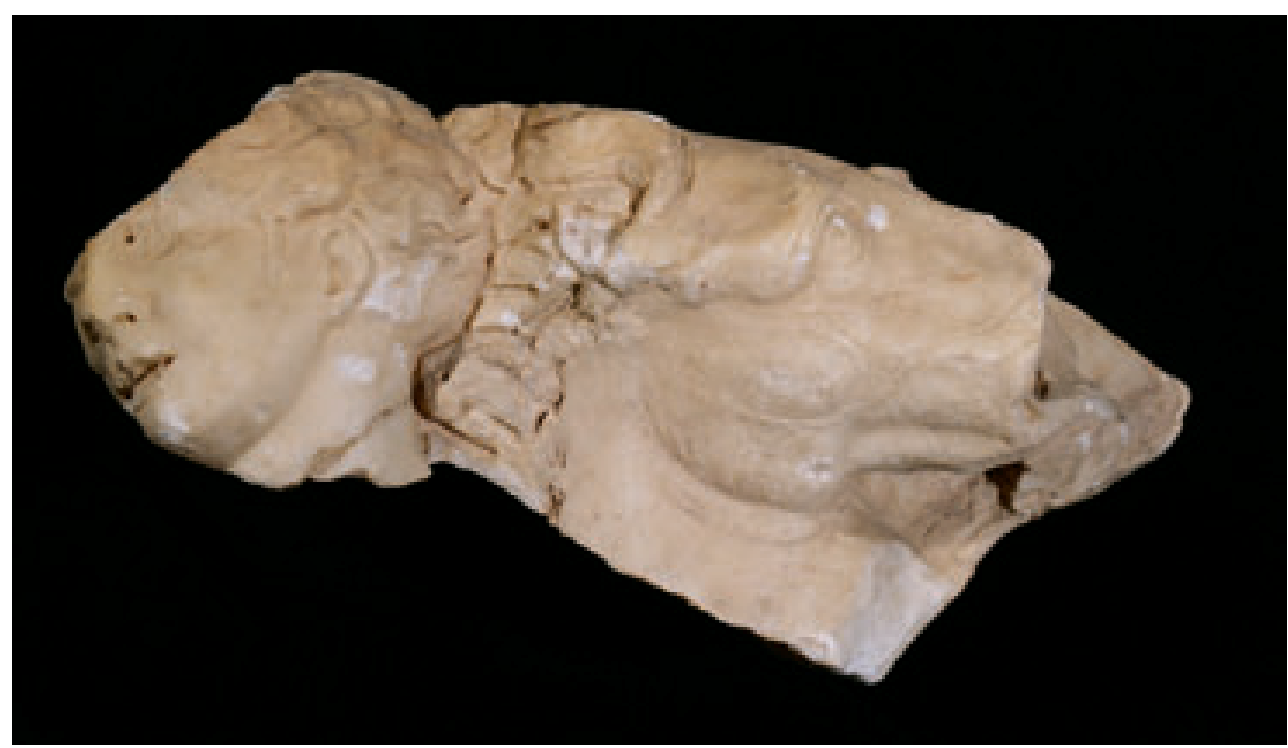

Abb. 179 Kat. 7, Kastenfragment eines Amazonomachie-Sarkophags. Selçuk, Efes Müzesi Inv. $14 / 61 / 80$

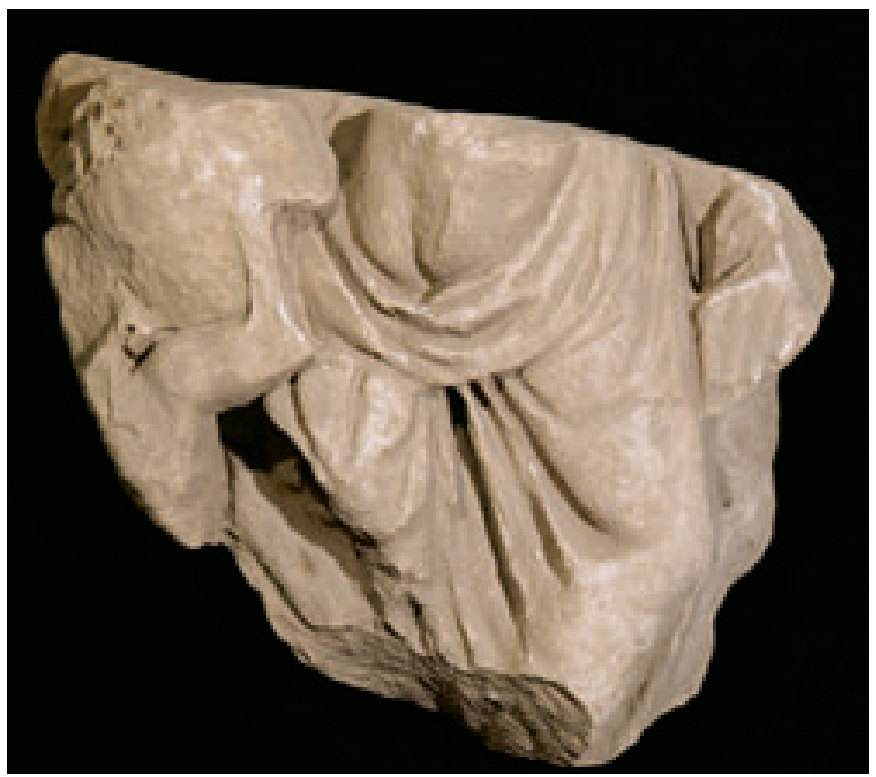

Abb. 180 Kat. 8, Kastenfragment eines dionysischen Sarkophags. Selçuk, Efes Müzesi Inv. 1/23/84

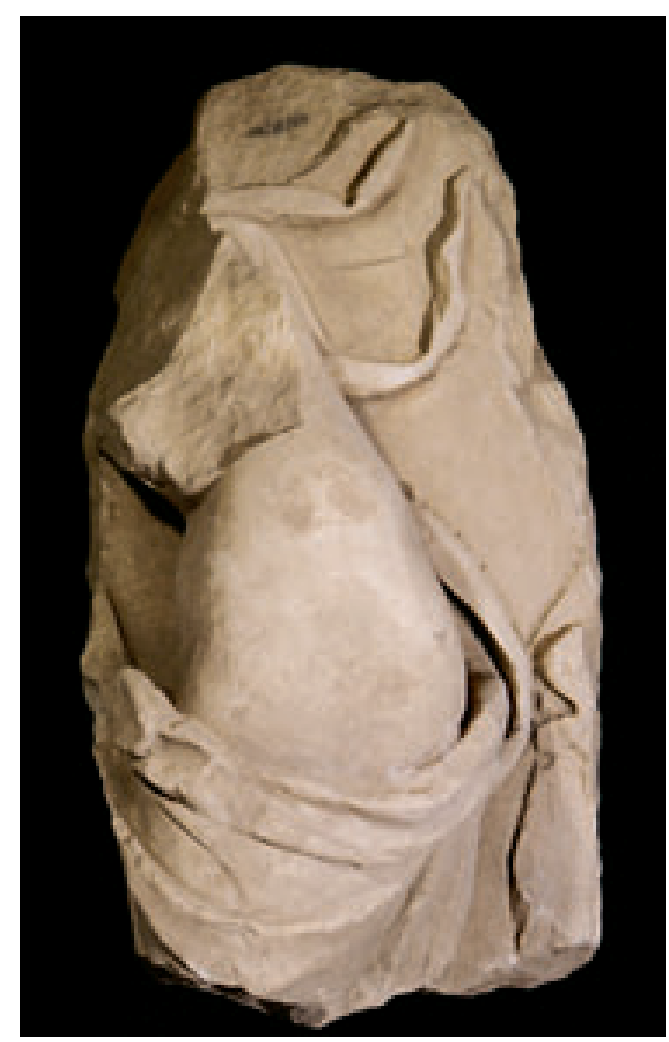

Abb. 181 Kat. 9, Kastenfragment eines dionysischen Sarkophags. Selçuk, Efes Müzesi Inv. 45/57/79 
Tafel 46

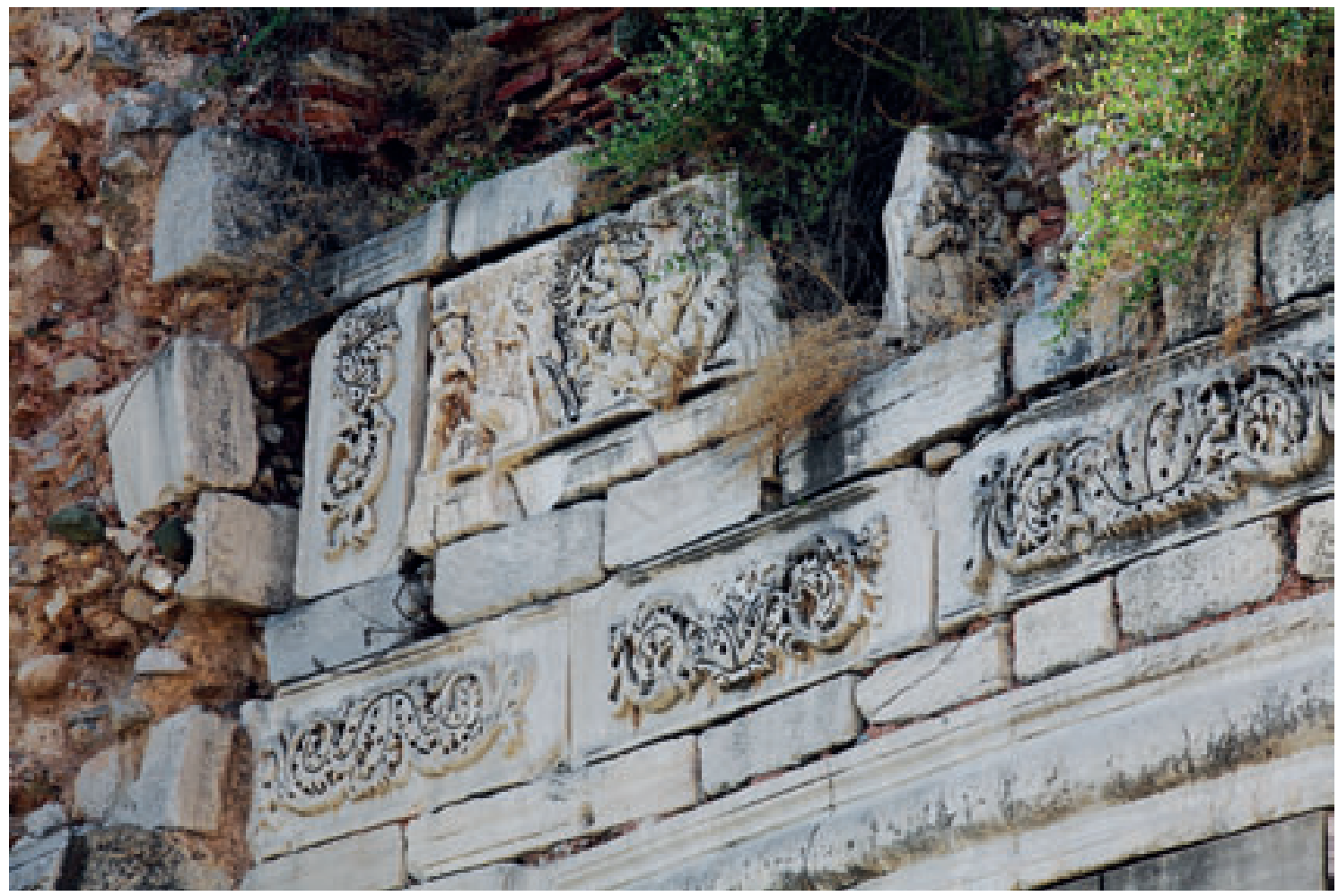

Abb. 182 Vorderseite und rechte Schmalseite

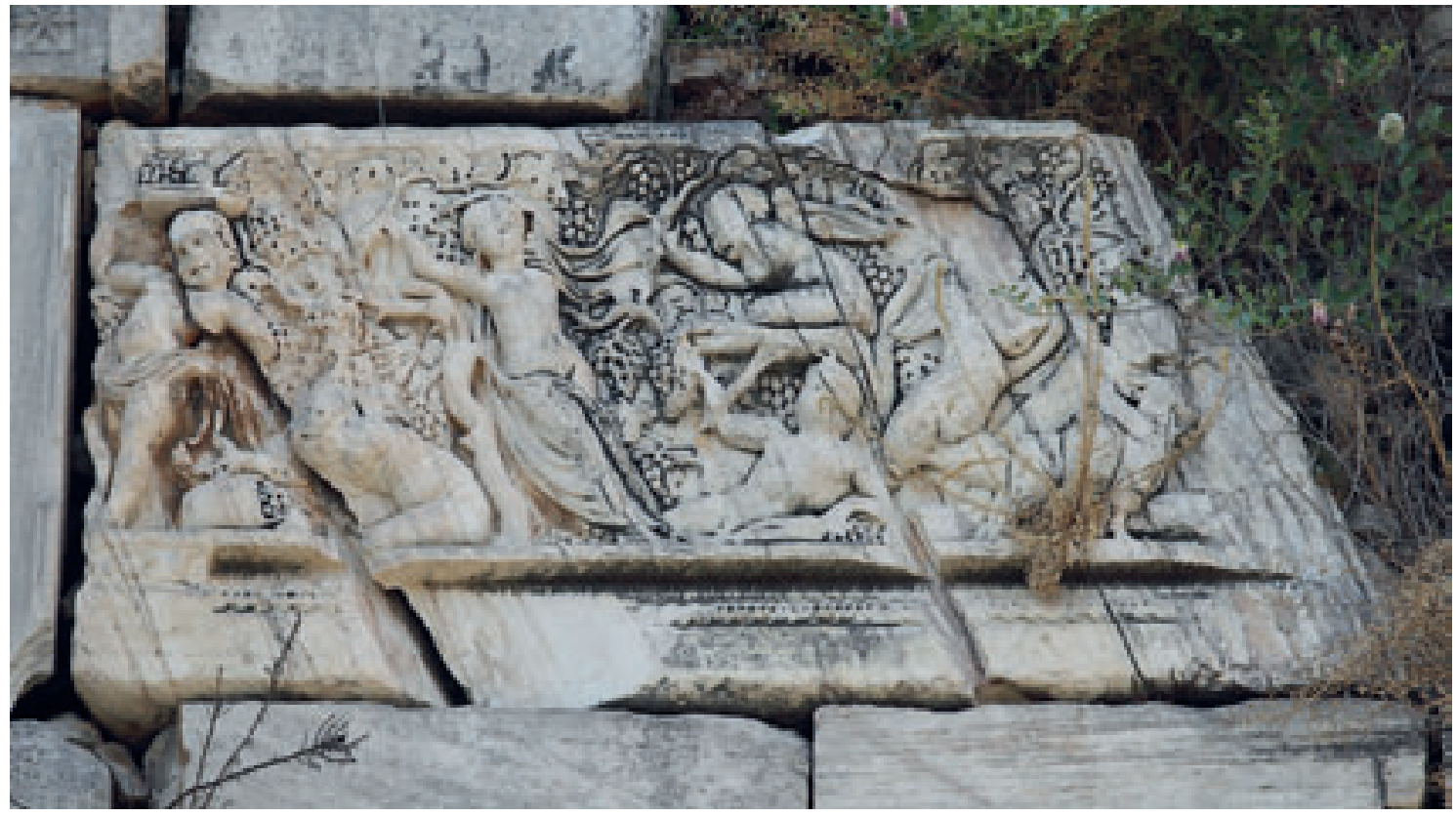

Abb. 183 Vorderseite

Kat. 10 Fragmentierter Kasten eines Eroten-Weinlese-Sarkophags. Selçuk, verbaut im >Tor der Verfolgung، 
Tafel 47
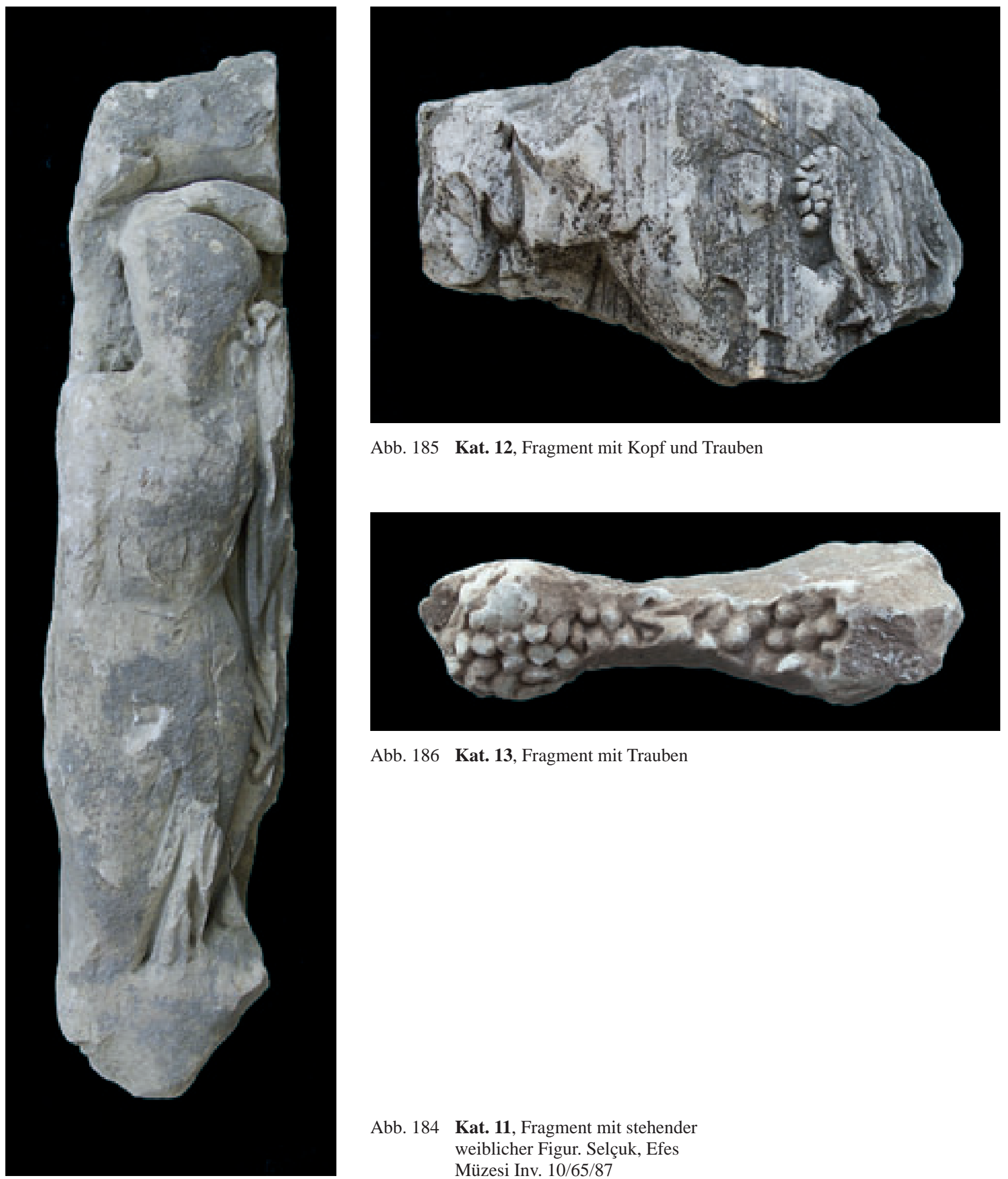

Abb. 185 Kat. 12, Fragment mit Kopf und Trauben

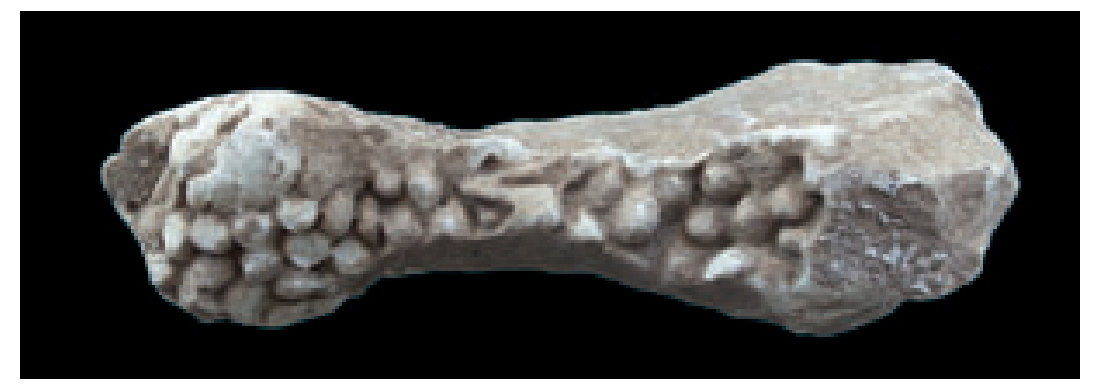

Abb. 186 Kat. 13, Fragment mit Trauben

Abb. 184 Kat. 11, Fragment mit stehender weiblicher Figur. Selçuk, Efes Müzesi Inv. 10/65/87 
Tafel 48

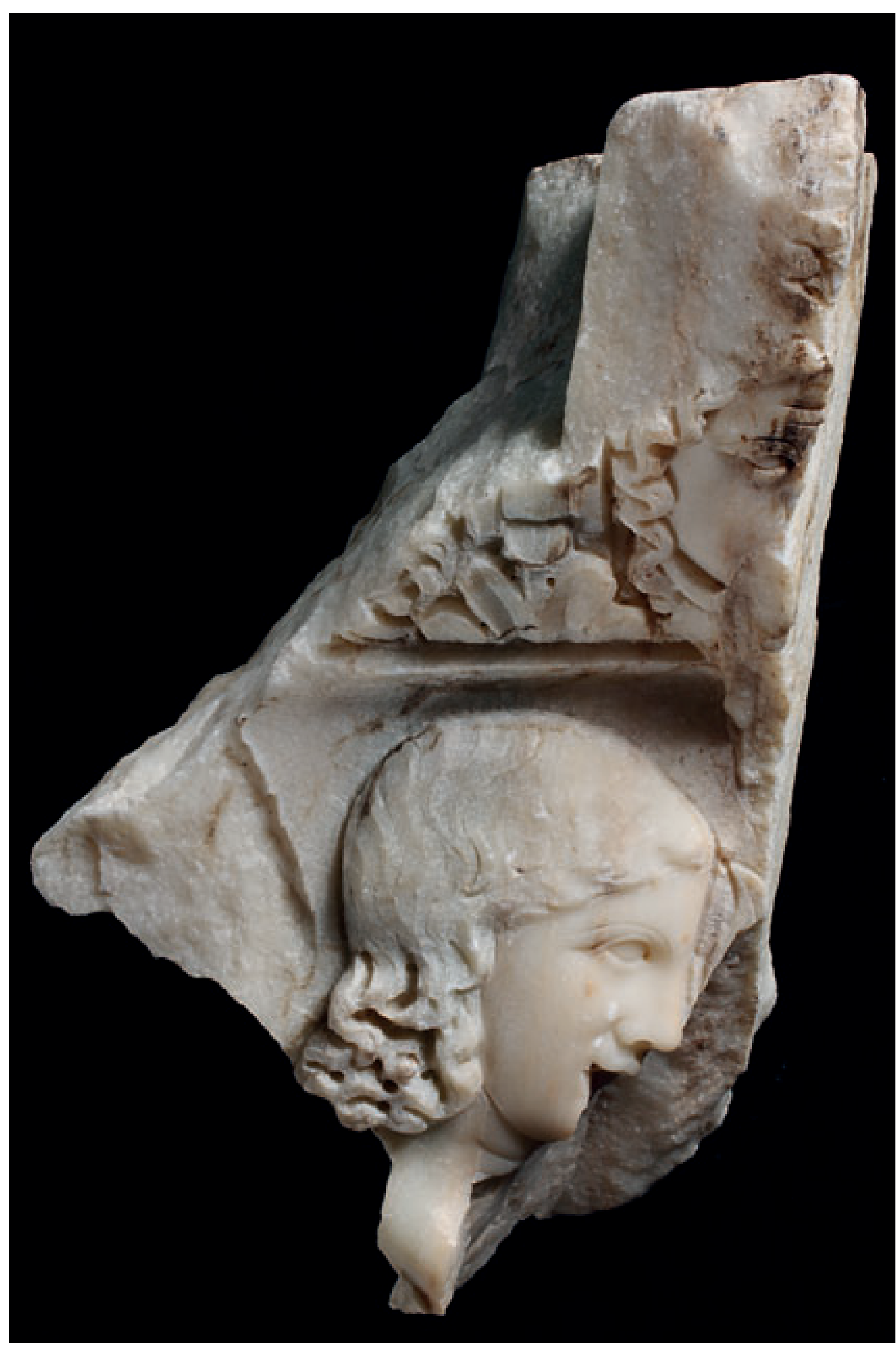

Abb. 187 Kat. 14, Fragment mit jugendlichem Kopf (Eros [?]). Selçuk, Efes Müzesi Inv. nicht bekannt 
Tafel 49

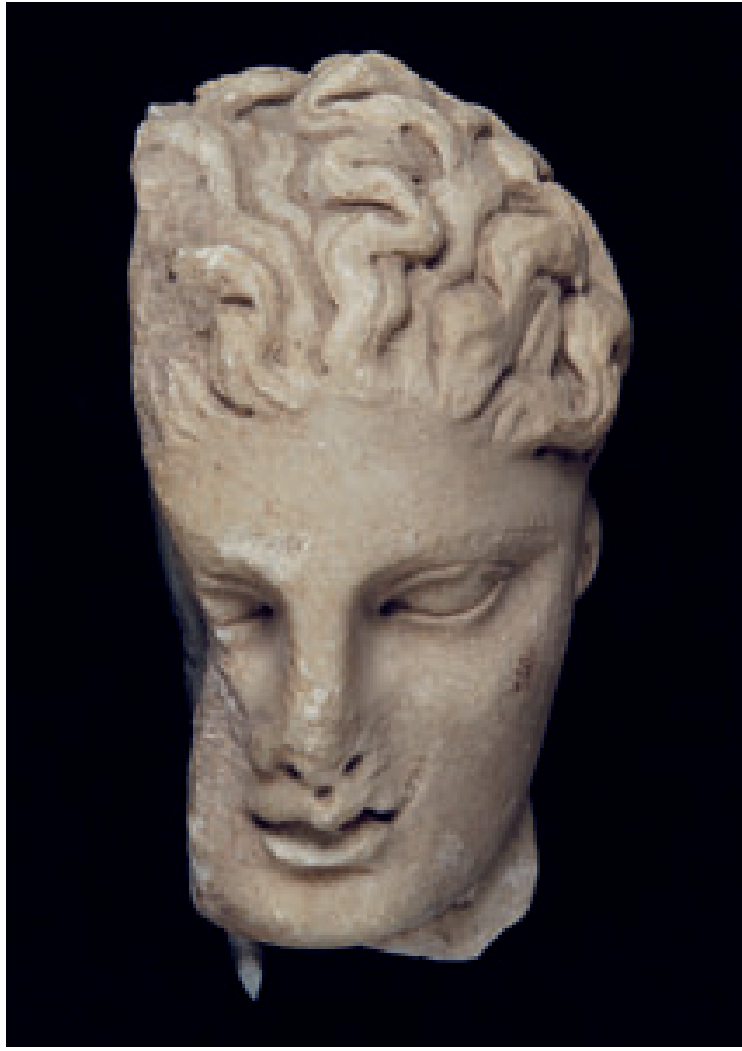

Abb. 188 Jünglingskopf, Vorderseite Fragment 1, Selçuk, Efes Müzesi Inv. 111

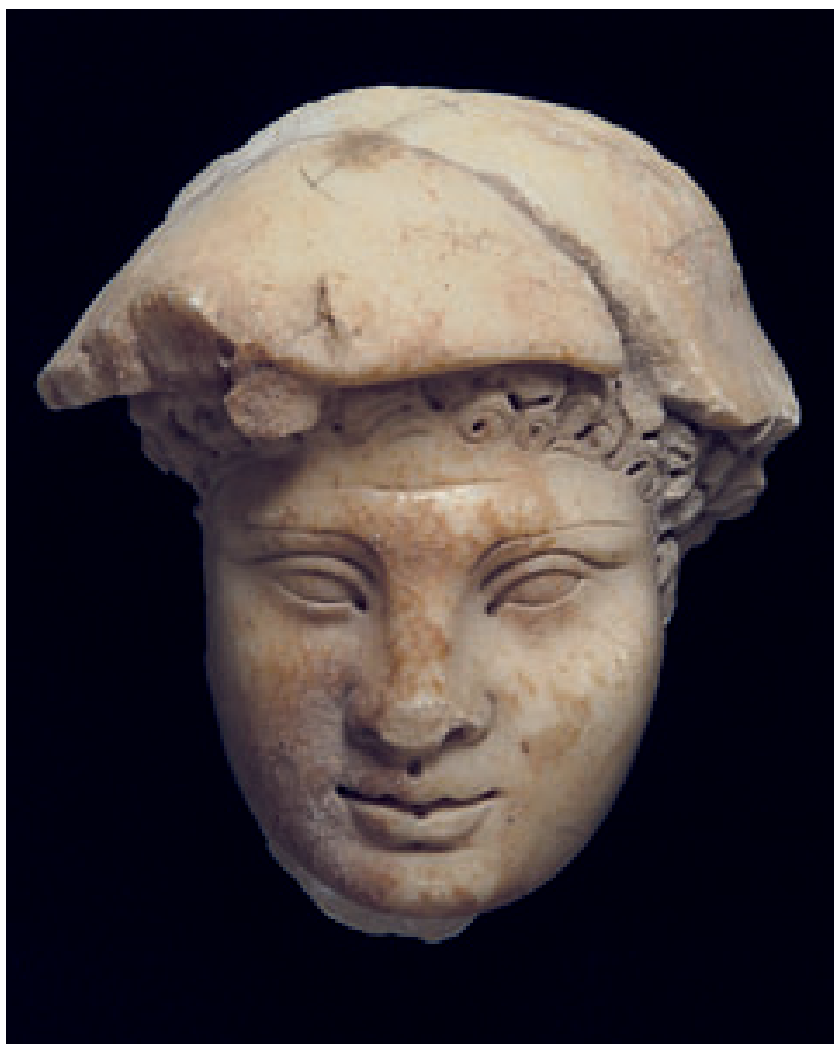

Abb. 190 Jüngling mit Hut, Vorderseite Fragment 3, Selçuk, Efes Müzesi Inv. 115

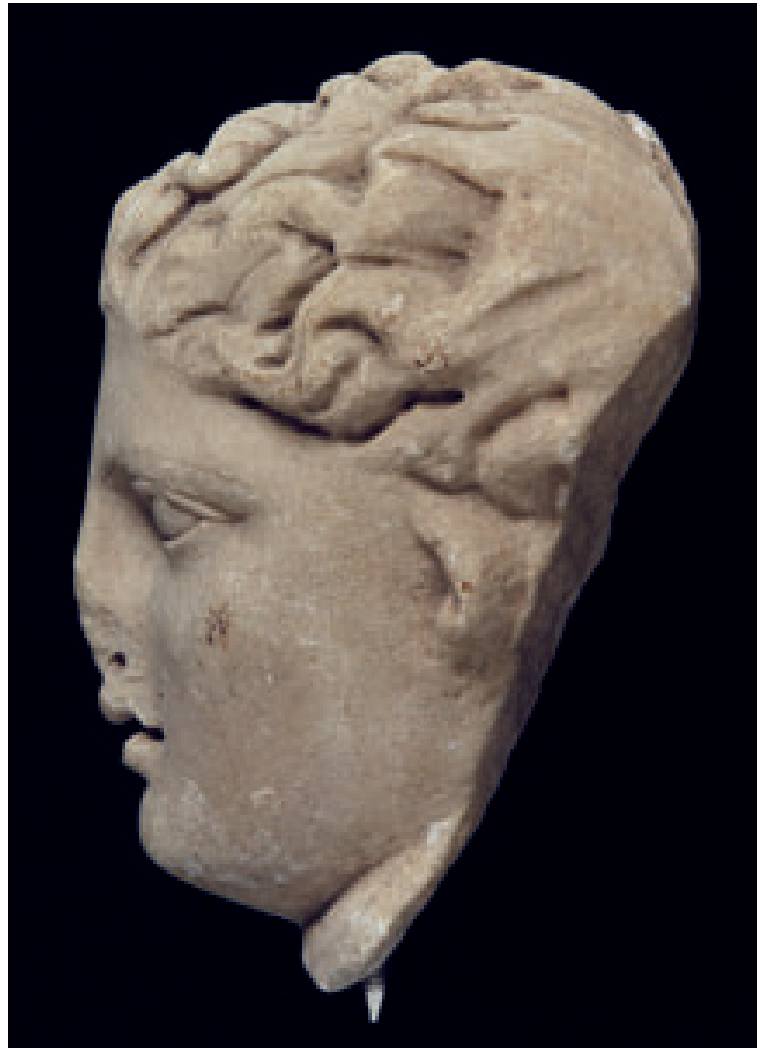

Abb. 189 Jünglingskopf, Seitansicht Fragment 1

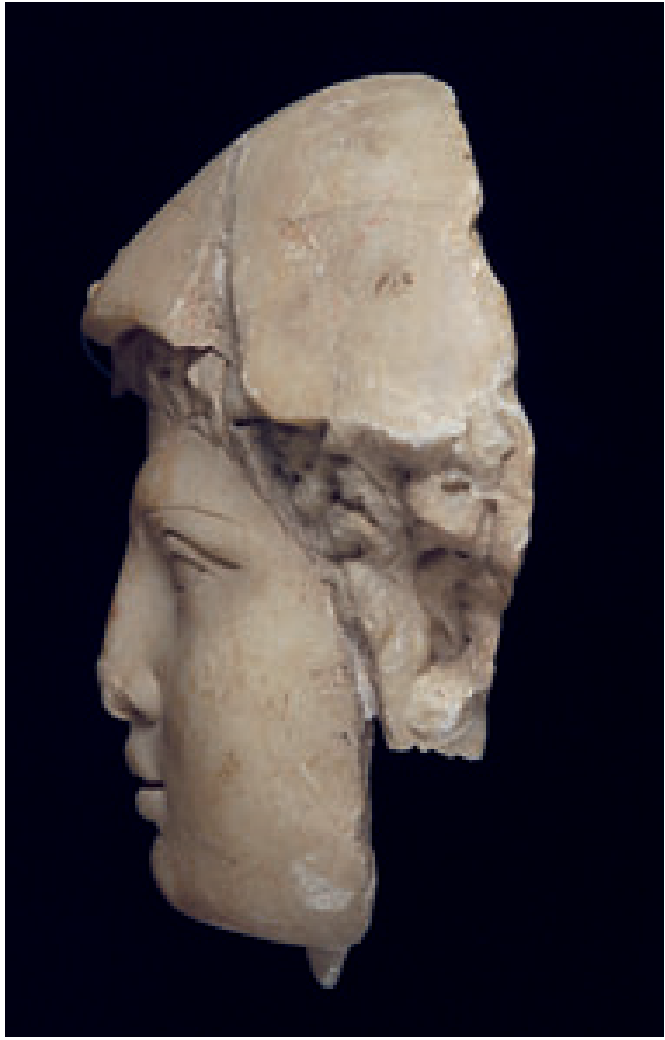

Abb. 191 Jüngling mit Hut, Seitenansicht Fragment 3

Kat. 15 Hippolytos-Sarkophag aus einem Grabhaus der Nekropole nördlich des Hafenkanals in Ephesos, Köpfe der Hauptansichtsseiten 
Tafel 50

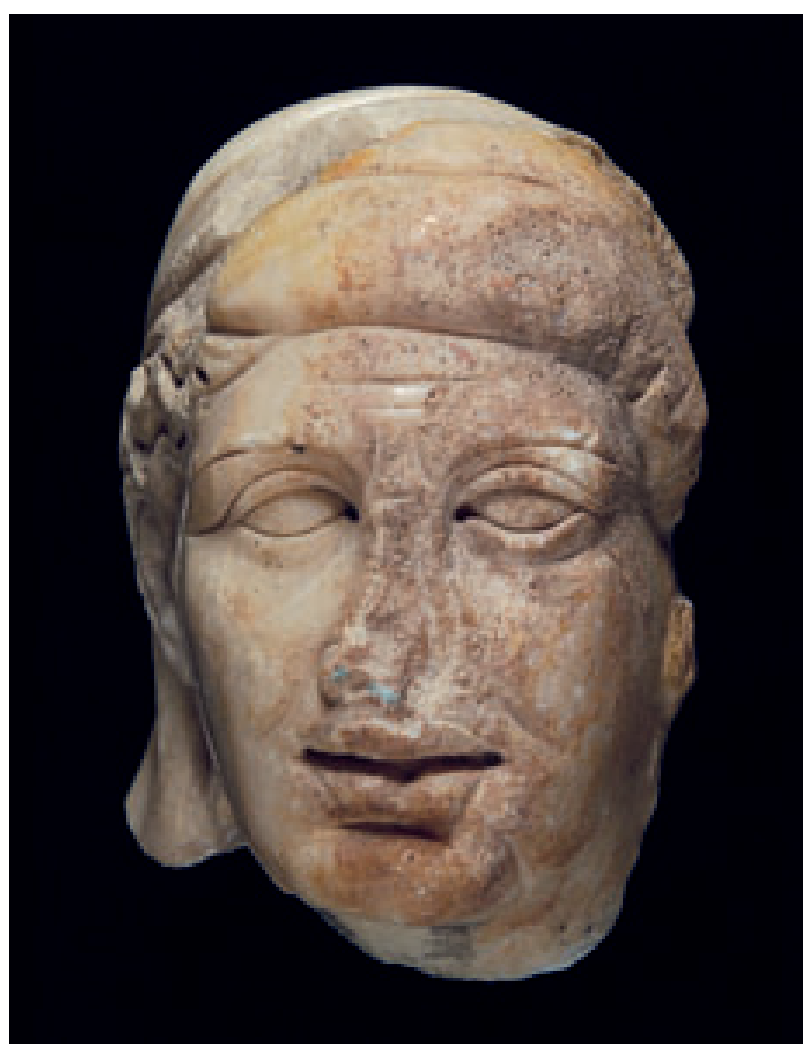

Abb. 192 Kopf der Amme, Vorderseite Fragment 2. Selçuk, Efes Müzesi Inv. 114

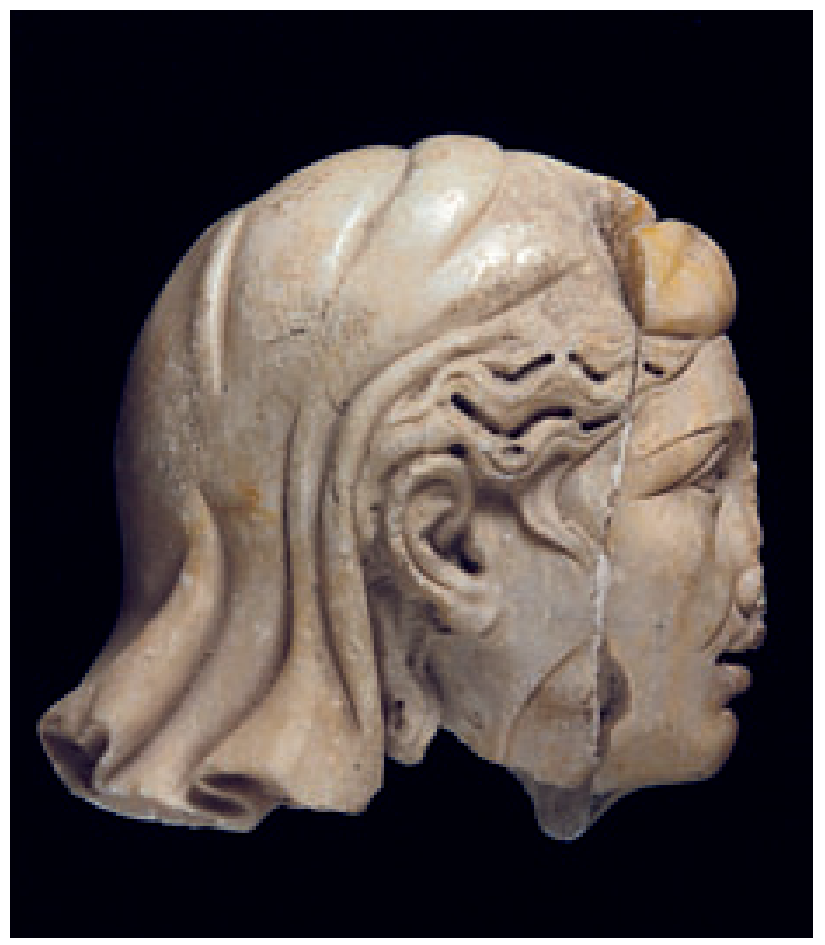

Abb. 194 Kopf der Amme, Seitenansicht Fragment 2

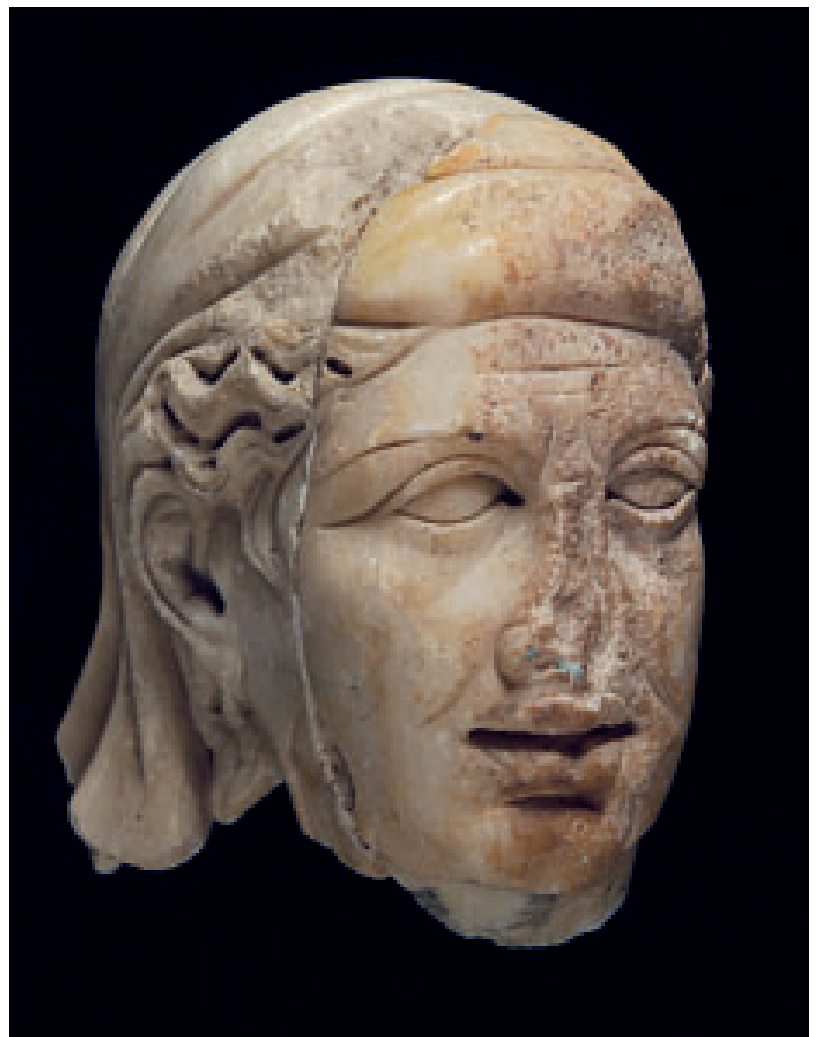

Abb. 193 Kopf der Amme, Fragment 2

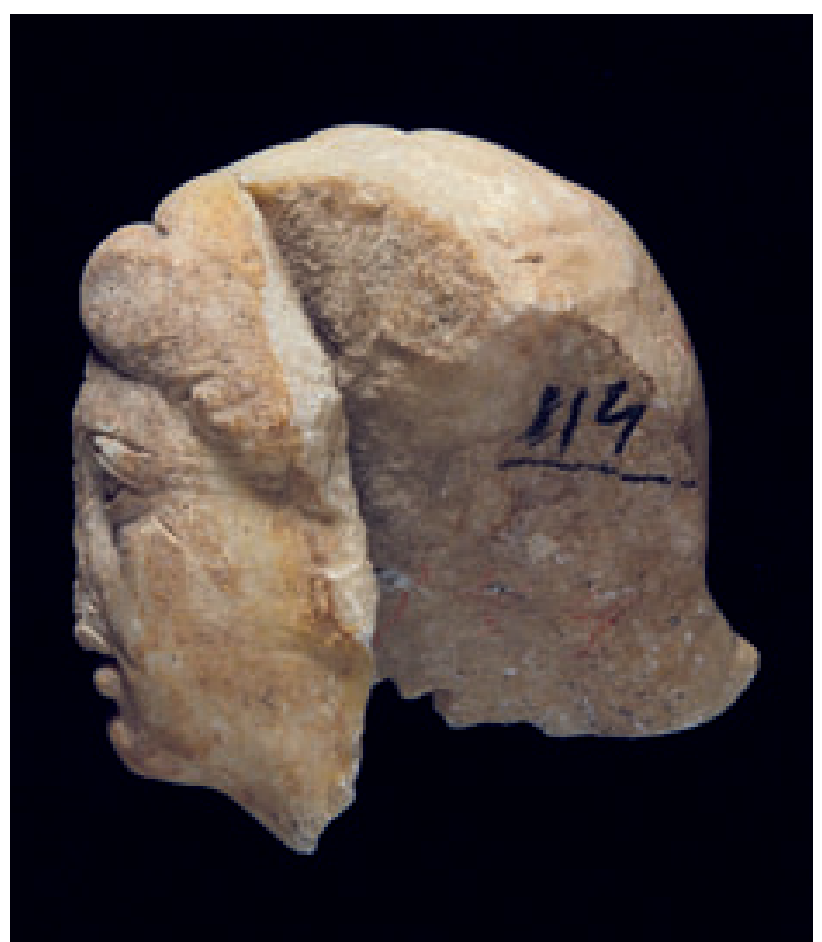

Abb. 195 Kopf der Amme, Seitenansicht Fragment 2

Kat. 15 Hippolytos-Sarkophag aus einem Grabhaus der Nekropole nördlich des Hafenkanals in Ephesos 
Tafel 51

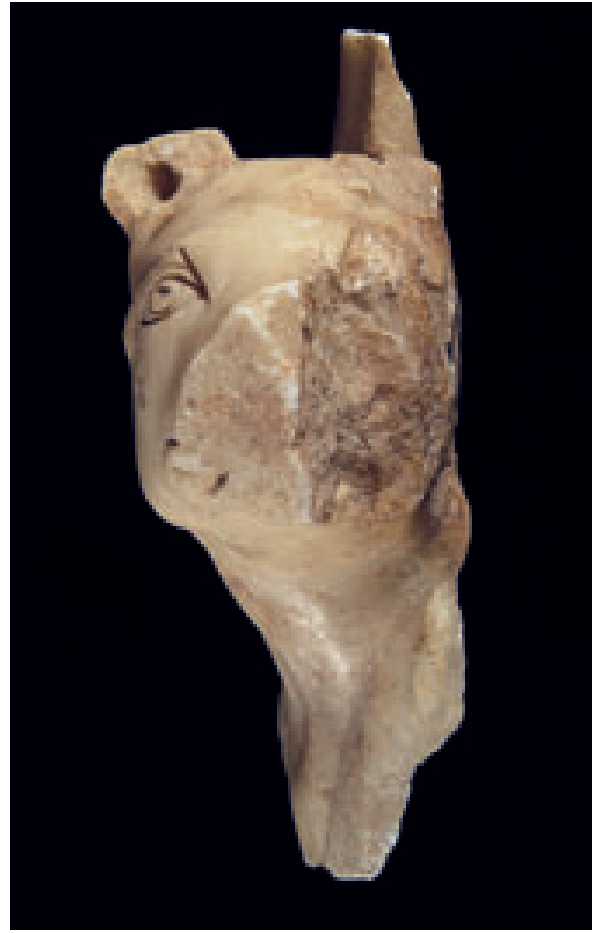

Abb. 196 Hundekopf, frontale Ansicht (Fragment 4). Selçuk, Efes Müzesi Inv. 138

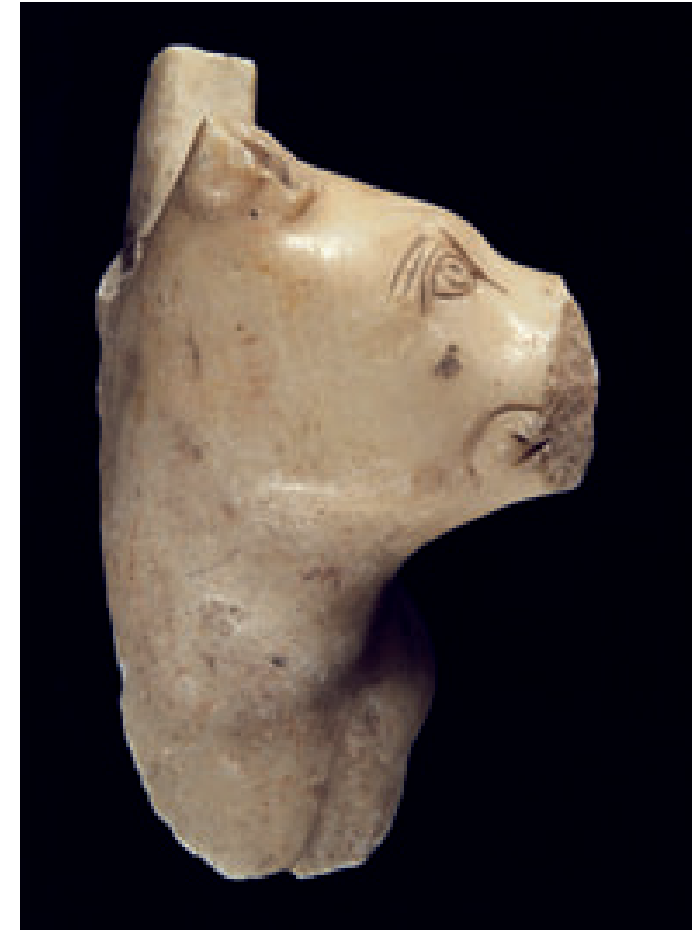

Abb. 197 Hundekopf, seitliche Ansicht (Fragment 4)

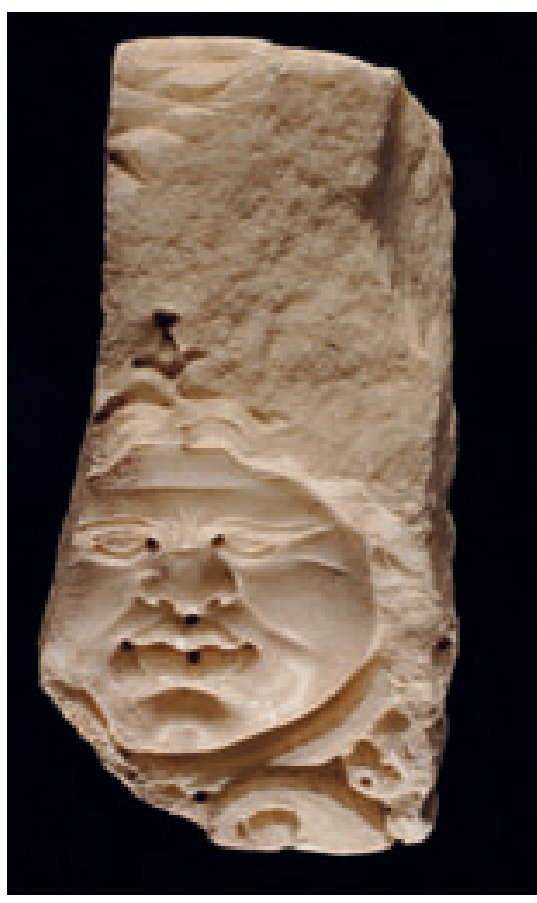

Abb. 198 Fragment des oberen Kastenabschlusses (Fragment 5)

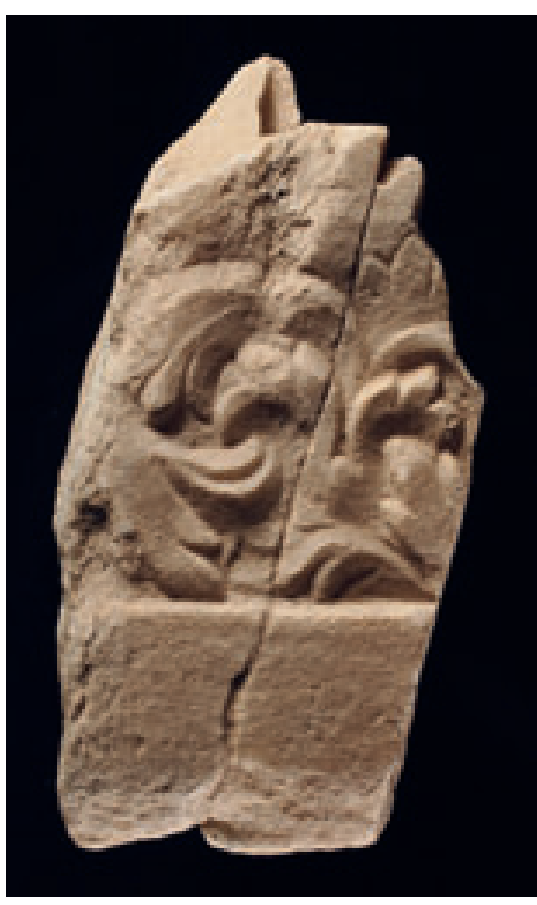

Abb. 199 Fragment des Sockels (Fragment 10)

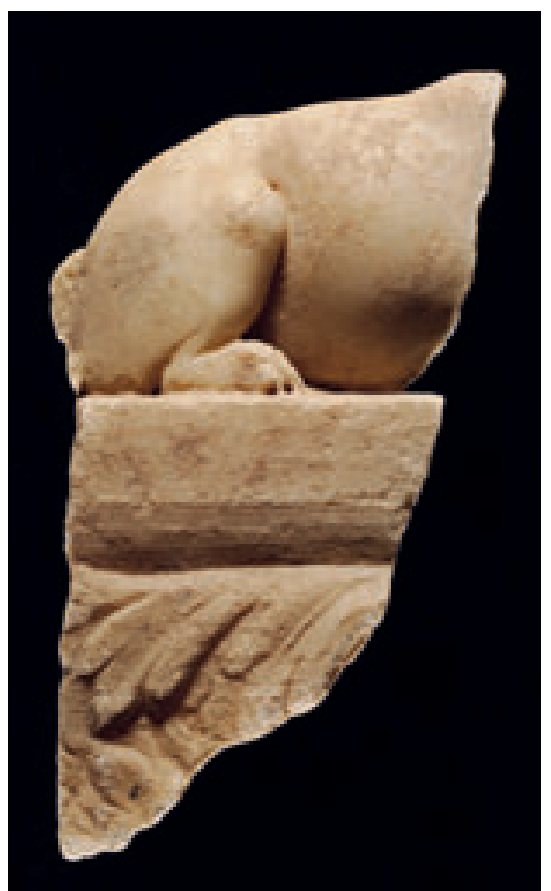

Abb. 200 Fragment des Sockels (Fragment 11)

Kat. 15 Hippolytos-Sarkophag aus einem Grabhaus der Nekropole nördlich des Hafenkanals in Ephesos, Fragmente der Hauptansichtsseiten 
Tafel 52

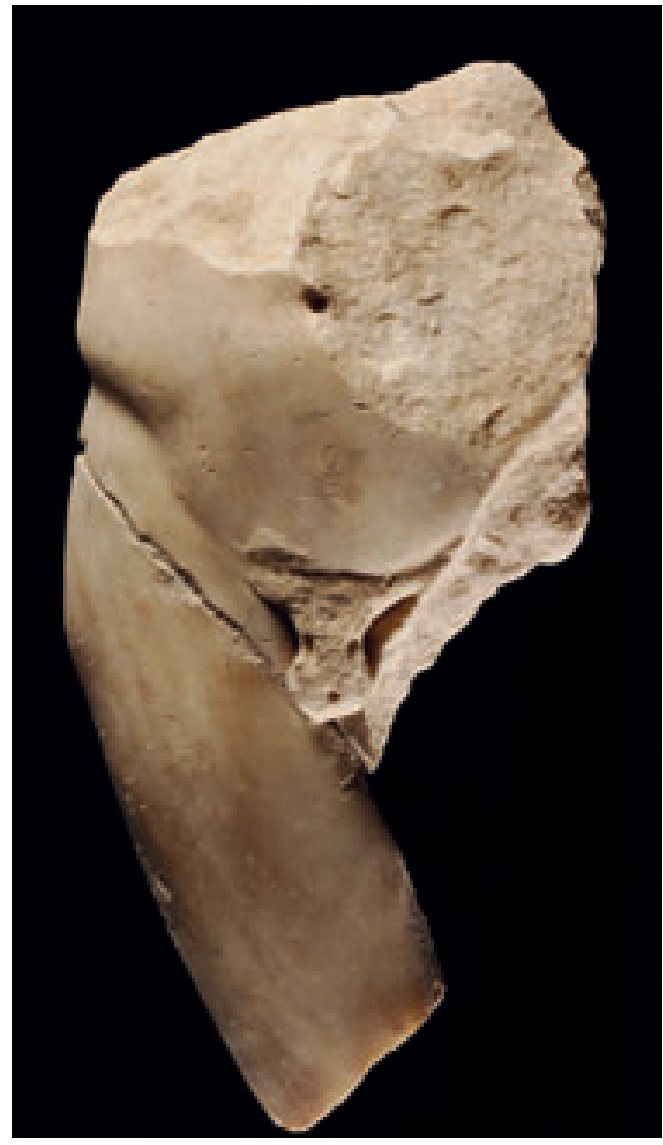

Abb. 201 Fragment 6

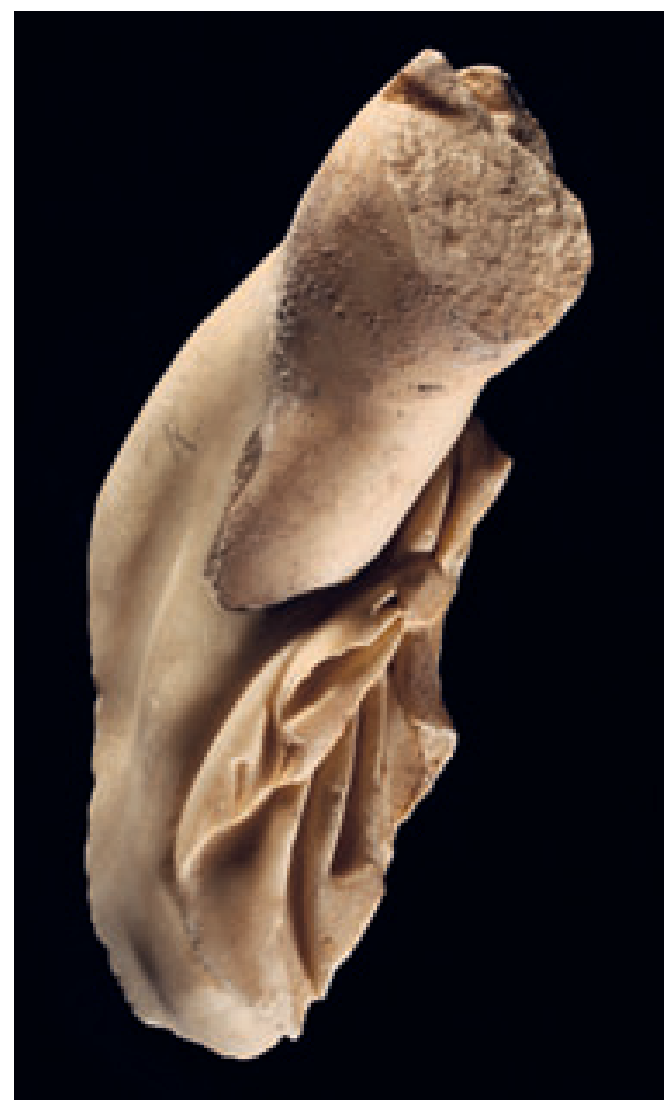

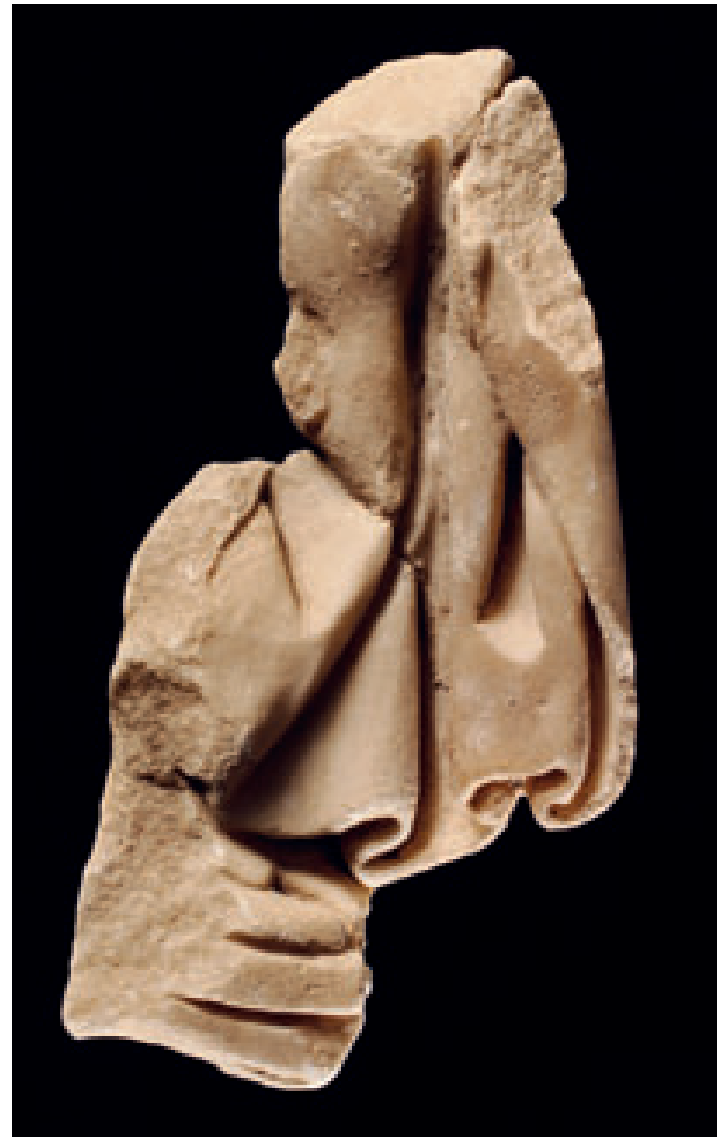

Abb. 202 Fragment 7

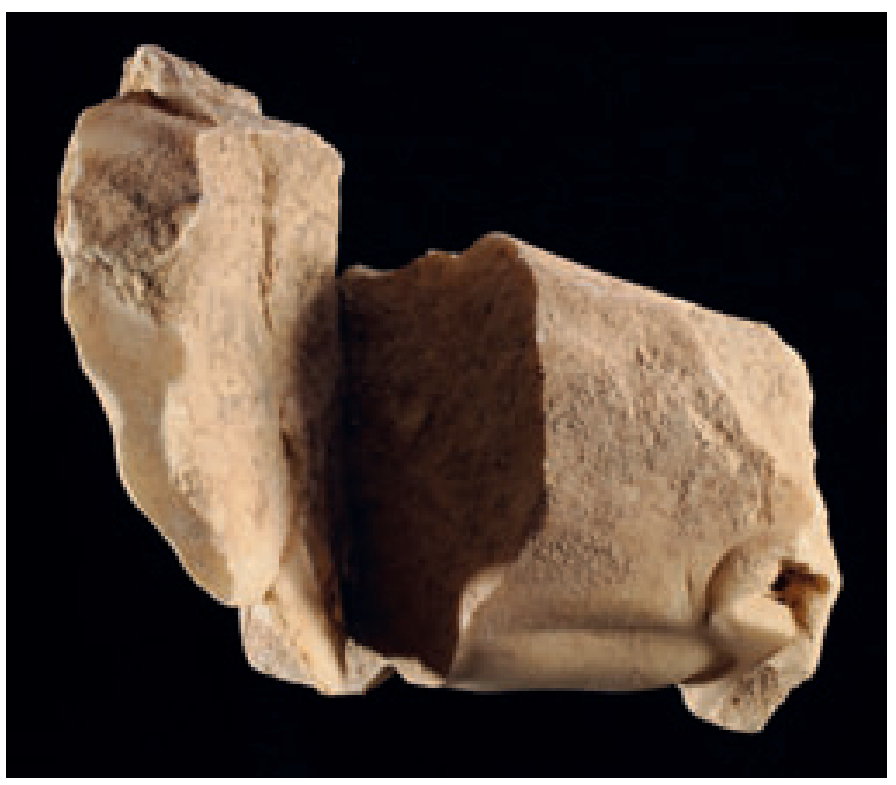

Abb. 204 Fragment 9

Abb. 203 Fragment 8

Kat. 15 Hippolytos-Sarkophag aus einem Grabhaus der Nekropole nördlich des Hafenkanals in Ephesos, Fragmente der Hauptansichtsseiten 
Tafel 53

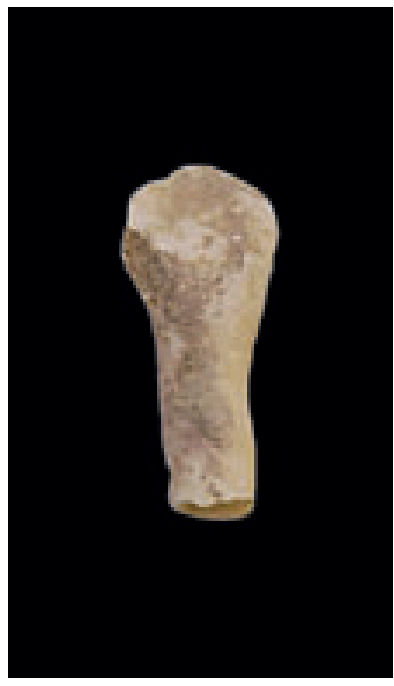

Abb. 205

Fragment einer

Keule (Fragment 12)

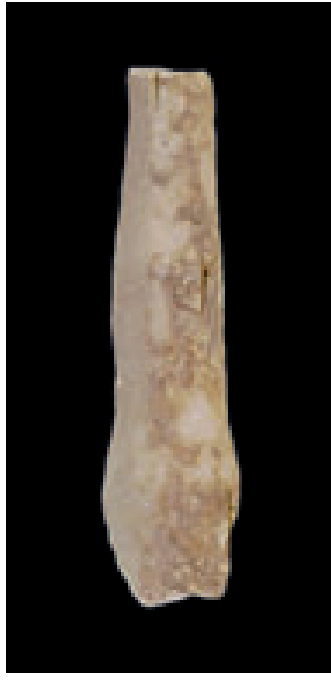

Abb. 206

Fragment einer

Keule (Fragment 13)

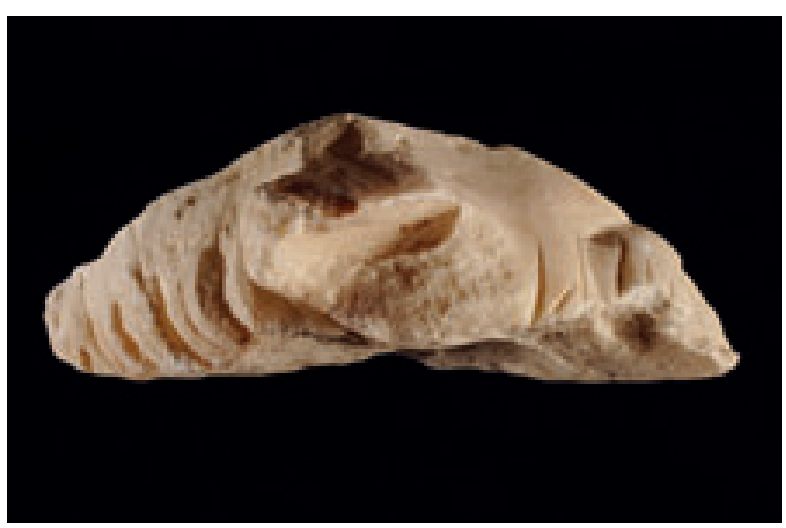

Abb. 207 Fragment eines Pferdekopfes (Fragment 14)

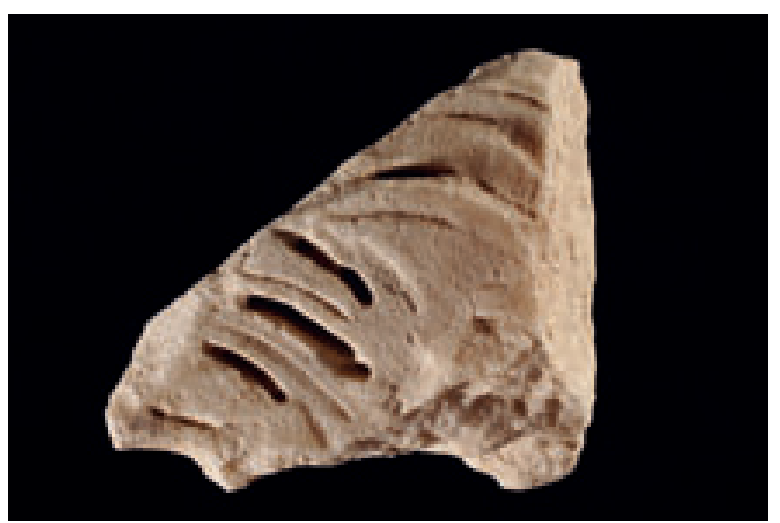

Abb. 208 Fragment einer Pferdemähne (Fragment 15)

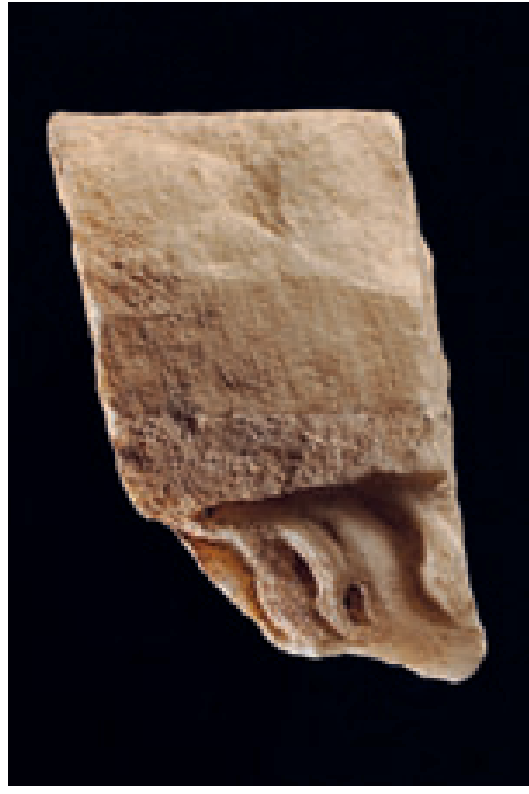

Abb. 209 Fragment mit oberen Kastenabschluss einer vernachlässigt gearbeiteten Sarkophagseite (Fragment 16)

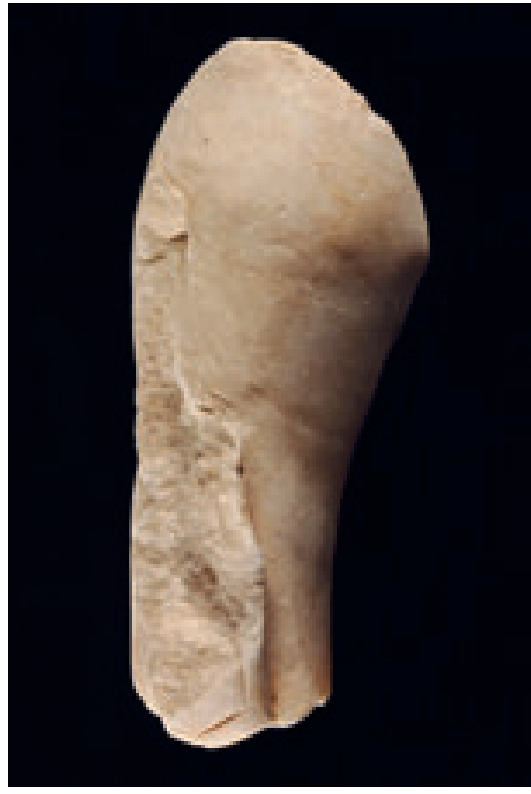

Abb. 210 Fragment vielleicht mit Oberarm (Fragment 17)

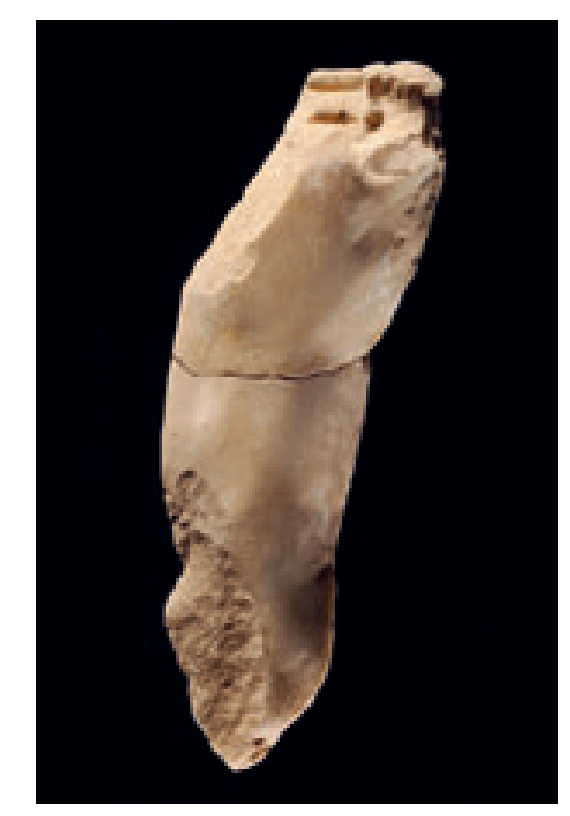

Abb. 211 Fragment 18 
Tafel 54

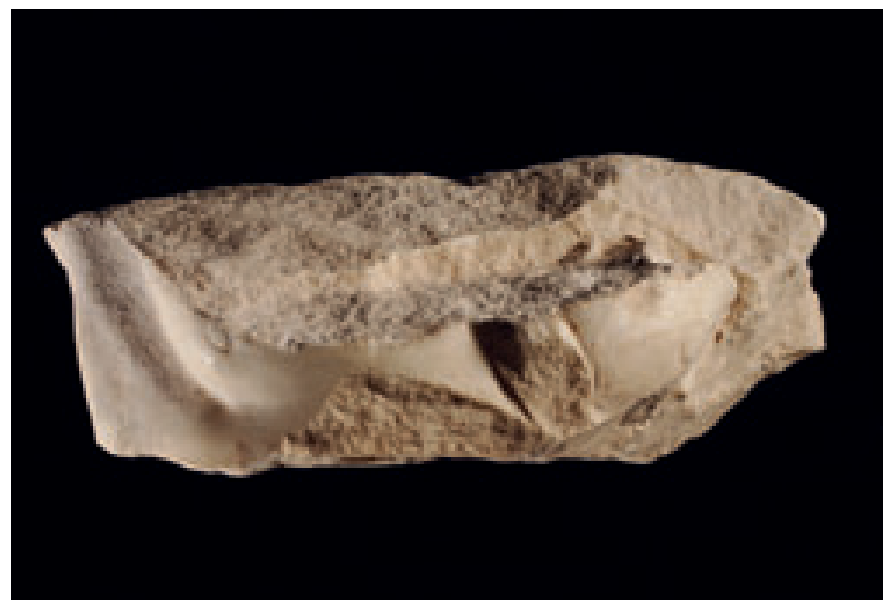

Abb. 212 Fragment 19

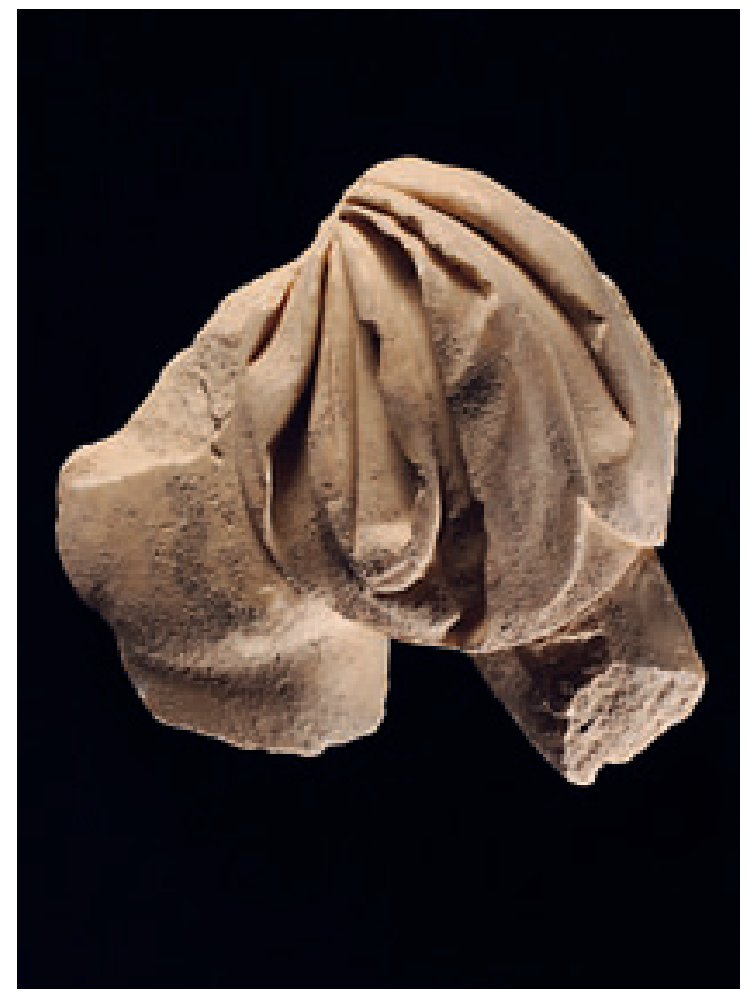

Abb. 213 Fragment 20

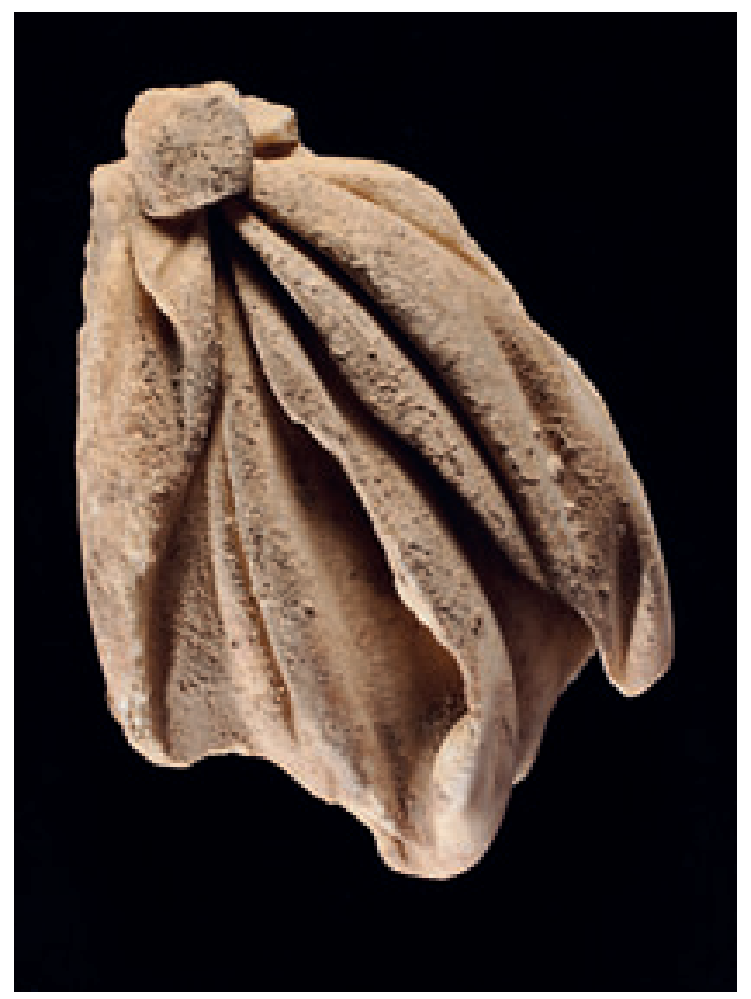

Abb. 214 Fragment 21

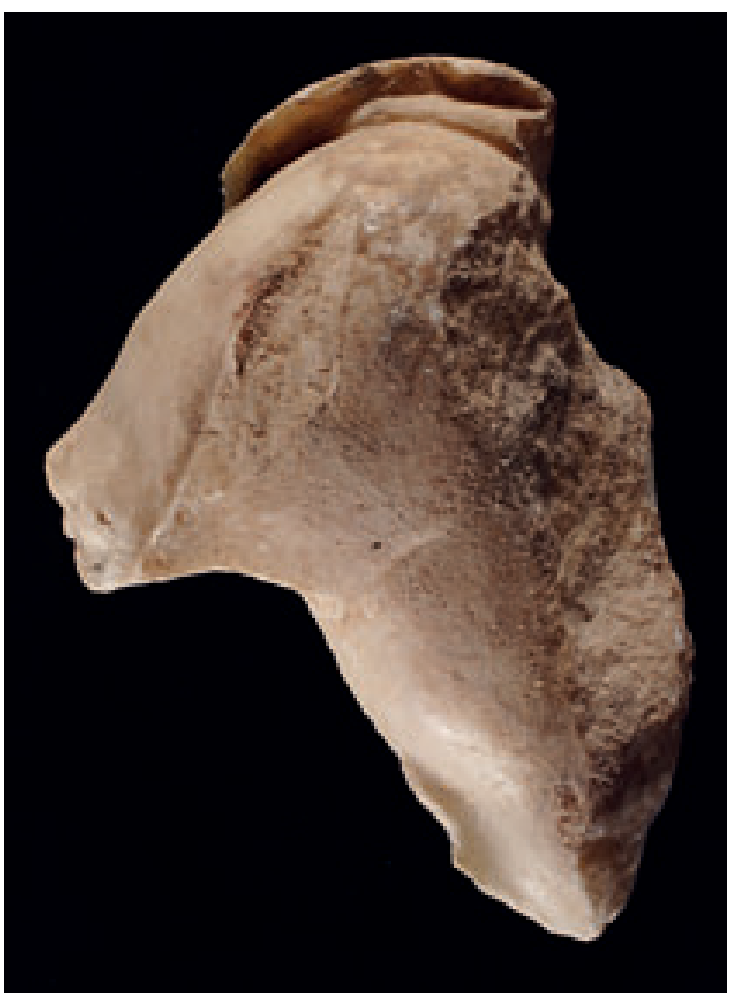

Abb. 215 Fragment 22

Kat. 15 Hippolytos-Sarkophag aus einem Grabhaus der Nekropole nördlich des Hafenkanals in Ephesos, zugeordnete Friesfragmente 
Tafel 55

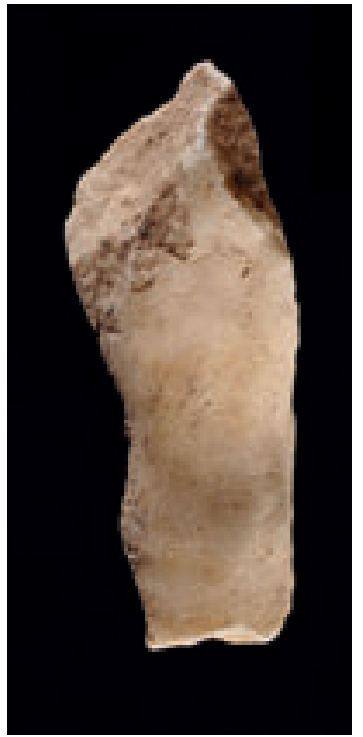

Abb. 216 Fragment 23

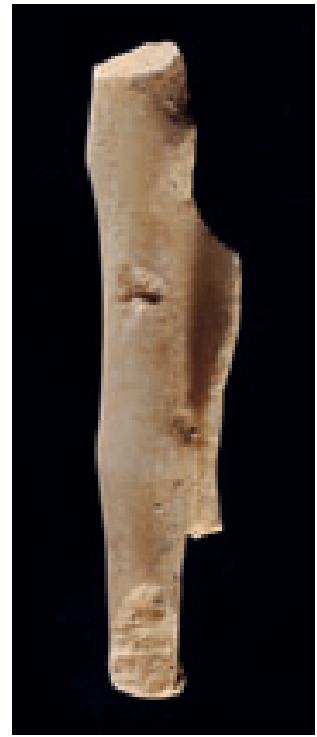

Abb. 217 Fragment 24

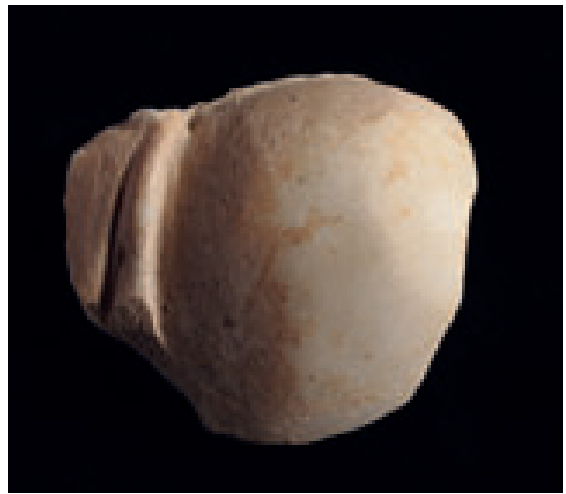

Abb. 218 Fragment 25

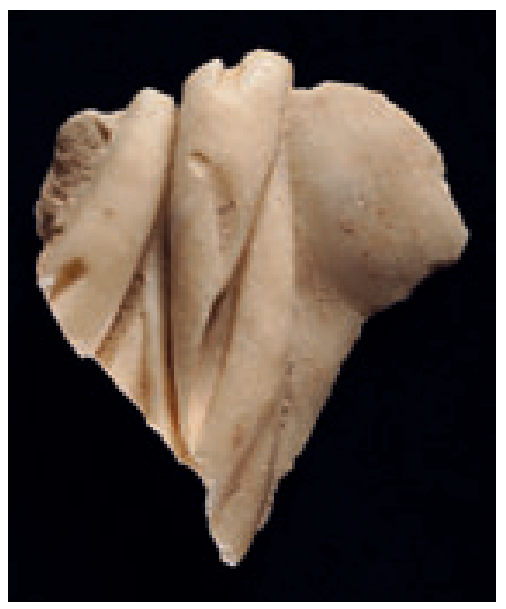

Abb. 219 Fragment 26
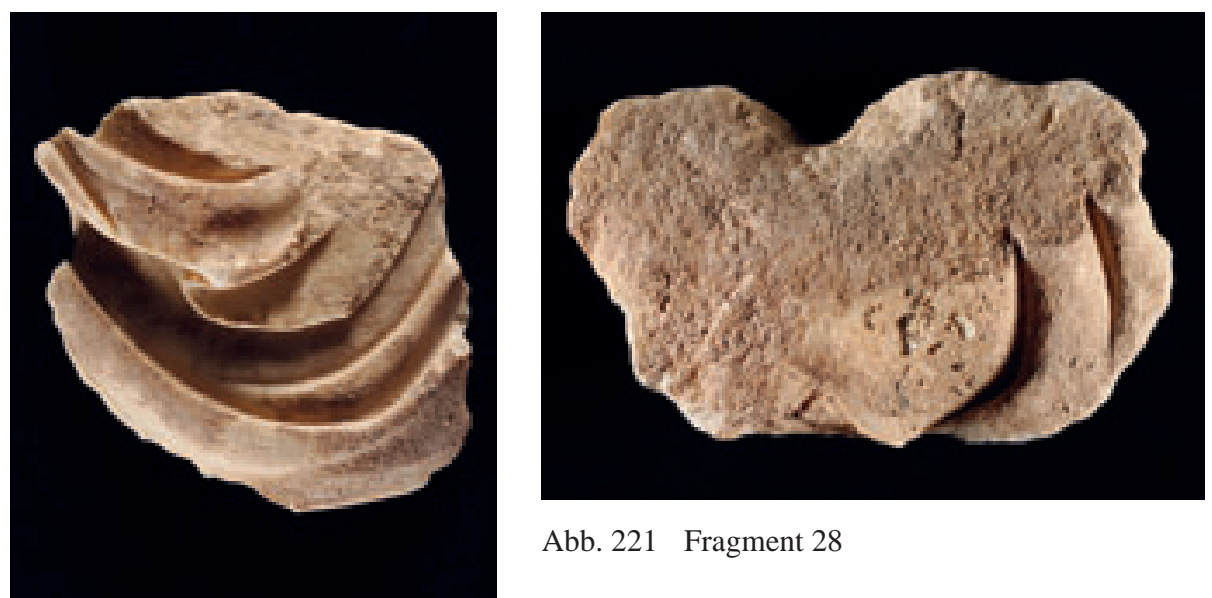

Abb. 221 Fragment 28

Abb. 220 Fragment 27

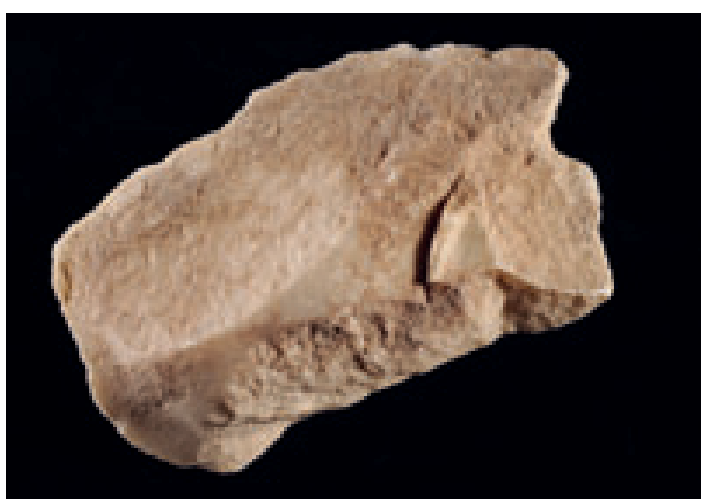

Abb. 222 Fragment 29

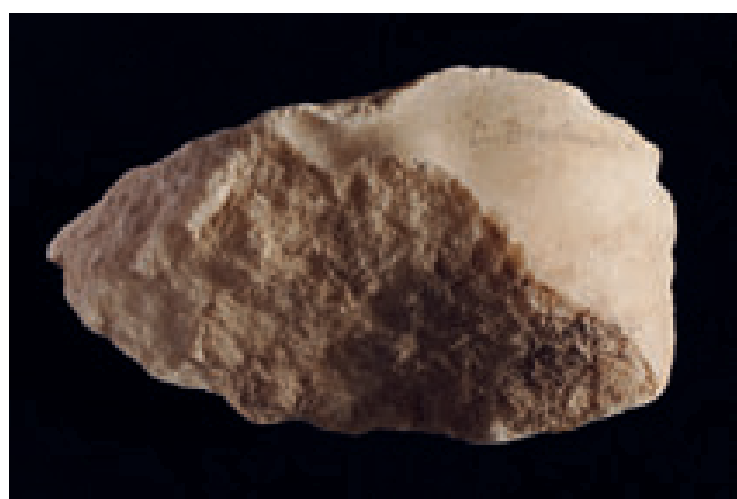

Abb. 223 Fragment 30

Kat. 15 Hippolytos-Sarkophag aus einem Grabhaus der Nekropole nördlich des Hafenkanals in Ephesos, zugeordnete Friesfragmente 
Tafel 56

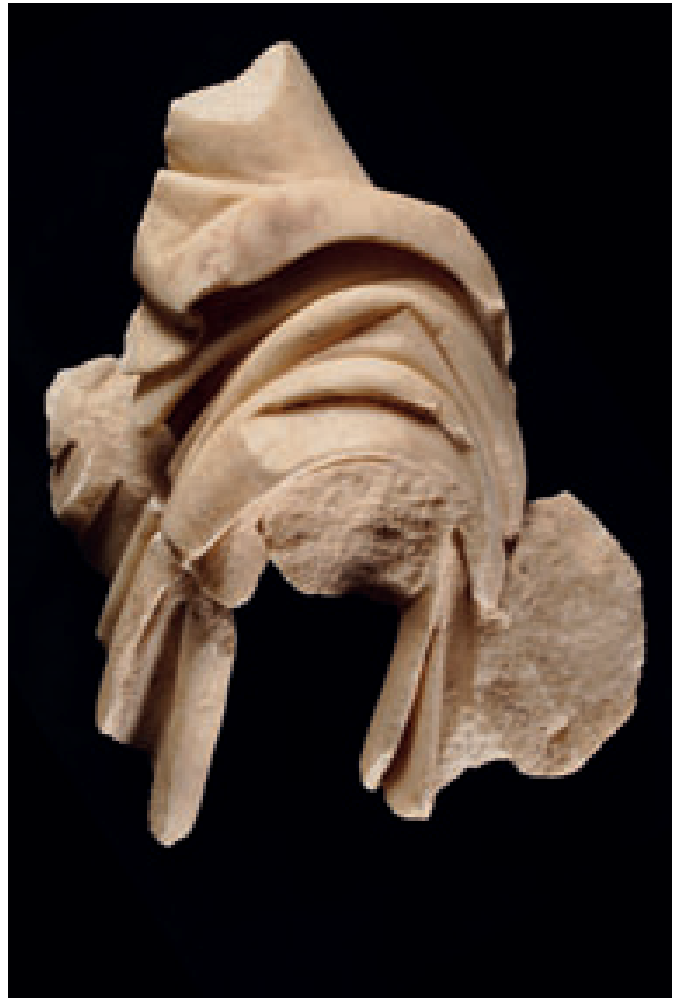

Abb. 224 Fragment 31

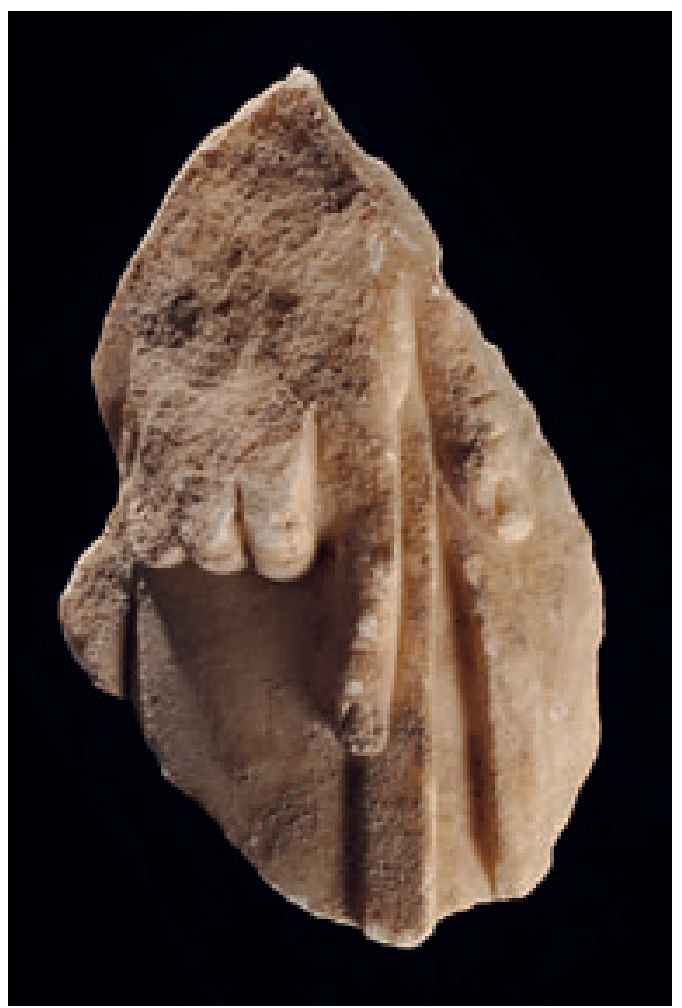

Abb. 226 Fragment 33

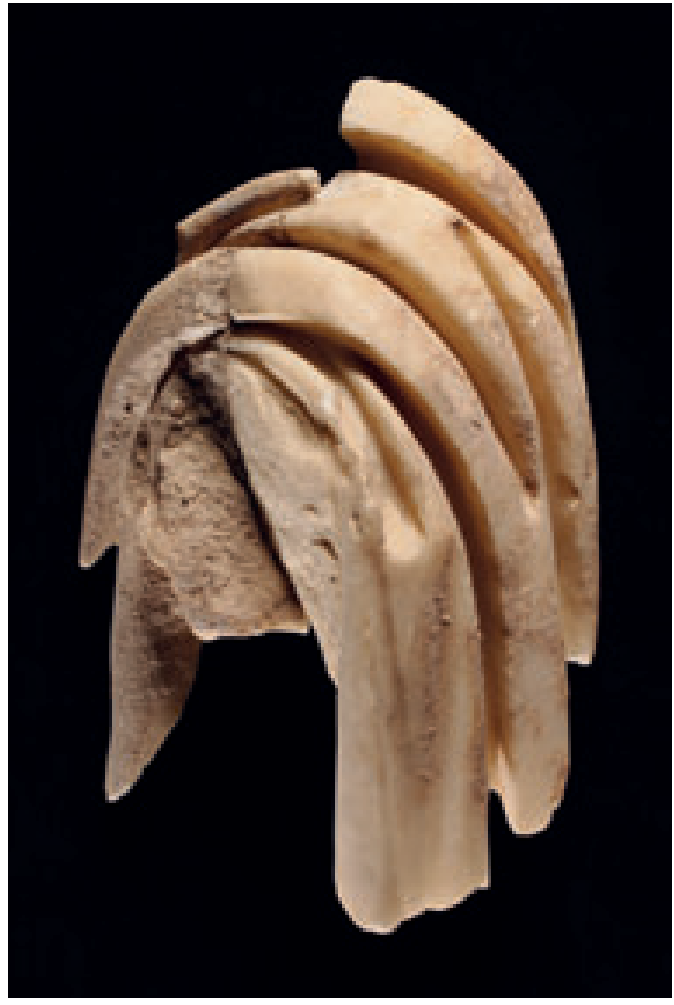

Abb. 225 Fragment 32

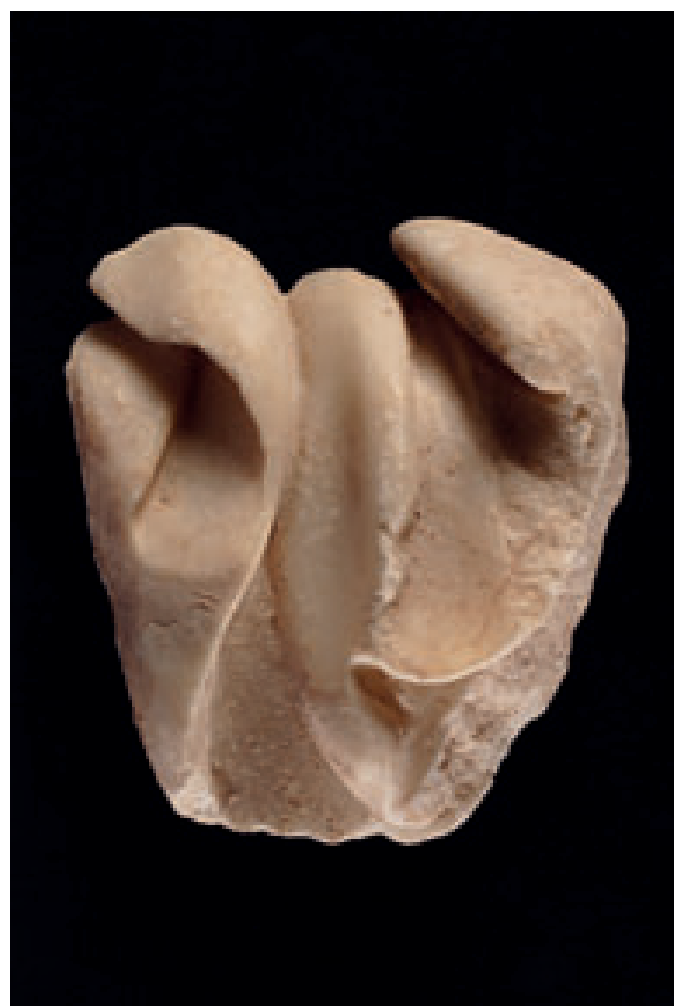

Abb. 227 Fragment 34

Kat. 15 Hippolytos-Sarkophag aus einem Grabhaus der Nekropole nördlich des Hafenkanals in Ephesos, zugeordnete Friesfragmente 
Tafel 57

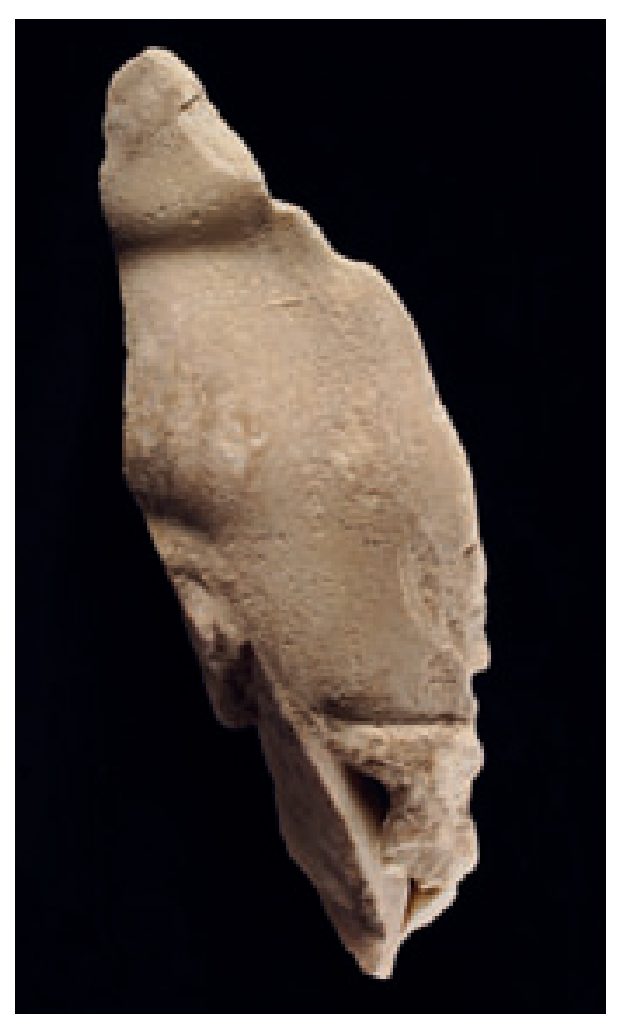

Abb. 228 Fragment 35

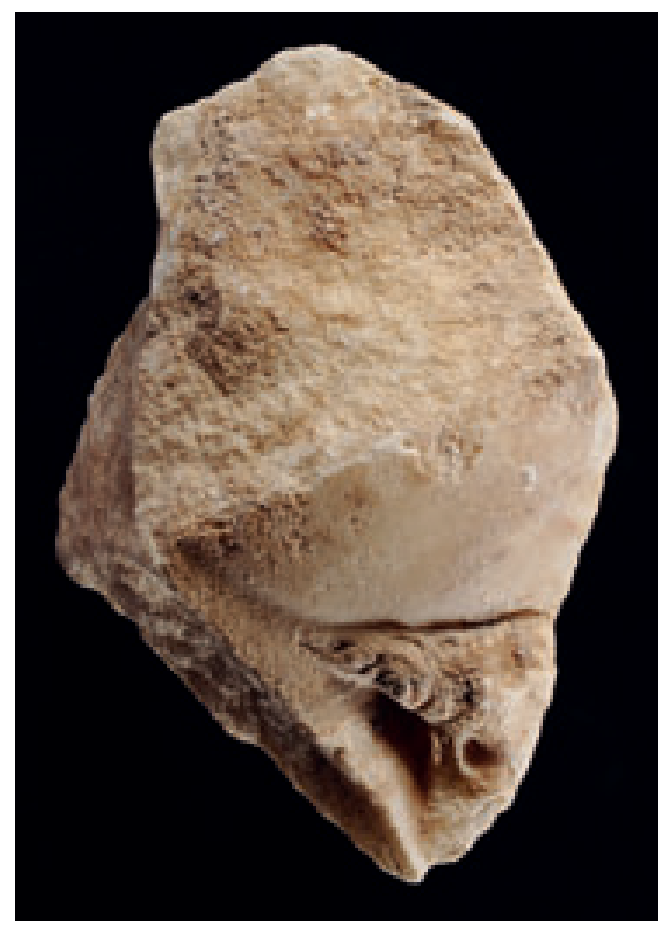

Abb. 230 Fragment 37

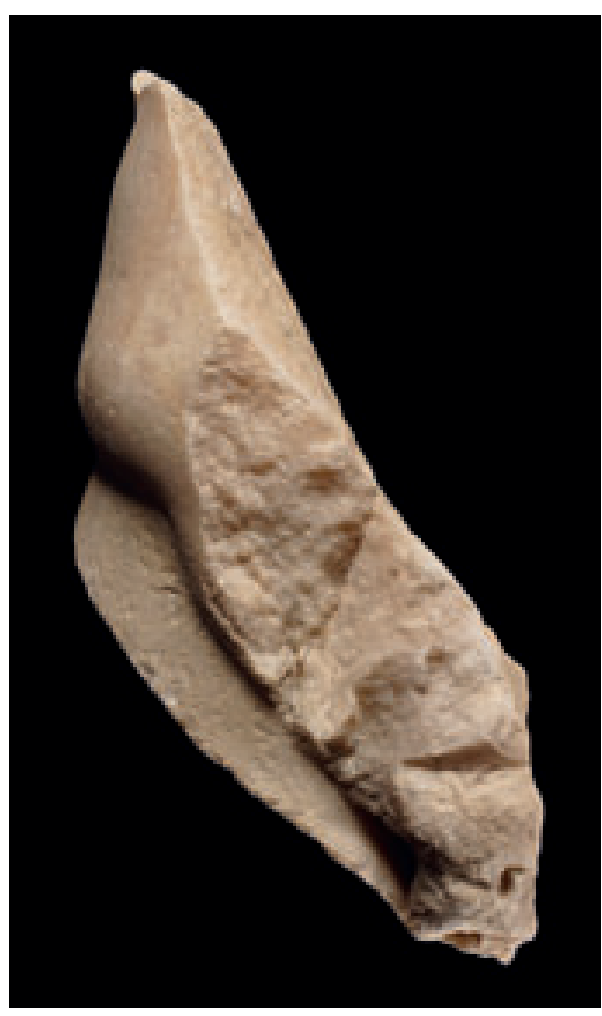

Abb. 229 Fragment 36

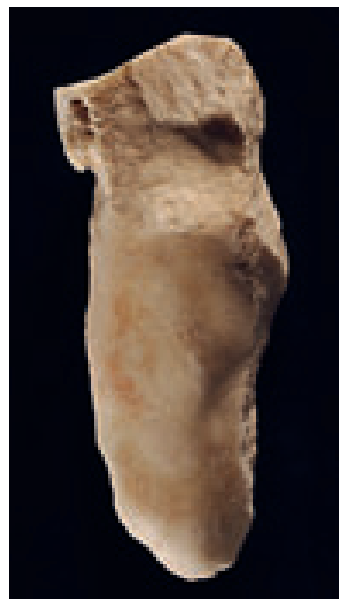

Abb. 231

Fragment 38

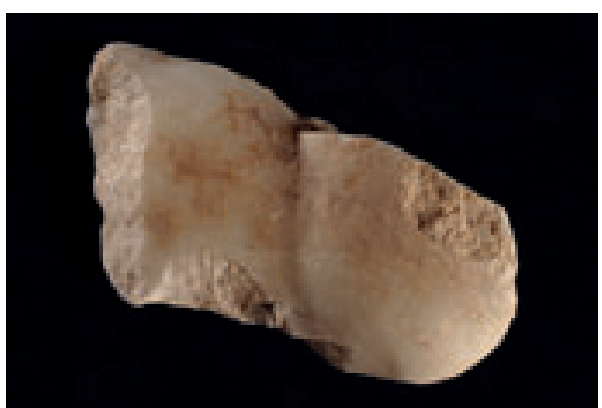

Abb. 232 Fragment 39

Kat. 15 Hippolytos-Sarkophag aus einem Grabhaus der Nekropole nördlich des Hafenkanals in Ephesos, zugeordnete Friesfragmente 
Tafel 58
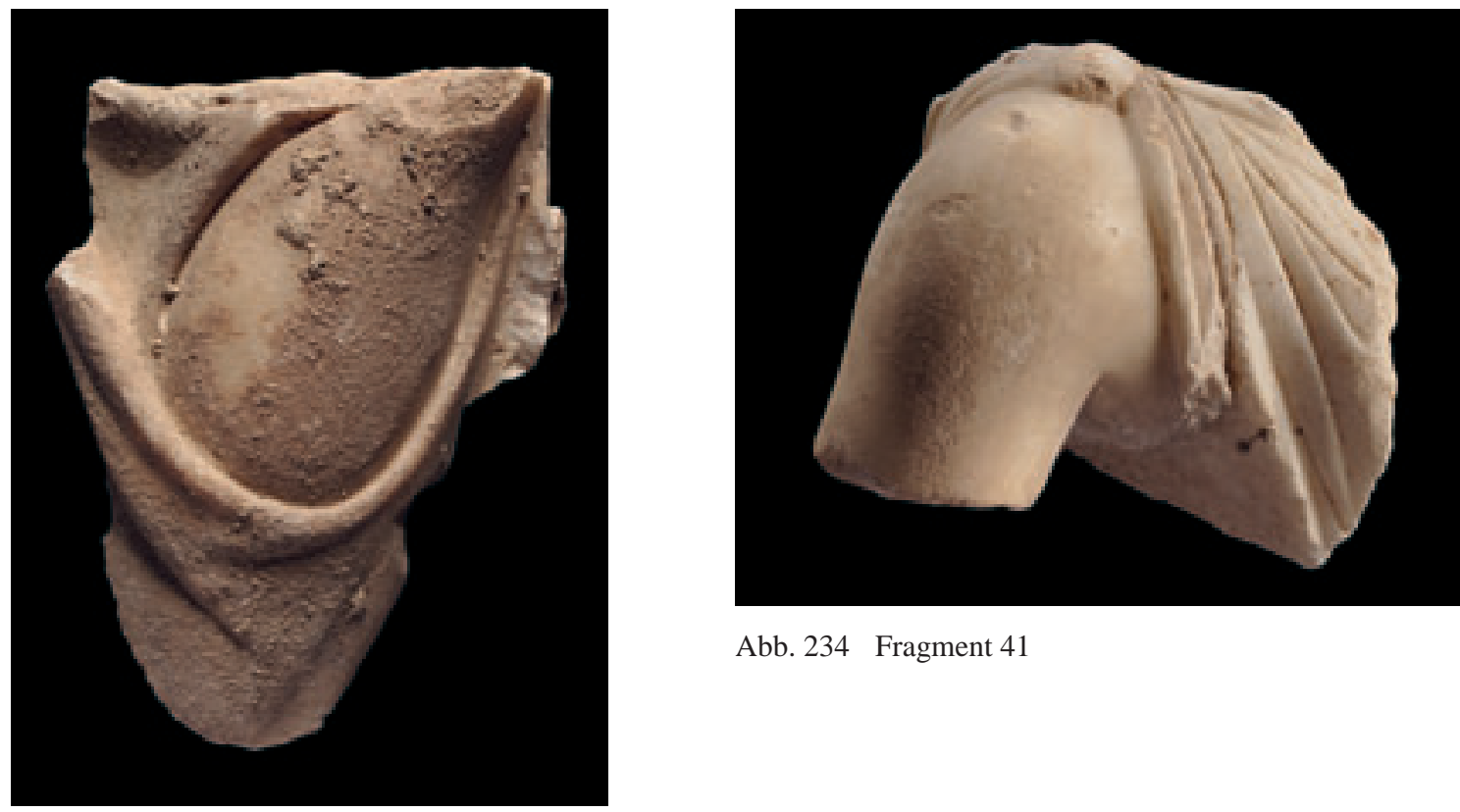

Abb. 234 Fragment 41

Abb. 233 Fragment 40

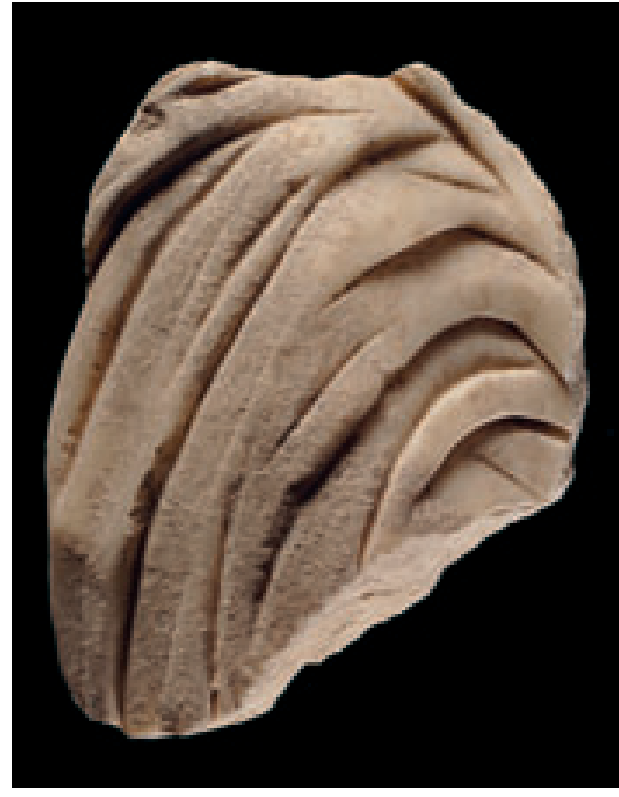

Abb. 235 Fragment 43

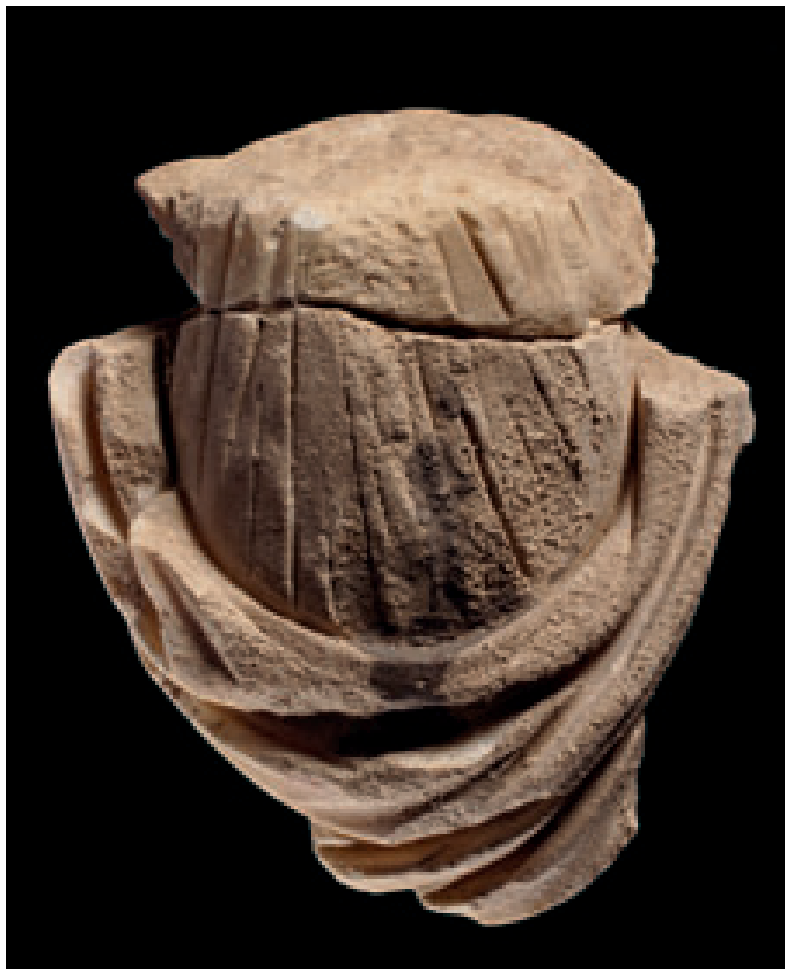

Abb. 236 Fragment 42

Kat. 15 Hippolytos-Sarkophag aus einem Grabhaus der Nekropole nördlich des Hafenkanals in Ephesos, zugeordnete Friesfragmente 
Tafel 59

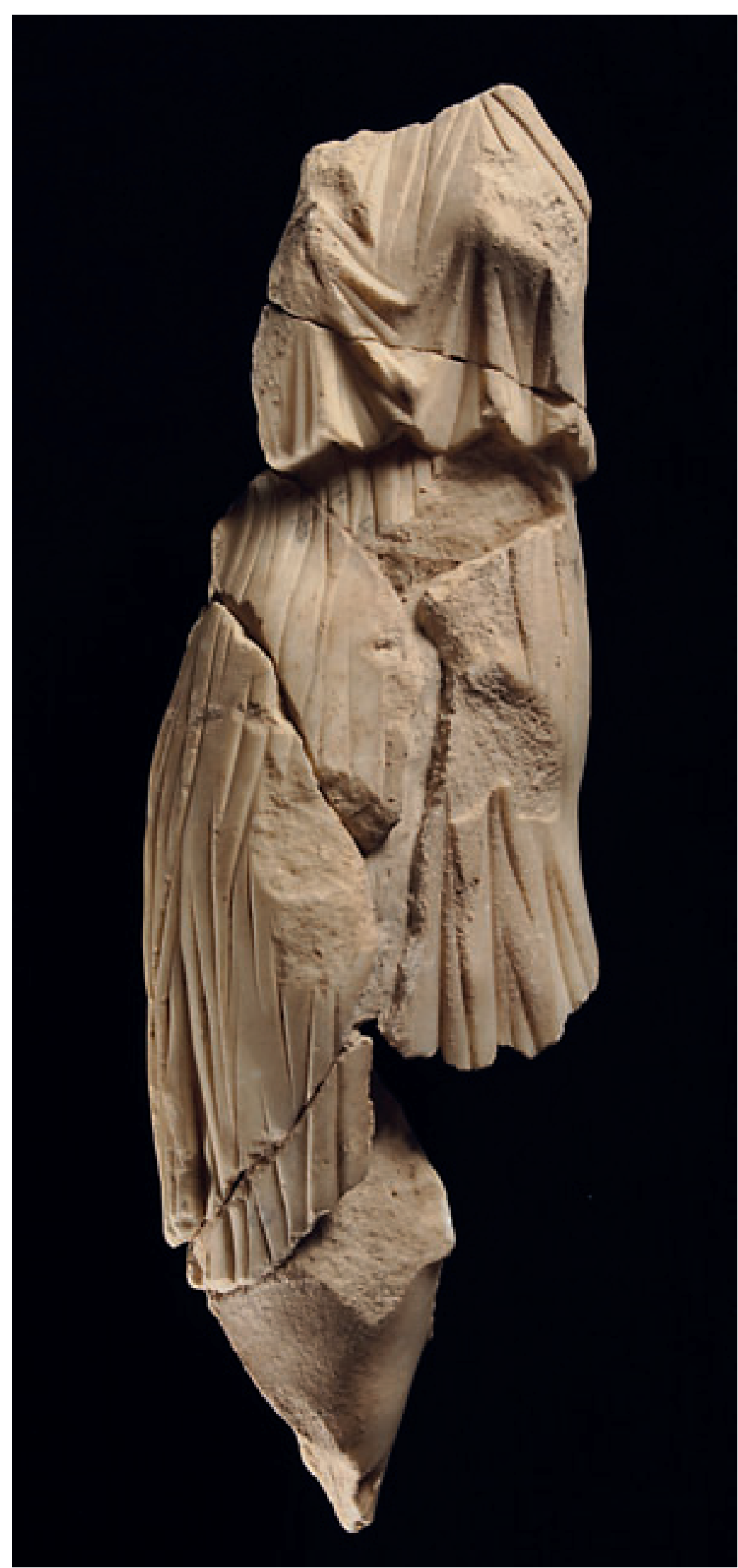

Abb. 237 Weibliche Figur (Fragment 44)

Kat. 15 Hippolytos-Sarkophag aus einem Grabhaus der Nekropole nördlich des Hafenkanals in Ephesos, zugeordnetes Fragment 
Tafel 60

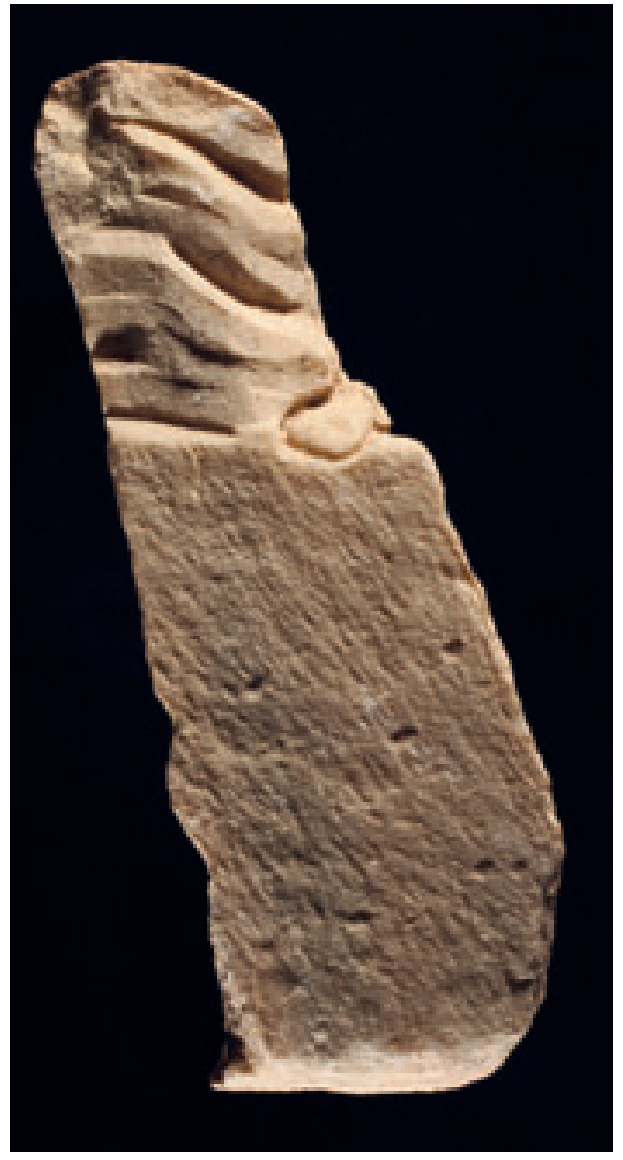

Abb. 238 Fragment 45

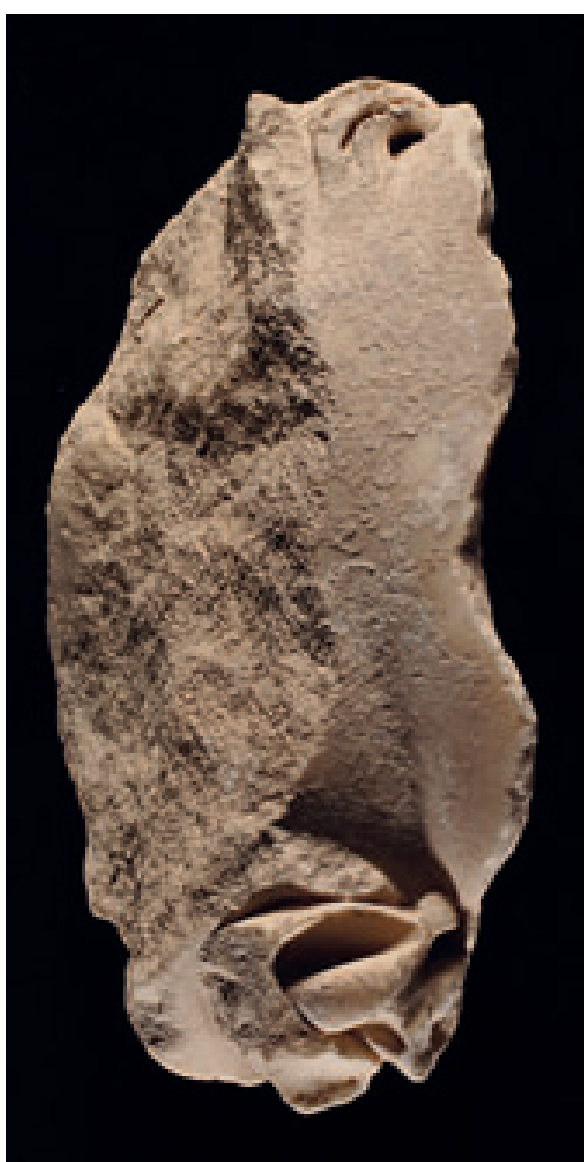

Abb. 239 Fragment 46

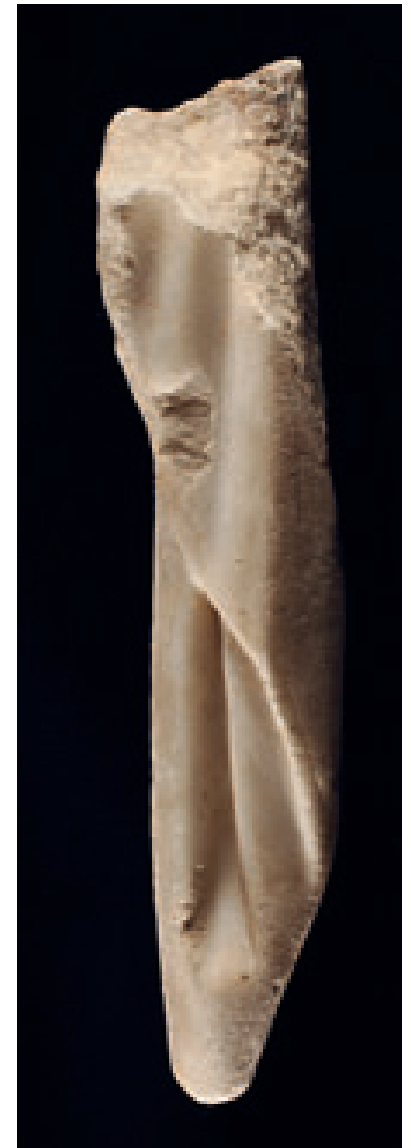

Abb. 240 Fragment 47

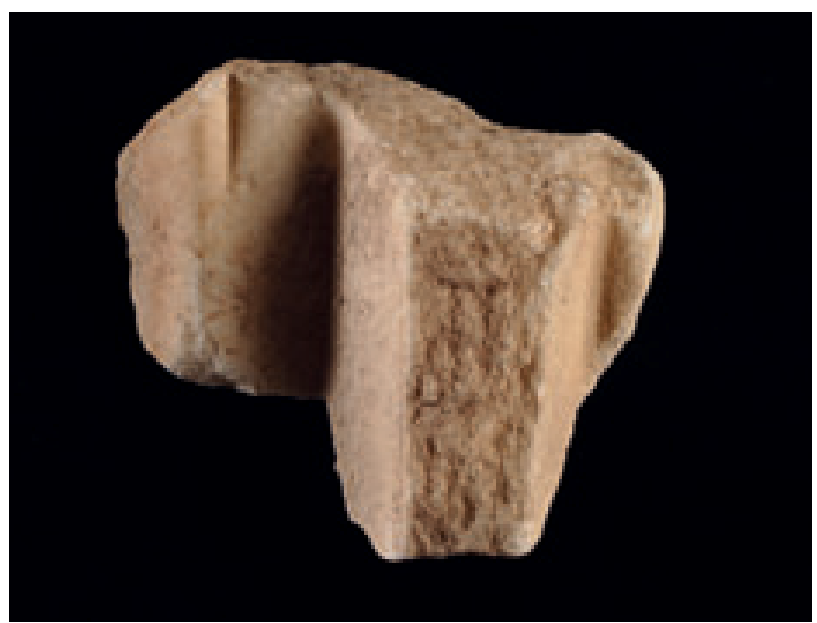

Abb. 241 Fragment 48

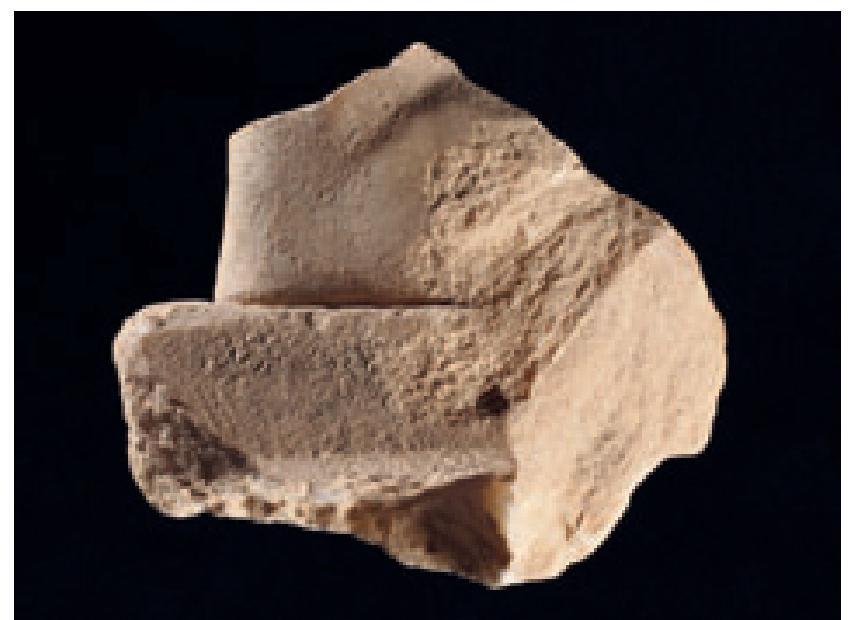

Abb. 242 Fragment 49

Kat. 15 Hippolytos-Sarkophag aus einem Grabhaus der Nekropole nördlich des Hafenkanals, zugeordnete Friesfragmente 
Tafel 61

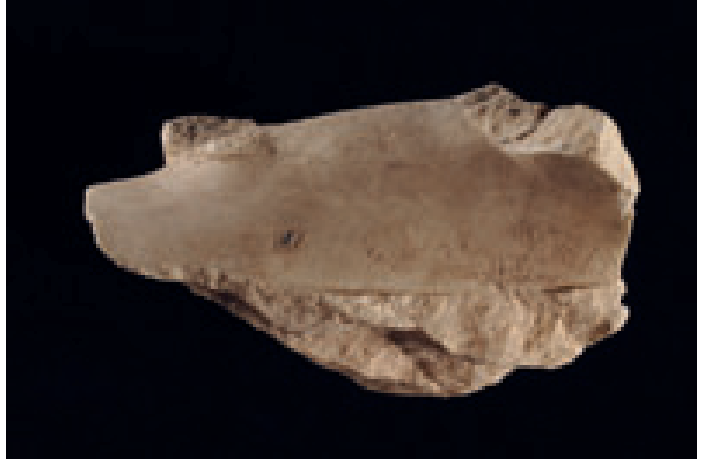

Abb. 243 Fragment 50

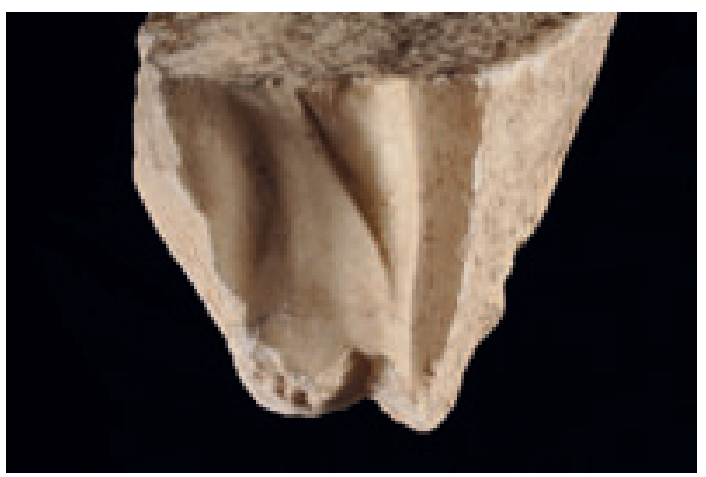

Abb. 245 Fragment 52

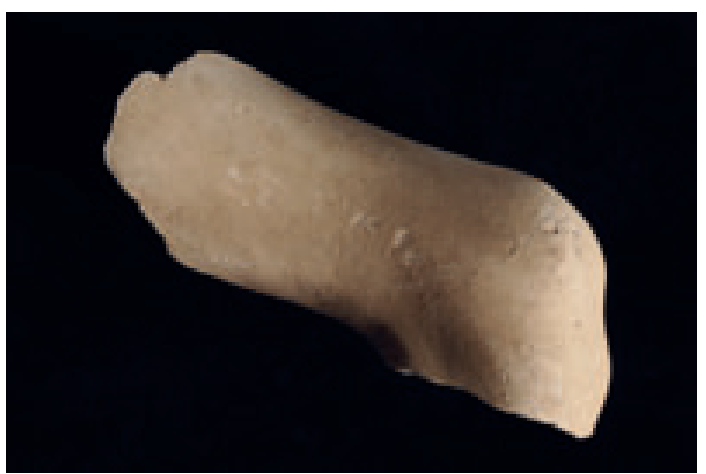

Abb. 247 Fragment 54

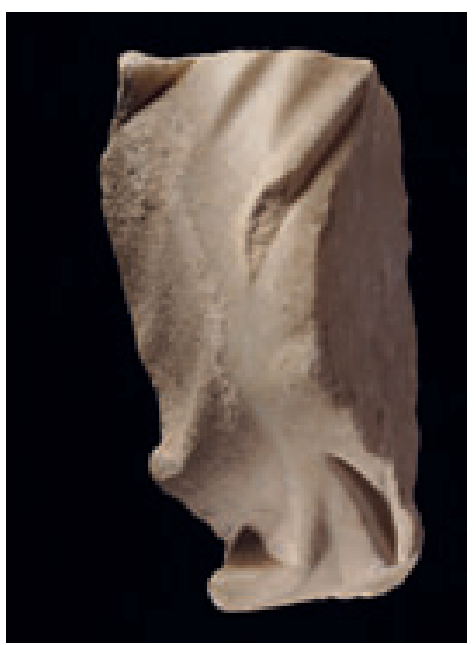

Abb. 249 Fragment 56

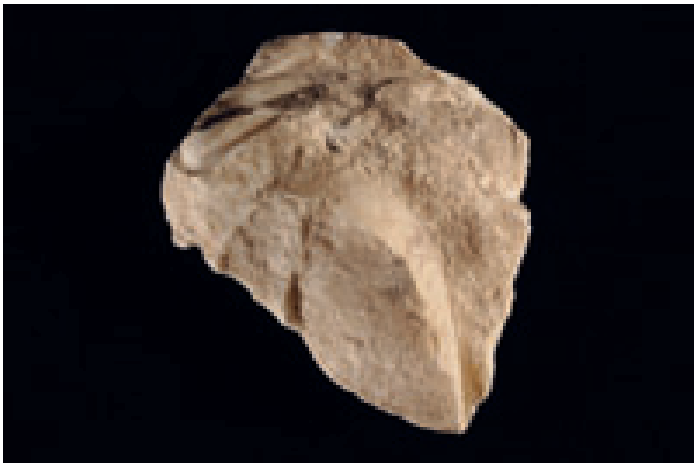

Abb. 244 Fragment 51

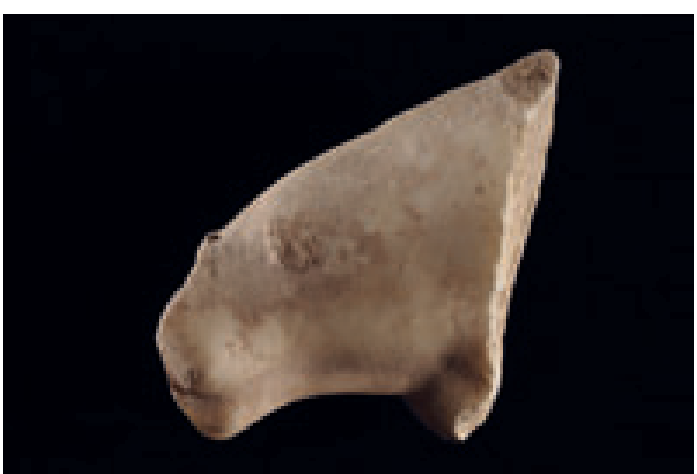

Abb. 246 Fragment 53

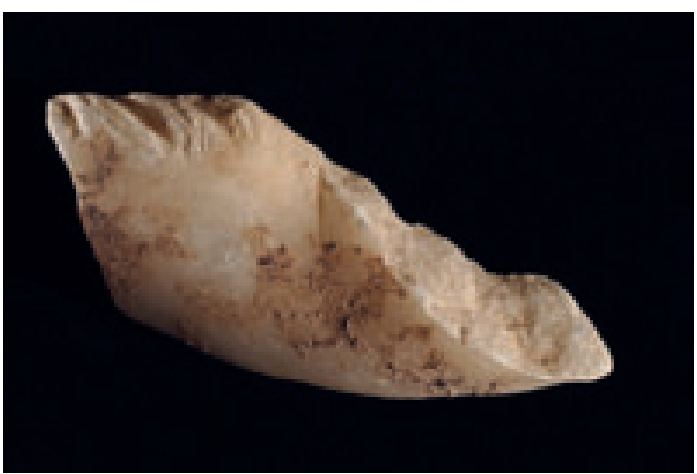

Abb. 248 Fragment 55

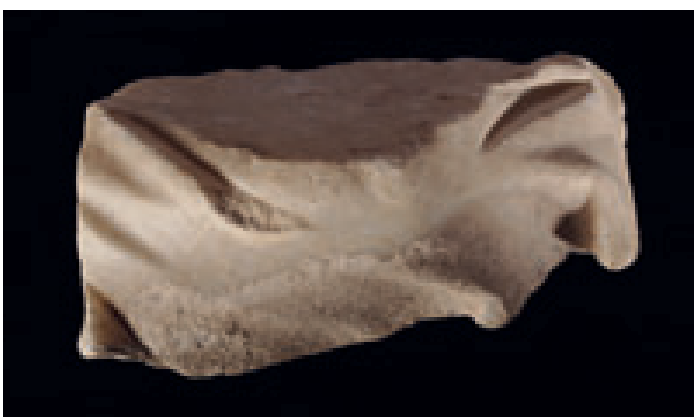

Abb. 250 Fragment 56

Kat. 15 Hippolytos-Sarkophag aus einem Grabhaus der Nekropole nördlich des Hafenkanals in Ephesos, mögliche Zuordnungen von Friesfragmenten 
Tafel 62

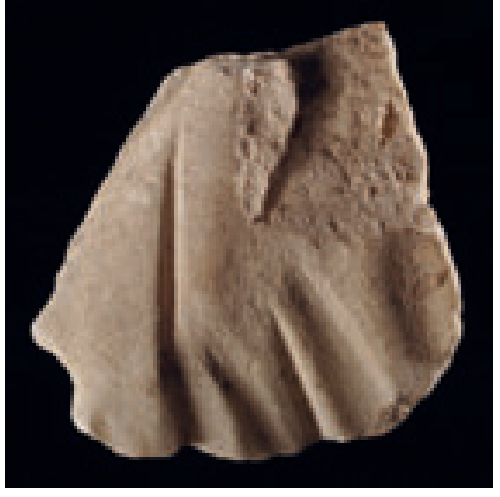

Abb. 251 Fragment 57

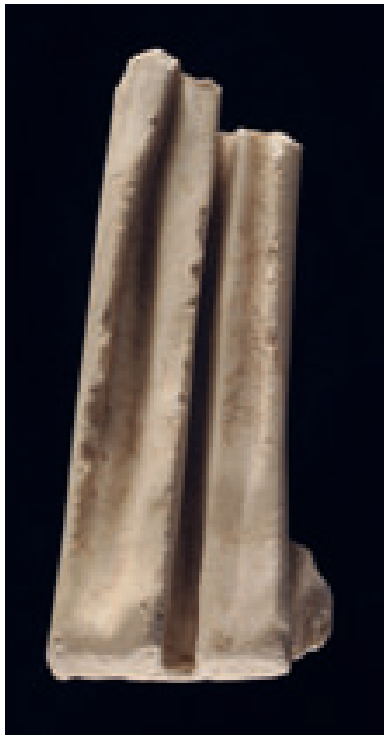

Abb. 254 Fragment 60

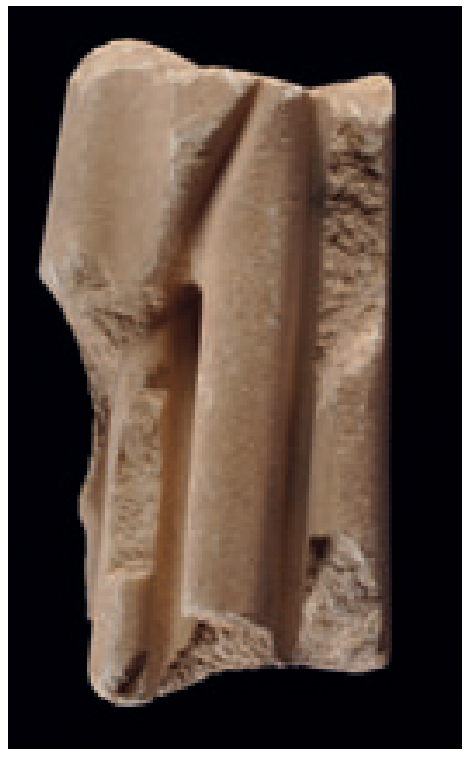

Abb. 257 Fragment 63

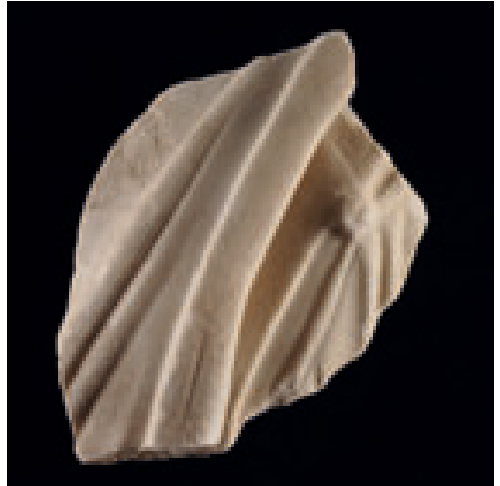

Abb. 252 Fragment 58

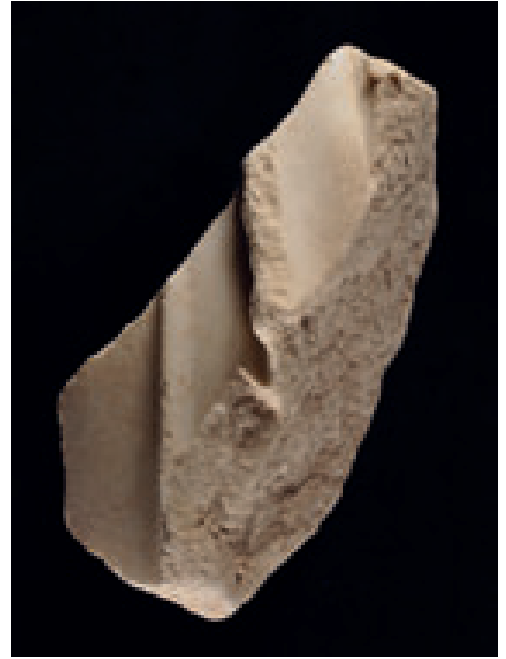

Abb. 253 Fragment 59

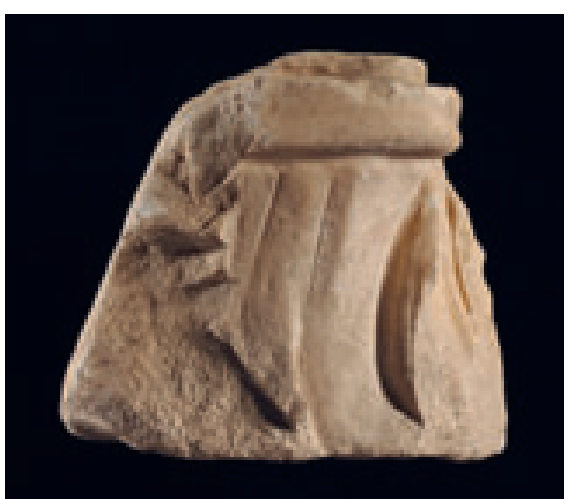

Abb. 255 Fragment 62

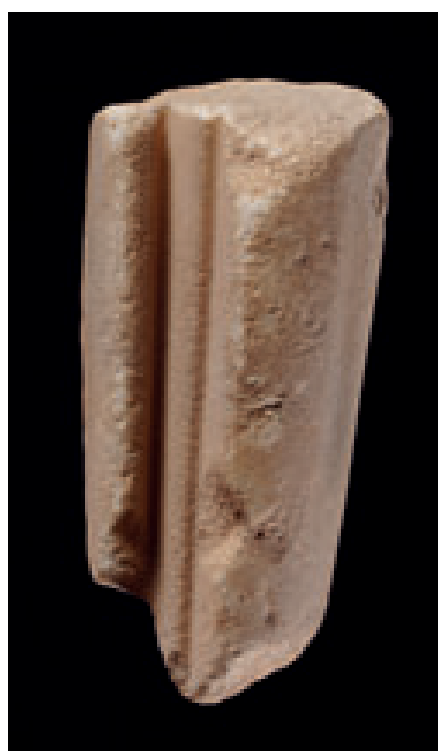

Abb. 258 Fragment 64

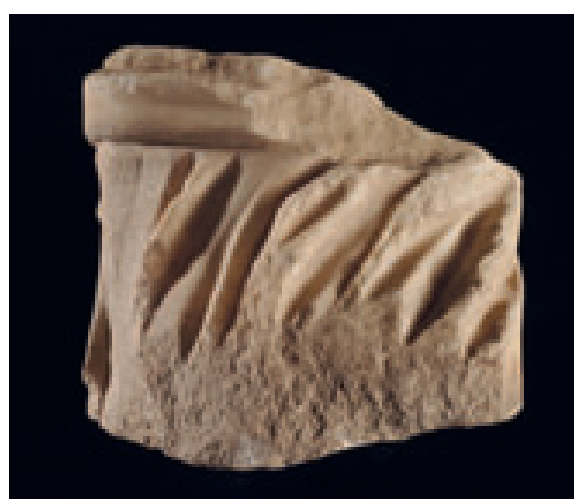

Abb. 256 Fragment 62

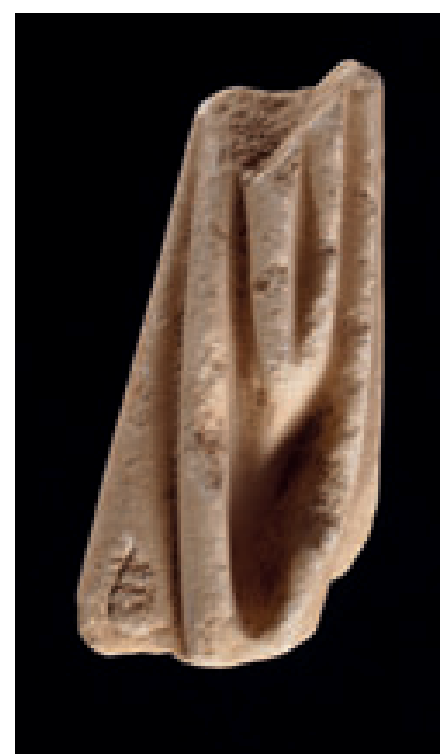

Abb. 259 Fragment 65

Kat. 15 Hippolytos-Sarkophag aus einem Grabhaus der Nekropole nördlich des Hafenkanals in Ephesos, mögliche Zuordnungen von Friesfragmenten 
Tafel 63

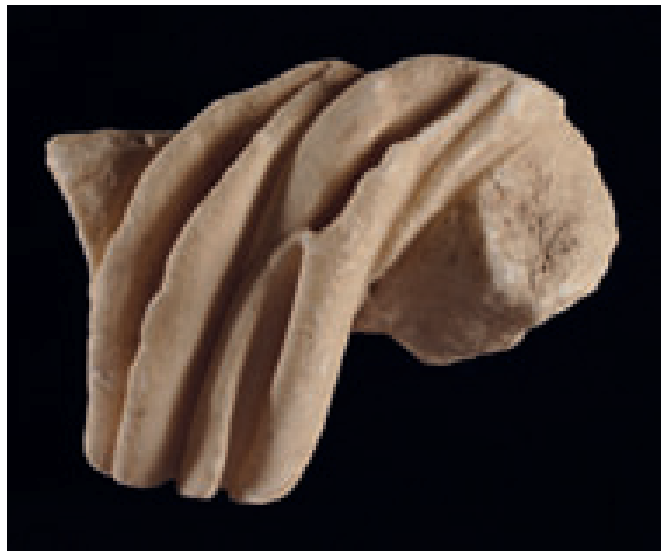

Abb. 260 Fragment 66

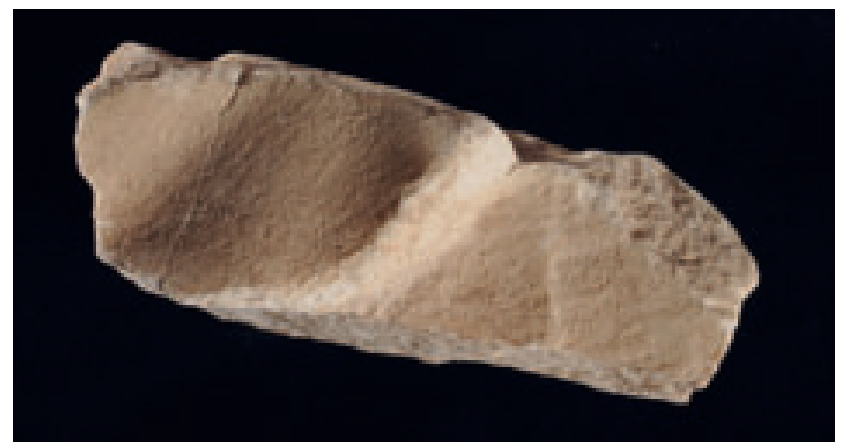

Abb. 262 Fragment 68

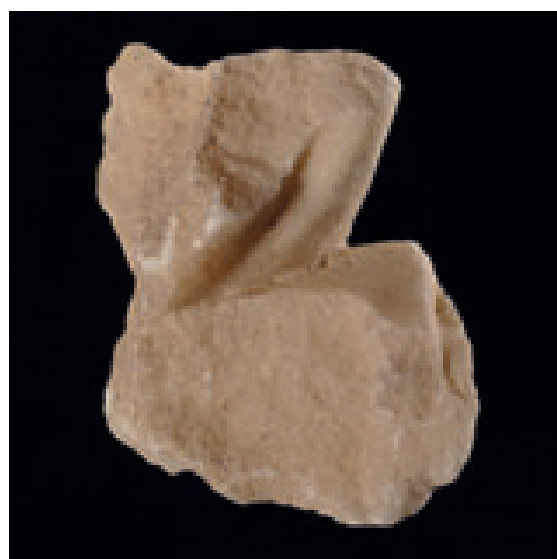

Abb. 261 Fragment 67

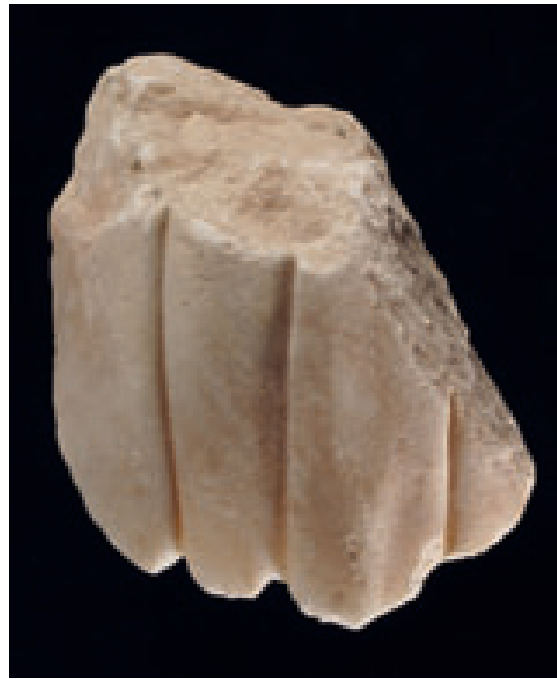

Abb. 263 Fragment 61

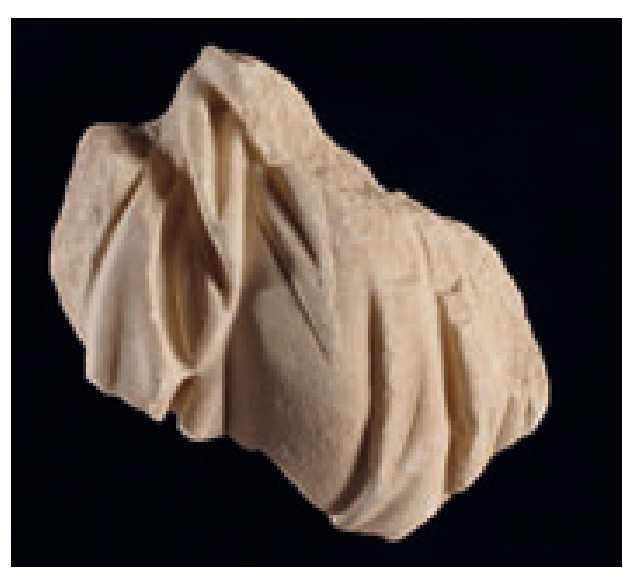

Abb. 264 Fragment 69 mit fraglicher Zugehörigkeit

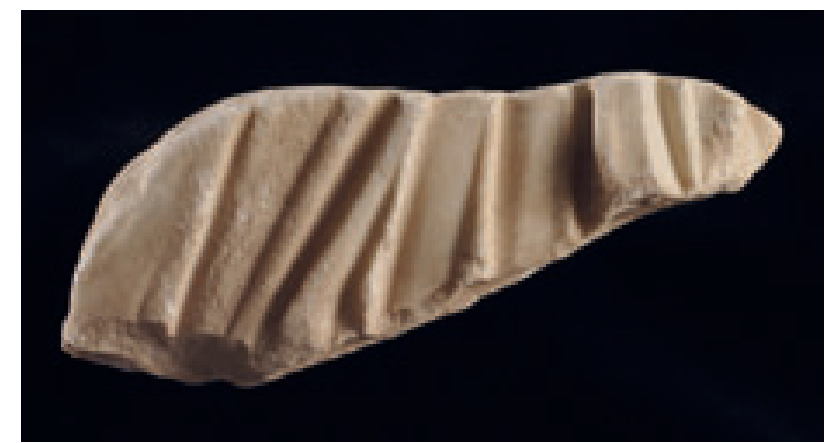

Abb. 265 Fragment 70 mit fraglicher Zugehörigkeit

Kat. 15 Hippolytos-Sarkophag aus einem Grabhaus der Nekropole nördlich des Hafenkanals in Ephesos, mögliche Zuordnungen von Friesfragmenten 
Tafel 64

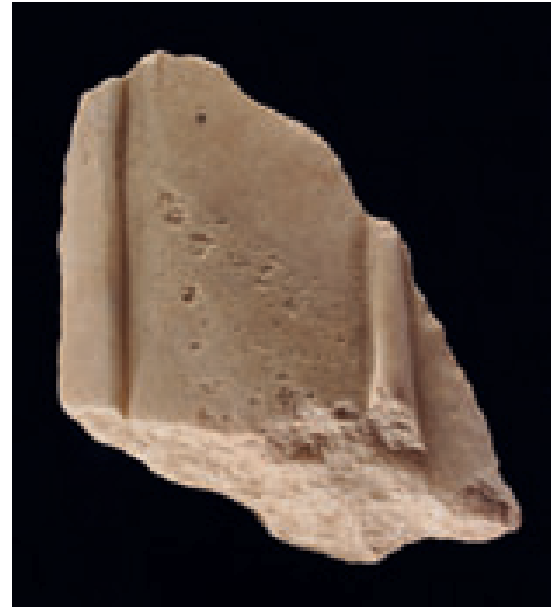

Abb. 266 Fragment 71

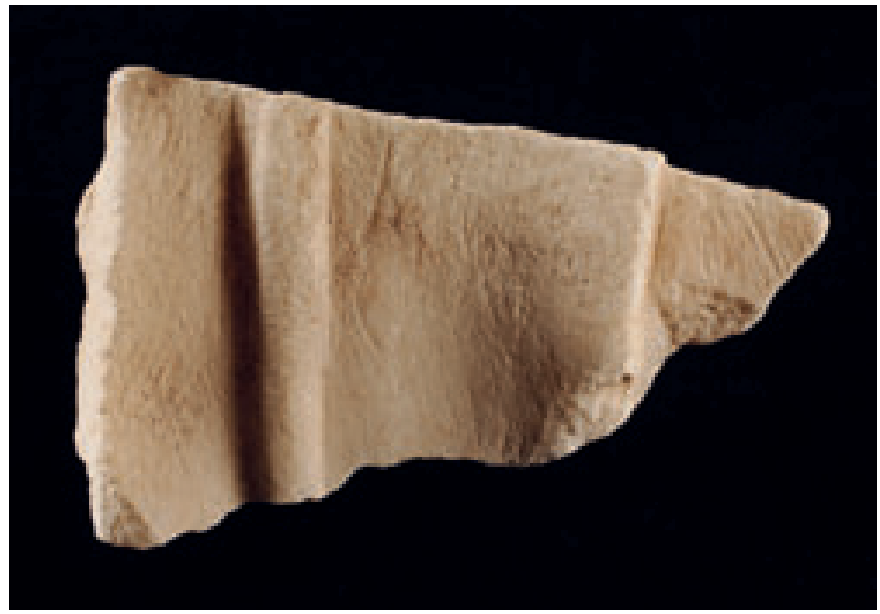

Abb. 267 Fragment 72

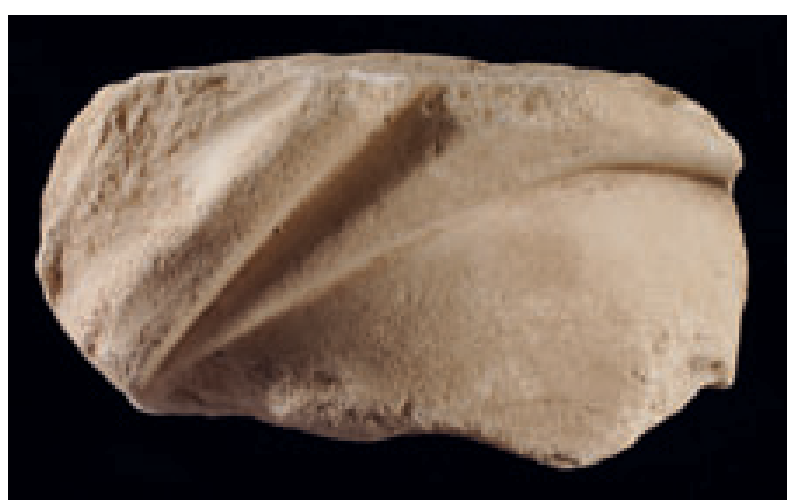

Abb. 268 Fragment 73

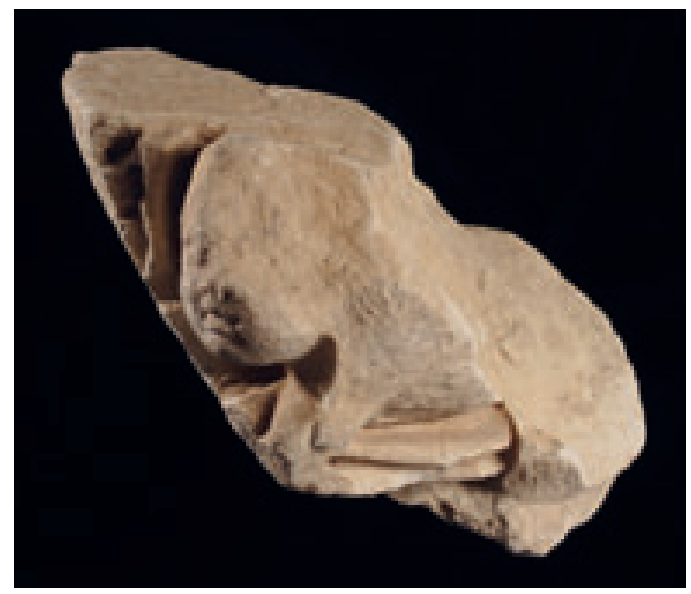

Abb. 270 Fragment 75

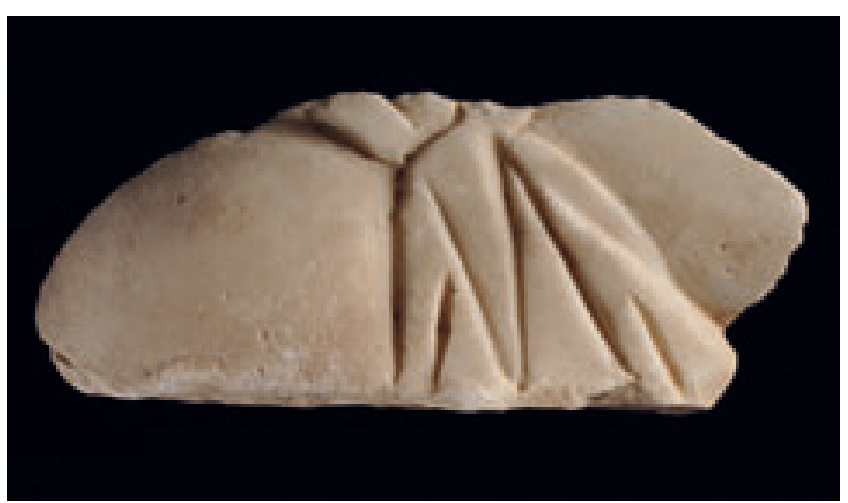

Abb. 269 Fragment 74

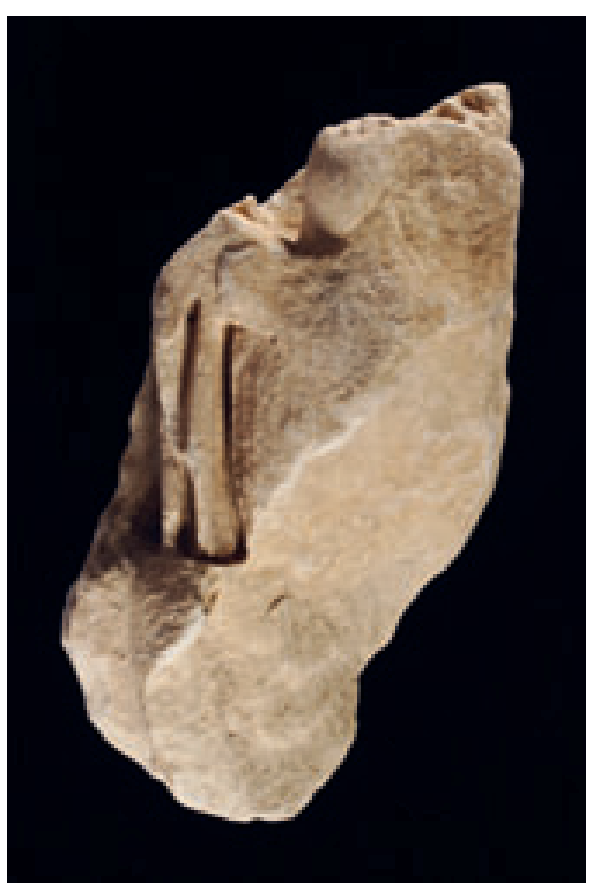

Abb. 271 Fragment 75

Kat. 15 Hippolytos-Sarkophag aus einem Grabhaus der Nekropole nördlich des Hafenkanals in Ephesos, Fragmente mit fraglicher Zugehörigkeit 
Tafel 65

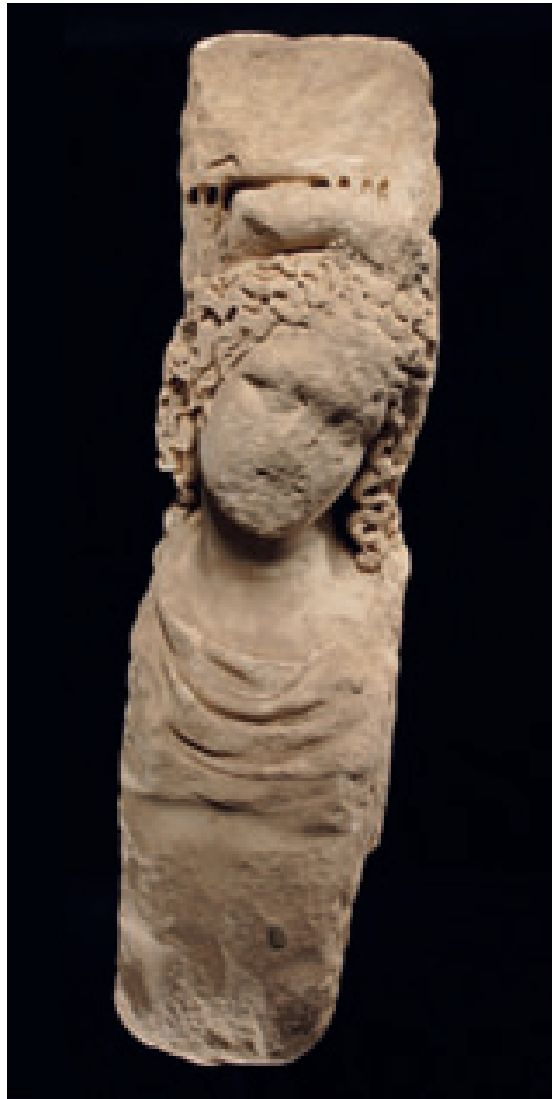

Abb. 272

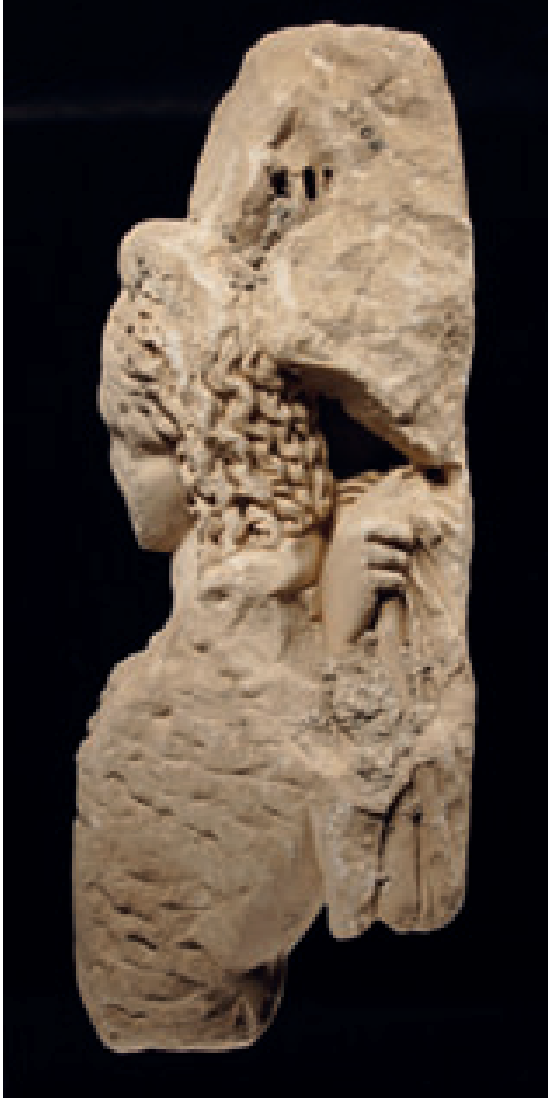

Abb. 273 Rechte Schmalseite

Kat. 16 Eckfragment eines Hippolytos-Sarkophags. Selçuk, Efes Müzesi Inv. 2268

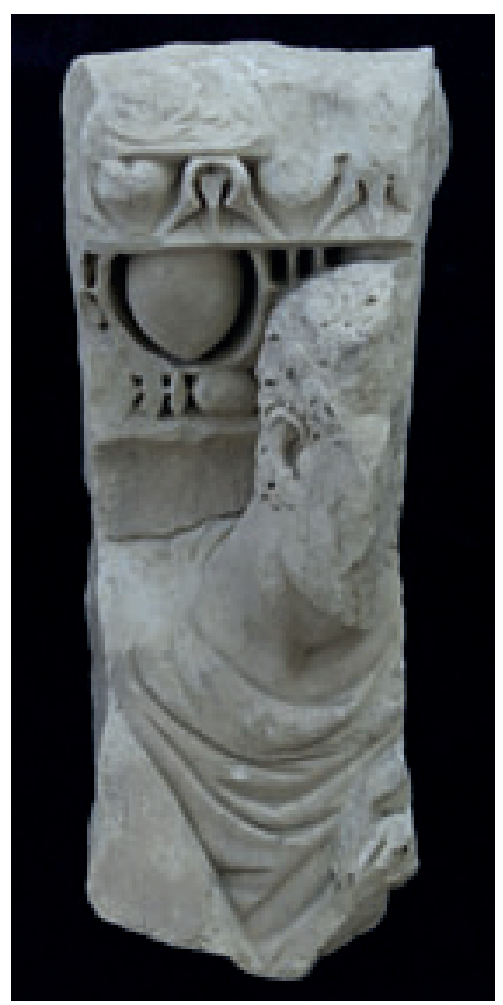

Abb. 274 Kat. 17, Fragment eines Hippolytos-Sarkophags (?). Selçuk Efes Müzesi Inv. 2321

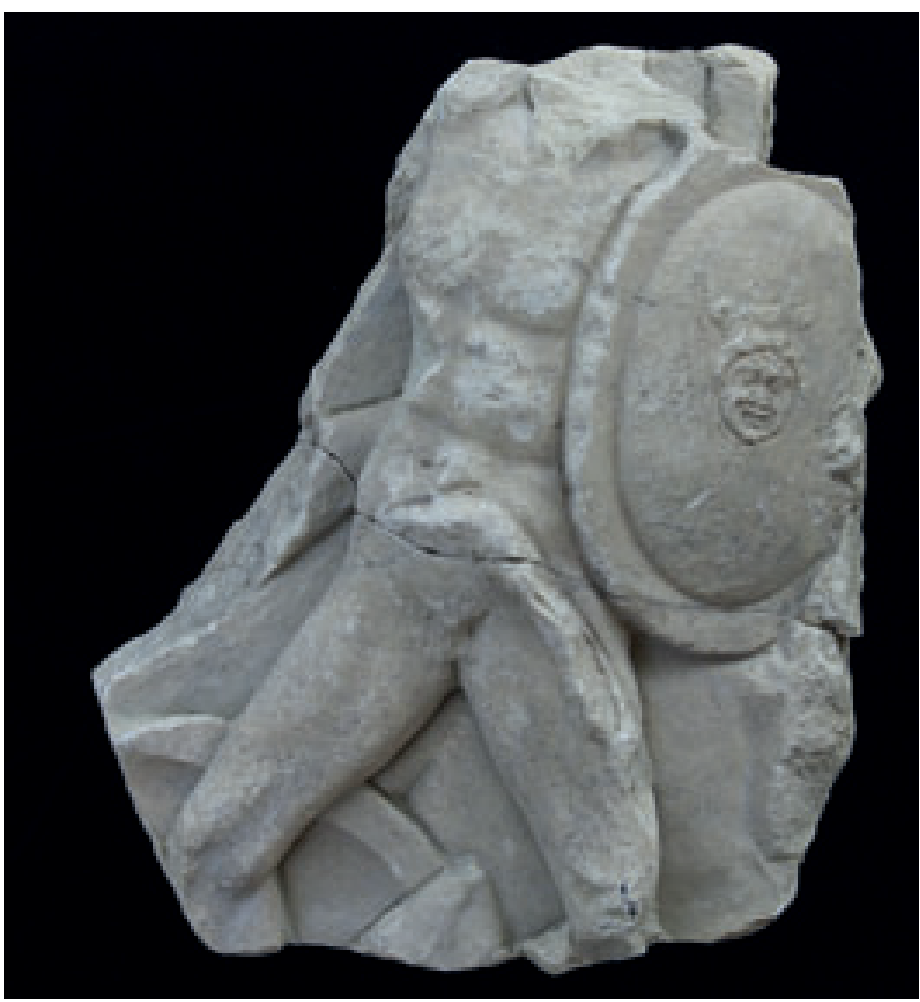

Abb. 275 Kat. 18, Fragment mit Schlachtszene. Selçuk Efes Müzesi Inv. 2/34/77 
Tafel 66

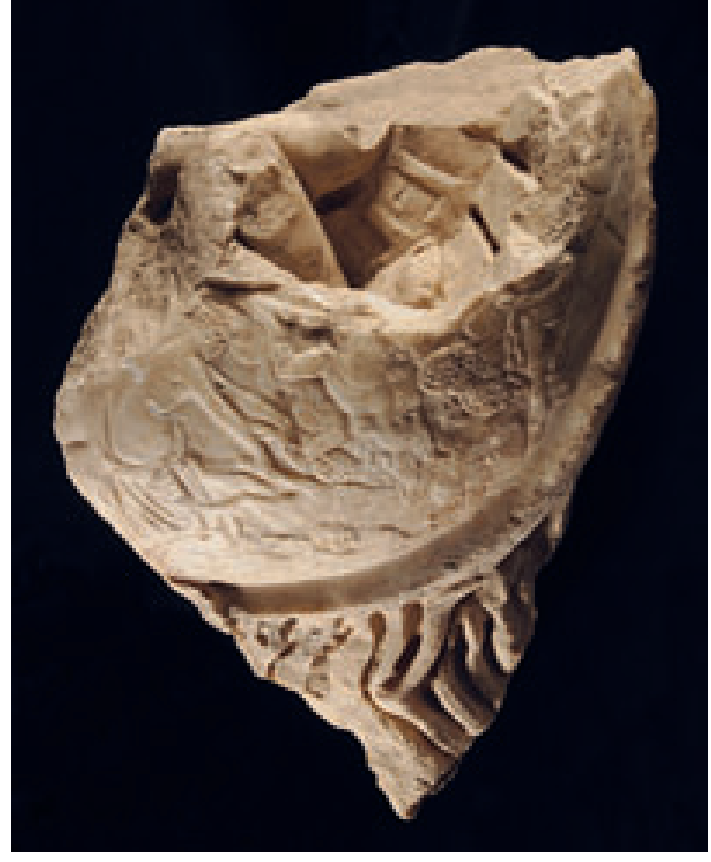

Abb. 276

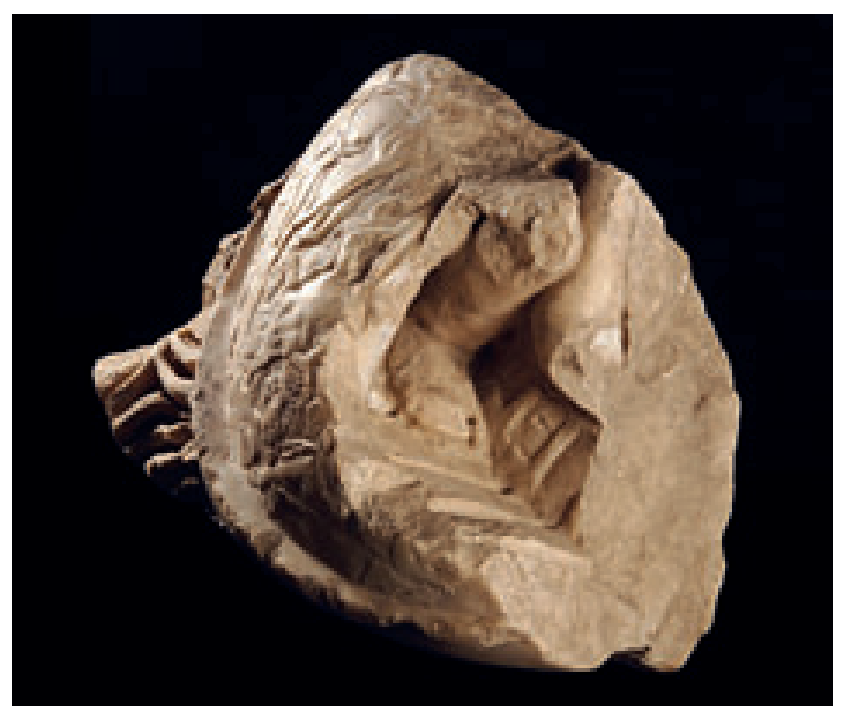

Abb. 277

Kat. 19 Fragment mit einer Schlacht bei Schiffen. Selçuk, Efes Müzesi Inv. 10/1/95

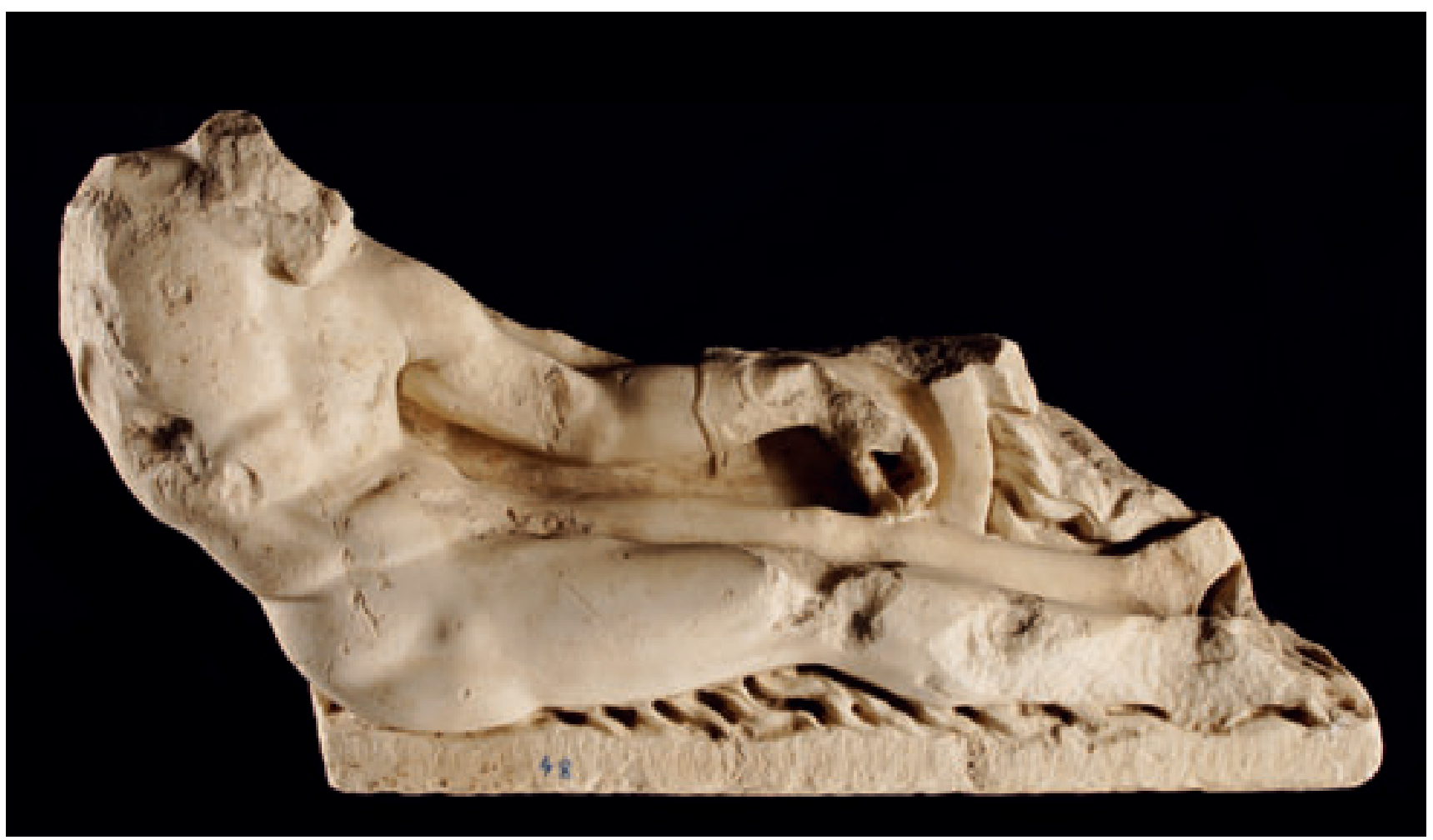

Abb. 278 Kat. 20, Fragment mit einer Schlacht bei Schiffen. Selçuk, Efes Müzesi Inv. 48 
Tafel 67
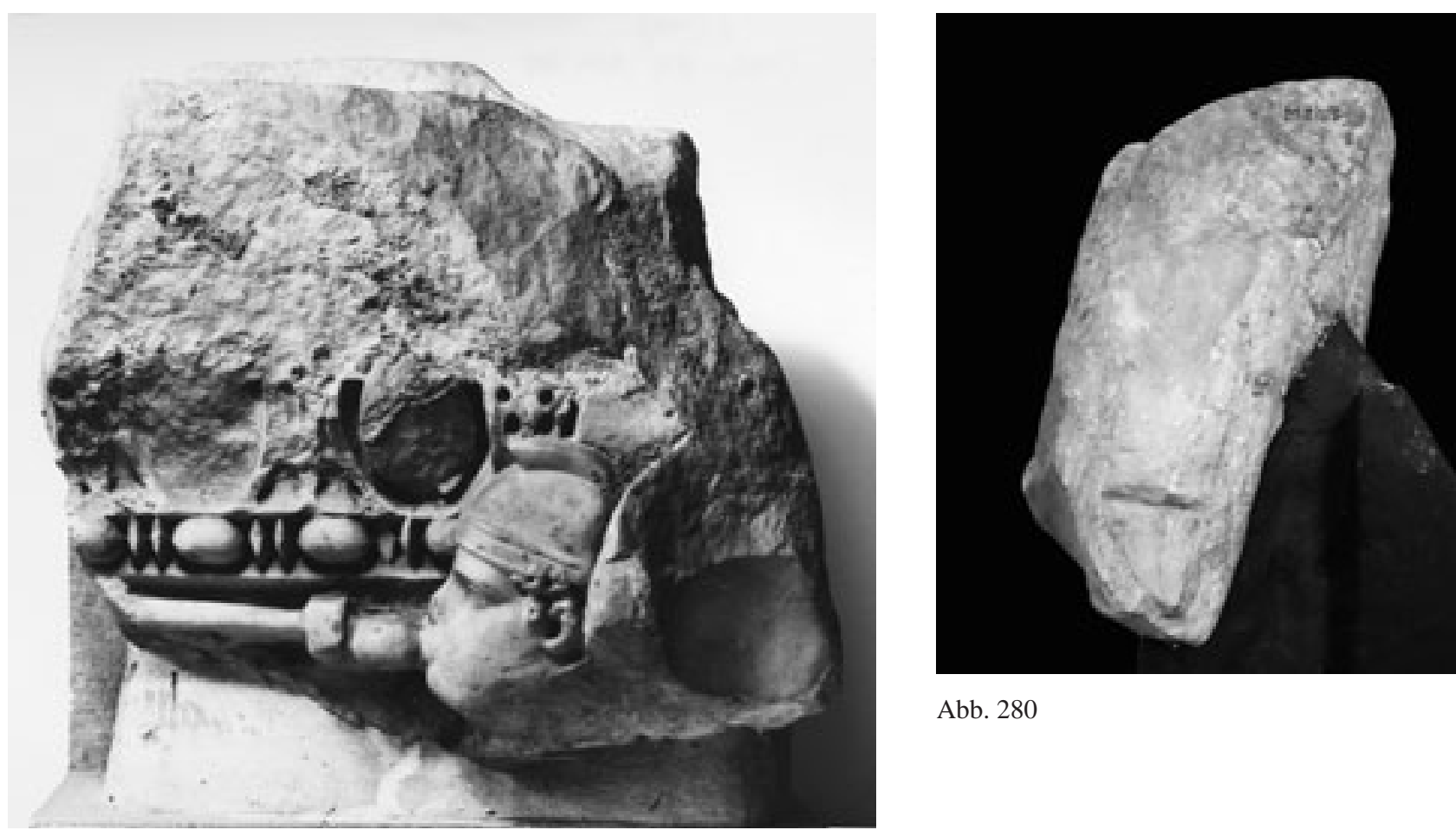

Abb. 280

Abb. 279

Kat. 21 Eckfragment mit Trompeter. Oxford, Ashmolean Museum Inv. ANMichaelis. 218.a

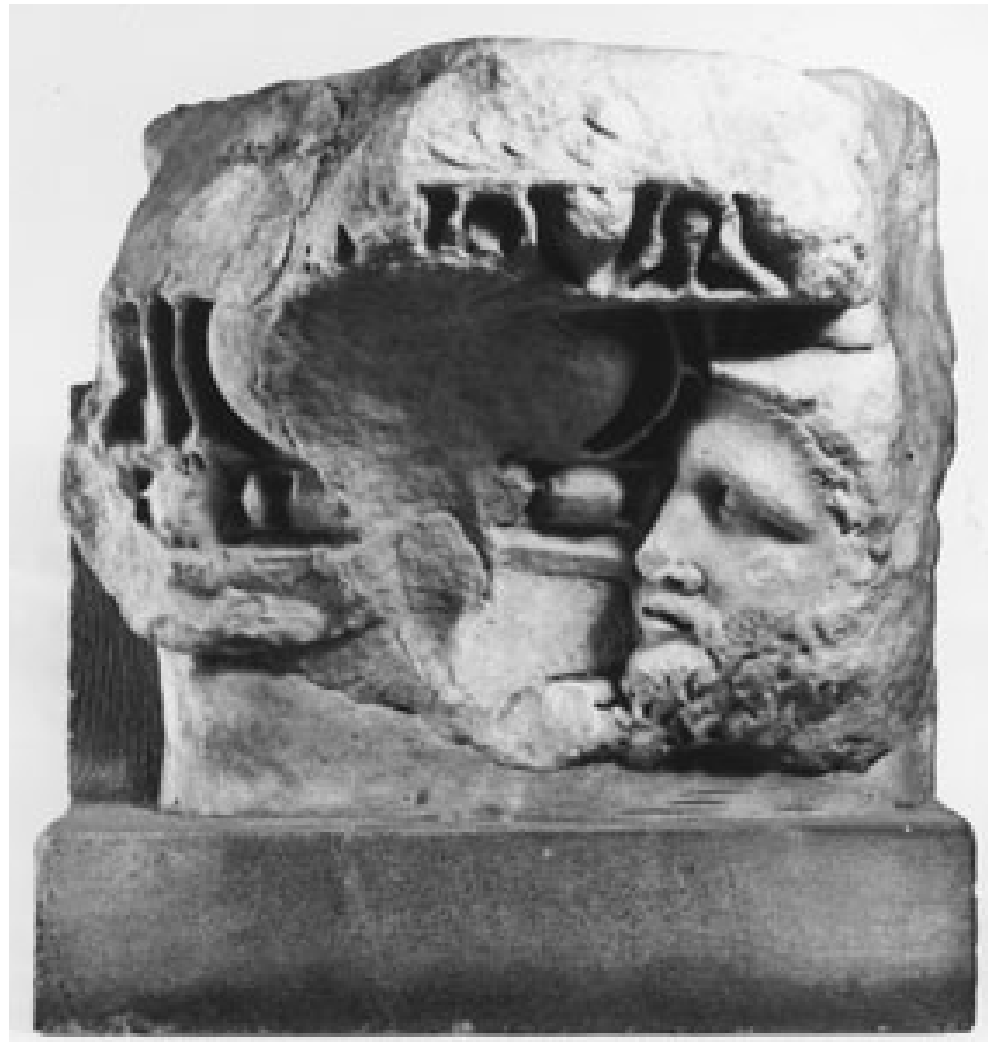

Abb. 281 Kat. 22, Fragment mit Bärtigem. Oxford, Ashmolean Museum Inv. ANMichaelis. 218.b 
Tafel 68

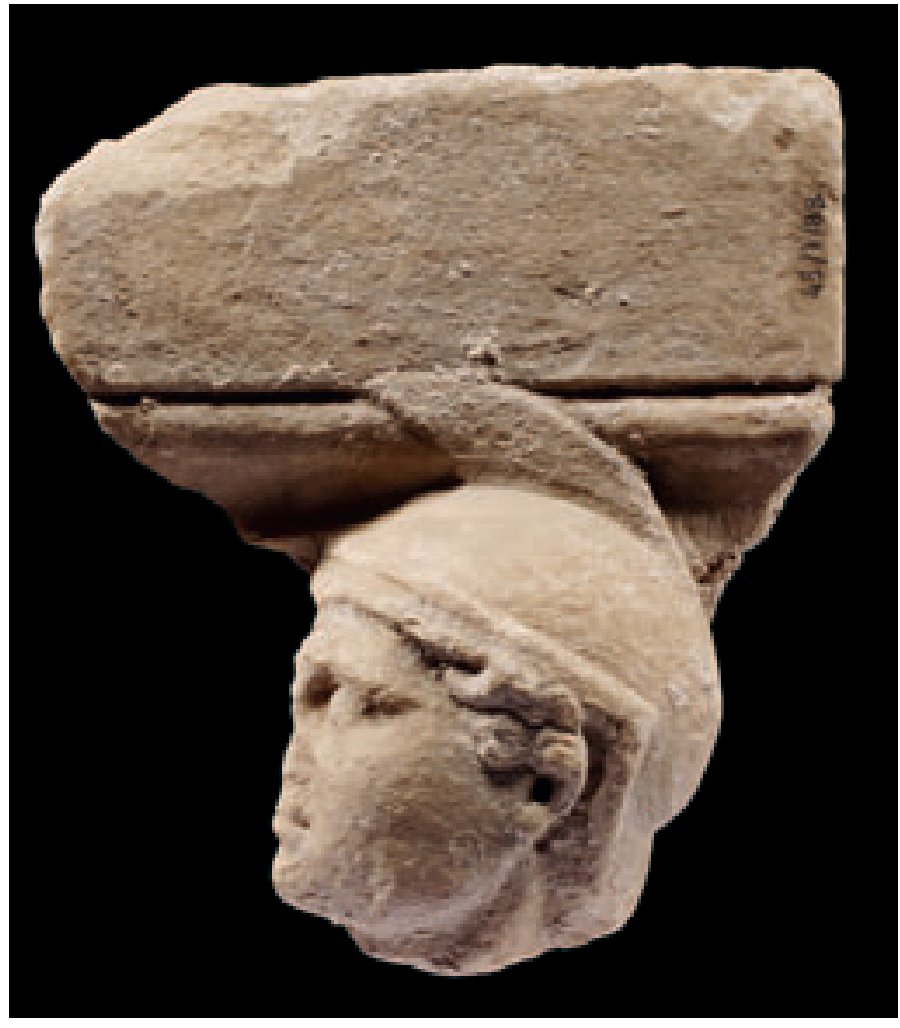

Abb. 282 Vorderansicht

Kat. 23 Eckfragment mit Kriegerkopf. Selçuk, Efes Müzesi Inv. 43/1/88
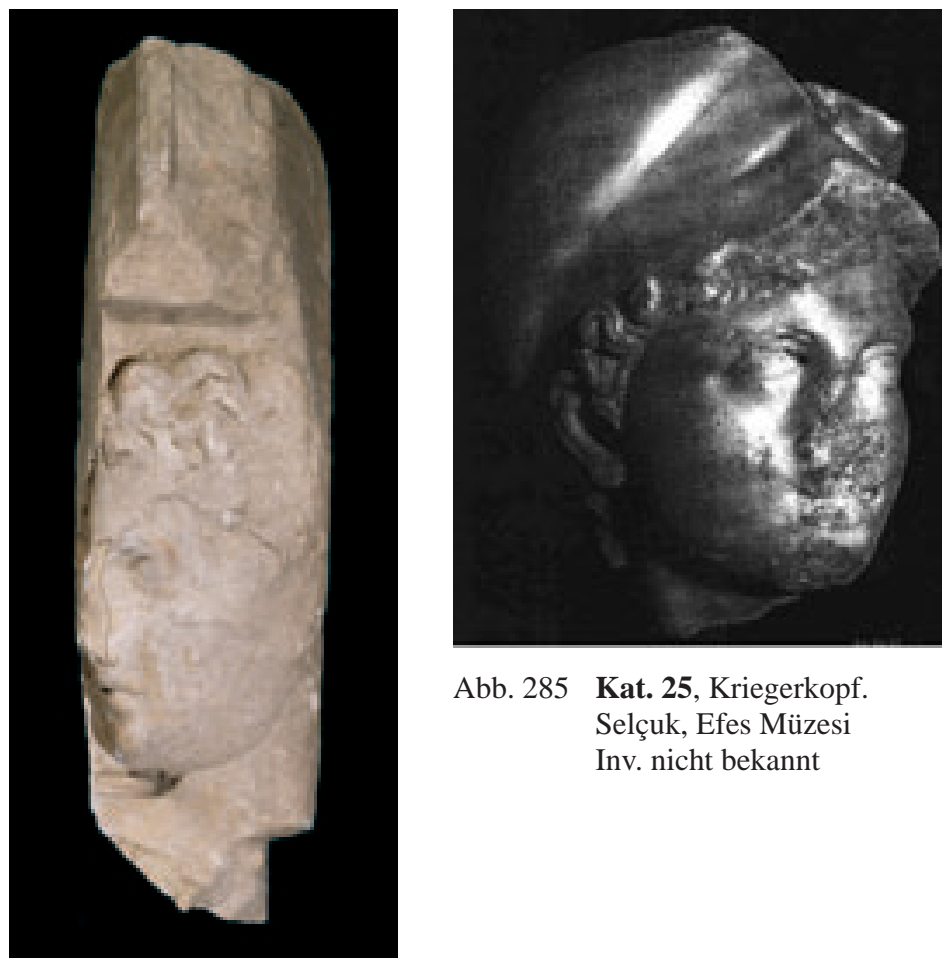

Abb. 285 Kat. 25, Kriegerkopf. Selçuk, Efes Müzesi Inv. nicht bekannt

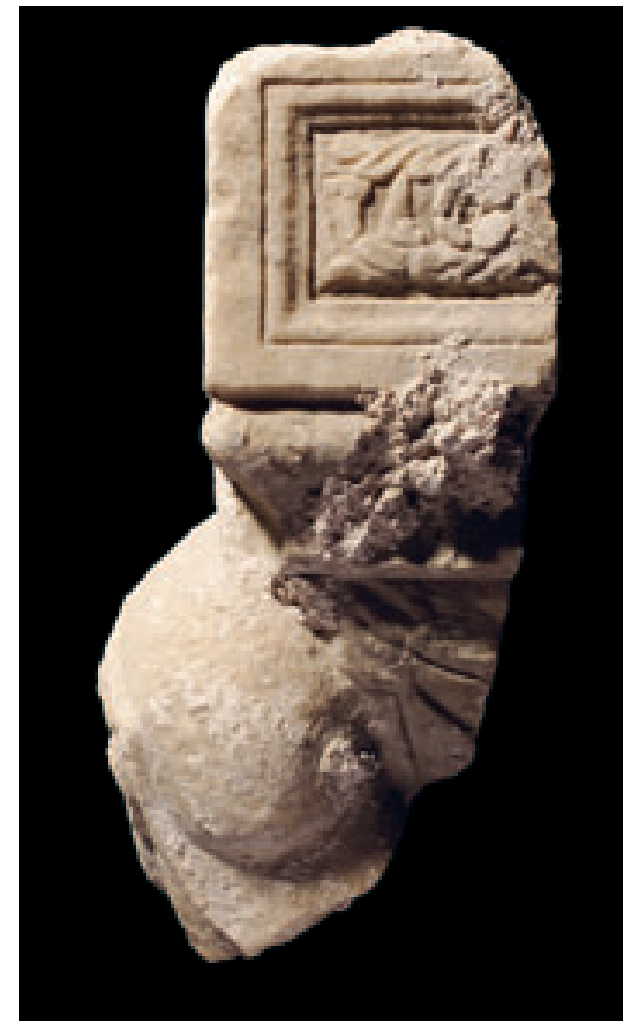

Abb. 283 Seitenansicht

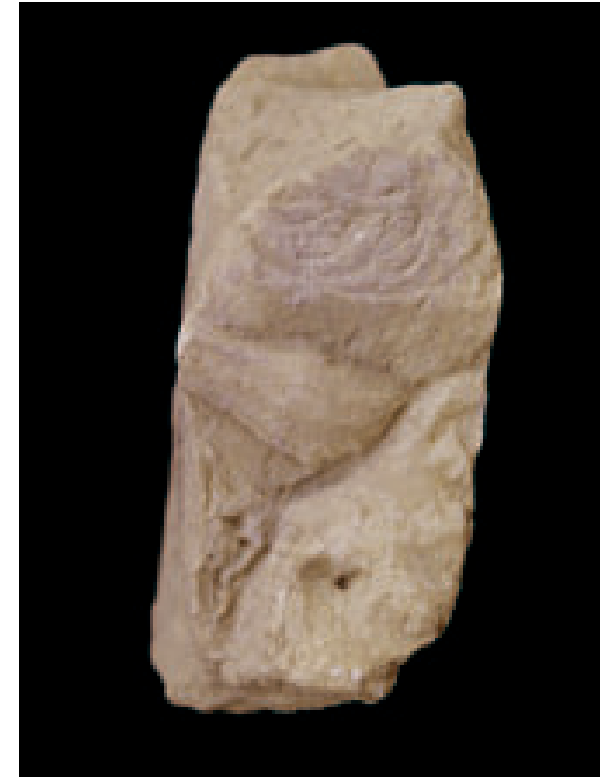

Abb. 286 Kat. 26, Fragment des oberen Kastenabschlusses. Selçuk, Efes Müzesi Inv. 17/8/82

Abb. 284 Kat. 24, Kopf eines Jünglings. Selçuk, Efes Müzesi Inv. 1/8/74 
Tafel 69

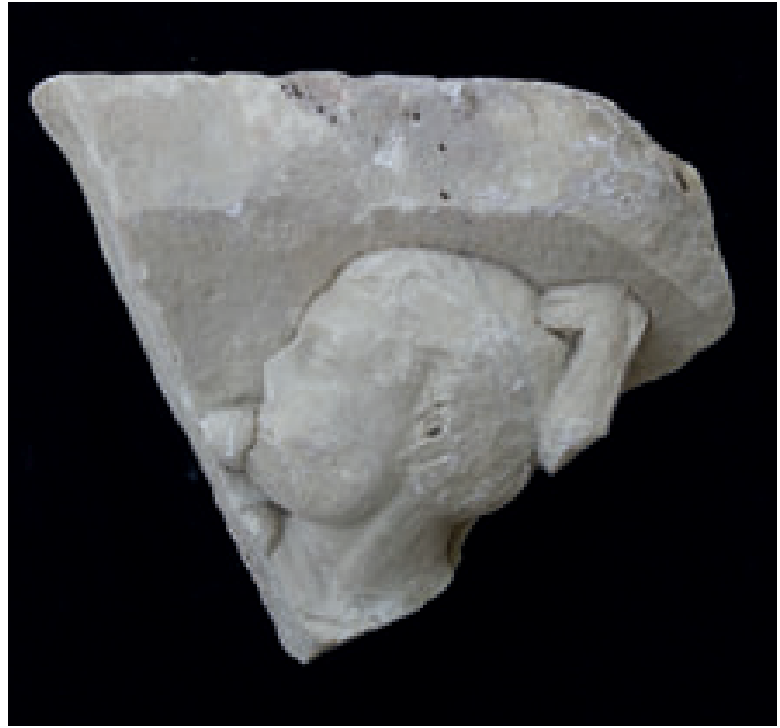

Abb. 287 Kat. 27, oberes Kastenfragment mit Trompeter. Selçuk, Efes Müzesi Inv. 17/71/78

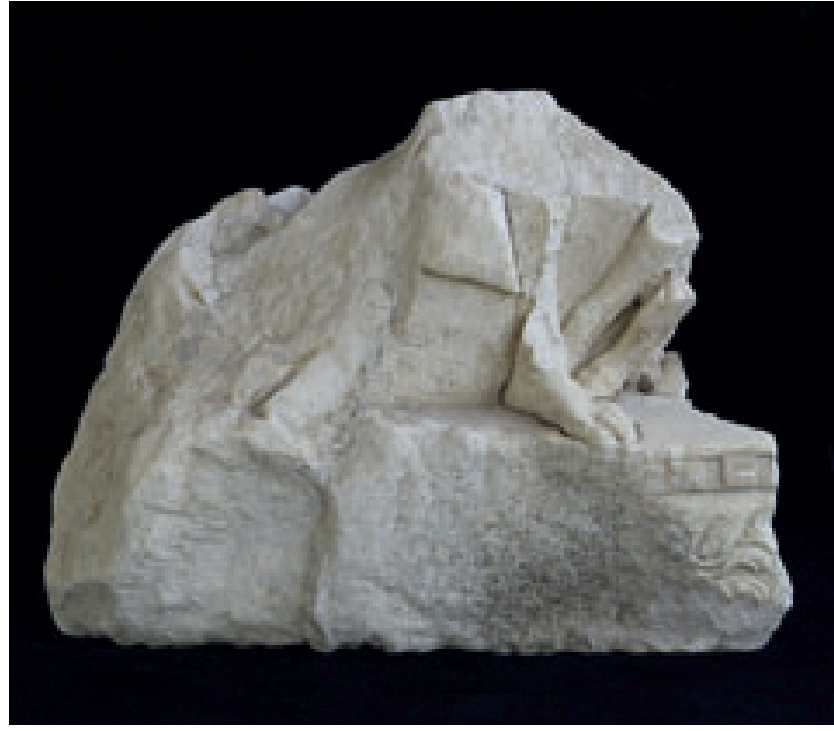

Abb. 288 Kat. 28, Kastenfragment mit Sockelzone. Selçuk, Efes Müzesi o. Inv.

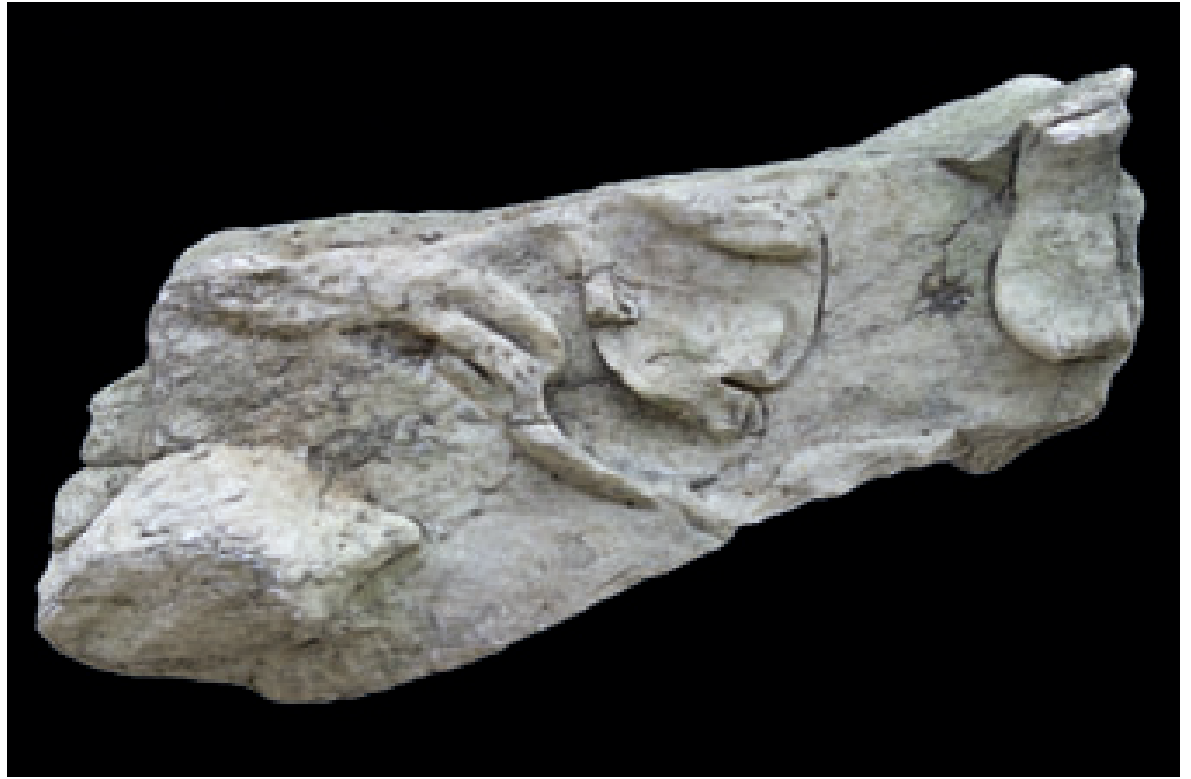

Abb. 289 Kat. 29, Fragment eines Kastenreliefs. Selçuk, Efes Müzesi o. Inv.

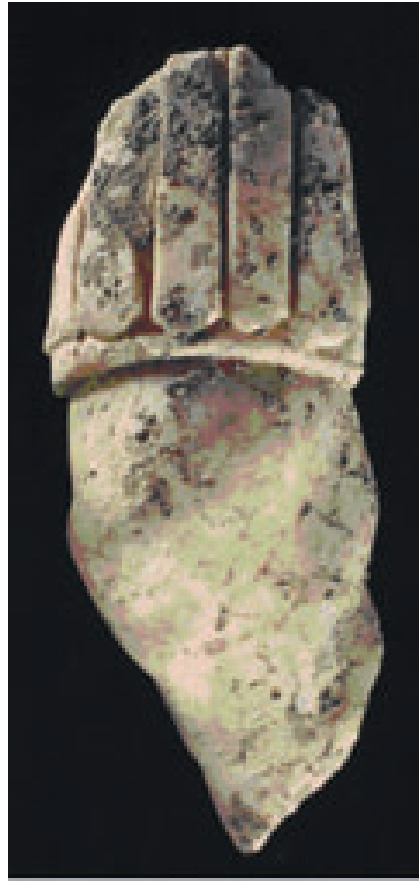

Abb. 290 Kat. 30, Kastenfragment mit Kriegerbein. Selçuk, Depot im österreichischen Grabungshaus 
Tafel 70
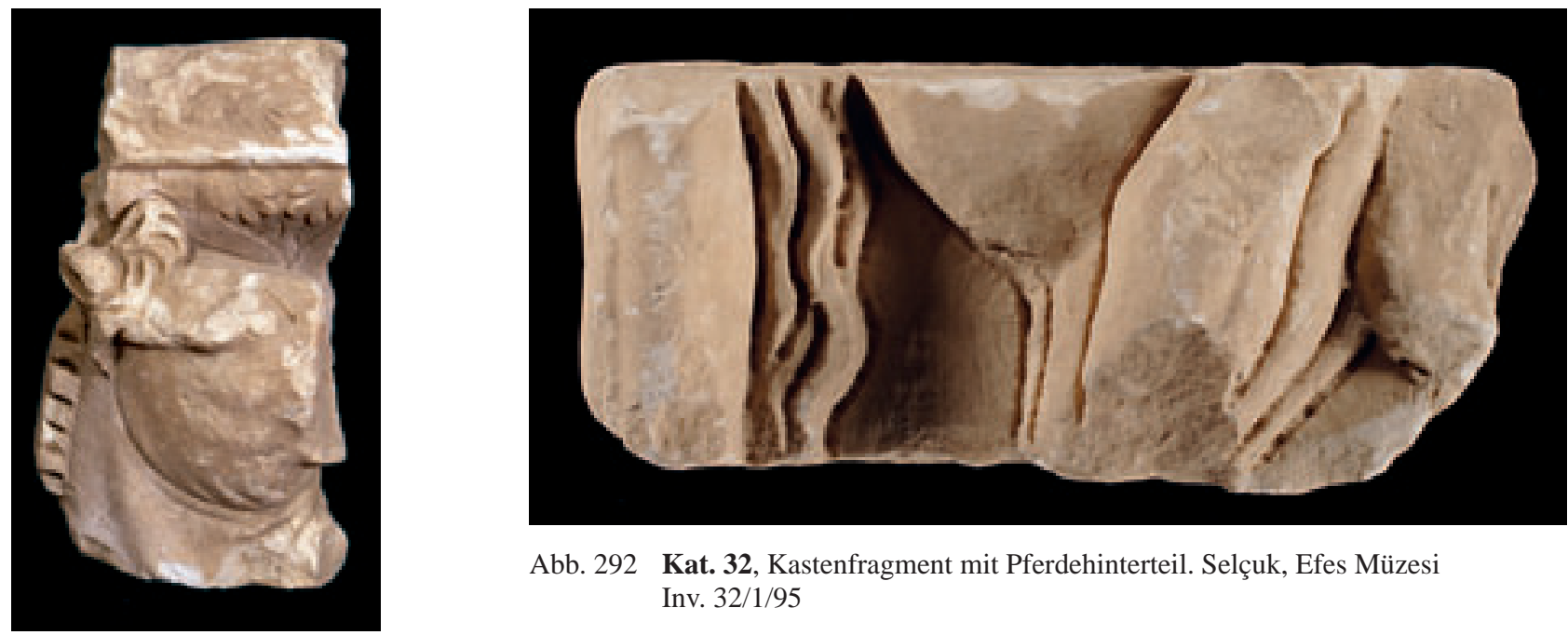

Abb. 292 Kat. 32, Kastenfragment mit Pferdehinterteil. Selçuk, Efes Müzesi Inv. 32/1/95

Abb. 291 Kat. 31, oberes

Kastenfragment mit Pferdekopf. Selçuk,

Efes Müzesi

Inv. 5/34/84

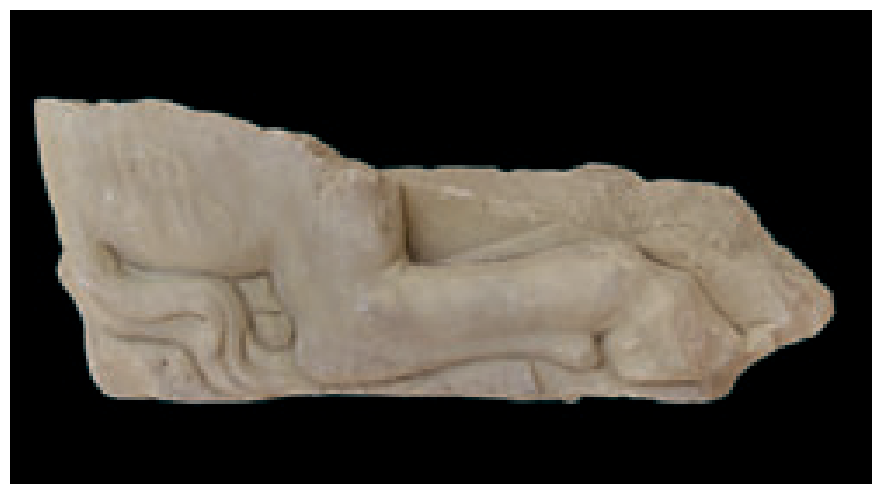

Abb. 293

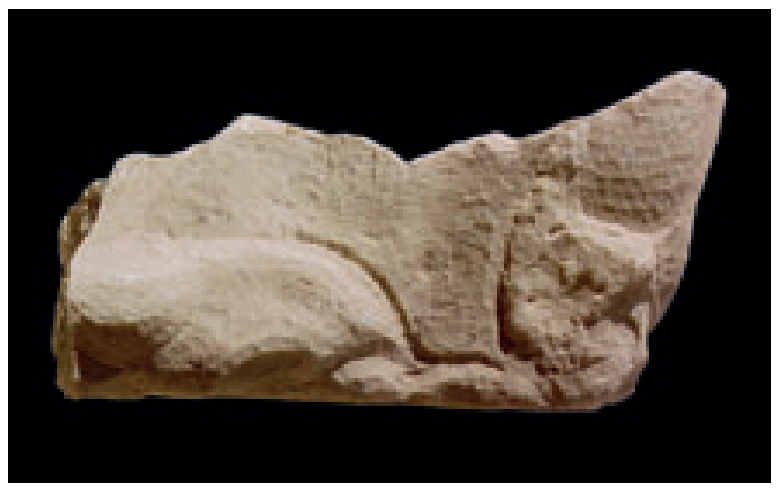

Abb. 294 Vernachlässigt gearbeitete Seite

Kat. 33 Unteres Eckfragment mit Pferdehinterteil. Selçuk, Efes Müzesi Inv. 28/13/00

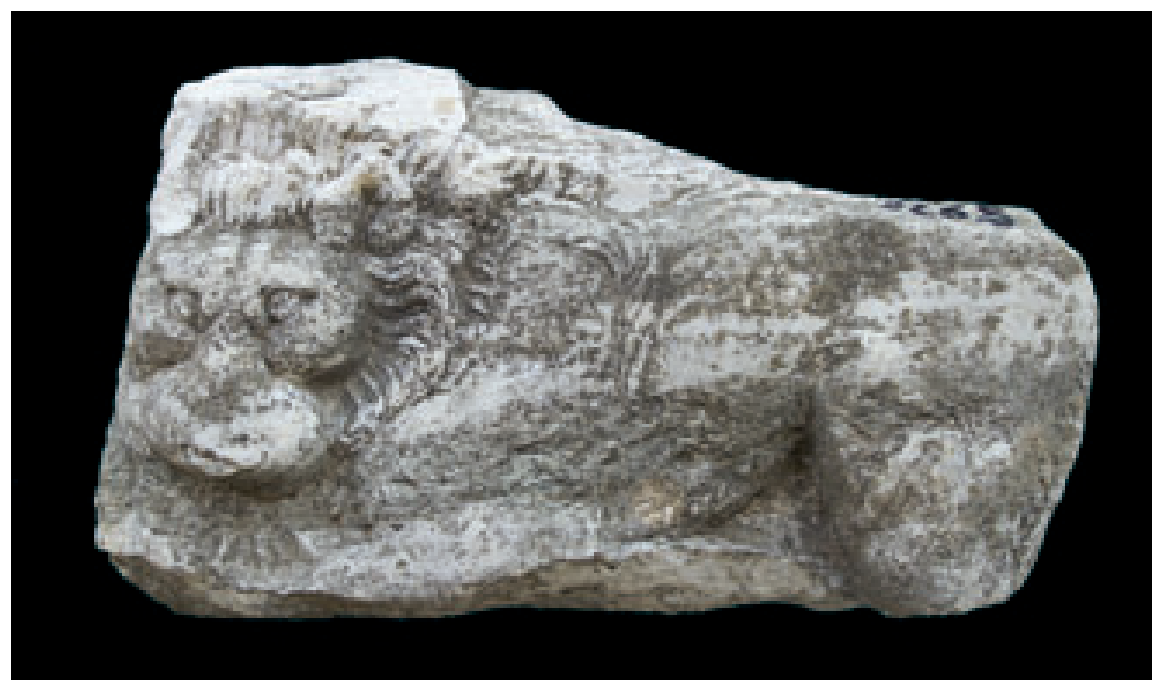

Abb. 295 Kat. 34, Rückseitenfragment mit Löwe. Selçuk, Efes Müzesi Inv. 2265 
Tafel 71

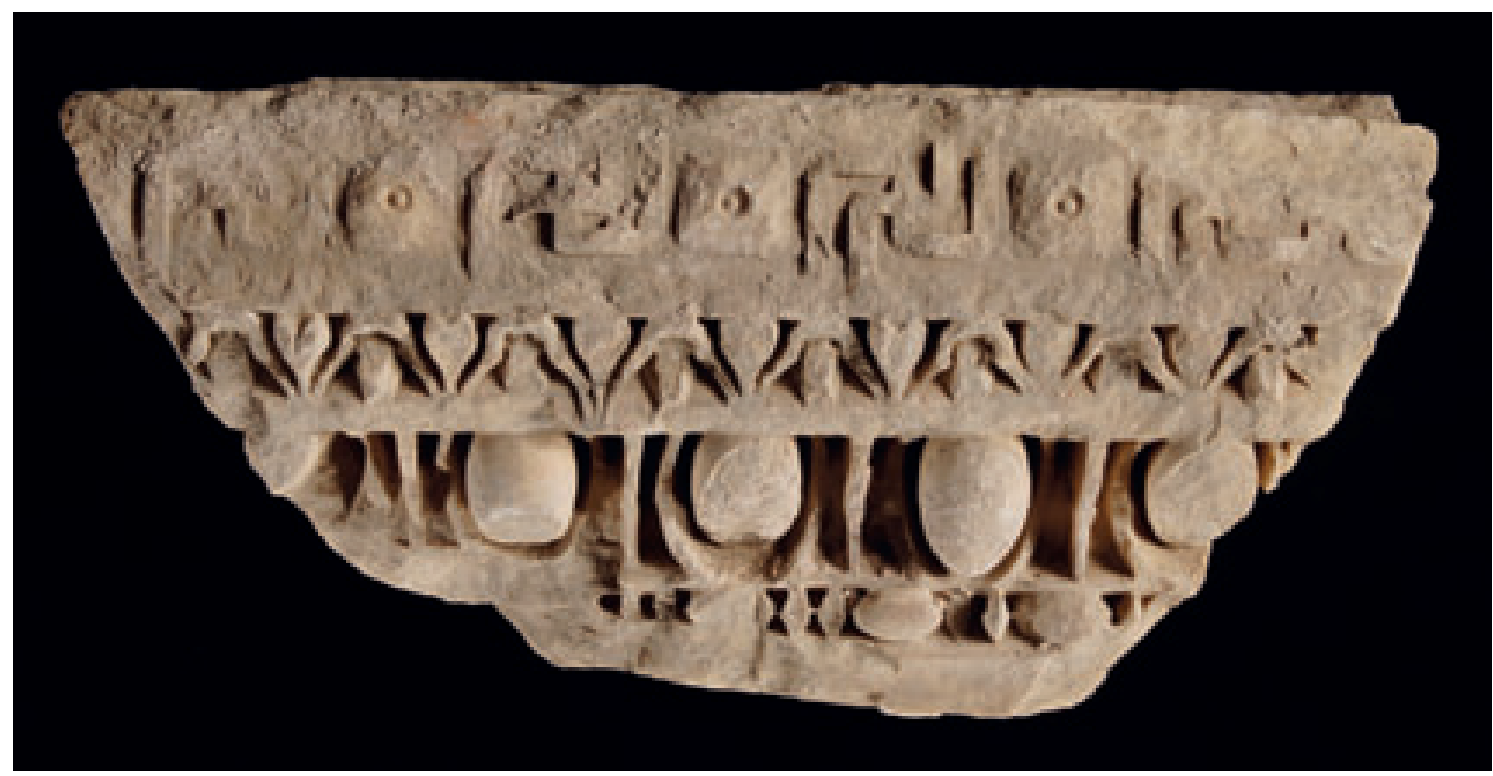

Abb. 296 Kat. 35, Fragment des oberen Kastenabschlusses. Selçuk, Efes Müzesi o. Inv.

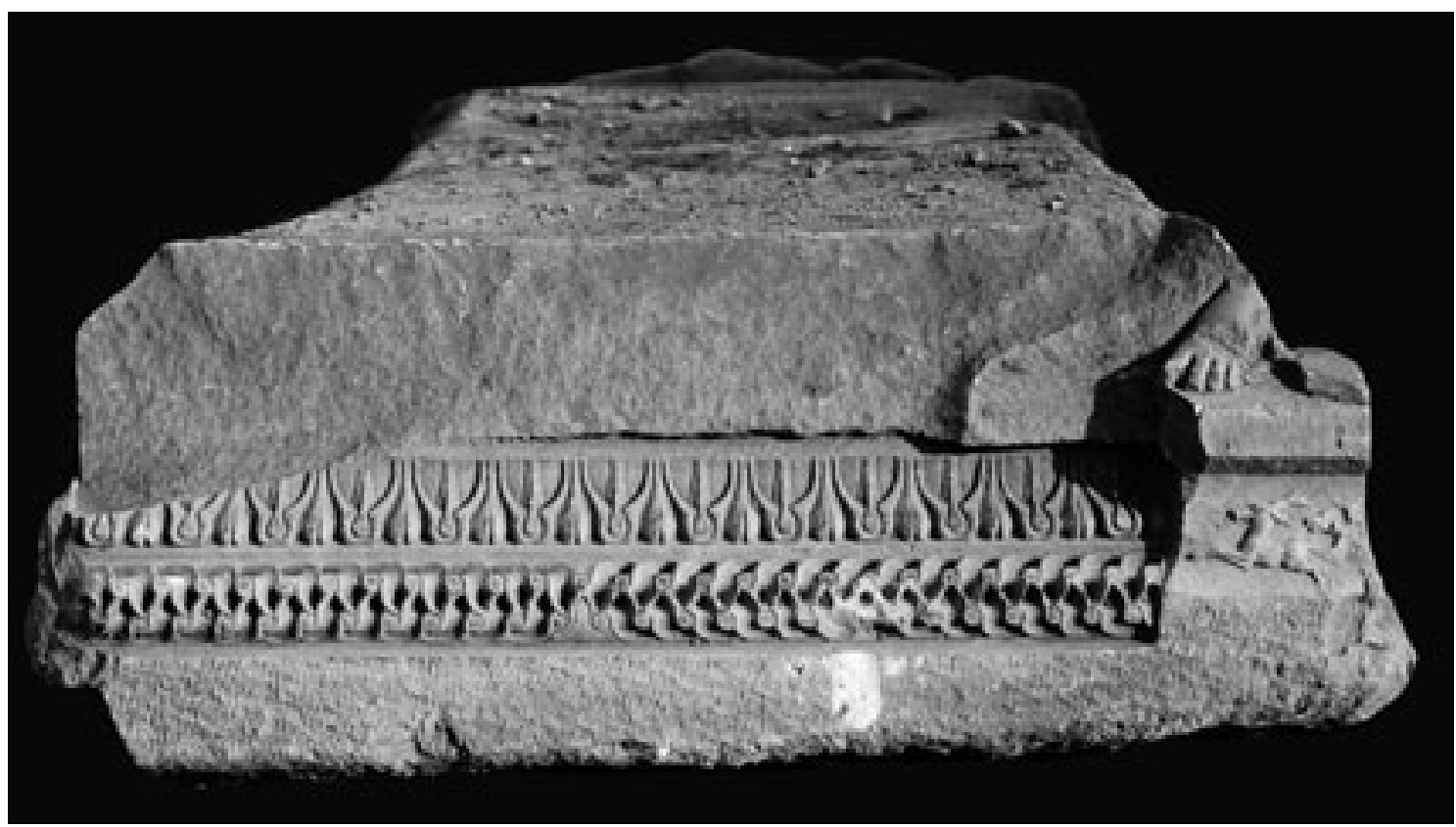

Abb. 297 Kat. 36, Kastenboden mit Sockel 
Tafel 72

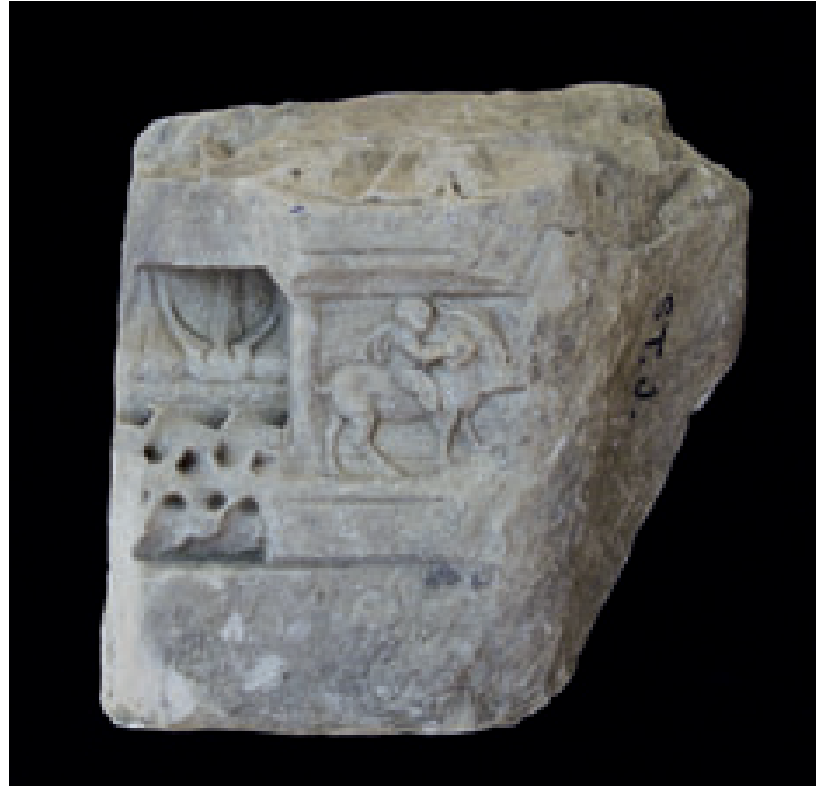

Abb. 298 Kat. 37, Fragment einer Sockelecke. Selçuk, Efes Müzesi Inv. 9/13/00

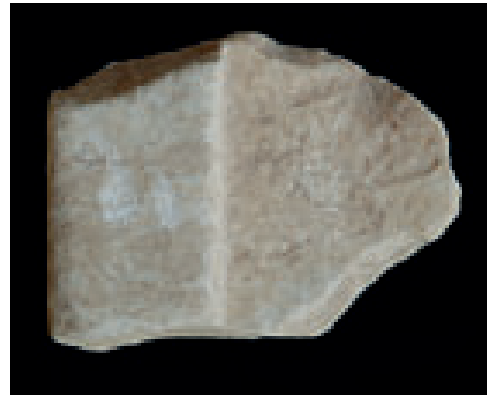

Abb. 299 Kat. 38, Fragment von Oberseite mit Falz, Selçuk, Depot des österreichischen Grabungshauses

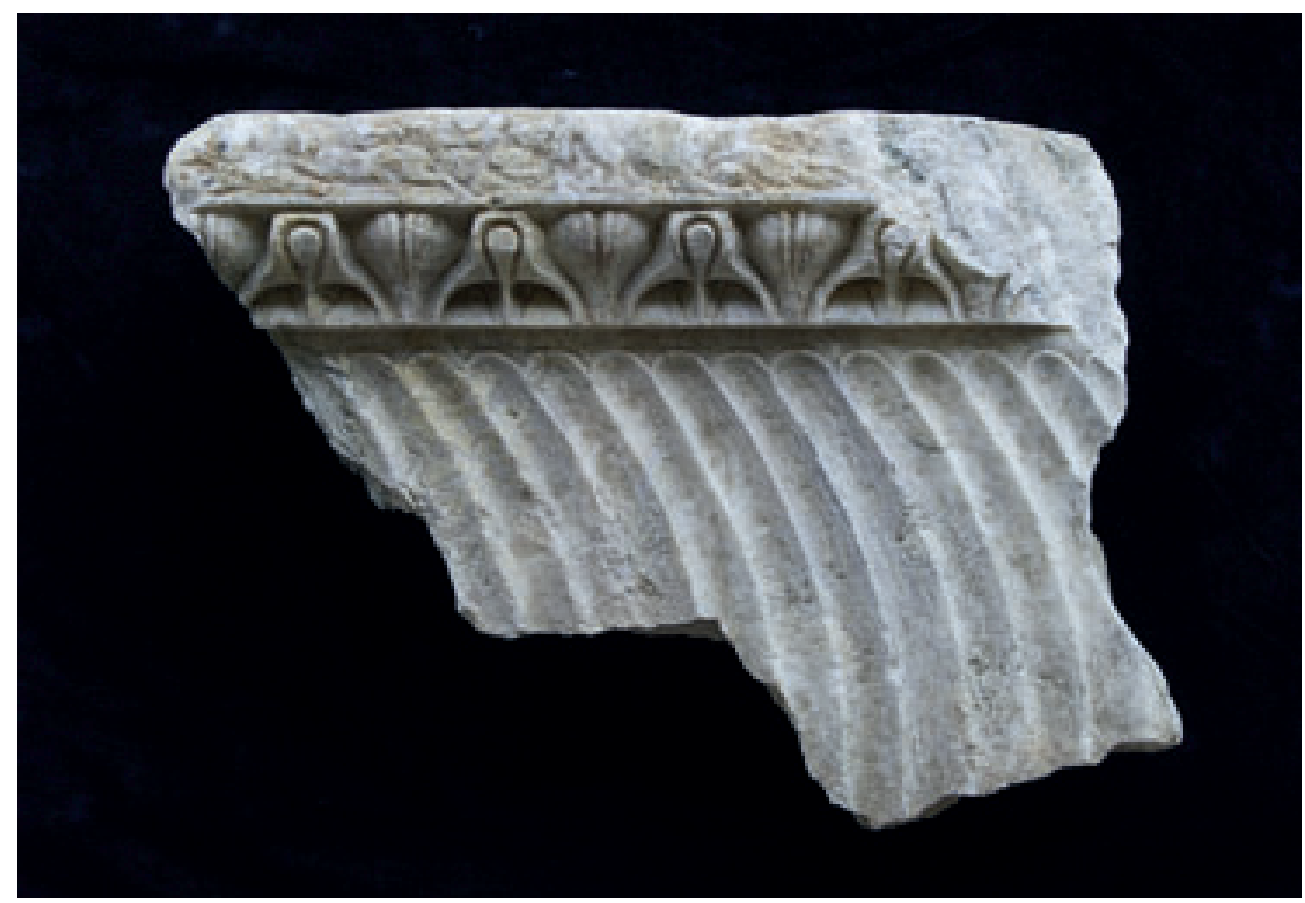

Abb. 300 Kat. 39, Fragment eines Klinen-Riefel-Sarkophags. Selçuk, Efes Müzesi o. Inv. 
Tafel 73

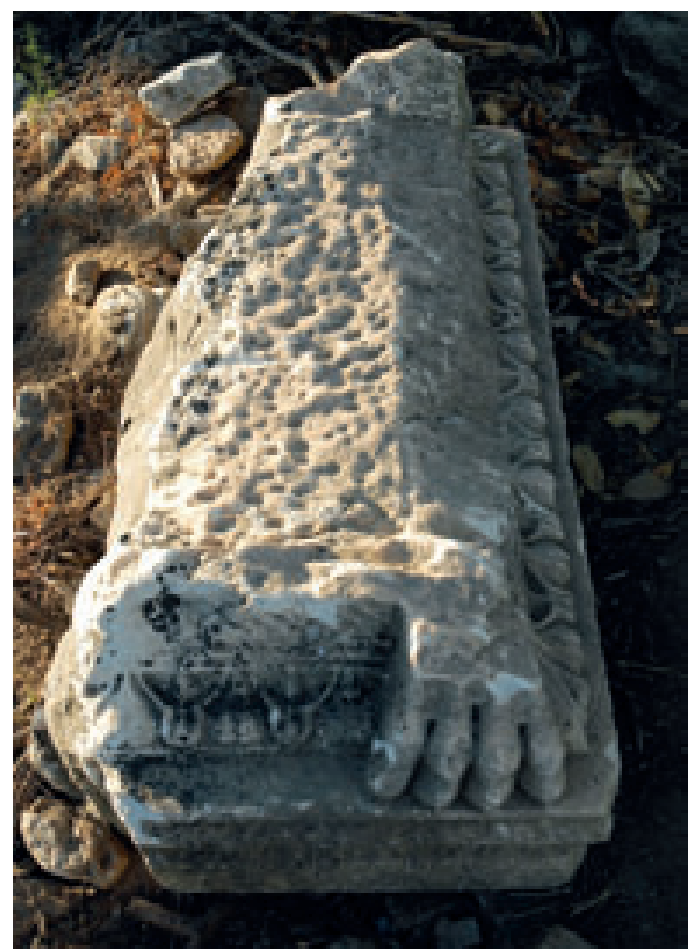

Abb. 301 Fragment

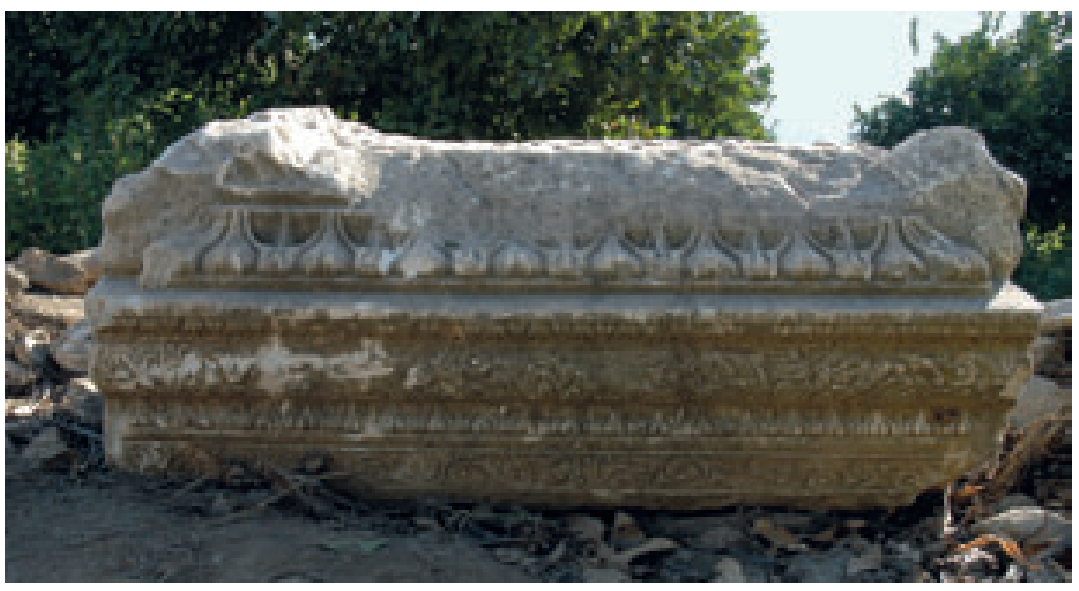

Abb. 302 Rechte Schmalseite

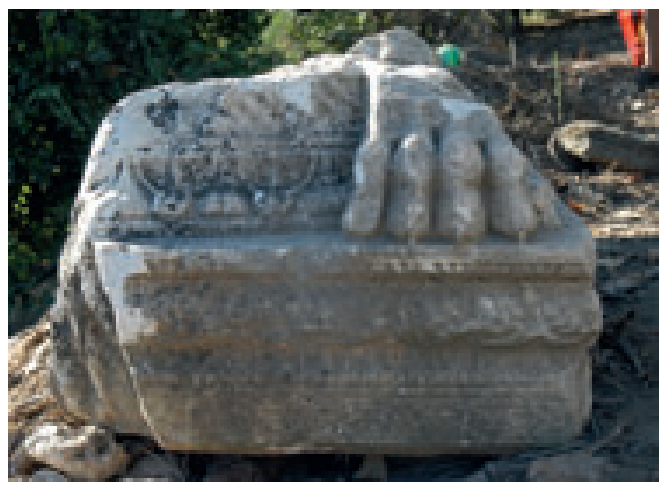

Abb. 303 Vorderseite

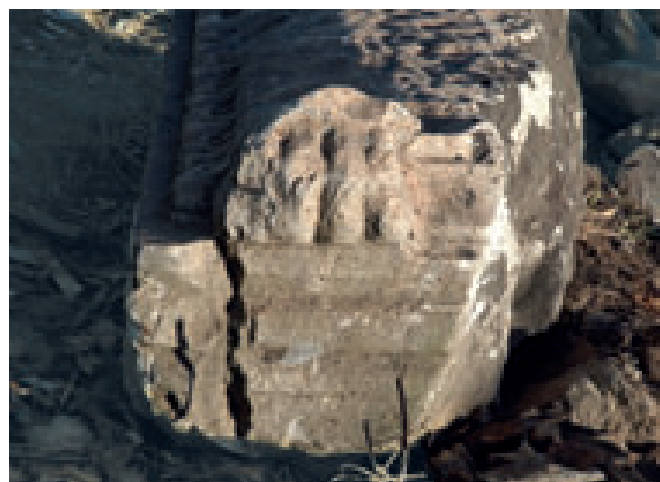

Abb. 304 Rückseite

Kat. 40 Fragment eines Klinen-Riefel-Sarkophags, Ephesos 
Tafel 74

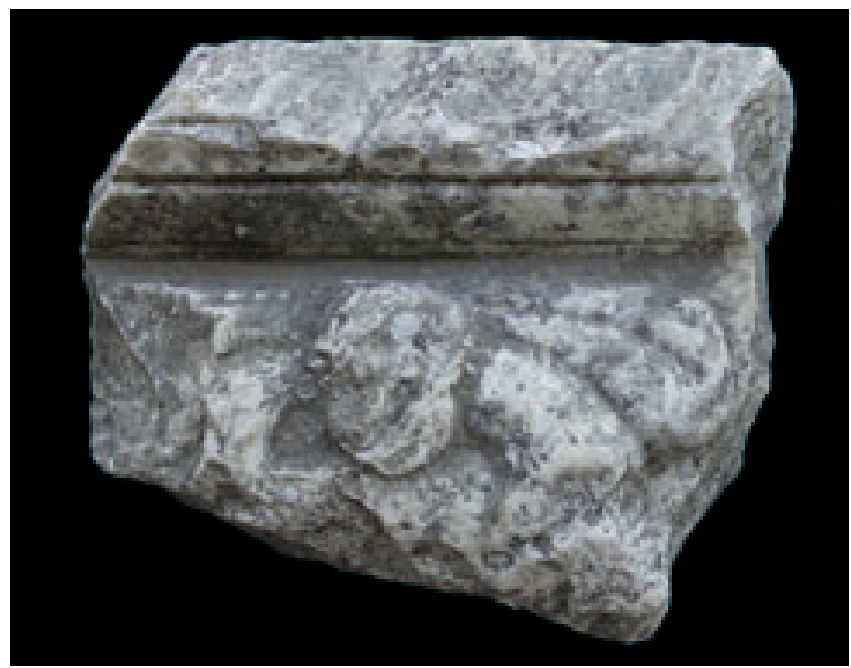

Abb. 305 Kat. 41, Fragment eines Girlandensarkophags. Selçuk, Efes Müzesi Inv. 346

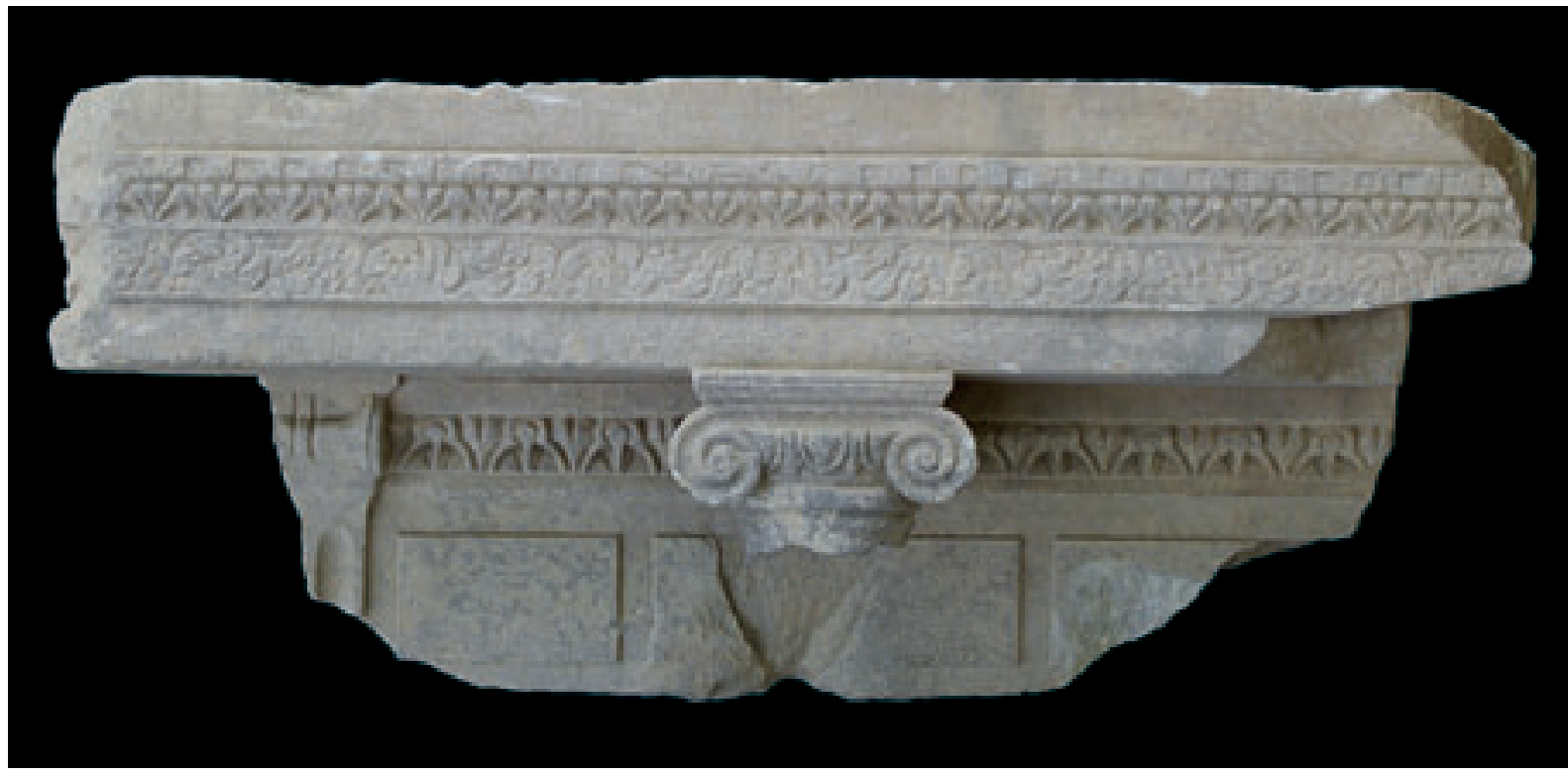

Abb. 306 Kat. 42, Fragment A eines attischen Säulensarkophags (?). Selçuk, Efes Müzesi Inv. 29/13/00

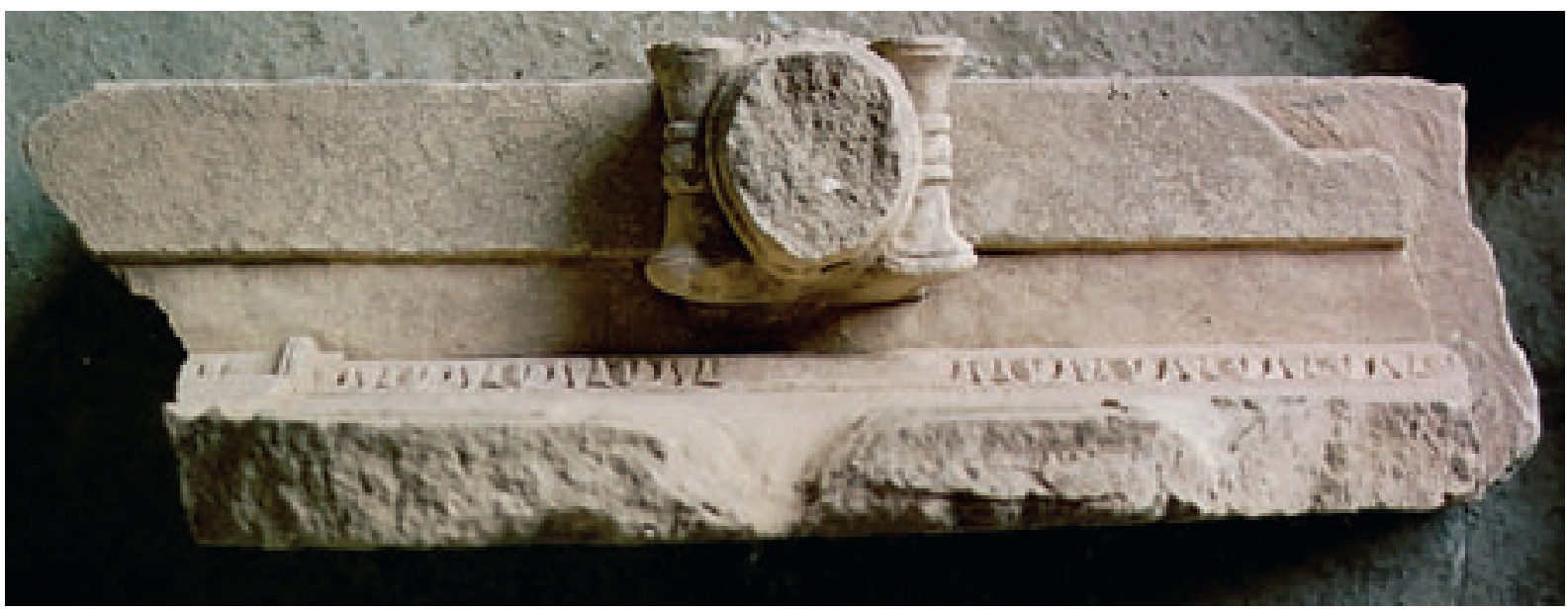

Abb. 307 Kat. 42, Fragment A eines attischen Säulensarkophags (?) 
Tafel 75

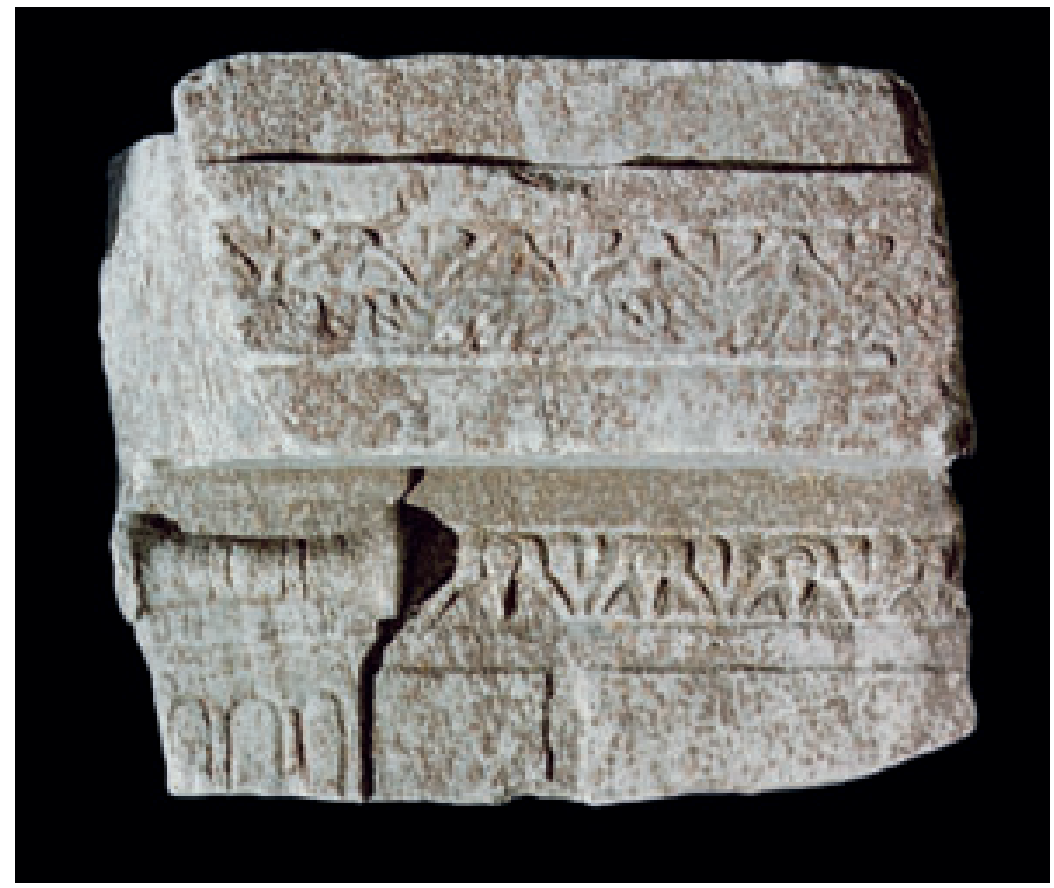

Abb. 308

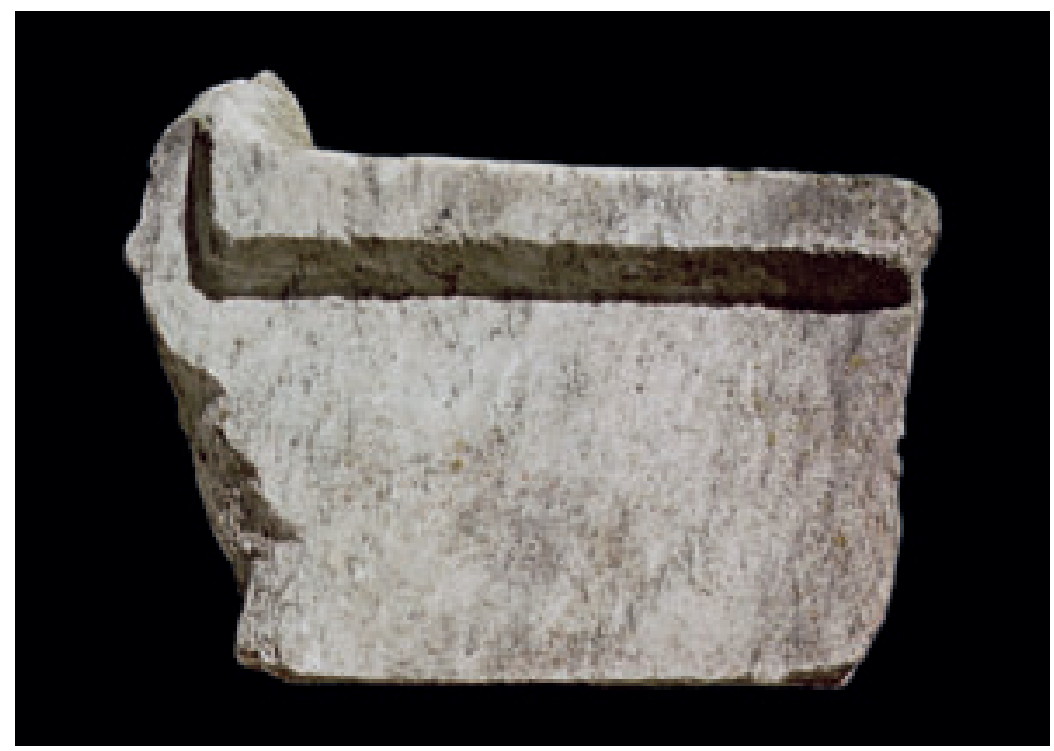

Abb. 309

Kat. 42 Fragment B eines attischen Säulensarkophags (?). Selçuk, Efes Müzesi Inv. 29/13/00 
Tafel 76

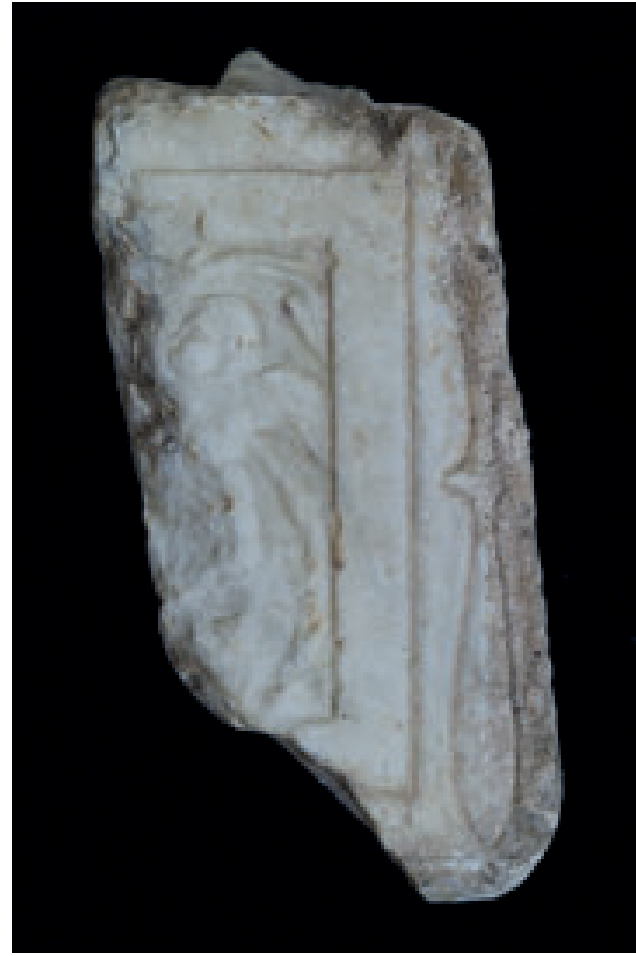

Abb. 310 Kat. 44, Eckfragment eines Klinendeckels. Selçuk, Depot des Grabungshauses

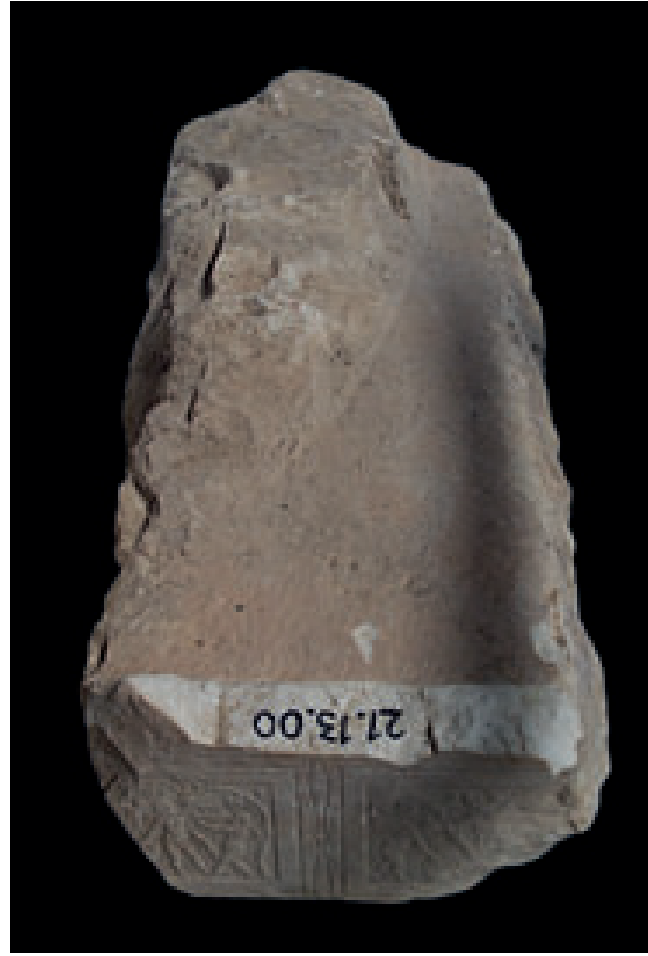

Abb. 311 Kat. 43, Fragment eines Klinendeckels. Selçuk, Efes Müzesi Inv. 21/13/00

Abb. 312

Kat. 43, Fragment eines Klinendeckels. Klinenlehne. Selçuk, Efes Müzesi Inv. 21/13/00

Abb. 313

Kat. 45, Vorderseitenfragment eines Klinendeckels. Selçuk, Efes Müzesi Inv. 2322
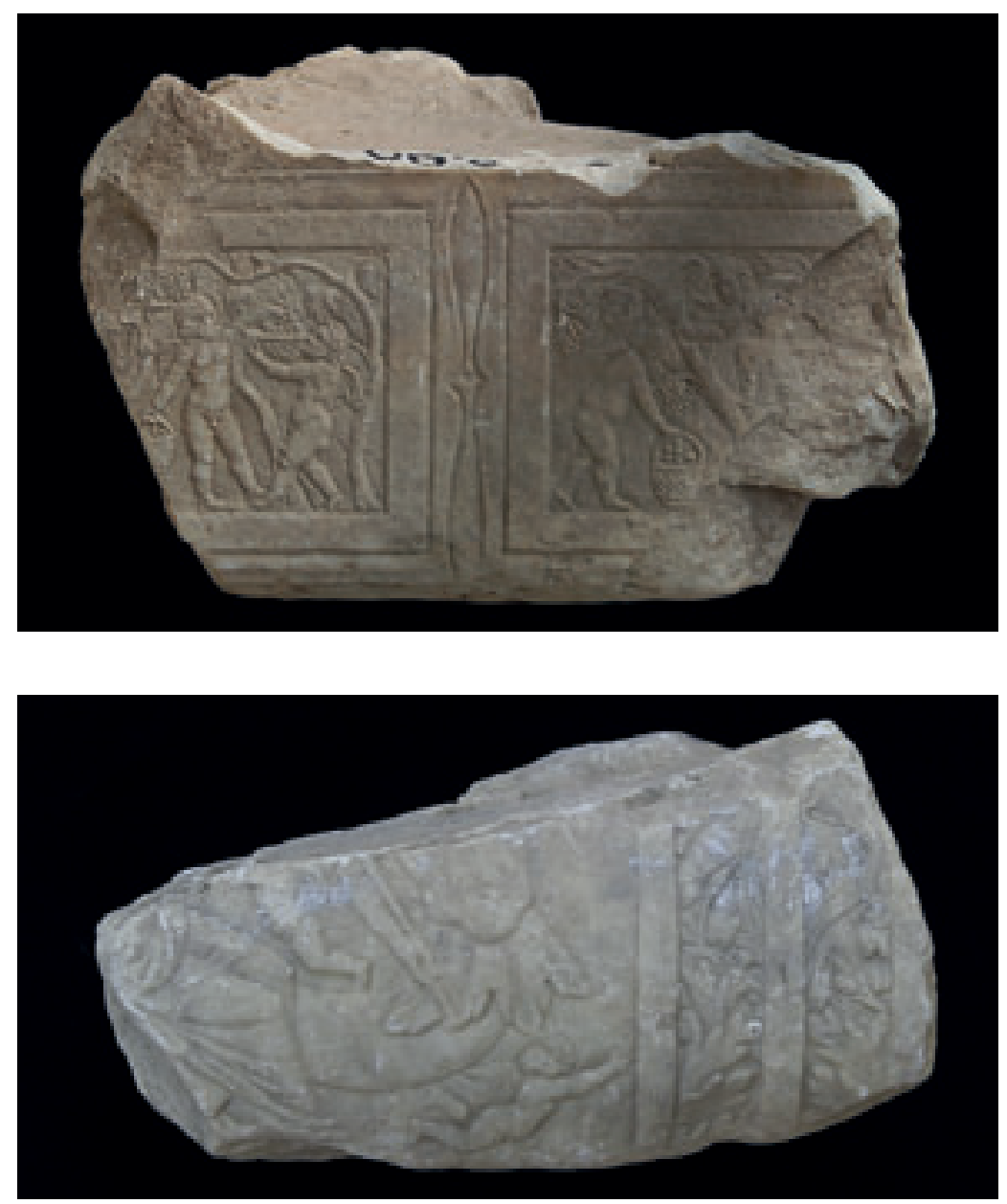
Tafel 77

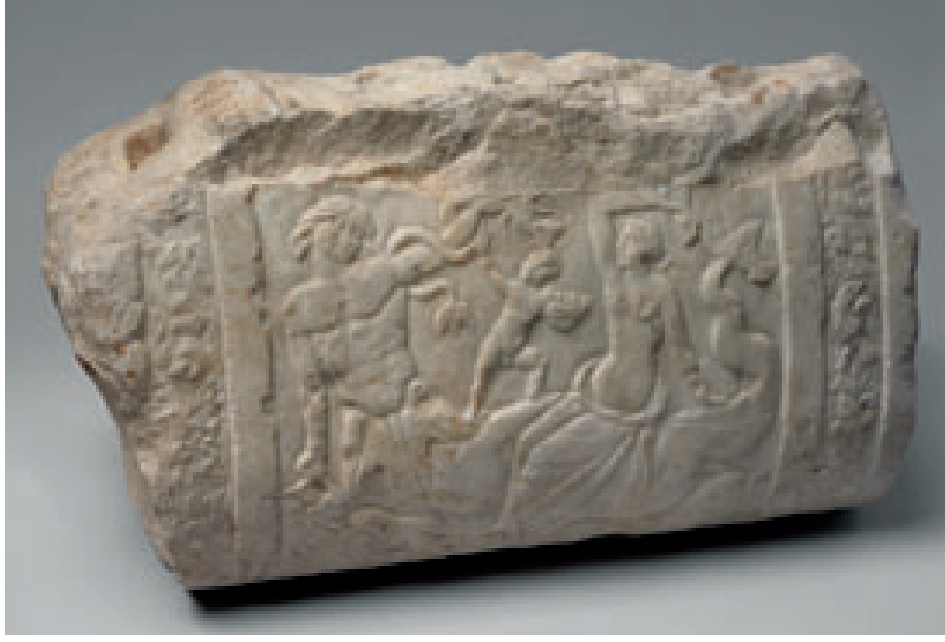

Abb. 314 Kat. 46, Vorderseitenfragment eines Klinendeckels. Wien, Kunsthistorisches Museum Inv. I 929

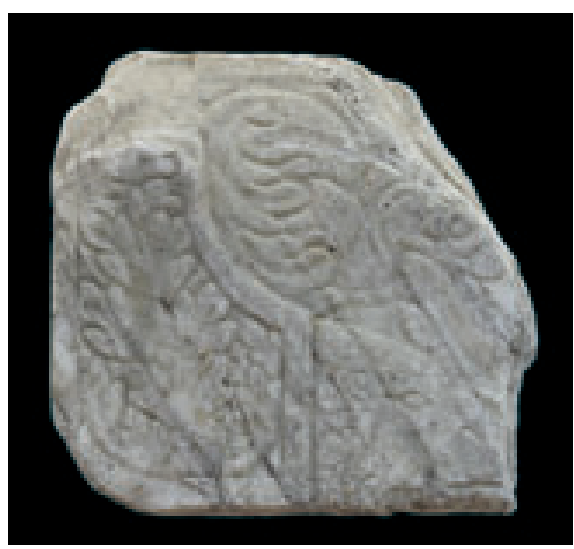

Abb. 315 Kat. 47, linke Ecke eines Klinendeckels, Vorderseite. Selçuk, Efes Müzesi

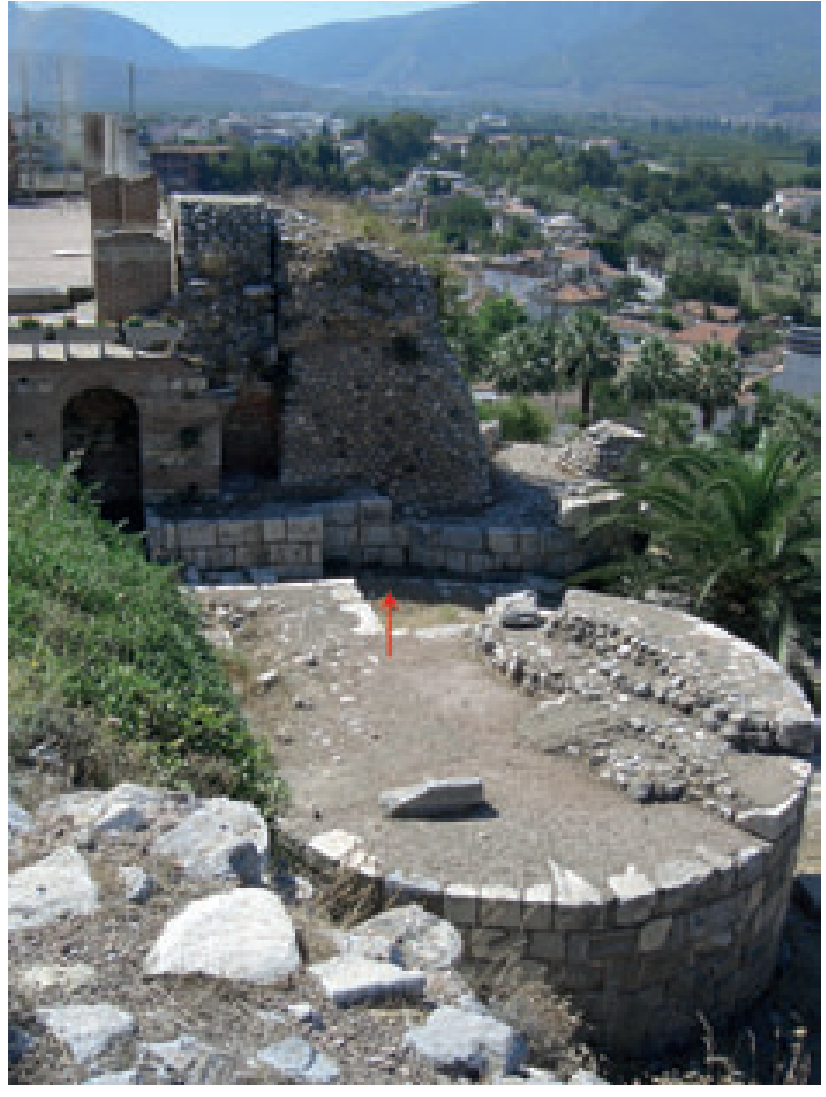

Abb. 317 Kat. 48, Überblick zur Lage Richtung Johannesbasilika, Atrium

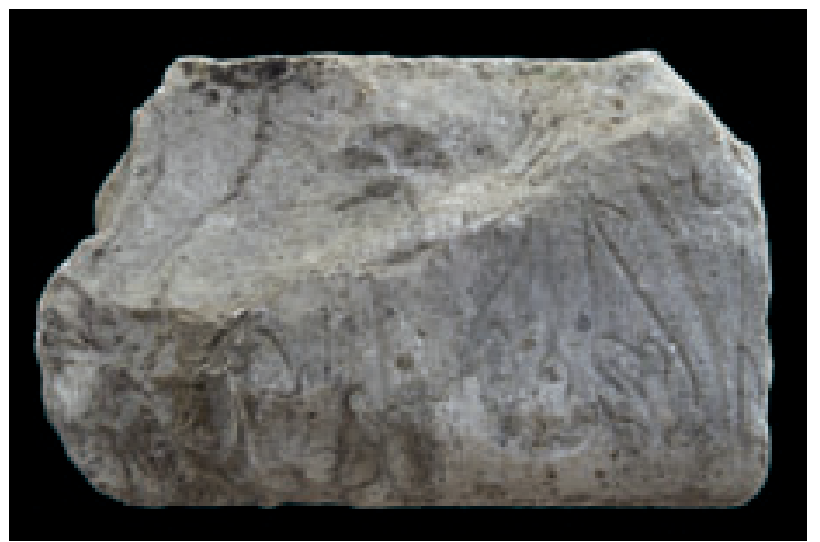

Abb. 316 Kat. 47, linke Ecke eines Klinendeckels, linke Schmalseite. Selçuk, Efes Müzesi

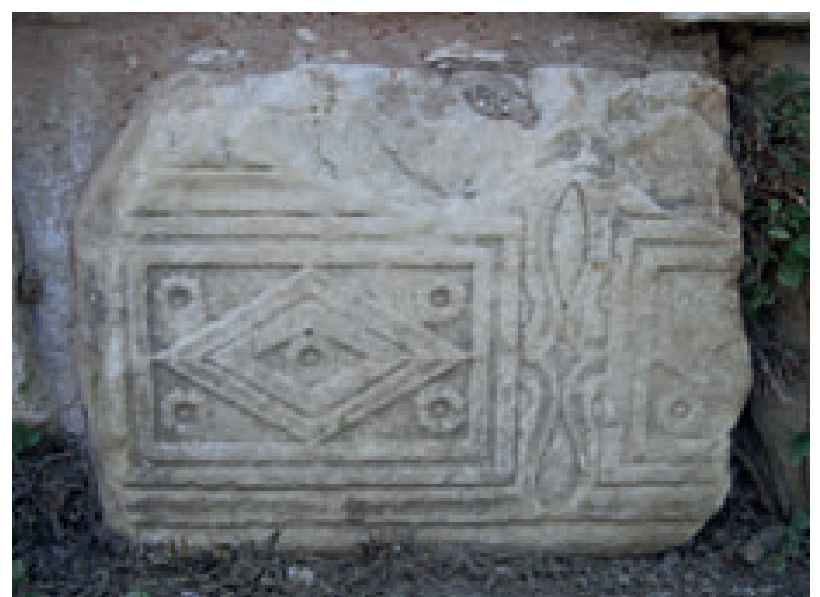

Abb. 318 Kat. 48, Schmalseitenfragment eines Klinendeckels, verbaut in Stützmauer des Atriums 
Tafel 78

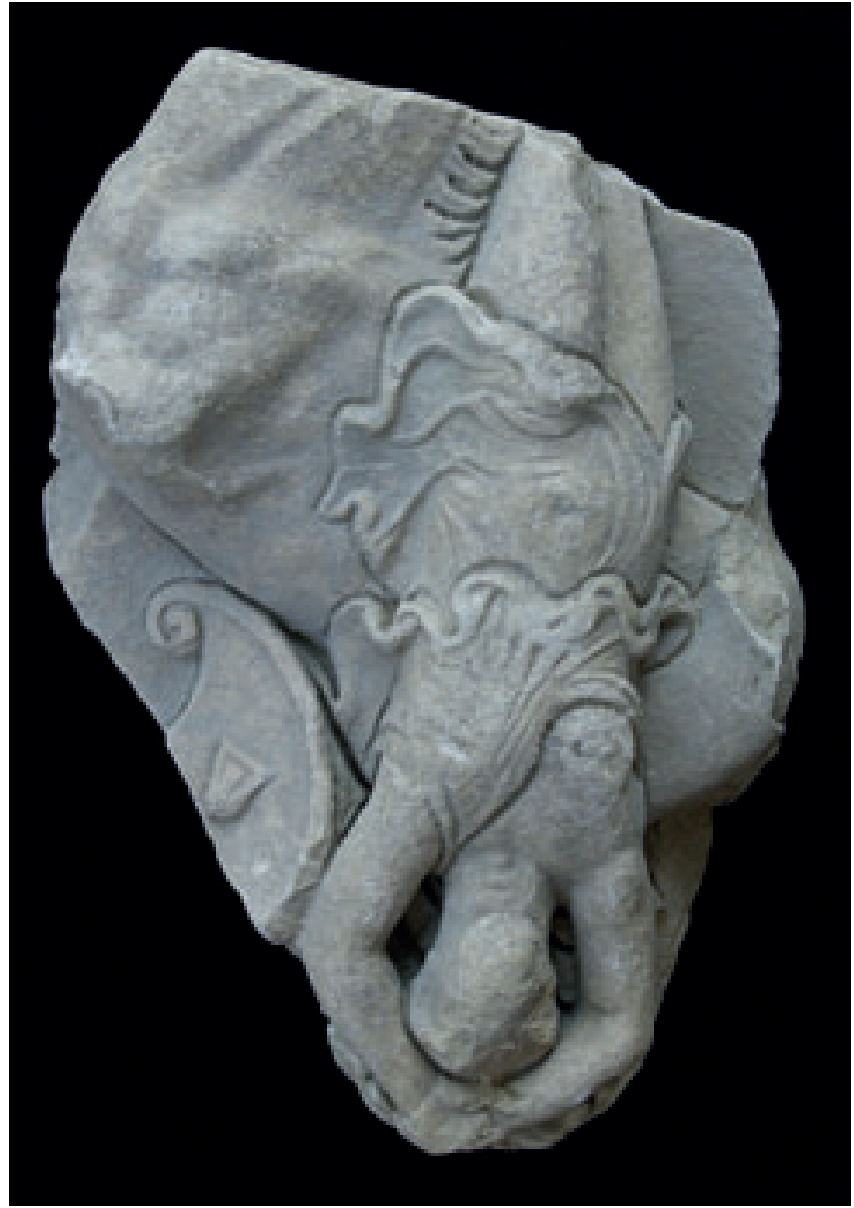

Abb. 319

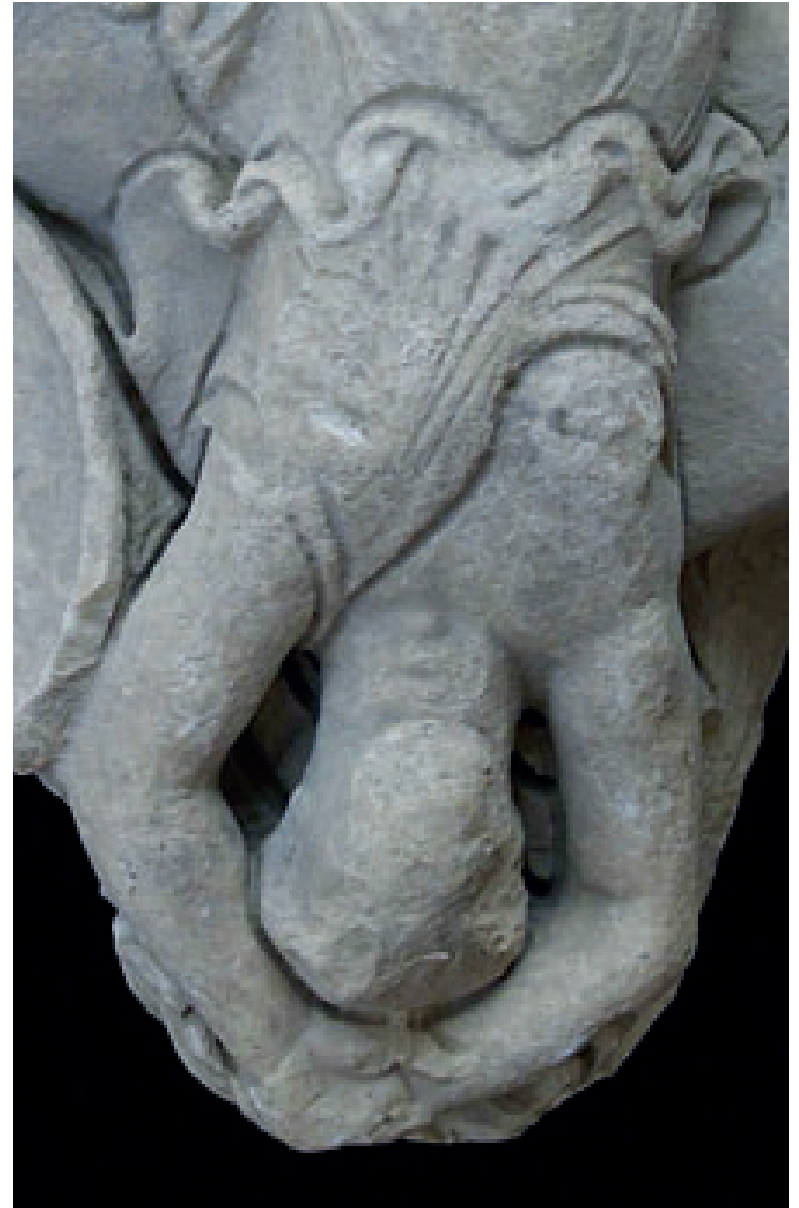

Abb. 320 Detail

Kat. L1 Lokales Fragment mit Amazone. Selçuk, Efes Müzesi Inv. 1883

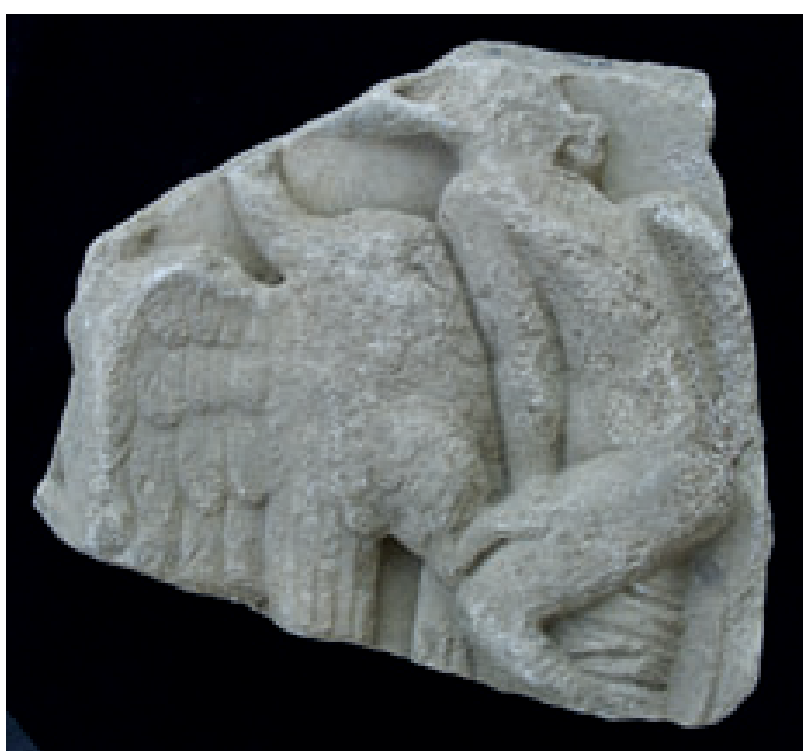

Abb. 321 Kat. L2, lokales Fragment mit Leda und dem Schwan. Selçuk, Efes Müzesi Inv. 1839

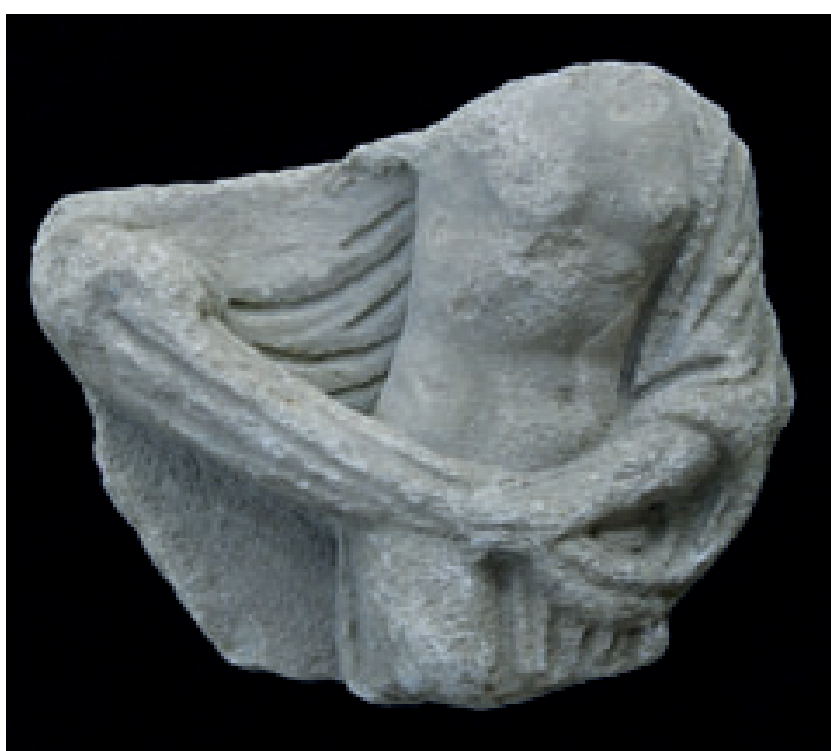

Abb. 322 Kat. L3, lokales Fragment mit Leda (?). Selçuk, Efes Müzesi, Efes Kapalı Deposu, Etd.Nr. L. 168 
Tafel 79

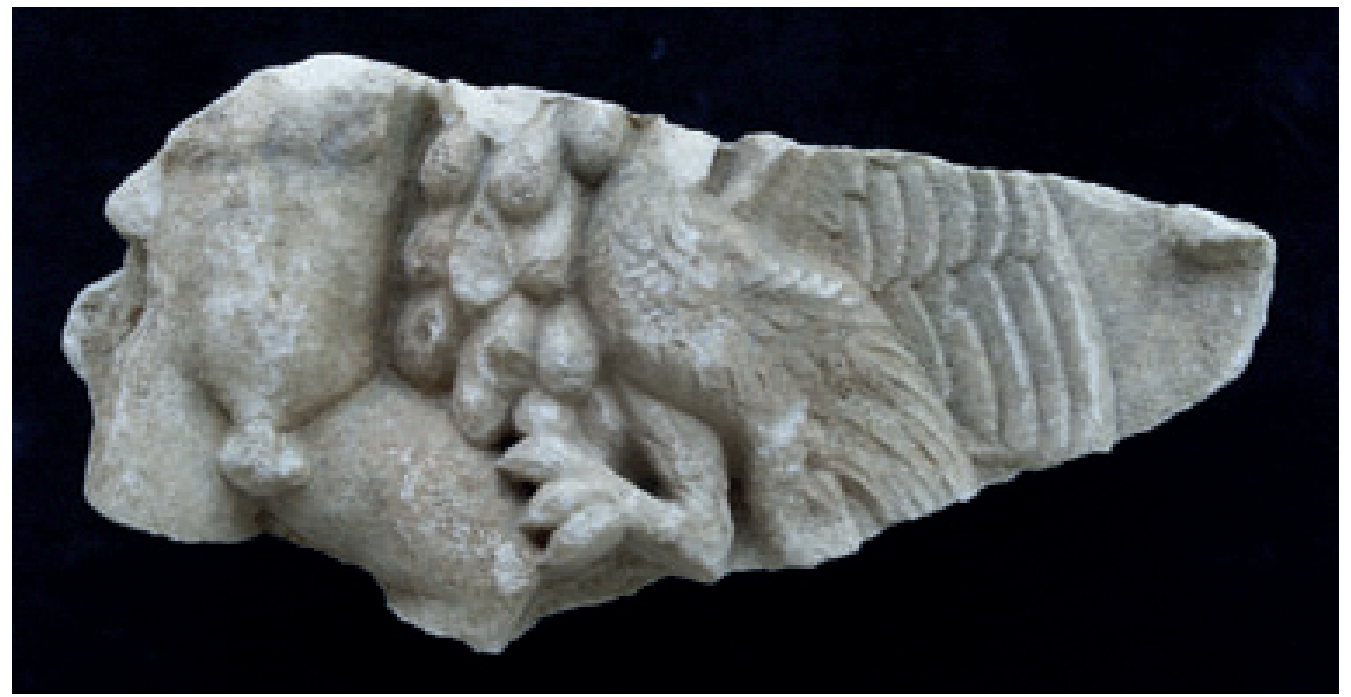

Abb. 323 Kat. L4, lokales Fragment eines Eroten-Weinlese-Sarkophags (?). Selçuk Efes Müzesi Inv. $4 / 13 / 00$

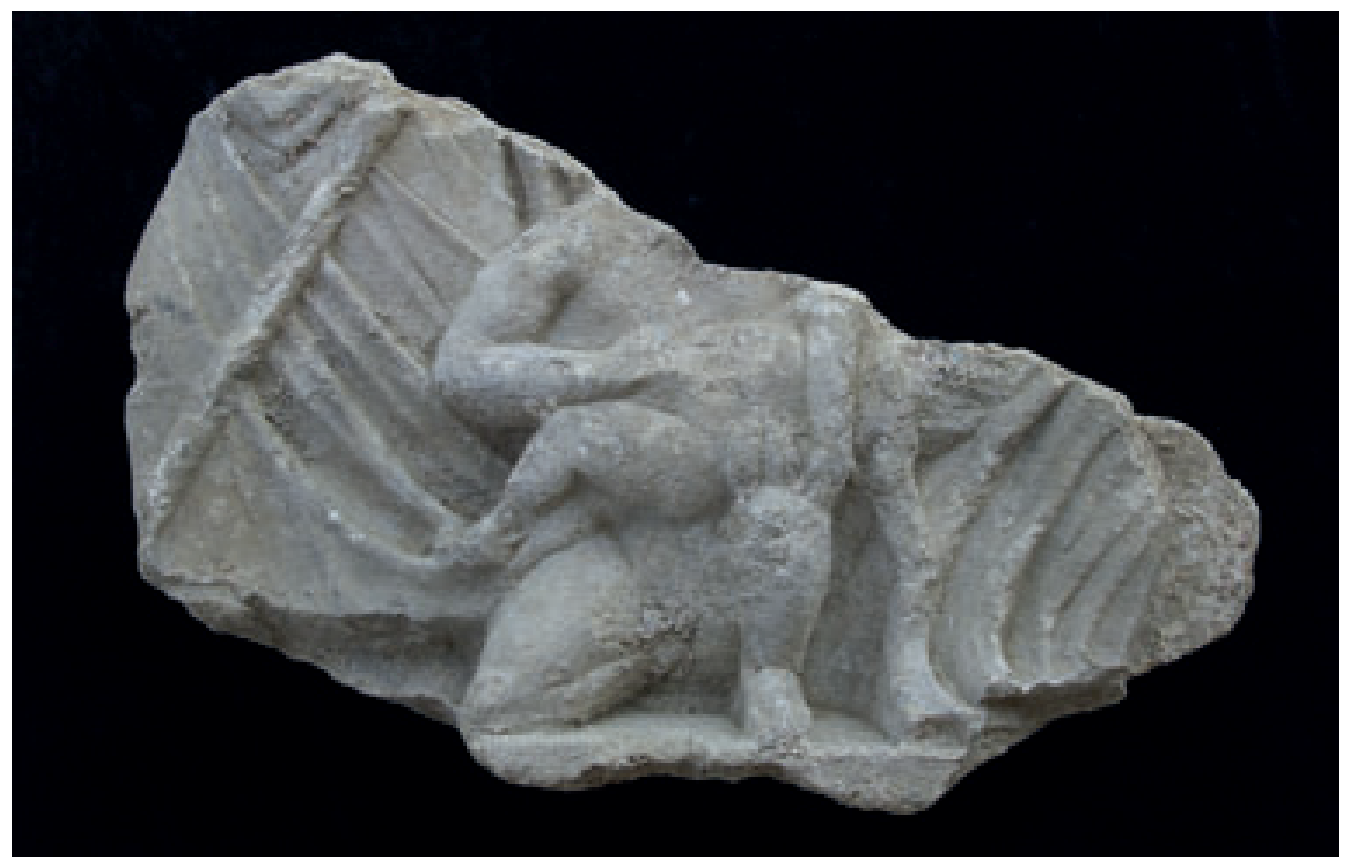

Abb. 324 Kat. L5, lokales Fragment eines Kastens. Selçuk Efes Müzesi Inv. 12/61/80

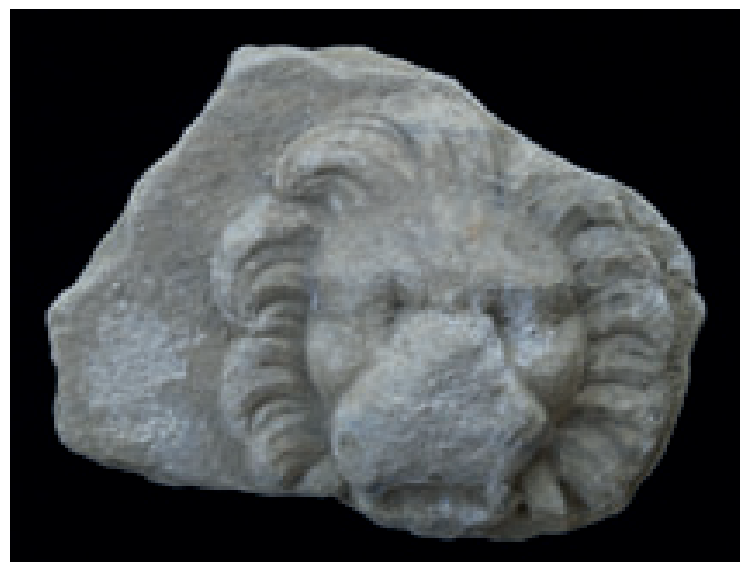

Abb. 325

Kat. L6, lokales

Fragment mit

Löwenprotom.

Selçuk, Efes Mü-

zesi, Efes Kapal1

Deposu, Etd.Nr.

L. 170 
Tafel 80

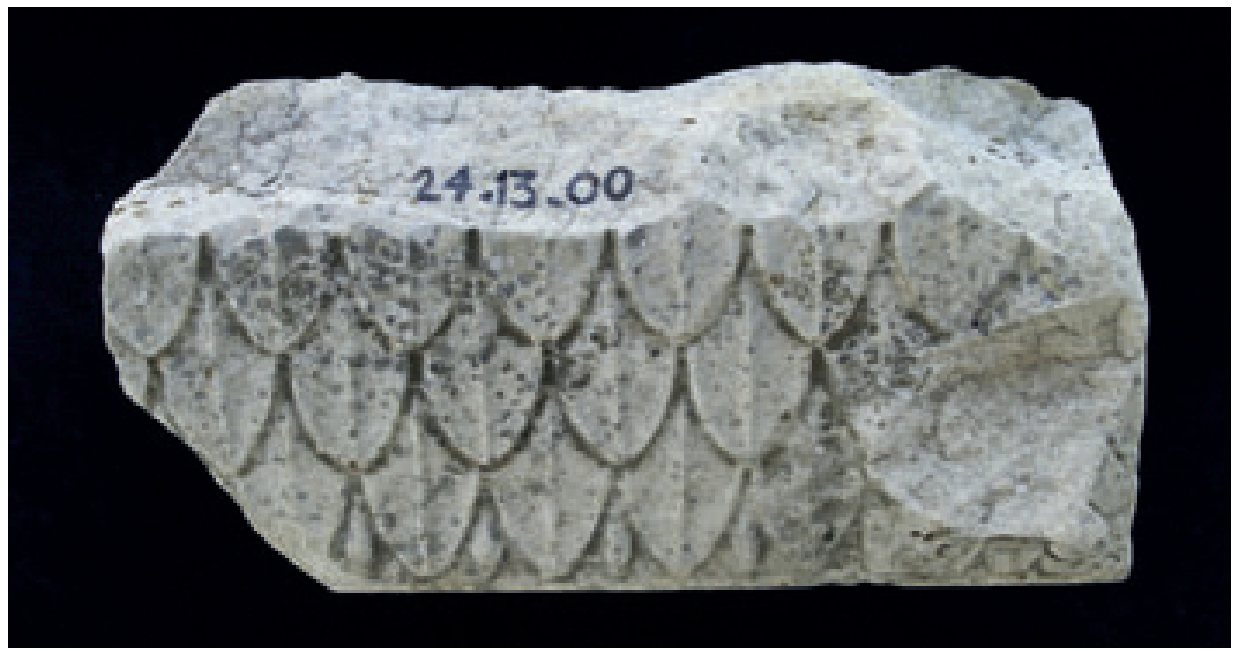

Abb. 326 Aufsicht

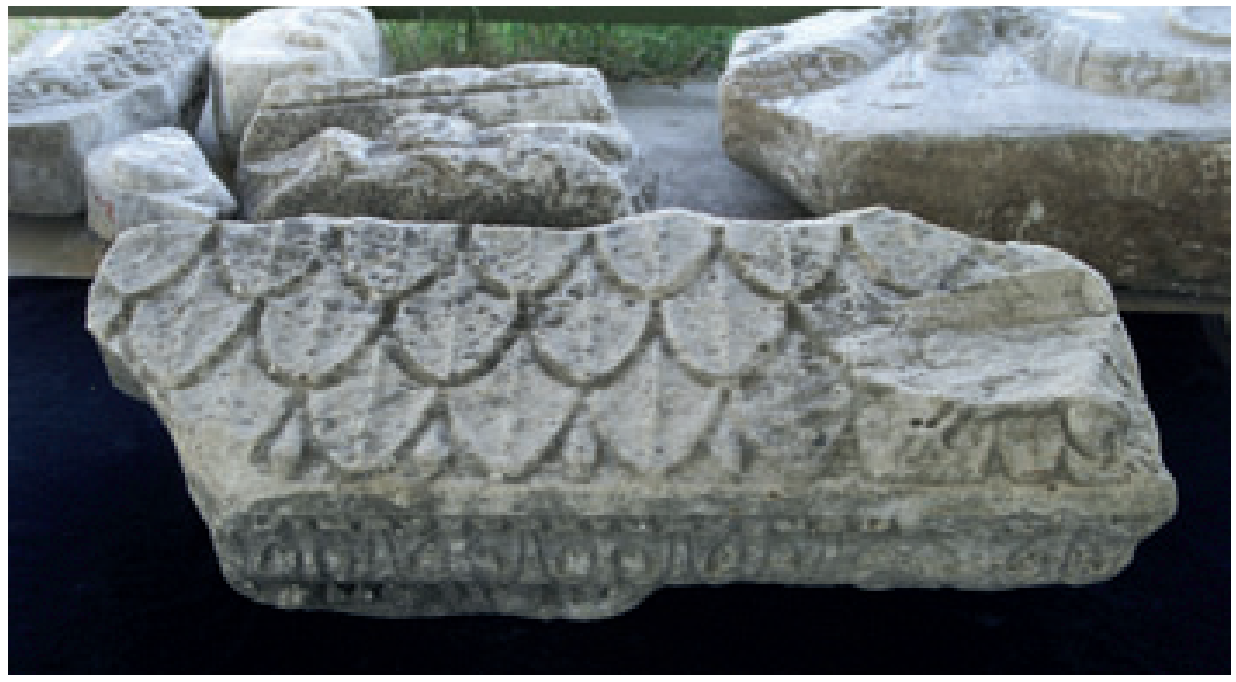

Abb. 327 Seitenansicht

Kat. L7 Lokales Fragment eines Dachdeckels. Selçuk, Efes Müzesi Inv. 24/13/00

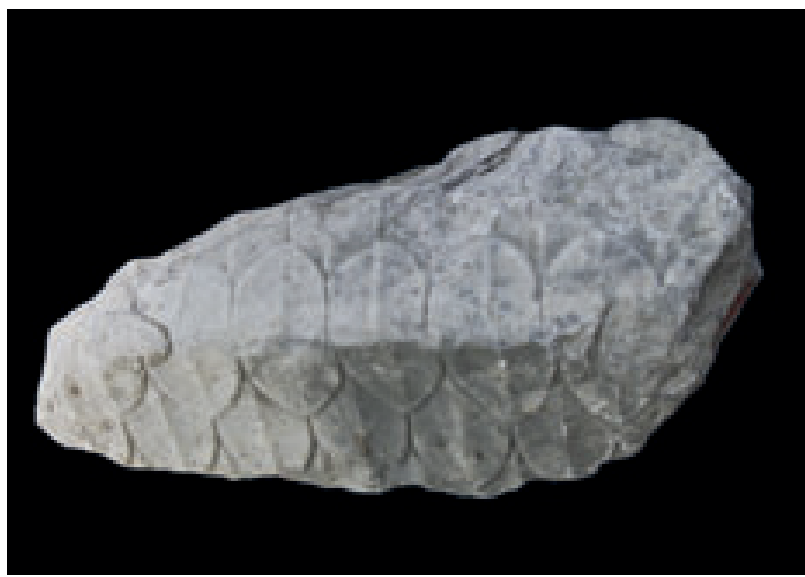

Abb. 328 Kat. L8, lokales Dachdeckelfragment. Selçuk, Efes Müzesi, Açık Hava Deposu, Etd.Nr. L. 120

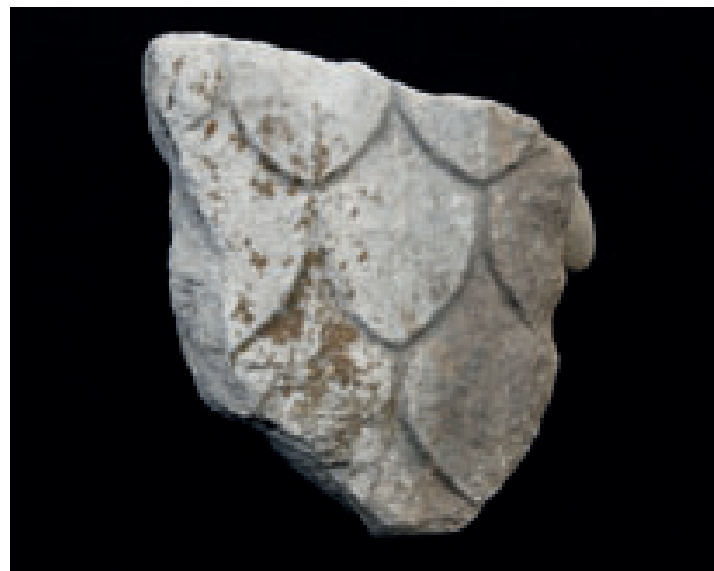

Abb. 329 Kat. L9, lokales Dachdeckelfragment. Selçuk, Johannesbasilika, Freiluftdepot 
Tafel 81

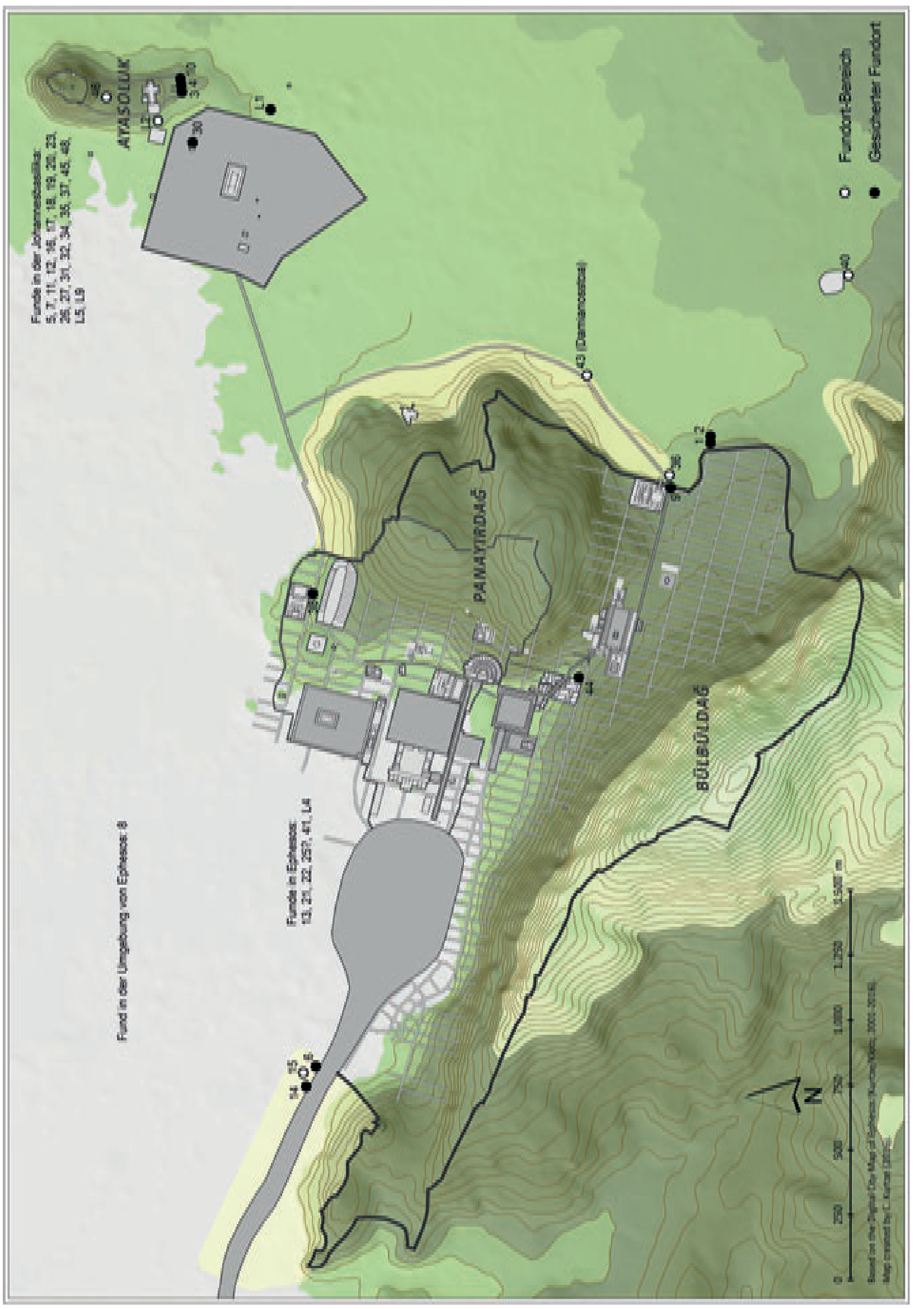

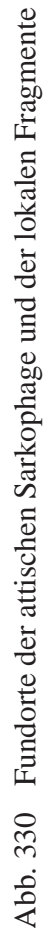


